\title{
Granular-Bed and Ceramic Candle Filters in Commercial Plants - A Comparison
}

Topical Report

K.B. Wilson

J.C. Haas

M.B. Eshelman

Work Performed Under Contract No.: DE-AC21-90MC27423

\author{
For \\ U.S. Department of Energy \\ Office of Fossil Emergy \\ Morgantown Energy Technology Center \\ P.O. Box 880 \\ Morgantown, West Virginia 26507-0880
}

$\mathrm{By}$

Combustion Power Company

1020 Marsh Road, Suite 100

Menlo Park, Calliformia 94025 


\title{
Granular-Bed and Ceramic Candle Filters in Commercial Plants - A Comparison
}

\section{Topical Report}

\author{
K.B. Wilson \\ J.C. Haas \\ M.B. Eshelman
}

April 1993

Work Performed Under Contract No.: DE-AC21-90MC27423

For

U.S. Department of Energy

Office of Fossil Energy

Morgantown Energy Technology Center

Morgantown, West Virginia

By

Combustion Power Company

Menlo Park, California

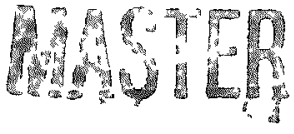

- A- - . - . 


\section{DISCLAIMER}

This report was prepared as an account of work sponsored by an agency of the United States Govermment. Neither the United States Government nor any agency thereof, nor any of their employees, makes any warranty, express or implied, or assumes any legal liability or responsibility for the accuracy, completeness, or usefulness of any information, apparatus, product, or process disclosed, or represents that its use would not infringe privately owned rights. Reference herein to any specific commercial product, process, or service by trade name, trademark, manufacturer, or otherwise does not necessarily constitute or imply its endorsement, recommendation, or favoring by the United States Government or any agency thereof. The views and opinions of authors expressed herein do not necessarily state or reflect those of the United States Government or any agency thereof.

This report has been reproduced directly from the best available copy.

Available to DOE and DOE contractors from the Office of Scientific and Technical Information, P.O. Box 62, Oak Ridge, TN 37831 ; prices available at (615) 576-8401

Available to the public from the National Technical Infomation Service, U.S. Department of Commerce, 5285 Port Royal Rd., Springfield, VA 22161; phone orders accepted at (703) 487-4650. 


\section{DISCLAIMER}

Portions of this document may be illegible in electronic image products. Images are produced from the best available original document. 


\begin{abstract}
Advanced coal fired power cycles require the removal of coal ash at high temperature and pressure. Granular-bed and ceramic candle filters can be used for this service. Conceptual designs for commercial size applications are made for each type of filter. The filters are incorporated in the design of a Foster Wheeler $450 \mathrm{MWe}$ second generation pressurized fluidized bed combustion plant which contains a pressurized fluidized combustor and carbonizer. In a second application, the filters are incorporated in the design of a $100 \mathrm{MWe}$ KRW (air) gasifier based power plant. The candle filter design is state of the art as determined from the open literature with an effort to minimize the cost. The granular-bed filter design is based on test work performed at high temperature and low pressure, tests at New York University performed at high pressure and temperate, and new analysis used to simplify the scale up of the filter and reduce overall cost. The incorporation of chemically reactive granules in the granular-bed filter for the removal of additional coal derived contaminants such as alkali or sulfur is considered. The conceptual designs of the granular-bed filter and the ceramic candle filter are compared in terms of the cost of electricity, capital cost, and operating and maintenance costs for each application.
\end{abstract}




\section{ACKNOWLEDGMENTS}

This work was performed by Combustion Power Company (CPC) under U.S. DOE Contract DE-AC21-90MC27423. Chuck Zeh was the first project manager, and Richard Dennis was the second project manager for DOE at the Morgantown Energy Technology Center.

Robert W. Swindeman, Oak Ridge National Laboratory, provided valuable assistance in materials understanding and selection.

Mark Rodamaker, MCR Associates, and Robert H. Mallett, Ph.D. of Mallett Software Technology performed analysis on the granular-bed and candle filter configurations.

J.F. Zievers, Industrial Filter \& Pump Mfg. Co. provided insight into the design of candle filters. 
EXECUTIVE SUMMARY 1

Introduction

Summary of Conclusions

Plant Descriptions

Granular-Bed Filter Description 3

Candle Filter Description $\quad 5$

Heat Loss and Pressure Drop $\quad 10$

Filter Costs $\quad 11$

Future Work 15

$\begin{array}{ll}\text { References } & 16\end{array}$

$\begin{array}{lr}\text { I. INTRODUCTION } & 17\end{array}$

1.1 Program Objectives 17

$\begin{array}{lll}1.2 & \text { General Approach } & 17\end{array}$

1.2.1 Basis for Conceptual Designs 18

1.2.2 GBF Conceptual Designs 18

1.2.3 Candle Filter Design 19

1.2.4 Design and Cost Estimate 19

1.2.5 Comparison of Granular-Bed Filter and Candle Filter 20

1.3 References 21

II. OVERALL PLANT DESCRIPTIONS AND FILTER REQUIREMENTS 22

2.1 Plant Site Description $\quad 22$

2.2 Second Generation PFB Combustion Plant 23

$2.3 \quad$ Gasifier Based Power Plant $\quad 23$

2.4 References 28

$\begin{array}{lr}\text { III. GRANULAR-BED FILTERS } & 29\end{array}$

3.1 Previous Development Efforts 29

3.2 Conceptual Designs of Granular-Bed Filters 35

3.2.1 Single Entry Filter $\quad 35$

3.2.2 Multiple Entry Filter 36

$\begin{array}{lll}3.2 .3 & \text { Screened Filter } & 37\end{array}$

3.2.4 High Flow Filter 39

$\begin{array}{lll}3.3 & \text { Preliminary Cost Comparison } & 43\end{array}$

3.4 Computational Fluid Dynamics (CFD) Analysis 45 
TABLE OF CONTENTS (cont)

3.5 Preliminary Design of Granular-Bed Filters 47

3.5.1 Process Description 47

3.5.1.1 Process Flow for GBF - CPFBC 54

3.5.1.2 Process Flow for Carbonizer GBF 56

3.5.1.3 Process Flow for KRW Gasifier GBF 56

3.5.2 Instrumentation and Control 60

$\begin{array}{ll}\text { 3.5.3 Granular-Bed Filter Configurations } & 70\end{array}$

$\begin{array}{lll}\text { 3.5.3.1 Refractory } & 71\end{array}$

3.5.3.2 Metal Internals $\quad 72$

3.5.4 Granular-Bed Filter Plant Arrangements 73

3.6 Granular-Bed Filter Auxiliary Equipment/Specs 87

$\begin{array}{ll}\text { 3.6.1 De-Entrainment Vessels } & 87\end{array}$

$\begin{array}{lll}\text { 3.6.2 Media Make-up Hoppers } & 87\end{array}$

3.6.3 Media Valves, Seal Legs, Lift Pipes 88

3.6.4 Media Addition Hoppers 88

$\begin{array}{lll}3.6 .5 & \text { Baghouses } & 89\end{array}$

3.6.6 Regenerative Heat Exchangers 90

$\begin{array}{lll}3.6 .7 & \text { Boost Blowers } & 91\end{array}$

3.6.8 Water-Cooled Heat Exchangers 93

3.6.9 Mist/Particle Eliminators 93

3.7 Filter Plant Construction 94

$\begin{array}{lll}3.8 & \text { References } & 114\end{array}$

$\begin{array}{ll}\text { IV. CERAMIC CANDLE FILTERS } & 116\end{array}$

4.1 Candle Filter Development Status 116

4.1.1 Pilot Plant Filter at Grimethorpe 118

4.1.2 Tidd Candle Filter Design 118

4.1.3 Pilot Plant Testing at Aachen, Germany 119

4.1.4 Candle Filters with Vacuum Formed Ceramic

4.2 Conceptual Candle Filter Designs 121

4.2.1 Candle Filter Specification 122

4.2.2 Pulse Gas Requirements 125

4.2.3 Tubesheet/Support Specification 126

4.2.4 Tiered vs. Single Tubesheet 130

4.2.5 Tubesheet/Support Structural Analysis 132

4.2.6 Preliminary Cost Comparisons 133

4.3 Preliminary Design of Candle Filters 134

$\begin{array}{lll}\text { 4.3.1 Process Description } & 134\end{array}$

4.3.1.1 Process Flow for CPFBC Candle Filter 135

4.3.1.2 Process Flow for Carbonizer

Candle Filter 136

$\begin{array}{ll}\text { 4.3.1.3 Process Flow for KRW Gasifier } & 136 \\ & \text { Candle Filter }\end{array}$

4.3.2 Instrumentation and Control 141 
4.3.3 Candle Filter Configurations 144

$\begin{array}{lll}\text { 4.3.3.1 Refractory } & 159\end{array}$

4.3.3.2 Metal Internals 160

4.3.4 Candle Filter Plant Arrangements 160

4.4 Candle Filter Auxiliary Equipment/Specifications 161

4.4.1 Pulse System, CPFBC 161

4.4.2 Pulse System, Carbonizer/Gasifier 166

$\begin{array}{ll}\text { 4.4.3 Pulse Gas Distribution } & 168\end{array}$

4.4.4 Ash Handling, CPFBC/Carbonizer 169

4.4.5 Ash Handling, Gasifier 169

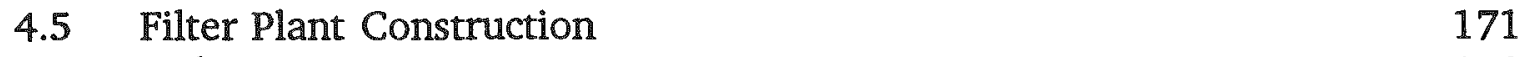

$\begin{array}{lll}4.6 & \text { References } & 178\end{array}$

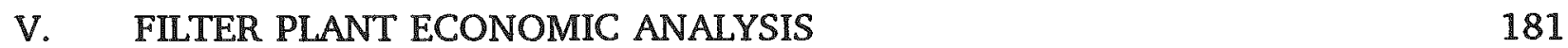

$\begin{array}{lll}5.1 & \text { Cost Estimating Procedures } & 181\end{array}$

5.2 Base Cost of Electricity Calculations 183

5.2.1 Second generation PFB Combustion Plant 184

5.2.2 KRW Gasifier Based Power Plant 186

$\begin{array}{lll}5.3 & \text { Granular-Bed Filters Costs } & 189\end{array}$

5.3.1 Capital Costs of Granular-Bed Filters 189

5.3.2 Maintenance Costs 190

5.3.3 Operating Labor Costs 192

5.3.4 Utility Requirements 193

5.3.5 Consumables Operating Costs 193

5.4 Ceramic Candle Filters Costs 1.96

5.4.1 Capital Costs of Candle Filters 196

$\begin{array}{ll}\text { 5.4.2 Maintenance Costs } & 198\end{array}$

5.4.3 Operating Labor Costs 198

5.4.4 Utility Requirements 198

5.4.5 Consumables Operating Costs 200

5.5 COE Comparison, Second Generation PFB Combustion Plant 203

5.5.1 Bare Erected Costs, CPFBC \& Carbonizer Filters 203

5.5.2 Ducting \& Foundations 206

5.5.3 Ash Systems 206

5.5.4 Power Plant Maintenance 207

5.5.5 Cost of Electricity 207

5.6 COE Comparison, KRW Gasifier Based Power Plant 219

5.6.1 Zinc Ferrite Plant Cost Update 219

5.6.2 Bare Erected Costs, Gasifier Filters 223

5.6.3 Power Plant Maintenance 223

$\begin{array}{ll}\text { 5.6.4 Cost of Electricity } & 223\end{array}$

$\begin{array}{lll}5.7 & \text { References } & 235\end{array}$ 
TABLE OF CONTENTS (cont)

VI. DEVELOPMENT OF MULTI-CONTAMINANT CONTROL GRANULAR-BED $\frac{\text { Page }}{236}$ FILTERS

6.1 Objective 236

6.2 Combustion Power's Approach to Multi-Contaminant Control 236

$\begin{array}{lll}6.3 & \text { Background } & 237\end{array}$

6.3.1 Control of Sulfur Emissions 237

$\begin{array}{lll}\text { 6.3.1.1 } & \mathrm{SO}_{2} \text { Control } & 237\end{array}$

6.3.1.2 $\mathrm{H}_{2} \mathrm{~S}$ Control $\quad 238$

$\begin{array}{ll}\text { 6.3.2 Control of Nitrogen Compounds } & 239\end{array}$

6.3.3 Alkali Control 240

6.3.4 Trace Species Control 243

6.3.5 Halogen Control 244

6.4 Developmental Work Plan for Multi-Contaminant GBF 245

6.4.1 Literature Review and Definition of Contaminant Levels 245

6.4.2 Process Definition 245

6.4.3 Basis of Conceptual Design 245

6.4.4 Test Plans for Proof of Concept Testing 246

6.4.5 Topical Report 246

$\begin{array}{lll}6.5 & \text { References } & 247\end{array}$

VII. CONCLUSIONS AND RECOMMENDATIONS 251

VIII. ACRONYMS AND ABBREVIATIONS 255

APPENDIX A and B 


\section{LIST OF FIGURES}

Figure

Page

1 Process Flow Diagram for Granular-Bed Filter 6

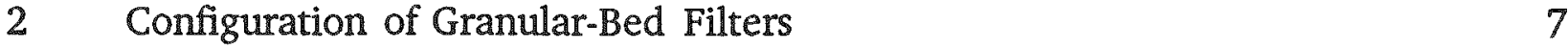

$3 \quad$ Configuration of Candle Filters $\quad 9$

$4 \quad$ Simplified Schematic of Second-Generation PFB Combustion Plant 26

$5 \quad$ Simplified Schematic of KRW Air-Blown Gasification Process 27

$6 \quad$ Screenless Counterflow Granular-Bed Filter $\quad 32$

$7 \quad$ Granular-Bed Filter Installation at NYU

$8 \quad$ Schematic of Screenless Granular-Bed Filter Tested at NYU 34

$9 \quad$ Multi-Entry Granular-Bed Filter $\quad 41$

10 High Flow Granular-Bed Filter 42

11 Idealized Sketch of the GBF Tested at NYU 48

12 Effect of GBF Inlet Diameter on Flow Rate 49

13 Schematic of the Geometry of $20 \mathrm{ft}$ Diameter GBF with a $5 \mathrm{ft}$ Deep Bed 50

14 Streamlines for $20 \mathrm{ft}$ Diameter GBF with a $5 \mathrm{ft}$ Deep Bed 51

15 Pressure contours for $20 \mathrm{ft}$ Diameter GBF with a $5 \mathrm{ft}$ Deep Bed

16 Outlet Flow Profile for $20 \mathrm{ft}$ Diameter GBF with a $5 \mathrm{ft}$ Deep Bed 53

17 Process Flow Diagram, GBF for CPFBC $\quad 57$

18 Process Flow Diagram, GBF for Carbonizer $\quad 58$

19 Process Flow Diagram, GBF for KRW Gasifier $\quad 59$

20a P \& I D, Granular-Bed Filter for CPFBC 62

20b P \& I D, Granular-Bed Filter for CPFBC

21a P \& I D, Granular-Bed Filter for Carbonizer 


\section{LIST OF FIGURES (cont)}

Figure

$\underline{\text { Page }}$

21b P \& I D, Granular-Bed Filter for Carbonizer $\quad 65$

22a P \& I D, Granular-Bed Filter for KRW Gasifier 66

22b P \& I D, Granular-Bed Filter for KRW Gasifier $\quad 67$

23 Control System Architecture, GBF for CPFBC 68

24 Control System Architecture, GBF for Carbonizer and Gasifier 69

25 Granular-Bed Filter Configuration $\quad 76$

$\begin{array}{lll}26 & \text { Granular-Bed Filter Pressure Vessel, CPFBC } & 77\end{array}$

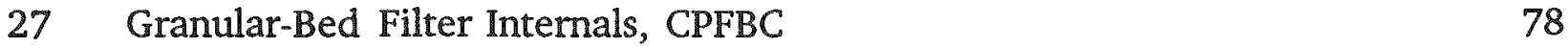

28 Granular-Bed Filter Pressure Vessel, Carbonizer $\quad 79$

29 Granular-Bed Filter Internals, Carbonizer $\quad 80$

$30 \quad$ Granular-Bed Filter Pressure Vessel, KRW Gasifier 81

$31 \quad$ Granular-Bed Filter Internals, KRW Gasifier $\quad 82$

32a General Arrangement, CPFBC GBF 83

32b General Arrangement, CPFBC GBF

33 General Arrangement, Carbonizer GBF $\quad 85$

34 General Arrangement IGCC (KRW Airblown) Gasifier GBF 86

35a De-Entrainment Vessel, CPFBC GBF 95

35b De-Entrainment Vessel, CPFBC GBF 96

36a De-Entrainment Vessel, Carbonizer GBF 97

36b De-Entrainment Vessel, Carbonizer GBF 98

37a De-Entrainment Vessel, KRW Gasifier GBF 99

$\begin{array}{lll}37 b & \text { De-Entrainment Vessel, KRW Gasifier GBF } & 100\end{array}$ 


\section{LIST OF FIGURES (cont)}

Figure

Page

38 Media Make-up Hopper, CPFBC 101

39 Media Make-up Hopper, Carbonizer 102

40 Media Make-up Hopper, KRW Gasifier 103

41 Media Valve, CPFBC Filter 104

42 Media Valve, Carbonizer Filter 105

43 Media Valve, Gasifier Filter 106

44 Typical Baghouse Configuration $\quad 107$

45 Arrangement for Regenerative Heat Exchangers 108

46 Candle Filter at Grimethorpe 120

$47 \quad$ Candle Filter at Tidd 131

$48 \quad$ Candle Filter at Aachen, Germany 137

49 Candle Filter W/Ceramic Fiber Material Internals 138

50 Heat-up Transient, Commercial Design 139

51 Candle Filter Configuration 140

52a P \& I D, Candle Filter for CPFBC 145

52b P \& I D, Candle Filter for CPFBC 146

53 P \& I D, Candle Filter for Carbonizer 147

$\begin{array}{lll}\text { 54a } & \text { P \& I D, Candle Filter for KRW Gasifier } & 148\end{array}$

54b P \& I D, Candle Filter for KRW Gasifier 149

55 Control System Architecture, Candle Filter for CPFBC 150

56 Control System Architecture, Candle Filter for Carbonizer 151 


\section{ILIST OF FIGURES (cont)}

Figure

$\underline{\text { Page }}$

57 Control System Architecture, Candle Filter for KRW Gasifier

58 Candle Filter Pressure Vessel, CPFBC

59 Candle Filter Internals, CPFBC

60 Candle Filter Pressure Vessel, Carbonizer

61 Candle Filter Internals, Carbonizer

62 Candle Filter Pressure Vessel, KRW Gasifier

63 Candle Filter Internals, KRW Gasifier

64 General Arrangement, CPFBC Candle Filter

65 General Arrangement, Carbonizer Candle Filter

66 General Arrangement KRW Gasifier Candle Filter

67 Pulse Gas Piping

68 Water-Cooled Screw

69 General Reactions of Alkali Vapors with Aluminosilicate Additives at $1500^{\circ}-1800^{\circ} \mathrm{F}$ 


\section{LIST OF TABLES}

Number

Page

1 Summary Cost of Electricity Values 2

2 Filter Pressure/Temperature Drop 10

$3 \quad$ CPFBC Filter Cost Comparisons 12

4 Carbonizer Filter Cost Comparisons 13

$5 \quad$ KRW Gasifier Filter Cost Comparisons 14

6 HGCU Filter Requirements for each CPFBC Module 24

$7 \quad$ HGCU Filter Requirements for IGCC Plant 25

8 GBF Operating Parameters, NYU 30

$9 \quad$ Particulate Sampling Results, NYU 31

10 Design Parameters for the Multiple Gas Entry Filter 38

11 Screened Filter Design $\quad 40$

12 Cost Comparison of Filter Designs for 452 MWe Foster Wheeler CPFBC 44

13 Comparison of NYU Data with CFD Model Prediction 46

14 Gas Composition for each Filter Application 55

15 Granular-Bed Filter Materials $\quad 74$

16 Nominal Composition of Heat-Resistant Alloys (wt\%)

17 Baghouse Design Criteria $\quad 89$

$\begin{array}{lll}18 & \text { Baghouse Equipment Selection } & 90\end{array}$

19 Recuperative Heat Exchanger Design Criteria 91

20 Boost Blower Sizing Criteria $\quad 92$

21 Water-Cooled Heat Exchanger Design Criteria 94

22 CPFBC Granular-Bed Filter Equipment - 225 MWe Module 111 


\section{LIST OF TABLES (cont)}

Number

Page

23 Carbonizer Granular-Bed Filter Equipment - 225 MWe Module

24 KRW Gasifier Granular-Bed Filter Equipment - 100 MWe Plant

25 Ceramic Barrier Filter Experience

26 Filter Face Velocities

27 Candle Filter Pressure Drop/Pulse Gas Parameters

28 Tubesheet Design and Operation Conditions

29 Tubesheet Load Change Transients (100-50-100)

30 CPFBC Pulse Air System (226 MWe Basis)

31 Pulse Gas Parameters - Carbonizer/Gasifier

32 CPFBC Candle Filter Equipment - 226 MWe Module

33 Carbonizer Candle Filter Equipment - 226 MWe Module

34 Gasifier Candle Filter Equipment - 100 MWe Plant

35 Components of Capital Cost

36 Second Generation PFB Combustion Plant

Base Cost of Electricity - Comparisons

37 Second Generation PFB Annual Operating Costs

38 KRW Gasifier Power Plant Cost of Electricity - Comparisons

$39 \quad$ KRW Gasifier Plant Annual Operating Costs

40 Granual-Bed Filter Capital Costs

41 Annual GBF Maintenance Costs

42 Granular-Bed Filter Utility Requirements

43 Ceramic Candle Filter Capital Costs

44 Annual Candle Filter Maintenance Cost 


\section{LIST OF TABLES (cont)}

Number

$\underline{\text { Page }}$

45 Candle Filter Utility Requirements 201

46 Bare Erected Cost Comparison CPFBC Filter, 452 Mwe 204

47 Bare Erected Cost Comparison Carbonizer Filters, 452 Mwe 205

48 Cost Summary, HGCU/Piping \& Ash Handling System 209

49 Cost of Electricity Comparison 210

50 COE Calculation, PFB Combustion Plant with GBF 211

51 COE Calculation, PFB Combustion Plant with Candle Filter 215

52 Relative Plant Capacities for Zinc Ferrite Plant 220

53 Material Cost Breakdown for Zinc Ferrite Plant 221

54 Factored Cost Summary for Zine Ferrite Plant - Dec. 1991 Dollars 222

55 Bare Erected Cost Comparison Gasifier Filters, 100 Mwe 224

56 Cost Summary, KRW Gasifier Based Power Plant 225

57 Cost of Electricity Comparison 226

58 COE Calculation, KRW Gasification Plant with GBF 227

59 COE Calculation, KRW Gasifier Plant with Candle Filter 231

$60 \quad$ Filter Comparisons 253 


\section{INTRODUCIION}

The objective of this program task is to develop conceptual design(s) of moving granular-bed filter and ceramic candle filter technology for control of particles from integrated gasification combined cycle (IGCC) systems, pressurized fluidized-bed combustors (PFBC), and direct coal fueled turbine (DCFT) environments. The conceptual design(s) of these filter technologies are to be compared, primarily from an economic perspective.

The U.S. Department of Energy is currently sponsoring programs to develop advanced coal fired, pressurized fluidized-bed combustors (PFBC's) and gasifiers to be used in combined-cycle, power generating systems. In these systems, a portion of the electricity is generated using a gas turbine driven by the high-temperature, high-pressure process gases. A hot gas cleanup train must be used before the gas turbine to remove the major portion of the particulate. This is necessary to prevent erosion of turbine materials and deposition of particles within the turbine.

The Department of Energy (DOE) specified two existing system studies to be used as the basis for developing conceptual designs and economics for both filter systems. One is a study by Foster Wheeler on a $452 \mathrm{MWe}$, second-generation pressurized fluidized-bed combustion plant ${ }^{1}$. The other is a study by Westinghouse on a 100 MWe integrated gasification combined-cycle (IGCC) plant which uses a Kellogg-Rust-Westinghouse (KRW) air blown gasifier ${ }^{2}$. Ceramic cross-flow filters in both of these systems are replaced with moving granular-bed and ceramic candle filters designed based on current technology.

\section{SUMMARY OF CONCLUSIONS}

The economic study shows that the granular-bed filter compares favorably with the ceramic candle filter from an economic standpoint. For the granular-bed filters, the capital costs are less, the projected maintenance costs are less, the costs of electricity (COE) are less. The summary COE's are presented in Table 1.

The cost of electricity is stated in terms of $10^{\text {th }}$ year levelized dollars. Currentdollar analysis includes expected effects of inflation on capital carrying charges and operating costs. It is used by most utilities in evaluating their business investments. Constant-dollar analysis does not incorporate inflation effects in capital carrying charges and operating costs. It is generally preferred by economic analysts; it makes levelized values appear close to today's values. 
Table 1 Summary Cost of Electricity Values

\begin{tabular}{lcc}
\hline & Plant with & Plant with \\
& Granular-Bed & Candle \\
Cost of Electricity & Filters & Filters \\
\hline
\end{tabular}

452 MWe Second Generation PFB Plant

Current $\$$, mills $/ \mathrm{kWh}$

74.1

76.5

Constant $\$$, mills $/ \mathrm{kWh}$

52.8

54.5

100 MWe KRW (Air) Gasifier Plant

Current $\$$, mills $/ \mathrm{kWh}$

133.2

134.0

Constant $\$$, mills $/ \mathrm{kWh}$

91.8

92.4

\section{PLANT DESCRIPTIONS}

The plant site given for the second generation, pressurized fluidized bed (PFB) combustion plant in the Foster Wheeler study is in the Ohio River Valley of southwestern Pennsylvania/eastern Ohio $^{1}$. This site is considered within 15 miles of a medium-sized metropolitan area and with a well established infrastructure capable of supporting the required construction work force. The site is served by a river with adequate flow to serve as a navigable waterway suitable for shipping shop-fabricated major components to the site. The site is also considered to be served by a well developed road network capable of carrying AASHTO H-20 S-16 loads, with overhead restrictions not lower than $16 \mathrm{ft}$ (Interstate Standard). No such assumptions were made in the study for the KRW gasifier based power plant; so to simplify our task, we used the same assumptions for both plants.

All filter systems were designed to fit within the plant areas chosen by the original designers. For the second generation PFB combustion plant, layouts published in the report were used to define these areas. Elevations of the filters were set by the inlet ducting locations. For the KRW gasification plant, only process schematics were published. Layouts were prepared based on separately supported filters. Both sites are considered to be on relatively flat land.

In this second generation PFB combustion plant concept, coal is fed to a pressurized carbonizer which produces a low BTU fuel gas and a char. The char from the carbonizer is burned in a CPFBC with high excess air. Hot gas clean up (HGCU) devices

a. American Association of State Highway and Transportation Officials. 
are used to remove the particulate from the carbonizer fuel gas and from the vitiated air from the combustor. The cleaned fuel gas is burned in a topping combustor with the cleaned vitiated air from the combustor. The high temperature, high pressure products of combustion from the topping combustor expand in a gas turbine which in turns drives an electric generator and a compressor which supplies air to the combustor and carbonizer. Steam generated in a heat recovery steam generator downstream of the gas turbine and in a fluidized bed heat exchanger, drives the steam turbine generator which supplies the balance of the plant electricity.

The proposed plant produces $452.8 \mathrm{MWe}$ at a heat rate of $7822 \mathrm{Btu} / \mathrm{kWh}$. The plant is divided into two modules with each module consisting of a carbonizer, a CPFBC, HGCU, and a gas turbine module. A $2400 \mathrm{psig} / 1000^{\circ} \mathrm{F} / 1000^{\circ} \mathrm{F} / 2-1 / 2 \mathrm{in}$. $\mathrm{Hg}$ steam turbine is supplied with steam from each module. The carbonizer operates at $1500^{\circ} \mathrm{F}$, the PFBC at $1600^{\circ} \mathrm{F}$, and the topping combustor at $2100^{\circ} \mathrm{F}$.

Each HGCU module for the CPFBC is sized for $175,000 \mathrm{acfm}$ at $1600^{\circ} \mathrm{F}$ and 188 psia $(2,644,236 \mathrm{lb} / \mathrm{hr})$ with an inlet ash concentration of $4000 \mathrm{ppmw}$. There are four granular-bed or ceramic candle filters per 226 MWe module. Each HGCU module for the carbonizer is sized for $15,800 \mathrm{acfm}$ at $1500^{\circ} \mathrm{F}$ and $208 \mathrm{psia}(244,650 \mathrm{lb} / \mathrm{hr})$ with an inlet ash concentration of 10,000 ppmw. In the original study by Foster Wheeler, the PFB combustor had two ceramic cross-flow filters for each 226 MWe module and the carbonizer had one ceramic cross-flow filter. The ceramic cross-flow filters are replaced with moving granular-bed filters and for cost comparison purposes, with ceramic candle filters.

The KRW air blown gasifier ${ }^{2}$ was designated as the second power cycle to be considered in the conceptual designs of the filters. In this process, coal is gasified in an entrained flow reactor using air as the oxidant. Fuel gas and recycle solids from the gasifier are quenched with cooled recycle gas. A primary cyclone returns recycle solids to the gasifier. A secondary cyclone removes additional solids from the fuel gas before the fuel gas enters the HGCU device. The gas is further cooled in a heat recovery boiler and then passes through a fixed bed of zinc ferrite for removal of $\mathrm{H}_{2} \mathrm{~S}$. The fuel gas is burned in a gas turbine with air from the turbine driven compressor. Further heat is recovered in a heat recovery boiler which generates steam for the steam turbine. The plant power output is 100 MWe with a net heat rate of $9000 \mathrm{Btu} H H V / \mathrm{kWh}$. The gas flow to the filter is $12,600 \mathrm{acfm}$ at $1600^{\circ} \mathrm{F}$ and $385 \mathrm{psia}(312,800 \mathrm{lb} / \mathrm{hr})$. As in the Foster Wheeler study, the ceramic cross-flow filters are replaced with moving granular-bed filters and, for cost comparison purposes, with ceramic candle filters.

\section{GRANULAR-BED FILTER DESCRIPTIONS}

Although the filter tested at New York University (NYU) was able to achieve high particulate removal efficiency and meet New Source Performance Standards, the multiple element approach to a commercial design ${ }^{3}$ was perceived to be undesirable due to weight, complexity and cost. It is the goal of this study to improve the commercial design of the moving granular-bed filter, and show that it can be simpler and less costly. Four conceptual designs of moving granular-bed filters were considered. The first design was 
a screenless granular-bed filter configuration like that tested at New York University ${ }^{3}$. To simplify this design, and increase the throughput, we abandoned the multi-element approach in favor of simply increasing the single element size. The second type of filter considered was a screenless filter with multiple gas inlets instead of a single centrally located gas inlet. Next considered was a screened filter in which louvered screens retain the downward moving media while the gas passes horizontally through the screens and the media. The fourth design considered was a high throughput filter which features a screenless inlet and a screened outlet. The lowest cost approach is a single-inlet filter, such as that tested at NYU. Most of the other approaches are within $20 \%$ in estimated cost.

To better understand the fluid mechanics and flow patterns in a larger diameter single entry filter, a computational fluid dynamics (CFD) model was created. The model provides data on the streamline pattern, the flow distribution, and the pressure drop through the filter. The use of the model provides a means of evaluating the effects of changes in filter geometry and flow conditions.

For the CPFBC, the carbonizer, and the KRW gasifier, the granular-bed filter process is nearly identical. Figure 1 shows the general process flow diagram for a granular-bed filter. For each CPFBC there are four filter vessels that are serviced by a single media circulation system. Each carbonizer and gasifier is serviced by a single filter vessel. The following description applies to the granular-bed filters used with the CPFBC, carbonizer, and the gasifier.

Particle laden gas enters each filter vessel through a centrally located, vertical duct submerged in filter media. The media moves continuously downward toward the cone section of the filter. Particles are removed as the gas turns and flows upward through the filter media. The particle-laden media from each filter is withdrawn at the bottom of the filter element and transported pneumatically in a lift pipe to a de-entrainment vessel where the filter media and the ash particles are separated. The clean media flows by gravity back to each filter vessel. The media is distributed in the filter vessel through numerous pipes and through an annulus around the central inlet pipe. The lift gas and the particles leaving the de-entrainment vessel are cooled to $500^{\circ} \mathrm{F}$ in a regenerative heat exchanger. Ash is removed from the cooled lift gas in a pressurized baghouse. The lift pipe transport gas is further cooled to $250^{\circ} \mathrm{F}$ in a water-cooled heat exchanger, boosted in pressure with a blower, reheated in the regenerative heat exchanger and recycled to convey particle-laden media up the lift pipe. Figure 2 shows the basic configuration of the granular-bed filter.

The media used in the filter are $6 \mathrm{~mm}$, manufactured spheres composed mainly of aluminum oxide and mullite. Bulk density is $110 \mathrm{lb} / \mathrm{ft}^{3}$. Based on experience with $2 \mathrm{~mm}$ and $3 \mathrm{~mm}$ media at NYU and Combustion Power, it is expected to be very tough and wear resistant. Wear rates on similar $3 \mathrm{~mm}$ media used in the testing at NYU were too low to be measured. 
The $452 \mathrm{MWe}$, second generation PFB combustion plant is arranged in two identical trains of equipment, each sized for 226 MWe. Each train includes a CPFBC and a carbonizer. There are four granular-bed filter vessels for each $C P F B C$ and one granularbed filter vessel for each carbonizer.

For the CPFBC, the granular-bed filter inside diameter is $20^{\prime}-0^{\prime \prime}$; see Figure 2. Gas flow to each of the four filter vessels in each $226 \mathrm{MWe}$ train is $661,000 \mathrm{lb} / \mathrm{hr}$ at $1600^{\circ} \mathrm{F}$ and $188 \mathrm{psia}$, with an inlet particulate loading of $4000 \mathrm{ppmw}$.

The carbonizer will use one granular-bed filter with an inside diameter of 14'-0" for each $226 \mathrm{MWe}$ module. The gas flow to each filter is $244,650 \mathrm{lb} / \mathrm{hr}$ at $1501^{\circ} \mathrm{F}$ and 208 psia. The ash concentration in the inlet gas stream is $10,000 \mathrm{ppmw}$.

For the 100 MWe, KRW, air blown gasifier, a single granular-bed filter vessel is proposed. The KRW gasifier will use a 14'-0" diameter filter similar to that used for the carbonizer. The gas flow to the filter is $312,800 \mathrm{lb} / \mathrm{hr}$ at $1600^{\circ} \mathrm{F}$ and 385 pisa. The ash concentration in the inlet gas stream is 8,500 ppmw.

\section{CANDLE FIITER DESCRIPTIONS}

Currently, the ceramic candle filter appears to have the most promise for successful development. Ceramic candle filter elements are commercially available from a few sources. These filter elements are rigid tubes, closed at the bottom and flanged at the top. They are formed by bonding ceramic fibers and/or grains with an aluminosilicate binder. Lengths are typically 1 to $1.5 \mathrm{~m}$ and outside diameters are $60 \mathrm{~mm}$ with a wall thickness of 10 to $15 \mathrm{~mm}$. Candle filter elements are mounted in tubesheets, utilizing a variety of arrangements to clamp and seal the filter element flanges. Tubesheets not only support the candle filters, but seal the clean gas plenum from dirty gases. Candle filters are cleaned periodically by high pressure bursts of gas delivered near the filter element outlets. In combustion systems, high pressure air is used to clean the filter elements. In gasifiers, nitrogen or process gas is used.

In our literature search, design variables and potential configurations for candle filters were identified. The most critical design variable is filter face velocity, expressed in $\mathrm{ft} / \mathrm{min}$ (or $\mathrm{cm} / \mathrm{sec}$ ). This is the average velocity at which the process gas approaches the candle filter elements. Although a data base is forming, there are considerable, and varying, opinions on this variable.

Ash from the process collects on one side of the filter element. Periodically, the ash is removed by back flushing with a high pressure pulse of air or gas. The amount of pulse air, or gas, needed to clean each filter element is another important design parameter. There in quite a divergence between early design values, lab measured quantities, and field measured quantities. This flow is significant because it lowers the process gas temperature, can be a source of heat loss, and requires equipment of considerable capital cost. 


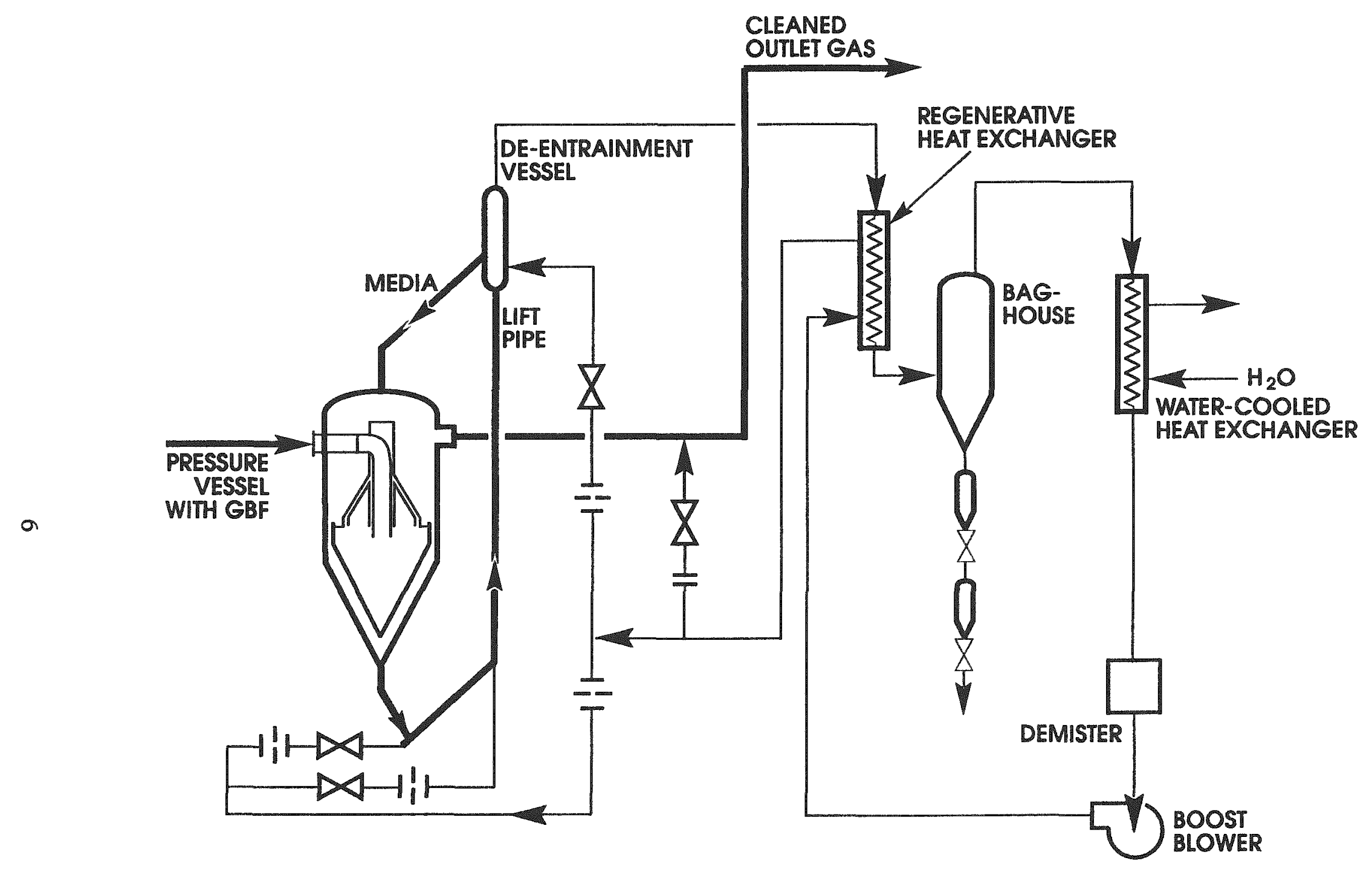

Figure 1 Process Flow Diagram for Granular-Bed Filter 


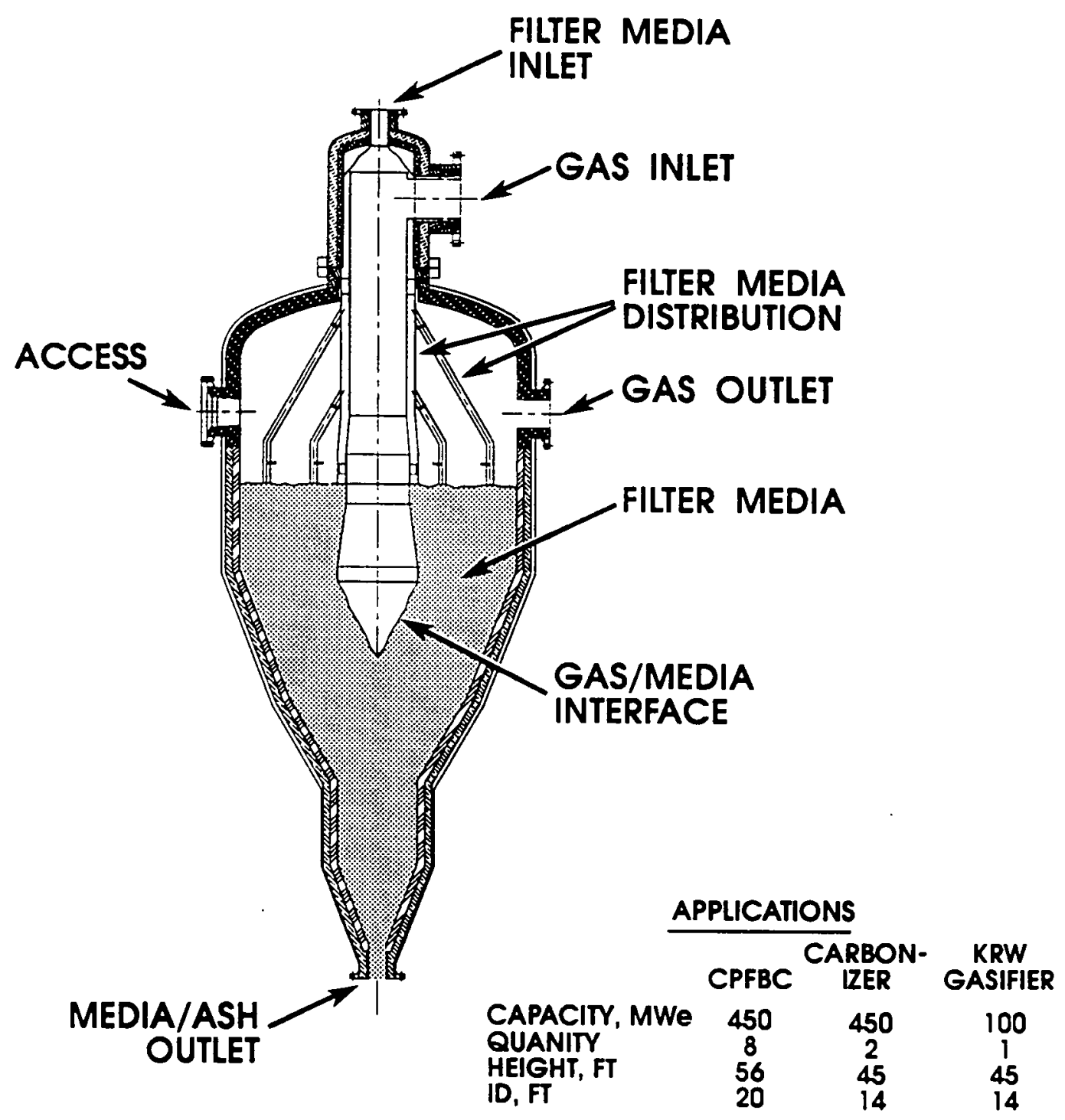

Figure 2 Configuration of Granular-Bed Filter 
The number of filter elements that can be pulsed by single manifold is another difficult tradeoff. A large quantity of filter elements serviced by a single manifold results in fewer manifolds and a less bulky supply system. The drawback is in attenuation of the air or gas pulse as it is spread through a higher volume manifold. Other design parameters can also have a profound effect on the filter design. These are: filter element size, filter element spacing, and pulse gas pressure.

The candle filter configuration shown on Figure 3 is based on utilizing the largest tubesheet possible. This was shown feasible by stress analysis on a unique tubesheet and tubesheet support design. All filter elements are attached to the tubesheet to simplify the filter element layout and the pulse gas piping. In this configuration, filter elements can be inspected and maintained from inside the filter vessel.

Hot process gases and particulate enter at a single port on the side of the vessel below the tubesheet, and are distributed by a cylindrical baffle around the outer edge of the candle filter array near the upper end of the candle filters. The ash cake collected on the outside surface of the elements is dislodged by periodic high pressure bursts of pulse gas. For filters in oxidizing atmospheres, air is used for pulse cleaning of the filter elements. For filters in gasification environments, either process gas or nitrogen may be used for pulse gas. The ash cake dislodged from the filter elements is collected in the conical hopper below the tubesheet and is discharged into a suitable ash handling system. In the gasifier filter, the ash is first cooled using a water-cooled screw and then depressurized the through lock-hoppers. In the CPFBC system the ash is depressurized through a restricted pipe discharge (RPD) vessel as proposed in the Foster Wheeler study and then cooled using a water-cooled screw. In the carbonizer, the hot pressurized ash is fed directly into the PFBC according to the Foster Wheeler study.

Each of the two CPFBC's has a filter module composed of four candle filter vessels. Each filter vessel has an inside refractory diameter of $20^{\prime}-6^{\prime \prime}$ and tubesheet diameter of $18^{\prime}-0^{\prime \prime}$. The inlet gas flow to each filter vessel is $657,652 \mathrm{lb} / \mathrm{hr}$ at $1600^{\circ} \mathrm{F}$ and 188 psia. This inlet gas flow is slightly lower then for the CPFBC granular-bed filters by the amount of pulse air added to the CPFBC candle filters. This allows for equal outlet gas flow for both the CPFBC candle filters and granular-bed filters. The ash concentration in the inlet gas stream is $4,000 \mathrm{ppmw}$. A filter face velocity of $10 \mathrm{ft} / \mathrm{min}$ was specified for the $\mathrm{CPFBC}$ filter.

The candle filter for the carbonizer on each of the two CPFBC's has a single filter vessel in which the refractory inside diameter is $18^{\prime}-0^{\prime \prime}$ and the tubesheet diameter is $15^{\prime}$ $6^{\prime \prime}$. The inlet gas flow to each filter vessel is $244,650 \mathrm{lb} / \mathrm{hr}$ at $1500^{\circ} \mathrm{F}$ and 207.90 psia. The ash concentration in the inlet gas stream is 10,000 ppmw. A filter face velocity of $5 \mathrm{ft} / \mathrm{min}$ was specified for the carbonizer. 


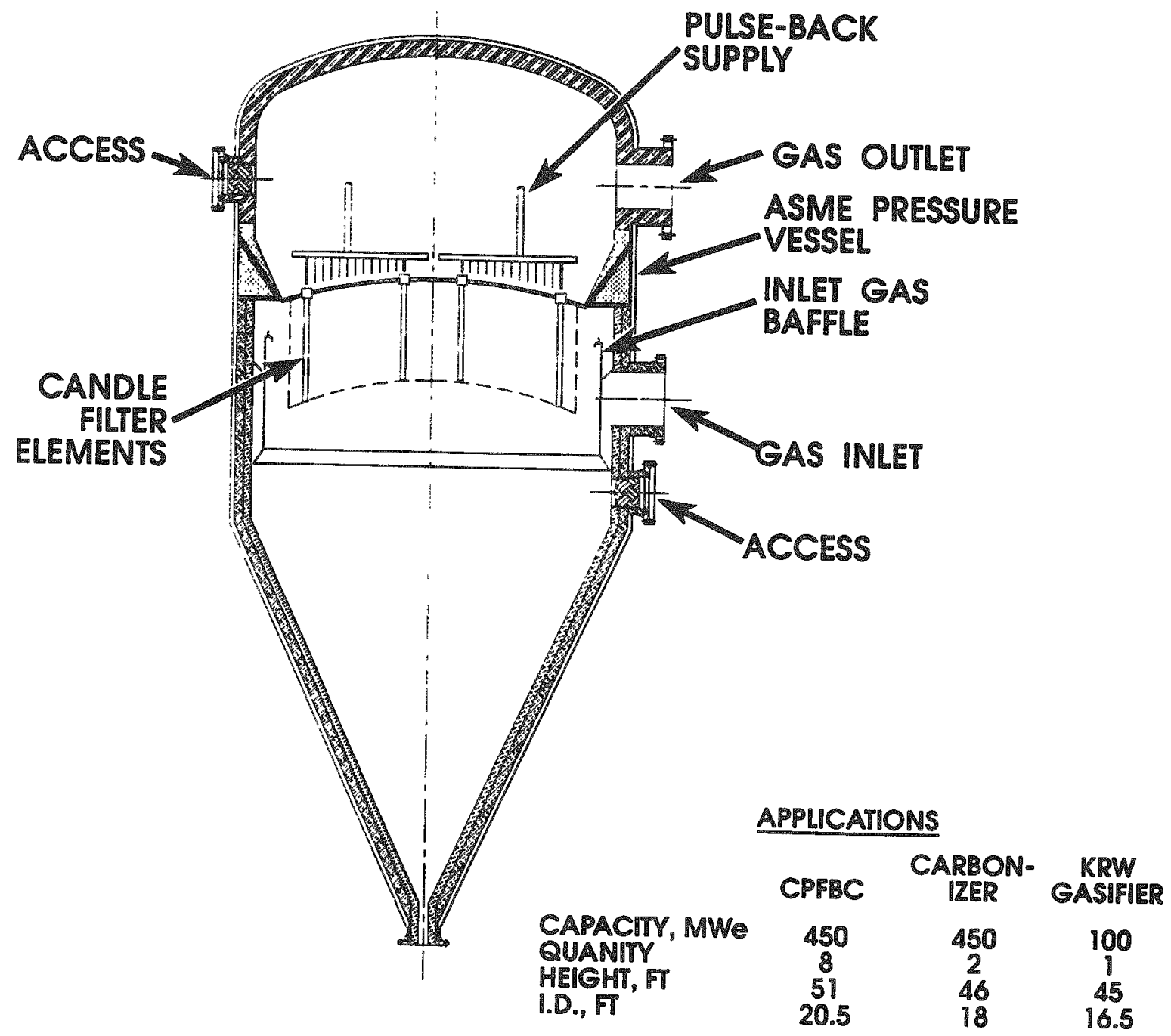

Figure 3 Configuration of Candle Filters 
The candle filter for the gasifier has a single filter vessel in which the refractory inside diameter is $16^{\prime}-6^{\prime \prime}$ and the tubesheet diameter is $14^{\prime}-0^{\prime \prime}$. The inlet gas flow to the filter vessel is $312,800 \mathrm{lb} / \mathrm{hr}$ at $1600^{\circ} \mathrm{F}$ and $385.00 \mathrm{psia}$. The ash concentration in the inlet gas stream is $8,500 \mathrm{ppmw}$. A filter face velocity of $5 \mathrm{ft} / \mathrm{min}$ was specified for the gasifier.

\section{HFAT LOSSES AND PRESSURE DROP}

Heat loss and pressure drop across each filter is accounted for in the calculation for the COE. Filter pressure drop represents a loss in power generation. Heat losses show up as temperature drop across the filter and can be accounted for by burning or gasifying more coal. These values are shown in Table 2. The candle filter pressure drop was predicted using filter cake resistivity measurements made by $\mathrm{METC}^{4}$ researchers, and the GBF pressure drop was established by finite element (CFD) analysis as described above. Heat loss for the candle filters includes radiation and convection losses from the filter vessels and heat loss from cooling process gas for use as pulse gas. Since pulse air for the CPFBC candle filter is not cooled prior to usage, it does not represent a heat loss. For the granular bed filter, heat loss includes radiation and convection losses from the filter vessel and the media circulation system components, and heat loss from cooling filter media circulation gases. This heat could be used to heat boiler feedwater, but this is not proposed.

Table 2 Filter Pressure/Temperature Drop

Item

Granular-Bed

Candle Filters

Filters

CPFBC Filter

Pressure Drop, psi

3.0

2.66

Temperature Drop, ${ }^{\circ} \mathrm{F}$

20

12

Carbonizer Filter

Pressure Drop, psi

Temperature Drop, ${ }^{\circ} \mathrm{F}$

34

27

$\underline{\text { KRW Gasifier Filter }}$

Pressure Drop, psi

1.31

1.99

Temperature Drop, ${ }^{\circ} \mathrm{F}$

35

31 


\section{FIITER COSTS}

Costs, in December, 1991 dollars, for the commercial size granular-bed and ceramic candle filter plants are presented in Tables 3,4 , and 5 for comparison. Filters for the CPFBC and the carbonizer in the second generation PFB combustion plant are presented in Tables 3 and 4, respectively. Gasifier filter costs are presented in Table 5. Bare erected costs include capital and installation costs for equipment. The granular-bed filter system includes: filter media circulation and cleaning, ash cooling, and ash discharge equipment. The candle filter system includes: pulse gas supply, ash cooling, and ash discharge equipment. The candle filter vessels are larger and heavier than the granular-bed filter vessels, accounting for the higher cost. Granular-bed filter internals are lighter than the candle filter internals (tubesheet and support); thus, costs are lower. For the granular-bed filter, the media circulation system separates ash from the filtration media, serving a similar function as the candle filter pulse cleaning system. For the granular-bed filter, the regenerative heat exchanger cools the ash; the candle filter uses a water-cooled ash screw (except for the carbonizer filter which feeds ash directly to the $\mathrm{PFBC}$ ).

Annual maintenance costs are determined as a percentage of the bare erected cost of the filter system plus the cost of replacing systems expected to have a short life. The EPRI TAG recommends maintenance costs ranging from $3 \%$ to $6 \%$ of the bare erected cost for processes handling solids at high temperature and pressure. Four percent is used in this study since the maintenance cost of major pieces of equipment needing periodic replacement are added to this base maintenance cost.

For the granular-bed filter, three areas are identified that will require periodic replacement. The bags in the pressurized baghouse are recommended for replacement on a yearly basis by the vendor. The lift pipe liner is assumed to need replacement every three years, based on the limited data from testing at NYU, and the filter internals for the carbonizer and gasifier are assumed to need replacement every five years, based on corrosion rates for metals in high temperature, reducing atmospheres.

For the ceramic candle filters, four areas are identified that will require periodic replacement. It is assumed that filter elements will need replacement every three years. Solenoid pulse valve and isolating ball valve replacement is at $10 \%$ and $5 \%$ per year based on the high number of cycles. The filter internals for the carbonizer and gasifier are assumed to need replacement every five years, based on corrosion rates for metals in high temperature, reducing atmospheres.

Electrical requirements for the granular-bed filters include power for the boost blowers and for cooling water supply to the water-cooled heat exchanger. Most of the power is for the boost blowers. For the candle filter, power is required for pulse air/gas compressors and dryers, ash coolers, and miscellaneous cooling water needs. Most of the power is for the pulse air/gas compressors and dryers. 
Table 3 CPFBC Filter Cost Comparison

(452 Mwe Basis)

Granular-Bed Filter System

Candle Filter System

\begin{tabular}{lrlr}
\hline & $\$ / 1000$ & & \\
Filter Vessels (8) & 4,031 & Filter Vessels (8) & $5 / 1000$ \\
Filter Internals (8) & 2,121 & Filter Internals (8) & 7,385 \\
Vessel Refractory & 1,647 & Vessel Refractory & 2,142 \\
Filter Media & 2,070 & Filter Elements & 3,135 \\
Circulation System & & Pulse Back & 3,477 \\
$\quad$ Vessels/Piping & 2,476 & Piping/Valves & \\
$\quad$ Regen. Ht. Exch. & 5,412 & Compressors & 5,847 \\
$\quad$ Water-Cooled Hx. & 81 & Ash System & 1,108 \\
$\quad$ Baghouse & 412 & Vessels/Piping & \\
$\quad$ Boost/Maint. Blower & 1,094 & Ash Coolers & 390 \\
Instr/Controls & 200 & Ash Valves & 919 \\
Inlet/Outlet Ducting & 3,062 & Instr/Controls & 1,436 \\
Access/Support Steel & 1,551 & Inlet/Outlet Ducting & 196 \\
Foundation Mat'l & 56 & Access/Support Steel & 3,730 \\
Ash System & 275 & Foundation Mat'l & 1,486 \\
Erection & 1,160 & Erection & 42 \\
Engineering & 949 & Engineering & 2,871 \\
Freight & 743 & Freight & 949 \\
& & & 1,074 \\
Bare Erected Cost, $\mathrm{k} \$$ & 27,339 & & 38,187 \\
Maintenance Cost, $\mathrm{k} \$ / \mathrm{yr}$ & 1,040 & & 2,522 \\
Electrical Load, $\mathrm{kVa}$ & 349 & & 318 \\
\hline
\end{tabular}


Table 4 Carbonizer Filter Cost Comparison

(452 Mwe Basis)

Granular-Bed Filter System

Candle Filter System

\begin{tabular}{lrlr}
\hline & $\$ / 1000$ & & $\$ / 1000$ \\
Filter Vessels (2) & 460 & Filter Vessels (2) & 972 \\
Filter Internals (2) & 186 & Filter Internals (2) & 761 \\
Vessel Refractory & 232 & Vessel Refractory & 489 \\
Filter Media & 237 & Filter Elements & 784 \\
Circulation System & & Pulse Back & \\
$\quad$ Vessels/Piping & 1,182 & Piping/Valves & 1,181 \\
$\quad$ Regen. Ht. Exch. & 1,224 & Compressors & 771 \\
$\quad$ Water-Cooled Hx. & 32 & Ash System & - \\
$\quad$ Baghouse & 137 & Vessels/Piping & - \\
$\quad$ Boost/Maint. Blower & 382 & Ash Coolers & - \\
Instr/Controls & 148 & Ash Valves & 93 \\
Access/Support Steel & 450 & Instr/Controls & 450 \\
Foundation Mat'l & 28 & Access/Support Steel & 19 \\
Ash System & 168 & Foundation Mat'l & 698 \\
Erection & 442 & Erection & 377 \\
Engineering & 377 & Engineering & 200 \\
Freight & 166 & Freight & 6,795 \\
Bare Erected Cost & 5,851 & & 619 \\
Maintenance Cost, $\mathrm{k} \$ / \mathrm{yr}$ & 286 & & 123 \\
\hline Electrical Load, $\mathrm{kVa}$ & 59 & &
\end{tabular}


Table 5 KRW Gasifier Filter Cost Comparison

(100 Mwe Basis)

Granular-Bed Filter System

Candle Filter System

\begin{tabular}{lrlr}
\hline & $\$ / 1000$ & & \\
Filter Vessel & 405 & Filter Vessel & $\$ / 1000$ \\
Filter Internals & 99 & Filter Internals & 738 \\
Vessel Refractory & 116 & Vessel Refractory & 340 \\
Filter Media & 119 & Filter Elements & 182 \\
Circulation System & & Pulse Back & 314 \\
$\quad$ Vessels/Piping & 666 & Piping/Valves & \\
Regen. Ht. Exch. & 873 & Compressors/Coolers & 506 \\
Water-Cooled Hx. & 19 & Ash System & 542 \\
Baghouse & 78 & Ash Coolers & \\
$\quad$ Boost/Maint. Blower & 137 & Ash Hoppers & 570 \\
Instr/Controls & 74 & Ash Valves & 31 \\
Access/Support Steel & 213 & Instr/Controls & 74 \\
Foundation Mat'l & 10 & Access/Support Steel & 50 \\
Ash System & 87 & Foundation Mat'l & 113 \\
Erection & 217 & Erection & 8 \\
Engineering & 561 & Engineering & 300 \\
Freight & 102 & Freight & 561 \\
Bare Erected Cost, $\mathrm{k} \$$ & 3,775 & & 130 \\
Maintenance Cost, $\mathrm{k} \$ / \mathrm{yr}$ & 156 & & 4,458 \\
Electrical Load, $\mathrm{kVa}$ & 22 & & 300 \\
\hline
\end{tabular}




\section{FUTURE WORK}

Determination of capital and operation costs for commercial size granular bed and ceramic candle filters, and comparison of the resultant COE's, is the first task of a program that has three other options. These options will be funded by the Department of Energy at its discretion.

\section{Option I}

Component Testing provides the opportunity to test and evaluate different granular bed filter designs and critical sub-systems determined from the base study described above.

\section{Option II}

Moving granular bed filter proof tests will be performed at a Gasification and PFBC Test Facility. The granular-bed filter has been proven to be feasible in the tests at NYU. The new filter design has the same basic configuration, but different proportions. A new test series needs to be arranged to prove that the design is practical. Presumably, this can be resolved at the Southern Company Services test facility that is being designed at this time.

\section{OPTION III}

Successful development of the granular bed filter for multi-contaminant control will make this equipment unique. Besides removing particulate, a granular-bed filter has the potential of removing other pollutants in the gas stream. The filter is an excellent gas/solids contactor; in that, it has gas residence times in the order of several seconds, solids residence times in the order of several hours, uniform gas flow across the media, and the gas and filter media flow in opposite directions for the maximum driving potential.

The contaminants of major concern, besides particulate in coal utilization processes, are sulfur compounds, nitrogen compounds, alkali compounds, halogenated compounds, tars, and trace contaminants such as cadmium and mercury ${ }^{5}$. A granularbed filter which is able to capture particulate and one or more of these additional contaminants would have significant benefits over just a particulate removal system.

Many processes that are under development are able to meet current New Source Performance Standards, but may have trouble meeting more stringent requirements which could be promulgated in the future. As an example, pressurized fluidized bed combustors are able to meet New Source Performance Standards of $90 \%$ sulfur removal but probably will have difficulty obtaining 95-98\% sulfur removal. A granular-bed filter with an $\mathrm{SO}_{2}$ absorbing media may be able to increase the overall sulfur removal efficiency from $90 \%$ to $98 \%$ in a PFBC system while maintaining a cost effective calcium to sulfur ratio.

Having determined possible processes for multi-contaminant control, proof of concept testing will be required to establish feasibility of the proposed processes. In order 
to conduct the proof of concept testing, test plans and conceptual designs of the test equipment will be prepared. Actual testing will occur in the next phase of the program after approval of the test plans by DOE.

\section{REFERENCES}

1. Robertson, A., and R. Garland, R. Newby, A. Rehmat, and L. Rubow. September, 1989. Second-Generation Pressurized Fluidized Bed Combustion Plant Conceptual Design and Optimization of a Second-Generation PFB Combustion Plant, Phase 1, Task 1. Report DOE/MC/21023-2825, Vol.1. Prepared by Foster Wheeler Development Corporation, Livingston, New Jersey under contract No. DE-AC21-86MC21023.

2. D. F. Ciliberti, T. E. Lippert. 1986. Performance Evaluation of a Ceramic Cross-Flow Filter on a Bench-Scale Coal Gasifier. Westinghouse Eighth Quarterly Report and Monthly Project Status Report for September 1, 1986 - September 30, 1986. DOE/METC Contract No. DE-AC21-84-MC21338. Morgantown, West Virginia: Morgantown Energy Technology Center.

3. Wilson, K.B., J.C. Haas and J.C. Cooper. March, 1898. Performance Evaluation of a Screenless (Counter-Current) Granular Bed Filter on a Subpilot-Scale PFBC. In Proceedings of the Sixth Annual Coal-Fueled Heat Engines and Gas Stream Cleanup Systems Contractors Review Meeting, ed. R.C. Bedick, T.P. Dorchak, N.F. Rekos, H.A. Webb, 293303. Morgantown, WV. Morgantown Energy Technology Center. DOE/METC-89/6101 (DE89000952).

4. Dennis, R.A. August, 1990. Evaluation of Dust Cake Filtration at High Temperature With Effluence from an Atmospheric Fluidized-Bed Combustor. Technical note: DOE/METC91/4105. Morgantown, West Virginia: Morgantown Energy Technology Center.

5. Bossart, S.J., D.C. Cicero, C.M. Zeh, and R.C. Bedick. August, 1990. Gas Stream Cleanup-Technology Status Report. DOE/METC-91/0273. 


\section{SECTION 1}

\section{INTRODUCTION}

\subsection{Program Objectives}

The U.S. Department of Energy is currently sponsoring programs to develop advanced coal fired, pressurized fluidized-bed combustors (PFBC's) and gasifiers to be used in combined-cycle, power generating systems. In these systems, a portion of the electricity is generated using a gas turbine driven by the high-temperature, high-pressure process gases. A hot gas cleanup train must be used before the gas turbine to remove the major portion of the particulate. This is necessary to prevent erosion of turbine materials and deposition of particles within the turbine. The granular-bed filter (GBF) has shown considerable promise to date and has been chosen for further investigation by the U.S. Department of Energy.

The objective of the base portion of the contract is to develop conceptual design(s) of moving granular-bed filter and ceramic candle filter technology for control of particles from integrated gasification combined cycle (IGCC) systems, pressurized fluidized-bed combustors (PFBC), and direct coal fueled turbine (DCFT) environments. The conceptual design(s) of these filter technologies are to be compared, primarily from an economic perspective. The results of the base contract are reported in this topical report.

The development of moving granular-bed filter technology for control of particles in gasification and PFBC environments is directly applicable and transferable to the employment of moving granular-bed filter technology in the reduction ("fuel rich") and oxidation ("fuel lean") DCFT systems.

After the completion of the base contract, the Department of Energy will fund at its discretion three Options. The objective of Option I is to identify and resolve technical issues associated with development of moving granular-bed filter technology through the use of a component test facility. The objective of Option II is to test and evaluate the GBF at a Government-furnished hot gas cleanup test facility. This facility has been identified as the Southern Company Services, Power Systems Development Facility in Wilsonville, Alabama. The objective of Option III is to develop moving GBF technology for multicontaminant control of particles and other coal-derived contaminants such as sulfur and alkali.

\subsection{General Approach}

A technical work plan was developed to define the methodology which would be used to develop an improved granular-bed filter and determine the costs of GBF's and ceramic candle filters. The work plan is divided into the following steps. 


\subsubsection{Basis for Conceptual Designs}

The Department of Energy (DOE) specified two existing system studies to be used as the basis for developing conceptual designs and economics for both filter systems. One is a study by Foster Wheeler on a $452 \mathrm{MWe}$, second-generation pressurized fluidized-bed combustion plant ${ }^{1}$. The other is a study by Westinghouse on a 100 MWe integrated gasification combined-cycle (IGCC) plant which uses a Kellogg-Rust-Westinghouse (KRW) air blown gasifier ${ }^{2}$. Ceramic cross-flow filters in both of these systems are replaced with moving granular-bed and ceramic candle filters designed based on current technology.

\subsubsection{GBF Conceptual Designs}

Four design approaches of a moving granular-bed filter were investigated.

1. Single Gas Entry: The first approach was to scale the single gas entry, counterflow, screenless GBF, which was tested at New York University (NYU) to a larger diameter filter. The filter diameter was scaled from 5 to $28 \mathrm{ft}$ and has a filter bed depth based on scaling factors. As part of the scale-up effort, the media size was increased from $3 \mathrm{~mm}$, tested at NYU, to $6 \mathrm{~mm}$, the largest size commercially available. In order to investigate geometry changes, a computational fluid dynamics program was used to predict filter gas flow patterns and gas pressure drop.

2. Multiple Gas Entry: The second approach was to evaluate a large diameter, counterflow, screenless GBF with multiple gas entries. Some of the information gathered from testing at NYU was used in this conceptual design.

3. Screened Inlet and Outlet: The third type of filter evaluated was a screened or louvered type of granular-bed filter similar to that used commercially at low temperatures (up to $600^{\circ} \mathrm{F}$ ) and low pressure ( $1 \mathrm{psig}$ ).

4. Screened Outlet: This filter concept is a hybrid between the single inlet filter and a screened outlet filter. Its potential advantage is a much higher gas capacity than concepts 1 and 2 and for this reason is called a "high-flow" granular-bed filter.

\section{- Relative Cost Analysis of GBF Conceptual Designs}

A relative cost analysis and technical assessment was used to evaluate the relative merits of the granular-bed filter designs. The overall most attractive design for PFBC and for IGCC was further developed to provide a better cost estimate.

For each application, a conceptual design was prepared consisting of:

- Filter Vessel(s)

- Filter media circulation system

- Ash cooling and removal system 


\subsubsection{Candle Filter Design}

Combustion Power gathered background information on candle filter designs from published reports and DOE researchers. Vendors of ceramic candle filter elements were surveyed to determine design parameters and characteristics of filter elements. Based on current practice, a candle filter design was formulated for both Pressurized Fluidized Bed Combustion and Integrated Gasification Combined Cycle applications. Conceptual designs of candle filters were compared:

1. V-Support Tubesheet: Filter diameter limitations were explored utilizing a solid, V-support for the tubesheet.

2. Tiered Tubesheet: A large filter with multiple tiers to support the candles was compared with a filter with a single tubesheet.

3. Filter Quantities: The cost of numerous smaller filters was compared against fewer larger filters. Singles tubesheet were assumed for the comparison.

4. Modified Tubesheet Support: A unique conical tubesheet support was investigated. Tubesheet diameters up to $18^{\prime}-0^{\prime \prime}$ were analyzed.

- Comparison of Candle Filter Conceptual Designs

A relative cost analysis and technical assessment was used to evaluate the relative merits of the ceramic candle filter designs. The overall most attractive design for PFBC and for IGCC was further developed to provide a better cost estimate.

The filter design consists of:

- Filter vessel(s)

- Pulse cleaning system

- Ash cooling and removal system

- Gas distribution system

- Filter element supports and pressure seals

\subsubsection{Design and Cost Estimate}

The design effort and cost estimate consisted of:

- Design Package

- Supporting structure, ducting and foundations

- Process flow diagrams

- P \& ID 
- General arrangement drawings

- Utility requirements

- Major equipment specifications

\section{- Capital Cost}

We performed a Class II (preliminary) design and cost estimate as defined in the EPRI Technical Assessment Guide (TAG) ${ }^{\circledR}$. Capital costs of major pressure vessels and refractory are based on estimates from fabricators. Major equipment cost of items such as blowers, heat exchangers, ash coolers, and baghouses are based on vendor quotations. Cost of instruments, controls, structural steel, piping and ducting are based on recent purchase costs adjusted for inflation. The installation cost of each filter is based on an itemized construction cost estimate by a certified cost engineer. Process and project contingency and other parameters used to establish the capital cost of the base plants were used in costing the filters.

\section{- Operating and Maintenance Costs}

Operating costs for the all filter systems are based on guidelines given by the EPRI Technical Assessment Guide (TAG). Since no filter configuration constituted a major portion of the power plant, no adjustment to operation labor was made from the base studies that included cross-flow filters. Filter pressure drop and heat loss are include in the comparison. Maintenance costs for the granular-bed and the candle filters are compared by using EPRI TAG guidelines, and augmenting with items unique to each filter.

\section{- Cost of Electricity (COE)}

$\mathrm{COE}$ is determined by using a Lotus 1-2-3 spreadsheet provided by the Department of Energy, and is based on EPRI's Technical Assessment Guide, Volume 1, December, 1986. The COE is the basis for economic comparison between the granular-bed filter and the ceramic candle filter. The COE for each application is updated to December, 1991 cost using the Chemical Engineering Magazine Plant Cost Index. For the gasifier application, the cost of the zinc ferrite plant section is updated using costs from the EG\&G study ${ }^{3}$ submitted to us by DOE.

\subsubsection{Comparison of Granular-Bed Filter and Candle Filter}

The granular-bed filter is compared with the candle filter in terms of capital cost, maintenance requirements, utility demands, pressure and temperature drop, and cost of electricity. 


\subsection{REFERENCES}

1. Robertson, A., and R. Garland, R. Newby, A. Rehmat, and L. Rubow. September, 1989. Second-Generation Pressurized Fluidized Bed Combustion Plant Conceptual Design and Optimization of a Second-Generation PFB Combustion Plant, Phase 1, Task 1. Report DOE/MC/21023-2825, Vol.1. Prepared by Foster Wheeler Development Corporation, Livingston, New Jersey under contract No. DE-AC21-86MC21023.

2. D. F. Ciliberti, T. E. Lippert. 1986. Performance Evaluation of a Ceramic Cross-Flow Filter on a Bench-Scale Coal Gasifier. Westinghouse Eighth Quarterly Report and Monthly Project Status Report for September 1, 1986 - September 30, 1986. DOE/METC Contract No. DE-AC21-84-MC21338. Morgantown, West Virginia: Morgantown Energy Technology Center. 


\section{SECTION 2}

\section{OVERALL PLANT DESCRIPTIONS AND FILTER REQUIREMENTS}

\subsection{Plant Site Description}

The plant site given for the second generation pressurized fluidized bed (PFB) combustion plant in the Foster Wheeler study is in the Ohio River Valley of southwestern Pennsylvania/eastern Ohio ${ }^{1}$. This site is considered within 15 miles of a medium-sized metropolitan area and with a well established infrastructure capable of supporting the required construction work force. The site is served by a river with adequate flow to serve as a navigable waterway suitable for shipping shop-fabricated major components to the site. The site is also considered to be served by a well developed road network capable of carrying AASHTO H-20 S-16 ${ }^{\mathrm{a}}$ loads, with overhead restrictions not lower than $16 \mathrm{ft}$ (Interstate Standard). No such assumptions were made in the study for the KRW gasifier based plant; so to simplify our task, we used the same assumptions for both plants.

All filter systems were designed to fit within the plant areas chosen by the original designers. For the second generation PFB combustion plant, layouts published in the report were used to define these areas. Elevations of the filters were set by the inlet ducting locations. For the KRW Gasification Plant, only process schematics were published. Layouts were prepared based on separately supported filters. Both sites are considered to be on relatively flat land with a maximum difference in elevation within the site of about $30 \mathrm{ft}$. The topography of the area surrounding the site is rolling hills with elevation within 2000 yd not more than $300 \mathrm{ft}$ above the site elevation. Again, this is based on the second generation PFB combustion plant.

Site conditions, as defined by the Uniform Building Code, and ambient design conditions are:

$\begin{array}{ll}\text { Seismic } & \text { UBC, Zone 1 } \\ \text { Wind } & \text { UBC, 70 mph } \\ \text { Barometric Pressure } & 14.4 \text { psia } \\ \text { Dry Bulb Temperature } & 60^{\circ} \mathrm{F} \\ \text { Wet Bulb Temperature } & 52.5^{\circ} \mathrm{F}\end{array}$

This generic work site includes a sufficient work force of well-trained construction labors within a 50-mile radius of the site. Labor conditions are such that suitable work agreements can be obtained from labor organizations and contractors. All necessary bulk construction materials are available locally and can be delivered within a reasonable period of time.

a. American Association of State Highway and Transportation Officials. 
Although this generic site was prepared for the second generation PFB combustion plant, it was used to prepare cost estimates for the KRW gasification based power plant. Although specific site conditions could dictate design and cost changes, the comparisons in this report should be valid.

\subsection{Second Generation PFB Combustion Plant}

Foster Wheeler Development Corporation is developing a second-generation fluidized bed combustion plant. In this concept, coal is fed to a pressurized carbonizer which produces a low BTU fuel gas and a char. The char from the carbonizer is burned in a circulating pressurized fluidized bed combustor (CPFBC) with high excess air. Hot gas clean up (HGCU) devices are used to remove the particulate from the carbonizer fuel gas and from the vitiated air from the combustor. The cleaned fuel gas is burned in a topping combustor with the cleaned vitiated air from the combustor. The high temperature, high pressure products of combustion from the topping combustor expand in a gas turbine which in turns drives an electric generator and a compressor which supplies air to the combustor and carbonizer. Steam generated in a heat recovery steam generator downstream of the gas turbine and in a fluidized bed heat exchanger, drives the steam turbine generator which supplies the balance of the plant electricity.

The proposed plant produces $452.8 \mathrm{MWe}$ at a heat rate of $7822 \mathrm{Btu} / \mathrm{kWh}$. The plant is divided into two modules with each module consisting of a carbonizer, a CPFBC, a HGCU and a gas turbine module. A $2400 \mathrm{psig} / 1000^{\circ} \mathrm{F} / 1000^{\circ} \mathrm{F} / 2-1 / 2 \mathrm{in}$. Hg steam turbine is supplied with steam from each module. The carbonizer operates at $1500^{\circ} \mathrm{F}$, the $\mathrm{CPFBC}$ at $1600^{\circ} \mathrm{F}$, and the topping combustor at $2100^{\circ} \mathrm{F}$.

Table 6 shows the gas and solids flow rates, gas and solids compositions, and particle size for each of the two CPFBC modules. In the original study by Foster Wheeler, the PFB combustor had two ceramic cross-flow filters for each module and the carbonizer had one ceramic cross-flow filter. Figure 4 shows a simplified schematic of the secondgeneration PFB combustion plant with ceramic cross-flow filters as the HGCU devices. The ceramic cross-flow filters are replaced with moving granular-bed filters and for cost comparison purposes, with ceramic candle filters.

\subsection{Gasification Based Power Plant}

The KRW air blown gasifier ${ }^{2}$ was designated as the second power cycle to be considered in the conceptual design of a granular-bed or ceramic candle filter. In this process, coal is gasified in a fluidized bed reactor using air as the oxidant. Fuel gas and recycle solids from the gasifier are quenched with cooled recycle gas. A primary cyclone returns recycle solids to the gasifier. A secondary cyclone removes additional solids from the fuel gas before the fuel gas enters the HGCU device. The gas is further cooled in a heat recovery boiler and then passes through a fixed bed of zinc ferrite for removal of $\mathrm{H}_{2} \mathrm{~S}$. The fuel gas is burned in a gas turbine with air from the turbine driven compressor. Further heat is recovered in a heat recovery boiler which generates steam 
Table 6 HGCU Filter Requirements for Each CPFBC Module

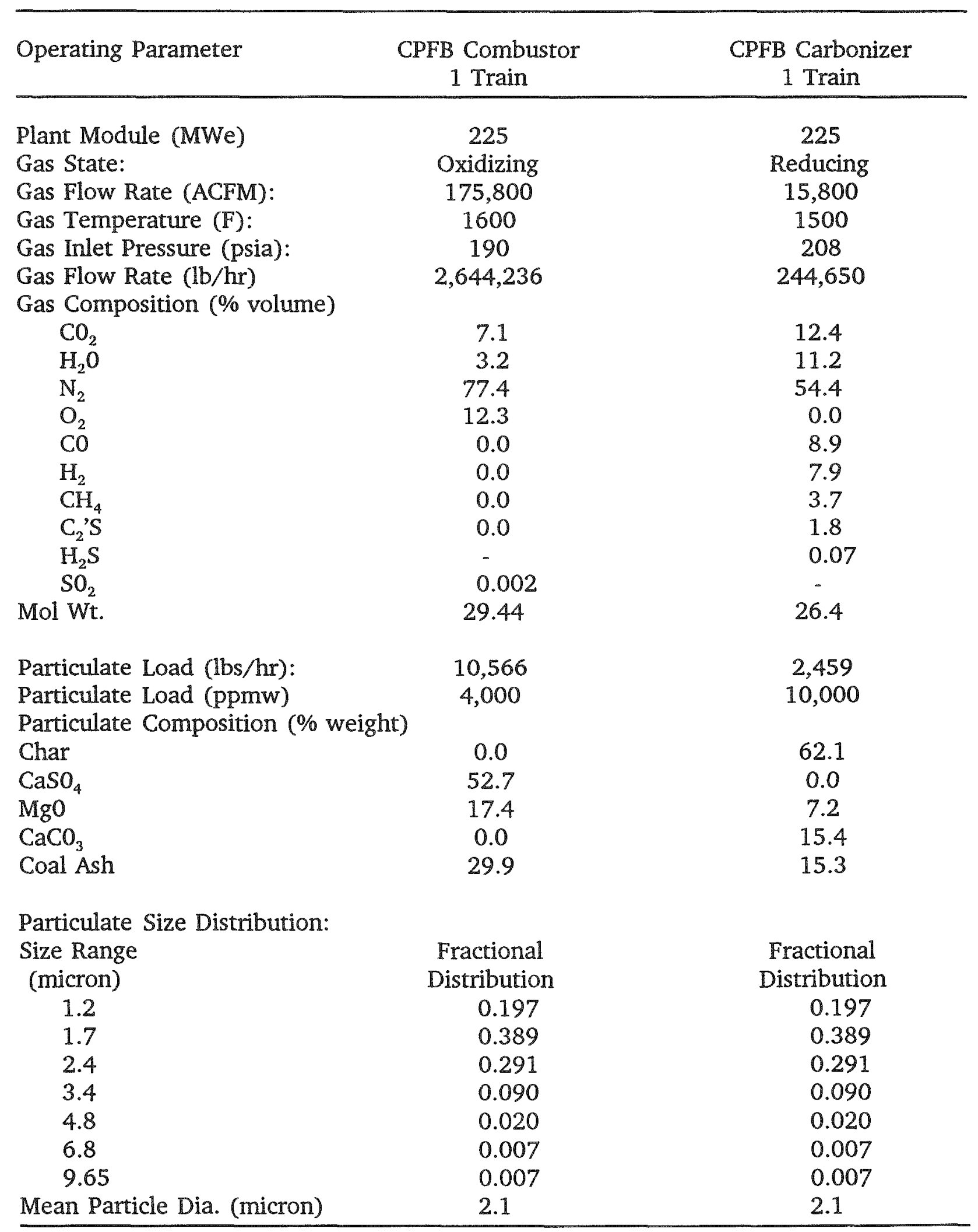


for the steam turbine. The plant power output is $100 \mathrm{MWe}$ with a net heat rate of 9000 Btu HHV/kWh. Figure 5 shows a schematic of the gasification and HGCU portion of the IGCC plant. In the schematic, ceramic cross-flow filters are shown as the HGCU device. As in the Foster Wheeler study, the ceramic cross-flow filters are replaced with moving granular-bed filters, and for cost comparison purposes, with ceramic candle filters. Table 7 shows the gas and solids flow rates, gas compositions, and particle size for the flow entering the HGCU device.

Table 7 HGCU Filter Requirements for IGCC Plant

\begin{tabular}{lc}
\hline Operating Parameter & Expected Value \\
\hline Plant Module (MWe): & 100 \\
Gas State: & Reducing \\
Gas Flow Rate (ACFM): & 12,600 \\
Gas Temperature (F): & 1600 \\
Gas Inlet Pressure (psia): & 385 \\
Gas Flow Rate (lb/hr) & 312,800 \\
Gas Composition (\% volume) & \\
$\mathrm{CO}_{2}$ & 17.1 \\
$\mathrm{H}_{2} \mathrm{O}$ & 4.3 \\
$\mathrm{~N}_{2}$ & 44.1 \\
$\mathrm{O}_{2}$ & 0.0 \\
$\mathrm{CO}$ & 9.2 \\
$\mathrm{H}_{2}$ & 24.5 \\
CH & 0.8 \\
$\mathrm{H}_{2} \mathrm{~S}$ & 0.07 \\
Mol Wt. & 23.2 \\
& \\
Particulate Load (lbs/hr): & 2660 \\
Particulate Load (ppmw): & 8,500 \\
Particulate Size Distribution: & \\
Size Range & Fractional \\
(micron) & Distribution \\
1.2 & 0.197 \\
1.7 & 0.389 \\
2.4 & 0.291 \\
3.4 & 0.090 \\
4.8 & 0.020 \\
6.8 & 0.007 \\
9.65 & 0.007 \\
Mean Particle Diameter (micron) & 2.1 \\
\hline
\end{tabular}




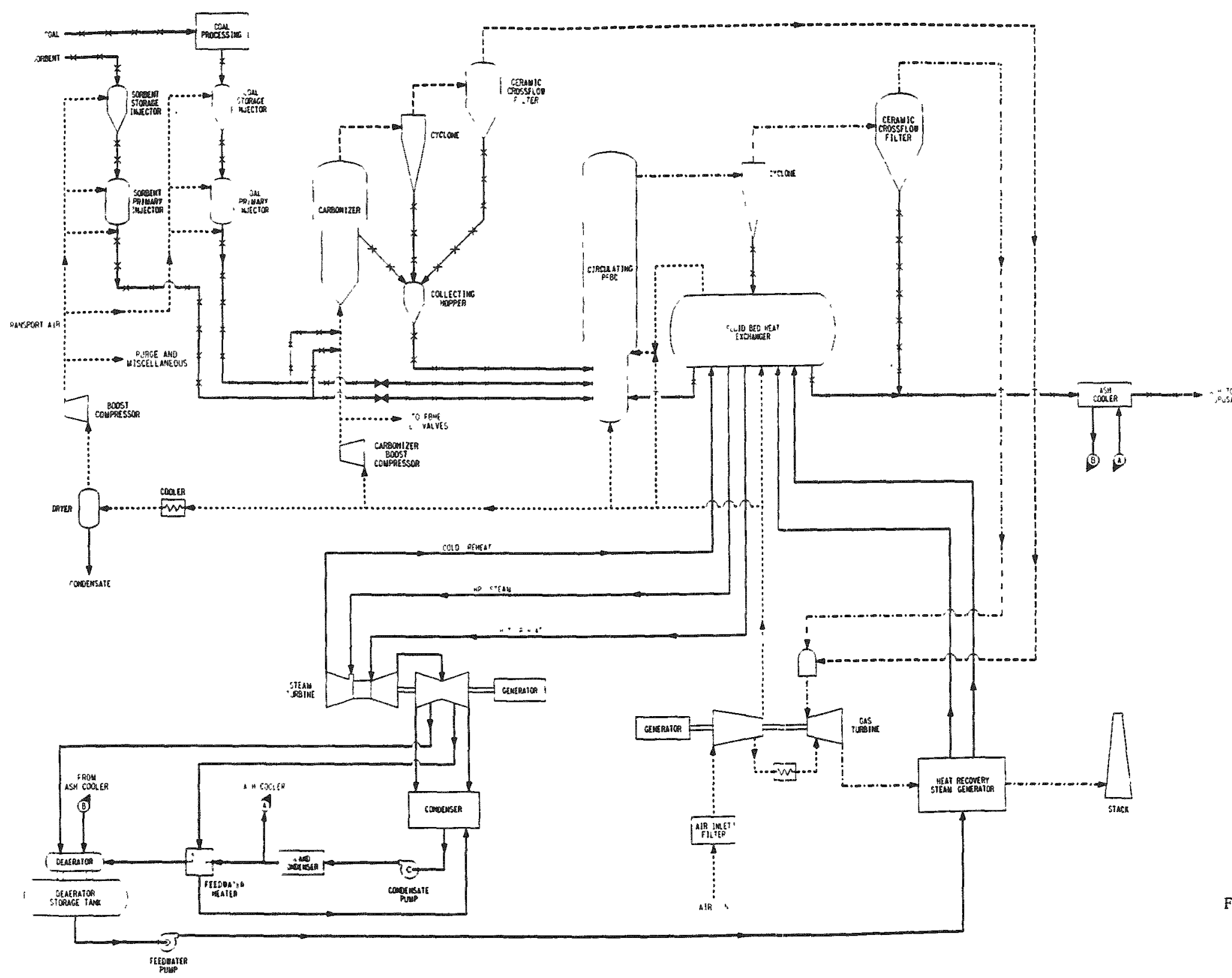

Figure 4 Simplified Schematic of Second. Generation PFB Combustion Plant " 


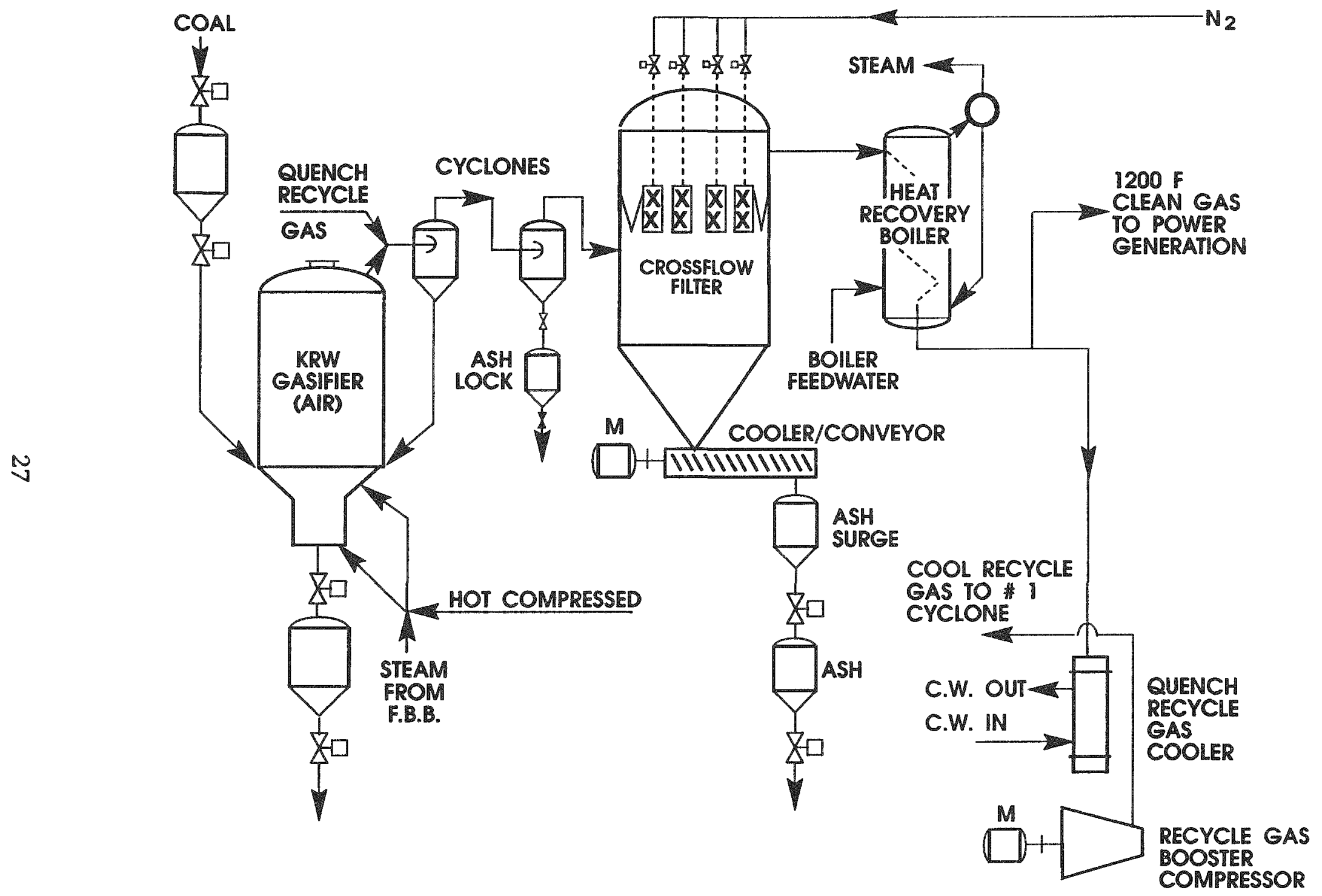

Figure 5 Simplified Schematic of KRW Air-Blown Gasification Process 


\subsection{REFERENCES}

1. Robertson, A., and R. Garland, R. Newby, A. Rehmat, and L. Rubow. September, 1989. Second-Generation Pressurized Fluidized Bed Combustion Plant Conceptual Design and Optimization of a Second-Generation PFB Combustion Plant, Phase 1, Task 1. Report DOE/MC/21023-2825, Vol.1. Prepared by Foster Wheeler Development Corporation, Livingston, New Jersey under contract No. DE-AC21-86MC21023.

2. D. F. Ciliberti, T. E. Lippert. 1986. Performance Evaluation of a Ceramic Cross-Flow Filter on a Bench-Scale Coal Gasifier. Westinghouse Eighth Quarterly Report and Monthly Project Status Report for September 1, 1986 - September 30, 1986. DOE/METC Contract No. DE-AC21-84-MC21338. Morgantown, West Virginia: Morgantown Energy Technology Center. 


\section{SECTION 3}

\section{GRANUILAR-BED FILTERS}

\subsection{Previous Development Efforts}

Initially, high temperature gas cleanup testing at Combustion power utilized the same technology developed for low to medium temperature applications; that is, $2 \mathrm{~mm}$ granular media was contained in the space between two concentric louvered screens ${ }^{1}$. Performance with this configuration was quite good, but continued difficulty was encountered with screen pluggage in low pressure tests and at temperatures above $1400^{\circ} \mathrm{F}$. The design eventually evolved away from the screened configuration, hence the label "screenless".

Figure 6 shows a schematic of the screenless configuration developed at a result of initial efforts up to the early $1980^{\prime} \mathrm{s}^{2}$. There are three zones of gas cleaning: a parallel-flow zone in which a high amount of ash is collected, a cross-flow zone, and a counterflow zone where the final ash collection and gas polishing takes place. Tests of this filter at atmospheric pressure and at a temperature of about $1600^{\circ} \mathrm{F}$ demonstrated successful operation over a 1500-hour test period. Collection efficiencies were $99 \%$ and no degradation of collection media occurred. The filter also operated successfully under upset conditions (inlet loadings 10 times normal and inlet flow rates $25 \%$ higher than normal).

Figure 7 shows the screenless filter essentials installed in a test pressure vessel at New York University (NYU). Particle laden gas entered the filter through a centrally located pipe submerged in a downward moving bed of $2 \mathrm{~mm}$ or $3 \mathrm{~mm}$ ceramic granules which act as the cleaning media. Fine particulate in the gas stream collected on the downward moving media. Clean media granules were distributed to the top of the filter and flowed downward through eight equally spaced pipes and the annulus formed around the central gas inlet. The particle-laden media was withdrawn at the bottom of the filter element and transported pneumatically for cleaning and reuse.

A schematic of the moving granular-bed filter tested at NYU is shown in Figure 8. The particle-laden media withdrawn from the bottom of the filter was conveyed in a lift pipe to a de-entrainment vessel where the filter media and the ash particles were separated. The clean media flowed by gravity to a media reservoir located above the filter vessel. From here, filter media was distributed back to the filter. The particles leaving the de-entrainment vessel were removed in a pressurized baghouse after the liftpipe transport gas was cooled to $500^{\circ} \mathrm{F}$. The lift pipe transport gas was boosted in pressure with a blower before it was reused to convey particle-laden media up the lift pipe. The NYU filter element had a diameter of $5 \mathrm{ft}$ with a gas inlet diameter of $1 \mathrm{ft}$ and a bed depth $2.5 \mathrm{ft}$.

NYU test equipment included a coal-fired, pressurized fluidized bed combustor (PFBC) with a fixed orifice to provide backpressure. This unit operated with a flue gas flows up $16,000 \mathrm{lb} / \mathrm{hr}$ at $60-135 \mathrm{psig}$ and $1400-1650^{\circ} \mathrm{F}$. Excess air was typically $20-30 \%$ 
as heat was removed from the fluidized bed by water coils. Particulate generated by the PFBC was 100-3000 ppmw. For the test series involving the granular-bed filter, the PFBC was fired on Kittanning bituminous coal containing 5-8\% ash. Sulfur sorbent was Ohio dolomite containing negligible amounts of alkali compounds. Five performance tests were run at NYU. Data from two of these tests is reported in Tables 8 and 9.

Table 8 compares low pressure GBF data with the contractual targets and actual results. The early prototype filter had the same critical dimensions as the NYU test module but was tested at low pressure; thus, not all parameters are directly comparable. The low pressure performance tests and some NYU tests including HG-204, used identical $2 \mathrm{~mm}$ media. These results compare closely except for pressure. Flows through the filters are best compared when referenced to minimum fluidizing velocity of the media. Temperatures reported for the NYU tests are typical for near steady state conditions, and indicate the heat loss experienced across the test module. These heat losses were anticipated as a result of the small pilot-plant scale. The lower heat loss on HG-205 was due to higher gas flow. In a commercial-scale unit, the temperature drop across the filter would be much less. Filter pressure drop depends mainly on gas flows, ash concentration and media circulation rate. It is normally steady since the media is circulated and cleaned continuously.

Table 8 GBF Operating Parameters, NYU

\begin{tabular}{|c|c|c|c|c|}
\hline \multirow[b]{2}{*}{ Parameter } & \multirow{2}{*}{$\begin{array}{l}\text { Low Pressure } \\
\text { GBF Tests }\end{array}$} & \multirow{2}{*}{$\begin{array}{c}\text { Contractual } \\
\text { Target }\end{array}$} & \multicolumn{2}{|c|}{$\begin{array}{c}\text { Representative } \\
\text { NYU Tests }\end{array}$} \\
\hline & & & HG-204 & $\mathrm{HG}-205$ \\
\hline Media Size & 2 & $2-3$ & 2 & 3 \\
\hline Pressure, psig & $1-4$ & $90-135$ & $90-115$ & $105-115$ \\
\hline \multicolumn{5}{|l|}{ Temperature } \\
\hline GBF in (Typ) & 1550 & $1550-1700$ & 1550 & 1550 \\
\hline GBF out (Typ) & -- & .- & 1350 & 1450 \\
\hline \multicolumn{5}{|l|}{ Flow } \\
\hline Gas To GBF, lb/hr & 2000 & $7200-14,400$ & 7200 & 12,515 \\
\hline Gas to GBF, acfm & 1550 & $700-1400$ & 700 & 1250 \\
\hline$\%$ Min. Fluidization & $28-33$ & $25-50$ & 25 & 31 \\
\hline \multicolumn{5}{|l|}{ Filter Pressure } \\
\hline Drop. IWC & $25-30$ & -- & $24-30$ & $18-22$ \\
\hline \multicolumn{5}{|l|}{ Media Circulation } \\
\hline Rate $\mathrm{lb} / \mathrm{min}$ & $20-40$ & $20-40$ & $20-70$ & $20-70$ \\
\hline
\end{tabular}

Particulate sampling results are shown on Table 9. The amount of ash entering the filter could be roughly controlled by adjusting sorbent feed to the PFBC. For HG-204 
inlet loadings below $200 \mathrm{ppmw}$ at the inlet were questionable; since, this data was not consistent with ash loadings estimated by the ash collected by the GBF. Therefore, the averages shown for HG-204 are for 18 of 26 samples during 74 hours of operation where inlet loadings were greater than 200 ppmw. For HG-205 there was 17 samples collected over 47 hours of operation. Having gained a general idea of how sorbent rates affected filter ash loadings, the ash input rate was raised to a high level during HG-204 (2800 ppmw) to observe the filter response. There was only a slight rise in pressure drop across the filter (1-2 IWC) during this one-hour period.

Table 9 Particulate Sampling Results, NYU

\begin{tabular}{|c|c|c|c|c|}
\hline \multirow[b]{2}{*}{ Parameter } & \multirow{2}{*}{$\begin{array}{c}\text { Low Pressure } \\
\text { GBF Tests }\end{array}$} & \multirow{2}{*}{$\begin{array}{l}\text { Contractual } \\
\text { Target }\end{array}$} & \multicolumn{2}{|c|}{$\begin{array}{c}\text { Representative } \\
\text { NYU Tests }\end{array}$} \\
\hline & & & HG-204 & HG-205 \\
\hline \multicolumn{5}{|l|}{ Ash Concentration } \\
\hline @ GBF Inlet, ppmw & $1500-40.000$ & -- & $80-2800$ & $160-1600$ \\
\hline o Avg & -- & $\leq 1200$ & 560 & 860 \\
\hline @ GBF Outlet ppmw & $30-60$ & 12 & $3-16$ & 1.10 \\
\hline$\circ$ Avg & -- & $\sim$ & 7 & 4 \\
\hline $\begin{array}{l}\text { Emissions } \mathrm{lb} / 10^{\circ} \mathrm{Btu} \\
\circ \mathrm{Avg}\end{array}$ & $-\infty$ & $\begin{array}{c}<.03 \mathrm{LB} / 10^{\circ} \mathrm{BTU} \\
\text { (NSPS) }\end{array}$ & $\begin{array}{c}.003-.013 \\
.008\end{array}$ & $\begin{array}{l}.001-.010 \\
.004\end{array}$ \\
\hline Collection Eff \% & $98-99.2$ & 99 & $94.3-99.9$ & $98-99.8$ \\
\hline o Avg & -- & $\sim$ & 98.6 & 99.7 \\
\hline$\%$ Ash in Media & $.1-4.3$ & 6 & $.03-1.0$ & $.1-1.0$ \\
\hline
\end{tabular}

Outlet loadings meet New Source Performance Standards (NSPS) of $.03 \mathrm{lb} / \mathrm{million}$ Btu and also will most likely meet turbine tolerance limits which actually can be more restrictive at large particulate sizes. With $3 \mathrm{~mm}$ media (HG-205), the outlet loadings were expected to increase over that measured at $2 \mathrm{~mm}$ (HG-204). One explanation for the higher efficiency of $3 \mathrm{~mm}$ media is that it was composed of alumina spheres ranging between 2.4 and $4.0 \mathrm{~mm}$. The $2 \mathrm{~mm}$ media was more uniform at 1.9 to $2.0 \mathrm{~mm}$. More opportunity for ash collection (by impaction, etc.) could exist with the wider size range of media than with an evenly sized media bed. Another explanation is that the higher gas velocity permitted by the larger media increased particulate collection by impaction.

The percent of ash in the media compares the ash collection rate to the media circulation rate. Although anticipated at NYU, it was not possible to circulate media slow enough to challenge the contractual target of $6 \%$ ash in the media. Other testing on this parameter was carried out at Combustion Power Company and demonstrated $6 \%$ as achievable $^{3}$. At NYU, some experiments involved no media circulation for various time periods, but this does not directly correlate to this parameter. 


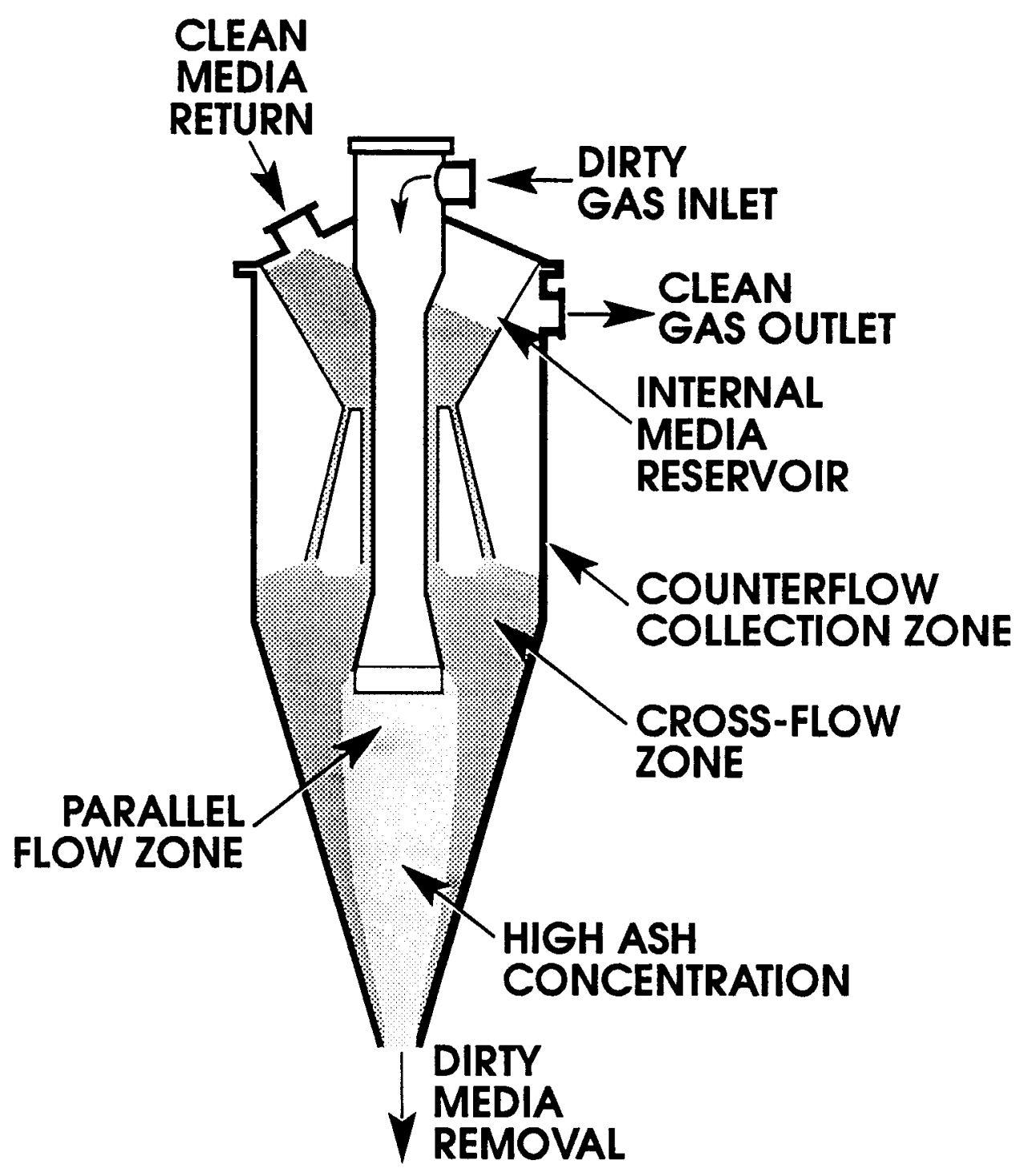

Figure 6 Screenless Counterflow Granular-Bed Filter 


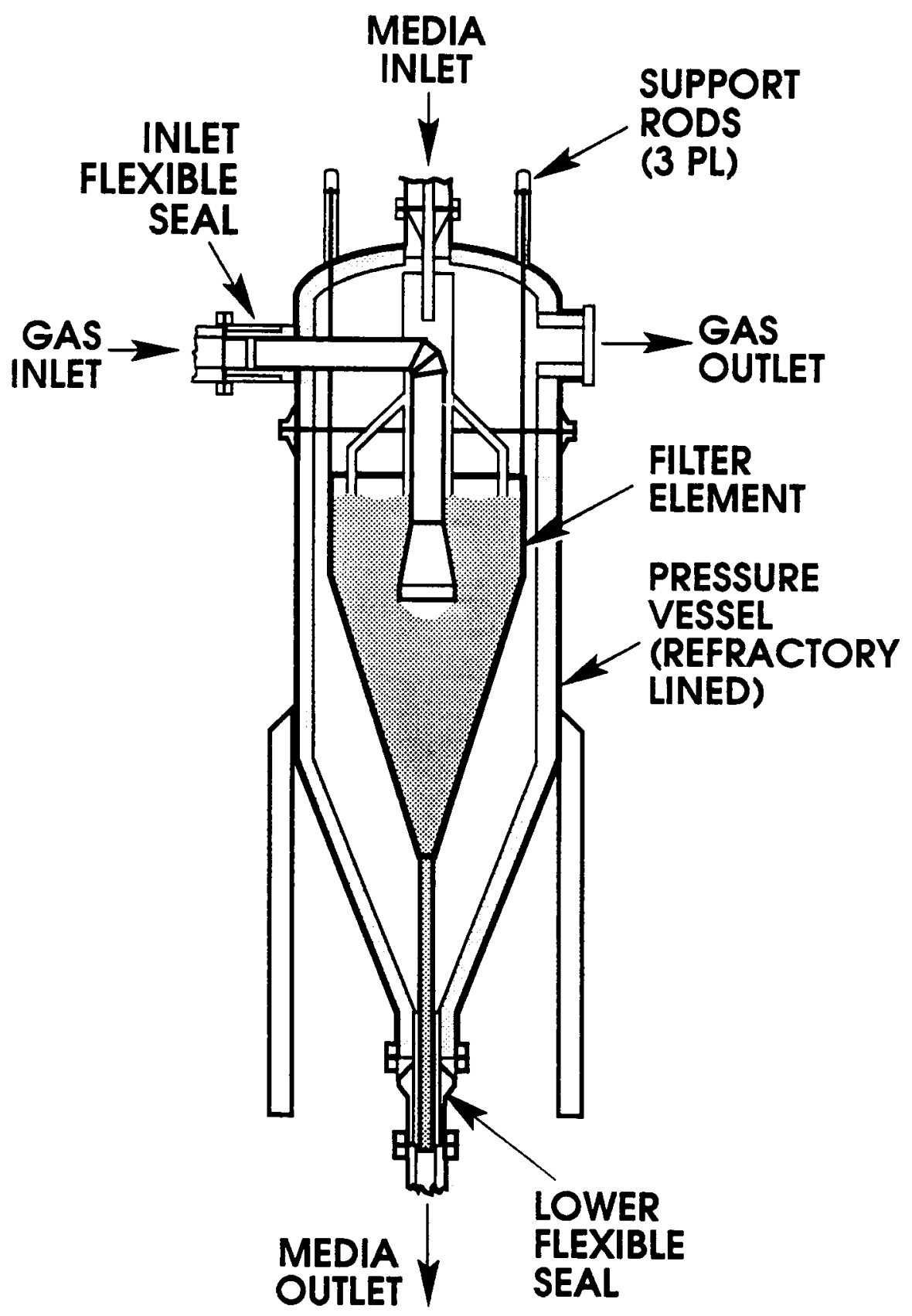

Figure 7 Granular-Bed Filter Installation at NYU 


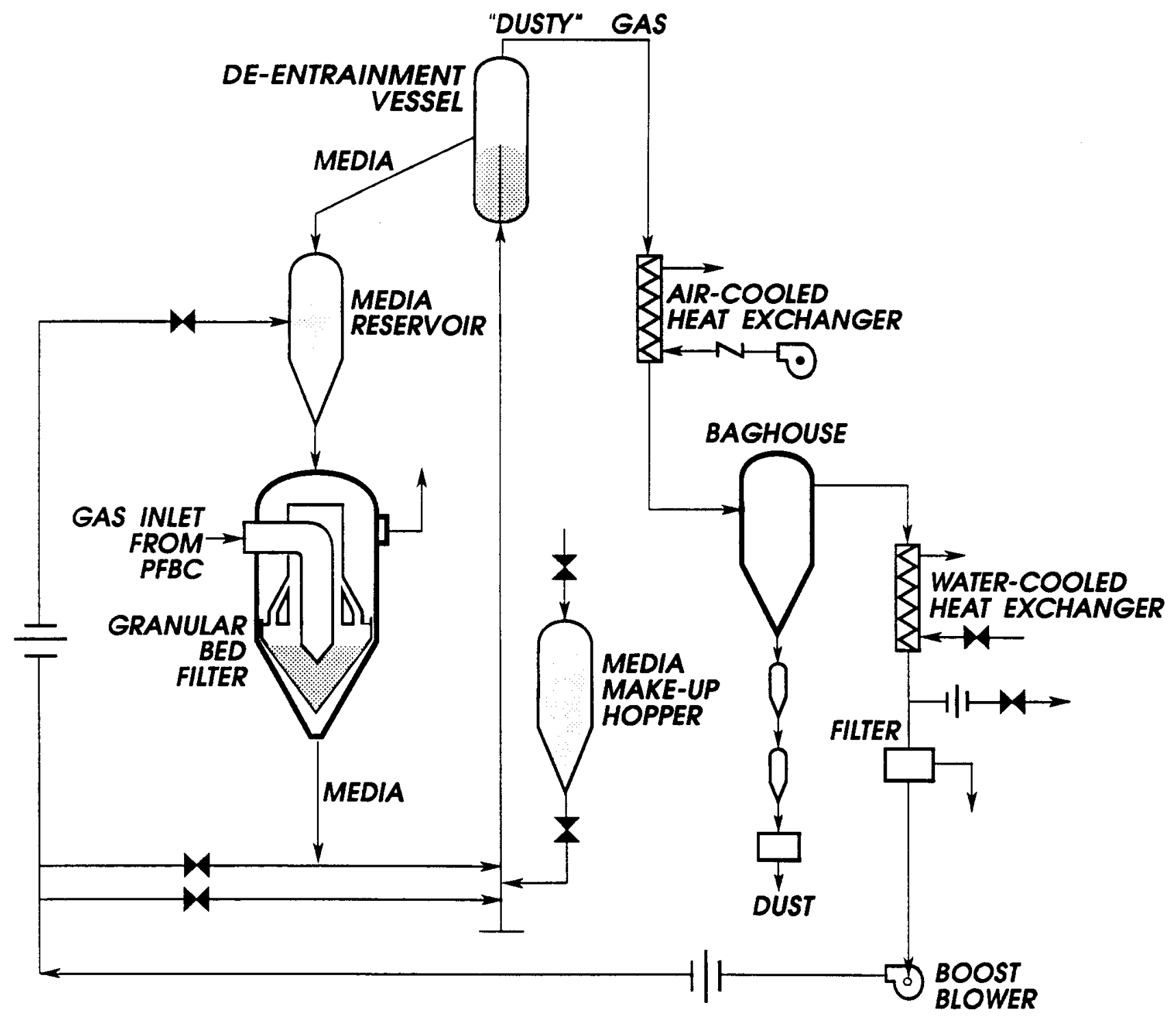

Figure 8 Schematic of Screenless Granular-Bed Filter Tested at NYU 


\subsection{Conceptual Designs of Granular-Bed Filters}

Although the filter tested at NYU was able to achieve high particulate removal efficiency and meet New Source Performance Standards, the multiple element approach proposed for commercial design ${ }^{3}$ was perceived to be undesirable due to weight, complexity and cost. It was the goal of this study to improve the commercial design of the moving granular-bed filter, and show that it can be simpler and less costly. Four conceptual designs of moving granular-bed filters were considered. The first design was a screenless granular-bed filter configuration like that tested at New York University ${ }^{4}$. To simplify this design, and increase the throughput, we abandoned the multi-element approach in favor of simply increasing the single element size. The second type of filter considered was a screenless filter with multiple gas inlets instead of a single centrally located gas inlet. Next considered was a screened filter in which louvered screens retained the downward moving media while the gas passes horizontally through the screens and the media. The fourth design considered was a high throughput filter which features a screenless inlet and a screened outlet.

\subsubsection{Single Entry Filter}

The filter successfully tested at New York University (NYU) was a single element from a multi-element conceptual design. This filter element had an inside diameter of $5 \mathrm{ft}$ with a process gas inlet diameter of 12". The filter bed depth was $2.5 \mathrm{ft}$ for both 2 $\mathrm{mm}$ and $3 \mathrm{~mm}$ filter media. An option to the multi-element approach, is to increase the size of the single element to handle more gas flow.

For the Foster Wheeler, circulating pressurized bed combustor ( $\mathrm{CPFBC}$ ), granularbed filter designs up to 24 feet in diameter were considered. The preliminary economic analysis discussed below, showed that the 20 foot diameter filter was the best choice for the CPFBC application. In addition to increasing the size of the filter element itself, the size of the media was increased to $6 \mathrm{~mm}$. The use of larger media allows more gas to pass through the moving bed of media without danger of causing fluidization or channeling of the gas. Previous tests at Combustion Power Company showed that the particulate collection efficiency is proportional to the number of collectors over which the gas moves ${ }^{5}$. To maintain collection efficiency, the minimum bed depth of the filter needs to be doubled as the media sized is doubled.

The computational fluid dynamics analysis, discussed below, shows that gas inlet diameter relative to that of the filter diameter should be increased in order to reduce the pressure drop through the filter. The filter tested at NYU had a gas inlet area that was $4 \%$ of the filter area. When this percentage was input to the computational fluid dynamics (CFD) model for large diameter filters with large media, the pressure drop determined was very high. For the 20 foot diameter filter, the model showed that the gas inlet area could be increased up to $16 \%$ of the filter area with a corresponding lower pressure drop. A further increase in the inlet area caused the pressure drop through the filter to increase. 
During testing at NYU it was confirmed that if the gas flow rate through the filter was too high, fluidization or gas channeling would result. This occurred at a gas velocity which was about $50 \%$ of that needed to fluidized a filter bed with ideal gas distribution. Subsequent analysis showed that for the test in which channeling occurred, the predicted pressure drop through the filter was nearly equal to the calculated pressure drop required to fluidized the media ${ }^{a}$. This indicates that the ratio of the predicted filter pressure drop to the pressure drop required to fluidize the media is an alternate filter capacity parameter to the percent minimum fluidization velocity. The single inlet filter for the CPFBC application is designed to have a pressure drop which is $80 \%$ of the pressure drop required to fluidize the bed and to operated at $54 \%$ of the minimum fluidization velocity.

The media circulation rate is determined by the ash loading to the filter. The ash loading from the PFB combustor is a moderate concentration of $4000 \mathrm{ppmw}$ while that for the carbonizer is $10,049 \mathrm{ppmw}$ and for the gasifier it is $8440 \mathrm{ppmw}$. The PFBC filter is designed to operate with an ash to media ratio of 0.02. The carbonizer and gasifier are both designed to operate with an ash to media ratio of 0.025 . As a result of the high ash loading in the gasifier and carbonizer applications, the gas velocity through the filter is reduced to $37 \%$ of the minimum fluidization velocity.

Conceptually, the media circulation system for the new filter designs is very similar to that used for the NYU tests. The major difference is that a regenerative heat exchanger has been added to reheat the lift pipe circulation gas which helps to minimizes heat loss from the filter system.

\subsubsection{Multiple Entry Filter}

A filter with multiple gas entry points achieves gas distribution through the use of a complex gas distribution system, but it has the potential advantage over a single entry filter of lower pressure drop and smaller filter size.

The gas enters any type of granular-bed filter through a gas manifold imbedded in the filter media or through a manifold external to the bed. It is essential that the gas manifold system does not disturb the mass flow of media in the region of the bed above the gas inlet. If the media departs from mass flow in this region, the filter will suffer a loss of efficiency due to particle re-entrainment as the media shears due to the relative motion between the individual media ${ }^{5}$. Vertical gas entry generally satisfies this criteria as shown by the testing at NYU.

The use of multiple gas entry points with a counterflow granular-bed filter allows flexibility in deciding the size of a filter module. Once an appropriate ratio of gas distribution elements to filter area has been chosen, the filter can be scaled accordingly.

a. The projected filter pressure drop was determined by the GBF model developed under contract AC21-77ET10373 which is specific to the filter geometry used at NYU. The predicted pressure drop required to fluidize the bed is equal to the weight of the media above the gas distributor divided by the area of the filter. 
In choosing this ratio, the design tested at NYU was considered as a maximum. The 19 sq ft, single entry filter tested at NYU had one gas entry point.

There is a trade off between the complexity of the gas distributor and how effectively it is able to distribute the gas to the filter. One would like a large number of gas entry points, but as the number of entry points increases, the gas and media distribution systems become extremely complex. Eighty distribution points were chosen as the optimum number of gas inlets which could be reasonably connected in a $25 \mathrm{ft}$ diameter filter. This corresponds to $6.1 \mathrm{sq} \mathrm{ft}$ of filter surface for each gas inlet, a considerable change from NYU.

CFD computer modeling was attempted for evaluating the placement of gas inlets and determining the influence of one gas distributor on neighboring distributors. The three dimensional CFD model necessary was not yielding useful results during initial trials; consequently, this effort was suspended.

Based on approximate relationships generated for sizing granular-bed filters, the multiple inlet filter was designed to operate at $68 \%$ of the minimum fluidization velocity. Bed depth chosen was $5.0 \mathrm{ft}$, the same as the single inlet filter, and based on scaling from NYU testing. The bed pressure drop is estimated to be about 60 IW. Table 10 shows the design parameters for the multiple gas inlet filter and Figure 9 shows the general arrangement.

A preliminary cost comparison between the single entry and the multiple entry filter showed that the multiple entry filter to have a slightly higher capital cost.

In order to have a more accurate comparison between a single inlet and multiple inlet filter, data will have to be collected during proof of concept testing. Comparison of performance data for the two design approaches will determine if the added complexity of multiple gas entry points is advantageous.

\subsubsection{Screened Filter}

The third filter concept explored is that of a screened filter. Past development efforts with a screened filter indicated problems with screen fouling ${ }^{5}$. Proper louver design or a change in characteristics of the gas to be cleaned could eliminate this

potential problem. The objective of this part of the design phase was to determine if the screened filter has an economic advantage compared to the counterflow filter. The design of the screened filter was based on the previous experience of Combustion Power Company with this type of filter. Combustion Power developed a low temperature screened filter which used an electrical grid to enhance collection efficiency. There was also considerable work done on the development of a high efficiency, high temperature screened filter. The design criteria used for these filters was applied to the design of a filter for the Foster Wheeler CPFBC for comparison to the other approaches. 
Table 10 Design Parameters for the Multiple Gas Entry Filter

\begin{tabular}{lc}
\hline Design Parameter & Expected Value \\
\hline Number of Filters & 25 \\
Filter Diameter (ft) & 88700 \\
Gas Flow Rate (acfm) & 12.8 \\
\% Inlet Area of & \\
Total Area & 68 \\
$\begin{array}{l}\text { Velocity as a Percent } \\
\text { of Minimum Fluidization } \\
\text { Velocity }\end{array}$ & \\
$\begin{array}{l}\text { Projected Filter } \\
\text { Pressure Drop (IW) }\end{array}$ & 60 \\
Media Size (mm) & 6 \\
$\begin{array}{l}\text { Number of Gas and } \\
\text { Media Distributors }\end{array}$ & 80 \\
\hline
\end{tabular}

The geometry of a cross-flow, or screened, GBF can be determined by five independent variables: volumetric gas flow, gas velocity at the outer screen, the dust to media ratio, bed thickness, and media velocity.

Previous experience has shown that at high exit gas velocities, the media is carried through the louvers and can not be retained in the moving bed. For this reason, the gas velocity at the outer screen of the filter is limited to $25 \%$ of the velocity which is capable of fluidizing the media.

The media for the filter will be $2 \mathrm{~mm}$ in diameter. Experience with larger media in a screened filter demonstrated that the high efficiency required for this application could not be obtained using $4.5 \mathrm{~mm}$ media in the screened configuration.

The proposed screened filter is designed to operate at a dust to media ratio of 0.005 . The filter performance is sensitive to this ratio. The screened filter at higher dust to media ratios becomes saturated with dust such that voids between the media granules are filled with dust. At higher dust concentrations, the media releases captured dust with a resulting drop in filter efficiency. The screenless, counterflow filter is able to handle dust concentrations of $0.025 \mathrm{lb}$ dust per $\mathrm{lb}$ of media, and perhaps up to $.06 \mathrm{lb}$ dust per lb media. 
The media velocity used in the previous development for a high efficiency screened filter ranged from $0.5 \mathrm{in} . / \mathrm{min}$ to $1.0 \mathrm{in} . / \mathrm{min}$. The proposed filter designs will use a media velocity of $1.0 \mathrm{in} . / \mathrm{min}$. Higher media velocities increase the possibility that dust particles will be dislodged due to media shear flow induced at high media velocities.

The bed thickness has a considerable affect on the aspect ratios of the filter. Once gas flow rate, dust to media ratio, gas approach velocity, and media velocity are determined, bed thickness determines the relation between filter height and diameter. Thicker beds lead to smaller diameter filters with increased screen height. The previous development efforts with a high efficiency screened filter used a $3.8 \mathrm{ft}$ diameter filter with a 15 in. thick bed. The low temperature, electrostatically enhanced filters are $8.3 \mathrm{ft}$ in diameter with a bed thickness ranging from 18 in. to $30 \mathrm{in}$. For the proposed screened filter, a $48 \mathrm{in}$. bed thickness was chosen to provide a reasonable ratio of filter height to filter diameter.

Table 11 shows the design parameters for the screened filter. The filter is housed in a pressure vessel with a $29 \mathrm{ft}$ inside diameter and would be $70 \mathrm{ft}$ tall. Four of these filters would be required for each 452 MWe module of two CPFBC's. The estimated pressure drop for the filter using $2 \mathrm{~mm}$ media is 41 IW.

\subsubsection{High Flow Filter}

The advantage of the screenless GBF, both the single entry and the multi-entry design, is high filtration efficiency and minimum ash fouling potential. The advantage of the screened filter is that media is trapped by mechanical barriers that prevent fluidization. These advantages can be combined in a hybrid type of filter that features a screen only at the outlet.

Figure 10 shows the schematic of such a filter. Gas enters through a single inlet pipe which delivers the gas to the center of the filter in a manner similar to the single entry filter. The gas turns and flows upward through downward moving media introduced at the top of the filter. The area of the outlet screen is sized for minimal restriction to gas flow and placed to obtain the desired collection efficiency. The bed of media continues some distance above the outlet screen. Little if any gas flows through this section of the filter. This upper section of media weighs down the media in the active filtration zone such that fluidization is not possible.

There are several advantages of a filter of this configuration. The filter can have very high gas throughput since the media is restrained from fluidizing by the media above the outlet screen. Since the gas flow exits below the top surface of the media, the contour of the top surface is no longer important. Therefore, this filter also has a simple, annular media distribution system as shown in Figure 10. Filter media spreads by gravity such that the top surface of the media is at the media angle of repose.

This filter design maintains counterflow filtration. The media at the filter inlet has the highest ash concentration because it does the initial filtration. The final filtration is accomplished with clean media, resulting in high efficiency particulate removal. 
Table 11 Screened Filter Design

\begin{tabular}{lc}
\hline Design Parameter & Expected Value \\
\hline Number of Filters & 4 \\
Bed Thickness (ft) & 4 \\
Gas Flow Rate (ACFM) & 87,900 \\
Estimated Pressure Drop (IW) & 41 \\
Velocity as a Percent of & \\
Minimum Fluidization velocity & 25 \\
Active Screen Height (ft) & 26.7 \\
Media Size (mm) & 2 \\
Number of Media Distributors & 16 \\
Filter Diameter (ft) & 28.8 \\
\hline
\end{tabular}

Another feature of a this filter is that it can function with smaller and/or less dense media than is used with the other filter configurations. This is possible because the it is not limited in capacity by the fluidization velocity of the media; which, increases with media density and size. This has advantages for a filter designed to control multicontaminants if low density, high porosity media is needed for sorption of gas contaminants. The screened outlet design could allow operation at a filter velocity which would otherwise cause light weight media to fluidize. 

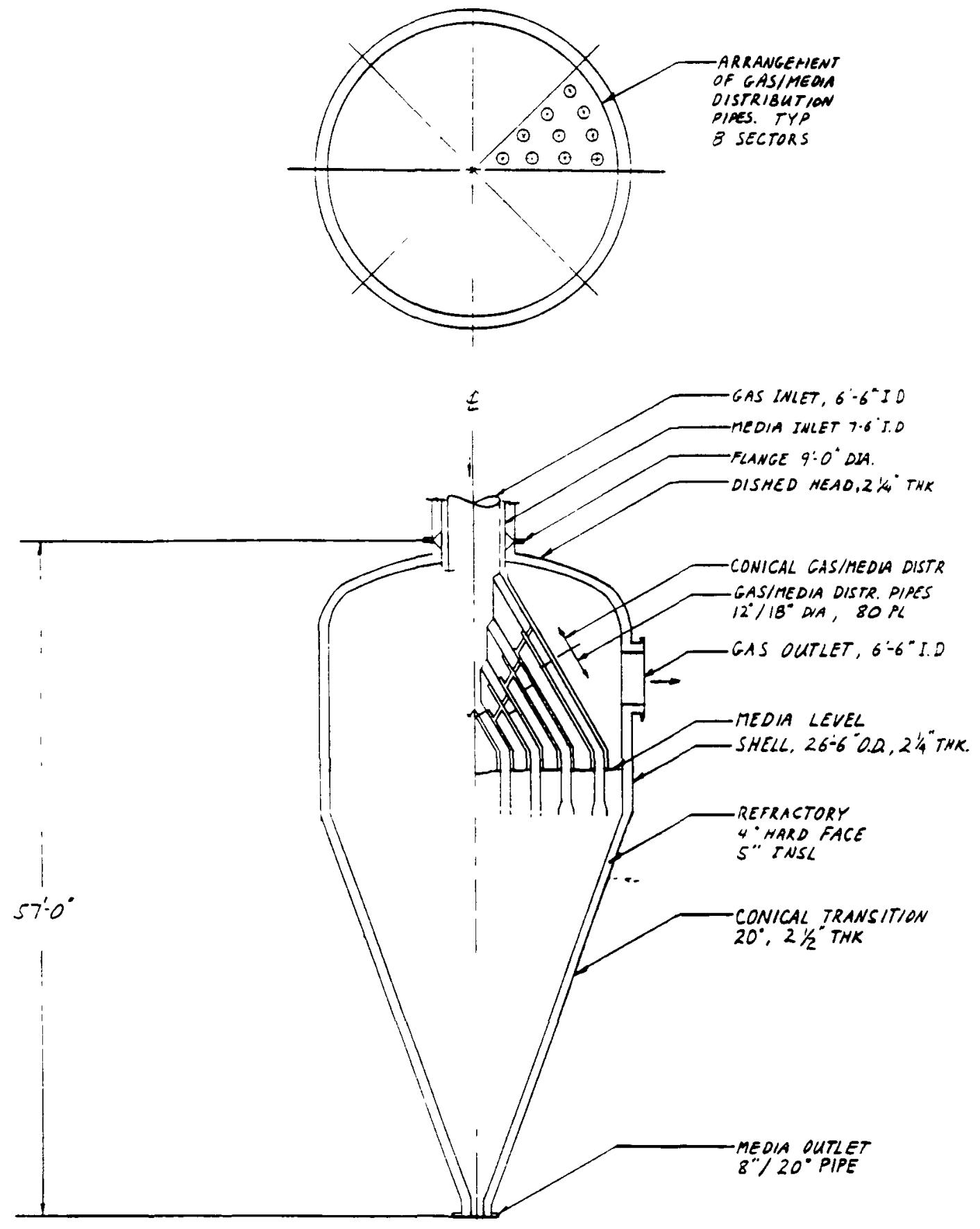

Figure 9 Multi-Entry Granular-Bed Filter 


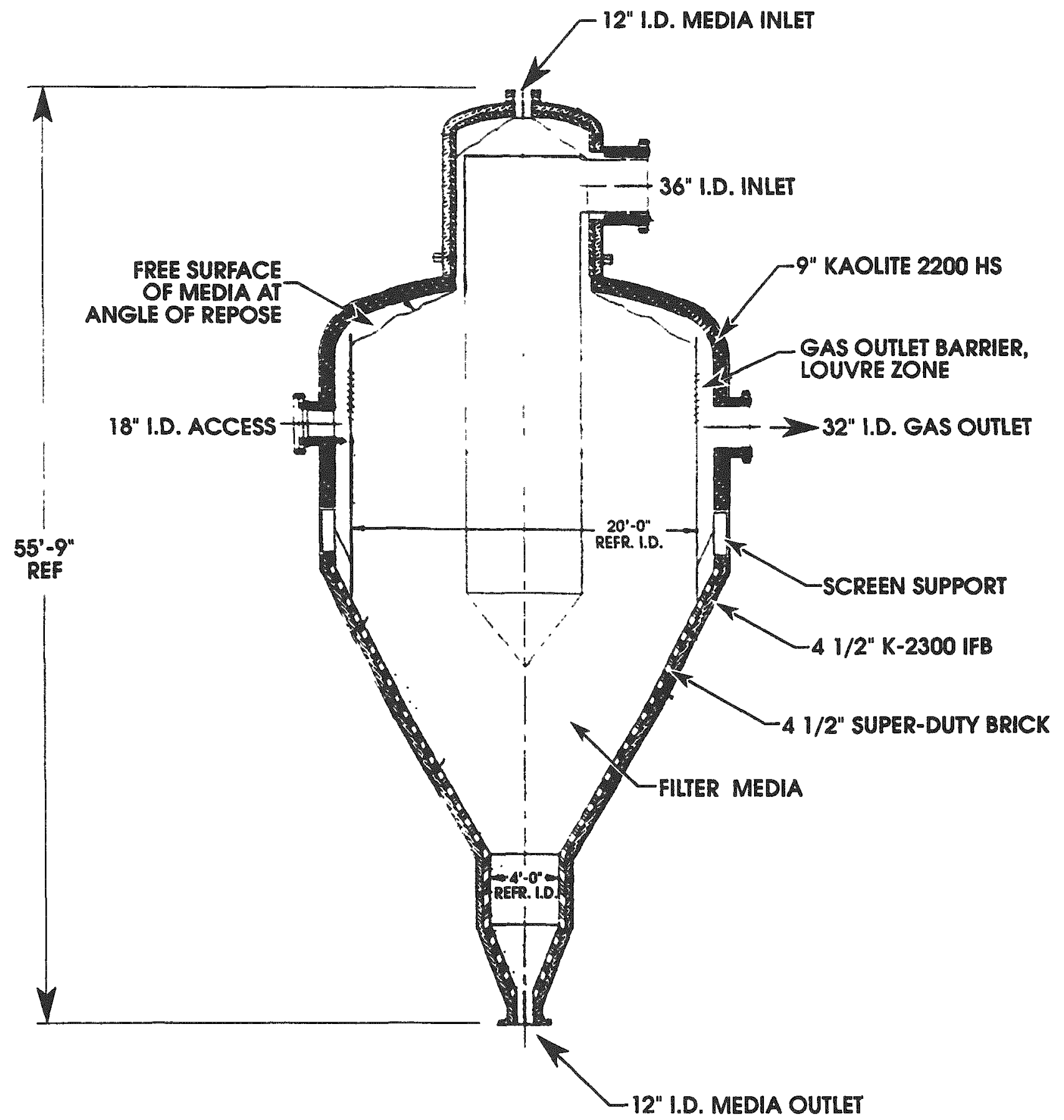

Figure 10 High Flow Granular-Bed Filter 


\subsection{Preliminary Cost Comparison}

The conceptual designs proposed were evaluated in terms of their relative costs to determine which design is most promising. All cases are for a CPFBC associated with the 452 MWe Foster Wheeler second generation PFBC plant. The cost in each case is based on estimated capital cost of equipment plus an operating cost due to filter pressure drop. Capital costs were estimated on a preliminary, but consistent basis, and did not include all items that were duplicated in each system. Therefore these costs cannot be considered accurate to $20 \%$.

An increase in filter pressure drop causes a reduction in the power produced by the plant. The cost of electricity (COE) program supplied by DOE was used to determine an equivalent capital cost associated with the incremental power production due to different filter pressure drops. This was accomplished by maintaining a constant COE by reducing the equipment cost to offset the reduction in power due to an increase in filter pressure drop above that used in the base study. The base study by Foster Wheeler used a filter pressure drop of $1.5 \mathrm{psi}$. Since GBF pressure drop exceeded this value in all cases but one, a cost penalty was added to all filter cases. More detail is given in Section 5.3.5 on the procedure for relating filter pressure drop to a change in net generated power and heat input.

Table 12 shows the results of the cost comparison. Cases A and B include an upstream (primary) cyclone to reduce the particle concentration to the filter; filter quantities were changed to observe the effect on size. All other cases do not utilize primary cyclones. Cases $\mathrm{C}$ through $\mathrm{F}$ are all single entry filters with costs evaluated at different quantities to observe the effect on economics. The high flow filter, in case $G$, has the lowest capital cost, but because of the high pressure drop, it is not the most economic approach. In systems where high pressure drop does not adversely affect the economics, this design may have a slight cost advantage. Cases $\mathrm{H}$ and I show how the multiple entry filter competes with the other approaches. Although the filters are smaller that their single inlet counterparts, costs are higher. This is mainly due to the additional stainless steel needed for filter internals. Finally, the screened filter results are presented in column $\mathrm{J}$. While the pressure drop is the lowest of all the filters considered, the capital cost is high. This is mainly due to the high cost of the screens and screen supports.

The lowest cost filter system is case $\mathrm{C}$, eight $20 \mathrm{ft}$ diameter single entry filters without primary cyclones. In terms of actual capital cost, case $\mathrm{G}$ was the least expensive but the high pressure drop across the filter increased the effective cost of the filter. Case $C$ is used in the rest of this study to develop more accurate cost and design data for the $\mathrm{GBF}$. But note that many of the other arrangements are close enough in cost to Case $\mathrm{C}$ that further development of these designs could give different results. 
Table 12 Cost Comparison of Filter Designs for 452 MWe Foster Wheeler CPFBC

\begin{tabular}{|c|c|c|c|c|c|c|c|c|c|c|c|}
\hline Case & & A & B & $\mathrm{C}$ & $\mathrm{D}$ & $E$ & $F$ & $\mathrm{G}$ & $\mathrm{H}$ & I & $J$ \\
\hline Type & & $S E^{(1)}$ & SE & SE & SE & $S E$ & $\mathrm{SE}$ & $\mathrm{HF}^{(2)}$ & $M E^{(3)}$ & $\mathrm{ME}$ & $\mathrm{SC}^{(4)}$ \\
\hline Volume flow per filter & acfm & 87900 & 43950 & 43950 & 21975 & 146650 & 10988 & 87900 & 87900 & 43950 & 87900 \\
\hline No. of filters & & 4 & 8 & 8 & 16 & 24 & 32 & 4 & 4 & 8 & 4 \\
\hline$\% \mathrm{Min}$ fluidization & $\%$ & 4 & 54 & 54 & 54 & 54 & 54 & 89 & 72 & 68 & 25 \\
\hline Filter I.D. & $\mathrm{ft}$ & 28 & 20 & 20 & 14 & 12 & 10 & 22 & 25 & 18 & 28.2 \\
\hline Filter depth & $\mathrm{ft}$ & 8 & 5 & 5 & 5 & 5 & 5 & 5 & 5 & 5 & 4 \\
\hline Primary cyclone eff & $\%$ & 80 & 80 & 0 & 0 & 0 & 0 & 0 & 0 & 0 & 0 \\
\hline Total press drop & inch water & 176 & 138 & 65 & 57 & 53 & 50 & 155 & 64 & 58 & 41 \\
\hline $\begin{array}{l}\text { Power required for excess } \\
\text { filter press drop }\end{array}$ & MWe & 3.28 & 2.35 & 0.59 & 0.39 & 0.29 & 0.22 & 2.77 & 0.57 & .41 & 0 \\
\hline Heat due to compression & MMBtu/hr & 10.78 & 7.70 & 1.88 & 1.23 & 0.87 & 0.64 & 9.08 & 1.80 & 1.28 & 0 \\
\hline $\begin{array}{l}\text { Equivalent capital cost due } \\
\text { excess press drop }\end{array}$ & $\mathrm{k} \$$ & 4235 & 3035 & 765 & 505 & 380 & 290 & 3580 & 737 & 536 & 0 \\
\hline Capital cost (partial) & $\mathrm{k} \$$ & 170746 & 15517 & 15139 & 17941 & 17803 & 19781 & 14278 & 18700 & 20300 & 18700 \\
\hline Equivalent capital cost & $\mathbf{K \$}$ & 21281 & 18552 & 15904 & 18446 & 18183 & 20071 & 17858 & 19437 & 20836 & 18700 \\
\hline $\begin{array}{l}\text { Ratio of filter cost to least } \\
\text { cost filter system }\end{array}$ & & 1.34 & 1.17 & 1.00 & 1.16 & 1.14 & 1.26 & 1.12 & 1.22 & 1.31 & 1.18 \\
\hline
\end{tabular}
(1) $\mathrm{SE}=$ Single Entry Filter
(2) $\mathrm{ME}=$ Multiple Entry Filter
(3) $\mathrm{HF}=$ High Flow Filter
(4) $\mathrm{SC}=$ Screened Filter 


\subsection{Computational Fluid Dynamics (CFD) Analysis}

To better understand the fluid mechanics and flow patterns in a larger diameter single entry filter, a CFD model was created. The model provides data on the streamline pattern, the flow distribution, and the pressure drop through the filter. The use of the model provides a means of evaluating the effects of changes in filter geometry and flow conditions. No attempt was made to model particle collection in the filter. The model was developed under subcontract to Combustion Power.

Figure 11 shows an idealized arrangement of the single entry GBF tested at New York University. The filter gas inlet pipe was 12 inches in diameter and extended $2.5 \mathrm{ft}$. below the surface of the media in the $5 \mathrm{ft}$. diameter filter vessel. It was assumed that the media at the inlet pipe formed a cone with an angle determined by testing performed previously at Combustion Power Company. ${ }^{5}$. To simplify the model without introducing significant error, it was assumed that the top surface of the media was level. After the model was developed, it was validated by comparing predicted flow rates with data collected at NYU.

The flow through the granular-bed filter was modelled by using the Ergun equation to predict the flow rate between nodes in a finite element grid. The ANSYS ${ }^{\circ}$ finite element program generated the grid used to described a particular filter geometry. Coefficients from the Ergun equation were matched to the momentum equation in the FIDAP $®$ computational fluid dynamics program. The FIDAP $\&$ program was then used to solve for the unknown flow conditions after the geometry and boundary conditions were specified. In order to insure that the FIDAPß program was giving the same results as the Ergun equation, a one dimensional porous media flow problem was solved. The flow rate predicted by the Ergun equation matched the flow predicted by the FIDAP® program.

The next step in establishing the validity of using the FIDAP® program was to show that a two dimensional axisymmetric model could match data collected at NYU. Data points from the operation at NYU were extracted for periods in which no particulate was entering the filter, and for a period of stable operation with particulate entering the filter. The void fraction used in the model was adjusted until the model predictions matched the data from NYU. Using a sphericity of 0.930 and a void fraction of 0.50 , the flow predicted by the model, on the average, was within $5.8 \%$ of the measured flow rate. Given that the media is moving, a void fraction of 0.50 appears to be reasonable and a sphericity of 0.93 also appears to be reasonable for the spherical media used at NYU. The data is summarized in Table 13. The close agreement between the NYU data and the CFD flow predictions indicate that the CFD model is a useful tool for predicting flow characteristics for the new filter geometries and operating conditions.

Having verified the general approach, the model was used to predict flow through a $20 \mathrm{ft}$. I.D. filter using the $6 \mathrm{~mm}$ media planned for the commercial cases and the $3 \mathrm{~mm}$ media used at NYU. The $20 \mathrm{ft}$. I.D. filter modelled was geometrically similar to the filter used at NYU. Initial modelling efforts showed that the pressure drop through the filter could be significantly reduced by increasing the diameter of gas inlet duct where it meets the filter media. A larger inlet reduces the gas velocity at the gas-media interface where 
a majority of the pressure drop was found to occur. Figure 12 is a plot of the flow rate at a constant pressure drop through the filter, as function of the gas inlet diameter. In this case, the filter I.D. is $20 \mathrm{ft}$., the bed depth is $10 \mathrm{ft}$., and the media diameter is $6 \mathrm{~mm}$. The maximum flow rate in the filter corresponds to a gas inlet duct diameter of 108 inches. Any further increase in gas inlet duct diameter reduces the filter flow rate because of the increase velocity and pressure drop in the upper portion of the filter.

Table 13 Comparison of NYU Data with CFD Model Prediction

\begin{tabular}{lcccc}
\hline Date Data Taken & $6 / 7 / 88$ & $6 / 7 / 88$ & $6 / 7 / 88$ & Typical \\
Time & $03: 29$ & $07: 38$ & $7: 09$ & None \\
\hline Filter Condition & Clean & Clean & Clean & Dirty \\
Gas Flow (lb/hr) & 10,400 & 11,490 & 10,900 & 12,515 \\
Avg. Filter Temp (F & 1261 & 1005 & 958 & 1400 \\
Outlet Press. (PSIG) & 80.4 & 80.0 & 80.3 & 110 \\
Measured Pres. Drop (IW) & 14.2 & 14.2 & 12.7 & 20.0 \\
& & & & \\
Calculated Valves & & & & \\
Viscosity X 10 (lbm/ft/s) & 2.76 & 2.49 & 2.44 & 3.00 \\
Density (lbm/ft $\left.{ }^{3}\right)$ & 0.151 & 0.184 & 0.183 & 0.174 \\
Void Fraction & 0.50 & 0.50 & 0.50 & 0.50 \\
Flow Rate (lbm/hr) & 9,522 & 10,750 & 10,109 & 12,362 \\
Model Run \# & Clh & Cli & $\mathrm{Clj}$ & $\mathrm{Clk}$ \\
\hline
\end{tabular}

Results with the $10 \mathrm{ft}$. bed depth indicated that further improvements could be made to reduce the filter pressure drop and lower the filter cost. The filter configuration was subsequently changed to include a $5 \mathrm{ft}$. deep bed. The filter inlet duct was also moved to a position lower in the filter compared to the previous cases. Figure 13 shows a sketch of this geometry. For a gas inlet duct diameter of $90 \mathrm{in}$., the CFD model predicts that the pressure drop through the filter will be $82 \mathrm{IW}$. Figure 14 shows the stream lines 
through the filter. The streamlines in the upper section of the filter are very parallel and uniform. Figure 15 shows the isobars in the filter. At the outlet end of the filter, the pressure is uniform across the filter and the pressure gradient is constant in the axial direction. Figure 16 shows the flow distribution at the outlet of the filter. There is a reduction of flow along the wall and a corresponding increase in flow slightly away from the wall;otherwise, the flow rate across the filter is fairly uniform. The figures indicate a favorable gas distribution pattern which is necessary for high particle collection efficiency. Figures like these were prepared for all other cases, including the NYU verification cases, and compare favorably.

Once the modelling procedure were completed for the CPFBC, similar techniques were applied to the carbonizer and the IGCC gasifier. For both these filters, the diameter was $14 \mathrm{ft}$., the bed depth was $5 \mathrm{ft}$., and the gas-media interface diameter (gas inlet duct) was varied between 48 and 78 inches. For both applications, the minimum pressure drop occurred with a gas inlet diameter of 78 inches. With this gas inlet diameter, the pressure drop in the carbonizer filter is 31.5 IW and in the gasifier the pressure drop is 34.8 IW. The flow patterns for each application are similar to those shown for the CPFBC filter.

\subsection{Preliminary Design of Granular-Bed Filter}

Four different approaches to filter design were considered from the cost standpoint. The cost analysis indicated that the single entry filters were the lowest cost design, and established the most economic quantities. The CFD study, performed in parallel to the cost analysis, yielded guidelines for determining optimum single entry filter dimensions. In this section, the preliminary designs for these filters are presented.

\subsubsection{Process Description}

For the CPFBC, the carbonizer, and the KRW gasifier, the GBF process is nearly identical. Furthermore, this process is scaled up from the system tested at NYU. The major change from NYU is the inclusion of a recuperative heat exchanger and an automatic filter media make-up system. Figure 17 shows the process flow diagram for the CPFBC granular-bed filter. In this filter, there are four filter vessels that are serviced by a single media circulation system. The following description for the CPFBC filter also applies to the granular-bed filters used with the carbonizer and the KRW gasifier.

Particle laden gas enters each of four filter vessels, stream 1 , through a centrally located duct submerged in filter media. The media moves continuously downward toward the cone section of the filter. Particles are removed as the gas turns and flows upward through the filter media. The particle-laden media from each filter is withdrawn at the bottom of the filter element, stream 3 , and transported pneumatically in a lift pipe, stream 6 , to a de-entrainment vessel where the filter media and the ash particles are separated. The clean media flows by gravity back to each filter vessel, stream 9 . The media is distributed in the filter vessel through numerous distribution pipes and an annulus around the central inlet pipe. The lift gas and the particles leaving the deentrainment vessel, stream 11 , are cooled to $500^{\circ} \mathrm{F}$ in a regenerative heat exchanger. 


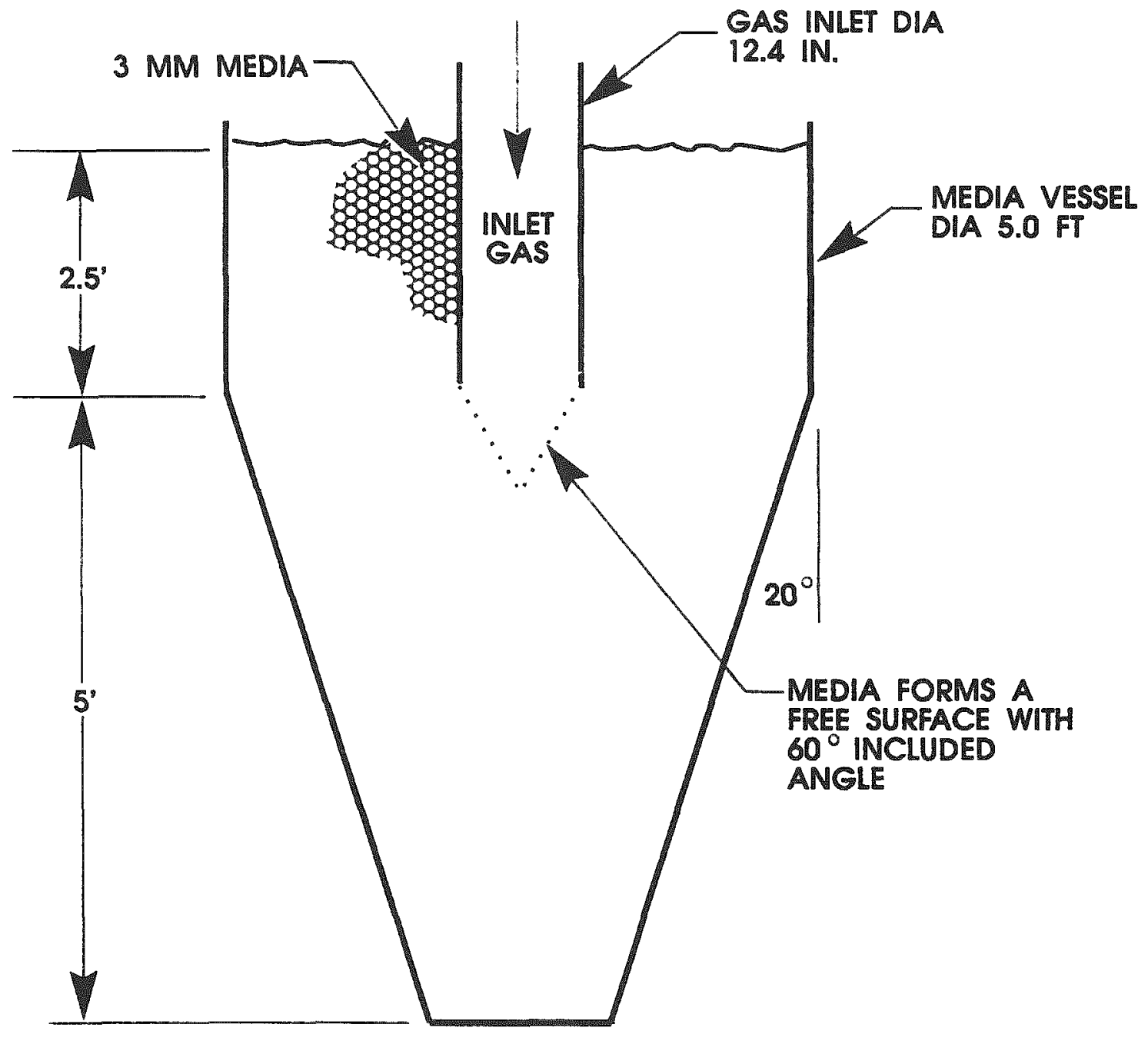

Figure 11 Idealized Sketch of the GBF Tested at NYU 


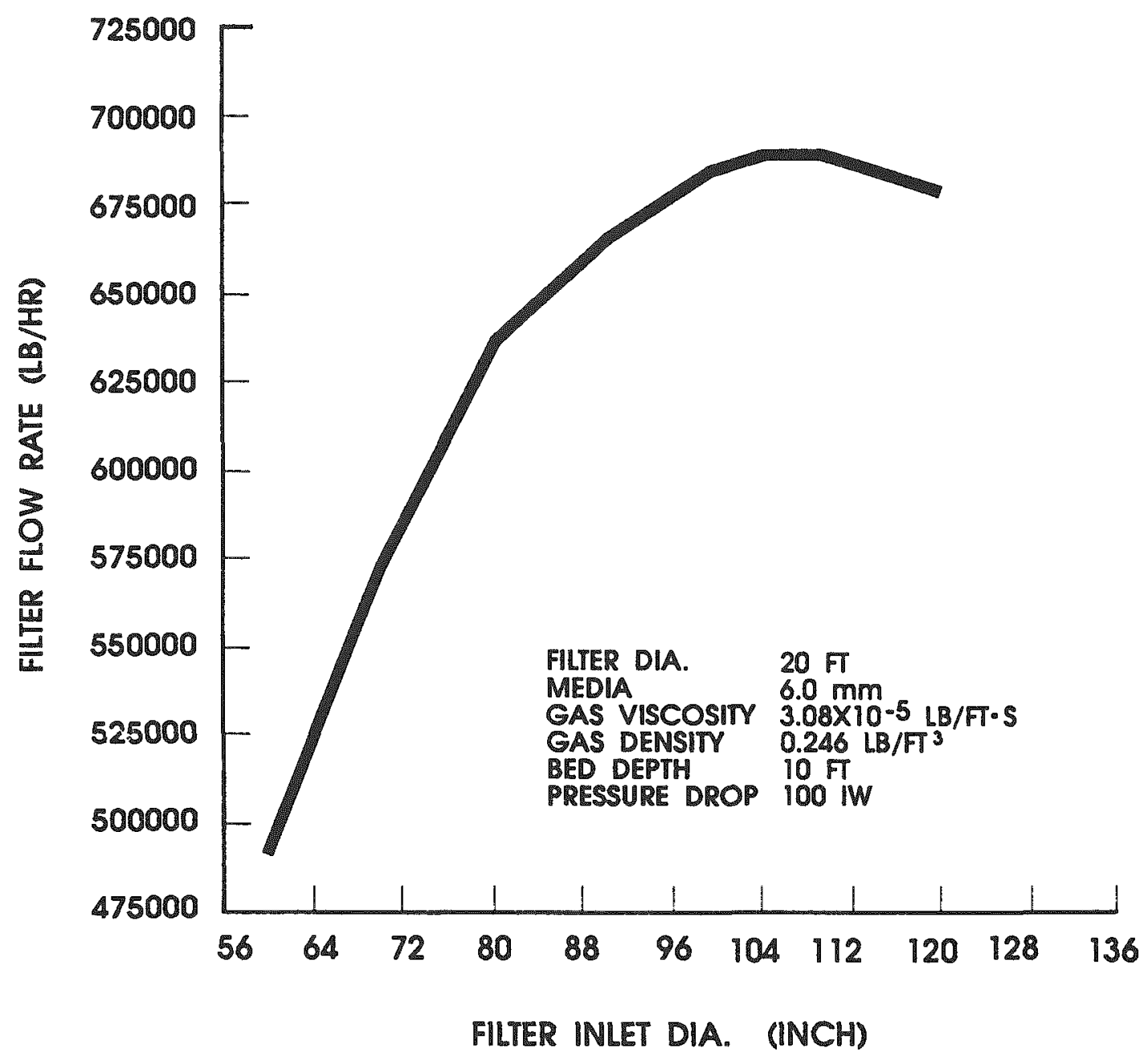

Figure 12 Effect of Filter Inlet Diameter on Filter Flow Rate 


\section{MM MEDIA-}

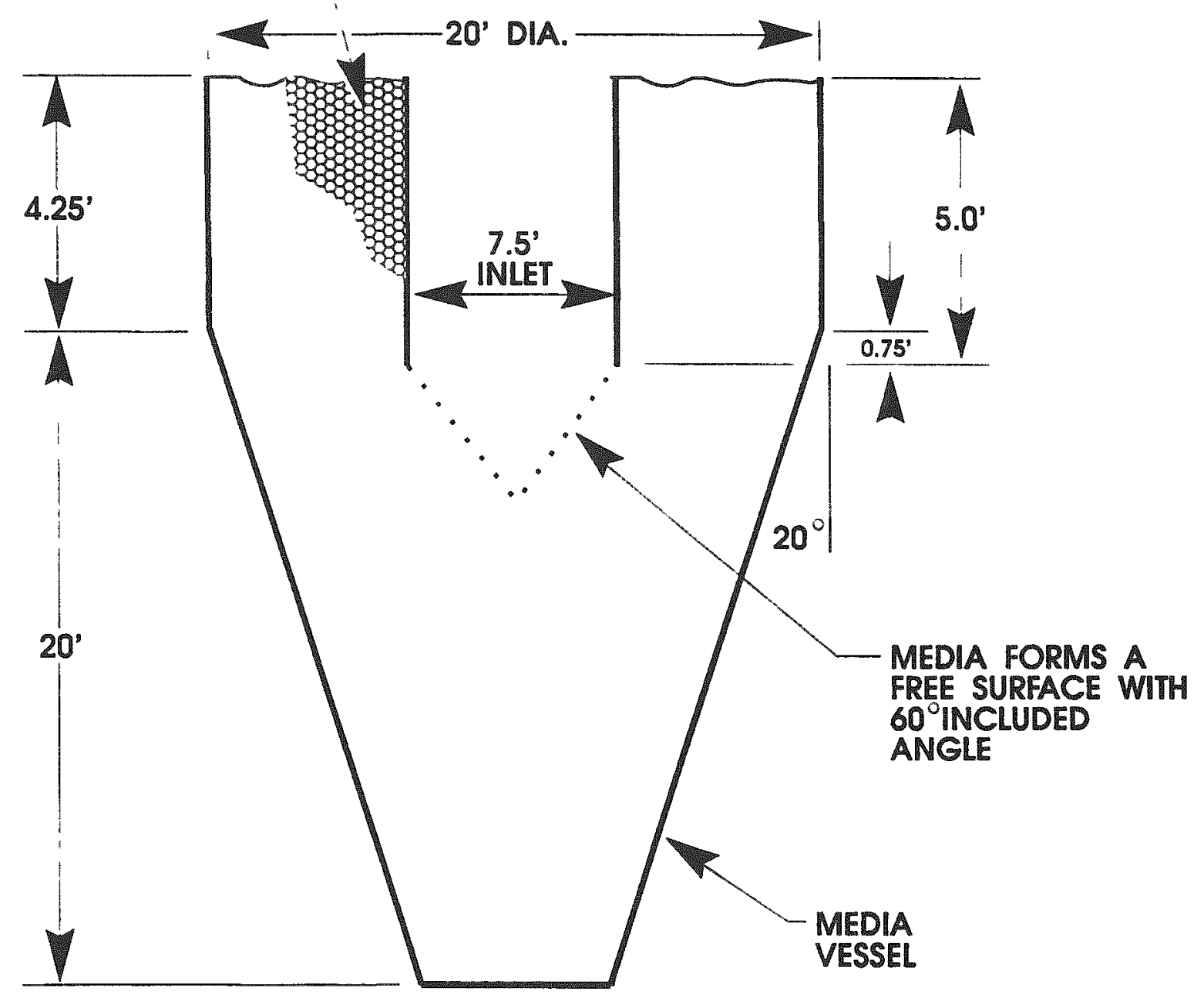

Figure 13 Schematic of the Geometry of $20 \mathrm{ft}$ Diameter Filter with a $5 \mathrm{ft}$ Deep Bed 


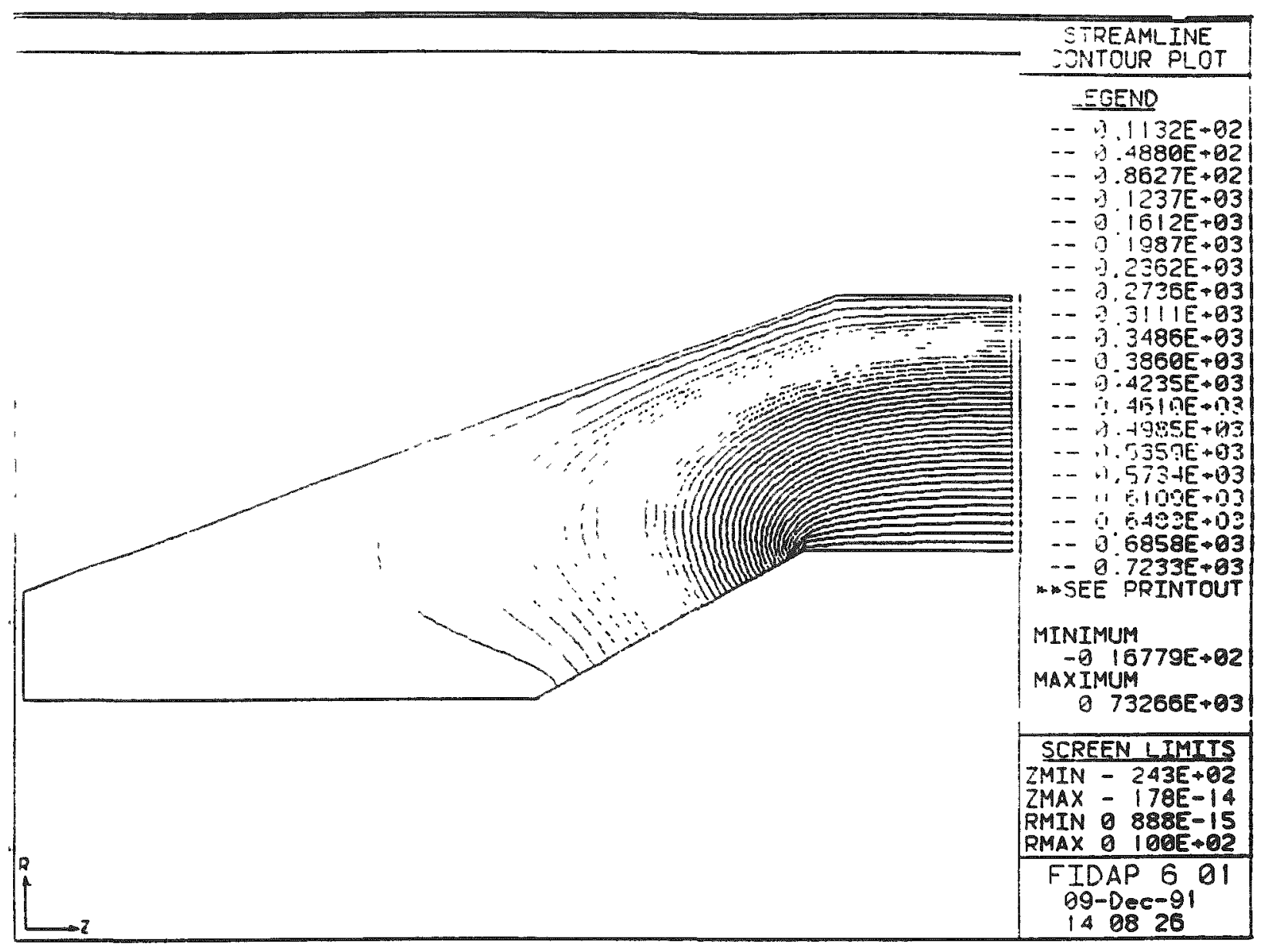

Figure 14 Streamlines for $20 \mathrm{ft}$ Diameter GBF with a $5 \mathrm{ft}$ Deep Bed 


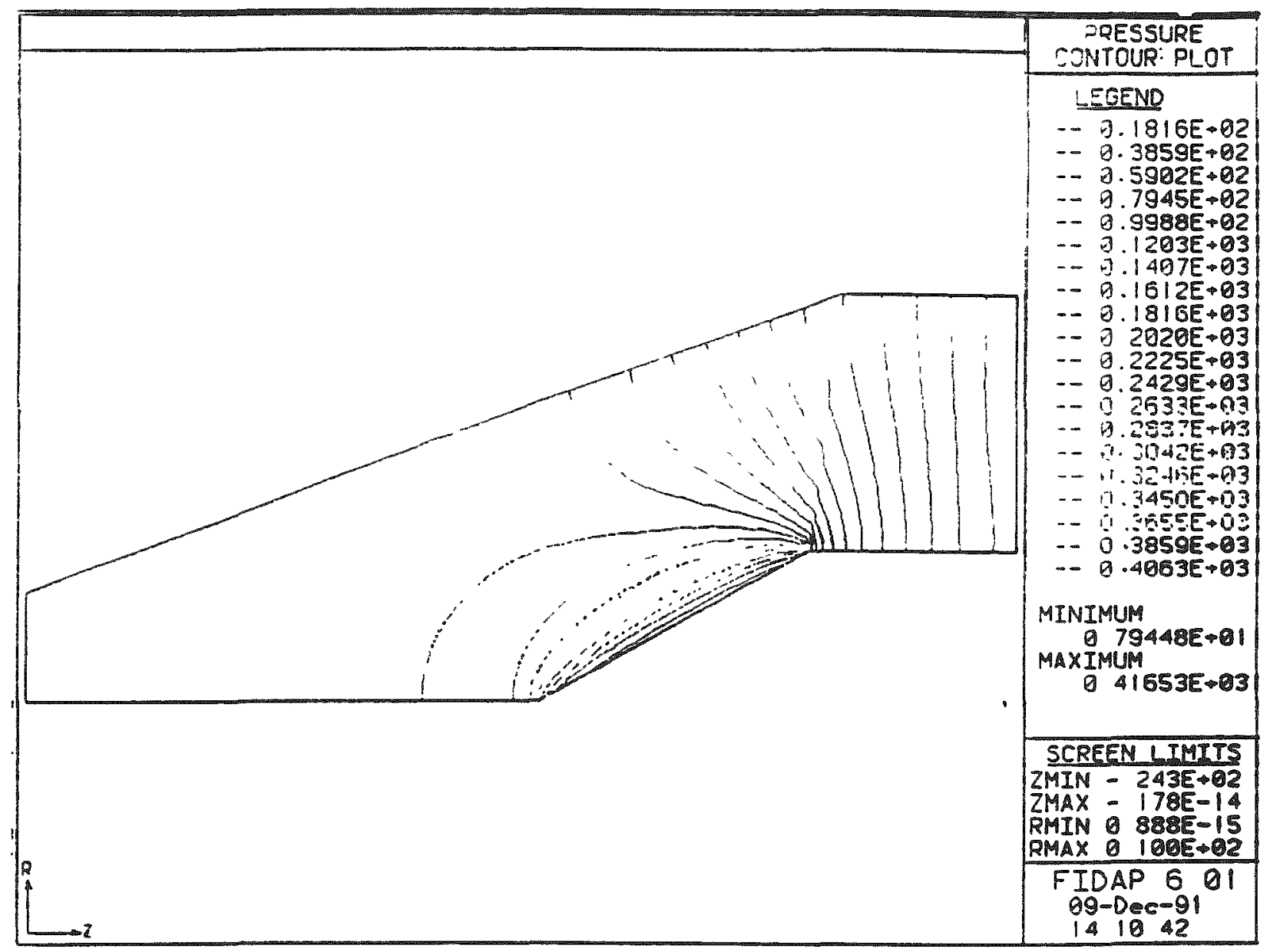

Figure 15 Pressure contours for $20 \mathrm{ft}$ Diameter GBF with a $5 \mathrm{ft}$ Deep Bed 


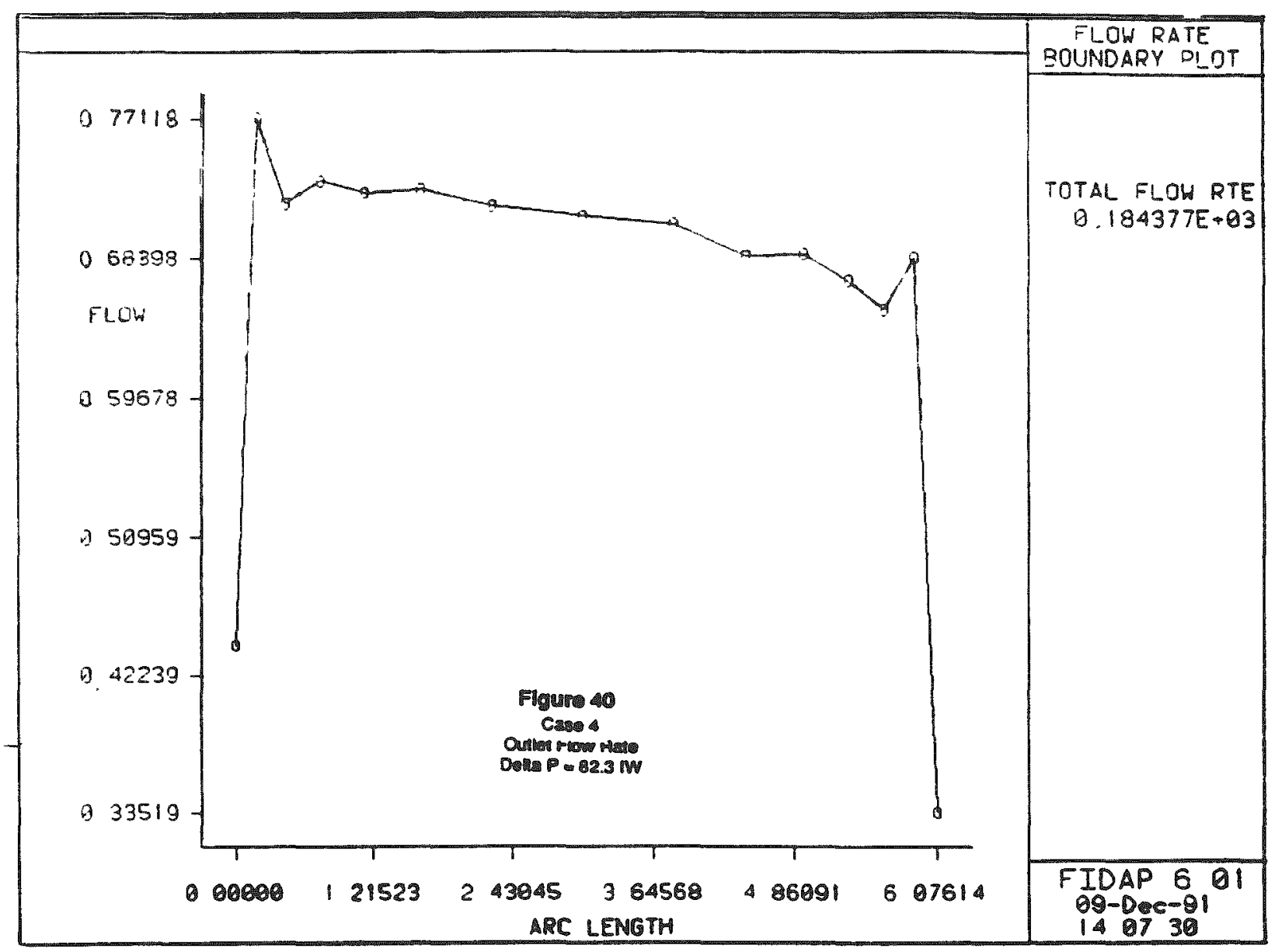

Figure 16 Outlet Flow Profile for $20 \mathrm{ft}$ Diameter GBF with a $5 \mathrm{ft}$ Deep Bed 
Ash is removed from the cooled lift gas in a pressurized baghouse, stream 21. The lift pipe transport gas is further cooled to $250^{\circ} \mathrm{F}$ in a water-cooled heat exchanger, boosted in pressure with a blower, reheated in the regenerative heat exchanger,and recycled to convey particle-laden media up the lift pipe. Pressure is balanced between the filter and the lift pipe, insuring that seepage gas flows down the lower seal leg in the same direction as the ash/media mix.

The recuperative heat exchanger serves two function: it reduces the temperature of the gas in the baghouse and it reheats the gas exiting the boost blower. The gas from the boost blower needs some degree of reheat to insure that any condensed liquids which may have formed during the gas compression in the boost blower are vaporized. An alternative to the recuperative heat exchanger would be to use a waste heat steam generator to reduce the temperature of the recirculation gas going to the baghouse. Although this would be a less expensive capital cost alternative, it would adversely impact the plant heat rate and would not provide for the potential problem of entrained liquids.

The baghouse is designed to operate at $500^{\circ} \mathrm{F}$ with standard fiberglass felt bags. For the CPFBC, the baghouse uses air as the pulse gas. For the carbonizer and KRW gasifier, the baghouse uses nitrogen as pulse gas. For the CPFBC, the ash discharges from the baghouse through a restricted pipe discharge (RPD) vessel as proposed in the Foster Wheeler study ${ }^{6}$. In the KRW gasification process, the ash from the baghouse discharges through lock hoppers.

The function of the water-cooled heat exchanger located after the baghouse is to reduce the temperature of the gas entering the boost blower. The heat from this exchanger could be recovered by incorporating the cooling stream into the feed water heating loop. No credit was taken for recycling the heat back into the power cycle.

Several types of compressors were evaluated for use as a boost blower. Lobe-type blowers were chosen, but single stage centrifugal blowers are an option.

The media used in the filter are $6 \mathrm{~mm}$, manufactured spheres composed mainly of aluminum oxide and mullite. Bulk density is $110 \mathrm{lb} / \mathrm{ft}^{3}$. Based on experience with $2 \mathrm{~mm}$ and $3 \mathrm{~mm}$ media at NYU and Combustion Power, it is expected to be very tough and wear resistant. Wear rates on similar $3 \mathrm{~mm}$ media used in the testing at NYU were too low to be measured.

Table 14 shows the gas composition entering the filters for each application.

\subsubsection{Process Flow for GBF - CPFBC}

Each of the two CPFBC's has a granular-bed filter module composed of four 20'-0" ,inside diameter, filter vessels; such that, the gas flow to each vessel is $661,000 \mathrm{lb} / \mathrm{hr}$, $1600^{\circ} \mathrm{F}, 188 \mathrm{psia}$. The ash concentration is $4000 \mathrm{ppmw}$. The projected filter pressure drop, based on the CFD model, is 82 IW assuming a 5' deep filtering bed. Figure 17 shows the mass and energy balance for the filters used with the CPFBC. Based on the test results from NYU, the filters are expected to have a particle collection efficiency of greater then $99 \%$. 
Table 14 Gas Composition for Each Filter Application (\% by Volume)

\begin{tabular}{lccc}
\hline Gas & CPFBC & Carbonizer & Gasifier \\
\hline $\mathrm{CO}_{2}$ & 7.1 & 12.4 & 17.1 \\
$\mathrm{H}_{2} \mathrm{O}$ & 3.2 & 11.2 & 4.3 \\
$\mathrm{~N}_{2}$ & 77.4 & 54.4 & 44.1 \\
$\mathrm{O}_{2}$ & 12.3 & 0.0 & 0.0 \\
$\mathrm{CO}$ & 0.0 & 8.9 & 9.2 \\
& & & \\
$\mathrm{CH}_{4}$ & 0.0 & 3.7 & 0.8 \\
$\mathrm{C}_{2}$ 's & 0.0 & 1.8 & 0.0 \\
$\mathrm{H}_{2} \mathrm{~S}$ & 0.0 & $700 \mathrm{PPM}$ & $700 \mathrm{PPM}$ \\
$\mathrm{SO}_{2}$ & $20 \mathrm{PPM}$ & 0.0 & 0.0 \\
\hline
\end{tabular}

The ash to media weight ratio used in sizing the media circulation system is 0.02 . In component testing associated with the NYU test program, ratios up to .06 were demonstrated in a media circulation system. Due to operating restrictions at NYU, this ratio could not be duplicated. The amount of ash which is allowed to accumulate in the filter has a critical effect on the design of the filter and its performance. A high ash concentration allows for a smaller media circulation system which favorably impacts filter cost and the filter temperature drop, but may adversely impact filter efficiency. The combination of the gas velocity and ash concentration chosen for this design is based on our experience previous to NYU operation. Testing will be required to confirm these values.

The data given on particulate size distribution indicates that a pre-collection cyclone would not effectively remove a significant portion of the ash to the filter. The expected mean diameter of the ash particles to the filter is 2.1 microns $^{7}$. Our initial economic evaluation showed that the penalty associated with the additional cost and pressure drop of pre-collection cyclones would not be offset by lower filter costs. This is because the pre-collection cyclone does not have a high collection efficiency on such small size particles. Should the size of the particles to the filter be such that a pre-collection cyclone could remove 85 to $90 \%$ of the ash, then the use of pre-collection cyclones would have to be reviewed.

Heat loss calculations for the CPFBC GBF are shown in Appendix B. Using the heat loss from each vessel, an energy balance is used to determine the temperature of the streams leaving each piece of equipment; the results of these calculations are shown in Figure 17. Due to the heat loss from the vessels and the heat rejected in the water-cooled heat exchanger, the CPFBC off-gas drops $20^{\circ} \mathrm{F}$ as it flows through the filter. If a recuperative heat exchanger were not used, the temperature drop through the filter would 
be about $60^{\circ} \mathrm{F}$. If unheated, once-through media were used, the temperature drop through the filter would be about $400^{\circ} \mathrm{F}$ for the media circulation rate shown.

\subsubsection{Process Flow for Carbonizer GBF}

The carbonizer will use one 14'-0" diameter single entry filter for each PFBC module. The gas flow to each filter is $244,650 \mathrm{lb} / \mathrm{hr}$ at $1501^{\circ} \mathrm{F}$ and 208 psia. The ash concentration in the inlet gas stream is $10,000 \mathrm{ppmw}$. Because of the relatively high ash concentration, the gas velocity through the filter is $37 \%$ of the minimum fluidization velocity, and the ash to media weight ratio is 0.025 . The filter bed depth is 5 feet and the expected pressure drop through the filter is 37 IW. Figure 18 shows the process flow diagram for the carbonizer filter.

The temperature drop through the filter is $35^{\circ} \mathrm{F}$. Heat loss calculations for the carbonizer GBF are shown in Appendix B. Both the size of the filter and the temperature drop through the filter are directly affected by the quantity of ash flowing to the filter. As with the CPFBC filter, a pre-collection cyclone was rejected because of the low collection efficiency expected due to small particle size. Nevertheless, any modification to the process which would reduce the ash concentration to the filter would reduce the capital cost of the filter and its operational cost. The gas flow rate through the filter was reduced from the $54 \%$ of minimum fluidization velocity used with the filter on the CPFBC to $37 \%$ to accommodate the high ash concentration. The high heat loss associated with the filter is a direct result of the higher ash concentration which requires a larger media recirculation system. If the inlet ash concentration were the same as that of the $\mathrm{CPFBC}$, the diameter of the filter would be reduced from 14 feet to 11.6 feet. The temperature drop through the carbonizer filter would then be about the same as through the CPFBC filter, $20^{\circ} \mathrm{F}$.

Table 14 shows the composition of the reducing gas from the carbonizer. The Foster Wheeler model of the carbonizer predicts the presence of $2.4 \mathrm{lb} / \mathrm{hr}$ of coal tars ${ }^{6}$. The tars or other high molecular compounds may crack and form coke as the reducing gas passes through the filter. It is not expected that the formation of coke in the GBF will cause an operation problem due to the movement of the media. Coking in a porous ceramic, candle filter could cause temporary blinding of the filter elements which would require periodic burnout to remove coke deposits.

\subsubsection{Process Flow for KRW Gasifier GBF}

The KRW gasifier ${ }^{8}$ will use a $14^{\prime}-0^{\prime \prime}$ diameter filter similar to that used for the carbonizer. The gas flow to the filter is $312,800 \mathrm{lb} / \mathrm{hr}$ at $1600^{\circ} \mathrm{F}$ and 385 pisa. The ash concentration in the inlet gas stream is $8,500 \mathrm{ppm}$. The gas velocity through the filter is $37 \%$ of the minimum fluidization velocity, and the ash to media ratio is 0.025 . The bed depth is 5 feet and the expected pressure drop through the filter is 36 IW. Figure 19 shows the process flow diagram for the KRW gasifier filter. 


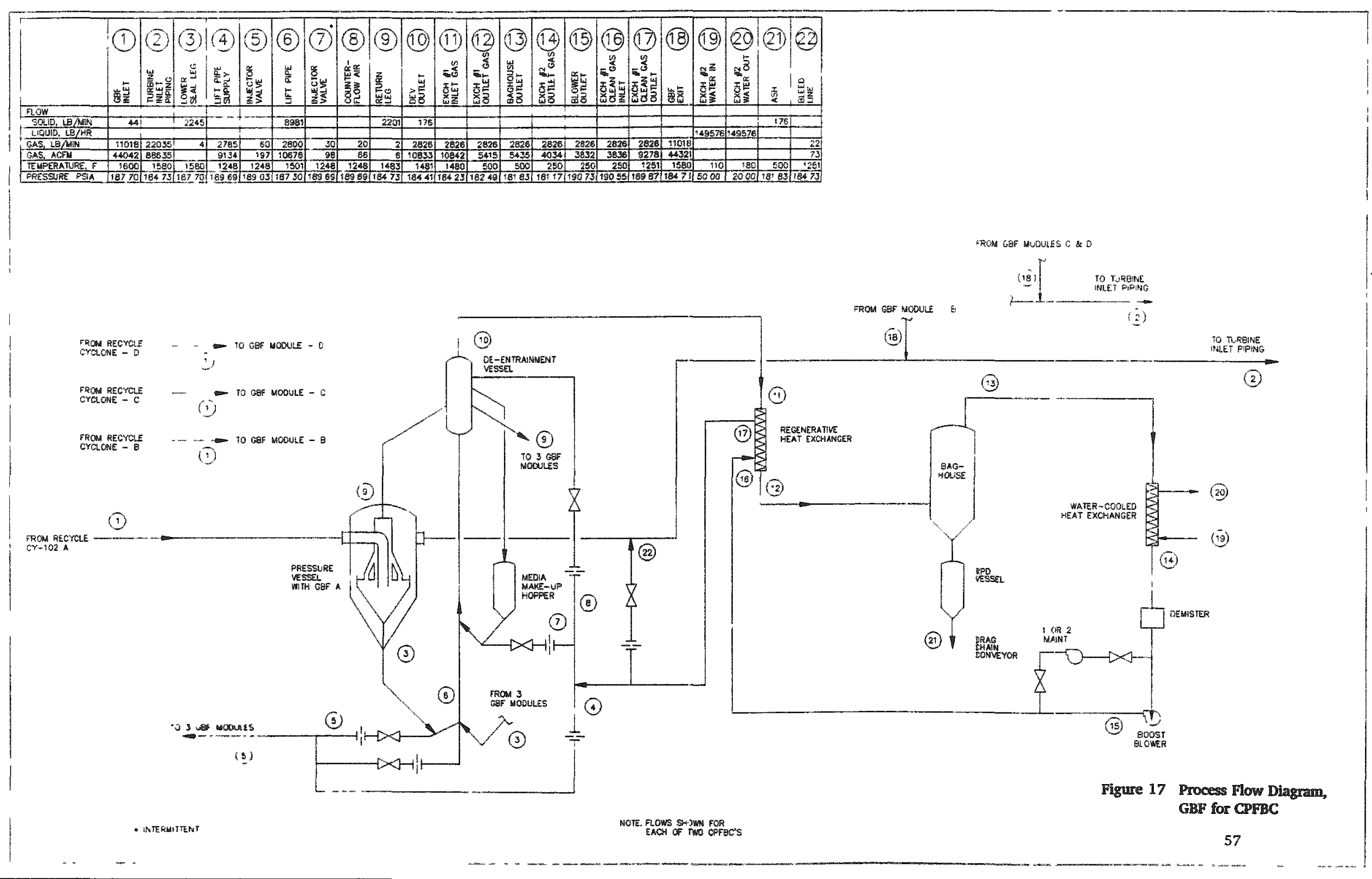




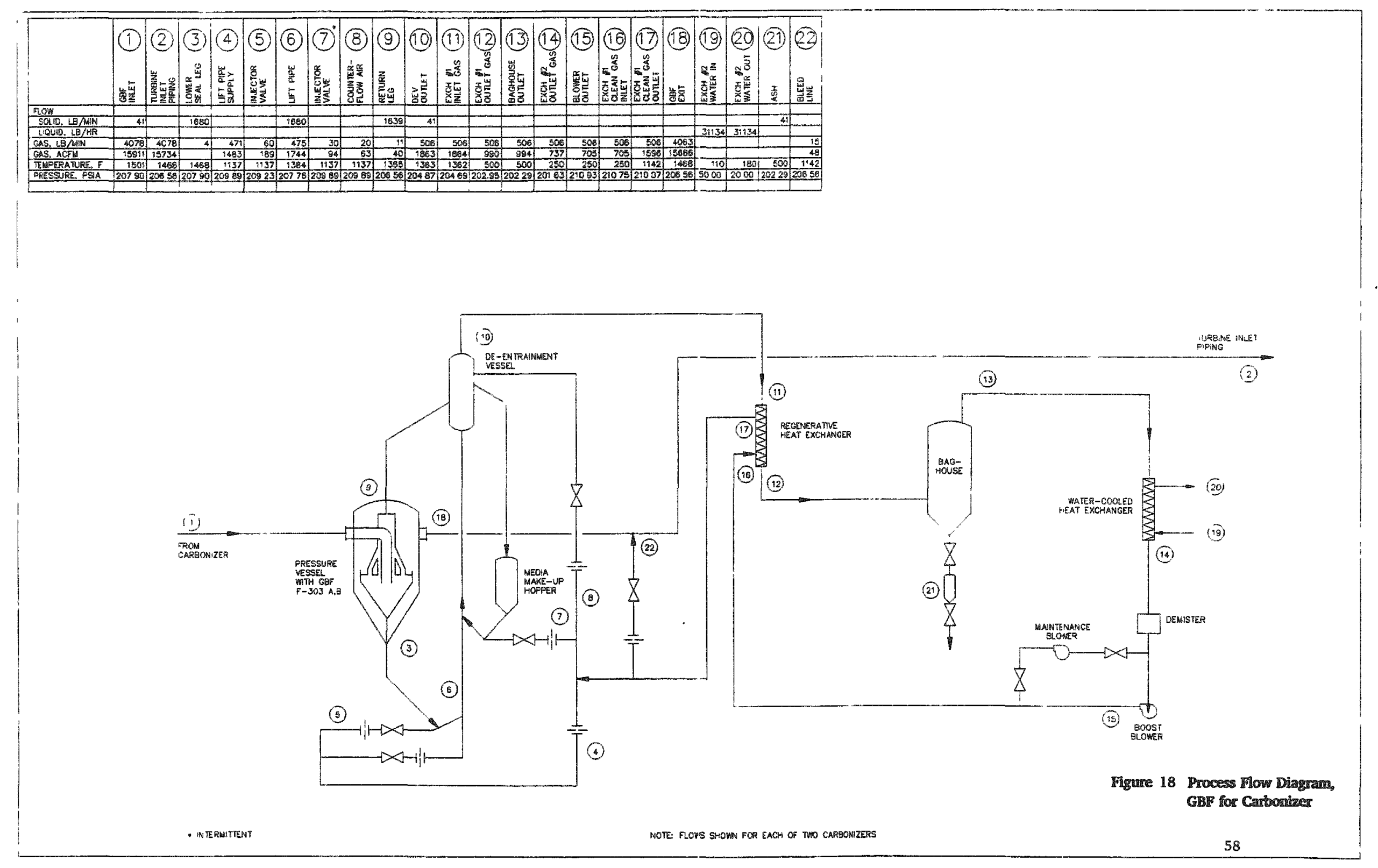




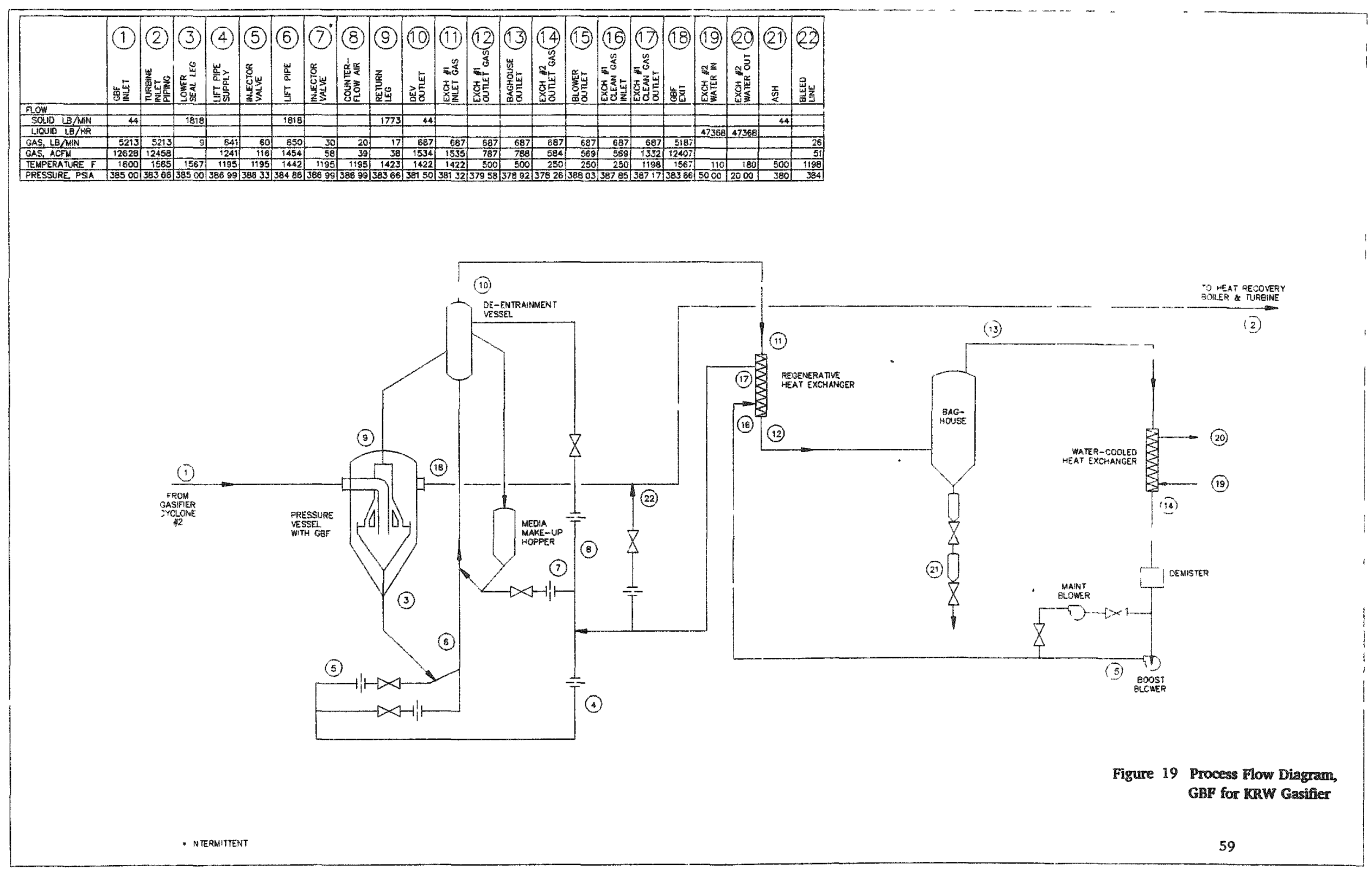

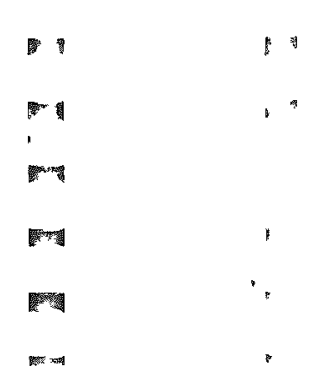

$m$
$m$
$m$
$m$


The temperature drop through the filter is $35^{\circ} \mathrm{F}$. As is the case for the carbonizer, the high heat loss is a result of the high ash concentration to the filter. Table 14 shows the composition of the gas entering the filter. Heat loss calculations for the gasifier GBF are shown in Appendix B.

In the KRW process, the gasification products are cooled after the HTHP gas cleanup device before entering the zinc ferrite $\mathrm{H}_{2} \mathrm{~S}$ removal process. There may be some benefits to partial cooling the gasification products before the gas cleanup equipment. A lower temperature gas stream would allow lower cost materials to be used for the filter internals, would reduce the size of the filter. Presently the GBF is designed to handle the high temperature gasification products, and the benefits of a lower temperature gas entering the filter were not evaluated.

\subsubsection{Instrumentation and Control}

An automatic control system maintains the system process parameters at specified set-points, provides system status and safe operation, and adjust filter operating conditions to match changes in the process gas stream. The automatic control system for each of the filter applications is nearly the same. Figures 20,21, and 22 show the Piping and Instrumentation Diagrams for each application.

Flow, temperature and pressure requirements are arranged to give complete definition of system operation at all times. Some redundant measurements are provided to cross check data. Computer control is utilized with a programmable logic controller.

The control system has four major control loops. They are:

- Filter pressure drop

This loop adjust the media circulation rate to maintain the filter pressure drop at a predetermined set point. The set point for the filter pressure drop is a function of the gas flow through the filter and is determined from tests during the initial startup of the filter. If the filter pressure drop is above the set point, the gas flow to the lift pipe "ell" valve is increased to increase the media circulation rate. The increased media circulation rate will lower the ash concentration in the filter which will reduce the filter pressure drop. An opacity meter or other solids monitoring device in the cooled turbine exhaust is used as a trim function for the filter pressure drop set point. If the opacity meter indicates poor filter efficiency, the filter pressure drop set point is increased to reduce the media circulation rate and increase filter efficiency.

- Lift gas flow

This loop maintains the gas flow through the lift pipe at the specified set-point by adjustment of the boost blower speed. The set-point for this loop is selected to minimize the media velocity in the lift pipe and is a function of the lift pipe pressure drop, pressure and temperature. 
- Pressure balancing

Flow control valve FCV-170 maintains the pressure balance between the filter element and the lift pipe by bleeding gas from the high pressure side of the boost blower to the process gas stream exiting the filter.

When large pressure excursion occur such as during startup or shutdown, PDCV006 and PDCV-006-2 automatically bleed gas into or out of the lift gas circulation system allowing the pressure in the media recirculation system to rapidly follow system pressure.

- Ash removal system

The CPFBC will use restricted pipe discharge (RPD) hoppers as proposed in the Foster Wheeler study to remove the ash captured in the baghouse. The ash drains from the baghouse hopper through a standpipe to the RPD hopper. A description of the operation and control of the RPD system can be found in the Foster Wheeler report ${ }^{6}$.

The KRW gasifier filter will use a lock hopper system to discharge high pressure ash from the baghouse hopper to the low pressure ash conveying system. The steps are:

A. Both ball valves start off closed while ash accumulates in the upper ash holding vessel.

B. At a preset time interval or at operator initiation, a pressure balancing valve opens to bleed system pressure into the lower ash holding vessel. A pressure switch proves status.

C. The upper ball valve opens and ash falls at equal pressure into the lower ash holding vessel.

D. After the upper ball valve closes to isolate the lower ash holding vessel, a bleed valve opens to vent pressure. Desired pressure is proven by a switch.

E. The lower ball valve opens to discharge ash at atmospheric pressure into the ash conveying line

F. The sequence ends after the lower ball valve closed.

- Computer Control System

The computer control system is based on a programmable logic controller (PLC). It is constructed on a modular basis using plug-in printed circuit cards installed in a control rack. See Figure 23 for the granular-bed filter for the CPFBC. Figure 24 shows the system for the carbonizer and the gasifier granular-bed filters. A central processing unit scans the user program and generates logic commands. Data collection is performed through the device called a "Genius I/O" (Input/Output) connected to the PLC. 


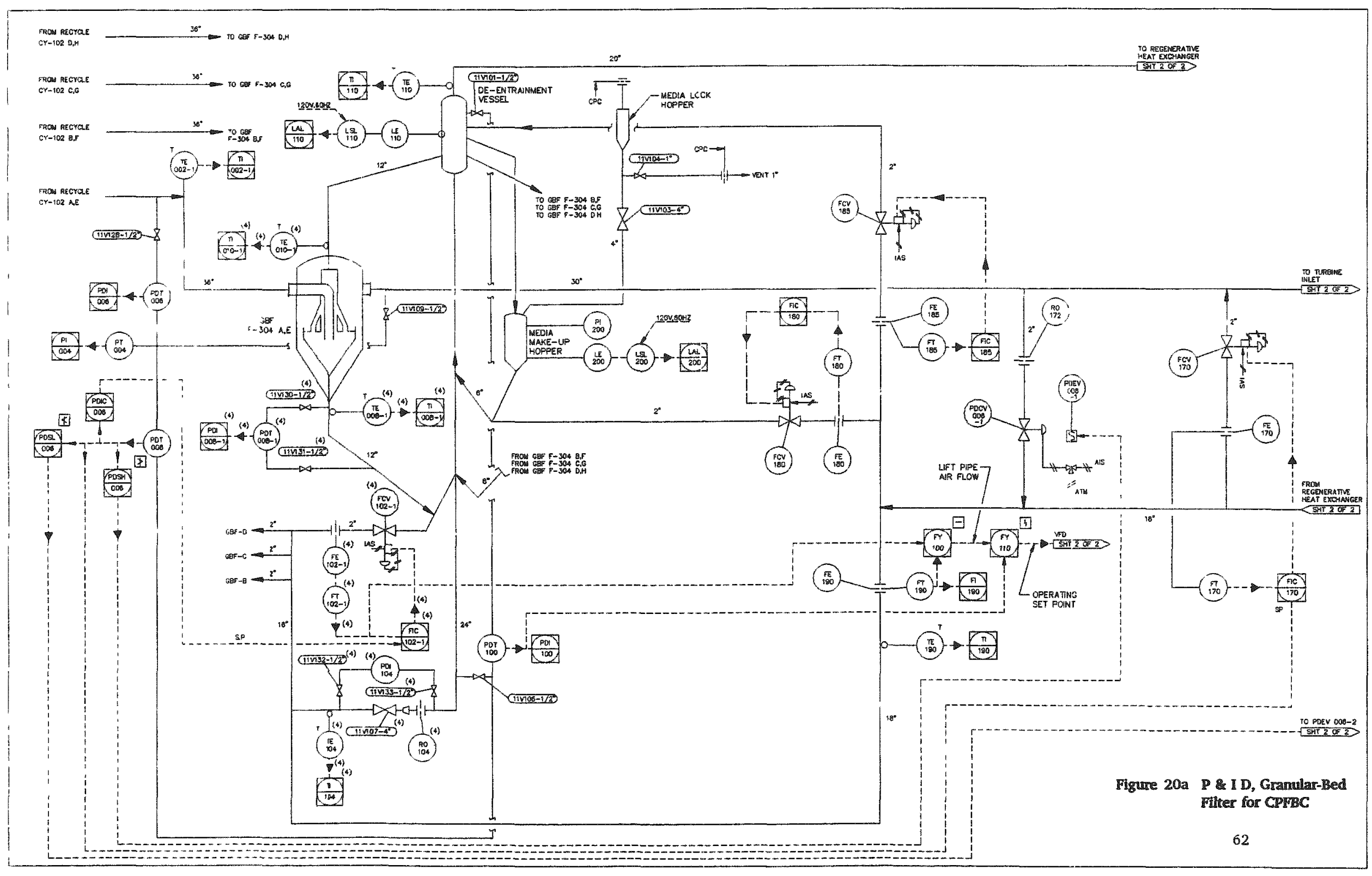




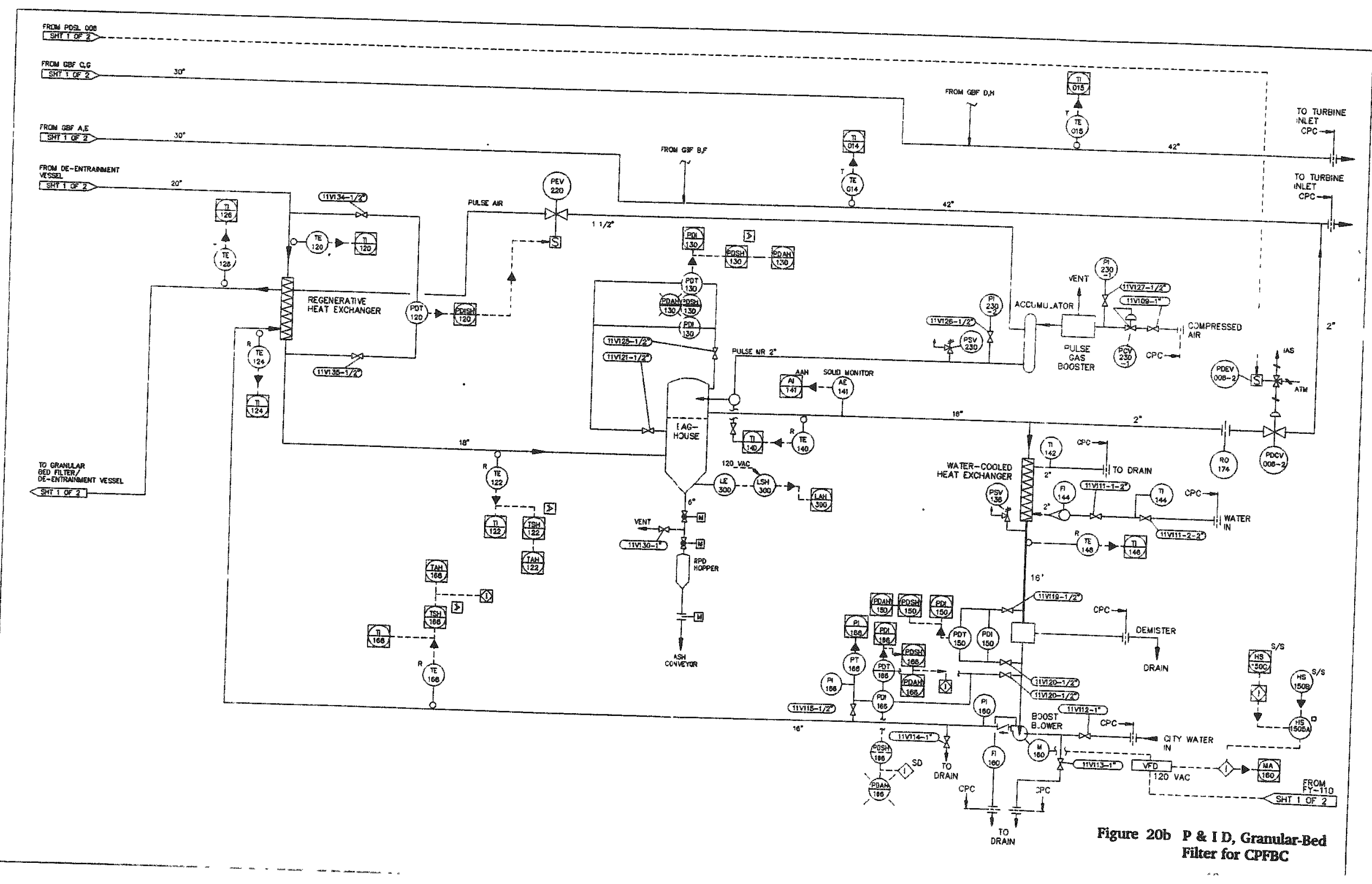




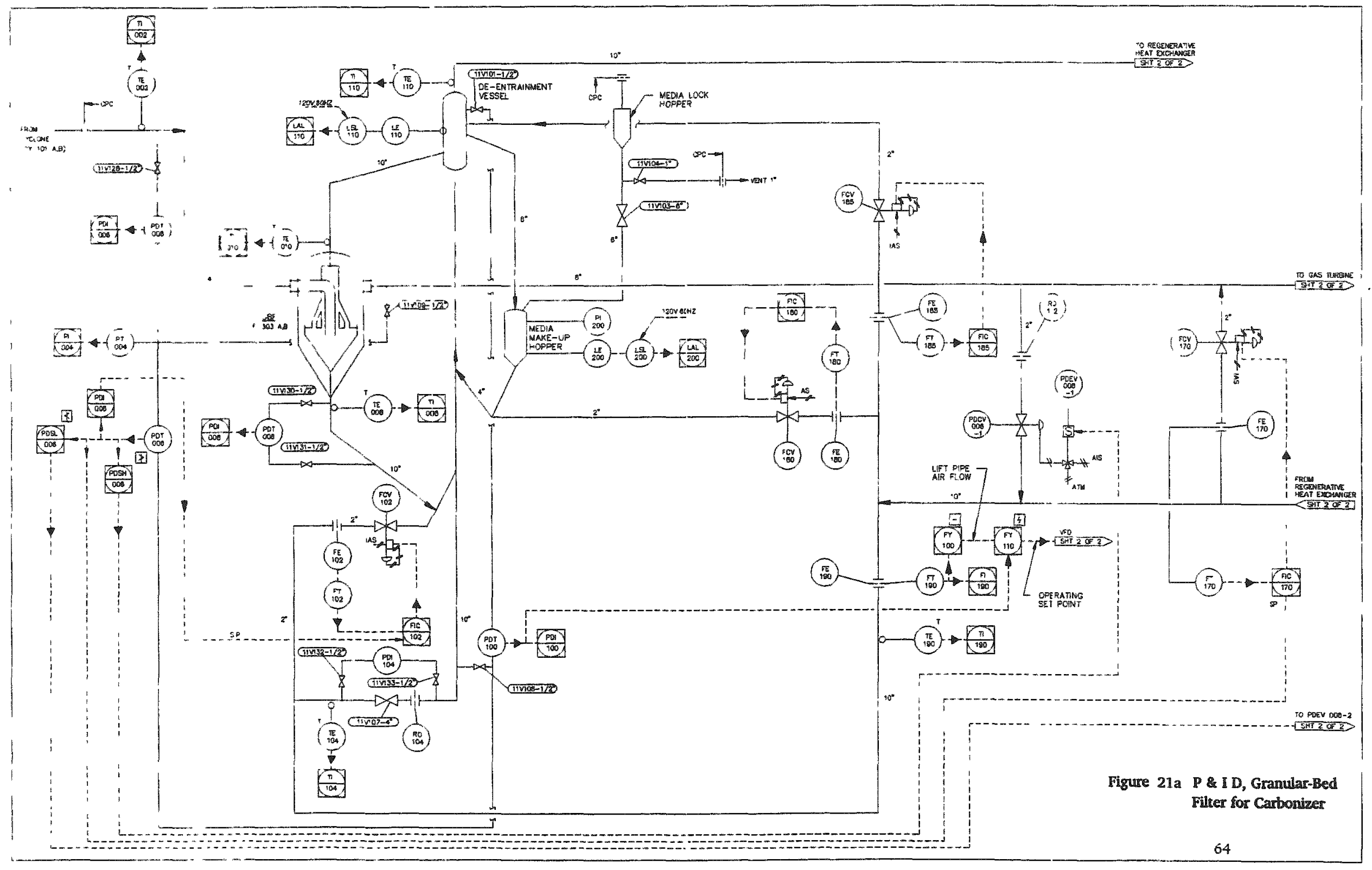




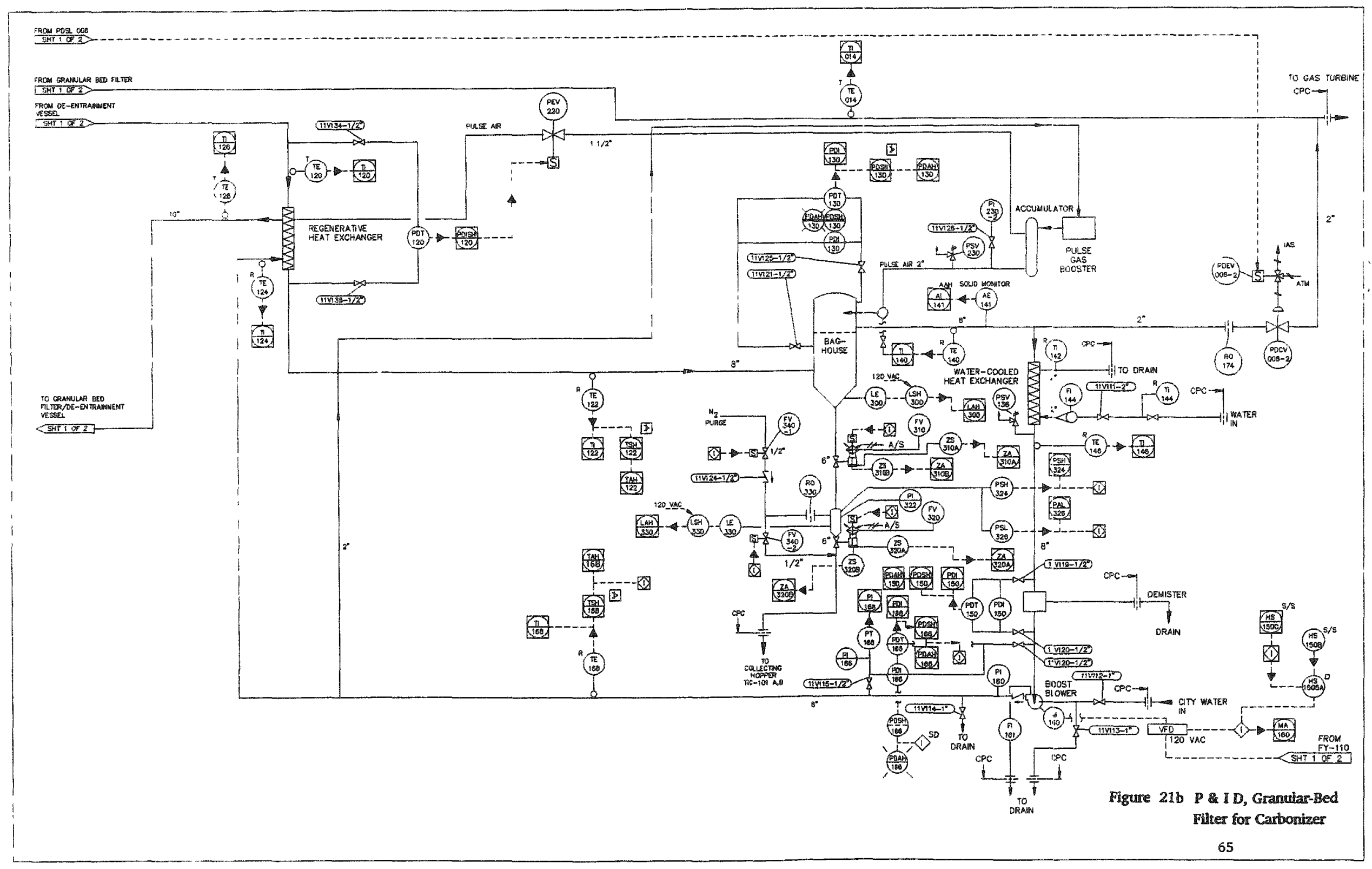




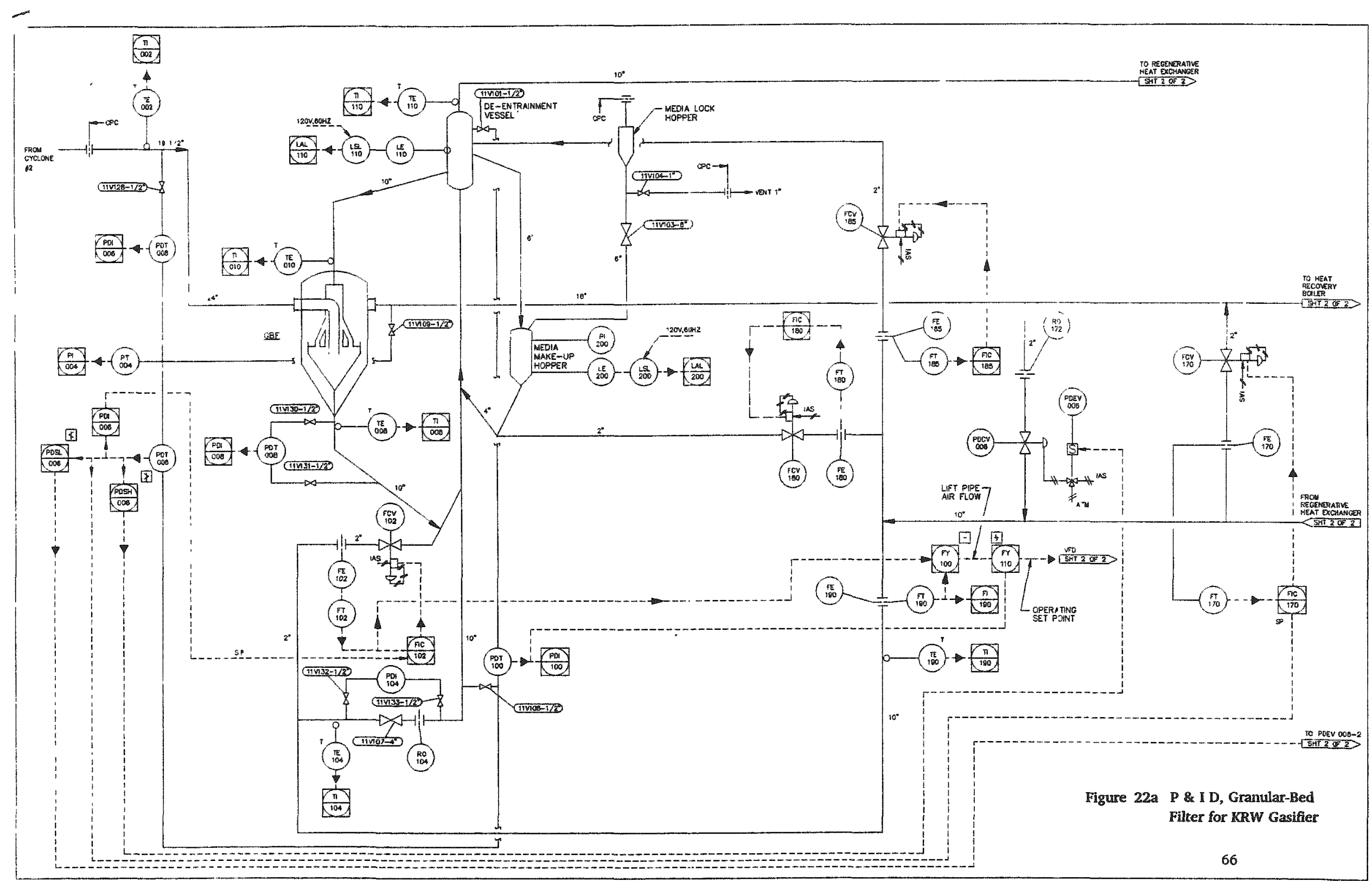




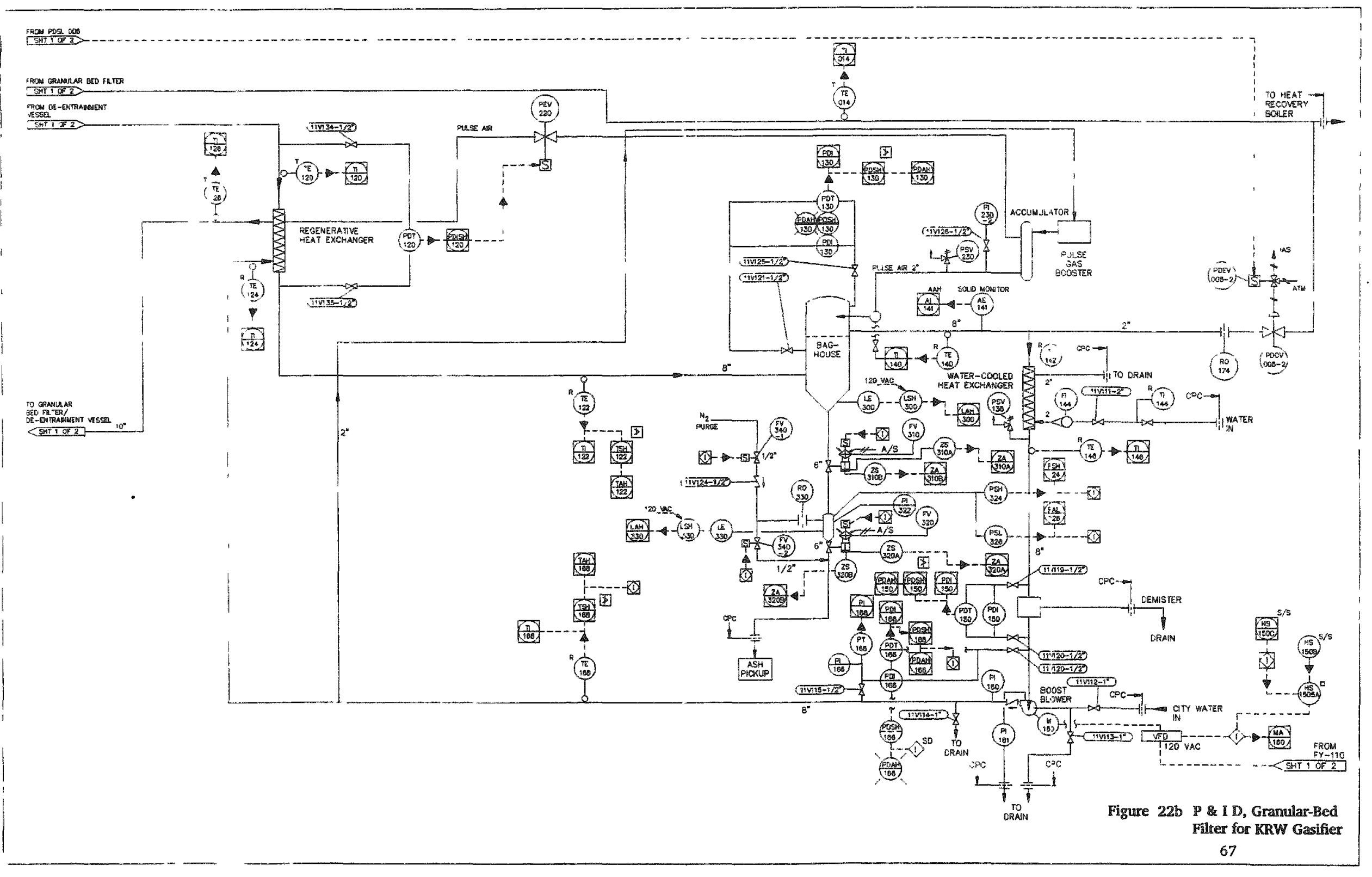




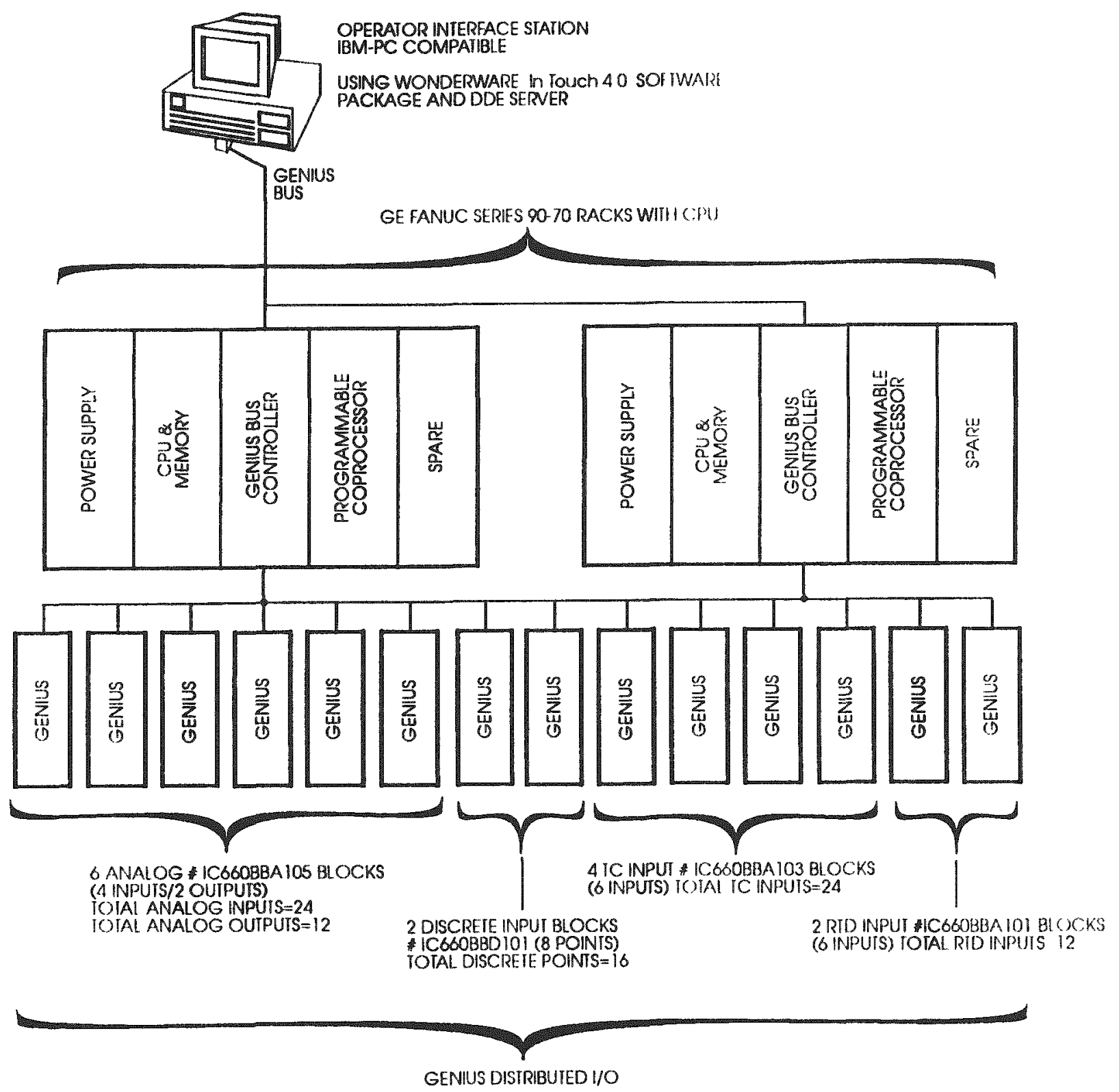

Figure 23 Control System Architecture, GBF for CPFBC 


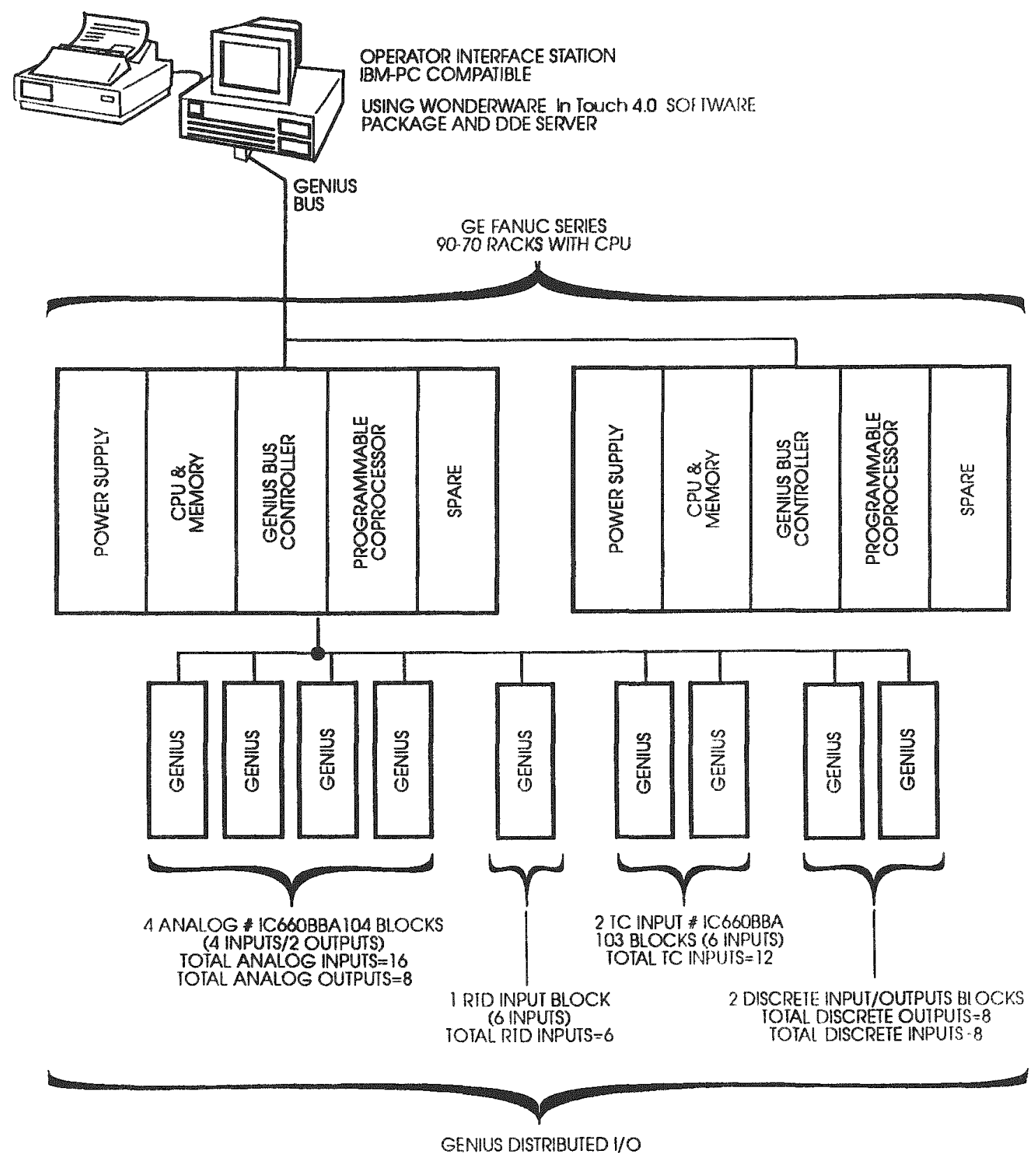

Figure 24 Control System Architecture, GBF for Carbonizer and Gasifier 
Unlike conventional remote $\mathrm{I} / \mathrm{O}$, this arrangement requires no central $\mathrm{I} / \mathrm{O}$ control cabinets, no racks, and no separate power supply. These $\mathrm{I} / \mathrm{O}$ devices are installed close to field instruments. Genius I/O automatically provides diagnostic information of field wiring and power conditions. This troubleshooting capability reduces time needed for control system debugging.

This mode of local computer control also cuts down on maintenance costs and system downtime because it eliminates the need for destructive fuses. When overloads and short circuits are detected, output circuits turn off immediately, protecting circuitry and wiring.

The software package provides monitoring, control, data acquisition, alarms, and graphics. All process data can be transferred in common data base programs; such as, Microsoft's data base program called EXCEL, to take advantage of data conversion capabilities. Using the proficiency of the software package, user programmed management reports can be prepared and printed at anytime, during operation or downtime. Selected data can be stored in computer memory for a predetermined amount of time, allowing historical review of operation.

Included with the computer control package are: analog transmitters, thermocouple inputs, RTD inputs, and analog outputs. The local computer control module includes: redundant CPU with memory, redundant rack, redundant power supply, redundant bus controller, redundant coprocessor with software, and required input and output blocks. Software includes programming to allow: standard displays, dynamic graphics and trending, configuration changes, alarming, and report generation. For monitoring the operation, a caliber 486SX personal computer is included with two serial ports, one parallel port, 105 Megabyte hard drive, 3.5" floppy drive, Super VGA monitor, keyboard, mouse, color printer, and interconnecting cables. Personal computer software includes MS DOS 5.0 and Windows 3.1.

\subsubsection{Granular-Bed Filter Configurations}

The 452 MWe, second generation PFB combustion plant is arranged in two identical trains of equipment, each sized for $226 \mathrm{MWe}$. Each train includes a CPFBC and a carbonizer. There are four granular-bed filter vessels for each $\mathrm{CPFBC}$ and one granularbed filter vessel for each carbonizer. These filter vessels replace two cross-flow filter vessels for each CPFBC and one cross-flow filter vessel for each carbonizer. For the 100 MWe, KRW, air blown gasifier, a single granular-bed filter vessel replaces the cross-flow filter originally utilized. Figure 25 shows the basic configuration of these granular-bed filters. The filters are enclosed in refractory-lined pressure vessels. Dirty gas enters through a nozzle incorporated into an vessel extension on top of the filter vessel. This gas is dispersed by metal ducting into the filter media at the gas/media interface. Clean filter media enters at the top of the filter and is distributed across the filter by numerous pipes and an annular distribution duct in the center. Ash is removed by the spherical, ceramic, filter media moving in the opposite direction of the ash-ladened process gases. Clean gas exits the open area above the filter bed and ash ladened media exits at the bottom of the filter. 


\subsubsection{Refractory}

Several approaches to lining the filter with refractory were considered.

- Cast insulation and hardface in the filter cone and partial sidewalls, and ceramic fiber product in the gas space above the filter media.

- Castable-type refractory applied by pneumatic gunning techniques installed in regions described above.

- Insulating and hardface brick in the filter cone with gunite insulation/hardface in the space above the filter media.

In the granular-bed filter vessel above the filter bed, conditions for the refractory are fairly mild, even in the reducing atmospheres for the carbonizer and the gasifier. There is virtually no ash, gas velocity is very low $(<10 \mathrm{ft} / \mathrm{sec})$ and operating temperatures are $1500^{\circ} \mathrm{F}$ to $1600^{\circ} \mathrm{F}$. Under these conditions, the most important refractory properties to consider are thermal conductivity to minimize heat loss and refractory stability to resist any kind of deterioration that could add particles to the gas stream leaving the filter.

Ceramic fiber products have very low thermal conductivity $\left(.5\right.$ to $1 \mathrm{Btu}$-in/hr $\mathrm{ft}^{2}$ ${ }^{\circ} \mathrm{F}$ ) and are available in a number of forms that could be suitable for lining this zone. Even though manufactures and installers claim otherwise, these products could deteriorate and add particles, in the form of ceramic fibers or chunks, to the gas stream exiting towards the gas turbine. Metal liners can be used to protect this material, but this is costly. Consequently, these materials are not proposed; although, consideration would be given in an actual application. Instead our choice is a lightweight, insulating gunning mix. These materials have slightly less insulating value when compared to ceramic fiber products, but are much stronger and more resistant to deterioration and chemical attach. A 60 to $70 \mathrm{lb} / \mathrm{ft}^{3}$ gunning mix could be applied as a combination insulating and hardface layer in the granular-bed filter operating in an oxidizing or reducing environment. Thermal conductivity is in the range of 1.3 to $1.6 \mathrm{Btu}$-in/ $\mathrm{hr} \mathrm{ft}^{2}{ }^{\circ} \mathrm{F}$ and good strength is indicated by a cold crushing strength of 300 to $500 \mathrm{psi}$ after heating to $1500^{\circ} \mathrm{F}$.

In the granular-bed filter area that houses filtration media in the form of $6 \mathrm{~mm}$ ceramic spheres, requirements are different. A hardface material must be fairly smooth to allow the filter media to move with minimal friction. Furthermore, the material must have good strength to hold the media weight and moderate abrasion resistance for long life. At New York University, the media reservoir was lined with A.P. Green Lo-Abrade castable hardface and a very lightweight, low strength insulating castable. This approach was satisfactory from both the process and strength standpoint. For small granular-bed filters, casting the cone and sidewall areas that enclose the media would be the preferred technique. Pneumatic gunning would not be suitable because the resulting surface tends to be very rough in comparison to formed castables. In larger granular-bed filters, forms for installing castables (similar to forms for installing concrete) are very large, bulky and expensive. There will be an economic break-point where alternate techniques are more 
suitable. Super-duty refractory brick can be installed in these larger diameters to achieve a smooth surface that we feel is equivalent to a cast refractory surface. Abrasion resistance and strength are also comparable to castable refractory hardfaces. Bricking is chosen for the large (14-20' diameter) granular-bed filters. For an insulation layer under the hardface bricks, we have also chosen an insulating brick of moderate strength and good thermal conductivity.

Insulating refractory brick comes in many grades, differentiated by suitability for temperature, thermal conductivity, and strength. In this case, temperature is not a factor, as typical insulating firebrick is rated to at least $2000^{\circ} \mathrm{F}$. Requirements for strength may govern the choice of brick as the weight of the filter media must be supported off the filter wall and cone. Thermal conductivities of insulating firebrick range from 1 to 2.5 $\mathrm{Btu}$-in/hr $\mathrm{ft}^{2}{ }^{\circ} \mathrm{F}$. Higher thermal conductivities are associated with higher strength materials.

\subsubsection{Metal Internals}

The life of the metallic internals used in the filters will greatly depend on the operating temperature and gas environment. For the CPFBC granular-bed filter operating at $1600^{\circ} \mathrm{F}$ with a high oxygen and a low sulfur dioxide environment, we expect that the loss of metal will be less than 5 mils/year. This corresponds to a service life of about 25 years. In candle filters for service in PFBC applications (oxidizing atmospheres) RA333 and 310 SS have been used with satisfactory results. ${ }^{9}$. RA333 has been used in regions of high stress, and 310 SS has been used in regions of low stress. Therefore, for the candle filter in the oxidizing atmosphere, the CPFBC candle filter, these materials are proposed as referenced in the section describing the ceramic candle filters. A different alloy, RA253MA has also shown good strength and corrosion resistance in oxidizing atmospheres ${ }^{10}$. The granular-bed filter internals are under minimal stress in the CPFBC filter, and since the additional high temperature strength of RA333 is not necessary, the bulk of the internals are proposed to be made from RA253MA. Minimally stressed internals for auxiliary granular-bed filter equipment are proposed in $310 \mathrm{SS}$.

The carbonizer and gasifier environments will be significantly more corrosive. In a $1500-1600^{\circ} \mathrm{F}$ reducing gas environment, the corrosion rate could be as high as 20 mils/year ${ }^{11}$. The expected service life in this situation could be only 5 years; less if "breakaway" corrosion occurs. Breakaway corrosion is a suddenly increasing corrosion rate occurring after a long period of relatively stable behavior. As the corrosion information available on metals in the reducing environments is limited, we believe that one of the functions of any future development program should be to collect corrosion data on promising alloys which can be used in this type of service.

Since sulfur is captured in the gasifier, sulfidation potential due to $\mathrm{H}_{2} \mathrm{~S}$ is considerably reduced downstream in the filter. Strength is an important factor for the candle filter tubesheet, but primary stresses in the granular-bed filter internals are low because the internals hang from the top of the vessel and basically support only their own weight. Welding must be sound from the standpoint of strength and corrosion. Consideration must be given to metal toughness, creep, creep fatigue, thermomechanical 
fatigue, and all types of corrosion, both low and high temperature. Primary stresses at $1500-1600^{\circ} \mathrm{F}$ must be low; $600-2500$ psi depending on the material choice. This design stress is typically determined by ASME Boiler Code guidelines even though the Code does not specifically apply to the internals of the filters or auxiliary equipment. The Code gives a number of criteria for the determining design stress. For the $1500-1600^{\circ} \mathrm{F}$ range, the criteria is usually based on some percentage of the average stress to produce rupture in 100,000 hours; or less, depending on the source and requirements. Candidate metals for carbonizer and KRW gasifier granular-bed filter systems are: 310 SS. RA85H, Haynes 556, Haynes HR-160, and Haynes 188. The choice is RA85H for both granular-bed and ceramic candle filter internals ${ }^{12}$ and 310 SS for other lightly-stressed components such as duct liners. This choice is made somewhat based on costs; since, other choices are considerably more expensive. Table 15 summarizes the materials chosen for the different components, and Table 16 lists the compositions of these materials. The first choice of materials is marked with an "X" in Table 15. In some cases the material choice is limited by its availability in the forms utilized in the granular-bed or the ceramic candle filter. Prices listed are for purchased plate, $1 / 4^{\prime \prime}$ to $1 "$ thick, and are rounded off the nearest dollar in most cases.

See Figures 26 and 27 for the configuration and dimensions of the CPFBC filter. Dimensions and pressure vessel design data are given on Figure 26. Information on the design of refractory and internals is given on Figure 27. The carbonizer, granular-bed filter is shown on Figures 28 and 29, and the IGCC (KRW, air blown gasifier) granularbed filter is shown on Figures 30 and 31 .

\subsubsection{Granular-Bed Filter Plant Arrangements}

Included with the moving granular-bed filter (GBF) is a media circulation and ash removal system as shown in Figures 32, 33, and 34. In all three systems, the particleladen media from the filter is withdrawn at the bottom and transported pneumatically in a lift pipe to a de-entrainment vessel where the filter media and the ash particles are separated. The clean media flows by gravity back to the filter vessel. The media is distributed in the filter vessel through distribution pipes and an annulus around the central inlet pipe. The lift gas and particles leaving the de-entrainment vessel are cooled to $500^{\circ} \mathrm{F}$ in a regenerative heat exchanger. Ash is removed from the cooled lift gas in a pressurized baghouse and depressurized through a restricted-pipe discharge (RPD) or lock-hopper system. The lift pipe, transport gas is further cooled to $250^{\circ} \mathrm{F}$ in a watercooled heat exchanger, boosted in pressure with a blower, reheated in the regenerative heat exchanger, and reused to convey particle-laden media up the lift pipe. 
Table 15 Granular-Bed Filter Materials

\begin{tabular}{ccccccc}
\hline $\begin{array}{c}\text { Application/ } \\
\text { Mat'l }\end{array}$ & Highly & Lightly & Pipe & Flats & Sr & $\begin{array}{c}\text { Approx. } \\
\text { Ptr Cost }\end{array}$ \\
& $\begin{array}{c}\text { Stressed } \\
\text { Plt/Sht }\end{array}$ & $\begin{array}{c}\text { Stressed } \\
\text { Plt/Sht }\end{array}$ & (1) & (1) & (2) & (\$/lb) \\
\hline
\end{tabular}

CPFBC

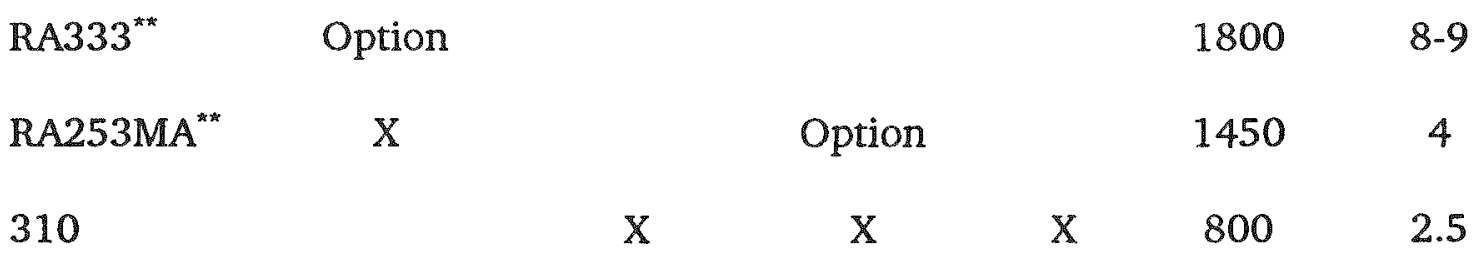

Carbonizer/

Gasifier

310

$\begin{array}{lllll}X & X & X & 800 & 2.5\end{array}$

\begin{tabular}{|c|c|c|c|}
\hline $\mathrm{RA} 85 \mathrm{H}^{\star \star}$ & $\mathrm{X}$ & Option & 1300 \\
\hline $556^{\mathrm{TM}^{*}}$ & Ref & & 3000 \\
\hline HR- $160^{\mathrm{TM}^{*}}$ & Ref & & 2500 \\
\hline $188^{\mathrm{TM}^{*}}$ & Ref & & 4000 \\
\hline
\end{tabular}

(1) Use 'Option' for highly stressed pipe.

(2) Average stress to rupture for 100,000 hours, psi.

* Haynes International, Inc (Haynes alloys 556, 188, HR-160)

** Rolled Alloys, Inc. 
Table 16 Nominal Composition of Heat-Resistant Alloys (wt \%)

\begin{tabular}{|c|c|c|c|c|c|c|c|}
\hline Alloy & UNS & $\mathrm{Fe}$ & $\mathrm{Cr}$ & $\mathrm{Ni}$ & Mo & Co & Others \\
\hline $\operatorname{RA} 333^{* \star}$ & N06333 & $\mathrm{Bal}$ & 26 & 46 & 3.3 & 3.3 & $\begin{array}{l}3.3 \mathrm{~W} \\
1.0 \mathrm{Si}\end{array}$ \\
\hline RA253MA & S30815 & Bal & 21 & 11 & & & $\begin{array}{l}1.7 \mathrm{Si} \\
0.06 \mathrm{Ce}\end{array}$ \\
\hline $310 \mathrm{SS}$ & S31000 & $\mathrm{Bal}$ & 25 & 20 & & & \\
\hline $\mathrm{RA} 85 \mathrm{H}^{* \star}$ & S30615 & Bal & 19 & 15 & & & $\begin{array}{l}3.6 \mathrm{Si} \\
1.0 \mathrm{Al}\end{array}$ \\
\hline $556^{\mathrm{TM}^{*}}$ & R30556 & $\mathrm{Bal}$ & 22 & 21 & 3.3 & 19 & $\begin{array}{l}2.8 \mathrm{~W} \\
0.8 \mathrm{Ta} \\
0.3 \mathrm{Al}\end{array}$ \\
\hline $188^{\mathrm{TM} *}$ & R30188 & 3 & 22 & 22 & & $\mathrm{Bal}$ & $14 \mathrm{~W}$ \\
\hline $\mathrm{HR}-160^{\mathrm{rM} \mathrm{M}^{\star}}$ & & 2 & 29 & 37 & & 29 & $\begin{array}{l}2.8 \mathrm{Si} \\
0.5 \mathrm{Ti}\end{array}$ \\
\hline
\end{tabular}




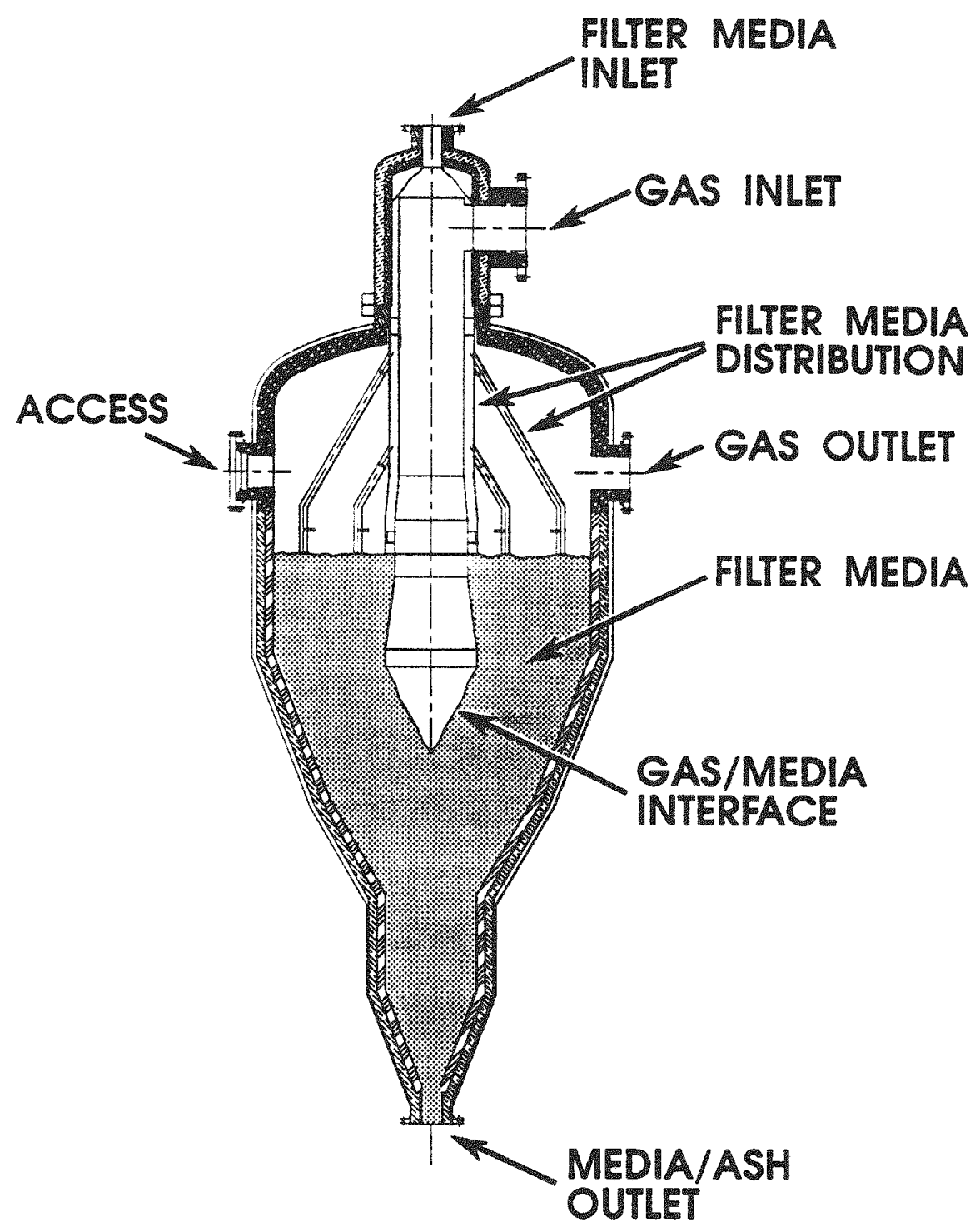

Figure 25 Granular-Bed Filter Configuration 


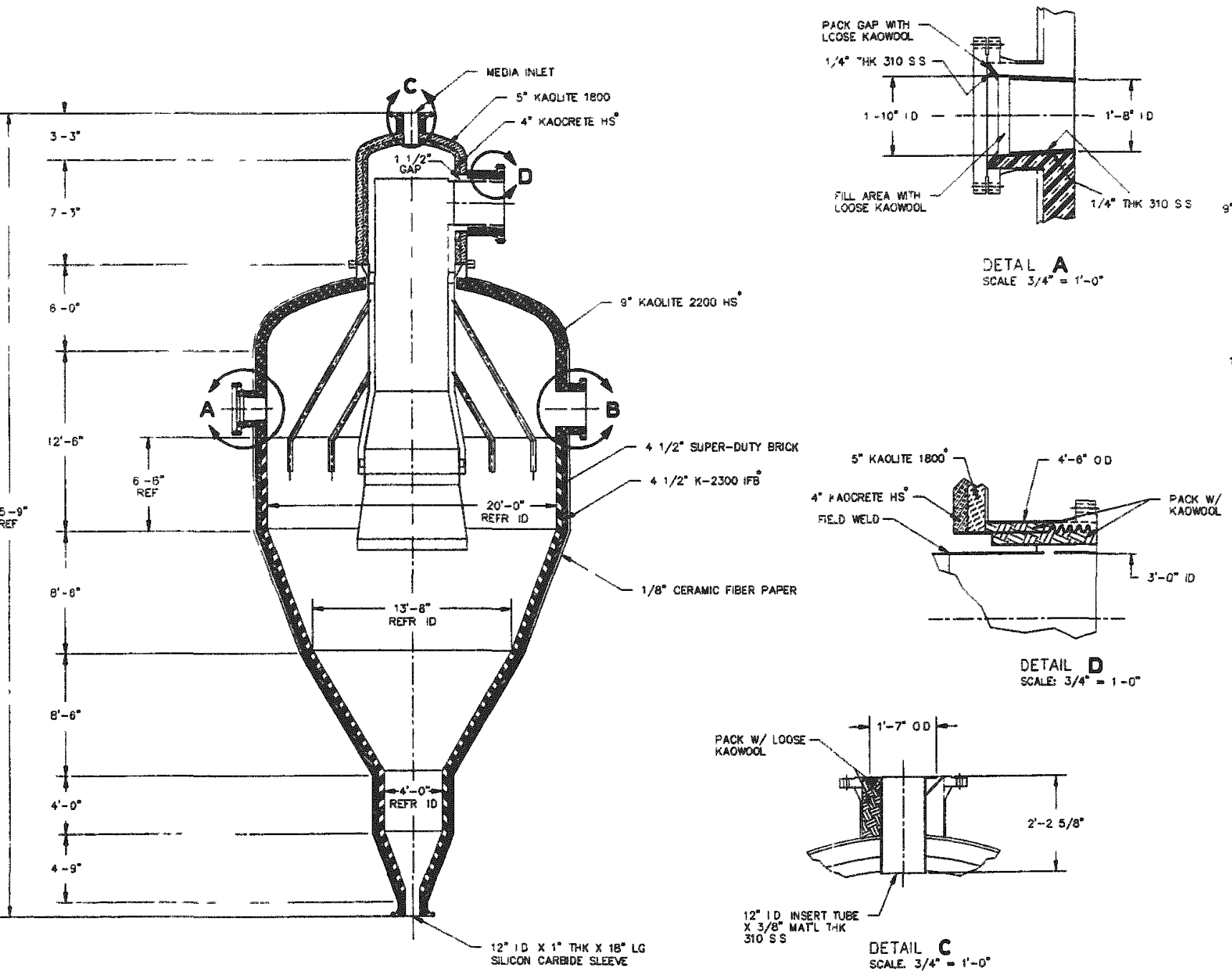

9" सAOUTE 2200 : "S -
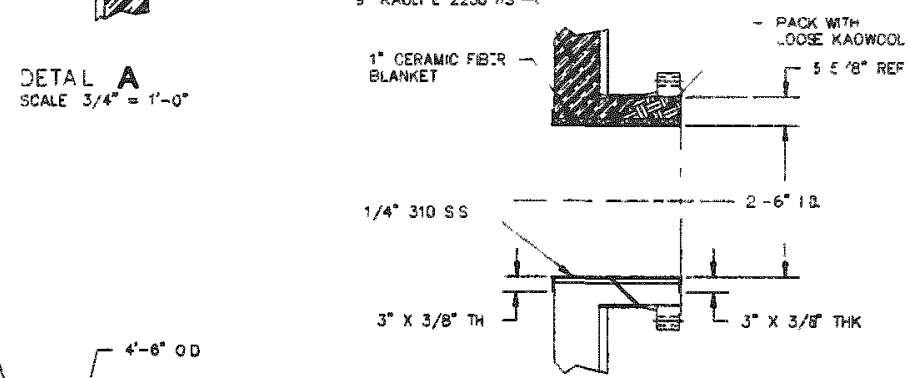

DETAIL $B$

ACK w' LOOSE

- Thermal ceramics Proovet

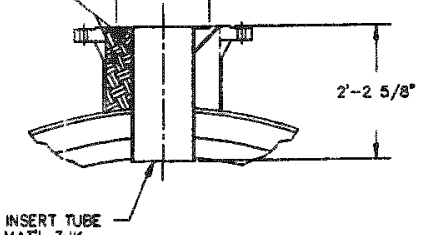

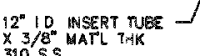

DECAAIL $C$

Figure 27 Granular-Bed Filter Internals, CPFBC 
v

學。

I.

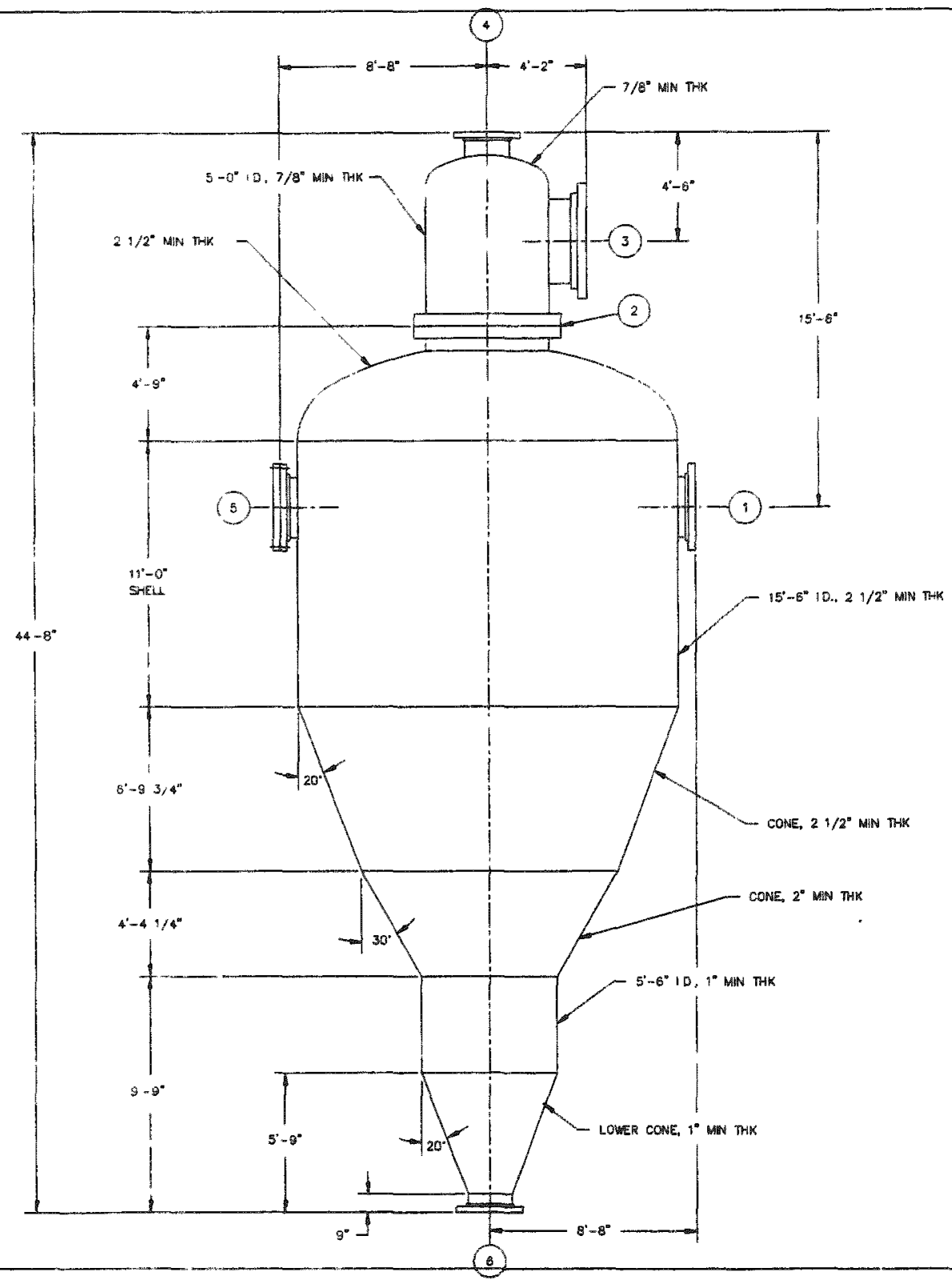

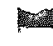

1)

- 4

2.

I
(4)

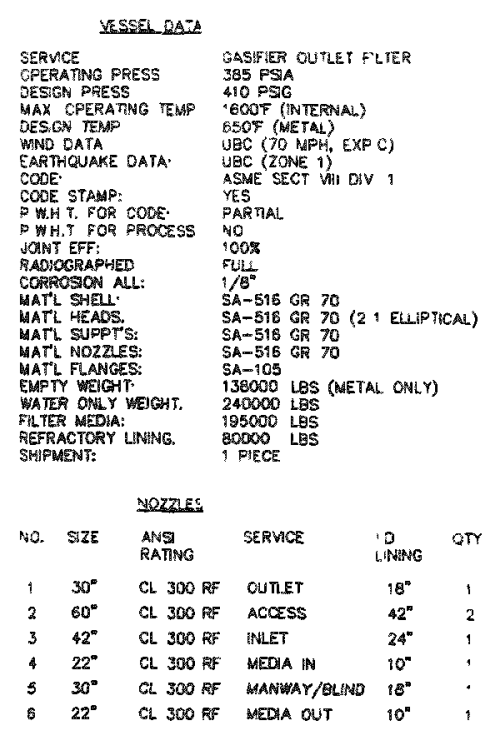

1 SEE SHEET 2 FOR REFRACTORY INSTALLATIOAS

Figure 28 Granular-Bed Filter Pressure Vessel, Carbonizer 


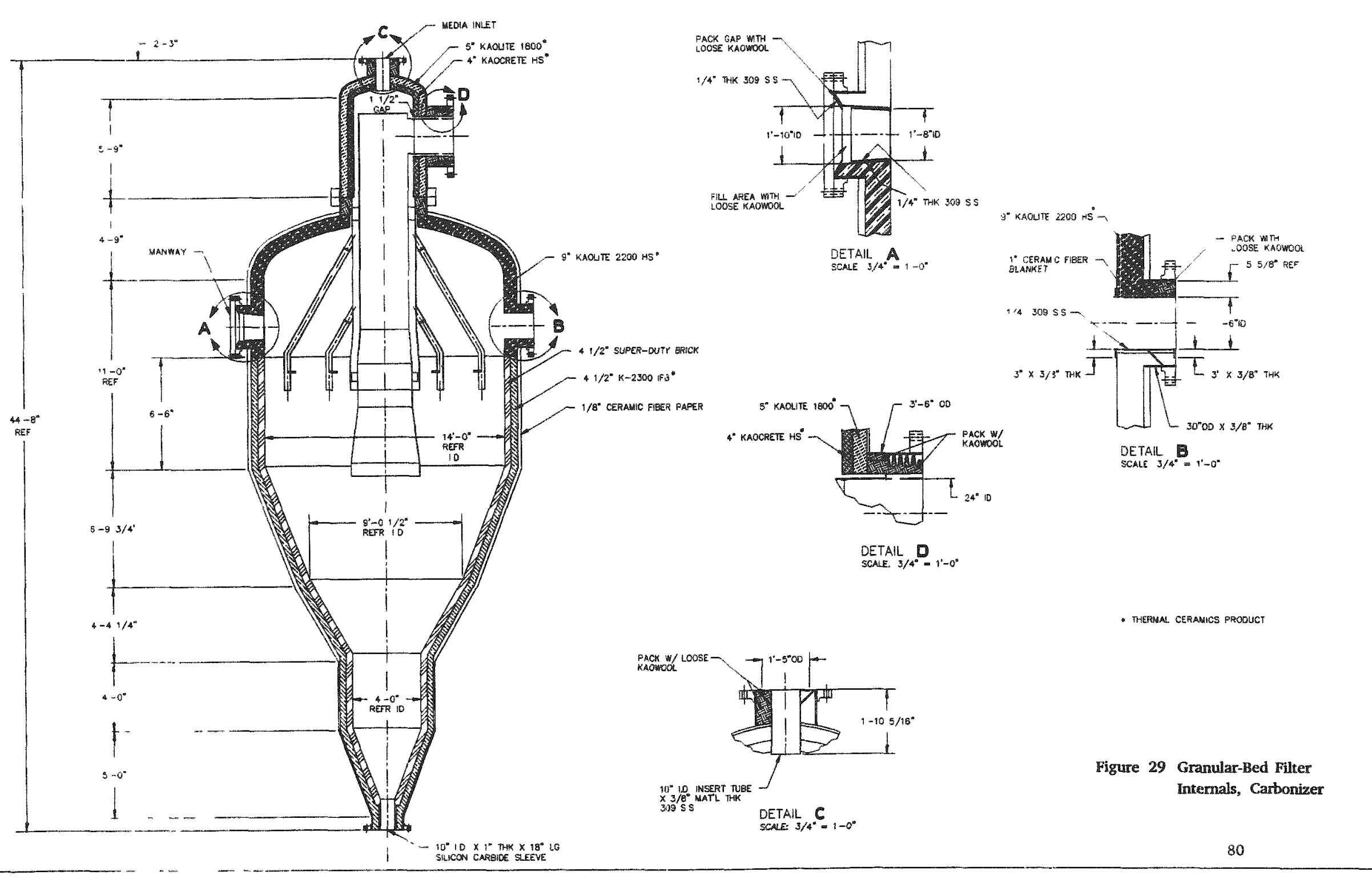




\begin{tabular}{|c|c|c|c|c|c|c|c|c|c|}
\hline & & 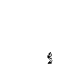 & & . & $\cdots$ & . & $m$ & & \\
\hline : & & 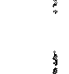 & 11 & 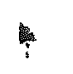 & i. & $\therefore$ & 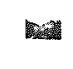 & 4 & A \\
\hline i & . & . & , . & I & $\because$ & 1 & 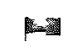 & A & . \\
\hline : & " & & $\cdot$ & $b$ & is & : & has & 1 & 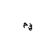 \\
\hline . & B & : & ;. & $E:$ & $\leadsto$ & $\therefore$ & B. & : & 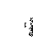 \\
\hline : & $B$ & b & ' & E. & - & $\therefore-d$ & 18 & 4 & \& \\
\hline
\end{tabular}

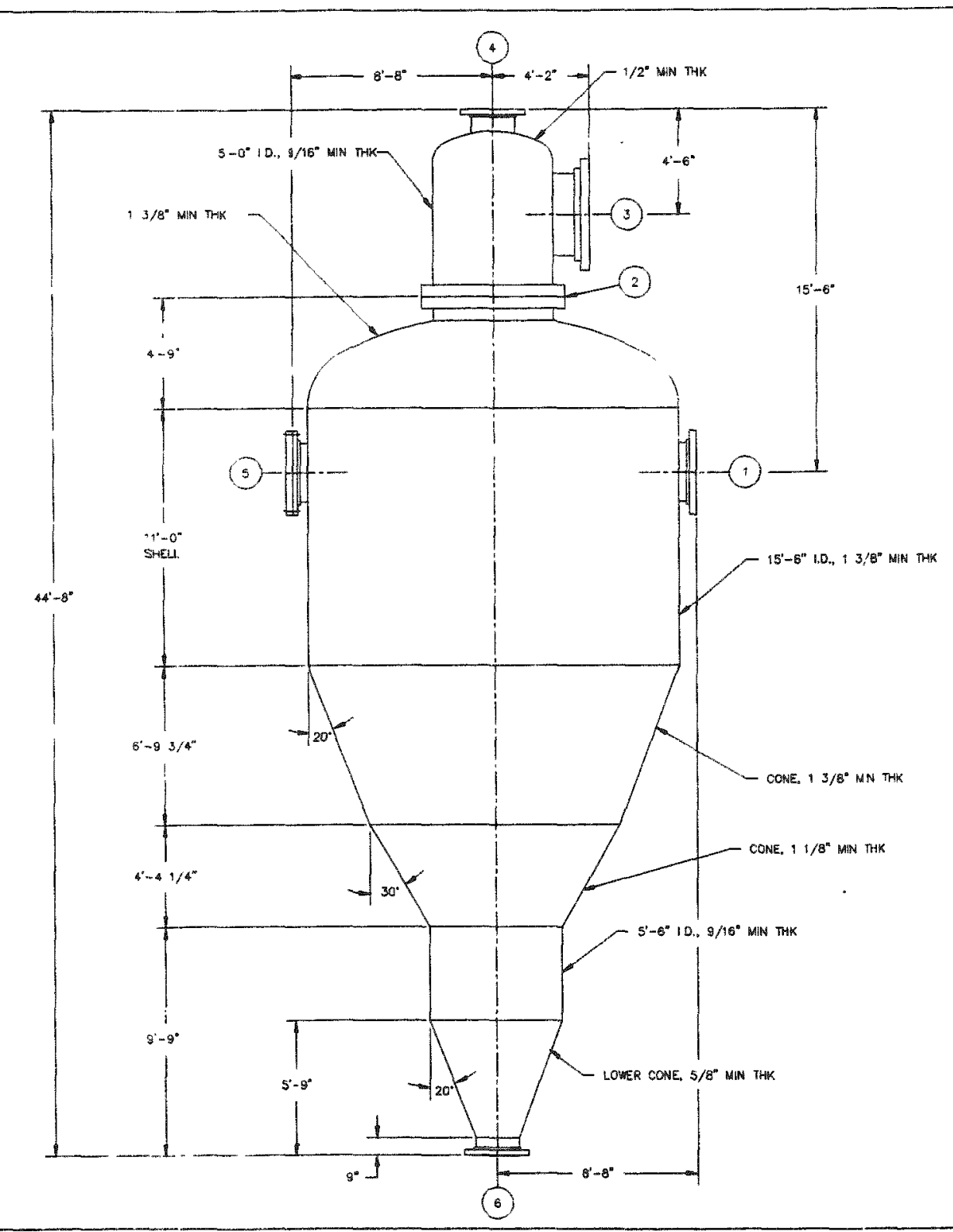

ISSSELediA

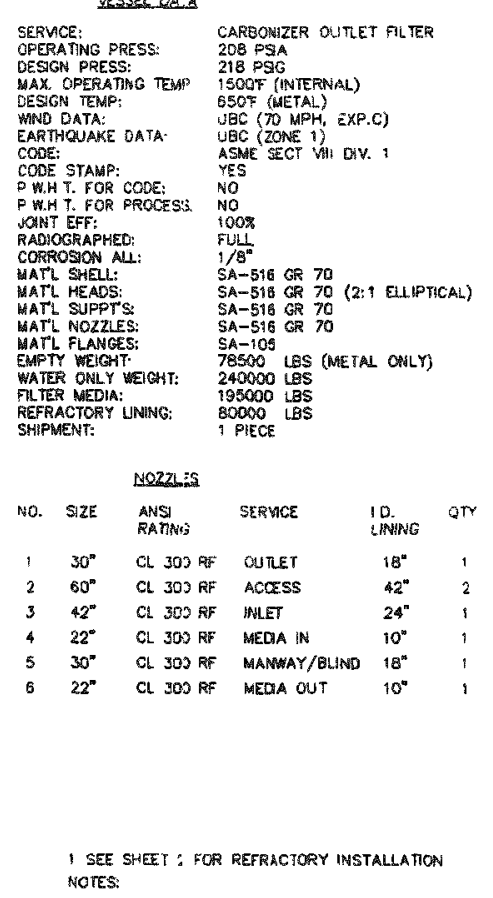

Figure 30 Granular-Bed Filter Pressure Vessel, KRW Gasifier 


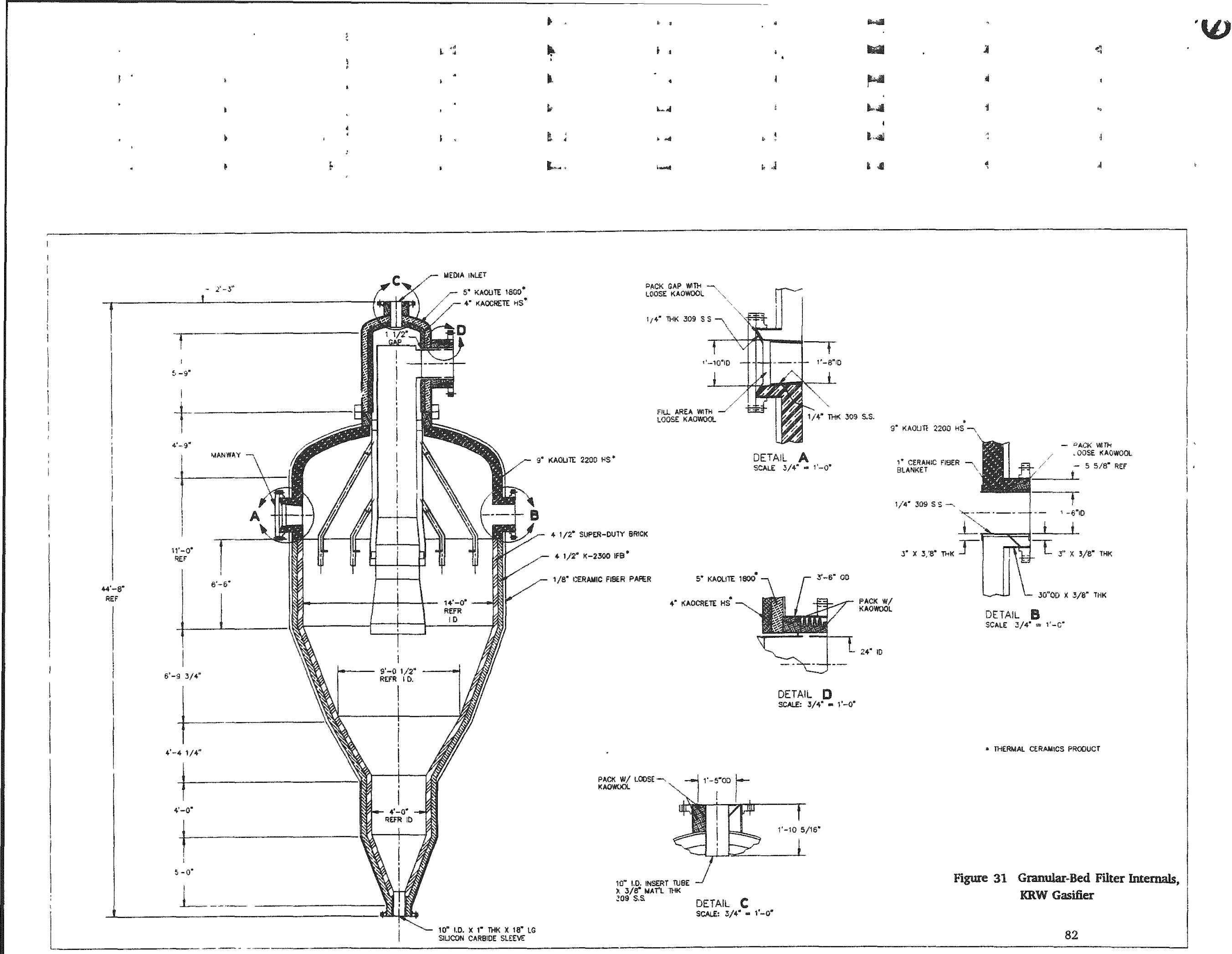

6 


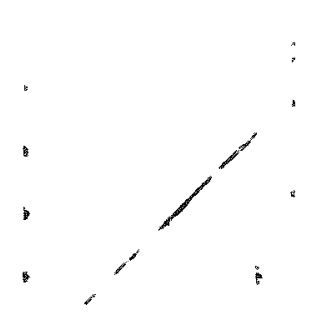

:
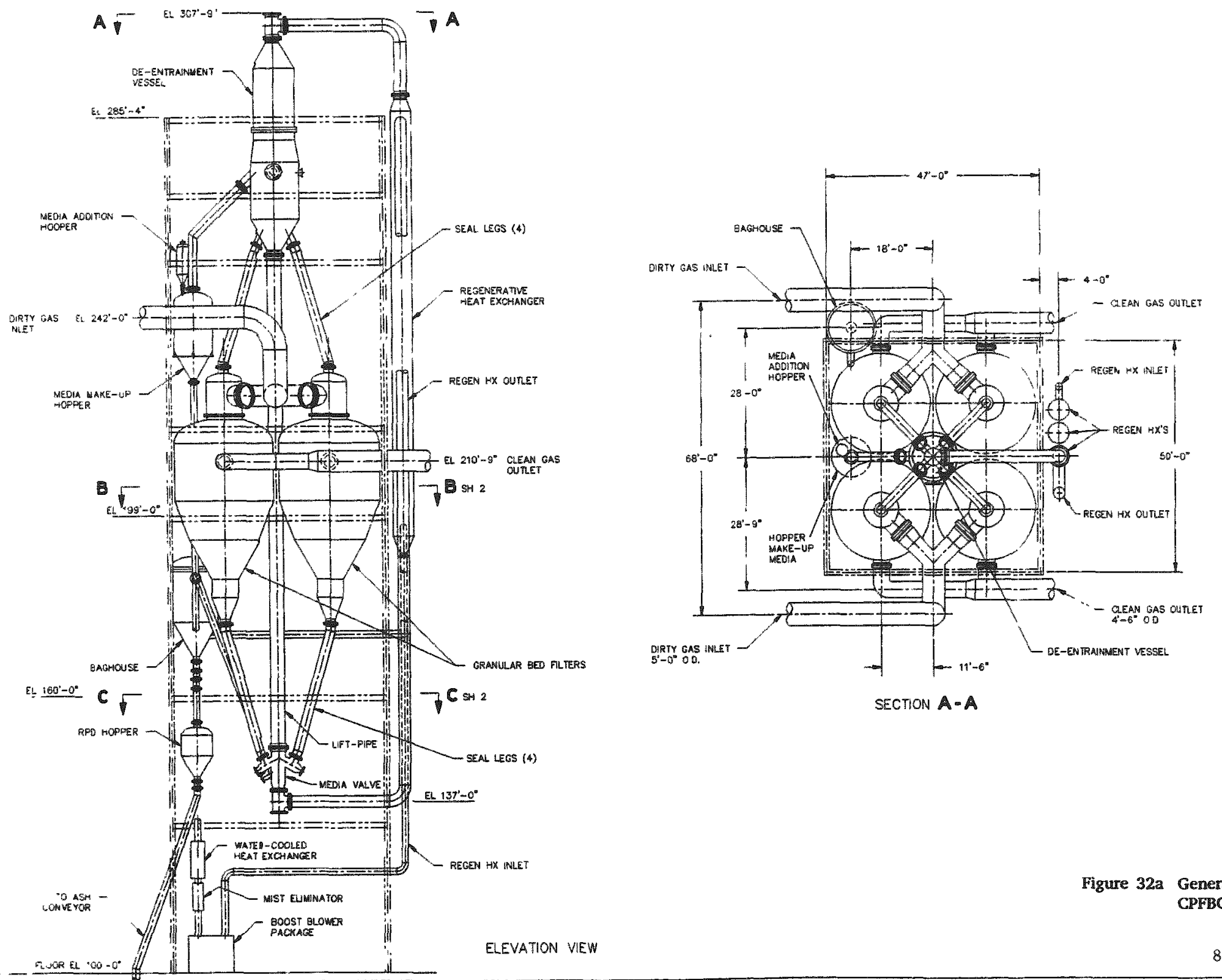

Figure 32 General Arrangement, CPFBC GBF 


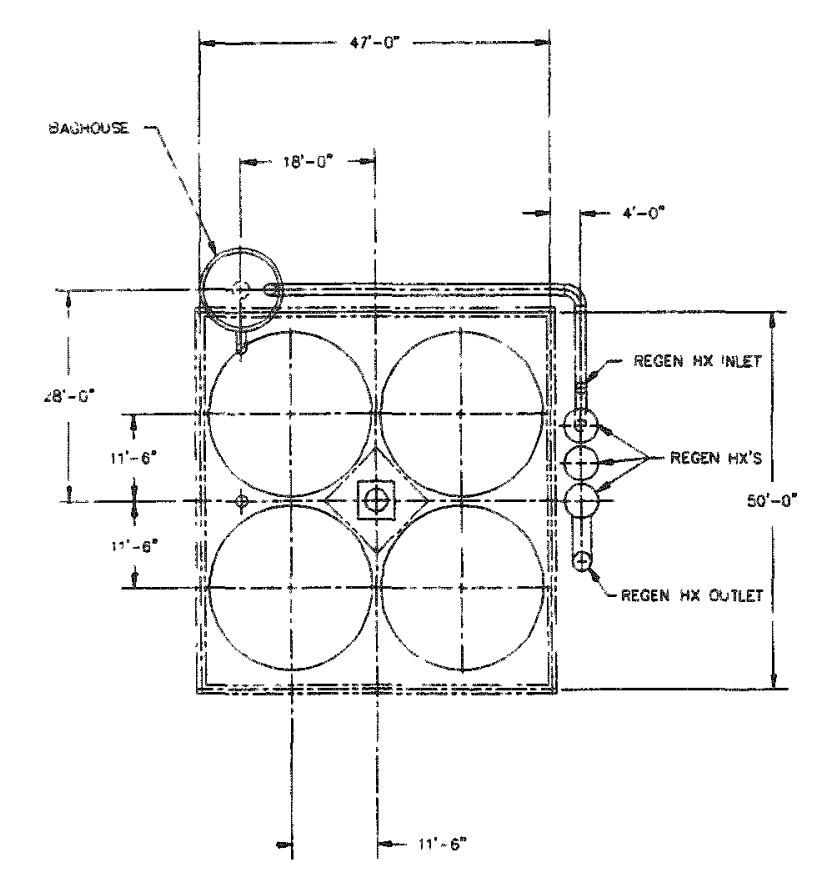

SECTION D-B SH

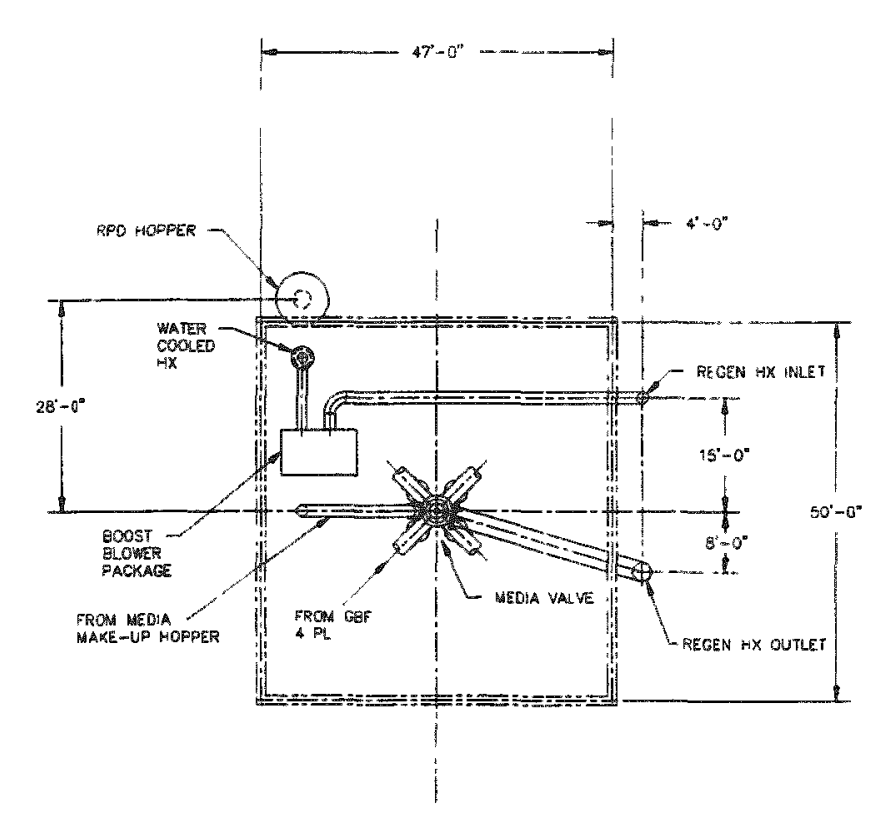

SECTION C $=\mathrm{C}_{\text {SH }}$ I

Figure $32 b$ General Arrangement, CPFBC GBF 


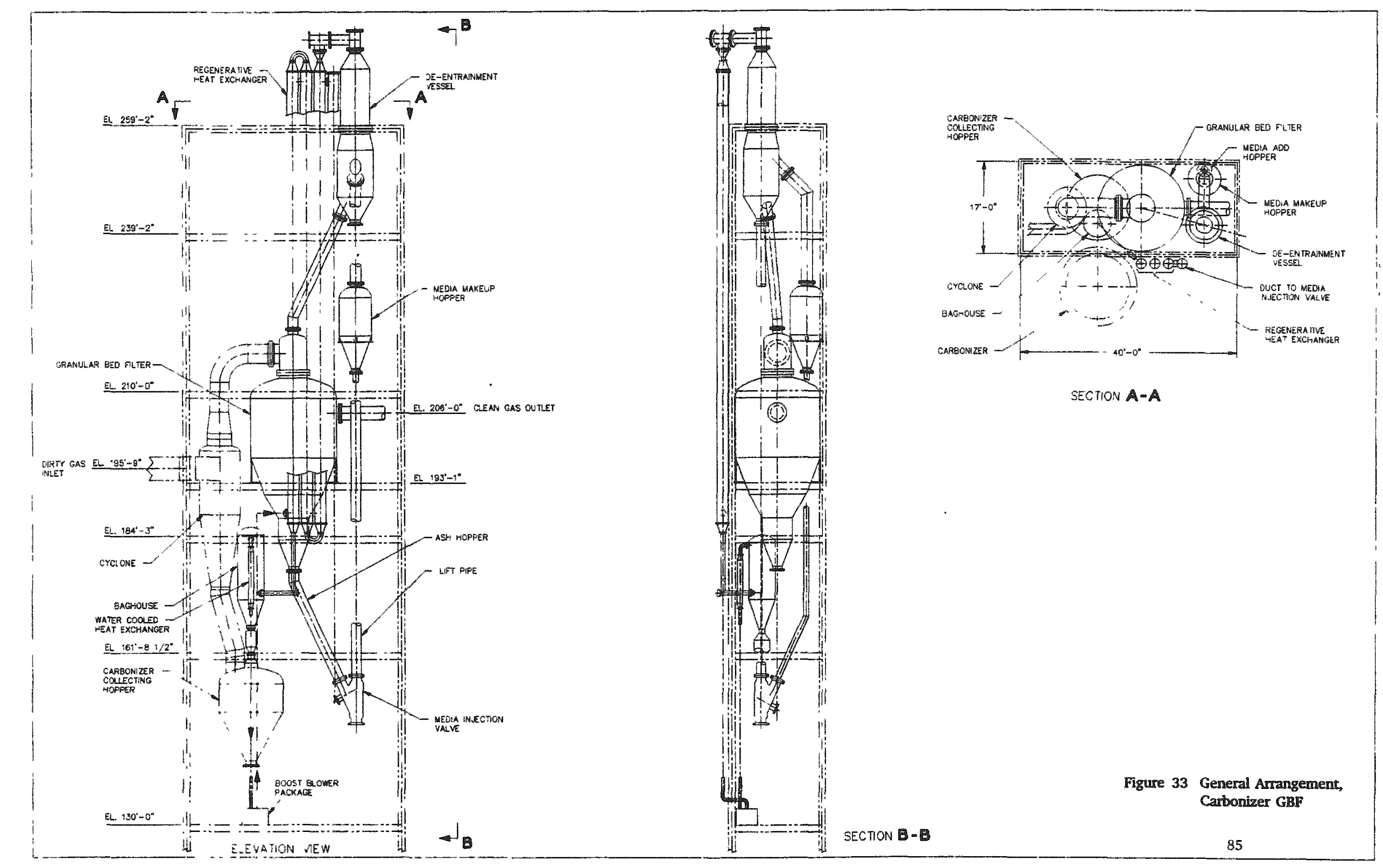



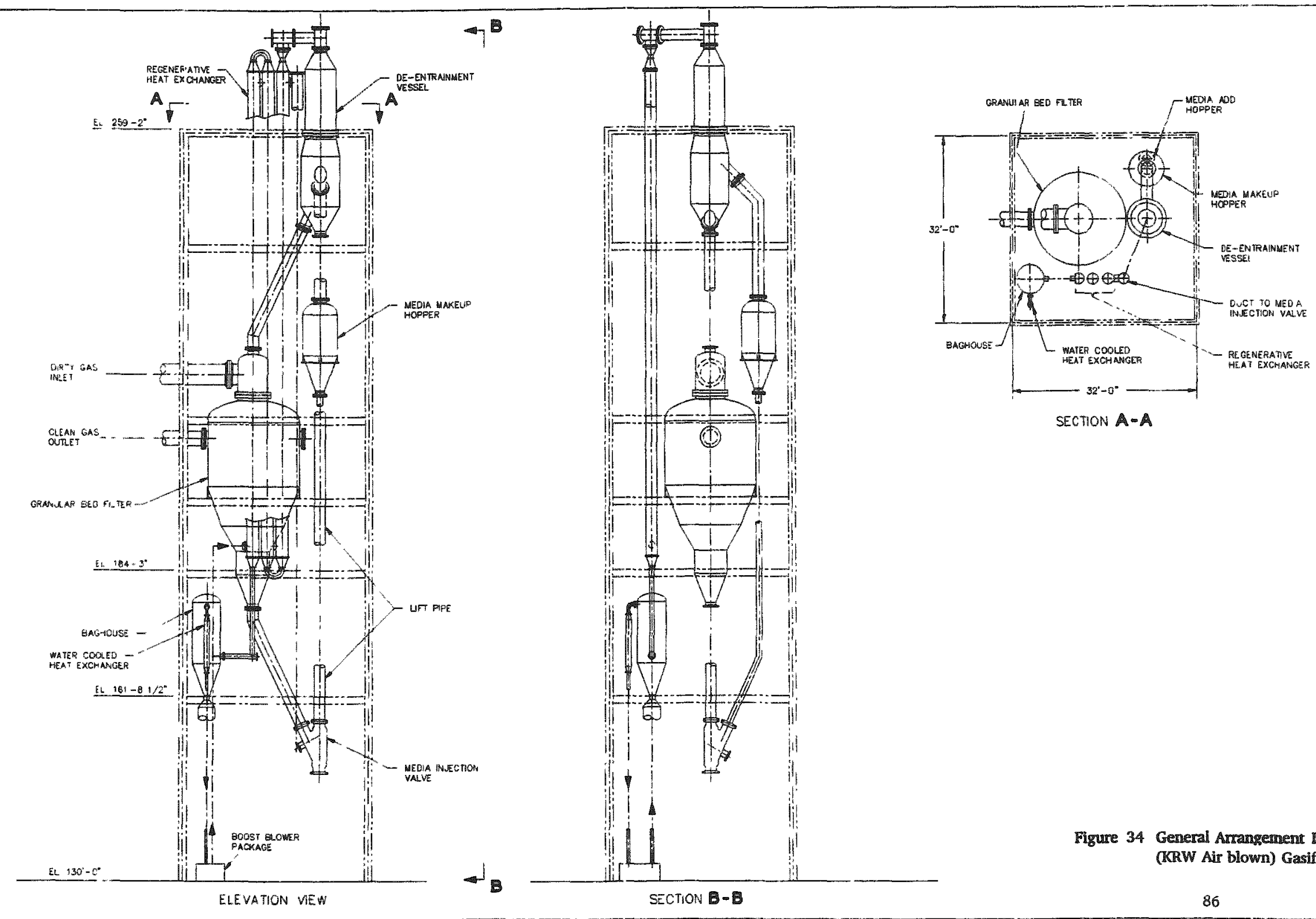

Figure 34 General Arrangement IGCC (KRW Air blown) Gasifier GBF 


\subsection{Granular-Bed Filter Auxiliary Equipment/Specs}

\subsubsection{De-Entrainment Vessels}

Filter media and ash are separated in the de-entrainment vessels shown in Figures 35,36 , and 37. These figures show the de-entrainment vessel configurations for the CPFBC, carbonizer, and KRW gasifier filter, respectively. Filter media falls out of the gas stream and collects in a reservoir at the bottom of the vessel. Ash follows the gas stream out the top of the vessel and continues to the ash handling components. The media reservoir in the bottom of the de-entrainment operates in an overflow mode to maintain a conservative excess volume of filter media in the system. During periods in which media is heating up or accumulating ash, the volume of the media increases. The increased media volume is accommodated by allowing excess media to overflow from the media reservoir to the media make-up hopper. During periods of operation when the media occupies less volume, media from the media make-up hopper is circulated to refill the reservoir. Temperatures in the de-entrainment vessels are $100-200^{\circ} \mathrm{F}$ lower than in the filter vessels, so even though the gas composition is the same, corrosive conditions are less severe. These temperatures range from $1380^{\circ} \mathrm{F}$ to $1500^{\circ} \mathrm{F}$ for the three applications studied.

The enclosures of the de-entrainment vessels are pressure vessels. These carbon steel enclosures are lined with a two component refractory system to minimize heat loss and to withstand the action of the process gases and filter media. Insulating refractory maintains the outside wall temperature to the range of $180-200^{\circ} \mathrm{F}$. The refractory hot face lining is erosion resistant to withstand the filter media movement, and will easily contend with the oxidizing and reducing gas atmospheres at de-entrainment vessel temperatures. In the top part of the de-entrainment vessel, the hot face lining is 6 " to provide extra durability. A flange is included in the body of the de-entrainment vessel to allow installation of refractory, metal internals, and to allow inspection, if necessary.

Metals in the de-entrainment vessels, type 310 stainless steel, are under minimal stress that is mainly thermal in nature. This metal was chosen as the most economic choice for corrosion resistance against the process gas stream components at process temperatures.

\subsubsection{Media Make-up Hoppers}

The media make-up hoppers serve a dual function. This is the location in the system where the media volume changes occur, and this is the place where media is added to make-up for attrition. These hoppers are shown of figures 38,39 , and 40 for the CPFBC, the carbonizer, and the KRW gasifier filters, respectively. During periods of media volume change, a small amount of media circulation is maintained from the media make-up hopper. If this media is not needed in the filter, a similar amount overflows the reservoir in the de-entrainment vessel. If more media is needed than is being provided, the low level switch is activated in the de-entrainment reservoir. If less media is needed, the excess overflows to the make-up hopper. During stable operation, the make-up hopper may only be operated once a shift or once a day for a short period. When the low 
level switch is energized in the media reservoir, media is added through the small media add hopper. Access for refractory installation and inspection is through manways.

These hoppers are pressure vessels lined on the inside with refractory. Pressure levels and gas compositions are nearly the same as in the respective filters, but temperatures are less by at least $100^{\circ} \mathrm{F}$. Refractory choices are the same as for the deentrainment vessel reservoirs for the same reasons. Nozzles for media flow are lined with ceramic sleeves for wear resistance.

\subsubsection{Media Valves, Seal Legs, Lift Pipes}

Refractory-lined piping items that contain moving filter media are all designed similarly. Carbon steel piping components are utilized to contain the pressure, and refractory linings provide insulation and erosion resistance.

Ash-ladened media from one or four filter vessels, depending on the application, is metered to a lift pipe by a media valve. In addition, an inlet nozzle is provided for the media from the media make-up hopper. Media valves are shown on Figures 41, 42 and 43 for the CPFBC, carbonizer, and KRW gasifier filters, respectively. Pressure and temperature in each media valve is almost the same as in the filter vessel. Refractory lining consists of silicon carbide sleeves for wear resistance against moving media with a backing of light weight castable refractory for insulation. The castable insulation also provides some structural support for the silicon carbide sleeves. Metals internals are nonstructural but do experience thermal stresses.

The seal legs that convey ash-ladened media away from the filter and return clean media, are made in $10 \mathrm{ft}$ long spools. Lift pipe segments are also made in $10 \mathrm{ft}$ long spools. Each spool is lined with 1" thick silicon carbide for wear resistance, and light weight castable insulation to minimize heat loss. These piping spools are bolted together during installation. Seal legs for the CPFBC filter are 24" pipe lined to 12 "I.D. refractory. The lift pipe is $36^{\prime \prime}$ pipe lined to 24" I.D. refractory. Seal legs for the carbonizer and KRW gasifier filter are $22^{\prime \prime}$ pipe lined to $10^{\prime \prime}$ I.D. refractory. The lift pipes are also $22^{\prime \prime}$ pipe lined to $10^{\prime \prime}$ I.D. refractory.

\subsubsection{Media Addition Hoppers}

A small, carbon steel media addition hopper is mounted on the top of each media make-up hopper. These hoppers are sized to hold about one pallet of bagged media, or about $3000 \mathrm{lbs}$. They are 30" O.D. and 9' $6^{\prime \prime}$ long including the conical bottom. The media inlet is $8^{\prime \prime}$ for ease of loading and the media outlet is $4^{\prime \prime}$. Media is added to the hopper while the hopper is at atmospheric pressure. The hopper is then closed and pressurized. When the hopper is at system pressure, a valve underneath the hopper is opened to unload the contents into the media make-up hopper. Since the media addition hopper is always at atmospheric temperature, it is not refractory lined. 


\subsubsection{Baghouses}

A baghouse is used as part of the filter media circulation and ash removal system for the granular-bed filter. Ash separated from the granular-bed filter media is cooled to $500^{\circ} \mathrm{F}$ in the regenerative heat exchanger, and conveyed to a pressurized baghouse for removal. A baghouse was chosen because it operates reliably at moderate temperatures $\left(500^{\circ} \mathrm{F}\right)$, utilizes standard filter bags, and delivers dry ash to an ash handling system. Baghouse design criteria is given on Table 17. Design gas flow rates allow for $15 \%$ margin over the operating values. Table 18 summarizes the baghouse equipment.

Table 17 Baghouse Design Criteria

\begin{tabular}{|c|c|c|c|}
\hline Parameter & $\begin{array}{l}\text { CPFBC } \\
\text { Filter }\end{array}$ & $\begin{array}{l}\text { Carbonizer } \\
\text { Filter }\end{array}$ & $\begin{array}{l}\text { Gasifier } \\
\text { Filter }\end{array}$ \\
\hline 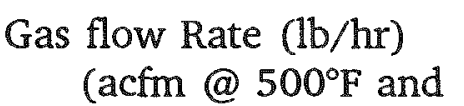 & 195,000 & 35,000 & 48,000 \\
\hline operating pressure) & 6,230 & 1,123 & 935 \\
\hline Inlet Gas Temp. $\left({ }^{\circ} \mathrm{F}\right)$ & 500 & 500 & 500 \\
\hline $\begin{array}{l}\text { Inlet Pressure (psig) } \\
\text { Design } \\
\text { Operating }\end{array}$ & $\begin{array}{l}200 \\
167\end{array}$ & $\begin{array}{l}218 \\
188\end{array}$ & $\begin{array}{l}410 \\
365\end{array}$ \\
\hline $\begin{array}{l}\text { Dust Loading }(\mathrm{lb} / \mathrm{hr}) \\
\text { Design } \\
\text { Operating }\end{array}$ & $\begin{array}{l}6,800 \\
3,435\end{array}$ & $\begin{array}{l}2,830 \\
2,460\end{array}$ & $\begin{array}{l}3,036 \\
2,640\end{array}$ \\
\hline Design (gr/acf) & 171 & 294 & 379 \\
\hline
\end{tabular}

The particle outlet loading from each baghouse (gr/acf) is expected to be about 0.2 gr/acf, which requires better than $99.9 \%$ ash removal efficiency.

The baghouses proposed for these applications are designed for access to the filter bags by unbolting the top head. ASME Code construction is used. Each baghouse is complete with insulation stubs, an access port, and a hinged, lift-off dished head. The filter assemblies include filter bags, carbon steel bag retainers, and stainless steel bag clamps. Ash removal hoppers have a $60^{\circ}$ side slope, gas inlet diffuser, and bag catch grid. Pulse cleaning assemblies include a solid state design cyclic timer (NEMA 4 enclosure), pulse gas supply header, pulse gas distribution pipes, right angle diaphragm valves and 
solenoid valves (NEMA 4). Filter bags are $41 / 2^{\prime \prime}$ in diameter, 8' long and made from 27 oz. fiberglass felt, a commonly used material in commercial and utility applications. See Figure 44 for a typical drawing of the baghouse used with the KRW gasifier, granular-bed filter. Baghouses utilized with the CPFBC filter and the carbonizer filter are similar.

Table 18 Baghouse Equipment Selection

\begin{tabular}{lrrr}
\hline Parameter & $\begin{array}{c}\text { CPFBC } \\
\text { Filter }\end{array}$ & $\begin{array}{c}\text { Carbonizer } \\
\text { Filter }\end{array}$ & $\begin{array}{c}\text { Gasifier } \\
\text { Filter }\end{array}$ \\
\hline Filter Area $\left(\mathrm{ft}^{2}\right)$ & 1678 & 395 & 395 \\
Filter Rate $\left(\mathrm{acfm} / \mathrm{ft}^{2}\right)$ & $2.80: 1$ & $2.84: 1$ & $2.37: 1$ \\
Filter Bags/Module & 178 & 42 & 42 \\
Bag Material & Fiberglass & Fiberglass & Fiberglass \\
Housing Thickness & $1 "$ & $1 / 2^{\prime \prime}$ & $1 "$ \\
Estimated Weight (lbs) & 30,000 & 8,750 & 14,650 \\
Pulse Gas (scfm) & 35 & 20 & 20 \\
Pulse Pressure & 267 & 288 & 465 \\
\hline
\end{tabular}

\subsubsection{Regenerative Heat Exchangers}

The function of the recuperative heat exchanger is to exchange heat between the hot gas stream leaving the lift pipe and the cool gas stream entering the lift pipe. The hot gas steam needs to be cooled to $500^{\circ} \mathrm{F}$ so that the suspended ash particles can be removed in a conventional baghouse. The gas stream entering the lift pipe is reheated in order to minimize heat loss and; consequently, the temperature drop through the filter.

The heat exchanger design proposed utilizes a "flue gas through the tubes" concept which has been proven on sludge incineration and carbon black processes throughout the world. The heat exchanger has hot gas flowing within the tubes while the heated gas moves over the outside of the tubes in multiple passes. The velocity of the gas inside the tubes along with the ash which is entrained tends to constantly scrub the surface of the tubes and consequently keep them from fouling. The hot gas flow is parallel to the tube walls, as opposed to normal, so that the high velocities do not cause erosion as can occur with standard convective coils. Ferrules are placed at the flue gas inlet of each tube of the heat exchanger in order to further protect the refractory covered tube sheet from erosion and the high heat flux expected. 
Table 19 shows the design criteria for the recuperative heat exchanger. Figure 45 shows a typical arrangement for the regenerative heat exchangers used with the granularbed filter.

Table 19 Regenerative Heat Exchanger Design Criteria

\begin{tabular}{lrrr}
\hline & $\begin{array}{c}\text { CPFBC } \\
\text { Filter }\end{array}$ & $\begin{array}{c}\text { Carbonizer } \\
\text { Filter }\end{array}$ & $\begin{array}{c}\text { Gasifier } \\
\text { Filter }\end{array}$ \\
\hline Hot Gas Side & & & \\
& & & \\
Inlet Temperature, ${ }^{\circ} \mathrm{F}$ & 1480 & 1362 & 1422 \\
Outlet Temperature, ${ }^{\circ} \mathrm{F}$ & 500 & 500 & 500 \\
Gas Flow, lbm/hr & 168,500 & 30,060 & 40,560 \\
Design Pressure, psia & 200 & 218 & 410 \\
Max. Pressure Drop, psi & $<2$ & $<2$ & $<2$ \\
& & & \\
Cold Gas Side & & & 250 \\
& 1251 & 1142 & 1198 \\
Inlet Temperature, ${ }^{\circ} \mathrm{F}$ & 168,500 & 30,060 & 40,560 \\
Outlet Temperature, ${ }^{\circ} \mathrm{F}$ & 200 & 218 & 418 \\
Gas Flow, lbm/hr & $<1$ & $<1$ & $<1$ \\
Design Pressure, psia & & & \\
Max Pressure Drop, psi & 239 & 250 & 250 \\
Log Mean Temp. Diff., ${ }^{\circ} \mathrm{F}$ & 45.0 & 8.1 & 13.5 \\
& & & \\
Heat Transferred, MMBtu/hr & & & \\
\hline
\end{tabular}

\subsubsection{Boost Blowers}

Boost blowers are used in the granular-bed filter media circulation systems to convey the media and ash mixture. These blowers must generate 6 to 10 psi above the system inlet pressure. They must be capable of providing a variable amount of gas flow for conveying at a range of pressures and temperatures. The range of flow is shown in Table 20.

Several types of machines were considered for this application. A rotary vane compressor was used for the 2 "lift system at New York University. This type of blower is limited in size, and has the disadvantage of needing lubricating oil added directly to the blower internals. While the lubricating oil can be dealt with, the limitation in size makes this type of blower unsuitable for the commercial systems defined above. Multi- 
stage, centrifugal blowers have the advantage of operating at inlet temperatures in the 500 to $750 \mathrm{~F}$ range. This is an attractive characteristic, but these machines are very expensive, starting at about $\$ 750,000$. Some single stage, centrifugal blowers are available, and will operate with an inlet temperature of up to $500^{\circ} \mathrm{F}$. These blowers are more competitively priced with the options selected.

Table 20 Boost Blower Sizing Criteria

\begin{tabular}{lccc}
\hline Parameter & $\begin{array}{c}\text { CPFBC } \\
\text { Filter }\end{array}$ & $\begin{array}{c}\text { Carbonizer } \\
\text { Filter }\end{array}$ & $\begin{array}{c}\text { Gasifier } \\
\text { Filter }\end{array}$ \\
\hline Design Pres., psig & 200 & 218 & 410 \\
Operating Inlet pres., psig & 167 & 188 & 65 \\
Operating Flow, acfm @ 250 $\mathrm{F}$ & 4,670 & 833 & 694 \\
Startup Flow, acfm @ 70 F & 6,500 & 1160 & 930 \\
Operating pressure rise, psi & 10 & 10 & 10 \\
Maintenance Operation, & 17,100 & 3,185 & 3,160 \\
acfm @ 70F, 15 psia & 8 & 8 & 8 \\
Maint. pres. rise, psi & & & \\
\hline
\end{tabular}

The boost blowers proposed are rotary-lobe type, positive displacement blowers. The blowers utilize two figure-eight impellers rotating in opposite directions to move entrapped air or gas around the case to the outlet port. Timing gears accurately position the impellers in relation to each other, maintaining the minute clearances which give high volumetric efficiency without metal-on-metal friction. For the CPFBC and the carbonizer, since the design pressure is 200 and 218 psig, respectively, the blowers can be housed in reinforced casings and supplied with suitable seals. Blowers are commercially available in high pressure casings. Drive motor sizes are $500 \mathrm{hp}$ and $60 \mathrm{hp}$ for the CPFBC and the carbonizer filter, respectively, based on start-up operation as defined in Table 20 above. Operating power usage is much less. For the gasifier filter, the inlet pressure of $410 \mathrm{psig}$ requires that the blower be enclosed in a pressure vessel. A shaft protruding through the pressure vessel is supported on both ends with bearings. The blower inside the pressure vessel is connected to the shaft with a flexible coupling, and the $40 \mathrm{hp}$ motor outside the pressure vessel is connected to the other end of the shaft with a flexible coupling. Shaft seals are purged with nitrogen to keep the process gases from leaking to the atmosphere. 
Boost blower packages include a mounting base, high pressure mechanical seals, electric motor, variable frequency drive, check valve, expansion joints, inlet and discharge silencers or sound enclosure, and protective instrumentation for the blower.

Separate blower packages are provided to allow for circulation of filter media during maintenance outages (atmospheric pressure circulation of filter media). These are standard, low pressure, single speed, rotary-lobe type, positive displacement blower packages. They are on standby to be connected to the circulation system when the pressure is atmospheric. For the CPFBC filter, there are two blowers, each rated at 8550 acfm at 15 psia, and each driven by a $400 \mathrm{hp} \mathrm{motor}$. For each carbonizer and gasifier filter, one blower is included, driven by a 175 hp motor. These blower packages include: blower, motor, baseplate, v-belt drive and guard, check valve, inlet and outlet expansion joints, inlet and outlet silencers, and safety switches for the blower.

\subsubsection{Water-Cooled Heat Exchangers}

The water-cooled heat exchanger cools the filter media transport gas just prior to the boost blower. The heat exchanger is needed because the boost blower cannot handle gas above about $250^{\circ} \mathrm{F}$ and the regenerative heat exchanger needs a reasonable differential temperature at the cold gas inlet to operate efficiently. The water-cooled heat exchangers are installed downstream of the pressurized baghouse in each application. The particle loading into each heat exchanger is less than $0.2 \mathrm{gr} / \mathrm{acf}$ as a result of baghouse cleaning efficiency.

For all water-cooled heat exchangers, moisture should not condense from the process gas as a result of being cooled to $250 \mathrm{~F}$. On the other hand, since the tube wall temperatures will be somewhat less than $250 \mathrm{~F}$, there may be some condensation formed on these walls. Table 21 shows the design parameters for the water-cooled heat exchangers.

The water-cooled heat exchangers are shell-and-tube construction with the gas flowing inside the tubes. The $5 / 8^{\prime \prime} \times 18$ Gage tubes are made of type 316 stainless steel. The exchangers are a straight tube design with a fixed tube sheet and with removable channel and bonnet construction. The exchangers are designed to conform to the requirements of: ASME Code, Section VIII Div. 1, TEMA "B" or "C", and ANSI B78.

\subsubsection{Mist/Particle Eliminators}

A mist/particle eliminator is installed downstream of each water-cooled heat exchanger, and is intended to protect the boost blower from liquids which may condense. The particle loading into each mist/particle eliminator will be less than $0.2 \mathrm{gr} / \mathrm{acf}$ as a result of the upstream baghouse cleaning efficiency. The particle size will be small enough to pass through the particle separator under normal circumstances. In addition, the small particles passing through the separator will not effect the boost blower.

A centrifugal type, in-line gas/ liquid separator is used. The separator is designed 
to remove $99 \%$ of all liquids and solids 10 micron and larger from the gas stream. The separation is accomplished by curved stationary blades causing the gas stream to enter into controlled centrifugal flow. This action forces the entrained liquids and solids to the outer wall for collection. The de-entrained liquids and solids are collected in a trap.

Table 21 Water-Cooled Heat Exchanger Design Criteria

\begin{tabular}{lccc}
\hline Application: & $\begin{array}{c}\text { CPFBC } \\
\text { Filter }\end{array}$ & $\begin{array}{c}\text { Carbonizer } \\
\text { Filter }\end{array}$ & $\begin{array}{c}\text { Gasifier } \\
\text { Filter }\end{array}$ \\
\hline Gas flow, lb/hr & 195,000 & 35,000 & 48,000 \\
Design pressure, psia & 200 & 218 & 410 \\
Gas inlet temperature, ${ }^{\circ} \mathrm{F}$ & 500 & 500 & 500 \\
Gas outlet temperature, ${ }^{\circ} \mathrm{F}$ & 250 & 250 & 250 \\
Gas pressure drop, psi & $<1$ & $<1$ & $<1$ \\
Heat given up, $\mathrm{MMBtu} / \mathrm{hr}$ & 12.2 & 2.6 & 4.0 \\
Water supply, ${ }^{\circ} \mathrm{F}$ & 110 & 110 & 110 \\
\hline
\end{tabular}

\subsection{Filter Plant Construction}

The Foster Wheeler study notes that considerable utility experience in bargeshipping and erection of large steam generator vessels exists as a result of the expanding nuclear industry in the 1960's and 1970's. Several vessels weighing up to 800 tons have been shipped and erected. Several contractors in the United States specialize in transporting and rigging this heavy equipment. Thus there appear no major obstacles to supplying the much smaller filter vessels in a similar way. Filter vessels are assumed to be moved from a barge to the construction site by crawler/transporters as shown in the Foster Wheeler report ${ }^{6}$.

- CPFBC Granular-bed filters

Table 22 lists the equipment for this plant. Each GBF plant consists of four filters as shown on Figure 32a. There are two identical GBF modules as the entire plant is divided into two identical trains of equipment, each sized for, nominally, 226 MWe. 


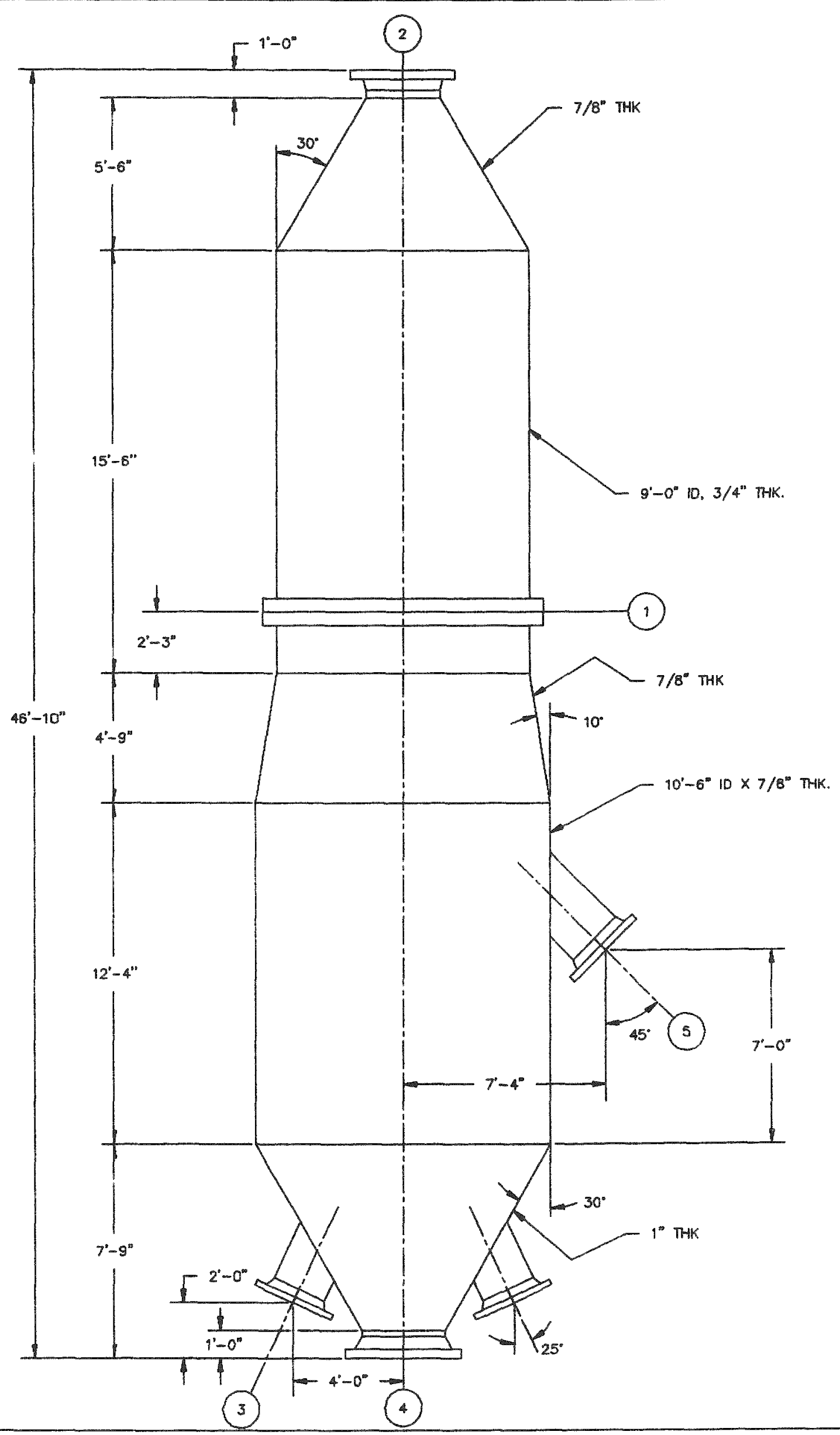




\section{YESSEL DATA}

SERVICE:

OPERATING PRESS:

DESIGN PRESS:

ASH/MEDIA SEPARATION

MAX. OPERATING TEMP.

185 PSIA

200 PSIG

DESIGN TEMP:

$1600^{\circ} \mathrm{F}$ (INTERNAL)

WIND DATA:

$650^{\circ} \mathrm{F}$ (METAL)

EARTHQUAKE DATA:

UBC (70 MPH, EXP.C)

CODE:

CODE STAMP:

P.W.H.T. FOR CODE:

UBC (ZONE 1)

ASME SECT VIII DIV. 1

YES

P.W.H.T. FOR PROCESS:

JOINT EFF:

RADIOGRAPHED:

CORROSION ALL:

MAT'L SHELL:

MAT'L HEADS:

MAT'L SUPPT'S.

MAT'L NOZZLES:

MAT'L FLANGES:

EMPTY WEIGHT:

WATER ONLY WEIGHT:

FILTER MEDIA:

NO

NO

$100 \%$

FULL

$1 / 8^{\prime \prime}$

$S A-516$ GR 70

SA-516 GR 70

$S A-516$ GR 70

SA-105

63000 LBS (METAL ONLY)

180000 LBS

83000 LBS

INSL/REFR:

80000 LBS

\section{NOZZLES}

$\begin{array}{llllll}\text { NO. } & \text { SIZE } & \begin{array}{l}\text { ANSI } \\ \text { RATING }\end{array} & \text { SERVICE } & \text { I.D } \\ \text { LINING } & \text { QTY } \\ 1 & 108^{\prime \prime} & \text { CL 300 RF } & \text { ACCESS } & 7^{\prime}-0^{\prime \prime} & 2 \\ 2 & 32^{\prime \prime} & \text { CL 300 RF } & \text { OUTLET } & 20 " & 1 \\ 3 & 24^{\prime \prime} & \text { CL 300 RF } & \text { MEDIA OUT } & 12 " & 4 \\ 4 & 36^{\prime \prime} & \text { CL 300 RF } & \text { INLET } & 24 " & 1 \\ 5 & 26 " & \text { CL 300 RF } & \text { MEDIA OUT } 12 " & 1\end{array}$

WALL THICKNESSES GIVEN ARE MINIMUM

Figure 35a De-Entrainment Vessel, CPFBC GBF 


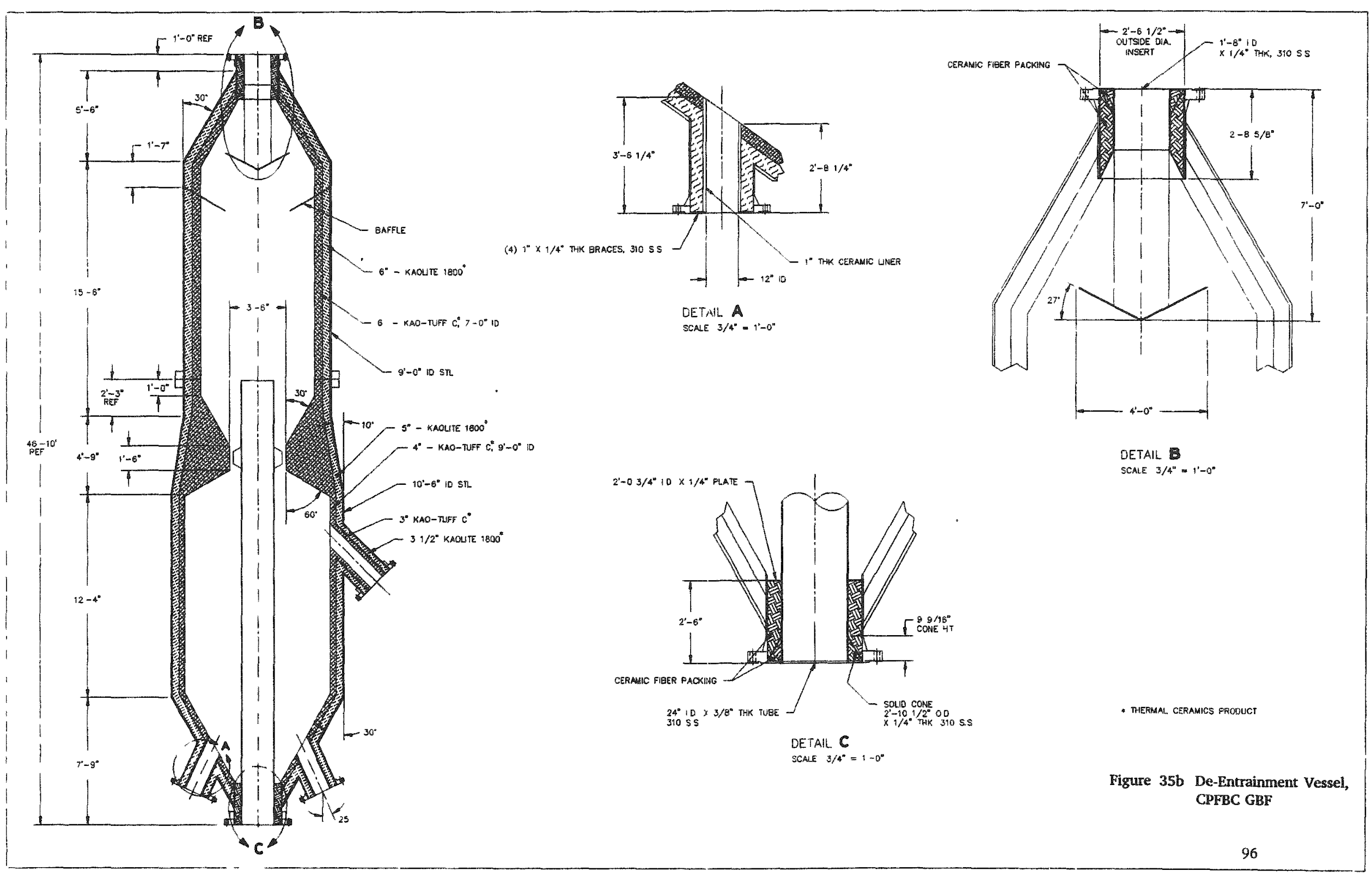




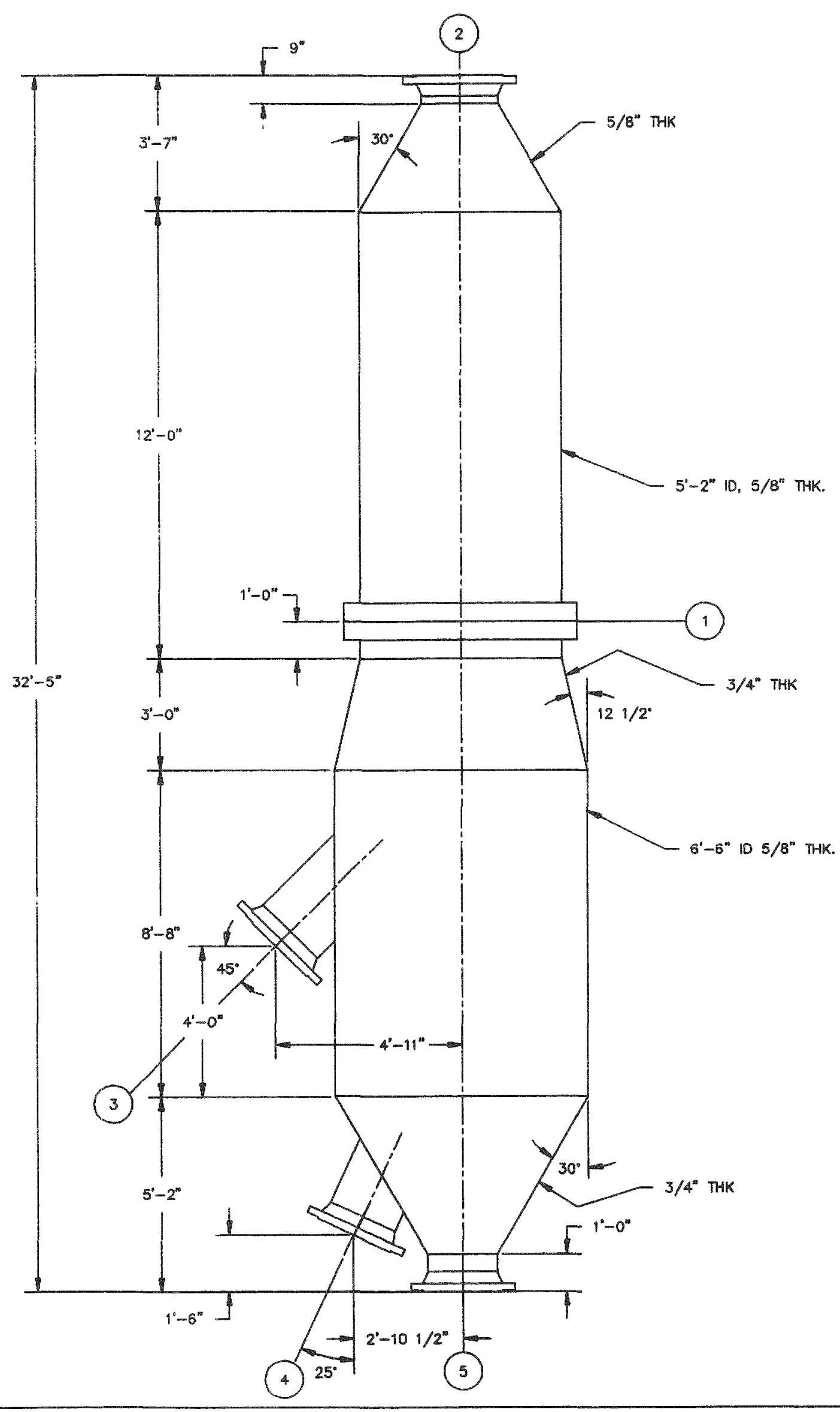


VESSEL DATA

SERVICE:

OPERATING PRESS:

DESIGN PRESS:

ASH/MEDIA SEPARATION

MAX. OPERATING TEMP:

DESIGN TEMP:

WIND DATA:

EARTHQUAKE DATA:

CODE:

CODE STAMP:

P.W.H.T. FOR CODE:

P.W.H.T. FOR PROCESS:

JOINT EFF:

RADIOGRAPHED:

CORROSION ALL.

MAT'L SHELL:

MAT'L HEADS:

MAT'L SUPPT'S:

MAT'L NOZZLES:

MAT'L FLANGES:

EMPTY WEIGHT:

WATER ONLY WEIGHT:

FILTER MEDIA:

INSL/REFR:

208 PSIA

218 PSIG

$1485^{\circ} \mathrm{F}$ (INTERNAL)

$650^{\circ} \mathrm{F}$ (METAL)

UBC (70 MPH, EXP.C)

UBC (ZONE 1)

ASME SECT VIII DIV. 1

YES

NO

NO

$100 \%$

FULL.

$1 / 8^{\circ}$

SA-516 GR 70

$S A-516$ GR 70

SA-516 GR 70

SA-105

21000 LBS (METAL ONLY)

46000 LBS

13000 LBS

33000 LBS

NOZZLES

\begin{tabular}{|c|c|c|c|c|}
\hline No. & SIZE & $\begin{array}{l}\text { ANSI } \\
\text { RATING }\end{array}$ & SERVICE & $\begin{array}{l}\text { D.D. } \\
\text { LINING }\end{array}$ \\
\hline 1 & $62^{\prime \prime}$ & OL 300 RF & ACCESS & $3^{\prime}-2^{3}$ \\
\hline 2 & $24^{\prime \prime}$ & $\mathrm{CL} 300 \mathrm{RF}$ & OUTLET & $10 "$ \\
\hline 3 & $24^{\prime \prime}$ & L $300 \mathrm{RF}$ & MEDIA OUT & $10^{\prime \prime}$ \\
\hline 4 & $22^{\prime \prime}$ & CL 300 RF & MEDIA OUT & $10^{\prime \prime}$ \\
\hline 5 & $22^{n}$ & CL 300 RF & INLET & $10^{\prime \prime}$ \\
\hline
\end{tabular}

NALL THICKNESS GIVEN ARE MINIMUM

Figure 36a De-Entrainment Vessel, Carbonizer GBF: 

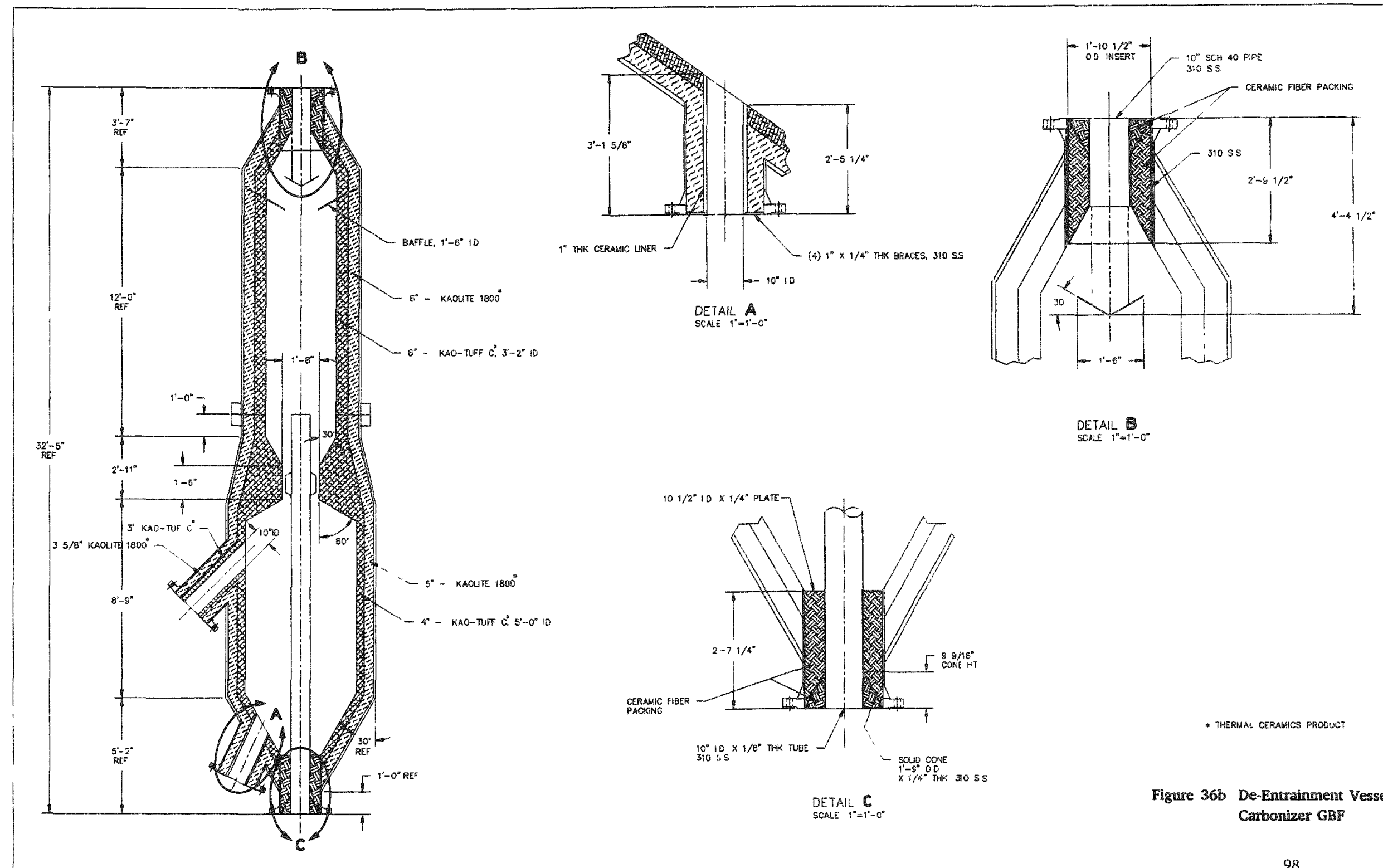

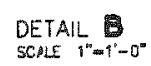

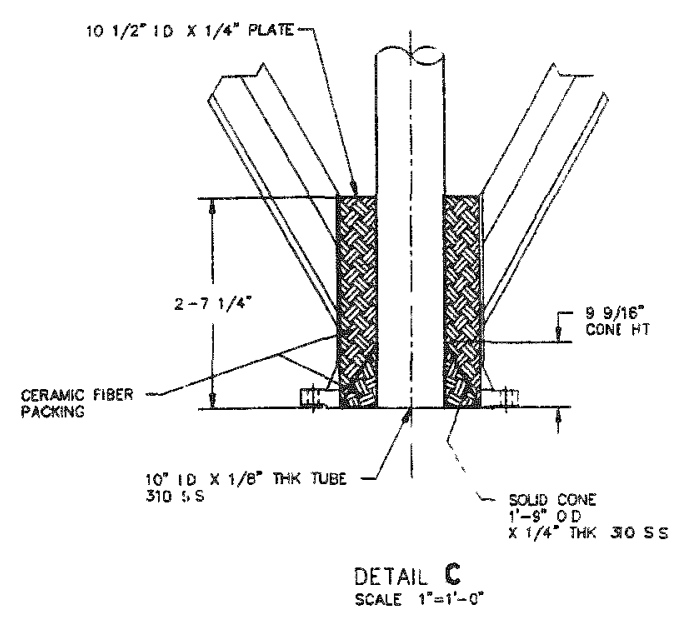

- thermal ceramils probuct

Figure 36b De-Entrainment Vessel, Carbonizer GBF 


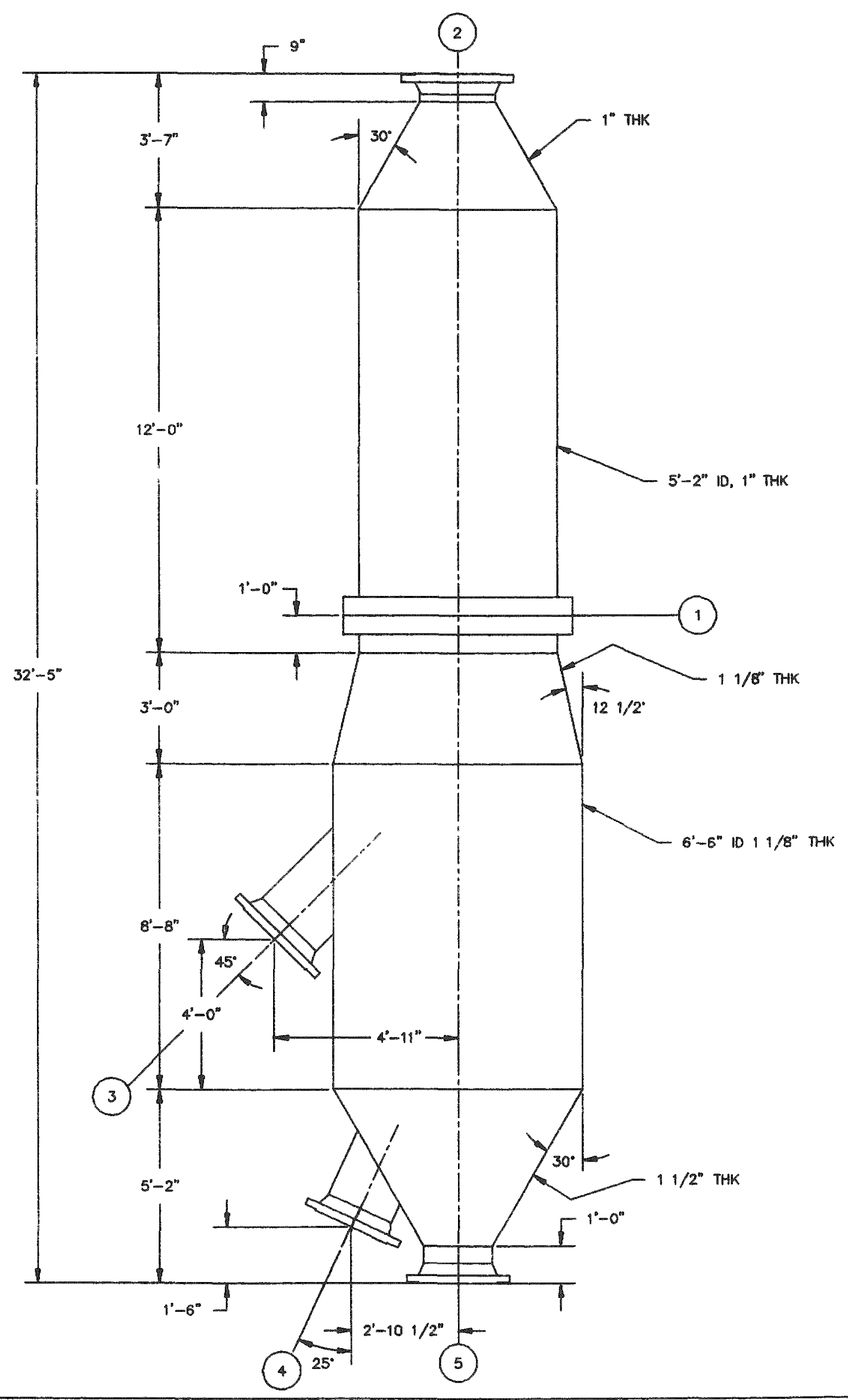




\section{VESSEL DATA}

\section{SERVICE:}

OPERATING FRESS:

DESIGN PRESS:

MAX. OPERA ING TEMP: DESIGN TEMP:

MND DATA:

EARTHQUAKE DATA:

CODE:

CODE STAMP

P.W.H.T. FOR CODE:

P.W.H.T. FOR PROCESS:

JOINT EFF:

RADIOGRAPHED:

CORROSION ALL:

MAT'L SHELL

MAT'L HEADS:

MAT'L SUPPT'S:

MAT'L NOZZLES:

MAT'L FLANGES:

EMPTY WEIGHT:

WATER ONLY WEIGHT:

FILTER MEDIA:

INSL/REFR:

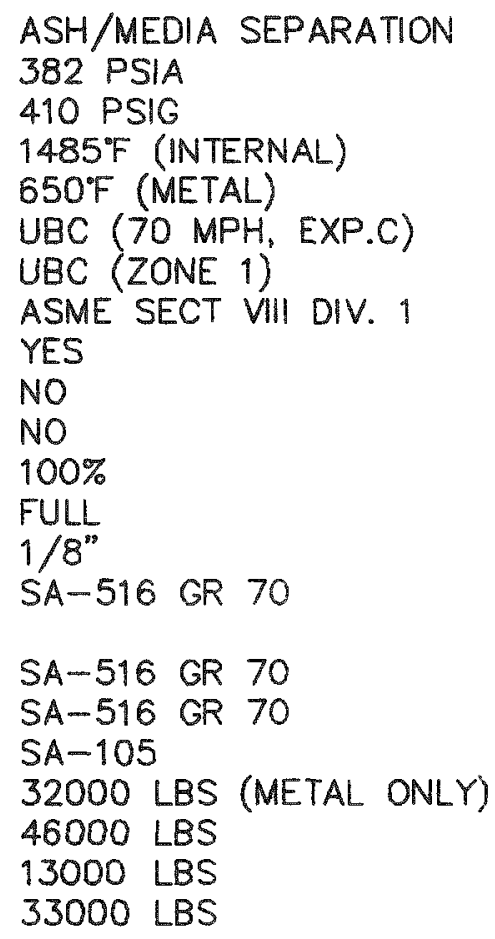

\begin{tabular}{|c|c|c|c|c|c|}
\hline \multirow[b]{2}{*}{ NO. } & \multicolumn{3}{|c|}{ NOZZLES } & \multirow[b]{2}{*}{$\begin{array}{l}\text { I.D. } \\
\text { LINING }\end{array}$} & \multirow[b]{2}{*}{ QTY } \\
\hline & SIZE & $\begin{array}{l}\text { ANSI } \\
\text { RATING }\end{array}$ & SERVICE & & \\
\hline 1 & $62^{\prime \prime}$ & $\mathrm{CL} 300 \mathrm{RF}$ & ACCESS & $3^{\prime}-2$ & 2 \\
\hline 2 & $24^{\prime \prime}$ & $\mathrm{CL} 300 \mathrm{RF}$ & OUTEET & $10^{\prime \prime}$ & 1 \\
\hline 3 & $24^{\prime \prime}$ & $C L 300 \mathrm{RF}$ & MEDIA OUT & $10^{\prime \prime}$ & 1 \\
\hline 4 & $22^{\prime \prime}$ & $\mathrm{CL} 300 \mathrm{RF}$ & MEDIA OUT & $10^{\prime \prime}$ & 1 \\
\hline 5 & $22^{\prime \prime}$ & CL 300 RF & INLET & $10^{\prime \prime}$ & 1 \\
\hline
\end{tabular}

WALL THICKNESS GIVEN ARE MINIMUM

Figure 37a De-Entrainment Vessel, KRW Gasifier GBF 


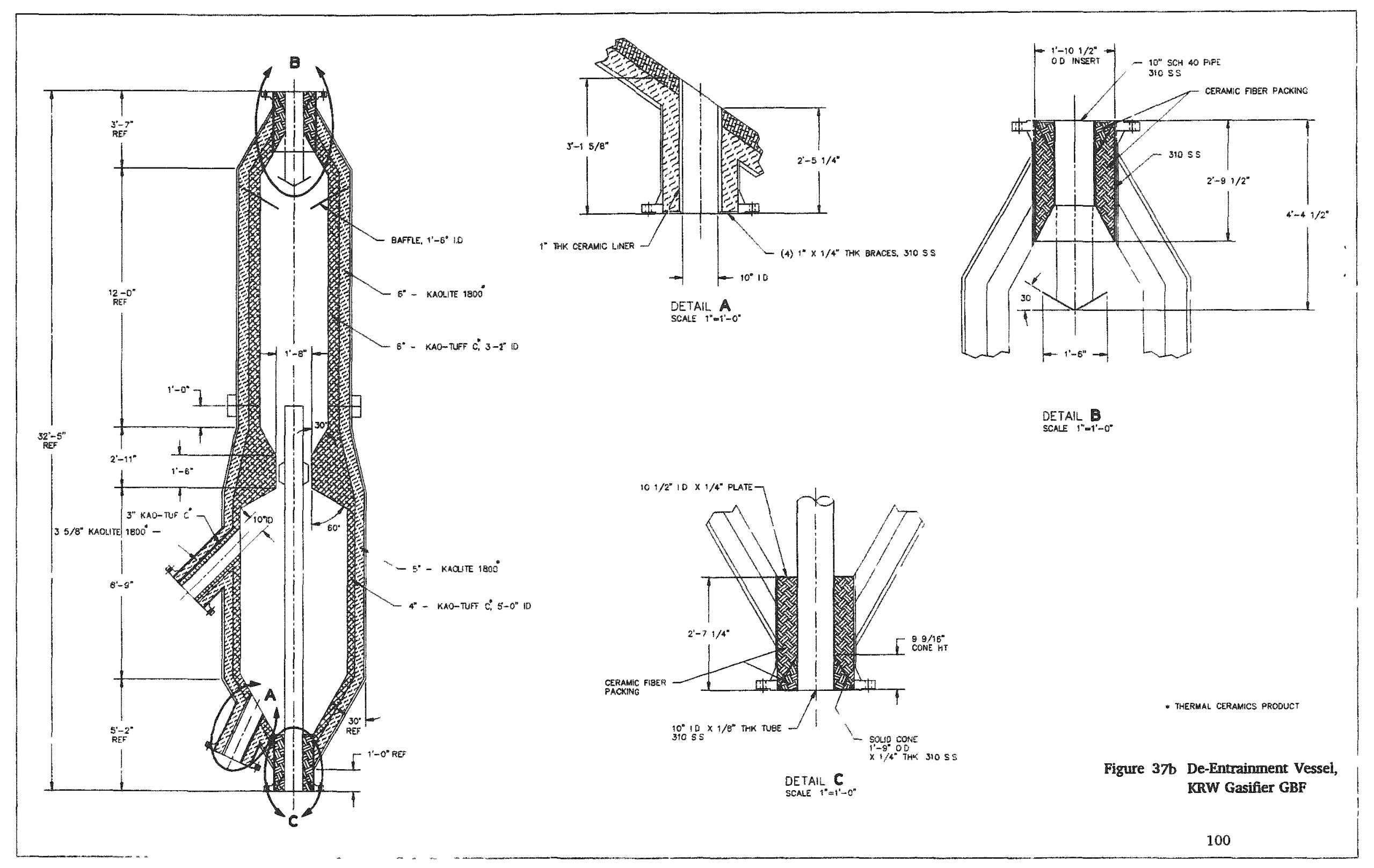




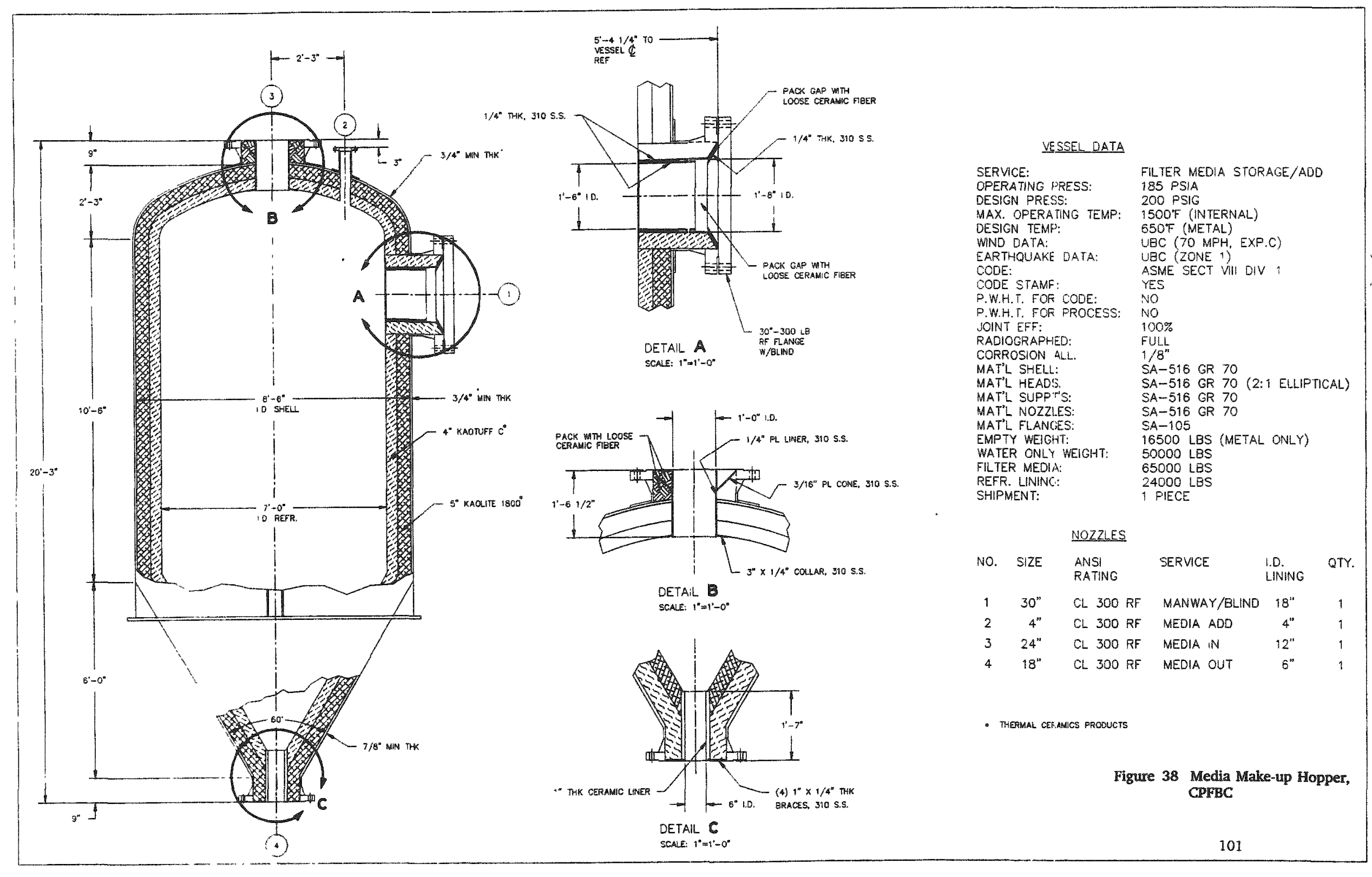




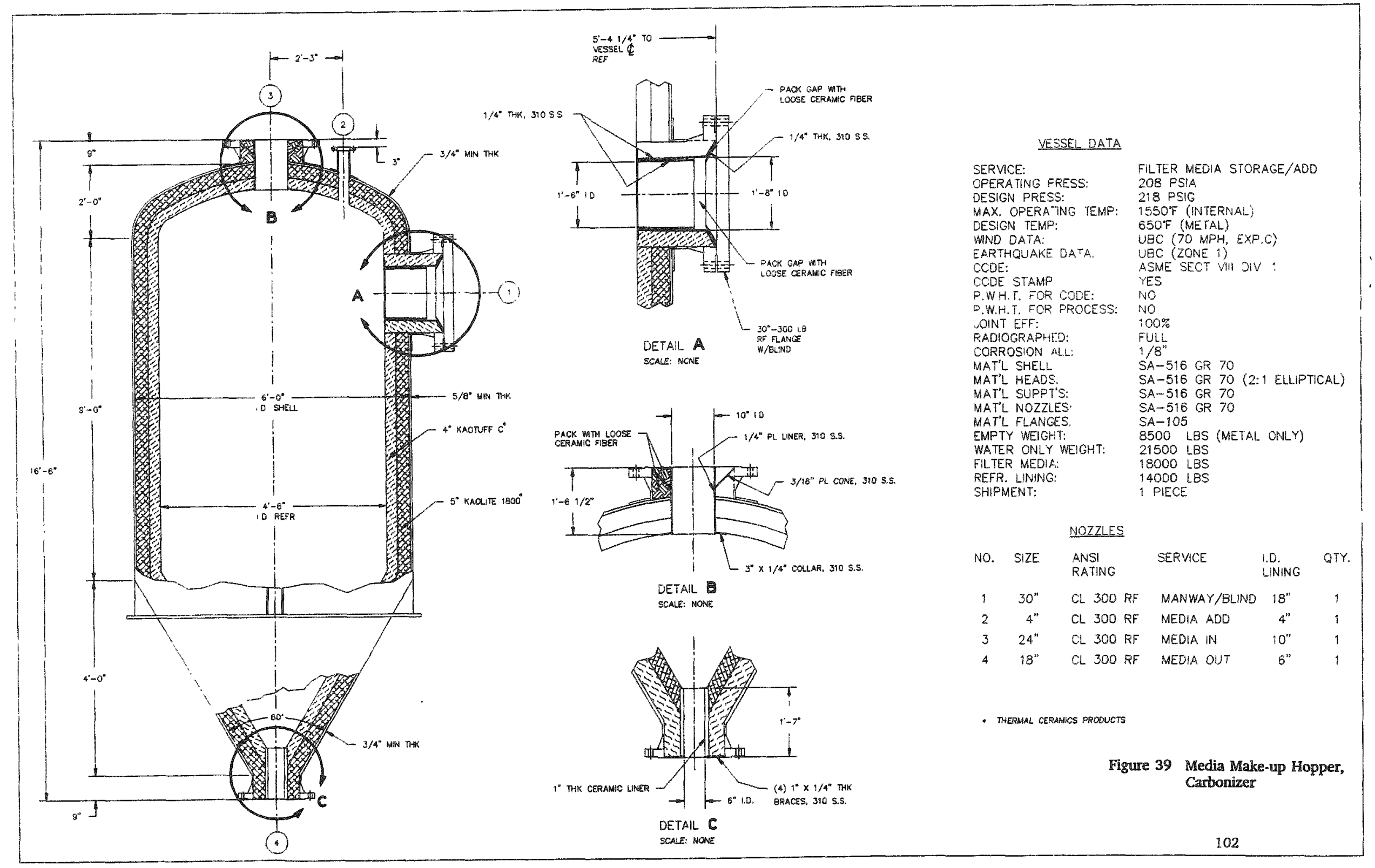




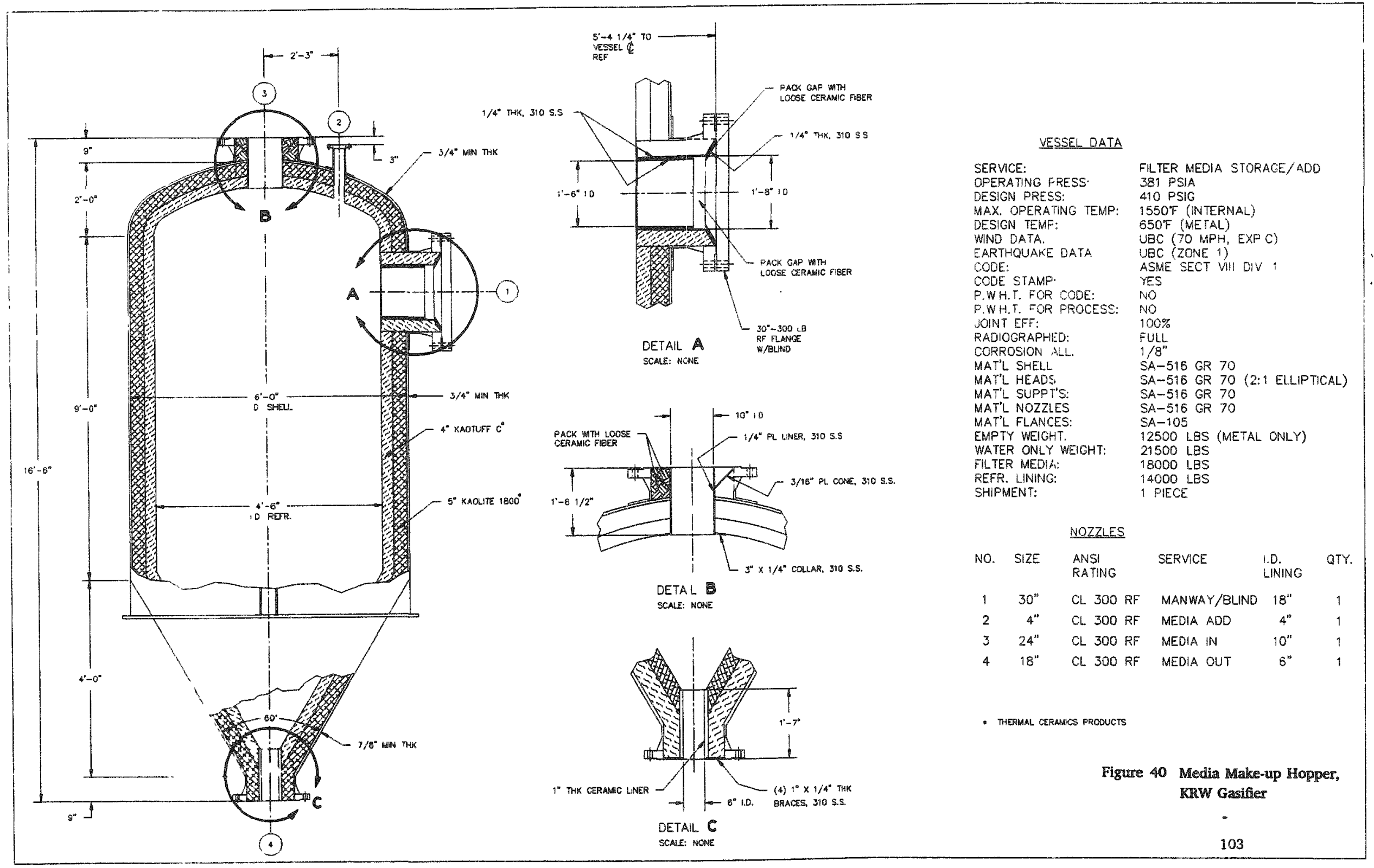



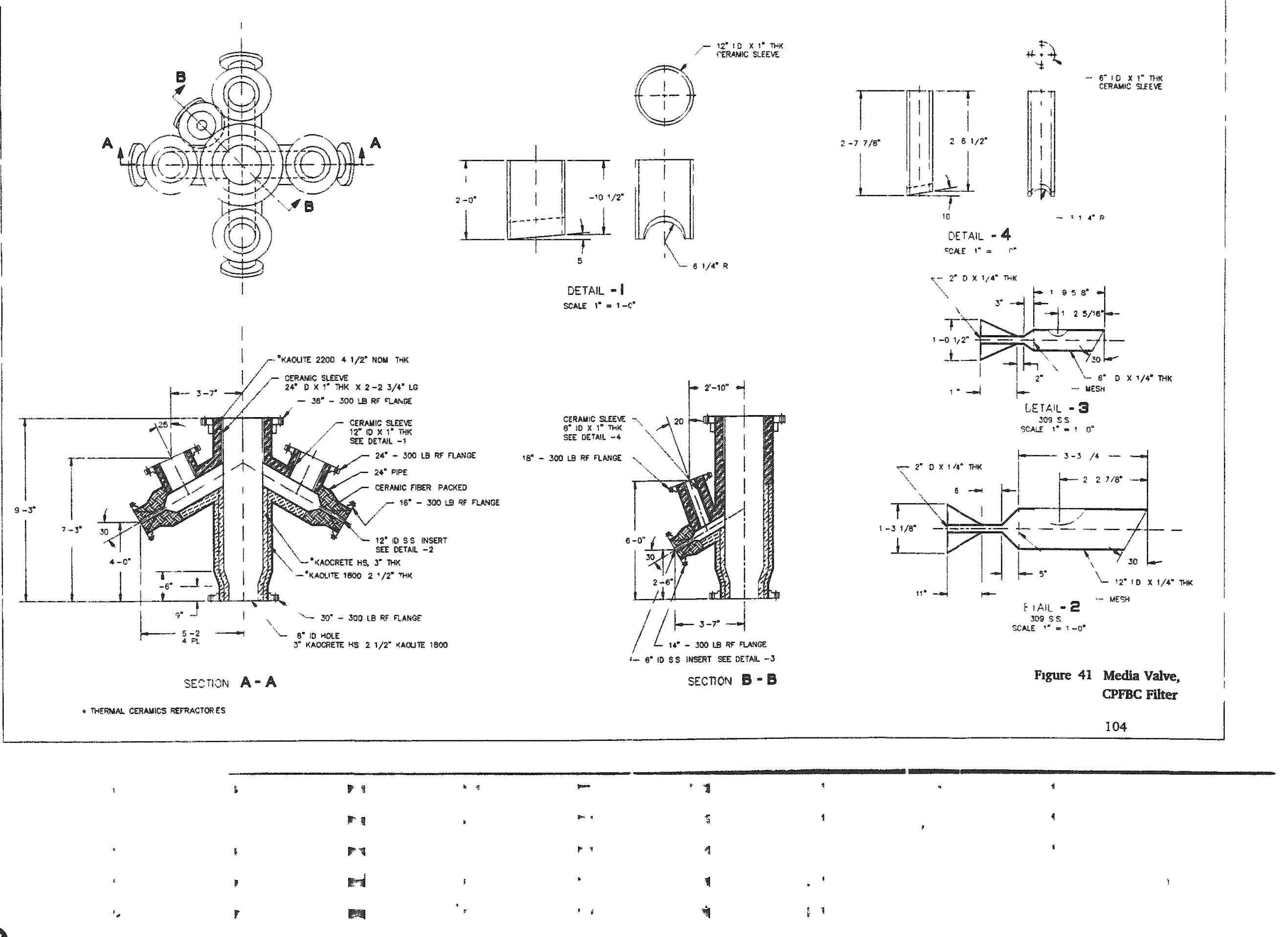


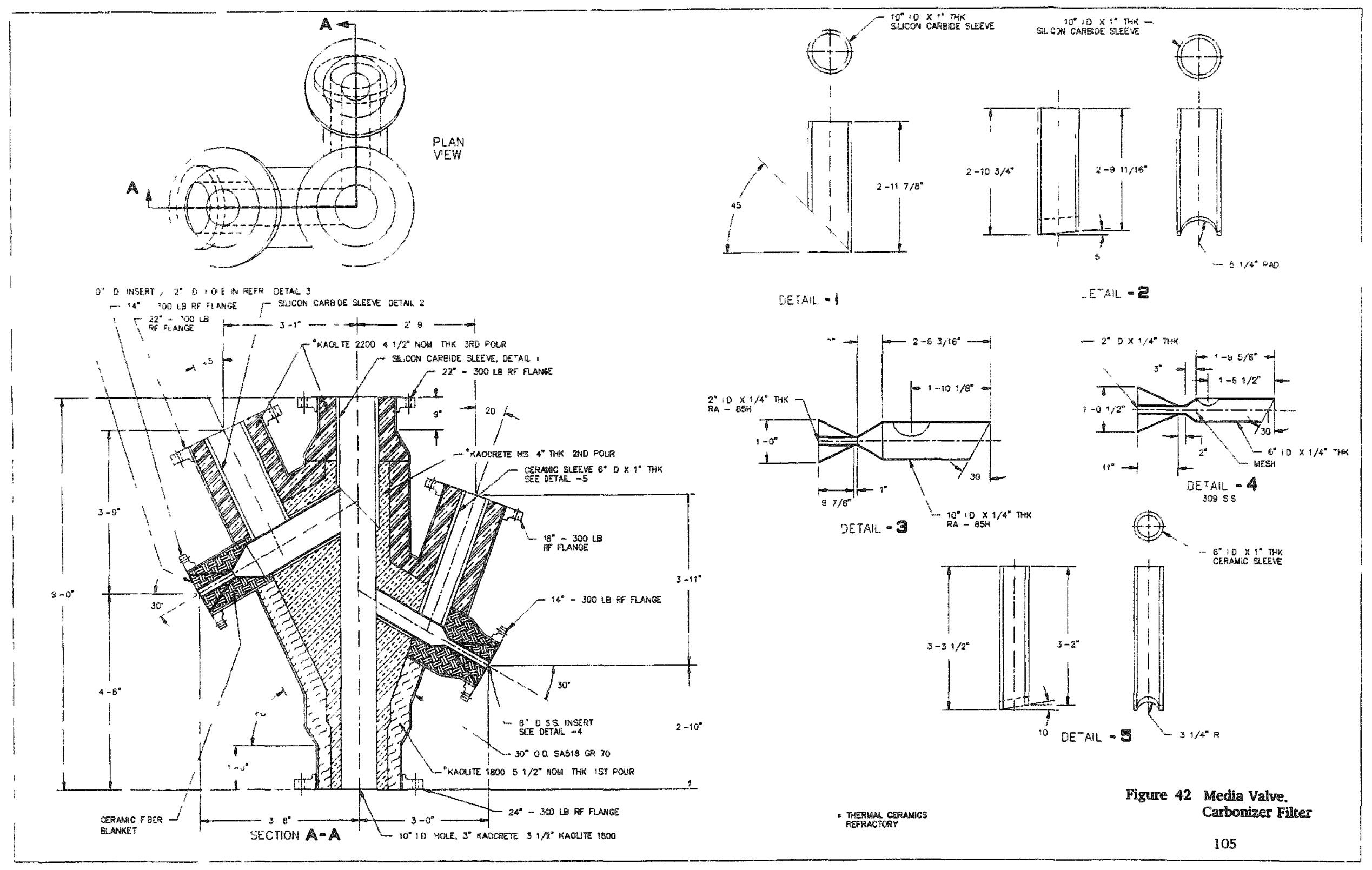





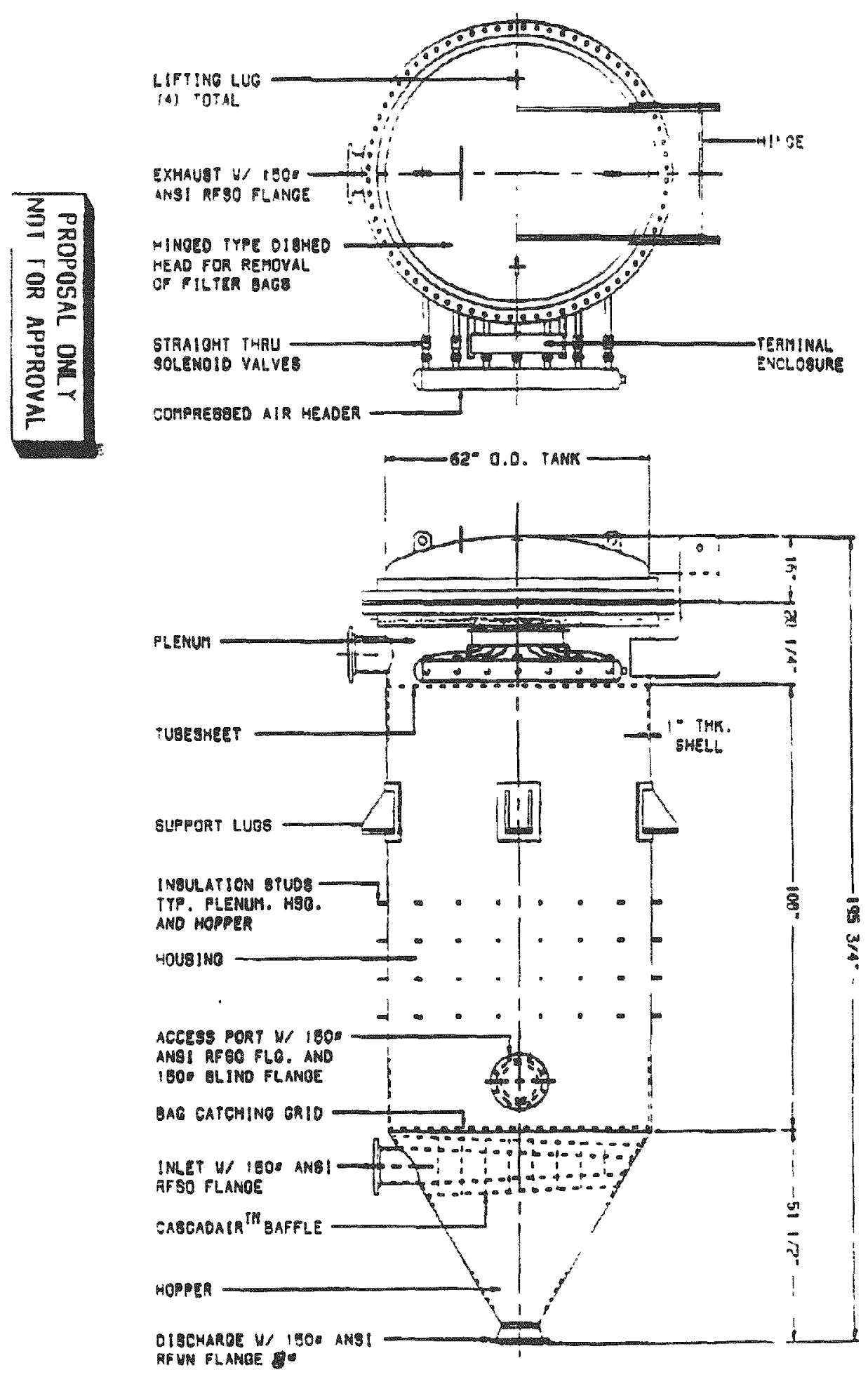

Figure 44 Typical Baghouse Configuration 


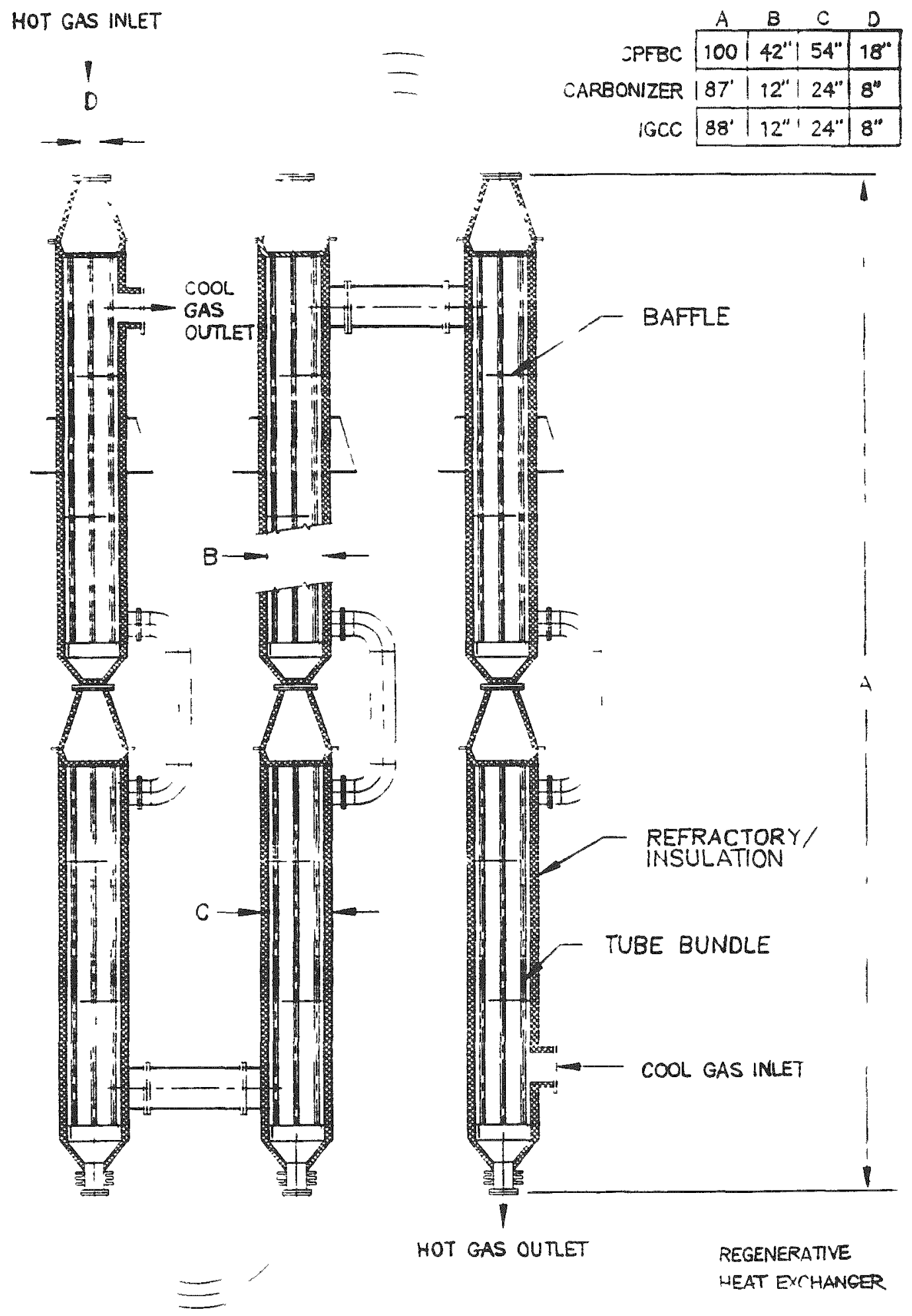

Figure 45 Arrangement for Regenerative Heat Exchangers 
Some costs are not included in the erection estimate. For example, refractory costs include installation. The filter vessel will have refractory installed on site, in place. The other, smaller items will have refractory installed off site. Filter media is installed by others during start-up. Installation costs for inlet and outlet ducting, instruments and controls, and filter media were estimated by Combustion Power based on factoring from the material costs.

Installation of the granular-bed filter vessel will require some field welding and handling. The filter vessel cap, at flange "2", Figure 26, ships separate. As shown on Figure 27, in details A, B, and C, the stainless components are field welded into place. This will occur prior to installation of refractory. After refractory is installed in the major vessel and the cap, filter internals are installed. There is a field butt weld just below flange "2" to attach the major filter internals. Care will need to be taken to assure that the internals are centered inside the vessel. After the vessel cap is installed, the expansion joint assembly, shown on Figure 27, Detail D, is installed. Kaowool blanket is fitted into the expansion joint assembly and a single butt weld attaches the assembly to the major bulk of the internals.

The installation of refractory lined pipe (lift pipe and seal legs) involves exact fitup; since there are no expansion joints. The assembly allows for field fit and welding of $6,24 "-300 \#$ weld neck flanges and includes extra handling to allow installation of a small amount of refractory at the tip of six $10^{\prime}$ long pipe spools. The remaining installation of pressure vessels and piping is routine. All piping and fittings were itemized to assist in the erection cost estimate.

\section{- Carbonizer Granular-Bed Filter}

Table 23 lists the equipment for this plant. Each filter module consists of one filter vessel with a media circulation system as shown on Figure 33. The cyclone and the carbonizer collecting hopper, shown phantom, are not part of the installation. There are two identical filter modules as the entire plant is divided into two identical trains of equipment, each sized for, nominally, $226 \mathrm{MWe}$.

Some costs are not included in the construction estimate. As with the CPFBC filter, this includes: installation of refractory, filter media, and instruments/controls. Inlet and outlet ducting is similar to that needed for the other filters considered for this plant, so it cancels out of the cost estimate. The filter will have refractory installed on site, in place. The other, smaller items will have refractory installed off site.

Installation of the granular-bed filter vessel with internals and refractory is accomplished the same as for the CPFBC filter. As with the CPFBC filter, the filter vessel cap, at flange " 2 ", Figure 28 , ships separate to assist installation. The reference drawings are Figures 28 and 29.

The installation of refractory lined pipe (lift pipe and seal legs) involves exact fitup; since there are no expansion joints. The assembly allows for field fit and welding of 1,22 "-300\# weld neck flange and includes extra handling to allow installation of a small amount of refractory at the tip of one $10^{\prime}$ long pipe spool. The remaining installation of 
pressure vessels and piping is routine. All piping is itemized for the plant to assist in the erection cost estimate.

\section{- KRW Gasifier Granular-Bed Filter}

Table 24 lists the equipment for this plant. Each filter module consists of one filter vessel with a filter media circulation system as shown on the general arrangement drawing, Figure 34. There is one filter vessel, sized for $100 \mathrm{MWe}$.

Some costs are not included in the construction estimate. As with the CPFBC, and carbonizer filter, this includes: refractory, filter media, inlet/outlet ducting, instruments, and controls. The filter will have refractory installed on site, in place. The other, smaller items will have refractory installed off site.

The arrangement of the cost estimating model allows all installation costs to be lumped together. No breakdown is needed for direct and indirect cost.

Installation of the granular-bed filter vessel with internals and refractory is accomplished the same as for the CPFBC filter. As with the CPFBC filter, the filter vessel cap, at flange " 2 ", Figure 30 , ships separate to assist installation. The reference drawings are Figures 30 and 31 .

The installation of refractory lined pipe (lift pipe and seal legs) involves exact fitup; since there are no expansion joints. As with the carbonizer, the assembly allows for field fit and welding of 1,22 "-300\# weld neck flange and includes extra handling to allow installation of a small amount of refractory at the tip of one 10' long pipe spool. The remaining installation of pressure vessels and piping is routine. 
Table 22 CPFBC Granular-Bed Filter Equipment - 226 MWe Module

\begin{tabular}{|c|c|c|c|c|}
\hline $\begin{array}{l}\text { Filter } \\
\text { Components }\end{array}$ & Qty & $\begin{array}{l}\text { Unit } \\
\text { Weight } \\
\text { (lbs) }\end{array}$ & $\begin{array}{l}\text { Size or } \\
\text { Capacity, } \\
\text { (each) }\end{array}$ & $\begin{array}{l}\text { Installed/ } \\
\text { Operating } \\
\quad \mathrm{Hp}\end{array}$ \\
\hline Filter Vessels & 4 & 171,327 & $21^{\prime} 6^{\prime \prime}$ OD X 56' & - \\
\hline Vessel Refractory & 4 & 139,709 & & - \\
\hline Filter Internals & 4 & 8,027 & & - \\
\hline Filter Auxiliaries & & & & - \\
\hline Filter Media & 4 & 484,406 & & - \\
\hline De-Entrain. Ves. & 1 & 58,196 & $10^{\prime} 6^{\prime \prime}$ OD X 47' & - \\
\hline Internals & 1 & 5,040 & & - \\
\hline Refractory & 1 & 81,414 & & - \\
\hline Media Valve & 1 & 8,422 & $24^{\prime \prime} \mathrm{ID}$ & - \\
\hline Internals & 1 & 860 & & - \\
\hline Refractory & 1 & 3,132 & & - \\
\hline Media Makeup Hpr. & 1 & 16,456 & $8^{\prime} 6^{\prime \prime} \mathrm{OD} \times 20^{\prime}$ & - \\
\hline Refractory & 1 & 24,150 & & - \\
\hline Refr Lined Pipe & 1 & 108,101 & 24" ID Refr & - \\
\hline Refractory & 1 & 104,215 & & - \\
\hline Regen. Ht. Exch. ${ }^{1}$ & 8 & 100,000 & $54^{\prime \prime}$ OD X 50' ea & - \\
\hline Water-cooled $\mathrm{Hx}$ & 1 & 18,000 & $34^{\prime \prime}$ OD X $13^{\prime}$ & - \\
\hline Baghouse & 1 & 30,000 & $97.5^{\prime \prime} \mathrm{OD} \times 16.5^{\prime}$ & - \\
\hline Boost Blower & 1 & 12,500 & $6500 \mathrm{acfm}$ & $500 / 290$ \\
\hline Maintenance Blower & 2 & 10,000 & $8550 \mathrm{acfm}$ & $400 / 370$ \\
\hline Piping/Valves & 1 Lot & 23,868 & & - \\
\hline Media Add Hopper & 1 & 1,056 & $30^{\prime \prime} \mathrm{OD} \times 9.5^{\prime}$ & - \\
\hline Insulation & 1 Lot & - & & - \\
\hline Access/Support Stl. & 1 Lot & 620,000 & & - \\
\hline Instr/Controls & 1 Lot & - & & - \\
\hline Inlet/Outlet Ducting & 1 Lot & 400,000 & & - \\
\hline \multicolumn{5}{|c|}{ Ash System for CPFBC Granular-Bed Filter: } \\
\hline $500^{\circ} \mathrm{F}$ Ball Valve & 2 & 100 & $6^{\prime \prime}$ & - \\
\hline $500^{\circ} \mathrm{F}$ Bleed Valve & 1 & 50 & $2^{\prime \prime}$ & - \\
\hline Throt'lng Slide Gate & 1 & 100 & $6^{\prime \prime}$ & - \\
\hline RPD Vessel-C'St] ${ }^{2}$ & 1 & 8,810 & $7^{\prime}$ OD X 12.5' & - \\
\hline \multicolumn{5}{|c|}{$\begin{array}{l}\text { Notes: } \\
\text { 1. Eight section at } 54^{\prime \prime} \text { OD x } 50^{\prime} \text { long for } 100,000 \text { lbs total. } \\
\text { 2. Restricted-Pipe Discharge hopper. }\end{array}$} \\
\hline
\end{tabular}


Table 23 Carbonizer Granular-Bed Filter Equip. - 226 MWe Module

\begin{tabular}{|c|c|c|c|c|}
\hline $\begin{array}{l}\text { Filter } \\
\text { Components }\end{array}$ & Qty & $\begin{array}{c}\text { Unit } \\
\text { Weight } \\
\text { (lbs) }\end{array}$ & $\begin{array}{c}\text { Size or } \\
\text { Capacity, } \\
\text { (each) }\end{array}$ & $\begin{array}{c}\text { Installed/ } \\
\text { Operating } \\
\text { Hp }\end{array}$ \\
\hline Filter Vessel & 1 & 78,264 & $15^{\prime} 6^{\prime \prime}$ OD X $45^{\prime}$ & - \\
\hline Vessel Refractory & 1 & 79,703 & & - \\
\hline Filter Internals & 1 & 6,329 & & - \\
\hline Filter Auxiliaries & & & & - \\
\hline Filter Media & 1 & 221,875 & & - \\
\hline De-Entrain. Ves. & 1 & 20,850 & $6^{\prime} 6^{\prime \prime}$ OD X $32^{\prime}$ & - \\
\hline Refractory & 1 & 32,298 & & - \\
\hline Internals & 1 & 2,081 & & - \\
\hline Media Valve W/Refr & 1 & 7,923 & $10^{\prime \prime} \mathrm{ID}$ & - \\
\hline Internals & 1 & 200 & & - \\
\hline Media Makeup Hopper & 1 & 8,642 & $6^{\prime}$ OD X $16.5^{\prime}$ & - \\
\hline Refractory & 1 & 13,994 & & - \\
\hline Refr Lined Pipe & 1 & 56,487 & 10" ID Refr & - \\
\hline Refractory & 1 & 52,954 & & - \\
\hline Regen. Ht. Exch. ${ }^{1}$ & 8 & 30,000 & $24^{\prime \prime}$ OD X 44' ea & - \\
\hline Water-Cooled $\mathrm{Hx}$ & 1 & 1,955 & $16^{\prime \prime}$ OD X 13' & - \\
\hline Baghouse & 1 & 8,750 & $60^{\prime \prime}$ OD X $16.5^{\prime}$ & - \\
\hline Boost Blower & 1 & 15,000 & $1160 \mathrm{acfm}$ & $60 / 48$ \\
\hline Maintenance Blower & 1 & 5,000 & $3185 \mathrm{acfm}$ & $175 / 165$ \\
\hline Piping/Valves & 1 Lot & 6,522 & & - \\
\hline Insulation & $1 \mathrm{Lot}$ & - & & - \\
\hline Media Add Hopper & 1 & 1,081 & $30^{\prime \prime}$ OD X $9.5^{\prime}$ & - \\
\hline Instr/Controls & 1 Lot & - & & - \\
\hline Access/Support Stl. & 1 Lot & 180,000 & & - \\
\hline
\end{tabular}

Ash System for Carbonizer Granular-Bed Filter:

$500^{\circ} \mathrm{F}$ Ball Valve

$500^{\circ} \mathrm{F}$ Bleed Valve

Ash Hopper

$\begin{array}{lr}2 & 100 \\ 1 & 50 \\ 1 & 3939\end{array}$

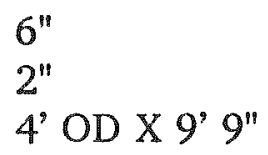

Notes:

1. Eight section at $24^{\prime \prime}$ OD $\times 44^{\prime}$ long for $30,000 \mathrm{lbs}$ total. 
Table 24 KRW Gasifier Granular-Bed Filter Equip. - 100 MWe Plant

\begin{tabular}{|c|c|c|c|c|}
\hline $\begin{array}{l}\text { Filter } \\
\text { Components }\end{array}$ & Qty & $\begin{array}{c}\text { Unit } \\
\text { Weight } \\
\text { (lbs) }\end{array}$ & $\begin{array}{c}\text { Size or } \\
\text { Capacity, } \\
\text { (each) }\end{array}$ & $\begin{array}{c}\text { Installed/ } \\
\text { Operating } \\
\text { Hp }\end{array}$ \\
\hline Filter Vessel & 1 & 137,863 & $15^{\prime} 6^{\prime \prime}$ OD X $45^{\prime}$ & - \\
\hline Vessel Refractory & 1 & 78,962 & & - \\
\hline Filter Internals & 1 & 6,749 & & - \\
\hline Filter Auxiliaries & & & & - \\
\hline Filter Media & 1 & 221,875 & & - \\
\hline De-Entrain. Ves. & 1 & 30,153 & $6^{\prime} 6^{\prime \prime}$ OD X 32' & - \\
\hline Refractory & 1 & 32,298 & & . \\
\hline Internals & 1 & 2,081 & & - \\
\hline Media Valve W/Refr & 1 & 8,590 & $10^{\prime \prime} \mathrm{ID}$ & - \\
\hline Internals & 1 & 200 & & - \\
\hline Media Makeup Hopper & 1 & 12,627 & $6^{\circ}$ OD X $16.5^{\circ}$ & - \\
\hline Refractory & 1 & 13,994 & & - \\
\hline Refr Lined Pipe & 1 & 61,678 & 10" ID Refr & - \\
\hline Refractory & 1. & 52,954 & & - \\
\hline Regen. Ht. Exch & 8 & 40,000 & $24^{\prime \prime}$ OD X $44^{\prime}$ & - \\
\hline Water-Cooled $\mathrm{Hx}$ & 1 & 2,310 & $14^{\prime \prime} \mathrm{OD} \times 13^{\prime}$ & - \\
\hline Baghouse & 1 & 14,650 & $62^{\prime \prime}$ OD X 16.5' & - \\
\hline Boost Blower & 1 & 20,000 & $930 \mathrm{acfm}$ & $100 / 64$ \\
\hline Maintenance Blower & 1 & 5,000 & $3160 \mathrm{acfm}$ & $175 / 166$ \\
\hline Piping/Valves & 1 Lot & 6,533 & & - \\
\hline Insulation & 1 Lot & - & & - \\
\hline Media Add Hopper & 1 & 1,564 & $30^{\prime \prime}$ OD X $9.5^{\prime}$ & - \\
\hline Instr/Controls & $1 \mathrm{Lot}$ & - & & - \\
\hline Access/Support Stl & 1 Lot & 170,000 & & - \\
\hline
\end{tabular}

Ash System for KRW Gasifier Granular-Bed Filter:

$\begin{array}{llrl}500^{\circ} \mathrm{F} \text { Ball Valve } & 2 & 100 & 6^{\prime \prime} \\ 500^{\circ} \mathrm{F} \text { Bleed Valve } & 1 & 50 & 2^{\prime \prime} \\ \text { Ash Hopper } & 1 & 3,939 & 4^{\prime} \text { OD X 9' } 9^{\prime \prime}\end{array}$

Notes:

1. Eight Sections at $24^{\prime \prime}$ OD X $44^{\prime}$ long for $40,000 \mathrm{lbs}$ total. 


\subsection{REFERENCES}

1. VanderMolen, Robert. June, 1984. Moving Bed Granular Filters for PFB Hot Gas Cleanup. Presented at the EPRI Pressurized Fluidized-Bed Combustion Power Plant Utility Conference.

2. Guillory, J.L., et al. May 1983. Granular Bed Filter Development Program, Phase II. Final Report. DOE/ET/10373-T10 (DE83014877). Menlo Park, CA.: Combustion Power Company.

3. Wilson, K.B., and J.C. Haas. October, 1989. Performance Analysis of a Screenless (Counter-Current) Granular Bed Filter on a Subpilot-Scale PFBC. Final Report presented to U.S. Department of Energy, Morgantown Energy Technology Center, Morgantown, West Virginia. DOE/MC/213335 (DEAC2184MC21335).

4. Wilson, K.B., J.C. Haas and J.C. Cooper. March, 1898. Performance Evaluation of a Screenless (Counter-Current) Granular Bed Filter on a Subpilot-Scale PFBC. In Proceedings of the Sixth Annual Coal-Fueled Heat Engines and Gas Stream Cleanup Systems Contractors Review Meeting, ed. R.C. Bedick, T.P. Dorchak, N.F. Rekos, H.A. Webb, $293-$ 303. Morgantown, WV. Morgantown Energy Technology Center. DOE/METC-89/6101 (DE89000952).

5. Guillory, J., Cooper,J., Ferguson, J., Goldbach, G., and F. Placer. May 1987. Granular Bed Filter Development Program. Phase II Final Report, 33-89. DOE/ET/10373-T10 (DE83014877). Combustion Power Company, Inc. Menlo Park, CA.

6. Robertson, A., and R. Garland, R. Newby, A. Rehmat, and L. Rubow. September, 1989. Second-Generation Pressurized Fluidized Bed Combustion Plant Conceptual Design and Optimization of a Second-Generation PFB Combustion Plant, Phase 1, Task 1. Report DOE/MC/21023-2825, Vol.1. Prepared by Foster Wheeler Development Corporation, Livingston, New Jersey under contract No. DE-AC21-86MC21023.

7. Memorandum of Technical Requirements High Temperature High Pressure (HTHP) Particulate Control Systems for PFBC. March 29, 1989, Revision 2. J.O. No. 15862.02, DOE Contract No. DE-AC21-86MC22222. Boston, Massachusetts: Stone \& Webster Engineering Corporation.

8. D. F. Ciliberti, T. E. Lippert. 1986. Performance Evaluation of a Ceramic Cross-Flow Filter on a Bench-Scale Coal Gasifier. Westinghouse Eighth Quarterly Report and Monthly Project Status Report for September 1, 1986 - September 30, 1986. DOE/METC Contract No. DE-AC21-84-MC21338. Morgantown, West Virginia: Morgantown Energy Technology Center.

9. Mudd, M.J., and J.D. Hoffman. July 1991. Update of Tidd PFBC Hot Gas Clean up Test Facility. In Proceedings of the Eighth Annual Coal-Fueled Heat Engines and Gas Stream Cleanup Systems Contractors Review Meeting, ed. H.A. Webb, R.C. Bedick, D.W. Geiling, D.C. Cicero, 89-97. DOE/METC-91/6122 (DE91002091). Morgantown, WV.: Morgantown Energy Technology Center. 
10. Hamer, J., R.M. Davison, D.W.Rahoi, and E.F. Reihl. August, 1985. Micro-Alloying Provides Heat and Corrosion Resistance with Leaner Alloys. Industrial Heating

11. Howes, Maurice A.H. August 1987. High-Temperature Corrosion In Coal Gasification Systems. IIT Research Institute, Chicago, Illinois as subcontractor to The Materials Properties Council, Inc., New York, New York for Gas Research Institute, Chicago, Illinois. Report No. IITRI-M08251-97. Chicago, Illinois: IIT Research Institute.

12. Kelly, J. September, 1991. RA-85H Performance in Hot Corrosion. In Heat Resistance Materials. Proceedings of the First International Conference, Fontana, Wisconsin, USA, ed. K. Natesan and D.J. Tillack, 653-658. Materials Park, Ohio: ASM International. 


\section{SECTION 4}

\section{CERAMIC CANDLE FIITERS}

\subsection{Candle Filter Development Status}

Interest in ceramic barrier filters has increased over the last 15-20 years. Development of the cross-flow filter has received a lot of attention because of the possibility of packaging a high amount of filter area in a small filter element. Cross-flow filters consist of thin, porous ceramic plates that contain troughs formed by ribbed segments. These plates are stacked and fired to form a continuous, porous structure in the shape of a rectangular cube. A flange is included on the element to provide a connection interface to metal exhaust ducting. Cross-flow filter systems have been field tested in both combustion and gasification, pilot test facilities. Typically, failure in the cross-flow filter element has been the result of either seam trough delamination, or crack formation along the flanged section. Modifications made in both fabrication and production of the cross-flow filter bodies, as well as redesign of the flange clamping arrangement has reduced these modes of failure. Nevertheless, increased interest has been shown in alternate shapes of ceramic, barrier filter elements.

Ceramic candle filter elements are commercially available from a few sources. These filter elements are rigid tubes, closed at the bottom and flanged at the top. They are formed by bonding ceramic fibers and/or grains with an aluminosilicate binder. Lengths are typically 1 to $1.5 \mathrm{~m}$ and outside diameters are $60 \mathrm{~mm}$ with a wall thickness of 10 to $15 \mathrm{~mm}$. Candle filter elements are mounted in tubesheets, utilizing a variety of arrangements to clamp and seal the filter element flanges. Tubesheets not only support the candle filters but seal the clean gas plenum from dirty gases. Candle filters (and cross-flow filters) are cleaned periodically by high pressure bursts of gas delivered near the filter element outlets. In combustion systems, high pressure air is used to clean the filter elements. In gasifiers, nitrogen or process gas is used. Candle filter elements have been vulnerable to cracking, especially near the flange portion. This has generally been attributed to problems that can be solved once understood. These problems are: excessive mechanical and thermal stresses that developed from improper mounting techniques, tubesheet design, pulse cleaning, candle design, or system transients.

Table 25 summarizes some of the relevant field test experience with both crossflow and candle filters ${ }^{1}$. Both types of filters have been successfully tested; although, some failures have occurred as noted. Furthermore, a variety of materials have been tested; many of which are not listed. Materials used for cross-flow filter construction include alumina/mullite, cordierite, aluminosilicate foam, cordierite-silicon nitride (CSN), and reaction-bonded silicon nitride (RBSN). Silicon carbide-based materials are currently used in the commercial manufacture of candle filters. Alternate candle filter materials include fireclay, aluminosilicate fibers, alumina, alumina/mullite, or chemical vapor infiltration of silicon carbide (CVI-SiC) matrices. 
Table 25 Ceramic Barrier Filter Experience

\begin{tabular}{llll}
\hline & & Gasif(G) & Operating \\
Location & Year & Comb(C) Mat'ls Hours & Experience \\
\hline
\end{tabular}

Ceramic Cross-Flow Filters DOE/METC 1970-80's degradation KRW

NYU

Texaco 1985-87 1988

WH-LTDTF $\quad 1989-91$

Ceramic Candle Filters

CRE 1984-85

Grimethorpe 1987

KRW

1985-87

DOE-METC Current

Solar Turbine 1990

IGT

Calvert

U. Aachen

Deusche

Babcock

Rheinbraun-

Berrenrath

Rheinbraun-

Wesselery

EPDC, Japan

Ahlstrom

ABB-Carbon

1983-85
G

Al/M 250 Delamination, but no performance

C $\quad \mathrm{Al} / \mathrm{M}$

168

$2 / 8$ elements delamination or cracked

C $\quad \mathrm{Al} / \mathrm{M} \quad 83$

$5 / 15$ delaminated or cracked

G $\quad \mathrm{Al} / \mathrm{M} \quad 250$

C $\quad \mathrm{Al} / \mathrm{M} \quad 1,300$

Failure along flange section

G/C FC

C $\quad \mathrm{SiC} \quad 800 \quad 1$ breakage after $300 \mathrm{~h} ; 4$ breakages due to system problems

G $\quad \mathrm{SiC} \quad 6-50 \quad$ Failure due to system problems

C $\mathrm{SiC} \quad$ Pressurized, entrained combustor

C $\quad \mathrm{SiC} \quad 50$

G $\quad \mathrm{SiC} \quad 150$
C $\quad 700 \quad 2$ tiers, 6 candles/tier

C $\quad \mathrm{SiC} \quad 5,800$

C $\quad \mathrm{SiC} \quad 3,500 \quad 2$ candles in parallel; $700^{\circ} \mathrm{C}$

G $\quad \mathrm{SiC}$ cycles 9 elements

G $\quad \mathrm{SiC} \quad 90$ elements

C $\quad \mathrm{SiC}$

\& Cor

C Cor

C Cor \&

others

Al/M - Alumina/mullite

FC - Filter coupons

$\mathrm{SiC}$ - Clay-bonded SiC

Cor - Cordierite 
Based on the experience summarized above, the ceramic candle filter represents the approach in which there is the most interest; therefore, the granular-bed filter is compared to the most economic commercial approach believed suitable for the applications studied in this effort. From the experience presented and some of the more recent endeavors, four filters (or filter groups) influenced the candle filter design proposed by Combustion Power. This includes the experience at the Grimethorpe PFBC Establishment, Barnsley, South Yorkshire, United kingdom; the Tidd PFBC Demonstration Plant, Brilliant, Ohio; Aachen Technical University (RWTH), Aachen, Germany; and Industrial Filter and Pump, Cicero, Illinois.

\subsubsection{Pilot Plant Filter at Grimethorpe}

The candle filter installed and tested at the Grimethorpe plant in the United Kingdom in 1987 was significant because it was one of the largest filters constructed and operated as of that date. This filter housed 130 filter elements inside an internally insulated filter vessel with a carbon steel enclosure $2.6 \mathrm{~m}(8.5 \mathrm{ft})$ in diameter and $8.9 \mathrm{~m}$ (29 ft) long. Filter elements were the Diaschumalith type manufactured by Schumacher $\mathrm{GmbH}$. These tubular filter elements were $1.5 \mathrm{~m}$ long, $60 \mathrm{~mm}$ outside diameter with a wall thickness of $15 \mathrm{~mm}$. The filter elements consisted of an inner, high porosity support layer made from silicon carbide granules; with a thin, low porosity, outer layer composed of fine alumina fibers and silicon carbide grains. The bonding agent used for the filter element materials was clay.

The tubesheet was a flat plate drilled to accept the filter elements and attached to the filter housing by a V-type support. Filter elements were held in place by a counterweighted venturi. A cylinder shaped shroud of constructed of alloy steel is installed around the filter elements in order to protect the elements from direct impingement of the dirty incoming flue gas onto the elements and to force the dirty flue gas to flow in an upward direction on the outside of the shroud. After the gas flows over the top of the shroud it turns and flows in a downward direction as it comes in contact with the filter elements. This downward flow of dirty flue gas is co-current with falling particulate filter cake and helps to keep reintrainment of particles to a minimum. High pressure air was used to remove ash accumulated on the outside of the candle filter elements by generating a periodic reversal of air flow inside the candle filter element. In the literature on the Grimethorpe filter ${ }^{2,3,4}$, there was sufficient information presented on the design and operation of the filter and on the pulse system that extrapolation of certain aspects of the design to commercial size was possible.

\subsubsection{Tidd Candle Filter Design}

The candle filter at the Tidd PFBC Demonstration Plant is currently undergoing testing, so actual performance data on the filter is not available; but literature ${ }^{5}$ on the candle filter design was useful in confirming many aspects of our candle filter design. The Tidd filter uses a candle filter element of $1.5 \mathrm{~m}$ length and $60 \mathrm{~mm}$ outside diameter constructed of two layers of sintered silicon carbide consisting of a thin outer layer of fine porosity material over a much thicker layer of courser porosity material. According to the 
literature, the elements used at Tidd are very similar in size and construction to those tested at Grimethorpe. The Tidd filter contains 384 candle filter elements arranged in three tiered clusters containing 128 elements each. Each tier cluster has three levels with the upper and middle tier of each cluster supporting 38 elements and the lower tier of each cluster supporting 52 elements.

A flat tubesheet with a V-type support similar to that used at Grimethorpe is used to support the three tiered element clusters. The filter element clusters are surrounded by a cylindrical, alloy steel shroud similar to the one used at Grimethorpe. This shroud serves the same functions in the Tidd filter as in the Grimethorpe filter described above. The three tiered element clusters and surrounding shroud are housed in an internally insulated carbon steel vessel of $10 \mathrm{ft}$. in diameter and $44 \mathrm{ft}$. length. Figure 47 shows a general arrangement of the Tidd candle filter vessel.

The pulse air system at Tidd consists of an air compressor system, refrigerated air dryer, primary air accumulator tank, duplex air filters, secondary air accumulator tanks, dual Atkomatic solenoid pulse valves (presumably, one is a spare), and automated ball valves. The outlet of each pulse valve feeds three different pulse manifolds, each isolate with an automated ball valve. Only when the manifold is being pulsed is the automated ball valve opened; thus, one pulse valve can service three manifolds sequenced as desired. This feature allows for multiple usage of the very costly pulse valves. The automated ball valves also serve as shut off valves in case the pulse valve fails in the open position. The pulse air system used at Grimethorpe is almost the same configuration as that used at Tidd except each pulse valve supplied pulse air to one single manifold, and there were no automated ball valves downstream of the pulse valves.

\subsubsection{Pilot Plant Testing at Aachen, Germany}

The filter unit installed and tested at Aachen Technical University (RWTH) Aachen, Germany in 1988 and 1989 was a small unit with only six candle filter elements. The six candle filter elements tested were Diaschumalith type elements manufactured by Schumacher GmbH similar to those used at Grimethorpe but only 1 meter in length. The six candle filter elements where supported in a flat tube sheet and arranged in a circular pattern. The sealing of the candle filter element flange and the tubesheet was provided by a ceramic fiber gaskets and a weighted element retainer. This retainer was similar to the counterweighted venturi used at Grimethorpe except it had a straight bore. The candle filter vessel was made of carbon steel with internal refractory lining. The dirty flue gas entered the vessel below the filter elements and was directed upward to near the underside of the tube sheet by a center duct so that the dirty flue gas flowed downwards along the filter elements. This arrangement serves the same function as the peripheral baffle used in the Grimethorpe and the Tidd filters. That is, the filter cake dislodged from the elements falls into the cone shaped ash hopper section of the filter vessel aided by co-current flow of the dirty flue gases. 


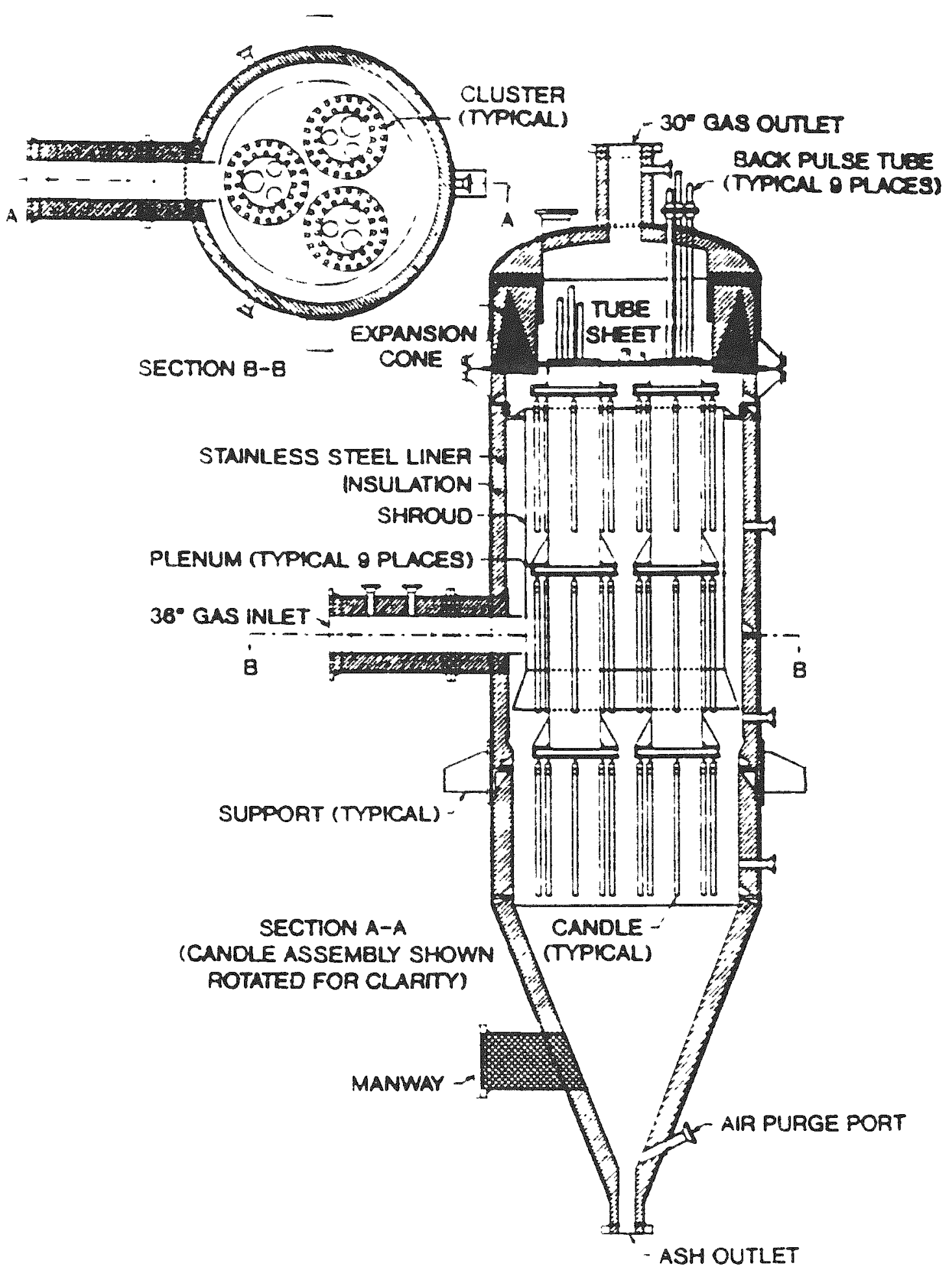

Figure 46 Candle Filter at Tidd ${ }^{5}$ 
The pulse air system for this filter consisted of a compressed air reservoir located above the filter vessel with a quick opening solenoid pulse valve connected to each of the six filter elements. In this filter each filter element was pulsed by a single solenoid pulse valve; unlike, the Grimethorpe and Tidd filters were multiple filter elements are pulsed by a single solenoid pulse valve. Literature ${ }^{6.7}$ on the design and performance of this filter provided background information that was useful in confirming pulse air pressures and capacities.

\subsubsection{Candle Filters With Vacuum Formed Ceramic Fiber Components}

In the three candle filter units discussed above, a non-cooled, alloy steel tube sheet supports candle filter elements made of hard sintered ceramic materials. Most of the candle filter units tested and reported in the literature to this date, have used this same approach. In addition to their work on these types of filters described above, Industrial Filter \& Pump Mfg. Co. (I.F.\& P.) of Cicero, Illinois is developing candle filter designs using lightweight vacuum formed ceramic fiber components. In these designs, the components such as the tubesheet, and the candle filter elements are made of vacuum formed ceramic fiber materials which are lightweight and suitable for high temperature serice $^{8}$ according to I.F.\& P. It is also proposed to incorporate the pulse air distribution system into the vacuum formed hold-down plate. One possible candle filter arrangement uses a steam cooled alloy steel tubesheet and components, such as candle elements and element hold-down plates, made from lightweight vacuum formed ceramic fiber materials. While use of ceramic fiber filter elements and components is an intriguing, and potentially inexpensive, alternative to other more conventional designs, there is limited information on large scale design, testing and performance of candle filters using these components. Information provided by I.F.\& P. in other areas of more traditional candle filter design was useful in confirming other aspects of the commercial approach.

\subsection{Conceptual Candle Filter Designs}

In our literature search, design variables and potential configurations for candle filters were identified. The most critical design variable was filter face velocity, expressed in $\mathrm{ft} / \mathrm{min}$ (or $\mathrm{cm} / \mathrm{sec}$ ). This is the average velocity at which the process gas approaches the candle filter elements. Although a data base is forming, there are considerable, and varying, opinions on this variable.

Ash from the process collects on one side of the filter element. Periodically, the ash is removed by back flushing with a high pressure pulse of air or gas. The amount of pulse air, or gas, needed to clean each filter element is another important design parameter. There in quite a divergence between early design values, lab measured quantities, and field measured quantities. This flow is significant because it lowers the process gas temperature, can be a source of heat loss, and requires equipment of considerable capital cost. The number of filter elements that can be back-pulsed by singlemanifold is another difficult tradeoff. A large quantity of filter elements serviced by a single manifold results in fewer manifolds and a less bulky supply system. The drawback is in attenuation of the air or gas pulse as it is spread through a higher volume 
manifold. Intuitively, this will result in a higher pulse volume required because of the pulse energy is dissipated. The capacity of available pulsing valves is also a practical limit. Other design parameters can also have a profound effect on the filter design. These are: Filter element size, filter element spacing, and pulse gas pressure.

There is similarity between some ceramic candle filters arrangements and industrial baghouses. Filter elements in both devices are tubular in nature and are supported by a structural plate separating the dirty gas plenum from the clean gas plenum. In baghouses, flexible cloth bags are held in a tubular shape by internal metal cages. Candle filter elements have the tubular structure built into the ceramic matrix. Ash buildup on the filter elements in both devices is removed by a reverse flow of gas. In "pulse jet" baghouses as in candle filters, the reverse flow of gas is generated by quick blasts of high pressure air. Pulse air distribution systems for baghouses are similar to those used in some candle filter pilot plant facilities. There is, although, a difference in the effect of the pulse air in a baghouse bag and in a candle filter element; since, the baghouse bag flexes and the ceramic candle remains essentially rigid.

The design parameter known as face velocity for candle filters is the same as the industrial baghouse filter design parameter known as air-to-cloth ratio. In the baghouse industry, this parameter is calculated by dividing the inlet gas flow in actual cubic feet per minute (acfm) by the area of filter cloth in square feet $\left(\mathrm{ft}^{2}\right)$. The result is the velocity of the gases approaching the filter bags in $\mathrm{ft} / \mathrm{min}$; which is the same as face velocity. For baghouses, the air-to-cloth ratio is based on the application. Users and manufactures have collected a vast amount of data to set this parameter. The value typically varies between baghouse manufactures. It is sometimes specified by the user.

\subsubsection{Candle Filter Specification}

Using information from current documents on candle filter technology, a mechanical design specifications was prepared for the commercial size, ceramic candle filter. Design guidelines from test filters were used directly or extrapolated to commercial size. Some of the candle filter design features were pushed beyond the tested limits on the assumption that these parameters could eventually be achieved. This specification forms the foundation for the commercial candle filter design.

- Candle Filter Elements: Although the candle filter tubesheet can be designed to accept any filter element, for the purpose of costing the filter, a description is needed. The most common filter element is a two layer element of silicon carbide with overall length of 1.5 meters and outside diameter of $60 \mathrm{~mm}$. Elements of these same dimensions and materials were used in the candle filters at Grimethorpe ${ }^{2}$ and Tidd $^{5}$. These elements are commercially available from manufacturers in thicknesses of $10 \mathrm{~mm}$ and $15 \mathrm{~mm}$. The outer layer of silicon carbide is made from fine material, for filtration, with a mean pore size of 22-30 micron (Grade 5-10). The inner layer of course material adds structural rigidity. Mean pore size is 125 micron (Grade 50 ). Quotes were received based on this description. 
- Filter Face Velocity: After a literature search and subsequent review by the Morgantown Energy Technology Center, we used a face velocity of $10 \mathrm{ft} / \mathrm{min}$ for the CPFBC filter (oxidizing atmosphere) and $5 \mathrm{ft} / \mathrm{min}$ for the carbonizer and gasifier filters (reducing atmospheres). For all filters, the particulate loading is fairly high at 4000 ppmw for the CPFBC filter, 10,000 ppmw for the carbonizer filter and $8500 \mathrm{ppmw}$ for the gasifier filter. Face velocity has to be balanced against pulse requirements. Filter face velocities used in other filter testing are listed in Table 26.

- Spacing of Elements on Tubesheet: Based mainly on the information published on the candle filter used at Grimethorpe, a $43 / 8^{\prime \prime}$ center to center spacing was used ${ }^{2}$. Although filter elements were spaced on a square, non-staggered, pattern at Grimethorpe, we found that a staggered patten resulted in a more efficient use of the available space on the tubesheet. Six open lanes were included on each tubesheet, giving them a pie-shaped pattern, so gas could penetrate to the central filter elements.

- Number of Elements per Pulse: Not more then 15 filter elements are pulsed at once. This is based mainly on industrial baghouse practice. There is a limit on how far a gas pulse can be spread before it dissipates. To keep the amount of pulse gas to a minimal amount, we felt it would be best to mimic the pulse distribution practice used in similar equipment. To confirm this selection, we verified that the flow capability of the pulse valve chosen would be adequate. At Grimethorpe, the test filter had 10-13 filter elements per pulse ${ }^{2,4}$. Industrial Filter \& Pump proposes pulsing up to 36 filter elements with a single pulse valve ${ }^{10}$. At Tidd, it is proposed to pulse up to 52 candles with a single pulse valve $^{5}$. Some more development is needed in this area as it would simplify the candle filter to utilize fewer parallel pulse paths.

- Pressure of Pulse Gas: The pulse gas system for each candle filter application was designed to supply pulse gas at pressures that range from 100 psi $(7 \mathrm{Bar})$ to a maximum of $300 \mathrm{psi}$ (21 Bar) above filter pressure. This is based on our literature search regarding testing of candle filter pulse systems. At Grimethorpe, the pulse pressure was 20 bar (290 psi) over system pressure mainly to improve operation of the pulse valves ${ }^{4}$. The Department of Energy at the Morgantown Energy Test Facility tested at 13.8 bar (200 psi) above filter pressure. pressure $^{7}$. I.F.\& P. proposes 6-8 bar (87-116) above filter pressure ${ }^{10}$. At Tidd, compressor capability is 1500 psig for a 150 psig filter system ${ }^{5}$. A pulse gas pressure of 100 psi over filter pressure is considered normal pulse gas system operating pressure for this report and this pressure is shown on the process flow sheets for each candle filter application but the pulse gas pressure can be adjusted upward to the maximum design value as needed. This flexibility is needed due to possible changes in the properties of the ash cake that may effect the cleaning of the candle filter elements.

- Pulse Valves: Use 2" Atkomatic quick opening, pilot actuated solenoid valves; with actuated, quick closing ball valves as a safety shutoff valve downstream of solenoid valve. 
Table 26 Filter Face Velocities

\begin{tabular}{|c|c|c|}
\hline Test Site & $\begin{array}{l}\text { Face Vel. } \\
\mathrm{ft} / \mathrm{min}\end{array}$ & Notes \\
\hline Grimethorpe $^{4}$ & $2.0-13.8$ & \\
\hline Grimethorpe $^{4}$ & 11.8 & longest Test, $230 \mathrm{hrs}$ \\
\hline RWTH Aachen ${ }^{7}$ & $7-19$ & 3700 test hours \\
\hline DOE/METC ${ }^{9}$ & 13 & single element \\
\hline I F \& $P^{10}$ & $15-28$ & recommendation \\
\hline Wakamatsu, Japan ${ }^{11}$ & $11.9-16.7$ & \\
\hline KRW Gasifier ${ }^{12,13}$ & $1.5-5.2$ & $\begin{array}{l}\text { gasification } \\
\text { conditions }\end{array}$ \\
\hline \multicolumn{3}{|c|}{ Commercial Filter Study: } \\
\hline CPFBC Filter & 10 & oxidizing atm. \\
\hline Carbonizer Filter & 5 & reducing atm. \\
\hline Gasifier Filter & 5 & reducing atm. \\
\hline
\end{tabular}

At this time the Atkomatic valve is the most widely used pulse valve in candle filter service. Atkomatic pulse valves have been reported to have been used at the Grimethorpe filter ${ }^{4}$ EPRI tier filter ${ }^{14}$, and the Tidd filter ${ }^{5}$.

Several solenoid valve manufacturers were contacted regarding quick opening solenoid valves suitable for high pressure service (450-750 psig) as a pulse valve on a candle filter. The pulse valve is required to open and close in one second or less. The only company identified to date that manufactures this type of valve in the required 2 " size is the Atkomatic Valve Company of Indianapolis, IN. Atkomatic has a standard valve that meets the requirements identified for a candle filter pulse valve. It is rated to $400^{\circ} \mathrm{F}$. Because these valves are expensive, one solenoid actuated valve is utilized to service three pulse air manifolds. These manifolds are isolated by automated ball valves.

- Pulse Air Element Venturi: The fixture we proposed to hold the filter element does not include a venture; although, to add one would not increase the cost substantially. 
- Tubesheet and Tubesheet Support Design: The intent was to choose the most economic tubesheet design. Various sizes and shapes were considered, including: thick, flat tubesheets; thinner, braced, flat tubesheets; and spherical segments. Single tubesheets were compared with tiered tubesheets. A "V-type" support similar to that used at Grimethorpe $e^{4}$ and Tidd ${ }^{5}$ was considered, but this limited the tubesheet diameter. Another design was chosen based on results of finite element analysis that was not as limited on diameter.

- Filter Element Sealing Material: Filter element sealing materials used in candle filter tests to date were reviewed. One type of candle element seal uses 3M Company "Interam" heat expanding type gasket material. This material is reported to have been used as the candle filter element gasket in candle filter test units by Industrial Filter \& Pump Mfg. $\mathrm{Co}^{15}$ and at the Department of Energy Morgantown Energy Test Facility ${ }^{9,16}$. The 3M Company was contacted for design information on "Interam" gasket material. Although this material is limited to use up to $1500 \mathrm{~F}$, we are assuming this material or one of similar cost and form will be suitable for use on a commercial size candle filter.

\subsubsection{Pulse Gas Requirements}

The pulse gas requirement for a candle filter depends on the application, face velocity, and desired pressure drop. Candle filter pressure drop varies considerably according to available sources. A review paper ${ }^{17}$ on high temperature, high pressure gas filtration states that the pressure drop across a ceramic barrier filter is expected to be 6 psi. A report on testing ceramic filter elements on a atmospheric fluidized bed ${ }^{14}$ relates a pressure drop of $0.75 \mathrm{psi}$. British $\mathrm{Coal}^{18}$ determined that the steady state permeance during three consecutive test periods for PFBC gas at $830^{\circ} \mathrm{C}$ was about $0.25 \mathrm{~m} / \mathrm{s} / \mathrm{bar}$. (Permeance is defined as the ratio of filtration face velocity to filter pressure drop.) Using this value of permeance, a $10 \mathrm{ft} / \mathrm{min}$ face velocity, used in the CPFBC filter, would cause a filter pressure drop of $2.92 \mathrm{psi}$ and a $5 \mathrm{ft} / \mathrm{min}$ face velocity, used in the carbonizer and in the gasifier filters, would cause a filter cake pressure drop of $1.46 \mathrm{psi}$. Added to this pressure drop would be the pressure drop from the flow through the filter housing and from the flow past the venturi. A limitation of Hudson data is that it does not account for the effect of pulse cleaning cycle time on filter pressure drop.

METC researchers ${ }^{9}$ collected data on the specific cake resistance, $K_{2}$, for ash from an atmospheric fluidized bed combustor. Specific cake resistance ranged from 33.0 to 40.7 (in $\mathrm{H}_{2} \mathrm{O} \mathrm{ft} \mathrm{min} / \mathrm{lb}$ ) for filter cakes formed from ash which had passed through a precollection cyclone. This data can be used to estimate the pressure drop through the cake for each application. The total pressure drop through the filter system is $50 \%$ of the pressure drop through the cake plus the pressure drop through the candle filter itself and through the filter housing. We used $50 \%$ of the cake resistance because filter elements are continuously being cleaned, and at any particular time, some filter elements have just been cleaned and some are ready to be cleaned. The steady state pressure drop through the cleaned filter for the two METC tests with pre-collection cyclones was about 75 IW at a face velocity of $13.1 \mathrm{ft} / \mathrm{min}$. If one assumes that the pressure drop through the cleaned filter is linearly proportional to the gas flow through the filter, the cleaned pressure drop through the filter can be calculated for the face velocities used in the the 
assigned applications. Table 27 summarizes parmeters used in estimating pulse air requirements for the CPFBC. For a specific cake resistance of 33 , the pressure drop is 2.7 psi.

Even less data is available on properties of filter cakes generated in a gasification environment. Texaco reports ${ }^{19}$ that their filter cakes had a high cake resistance, low cohesivity, and low density. Typical cleaning times for filter cakes from both the Texaco and the Shell process were about 5 minutes. Juhani Isaksson of Ahlstrom found that filter cakes from gasification processes have a permeability $1 / 3$ of cakes formed in a combustion process ${ }^{19}$. For the carbonizer and the gasifier, a specific cake resistance of 99 is used in the calculation results shown in Table 27. In order to keep the overall filter pressure drop less than 2 psi, the pulse gas cycle time is 8 minutes for the carbonizer and 6 minutes for the gasifier.

Based on the METC data, we designed the CPFBC filter for a pressure drop of 2.7 psi and the carbonizer and gasifier for a pressure drop of 2.0 psi. The results agree reasonably well with the data of Hudson.

As is the case for filter pressure drop, there is considerable variation reported in the quantity of pulse gas necessary to clean a filter element. Michael Durst of Schumacher ${ }^{19}$ indicated that $0.2 \mathrm{ft}^{3}$ of gas is required per element for pulse cleaning. An EPRI test on a atmospheric, tiered filter ${ }^{14}$, reported pulse gas quantities ranging from 0.2 to $0.76 \mathrm{ft}^{3}$ per pulse, with the pulse reservoir 4 bar above the filter pressure. The RWTH Aachen tests ${ }^{7}$ reported pulse gas quantities between 0.27 to $0.5 \mathrm{ft}^{3}$ with the pulse reservoir 4 bar above the filter pressure. Mattie Nieminen of the Technical Research Center of Finland found that a pulse reservoir pressure of 4 bar above filter pressure provided sufficient pressure in the pulse gas system. ${ }^{19}$ Researches at Grimethorpe ${ }^{3}$ report using $1.29 \mathrm{ft}^{3}$ of gas per pulse. As a design value CPC uses $0.40 \mathrm{ft}^{3}$ of pulse gas per element. Table 27 also shows the total quantity of pulse gas required for each application.

\subsubsection{Tubesheet/Support Specification}

A general specification for the tubesheets applied to the CPFBC and the carbonizer filter was prepared. This specification defined the commercial operating environment. Tubesheet operating conditions were described for the hot gas cleanup facility proposed for the second generation $\mathrm{PFB}$ combustion plant ${ }^{20}$. Although there are filters for the circulating pressurized fluidized bed combustor ( $\mathrm{CPFBC}$ ), the carbonizer, and the gasifier, only the CPFBC filter was analyzed based on this specification. The carbonizer filter and the gasifier filter are both smaller; the assumption was that it would be easier for conditions to be met in smaller sizes. Furthermore no operating conditions were given for the gasifier filter.

The hot gas filter vessels operate near $1600^{\circ} \mathrm{F}$ for the $\mathrm{CPFBC}$ and the gasifier, and near $1500^{\circ} \mathrm{F}$ for the carbonizer. The pressure inside these filters is around $200-400 \mathrm{psig}$ and the pressure vessel enclosures are protected by insulating refractory such that conventional design practices apply. 
Table 27 Candle Filter Pressure Drop/Pulse Gas Parameters

\begin{tabular}{|c|c|c|c|}
\hline Operating Parameter & $\begin{array}{l}\text { CPFBC } \\
\text { Filter }\end{array}$ & $\begin{array}{l}\text { Carbonizer } \\
\text { Filter }\end{array}$ & $\begin{array}{l}\text { Gasifier } \\
\text { Filter }\end{array}$ \\
\hline Plant Capacity, MWe & 226 & 226 & 100 \\
\hline Gas State & Oxidizing & Reducing & Reducing \\
\hline Gas Flow, $1 \mathrm{~b} / \mathrm{hr}$ & $2,644,236$ & 244,650 & 312,800 \\
\hline Gas Flow, acfm & 175,800 & 15,800 & 12,600 \\
\hline Ash Loading, ppmw & 4,000 & 10,000 & 8,500 \\
\hline Face Velocity, fpm & 10 & 5 & 5 \\
\hline No. of Elements & 6,288 & 1,130 & 906 \\
\hline $\begin{array}{l}\text { Specific Cake Res., } \\
\text { in } \mathrm{H} 20 \mathrm{ft} \mathrm{min} / \mathrm{lb}\end{array}$ & 33 & 99 & 99 \\
\hline $\begin{array}{l}\text { Pulse Gas Rate } \\
\text { acf/Pulse/Element } \\
\text { Cvcle time }\end{array}$ & 0.40 & 0.40 & 0.40 \\
\hline $\begin{array}{l}\text { psi } \\
\text { pulse Gas Density th/cf }\end{array}$ & 2.66 & 1.96 & 1.99 \\
\hline $\begin{array}{l}\text { Pulse Gas Density, } 1 \mathrm{D} / \mathrm{cr} \\
\text { at Operating Cond. } \\
\text { Pulse Gas Rate }\end{array}$ & 0.969 & 0.948 & 1.61 \\
\hline lb/pulse/element & 0.39 & 0.38 & 0.64 \\
\hline $\begin{array}{l}\text { Pulse Gas Rate } \\
\mathrm{lb} / \mathrm{hr} \\
\% \text { of Filter Gas Flow }\end{array}$ & 13,628 & 2,995 & 5,410 \\
\hline $\begin{array}{l}\text { percent } \\
\text { Pulse Gas Pressure, psia }\end{array}$ & 0.52 & 1.22 & 1.73 \\
\hline (100 psi above filter) & 290 & 308 & 485 \\
\hline
\end{tabular}

The tubesheet support provides the transition between the hot tubesheet and the cold pressure vessel shell. For heat transfer purposes, the tubesheets operate at 1500$1600^{\circ} \mathrm{F}$ and environment external to the pressure vessel is $70^{\circ} \mathrm{F}$.

Because of the high temperature environment, design of the tubesheet support is sensitive to the elevated temperature properties of the selected materials of construction. A suitable material must be able to withstand extended exposure to temperatures in the thermal creep domain and to withstand creep-fatigue damage due to temperature cycling. 
Information on the thermal transients is taken from the report on the second generation PBFC where available, and supplemented by information prepared for the 70-MWe Tidd PFBC Demonstration Plant located in Brilliant, Ohio $^{21}$. The material of construction for the CPFBC filter tubesheet is RA333, and for the carbonizer and gasifier tubesheet, RA85H stainless steel.

The tubesheet is not within the scope of the ASME Code. However, the design, analysis, and construction philosophy of Section VIII, Division 2 of the Code was applied, supplemented by appropriate elevated temperature design rules.

Transient and steady state thermal analysis, and linear and nonlinear structural analysis were considered using finite element analysis techniques. Design criteria based upon nonlinear analysis was used in evaluating the adequacy of the tubesheet. An erosion/corrosion allowance of $1 / 8$ " was assumed for the CPFBC tubesheet.

In Table 28, tubesheet design conditions are summarized. A design life of 100,000 hours was chosen to allow the CPFBC tubesheet a nominal 20 year life. This is based on the projected operating hours per year and capacity factor proposed for the second generation PFBC plant. The number of heatups, cooldowns, and load change transients is increased from that projected for a mature, commercial facility to assure a reasonable conservative design.

In Table 29, the load change transient temperatures and flows are those reported for the second generation PFBC. The rate of change of $2 \%$ per minute comes from the Tidd study, since there is no information on this subject for the second generation PFBC. The temperature change due to load change is minimal.

Figure 47, the heat-up transient ${ }^{22}$, is based on actual start-up data from the Tidd Plant. A gas turbine trip, while recognized as a transient, is not defined for the second generation PFBC and was not included in this analysis. While the report on the second generation PFBC does not include this level of detail, there is a statement that heating rates will be controlled to $200-300 \mathrm{~F} / \mathrm{hr}$ based on refractory limitations. This limitation also applies to refractory cooling rates. The heat-up rate shown for Tidd on Figure 47 exceeds this limit during some intervals, and in general, but is a reasonable and conservative estimate as far as the tubesheet is concerned. Controlled cooldown can be assumed to occur at rates less than $300^{\circ} \mathrm{F} / \mathrm{hr}$; so for the purpose of this study, we assume $300 \mathrm{~F} / \mathrm{hr}$.

This specification for the tubesheet operation basically defines long term operation as the governing design criteria. Load change transients do not create enough of a temperature change to be significant. There are not enough start-ups in the life of the plant to make thermal fatigue a factor. The analysis, therefore, keys on limits to rupture, creep, and yield stresses at temperature. 
TABLE 28 Tubesheet Design and Operation Conditions

\section{Design Conditions}

Life, hours

Temperature, ${ }^{\circ} \mathrm{F}$

Pressure, psig

Tubesheet Pressure Differential, psi

\section{Operating Conditions}

Temperature, ${ }^{\circ} \mathrm{F}$

Pressure, psia

Heatups \& Cooldowns

Load Change Transients (100-50-100\%) (See Table 29)

Gas Turbine Trip Transient

Tubesheet Pressure Differential

- Normal, psi

- Commence Pulse Cleaning, psi
CPFBC

100,000

1600

200

3

\section{6-1596 \\ 145-186}

30 first 2 years 100 each 10 years

40 first year $30 /$ year thereafter

1 per year

1

3

\section{Carbonizer}

30,000
1500
218
3

1403-1488

$160-206$

30 first 2 years 100 each 10 years

40 first year $30 /$ year thereafter

1 per year

1

3
Source

1

2

2

3

2

2

$1 \& 2$

$1 \& 2$

$1 \& 2$

3

3

3

Off Normal or Other Mechanical Loads

Non Considered

Sources: 1 - Combustion Power, 2 - Second Generation PFBC report, 3 - Tidd study. 
Table 29 Tubesheet Load Change Transients" (100-50-100)

\begin{tabular}{llll}
\hline Firing & Pressure & Temp & \multicolumn{2}{c}{ Gas Flow } \\
Rate & (psia) & $\left({ }^{\circ} \mathrm{F}\right)$ & $(\mathrm{lb} / \mathrm{hr})$ \\
& & & \\
\hline
\end{tabular}

CPFBC Filter Inlet Conditions

$\begin{array}{ccccc}100 & 186.2 & 1596 & 661,059 & 43,950 \\ 50 & 145.7 & 1546 & 642,938 & 41,705\end{array}$

Carbonizer Filter Inlet Conditions

$\begin{array}{ccccc}100 & 206.3 & 1488 & 244,650 & 15,800 \\ 50 & 160.1 & 1403 & 80,216 & 4,955\end{array}$

* For load change transient, assume a change of $2 \%$ (firing rate) per minute between the above listed conditions. Sufficient time between transients shall be allowed for temperature equilibrium to be reached.

\subsubsection{Tiered vs. Single Tubesheet}

A tiered tubesheet contains multiple levels of candle filter elements, such as that supplied at Tidd ${ }^{5}$. In this approach, the main tubesheet is structural in nature and typically contain no candle filter elements. The advantage is in packaging a large quantity of candle filter elements in a small diameter pressure vessel. Many types of supports have been proposed for support of candle filter tubesheets ${ }^{23}$. Some have undergone preliminary analysis, and some have undergone more detailed analysis. The design utilized most, to date, is the V-type support. Because of structural limitations, the $\mathrm{V}$-support it is limited in diameter to 8-10 ft. Therefore tiered candle filters are characterized by a fairly elaborate alloy metal structure to arrange the filter elements in multiple levels. Pulse piping and manifolds must be built into this structure. This complicates access for inspection, maintenance, modifications, and repairs.

A single tubesheet design, such as that tested at Grimethorpe is similar in arrangement to an industrial baghouse. All filter elements are installed in the same tubesheet and the pulse system is installed on top of the tubesheet. Access to the top of the tubesheet is easily arranged for direct inspection and maintenance of filter elements and pulse components. Limitation on the diameter of the tubesheet support is the major drawback. With a workable alternative, large diameter tubesheets could be built and, according to our estimate, a less expensive candle filter system could be proposed. 


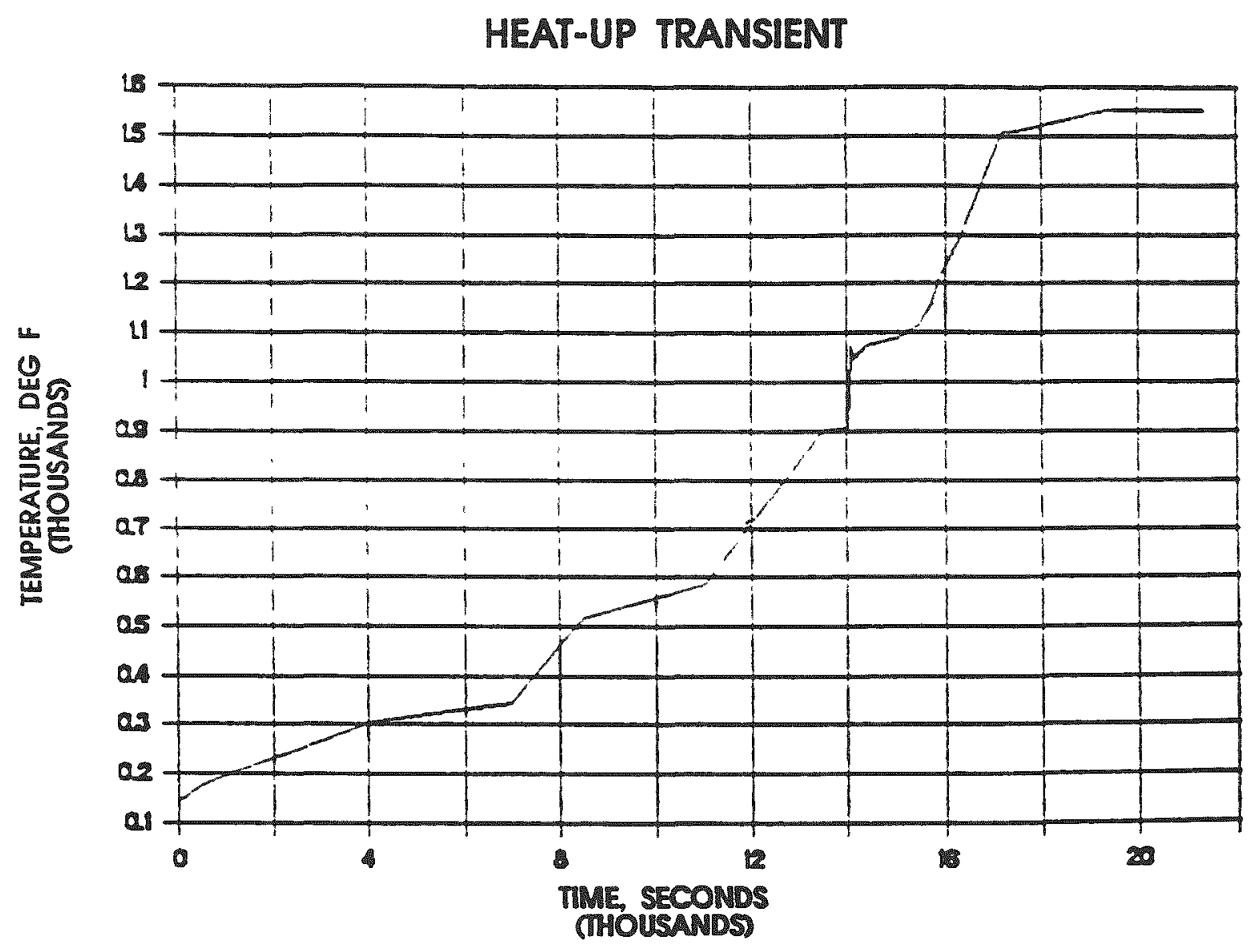

Figure 47 Heat-up Transient, Commercial Design ${ }^{22}$ 


\subsubsection{Tubesheet/Support Structural Analysis}

Allowable stress levels in the tubesheet and tubesheet support were found to be based on isothermal operation, as opposed to repeated thermal transients. This is because operating philosophy for commercial plants minimizes start-ups, and load changes for the assigned combustion and gasification processes are not accompanied by wide temperature changes. Therefore, thermal fatigue is not expected to be a limiting factor. During operation, primary stresses depend on the pressure drop across the tubesheet, but are offset by the weight of the tubesheet plus the candle filter elements. During a hot shutdown, the tubesheet and tubesheet support must support its weight. Primary stresses at $1500-1600^{\circ} \mathrm{F}$ must be low; $600-2500$ psi depending on the material choice. This is dictated by guidelines influenced by the ASME Boiler Code. Since creep and stress rupture govern the design at these high temperatures, the Code recommends that the maximum allowable stress value for materials must not exceed the lowest of the following:

- $100 \%$ of the average stress to produce a creep rate of $0.01 \%$ in 1000 hours at use temperature.

- $67 \%$ of the average stress to cause rupture at the end of 100,000 hours.

- $80 \%$ of the minimum stress to cause rupture at the end of 100,000 hours.

In the case of the tubesheet and support where finite element analysis is utilized, the guidelines for minimum allowable stress in elastic analysis were somewhat broadened. The membrane stress intensity at all parts of the component due to pressure and dead weight were not to exceed the lower of 1) $90 \%$ of the tabulated yield strength at the average temperature of the cross section for the average strain rate of the loading, and 2) $100 \%$ of the tabulated $S_{\mathrm{mr}}$ value at the average temperature of the cross section and for a time duration equal to the total duration of this loading/temperature combination. Under these guidelines, $S_{\mathrm{mt}}$ is the lower of one-half the ultimate strength, two-thirds the mininum value to cause rupture, or the average stress for 1\% creep. At temperatures in the creep range, stress-rupture or creep governs the allowable stress. This criteria allows the choice of design life; although, for CPFBC tubesheet analysis, 100,000 hours was chosen as suggested by the ASME Boiler Code. The other criteria utilized to assess the design of the internals was the value of the membrane plus bending stress. This stress at all parts of the component due to pressure and dead weight loadings was not allowed to exceed the lower of 1) $135 \%$ of the tabulated yield strength at the average temperature of the cross section for the average strain rate of the loading, and 2) $110 \%$ of the tabulated $S_{\mathrm{m}}$ value at the average temperature of the cross section and for a time duration equal to the total duration of this loading/temperature combination. $S_{\mathrm{mt}}$ is defined above, and was chosen based on a time duration of 100,000 hours. In addition to the above criteria, which sets limits to the primary stresses, a limit was set for the primary-plus-secondary stresses. Secondary stresses are those caused by thermal expansion. This limit was the yield strength at temperature. For these criteria, the limit for membrane stress due to pressure and dead weight for Rolled Alloys, RA333 at $1600^{\circ} \mathrm{F}$ for 100,000 hours operation is about 950 psi. The ASME Boiler Code limit is about $30 \%$ higher. For membrane plus bending stress due to pressure and dead weight, the limit is 
about 1050 psi for RA333 at $1600^{\circ} \mathrm{F}$ for 100,000 hours operation. The limit for primaryplus-secondary stresses is about 17,800 psi for RA333 at $1600^{\circ} \mathrm{F}$.

First analyzed was an $18^{\prime}$ diameter tubesheet formed from $2^{\prime \prime}$ thick flat plate reinforced by ribs perpendicular to the plate. Material assumed was RA333. It appeared that by manipulation of the reinforcing rib design, that this approach could meet the stress criteria. The other tubesheet configuration considered was a segment of a sphere. This configuration was analyzed only at the connection to the tubesheet support. The spherical segment is well suited for pressure containment and is a very stable shape at high temperature; it will inherently resist deformation if its temperature is uneven. Preliminary calculations indicated that a flat plate, stiffened to maintain the same stress level, could weigh more than twice that of the spherical segment. A few shops in the USA were approached about building a spherical segment up to $18^{\prime}$ diameter and; since this is similar to a pressure vessel head, we found that was feasible.

The "V" type support similar to that utilized at Grimethorpe and Tidd was analyzed in an 18' diameter configuration. At the steady state temperature conditions that govern the commercial design, primary and primary-plus-secondary stresses exceeded the design criteria. Modifications to the " $\mathrm{V}$ " type support were made to lower stresses to acceptable levels. A conical type support was also analyzed using similar modifications, and found to have acceptable stresses. Although these calculations were only made for RA333 material, it was assumed that a similar approach would be feasible for smaller diameter tubesheet supports in other materials, such as RA85H.

The analysis made was preliminary as described, and did not take all criteria into account. In a detailed design other details must be considered. Welding must be sound from standpoint of strength and corrosion. Other items to consider are metal toughness, creep, creep fatigue, thermomechanical fatigue, and all types of corrosion, both low and high temperature.

\subsubsection{Preliminary Cost Comparisons}

Early in our design effort it became apparent that a CPFBC candle filter module for 226 MWe would require more filter vessels then the two proposed for the cross-flow filters in the Foster Wheeler study ${ }^{20}$. Assuming a single tubesheet approach, we considered candle filter vessels of two different diameters: first a larger diameter vessel that would require four candle filter vessels for a 226 MWe CPFBC module, and second, a smaller diameter vessel that would require use of eight candle filter vessels for a 226 MWe CPFBC module. We found that while the smaller vessels needed thinner vessel walls, which relates to less weight and less cost, the smaller vessels also had increased surface area that meant additional costs for refractory. When the cost for the alloy metal tubesheets and baffles where added, it was found that there was little or no cost advantage of having eight smaller diameter vessels verses four larger vessels. On the other hand, an eight vessel module incurred additional complication, and cost, for the process gas ducting and the ash discharge system. Consequently, the base configuration chosen for CPFBC candle filters was a four filter vessel module for 226 MWe capacity. 
A cost estimate for a tiered candle filter module for 226 Mwe capacity was prepared based on the candle filter installed at Tidd. The Tidd candle filter vessel contains a total of 384 elements supported by three plenums with each plenum containing 128 elements on three different tiered levels. The lower level of each plenum contains 52 elements ( 156 total elements for lower level of three plenums) while each of the two higher levels contain 38 elements per plenum (114 elements total for each upper level of three plenums). For our cost estimate we added four additional upper tier levels by lengthening the vessels and plenums so that a total of eight (8) Tidd style vessels with seven (7) levels of tiers (one lower and 6 upper tiers) contained the required number of elements needed for a $226 \mathrm{MWe}$ CPFBC module (6288). When the costs for carbon steel pressure vessels, alloy metal internals, and refractory where compared with four, larger diameter, single tubesheet vessels, it was found that the single tubesheet configuration was about two-thirds the cost of the tiered configuration. The majority of the cost difference is in the value of the alloy metal internals that make up the tubesheet, tubesheet support, plenums and baffle. The savings in carbon steel pressure vessels costs, for the smaller tiered vessels, are overshadowed by the much higher costs of the alloy metal internals. It was concluded from this excersize that a large, single tubesheet configuration was the least cost alternate for a candle filter.

\subsection{Preliminary Design of Candle Filters}

\subsubsection{Process Description}

The candle filter configuration shown on Figure 48 is based on utilizing the largest tubesheet possible. All filter elements are attached to the tubesheet to simplify the filter element layout and the pulse gas piping. In this configuration, filter elements can be inspected and maintained from inside the filter vessel.

Hot process gases and particulate enter at a single port on the side of the vessel below the tubesheet and, are distributed by a cylindrical baffle around the outer edge of the candle filter array near the upper end of the filter elements. The particulate loaded gases pass through the filter elements leaving the particulate on the outside surface of the filter elements in the form of an ash cake. The clean process gases enter the inside of each candle filter element, collect in the chamber above the tubesheet, and exit through an outlet port. The ash cake collected on the outside surface of the elements is dislodged by periodic high pressure bursts of pulse gas. For filters in oxidizing atmospheres, air is used for pulse cleaning of the filter elements. For filters in reducing gas environments, either process gas or nitrogen may be used for pulse gas. The ash cake dislodged from the filter elements is collected in the conical hopper below the tubesheet and is discharged into a suitable ash handling system. In the gasifier filter, the ash is first cooled using a water-cooled screw and then depressurized through lock-hoppers. In the CPFBC system, the ash is depressurized through a restricted pipe discharge (RPD) vessel as proposed in the Foster Wheeler study ${ }^{20}$ and then cooled using a water-cooled screw. In the carbonizer, the hot pressurized ash is used directly in another operation.

Filter elements are 1.5 meters long, $60 \mathrm{~mm}$ outside diameter and made with two layer construction to minimize the possibility for ash to penetrate into the ceramic matrix. 


\subsubsection{Process Flow for CPFBC Candle Filter}

Each of the two CPFBC's has a filter module composed of four candle filter vessels. Each filter vessel has an inside refractory diameter of $20^{\prime}-6^{\prime \prime}$ and tubesheet diameter of $18^{\prime}-0^{\prime \prime}$. The inlet gas flow to each filter vessel is $657,652 \mathrm{lb} / \mathrm{hr}$ at $1600^{\circ} \mathrm{F}$ and 187.70 psia. This inlet gas flow is slightly lower then for the CPFBC granular-bed filters by the amount of pulse air added to the CPFBC candle filters. This allows for equal outlet gas flow for the candle filter module and the granular-bed filter module; since, the granularbed filter process does not require any appreciable amounts of additional gases. The ash concentration in the inlet gas stream is $4,000 \mathrm{ppmw}$. A filter face velocity of $10 \mathrm{ft} / \mathrm{min}$ was specified for the CPFBC filter. The filter pressure drop is calculated to be $2.66 \mathrm{psi}$ (74 IW) based on a $0.40 \mathrm{ACF} /$ Pulse/Element pulse gas flow rate and a pulse cycle time of every 10 minutes as presented in sections 4.2 .1 and 4.2.2. Figure 49 shows the process flow sheet for the CPFBC candle filter.

The process gas temperature drop through the filter is $12^{\circ} \mathrm{F}$. This temperature drop is due to both radiation heat loss through the shell of the filter and dilution of the process gases by the cooler pulse air. Heat loss calculations for the CPFBC candle filter are shown in Appendix B.

Pulse air for cleaning the candle elements is $13,628 \mathrm{lb} / \mathrm{hr}$ for the four filter module serving each 226 MWe CPFBC module. This pulse air supply is taken from the outlet stream of the transport air boost compressor at $176^{\circ} \mathrm{F}$ and 267.60 psia. This pulse air is precooled, compressed, aftercooled, dried and filtered before being supplied to the pulse air reservoirs 290 psia or approximately 100 psi above the candle filter internal pressure. Pulse air at a pressure of 100 psi above the candle filter pressure is considered a normal operating pulse air pressure for this study. The pulse air compressor system is designed to supply compressed air at up to $300 \mathrm{psi}$ above filter pressure or $490 \mathrm{psia}$. This ability to supply higher pressure pulse air may be needed for proper cleaning of the candle element depending on the properties of the ash cake.

Ash from two of the each four filter vessel module is collected in a small candle filter ash vessel. There are two candle filter ash vessels per CPFBC module. From the outlet of each candle filter ash vessel, the ash is depressurized through a restricted pipe discharge (RPD) vessel as it enters the same ash handling equipment proposed for the candle filter in the Foster Wheeler study ${ }^{20}$. The depressurized ash from each of the two RPD vessels per CPFBC module is combined in an ash collecting hopper. The outlet of the ash collecting hopper is split into two streams each feeding the inlet of ash screw coolers. Each ash screw cooler is sized for $100 \%$ ash capacity from a 226 MWe CPFBC module as proposed in the Foster Wheeler study. This allows for 100\% backup of ash screw coolers at design ash rates. If both cooling screws are operated, this also allows for cooling of increased ash loads in the event of reduction of CPFBC cyclone collection efficiency. 


\subsubsection{Process Flow for Carbonizer Candle Filter}

The candle filter for the carbonizer on each of the two CPFBC's has a single filter vessel in which the refractory inside diameter is $18^{\prime}-0^{\prime \prime}$ and the tubesheet diameter is $15^{\prime}$ $6^{\prime \prime}$. The inlet gas flow to each filter vessel is $244,650 \mathrm{lb} / \mathrm{hr}$ at $1500^{\circ} \mathrm{F}$ and $207.90 \mathrm{psia}$. The ash concentration in the inlet gas stream is $10,000 \mathrm{ppmw}$. A filter face velocity of $5 \mathrm{ft} / \mathrm{min}$ was specified for the carbonizer. The filter pressure drop is calculated to be 1.96 psi (54 IW) based on a $0.40 \mathrm{ACF} /$ Pulse/Element pulse gas flow rate and a pulse cycle time of every 8 minutes as presented in sections 4.2 .1 and 4.2.2. Figure 50 shows the process flow sheet for the carbonizer candle filter.

The process gas temperature drop through the filter is $27^{\circ} \mathrm{F}$. This temperature drop is due to both radiation heat loss through the shell of the filter and from the cooling of process gas that is reinjected into the filter as pulse gas. Heat loss calculations for the carbonizer candle filter are shown in Appendix B.

Pulse gas for cleaning the candle filter elements is $2,995 \mathrm{lb} / \mathrm{hr}$ total for each candle filter serving a CPFBC module. This pulse gas is recycled, clean process gas taken from the outlet of the carbonizer candle filter. The hot process gas is first cooled from $1474^{\circ} \mathrm{F}$ to $400^{\circ} \mathrm{F}$ using a simple fire tube boiler which produces low pressure saturated steam. The process gas is then further precooled, compressed, aftercooled, dried, and filtered before being supplied to the pulse gas reservoirs 307 psia or approximately 100 psi above the candle filter internal pressure. Pulse gas at a pressure of $100 \mathrm{psi}$ above the candle filter pressure is considered a normal operating pulse gas pressure for this study. The pulse gas compressor is designed to supply compressed process gas at pressures up to 300 psi above the filter pressure or 508 psia.

The ash collected by the carbonizer is returned to the second-generation fluidized bed process according to the Foster Wheeler study.

\subsubsection{Process Flow for KRW Gasifier Candle Filter}

The candle filter for the gasifier has a single filter vessel in which the refractory inside diameter is $16^{\prime}-6^{\prime \prime}$ and the tubesheet diameter is $14^{\prime}-0^{\prime \prime}$. The inlet gas flow to the filter vessel is $312,800 \mathrm{lb} / \mathrm{hr}$ at $1600^{\circ} \mathrm{F}$ and $385.00 \mathrm{psia}$. The ash concentration in the inlet gas stream is $8,500 \mathrm{ppmw}$. A filter face velocity of $5 \mathrm{ft} / \mathrm{min}$ was specified for the gasifier. The filter pressure drop is calculated to be 1.99 psi ( 55 IW) based on a 0.40 $\mathrm{ACF} / \mathrm{Pulse} /$ Element pulse gas flow rate and a pulse cycle time of every 6 minutes as presented in above sections 4.2 .1 and 4.2.2. Figure 51 shows the process flow sheet for the gasifier candle filter.

The process gas temperature drop through the filter is $31^{\circ} \mathrm{F}$. This temperature drop is due to both radiation heat loss through the shell of the filter and from the cooling of process gas that is reinjected into the filter as pulse gas. Heat loss calculations for the gasifier candle filter are shown in Appendix B. 


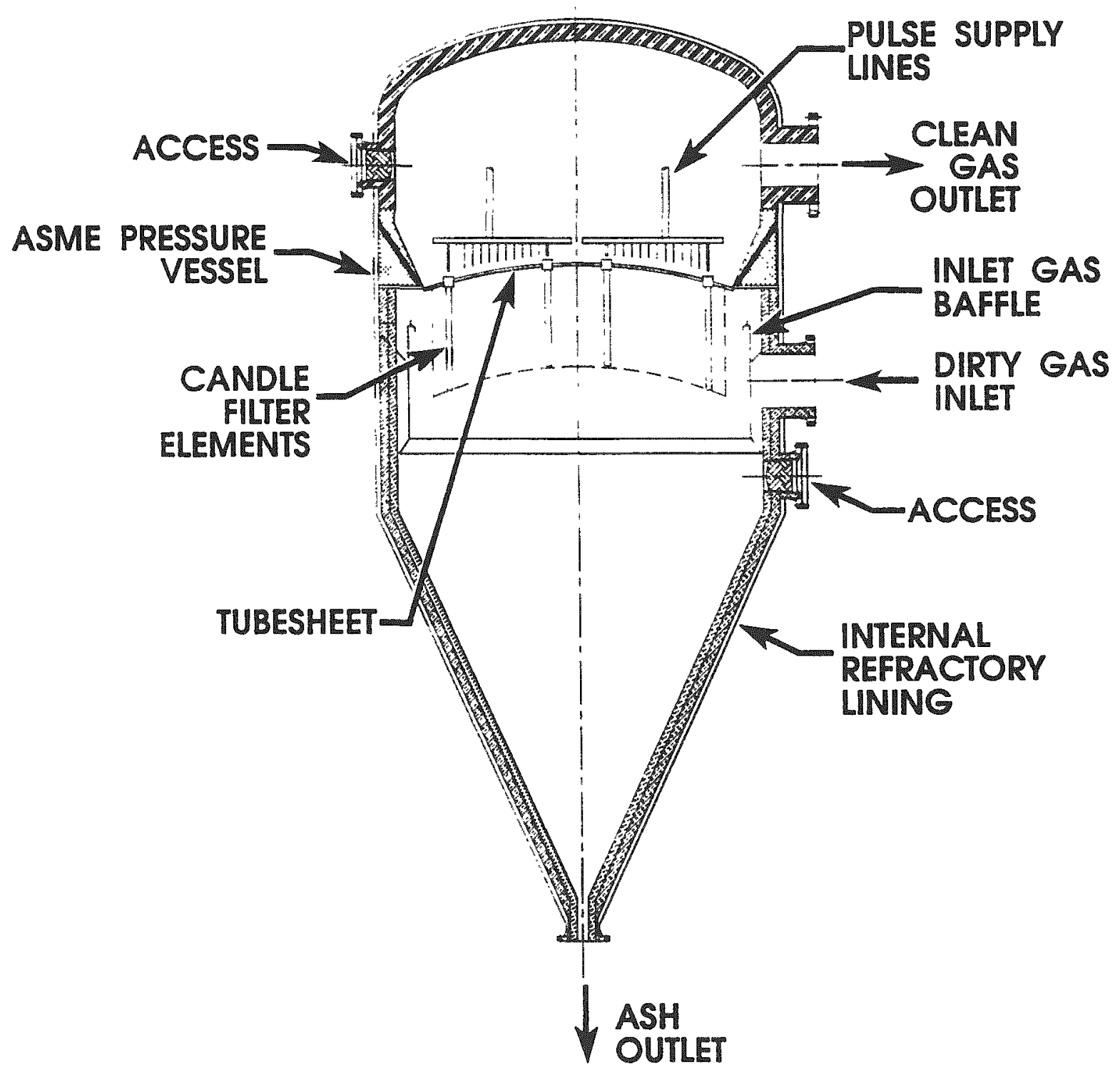

Figure 48 Candle Filter Configuration 


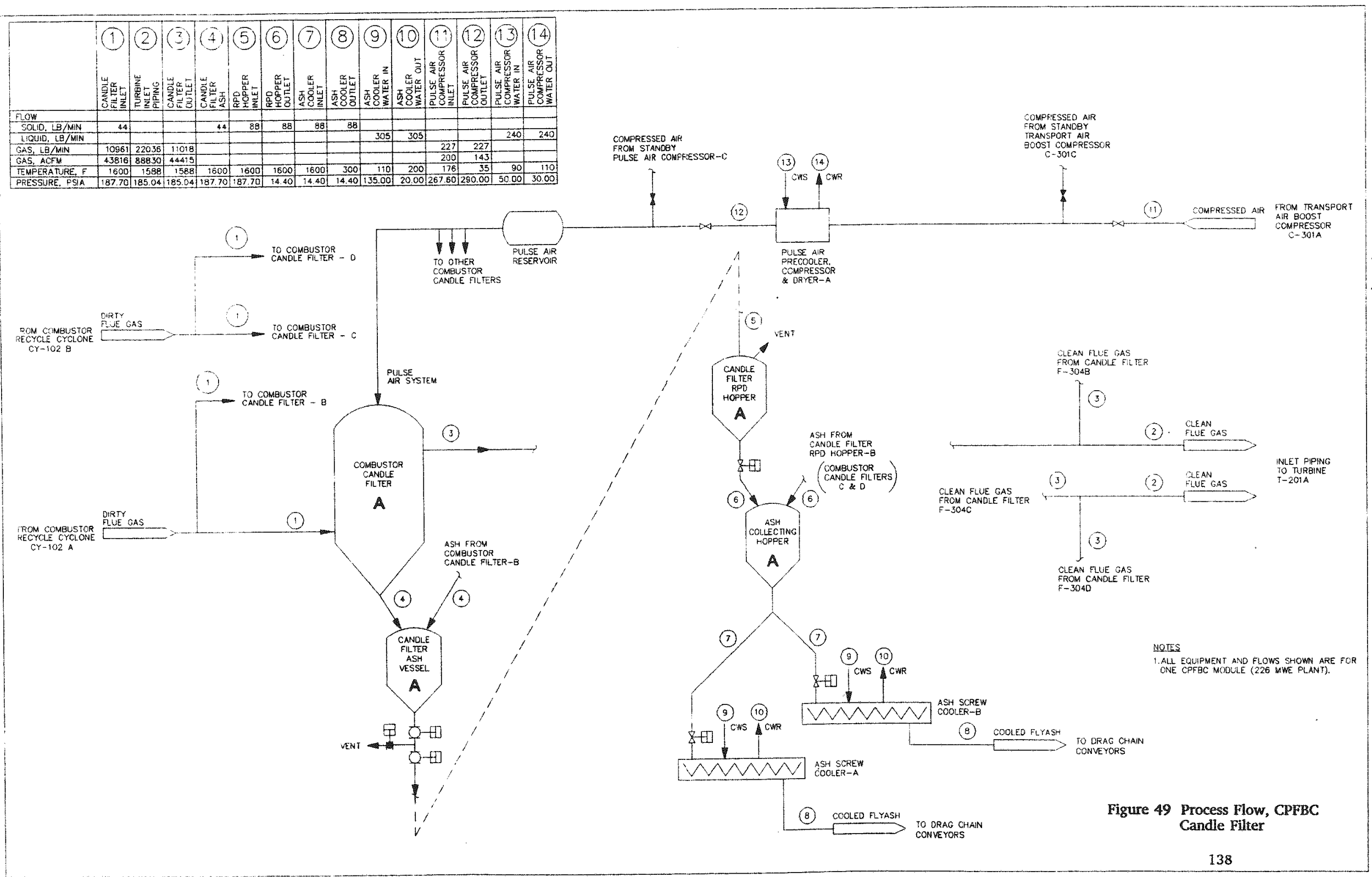




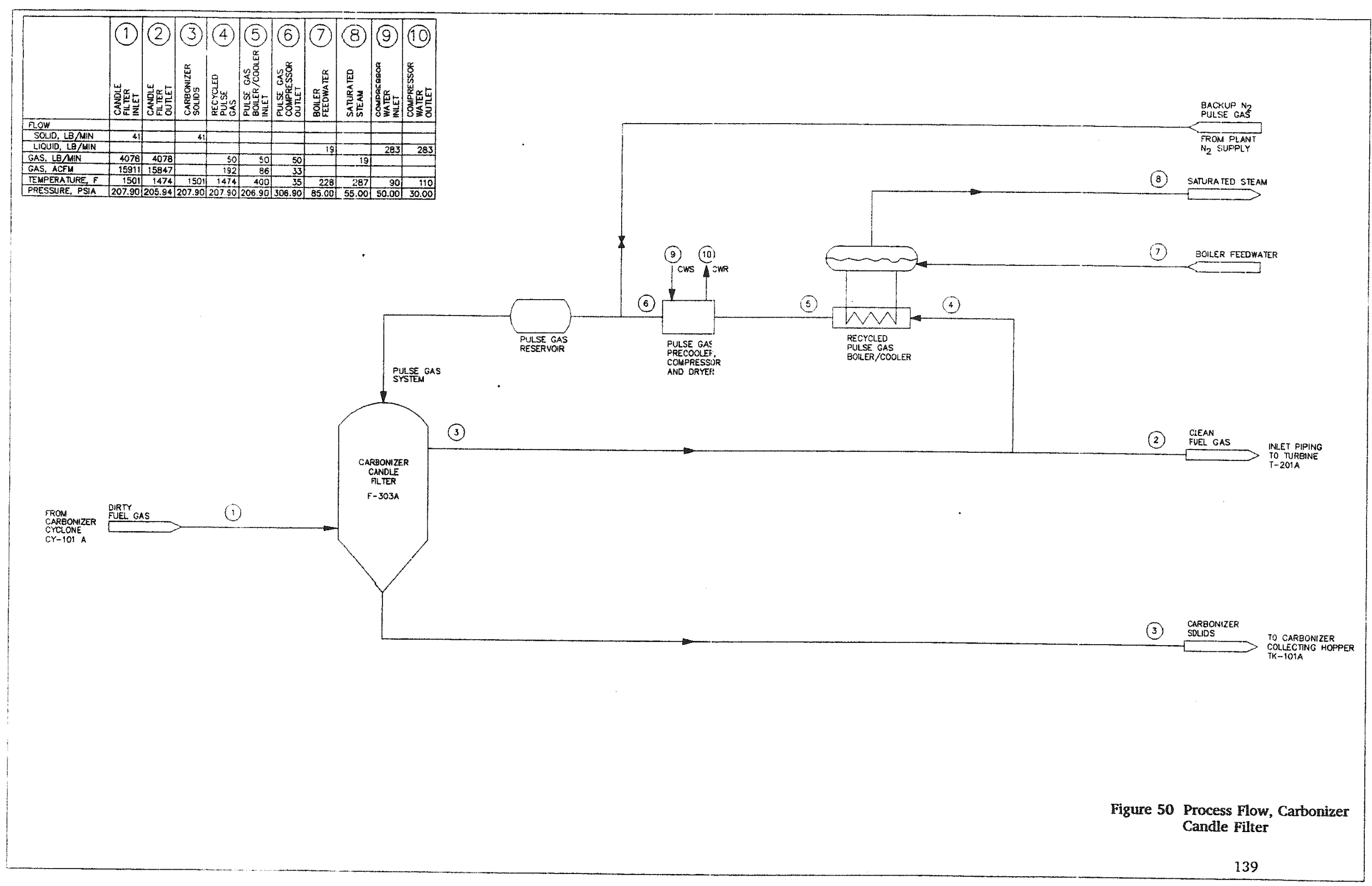




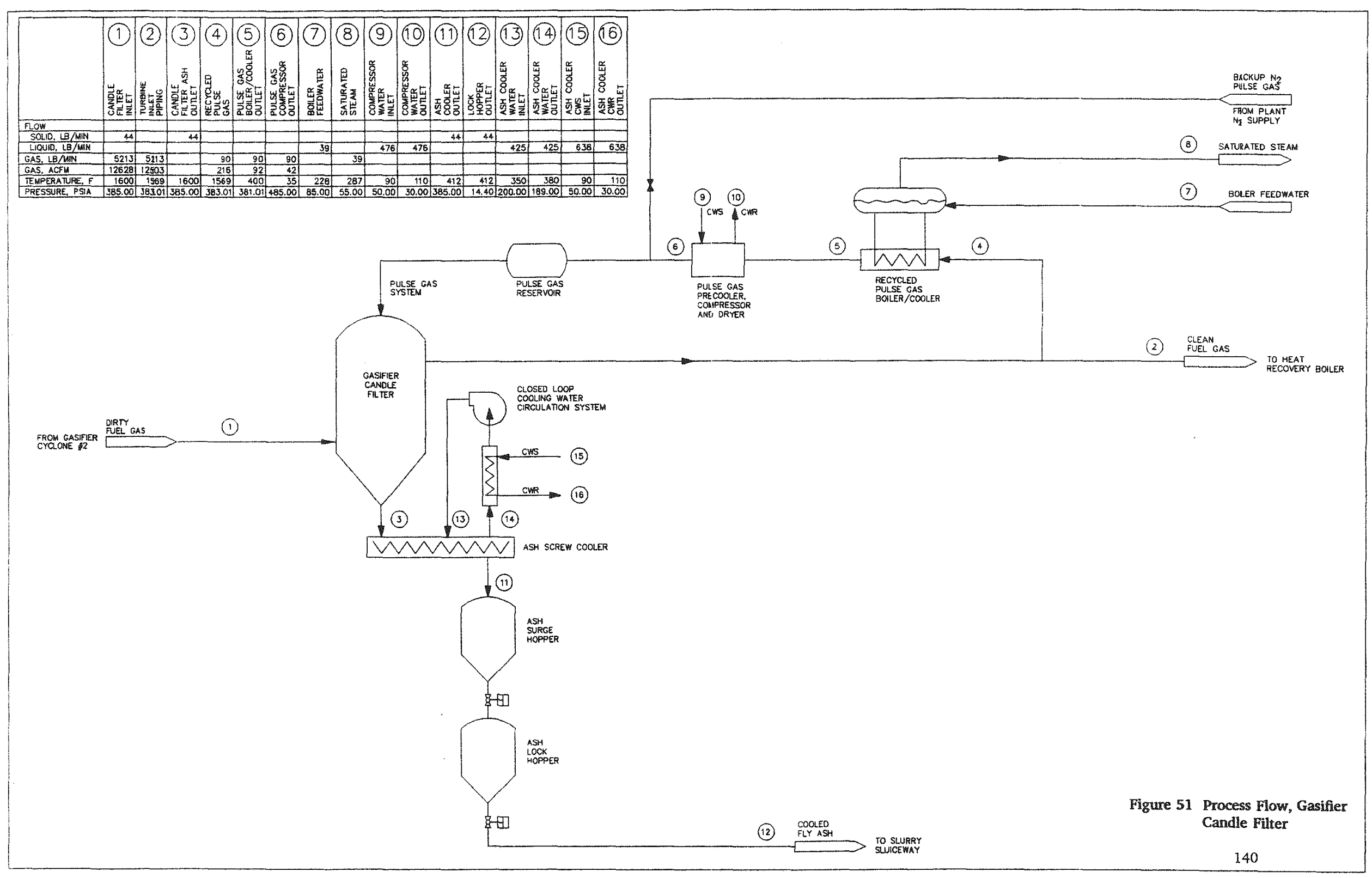


Pulse gas for cleaning the candle filter elements is $5,410 \mathrm{lb} / \mathrm{hr}$ for the gasifier candle filter. This pulse gas is recycled clean process gas taken from the outlet of the gasifier candle filter. The hot process gas is first cooled from $1569^{\circ} \mathrm{F}$ to $400^{\circ} \mathrm{F}$ using a simple fire tube boiler which produces low pressure saturated steam. The process gas is then further precooled, compressed, aftercooled, dried, and filtered before being supplied to the pulse gas reservoirs at 485 psia or approximately 100 psi above the candle filter internal pressure. Pulse gas at a pressure of 100 psi above the candle filter pressure is considered the normal operating pulse gas pressure for this study. The pulse gas compressor is designed to supply compressed process gas at pressures up to 300 psi above the filter pressure or 685 psia.

Ash from the gasifier candle filter is first cooled from $1600^{\circ} \mathrm{F}$ to about $400^{\circ} \mathrm{F}$ using a pressurized water-cooled screw conveyor. In order to prevent condensation of hot process gases on the metal surfaces of the screw cooler, a closed loop cooling water circulation system is provided for the ash screw cooler. This closed loop circulation system allows the metal surfaces of the ash screw cooler to be maintained at temperatures of $350^{\circ} \mathrm{F}$ to $380^{\circ} \mathrm{F}$. After the ash is cooled, it is depressurized using lock hoppers.

\subsubsection{Instrumentation and control}

An automatic computer control system maintains the filter operating parameters at specified set-points, provides indication of system status, provides alarms of abnormal process variables, and alarms indication of failed equipment. This allow for safe and steady operation of the filter with minimum plant personnel supervision. The automatic control system for each of the candle filter applications is nearly the same. All of the candle filter applications monitor or control:

- Process gas temperatures at filter inlet and outlet

- Filter pressure drop and pulse valve operation

- High ash level in candle filter hoppers

- Pulse gas compressor systems

The main differences between the control systems for the candle filter applications is the number of pulse valves operated and the ash system control. Figures 52, 53, and 54 show the Piping and Instrumentation Diagrams ( $P$ \& ID's) for the CPFBC filter, carbonizer filter, and gasifier filter, respectively. A description of monitoring functions and main control loops follows:

- Process gas temperatures at filter inlet and outlet

Local thermocouples monitor process gas inlet and outlet temperatures of each candle filter vessel. These analog inputs are used for information on system operation. On the CPFBC application where there are multiple filter vessels, inlet and outlet temperatures are useful in comparing operation and gas flows between filter vessels. Temperature data will be recorded and stored. This historical data is useful in troubleshooting changes in filter operation over longer periods of operation. 
- Filter pressure drop and pulse valve control

Control of the pulse valve system has three main control parameters, 1) the time duration between pulsing a filter element, which is the cycle time between opening of each pulse valve and is often referred to as valve "off-time";2) the time duration that the pulse valve is actually open allowing flow of pulse gas, referred to as valve "on-time"; and 3 ) the pressure of the pulse gas supplied to the reservoir upstream of the pulse valve. Adjustments in all three of these parameters can be utilized to vary the cleaning of the candle filter elements; which in turn, effects the filter pressure drop. It is assumed that the primary control parameter will be the valve off-time, with valve on-time and pulse gas pressure being secondary or cascaded control parameters. The cost estimate allows for programming the control of all three parameters in several different ways, with the flexibility for operator intervention.

The control system will also cause the opening of one of the three ball valves downstream of the pulse valve just prior to the pulse valve actuation, and then cause the closing of the ball valve after the pulse is completed. The control system will monitor the position of each ball valve and alarm any valve movement failures.

This portion of control system also includes instruments to monitor pulse gas flow into each secondary pulse air reservoir. Controls would be used to alarm the condition where a pulse value and ball valve fail in the open position. This part of the loop could function as follows: Since pulse gas only flows into the secondary reservoir to refill the reservoir directly after a pulse valve is actuated, there is exists a short time of high flow rate and then a quick drop-off of flow rate as the reservoir comes back up to operating pressure. Since this high pulse gas flow rate should only last for a short time the control loop could be programmed to alarm a condition of excessive time duration of high pulse gas flow rate. If this alarm occurs, the last pulse valve actuated could be electronically identified. The defective pulse valve could then be removed from the control loop pulsing sequence, and manual isolation valve upstream of the valve closed. The valve train is designed so a defective pulse valve can be manually isolated, then repaired or replaced.

- High ash level in candle filter hoppers level.

Ash level detection devices are installed each candle filter hopper to alarm high ash

- Pulse gas compressor system control

The reciprocating compressor package and refrigerated gas drier package will be supplied with an integrated control system. Each piece of equipment can be operated from a local control panel, with some overriding controls from the main control panel. Each package will have various discrete and analog inputs and outputs such as start/stop controls, output set points, and alarms. All of these inputs and outputs from each separate equipment package will be integrated into the candle filter computer control system so control of the entire pulse gas compressor system can be monitored and controlled as part of the candle filter system. 
On the carbonizer and gasifier filter there is a fire tube boiler for cooling the hot process gases for pulse gases. This boiler will use a two element feedwater control system. This two element feedwater control loop and other instruments that are part of the boiler will be controlled as part of the candle filter computer control system.

\section{- Ash removal systems}

The CPFBC candle filter systems will use the same basic ash system proposed in the Foster Wheeler study ${ }^{20}$. This includes restricted pipe discharge (RPD) hoppers for ash decompression, and ash cooling screws to cool the hot ash. A description of the operation and control of this ash system can be found in the Foster Wheeler study.

The gasifier candle filter will use a pressurized ash cooling screw to cool the ash before depressurizing. The lock hopper system utilized for depressurizing is the same for the granular-bed filter and is described in section 3.5.2. The pressurized ash cooling screw used on the gasifier candle filter will have two control loops, one for control of screw speed, and one for control of the closed loop cooling water circulation system. The controls for the closed loop cooling water circulation system includes: controls for system water level, operation of circulation pumps, flow of plant cooling water supply, operation of pressure maintaining boost pumps, operation of electric heater for heating the cooling water startup, and use of backup emergency water supply. In addition there are instruments for monitoring water flow to the ash screw cooler as well as instruments for monitoring and alarming pressures and temperatures throughout the system.

\section{- Computer Control System}

The computer control system is based on a programmable logic controller (PLC). It is constructed on a modular basis using plug-in printed circuit cards installed in a control rack. Figures 55, 56, and 57 show the control system architecture layout for the CPFBC filter, carbonizer filter, and gasifier filter, respectively. A central processing unit scans the user program and generates logic commands. Data collection is done through the device called a "Genius I/O" (Input/Output) connected to the PLC. Unlike conventional remote $1 / O$, this arrangement requires no central $1 / O$ control cabinets, no racks, no separate power supply. These $1 / O$ devices are installed close to field instruments. Genius I/O automatically provides diagnostic information of field wiring and power conditions. This troubleshooting capability reduces time needed for control system debugging.

This mode of local computer control also cuts down on maintenance costs and system downtime because it eliminates the need for destructive fuses. When overloads and short circuits are detected, output circuits turn off immediately, protecting circuitry and wiring.

The software package provides monitoring, control, data acquisition, alarms, and graphics. All process data can be transferred in common data base programs; such as, Microsoft's data base program called EXCEL, to take advantage of data conversion capabilities. Using the proficiency of the software package, user programmed management reports can be prepared and printed anytime, during operation or downtime. 
Selected data can be stored in computer memory for a predetermined amount of time, allowing historical review of operation.

Included with the computer control package are: analog transmitters, thermocouple inputs, RTD inputs, and analog outputs. The local computer control module includes: redundant CPU with memory, redundant rack, redundant power supply, redundant bus controller, redundant coprocessor with software, and required input and output blocks. Software includes programming to allow: standard displays, dynamic graphics and trending, configuration changes, alarming, and report generation. For monitoring the operation, a caliber $486 \mathrm{SX}$ personal computer is included with two serial ports, one parallel port, 105 Megabyte hard drive, 3.5" floppy drive, super VGA monitor, keyboard, mouse, color printer, and interconnecting cables. Personal computer software includes MS DOS 5.0 and Windows 3.1.

\subsubsection{Candle Filter Configurations}

The $452 \mathrm{MWe}$, second generation PFBC plant is arranged in two identical trains of equipment, each sized for 226 MWe. Each train includes a CPFBC and a carbonizer. There are four candle filter vessels for each CPFBC and one candle filter vessel for each carbonizer. As with the granular-bed filters, these candle filter vessels replace two crossflow filter vessels for each CPFBC and one cross-flow filter vessel for each carbonizer. For the 100 MWe KRW gasifier, a single candle filter vessel replaces the single cross-flow filter vessel originally utilized. Above Figure 48 shows the basic configuration of the candle filter used for all applications. The filters are refractory-lined with a single tubesheet supporting the candle filter elements. The dirty process gas enters the vessel through a single inlet nozzle located on the side of the vessel cylinder below the tubesheet. Inside the vessel is a cylinder shaped, alloy metal baffle that distributes the dirty gas around the outer edge of the filter element array near the upper end of the candle filter elements. The particulate loaded dirty gas passes through the porous filter element leaving the particulate on the outside surface of the filter element in the form of a ash cake. The clean gas exits each filter element, collects in the chamber above the tubesheet, and exits the vessel through an outlet nozzle on the side of the vessel. The clean side plenum of the vessel contains many manifolds for delivery of pulse air or gas to each candle filter element. Ash collected on the candle filter elements is dislodged by the pulse air or gas and falls into a conical hopper for exit into the ash handling system. Access doors are provided both above and below the tubesheet.

Figures 58,60 , and 62 show the pressure vessels and list the design criteria for the candle filter vessels for the CPFBC filter, carbonizer filter, and gasifier filter, respectively. Figures 59,61 , and 63 show the internal refractory and nozzle details for the candle filter vessels for the $\mathrm{CPFBC}$ filter, carbonizer filter, and gasifier filter, respectively. 


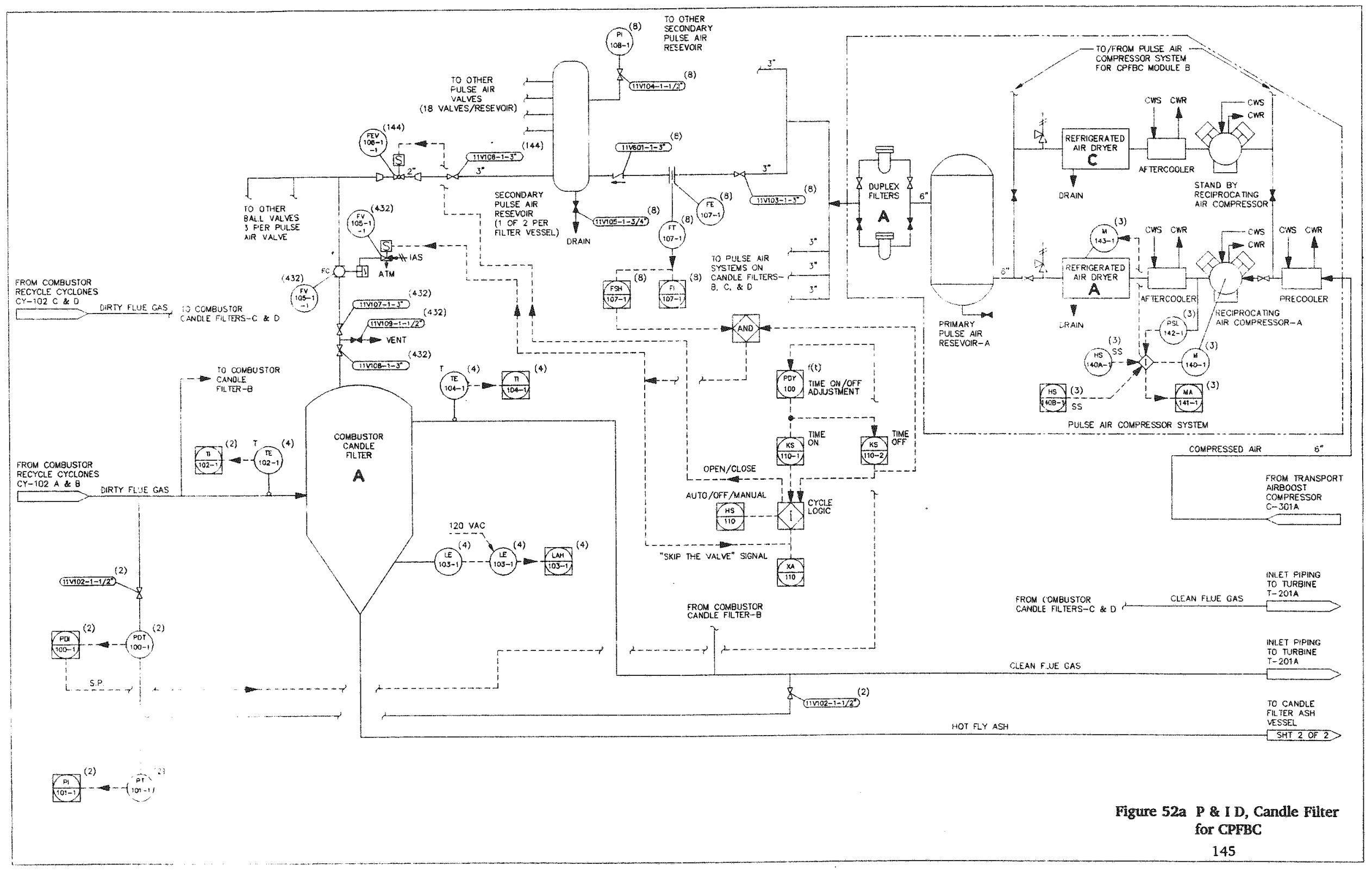




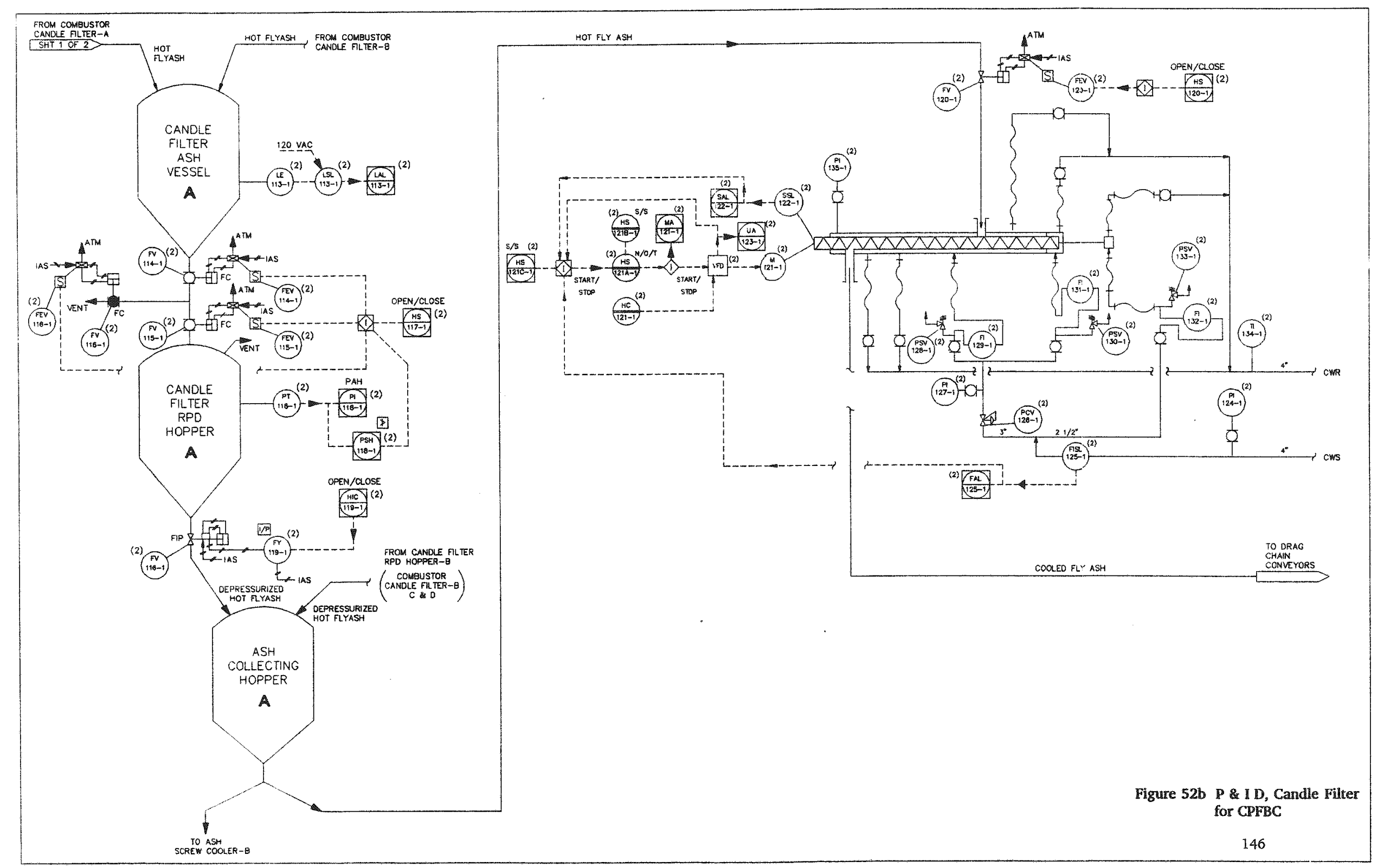




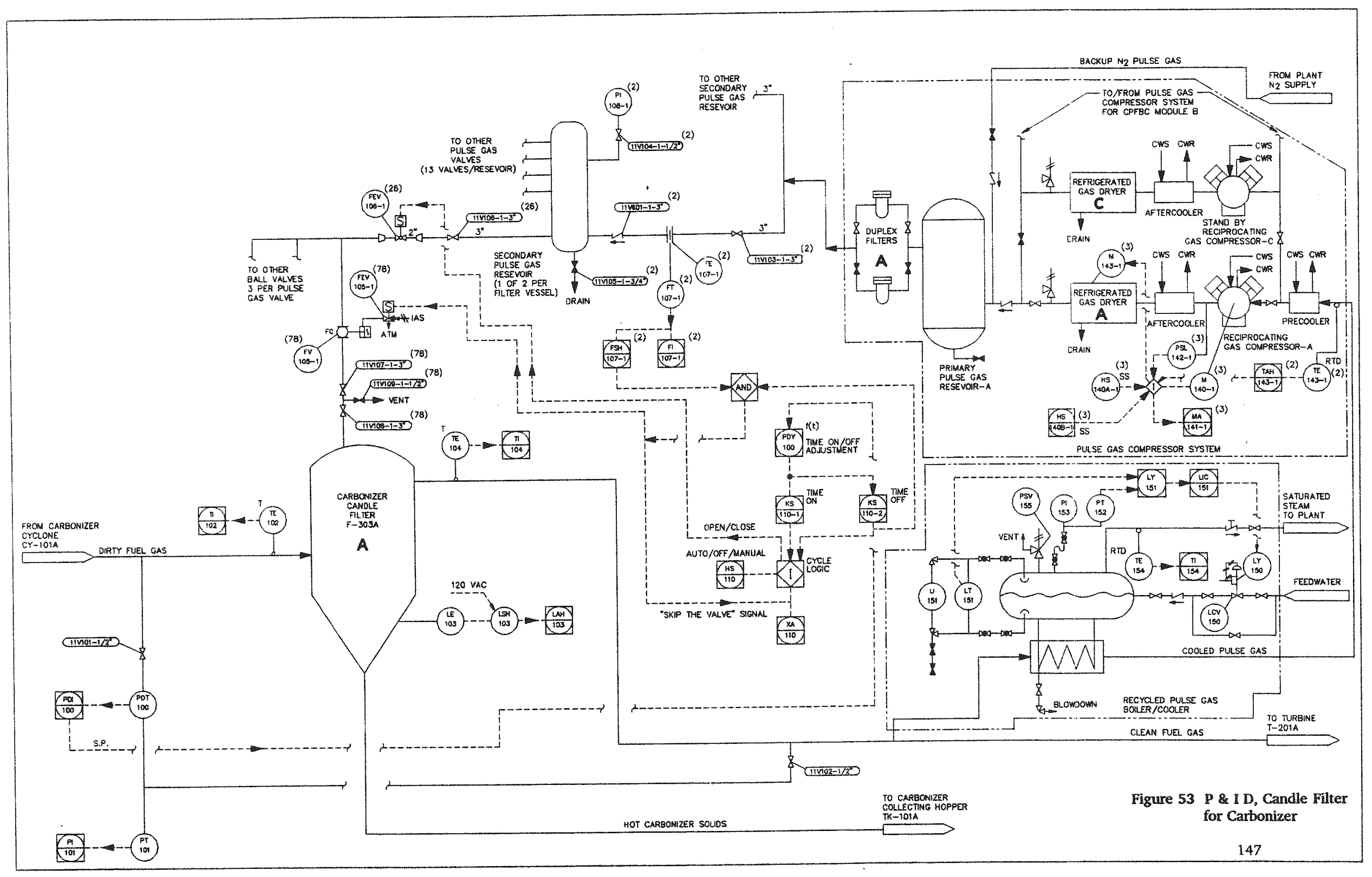




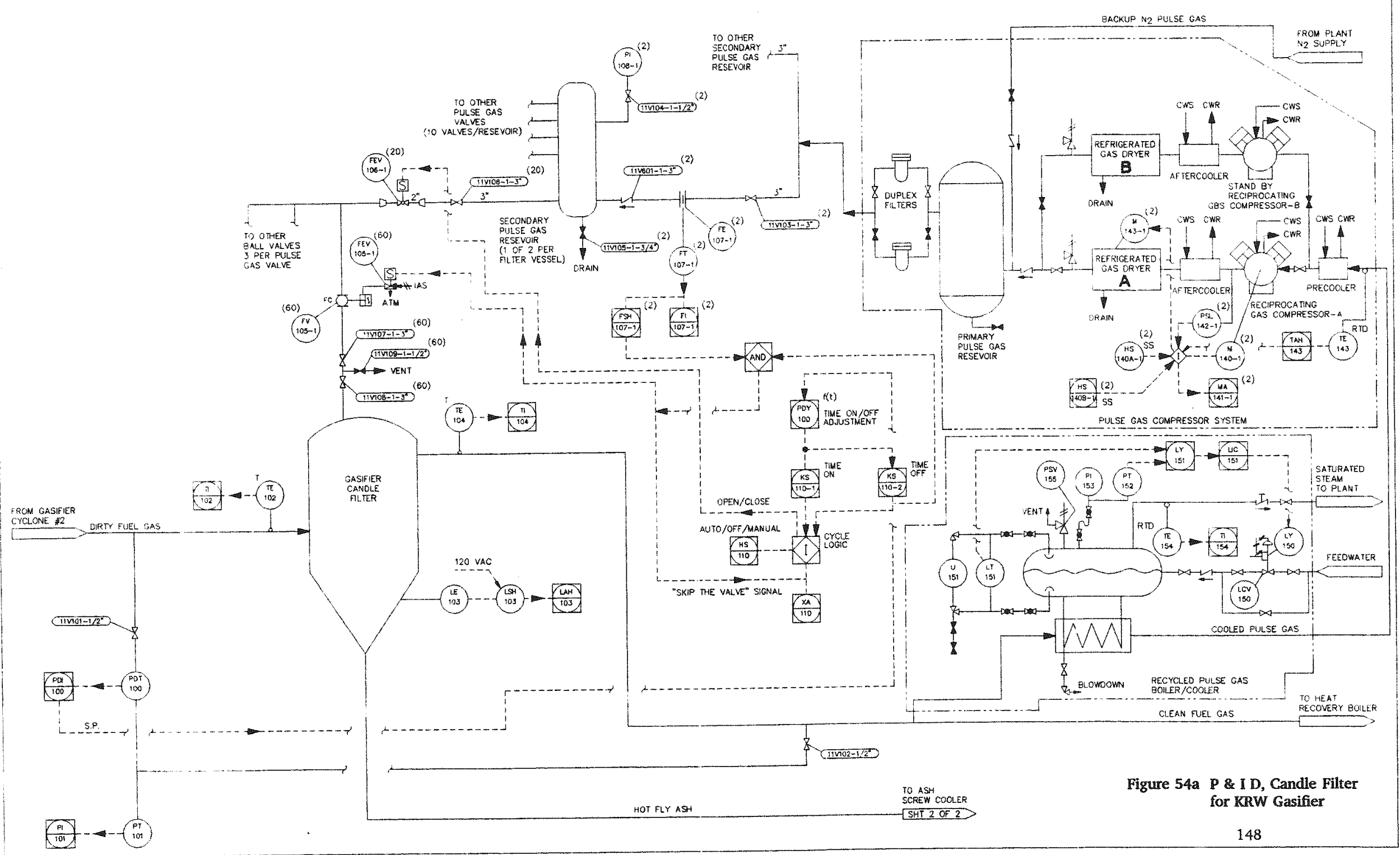




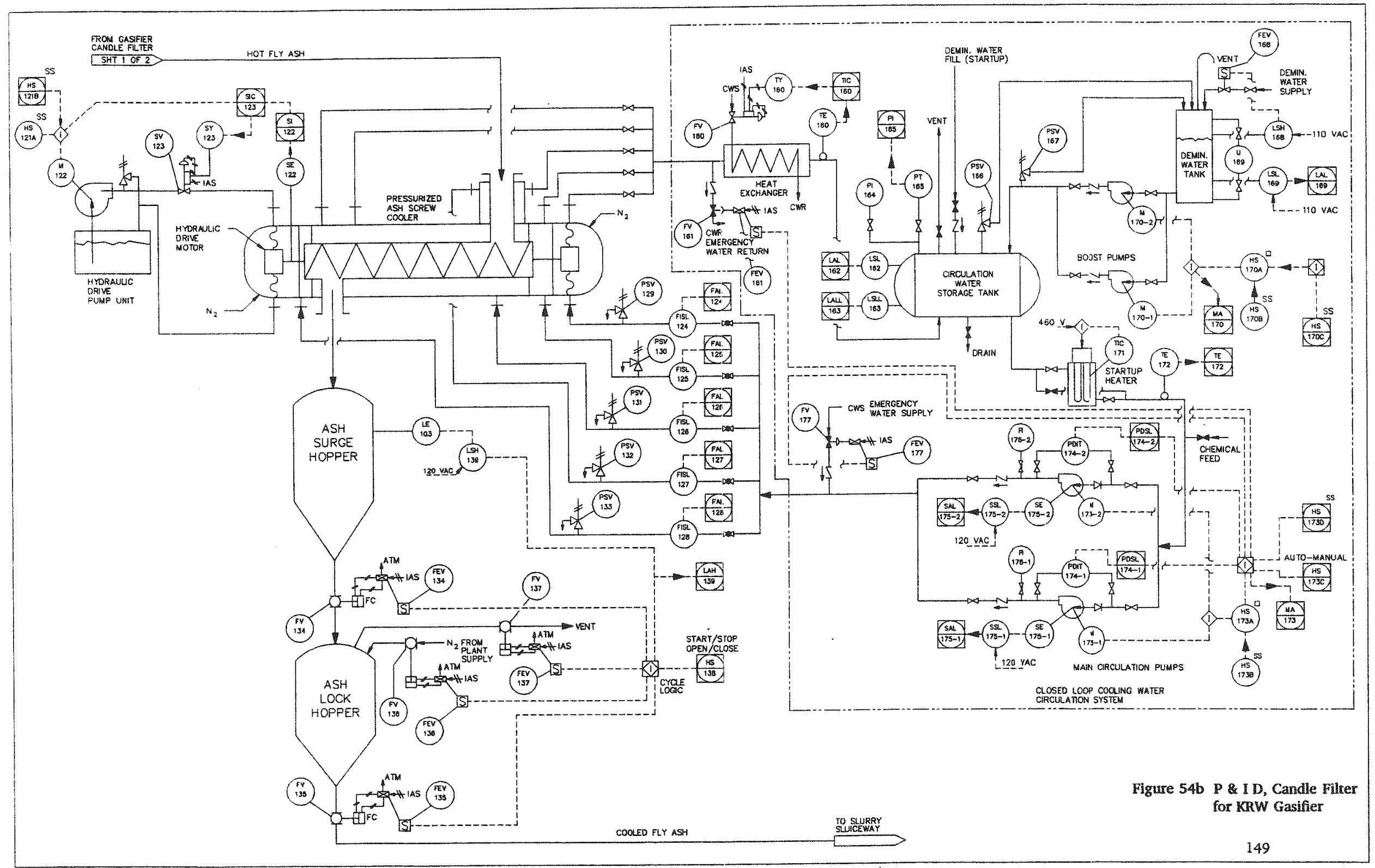




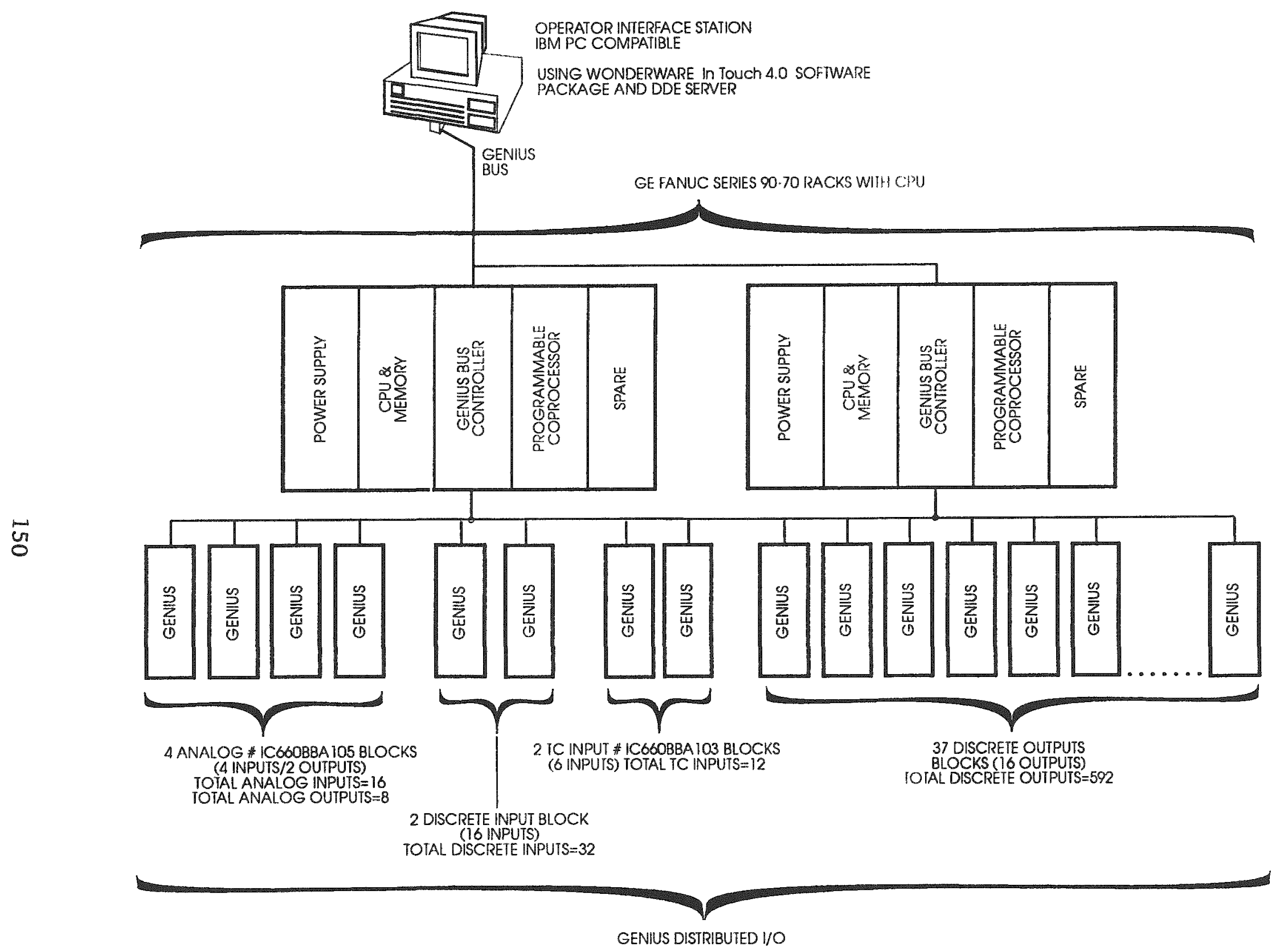

Figure 55 Control System Architecture, Candle Filter for CPFBC 


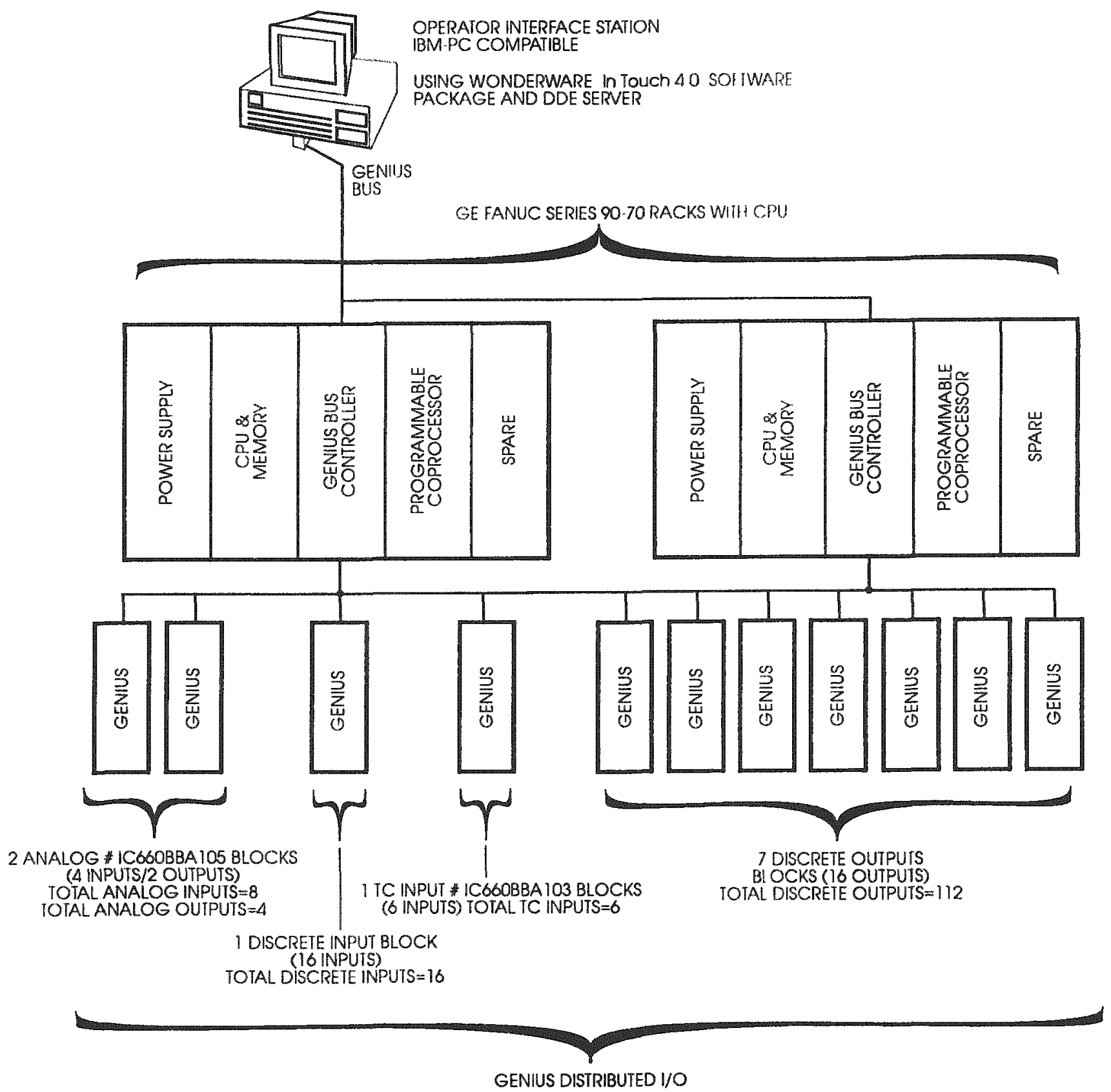

Figure 56 Control System Architecture, Candle Filter for Carbonizer 


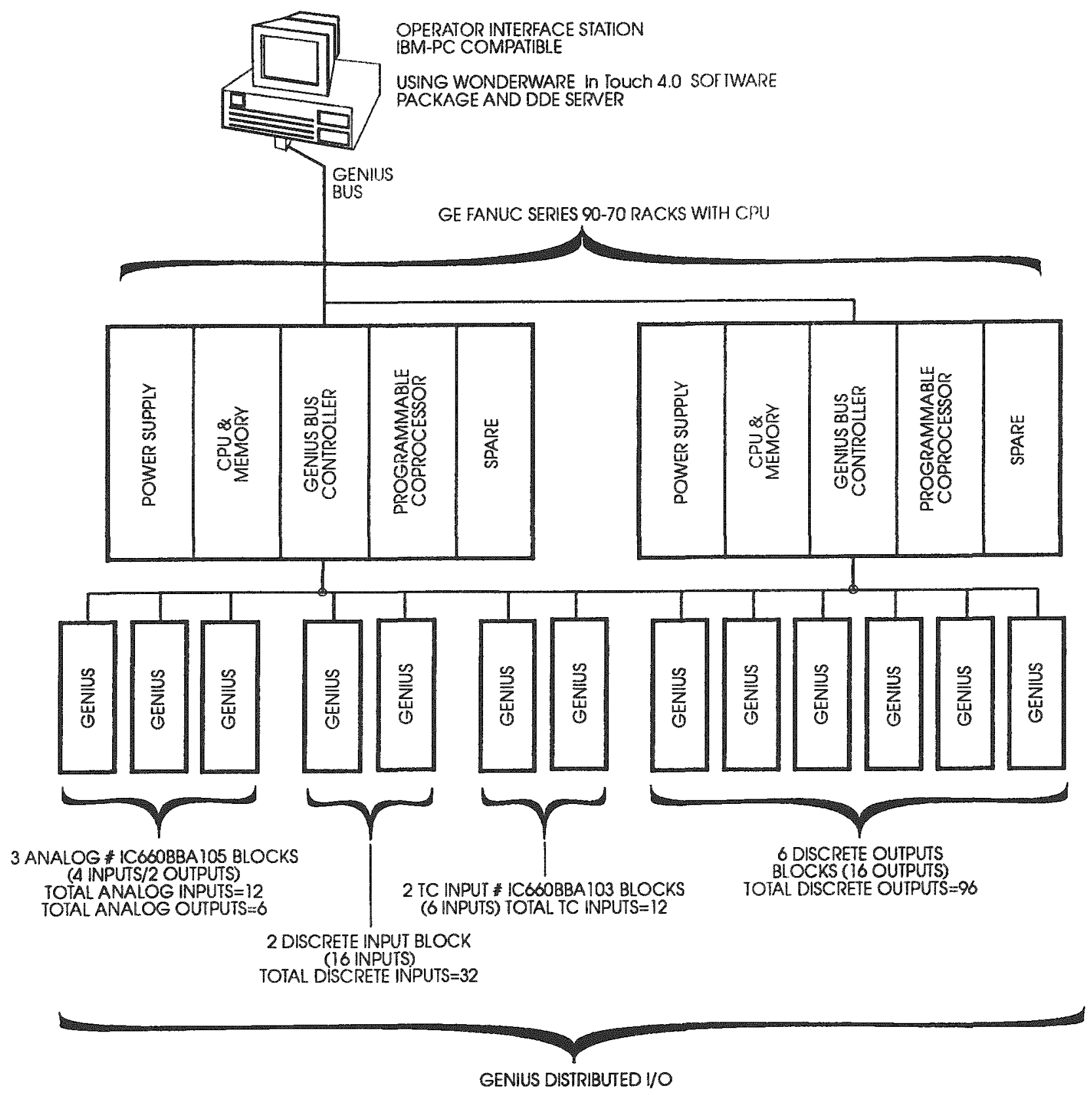

Figure 57 Control System Architecture, Candle Filter for KRW Gasifier 



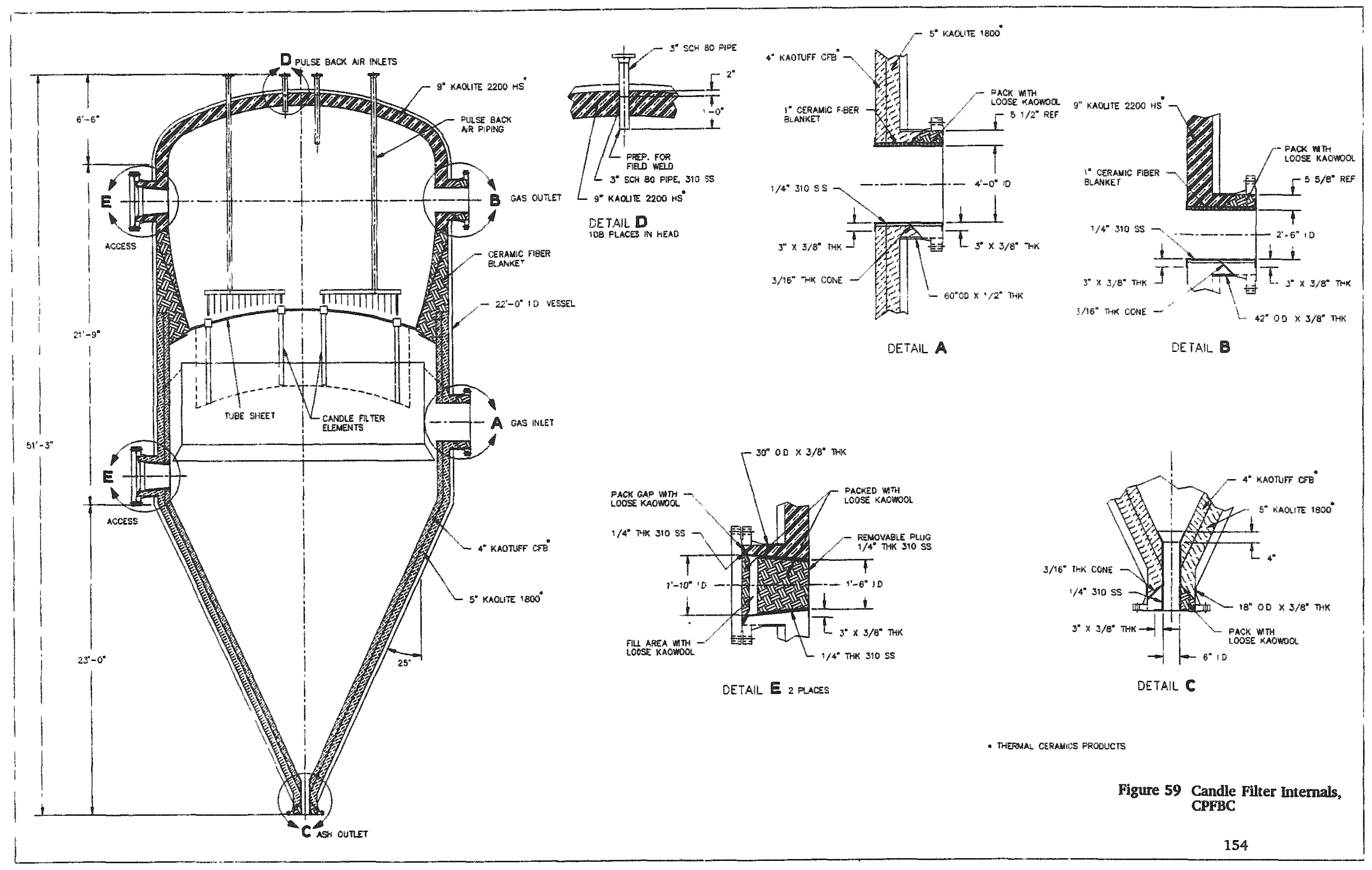




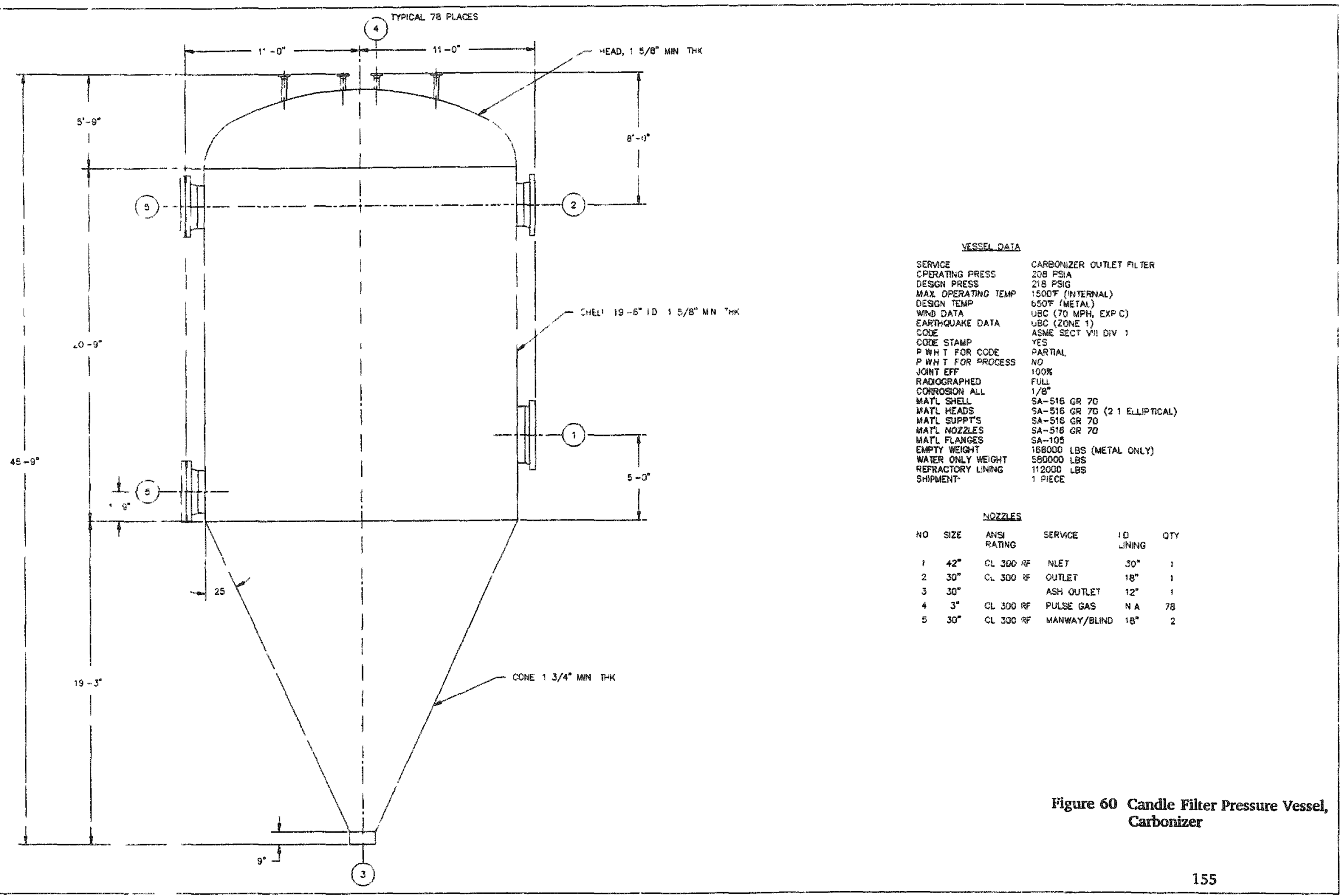




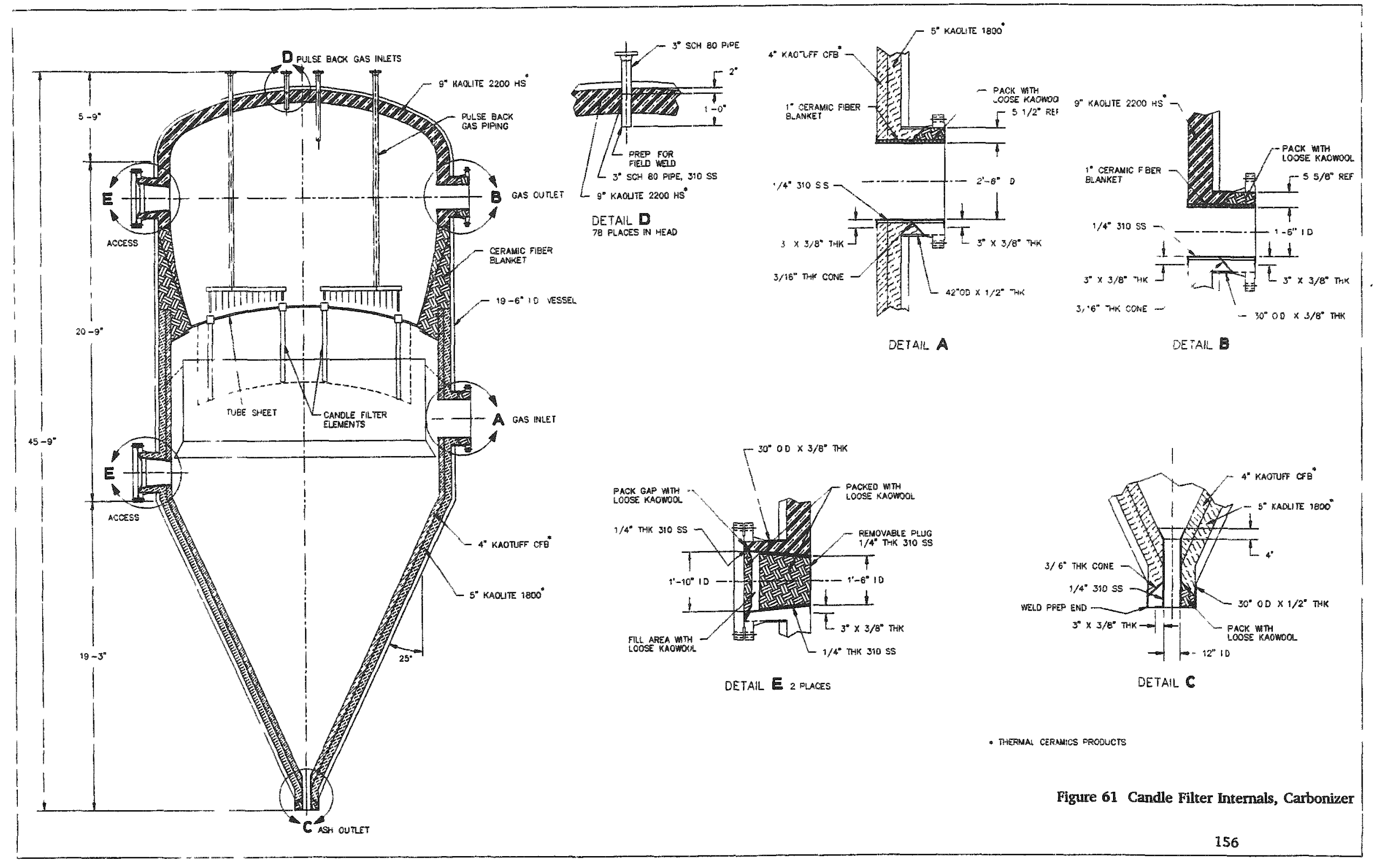





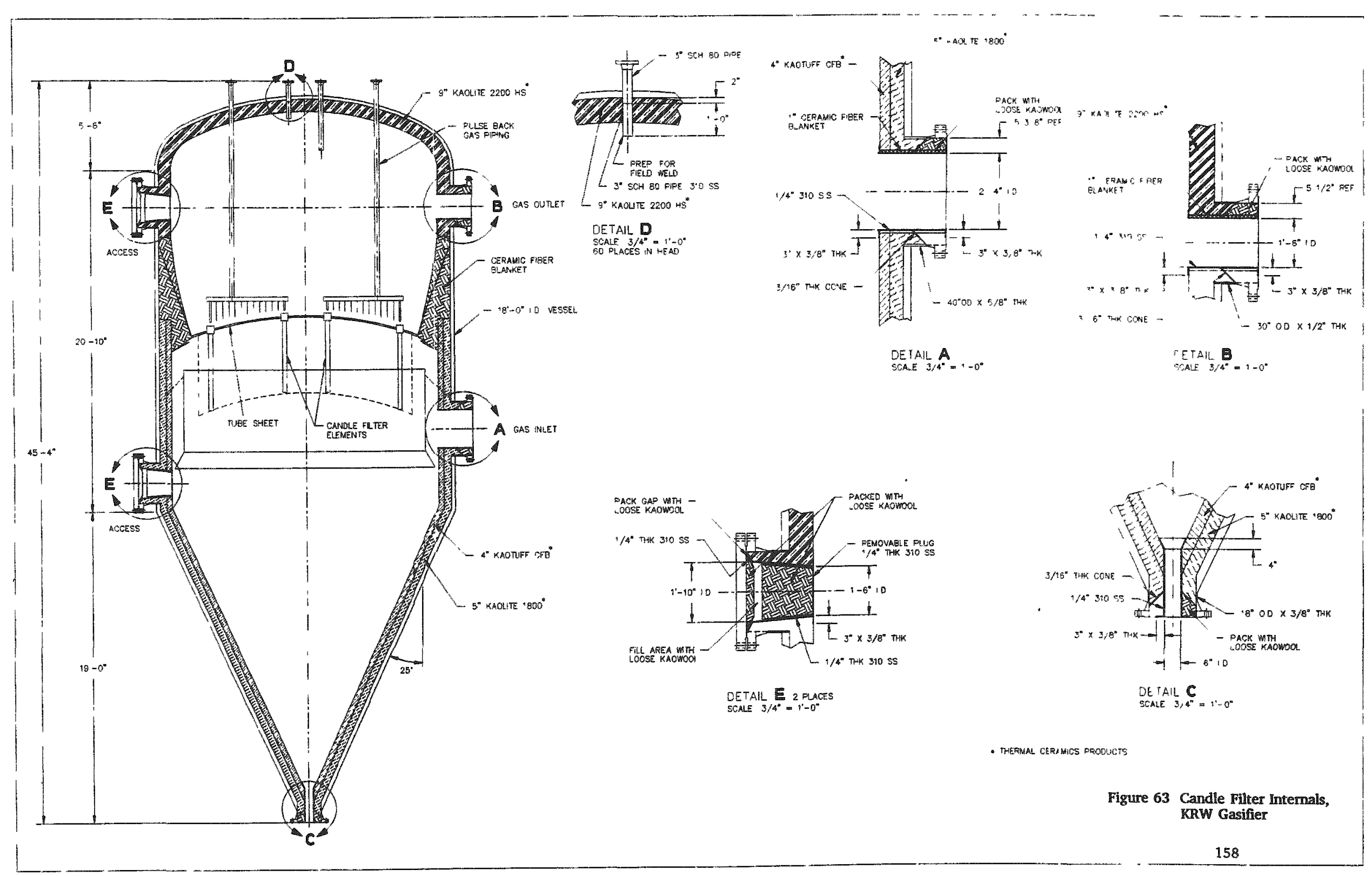

n. 


\subsubsection{Refractory}

considered.

Several approaches for lining of the candle filter vessel with refractory were

- Cast insulation and hardface in the vessel ash cone and cylinder sidewalls below the tubesheet and ceramic fiber product in the space above the tubesheet.

- Castable-type refractory applied by pneumatic gunning techniques installed in both regions above and below the tubesheet.

- A combination gunite insulation/hardface in the entire candle filter vessel.

In the candle filter vessel space above the tubesheet, conditions for the refractory are fairly mild, even in the reducing atmospheres for the carbonizer and the gasifier. There is virtually no ash, gas velocity is very low $(<10 \mathrm{ft} / \mathrm{sec})$ and operating temperatures are $1500^{\circ} \mathrm{F}$ to $1600^{\circ} \mathrm{F}$. Under these conditions, the most important refractory properties to consider are thermal conductivity to minimize heat loss and refractory stability to resist any kind of deterioration that could add particles to the cleaned gas stream exiting the filter.

Ceramic fiber products have very low thermal conductivity $\left(.5\right.$ to $1 \mathrm{Btu}-\mathrm{in} / \mathrm{hr} \mathrm{ft}^{2}$ ${ }^{\circ} \mathrm{F}$ ) and are available in a number of forms that could be suitable for lining the zone above the tubesheet. Although manufactures and installers claim otherwise, these products could deteriorate and add particles in the form of ceramic fibers or chunks to the gas stream exiting towards the gas turbine. Metal liners can be used to protect this material, but this is costly. Consequently, these materials are not proposed; although, consideration would be given in an actual application. Instead our choice is a lightweight, insulating gunning mix. These materials have slightly less insulating value when compared to ceramic fiber products, but are much stronger and more resistant to deterioration and chemical attach. A 60 to $70 \mathrm{lb} / \mathrm{ft}^{3}$ gunning mix could be applied as a combination insulating and hardface layer in the candle filter operating in an oxidizing or reducing environment. Thermal conductivity is in the range of 1.3 to $1.6 \mathrm{Btu}$-in/ $\mathrm{hr} \mathrm{ft}{ }^{2}$ ${ }^{\circ} \mathrm{F}$, and good strength is indicated by a cold crushing strength of 300 to 500 psi after heating to $1500^{\circ} \mathrm{F}$.

In the candle filter area below the tubesheet where the ash is collected, the requirements are different. The hard face refractory must have good strength to hold the ash weight and moderate abrasion resistance for long life. The insulating refractory must minimize heat loss to the surroundings.

For small candle filters, casting the cone and sidewall areas that enclose the ash would be the preferred technique. In larger candle filters, forms for installing castables (similar to forms for installing concrete) are very large, bulky, and expensive. There will be an economic break-point where pneumatic gunning is more suitable. Abrasion resistance and strength is comparable to castable refractory hardfaces. Gunning is chosen 
for the large (16-20' diam.) candle filters. For the insulation layer under the gunned hardface, a light-weight, gunned refractory material is proposed.

\subsubsection{Metal Internals}

The life of the metallic internals used in the filters will greatly depend on the operating temperature and gas environment. For the $\mathrm{CPFBC}$ candle filter operating at $1600^{\circ} \mathrm{F}$ with a moderate oxygen and a low sulfur dioxide environment, we expect that the loss of metal will be less than 5 mils/year. This corresponds to a service life of about 25 years. In candle filters for service in PFBC applications (oxidizing atmospheres) RA333 and 310 SS have been used with satisfactory results ${ }^{5}$. RA333 has been used in regions of high stress, and 310 SS has been used in regions of low stress. Therefore, for the candle filter in the oxidizing atmosphere, the CPFBC candle filter, these materials are proposed.

Since sulfur is captured in the carbonizer and gasifier, sulfidation potential due to $\mathrm{H}_{2} \mathrm{~S}$ is considerably reduced downstream in the filter. Regardless, the carbonizer and gasifier environments will be corrosive. In a $1500-1600^{\circ} \mathrm{F}$ reducing gas environment, the corrosion rate could be as high as 20 mils/year ${ }^{24}$. The expected service life in this situation could be only 5 years; less if "breakaway" corrosion occurs. Breakaway corrosion is a suddenly increasing corrosion rate occurring after a long period of relatively stable behavior. As the corrosion information available on metals in the reducing environments is limited, we believe that one of the functions of any future development program should be to collect corrosion data on promising alloys which can be used in this type of service. For the reducing atmospheres, we could find no precedent. Options are: 310 , RA85H, Haynes 556 , Haynes HR-160, and Haynes 188 , in order of material cost from $\$ 2.5 / \mathrm{lb}$ to $\$ 28 / \mathrm{lb}$. The choice for reducing atmospheres is RA85H for the candle filter tubesheet ${ }^{25}$ and 310 SS for other lightly-stressed components such as duct liners. This choice is made somewhat based on costs; since, other choices are considerably more expensive.

Table 15, Section 3 , summarizes the materials chosen for the different components, and Table 16, Section 3, lists the compositions of these materials. The first choice of materials is marked with an " $\mathrm{X}$ " in Table 15. In some cases the material choice is limited by its availability in the forms utilized in the ceramic candle filter. Prices listed are for purchased plate, $1 / 4^{\prime \prime}$ to 1 " thick, and are rounded off the nearest dollar in most cases.

\subsubsection{Candle Filter Plant Arrangements}

The CPFBC and carbonizer filters were arranged to fit into the existing plant layout and replace the originally proposed cross-flow filters for the Foster Wheeler, second generation PFB combustion plant ${ }^{20}$. Figure 64 shows the general arrangement of the $\mathrm{CPFBC}$ candle filter plant for one of two identical 226 MWe modules. The arrangement of the four candle filter vessels replaces the two cross-flow filters originally proposed with minimal increase in plan area and installed elevation. Inlet and outlet ducting is revised to accommodate the proposed candle filter module. The location, arrangement, and 
elevations of the ash handling equipment remain almost unchanged from the positions as shown for the cross-flow filter in the Foster Wheeler study.

Figure 65 shows the general arrangement of the carbonizer candle filter plant for one of the two identical 226 MWe modules. Since a single carbonizer candle filter vessel replaces a single cross-flow filter vessel of nearly the same size and shape there are very minor changes in the plant layout. The carbonizer candle filter vessel was arranged to connect with the carbonizer cyclone and ash collecting hopper without changing the position of these existing pieces of equipment. Locations of the inlet and outlet nozzles for the candle filter vessel are only slightly different than for the cross-flow filter vessel. These resulting gas ducting changes are considered irrelevant to the cost estimate.

In the Foster Wheeler study ${ }^{20}$, all of the pulse gas compressor systems for the crossflow filters are located at ground floor level, which is ideal for easy access and maintenance. The pulse gas compressor systems for the candle filters will also be located at ground floor level, and are not shown in our general arrangements for the CPFBC and gasifier candle filters.

Figure 66 shows the general arrangement of the gasifier candle filter plant. In the study by Westinghouse on the gasifier plant, no general arrangement drawings where prepared. Our arrangement of the gasifier candle filter plant was designed to be as compact as possible while still allowing space for access and maintenance. The structure for the gasifier candle filter and auxiliary equipment is a free standing unit that could be easily integrated into the layout of the complete gasifier plant. As with the CPFBC and carbonizer candle filters, the pulse gas compressor system is assumed to be located on the ground floor and is not shown in the general arrangement.

\subsection{Candle Filter Auxiliary Equipment/Specifications}

Auxiliary equipment for the candle filters includes: pulse gas supply equipment, ash handling equipment, and ducting. Pulse gas supply is fairly straightforward for the CPFBC filter because it is in an oxidizing atmosphere. Compressed air can be bypassed from the CPFBC supply, boosted in pressure and utilized. For the carbonizer and the gasifier, because of the reducing atmosphere, pulse systems utilizing process gas and nitrogen are compared. Since the least costly system uses process gas, it is chosen. Ash handling is accomplished as proposed for the filters in the base plants.

\subsubsection{Pulse System, CPFBC}

Equipment specified in each pulse air compressor system for the CPFBC candle filters consists of a inlet air cooler, single stage reciprocating compressor, refrigerated air dryer system, primary accumulator tank, and duplex air filters. In addition to each complete compressor system, there is a single standby boost compressor that can supply air to either of the two main systems. This compressor system approach is consistent with 


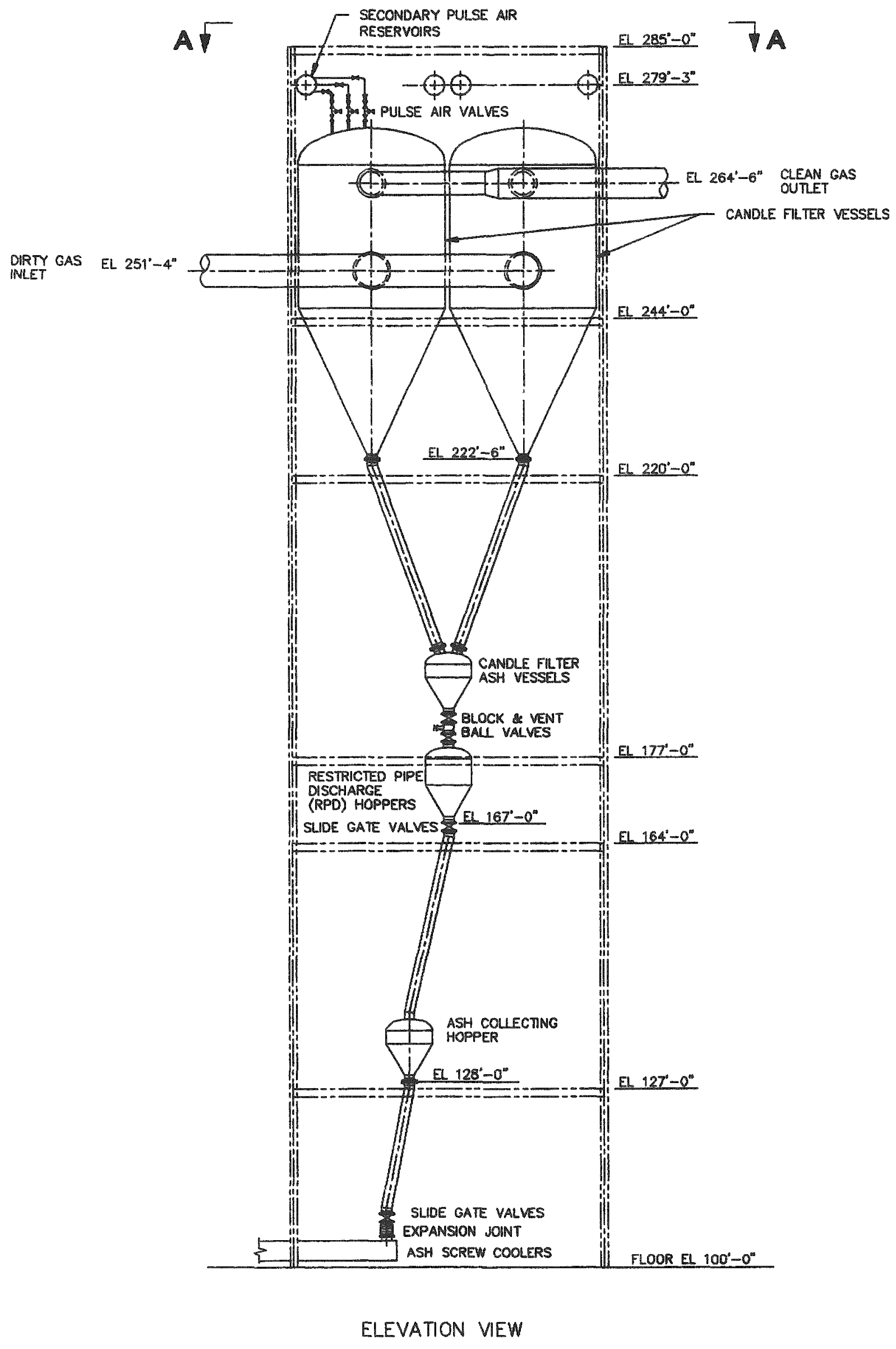




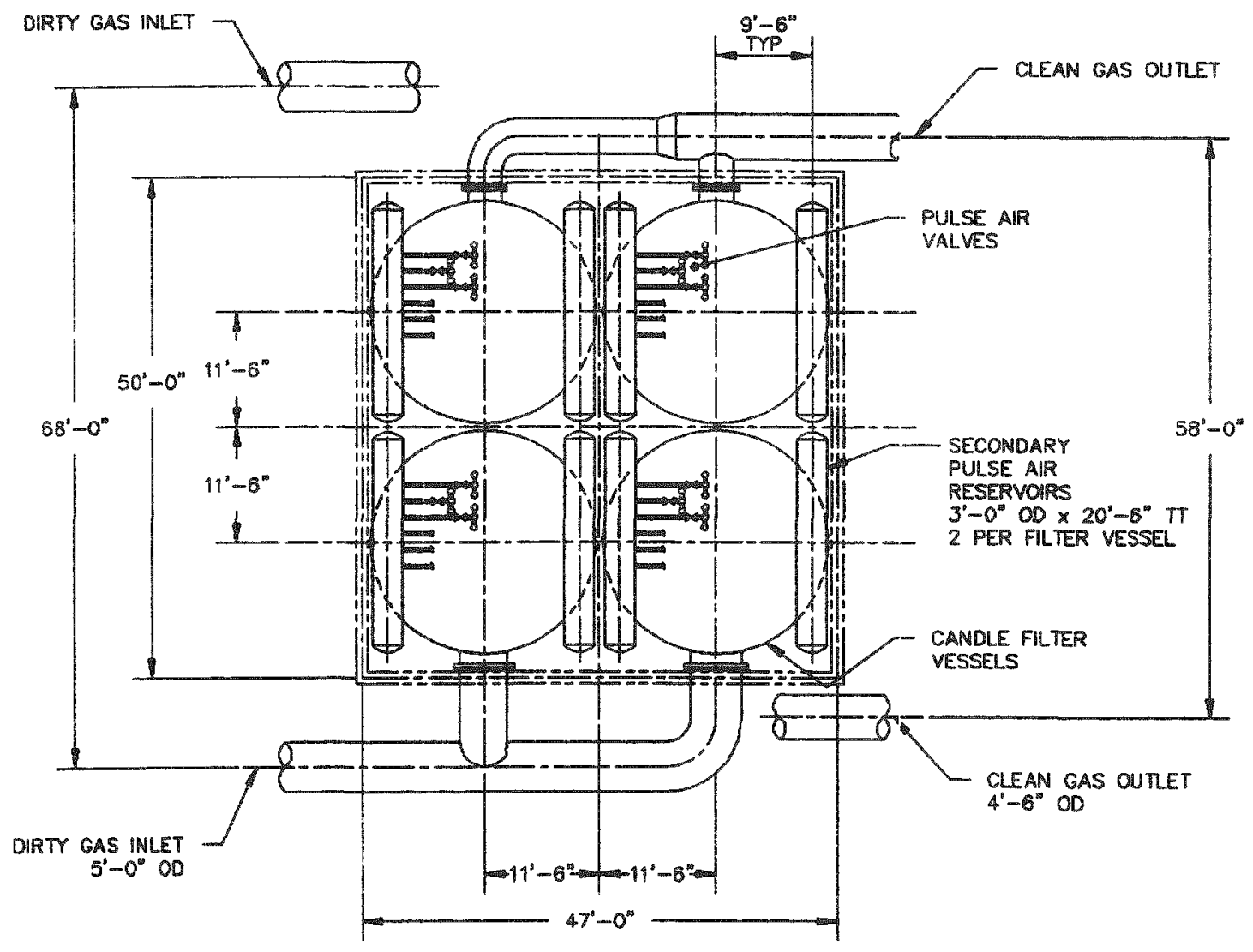

VIEW $\mathbf{A}-\mathbf{A}$

Figure 64 General Arrangement, CPFBC Candle Filter 

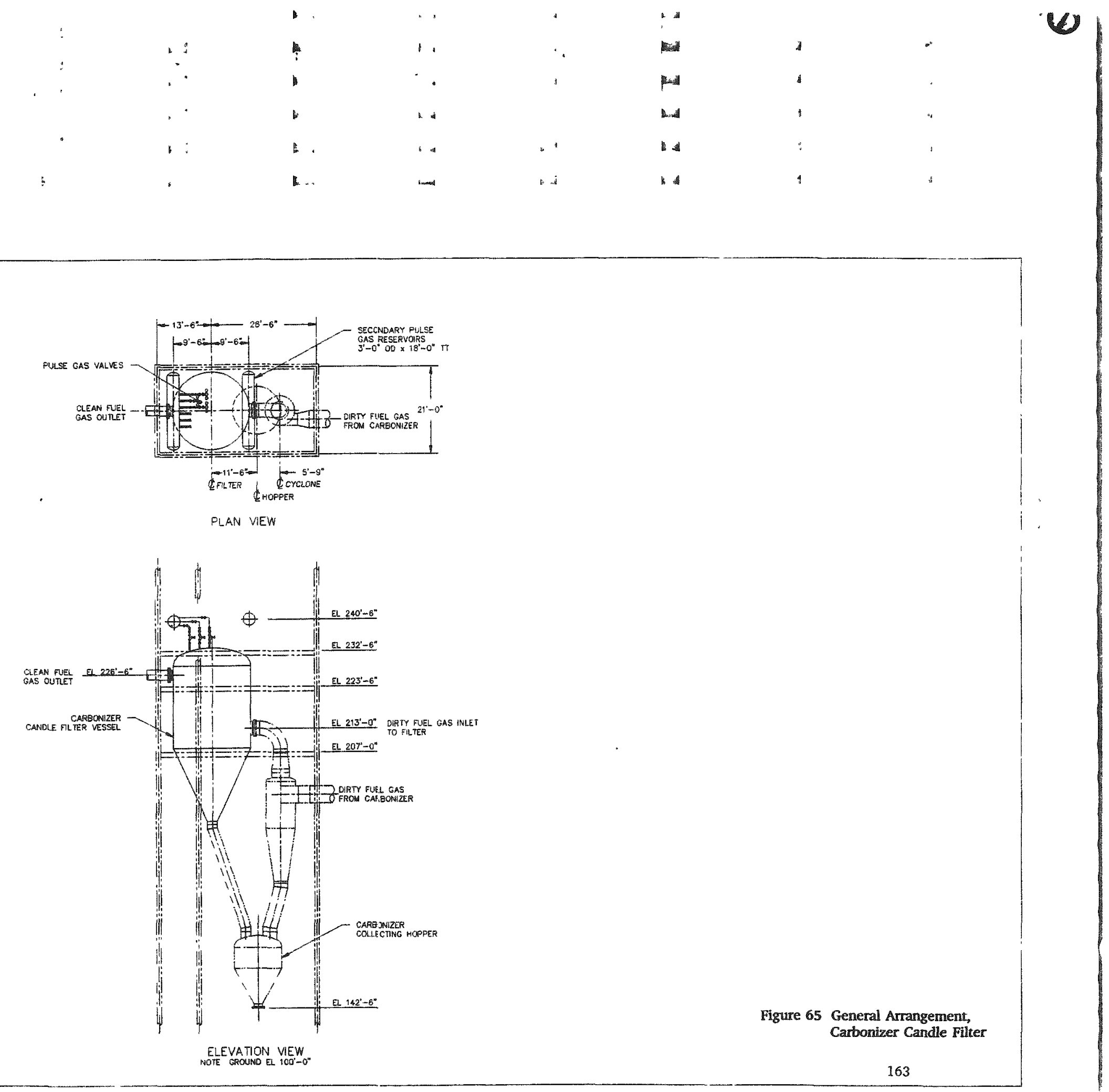


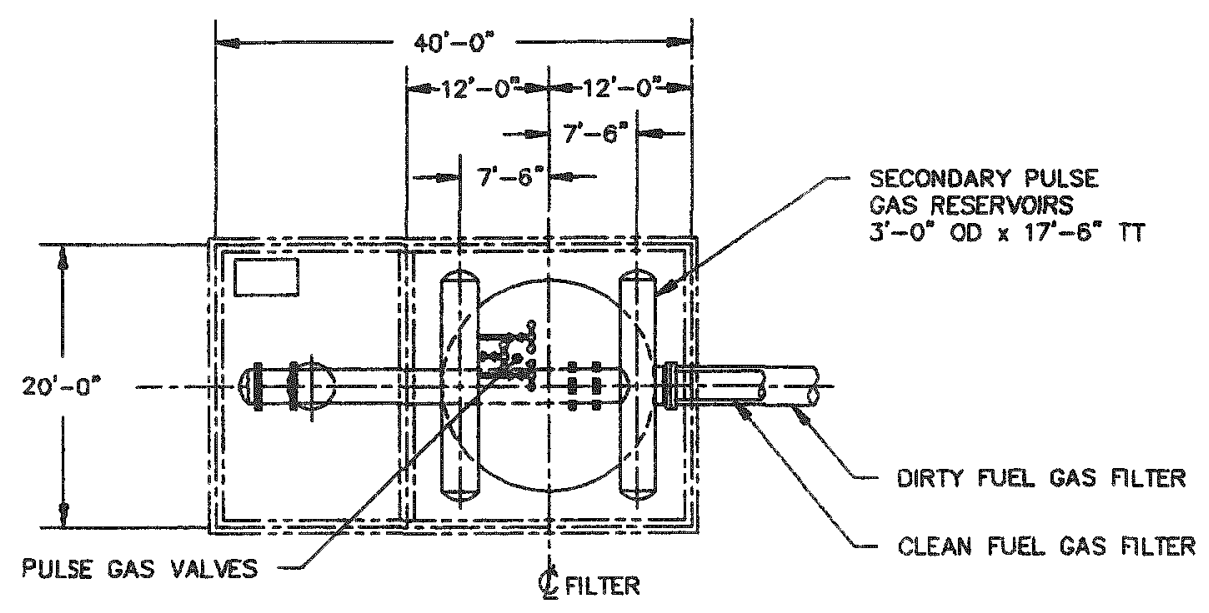

PLAN VIEW

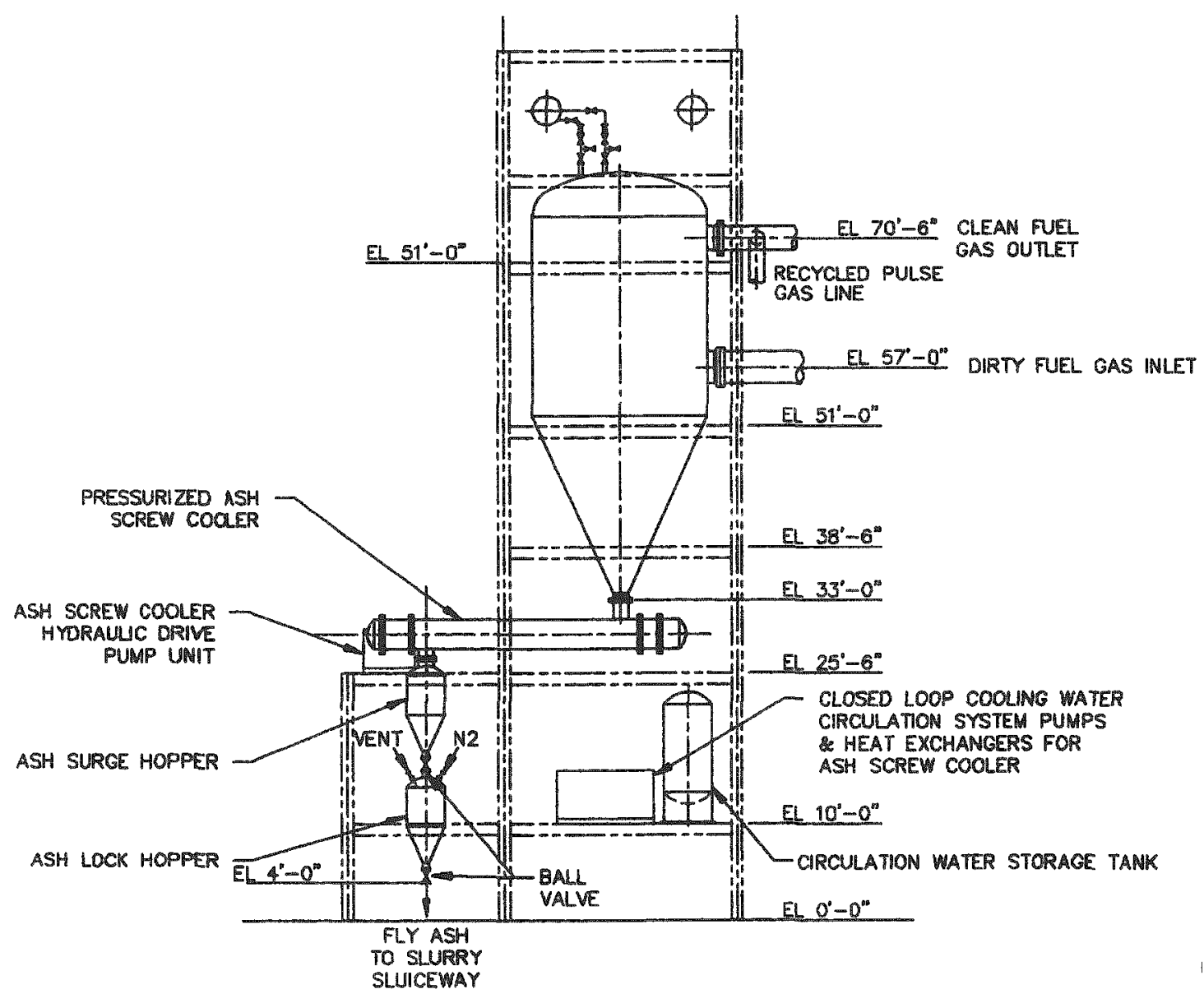

ELEVATION VIEW 
Figure 66 General Arrangement KRW Gasifier Candle Filter 
the pulse compressed air system described in the Foster Wheeler second generation PFBC study ${ }^{20}$, and the compressed air system being installed at the Tidd PFBC hot gas cleanup test facility ${ }^{5}$. Pulse air systems are supplied inlet compressed air from the transport air, boost compressor of the applicable CPFBC.

Each reciprocating compressor system has an unlimited source of pressurized air at the inlet at 268 psia and $176^{\circ} \mathrm{F}$. The outlet pressure is determined at the outlet of the duplex filters. See Table 30 for summary of pulse air design data.

In addition to the two identical and complete, reciprocating compressor trains, a third standby compressor and refrigerated air dryer is included. (See CPFBC P\&ID, Figure 52 above). Capacity of standby compressor and dryer are the same as listed in Table 30. The air dryer system for each compressor is designed for a $+35^{\circ} \mathrm{F}$ dew point at the compressor design air flow. Cooling water is assumed to be $90^{\circ} \mathrm{F}$ for the precoolers, aftercoolers, and oil cooler. An accumulator tank is supplied with each compressor train. This tank is sized using standard industry practices. A duplex type filter that allows servicing of the filter with the compressor system on line is provided on each compressor train. Filters remove particles down to three (3) micron in size. Maximum total oil or hydrocarbon content in the compressed air outlet does not exceed one (1) ppm w/w or $\mathrm{v} / \mathrm{v}$ under normal operating conditions.

Table 30 CPFBC Pulse Air System

(226 MWe Basis)

\begin{tabular}{lccc}
\hline & \multicolumn{2}{c}{ Flow } & Pressure \\
& $\mathrm{lb} / \mathrm{hr}$ & $\mathrm{scfm}^{*}$ & psia \\
\hline Design & 17,035 & 3786 & 490 \\
Normal Operation & 13,628 & 3028 & 390 \\
Minimum Operation & 6,814 & 1514 & 290 \\
Inlet & As Nec. & - & 268 \\
* Standard Air Density is $0.075 \mathrm{lb} / \mathrm{cu} . \mathrm{ft} @ 14.7$ psia and $70^{\circ} \mathrm{F}$ & \\
\hline
\end{tabular}

The driver supplied with each reciprocating compressor is a $250 \mathrm{hp}$, $460 \mathrm{~V} / 3 \mathrm{Ph} / 60 \mathrm{hz}$, induction type motor. At a discharge pressure of 490 psia and full capacity, 237 bhp is utilized. Electric controls and instruments are included in a NEMA 4 panel enclosure with local wiring and sense lines connected. 


\subsubsection{Pulse System, Carbonizer/Gasifier}

In the base studies for the Foster Wheeler second generation PFBC plant ${ }^{20}$ and the KRW air blown gasifier ${ }^{26}$, pulse gas for cleaning the candle filter elements was supplied by stored nitrogen. This approach was investigated for the candle filters based on the estimated pulse gas quantities calculated. Equipment initially defined for these applications consisted of liquid nitrogen storage tanks, a liquid nitrogen compressor, and a liquid nitrogen vaporizer system. This is the basic system proposed for the cross-flow filter that was originally part of the $100 \mathrm{MWe}$ KRW air blown gasifier ${ }^{26}$. Because of the large capacity of nitrogen specified, all suppliers contacted declined to quote based on liquid nitrogen storage. Instead, these suppliers recommended on-site generation. Two types of nitrogen producing plants were considered. Cryogenic plants produce nitrogen of very high purity, in the range of $99.9 \%$ or better, while pressure swing adsorption (PSA) type plants produce nitrogen with purity of 95 to $99 \%$. Our requirement for nitrogen purity for the candle filter back pulse gas was estimated at a minimum of $98 \%$. Since very high purity nitrogen (i.e. $99.9 \%$ or above) was not required, PSA type nitrogen generating plants were utilized for both applications.

Nitrogen is produced from air in the PSA process. The key components of this system are carbon molecular sieve beds which are exposed to compressed air, the only feedstock. The system is comprised of a compressor, refrigerated dryer, and pressure vessels charged with molecular sieves and controls. A microprocessor and sensing devices monitor, regulate, and control the adsorption and desorption nitrogen production cycle.

PSA nitrogen generating plants do not include any type of backup system to supply compressed nitrogen to the candle filter in the event of nitrogen generating plant failure. Since pulse gas usage is continuous, the loss of pulse gas would quickly curtail the operation of the candle filter. Consequently, a reliable standby source of nitrogen is included. A specification for a standby nitrogen gas system was prepared, based on the system described for the gasifier cross-flow filter in the Westinghouse gasifier study ${ }^{26}$. The liquid nitrogen tanks were sized to store only a 12-hour supply of nitrogen based on normal full load operation as opposed to a multi-day supply in the Foster Wheeler second generation PFBC. A 12-hour supply of nitrogen should allow ample time to repair the main PSA nitrogen generating system should this be necessary. If the PSA nitrogen generating system cannot be repaired in 12 hours, the standby liquid storage tank can be refilled as needed to keep the carbonizer or gasifier plant operational.

- Process Gas for pulse cleaning

Review of the quotations for the on-site nitrogen generating plant indicated that the capital costs and operating costs were quite high. In addition to the high cost of generating nitrogen, the injection of inert nitrogen in quantities of up to nearly $2 \%$ of total gas flow through the candle filter will dilute the fuel gas supplied to the turbine. As an option, process gas can be conditioned to serve as pulse gas. Conditioning would include cooling, cleaning, drying, and pressurizing.

Process gas from downstream of the candle filter can be cooled from $1500^{\circ} \mathrm{F}$ or $1600^{\circ} \mathrm{F}$, depending on the application, down to $120-250^{\circ} \mathrm{F}$ which is suitable for the inlet 
of a compressor system. Several types of heat exchangers and heat exchanger combinations are possible for this application. The least cost approach utilizes a small heat recovery boiler followed by water-cooled heat exchanger. With this approach, it is possible to cool to $120^{\circ} \mathrm{F}$. The simplest, but more costly, approach utilizes a single, natural draft type convection heat exchanger. With this approach, cooling to $250^{\circ} \mathrm{F}$ is more typical, and a compressor precooler is needed to reach $120^{\circ} \mathrm{F}$. Once cooled to $120^{\circ} \mathrm{F}$, the process gas enters a compressor system consisting of a duplex filter/mist eliminator, boost compressor, refrigerated gas dryer system, and accumulator tank.

The capital costs and operating costs for these alternatives were compared, and the results are presented on Table 31 . Clearly for these alternatives, it is less costly to use process gas for pulse cleaning of the candle filter elements. The use of a heat recovery boiler instead of a air cooled natural convection heat exchanger will probably not effect the overall economics of the filter plant, but is also less expensive. This study does not consider implications beyond the cost and data presented. There may be significant costs associated with matters that were not taken into account; such as disposal of waste condensate from process gas cooling.

The heat recovery boiler is sized to cool flue gas from the carbonizer filter outlet from $1500^{\circ} \mathrm{F}$ to $400^{\circ} \mathrm{F}$. It is followed by a water-cooled heat exchanger (trim cooler) which further reduces the flue gas temperature to $120^{\circ} \mathrm{F}$. For the gasifier, candle filter outlet gas is cooled from $1600^{\circ} \mathrm{F}$ to $400^{\circ} \mathrm{F}$ in the boiler, then to $120^{\circ} \mathrm{F}$ in the trim cooler. At $120^{\circ} \mathrm{F}$, the gas can be filtered and compressed without any further precooling. Steam produced is saturated at $40 \mathrm{psig}$ with a feedwater inlet temperature of $240^{\circ} \mathrm{F}$. Pricing for the boiler includes all standard boiler trim, and valves, from the feedwater control valve station through the steam outlet stop check valve. The optional, air-cooled, natural draft convection air heater contains no moving parts or controls. Hot flue gas is passed through heat exchanger tubing and is cooled by ambient air drawn through the unit by natural draft. Air is typically heated from ambient to $500^{\circ} \mathrm{F}$. At the high temperature flue gas inlet of the heat exchanger, the allowable tube stresses are very low, requiring heavy wall thicknesses. From the natural draft heat exchanger, the flue gas is typically cooled to $250^{\circ} \mathrm{F}$ requiring a precooler prior to the boost compressor.

Downstream of the heat recovery boiler and trim cooler is a packaged compressor system. For the carbonizer filter, process gas is boosted in pressure from 204 psia to a maximum of 508 psia, see Table 31. For the gasifier filter, the pressure rise is from 381 psia to a maximum of 685 psia. Reciprocating compressors fitted with suitable materials to resist corrosion from the fuel gas are motor driven through v-belt drives. Motor sizes are $125 \mathrm{HP}$ and $150 \mathrm{HP}, 1800 \mathrm{RPM}, 460 \mathrm{~V}, \mathrm{TEFC}$ for the carbonizer and the gasifier respectively. Compressor system auxiliaries include refrigerated dryer systems for $+35^{\circ} \mathrm{F}$ dew point gases, water-cooled aftercoolers, duplex air filters with switching valves, main air receivers tanks, and controls locally tubes or wired to a local panel. For the carbonizer, there is one complete compressor system for each 226 MWe filter module. A spare compressor, aftercooler, and refrigerated dryer is also supplied that can be valved into either filter module. For the gasifier, one complete compressor system is included with a spare compressor, aftercooler, and refrigerated gas dryer. 
Table 31 Pulse Gas Parameters - Carbonizer/Gasifier

\begin{tabular}{lrr}
\hline Parameter & Carbonizer & Gasifier \\
\hline Capacity Basis, MWe & 226 & 100 \\
Operating Flow, lb/hr & 2,995 & 5,410 \\
Inlet Operating Pres., psia* & 204 & 381 \\
Outlet Operating Pres., psia & 408 & 585 \\
Outlet Design Pres, psia & 508 & 685 \\
& & \\
Process Gas Flow, Design & & 7,150 \\
Wet, Inlet, lb/hr & 4,300 & \\
Nitrogen Gas Flow, Design & & 8,030 \\
lb/hr & 4,079 &
\end{tabular}

Pulse Gas Supply Alternatives
Nitrogen Storage
Nitrogen Generation, PSA
Power Usage, hp
Process Gas Conditioning
Power Usage, hp
Nitrogen Backup, 12-hr
Power Supply, hp

\section{Process Gas Cooling Alternatives}

Nat. Conv. Ht. Exchr.

Heat Recovery Blr
No Quote

$\$ 993,000$

640

$\$ 327,500$

105

$\$ 90,000$

10
No Quote

$\$ 1,946,000$

980

$\$ 405,000$

134

$\$ 270,000$

25

* Applies to process gas only: $+/-10 \mathrm{psi}$. Inlet operating pressure for nitrogen generating equipment is atmospheric.

\subsubsection{Pulse Gas Distribution}

The Tidd candle filter ${ }^{5}$ utilizes one solenoid valve to pulse three separate manifolds. These manifolds are isolated by actuated ball valves downstream of each solenoid valve. Assuming the extra piping and bends required to service these manifolds from one solenoid valve is not excessive, this arrangement should not degrade the pulse gas cleaning effectiveness. We are proposing a similar design; since, the number of solenoid valves is reduced by two-thirds and the cost of the solenoid valves is much greater than the ball valves used to isolate them. Each solenoid valve will pulse a maximum of three manifolds by branching to the three lines directly downstream of the solenoid valve. A 
normally closed, actuated ball valve will be installed in each manifold supply line. The ball valve at the inlet to each manifold will be opened a few seconds before the solenoid valve actuates. The ball valves on the other two lines will remain closed. After the manifold is pulsed, the ball valve will be closed. Since the normal position of the ball valves will be closed, the chance for leakage of pulse gas into the filter is minimized. Figure 67 shows the proposed distribution of pulse gas from the secondary reservoirs installed local to the filter vessels. There is no back-up solenoid valve as provided at Tidd because these are all large systems, and the temporary loss of a single pulse circuit can be temporarily compensated for by pulsing the other circuits more often. The pulse valves proposed are 2" Atkomatic quick opening pilot actuated solenoid valve.

\subsubsection{Ash Handling, CPFBC/Carbonizer}

The CPFBC candle filter ash handling system uses the same components and configuration as proposed in the Foster Wheeler study ${ }^{20}$ except for the addition of one small refractory lined vessel for each two candle filter vessels. This small refractory lined vessel, called a candle filter ash vessel, is required because there are two candle filter vessels to replace each cross-flow filter vessel. This vessel combines the ash from two candle filter vessels so that the ash system equipment beyond the outlet of this vessel is identical to the equipment described in the Foster Wheeler study ${ }^{20}$. The ash is depressurized using restricted pipe discharge (RPD) vessels and then cooled using watercooled screw conveyors. A detailed description of the CPFBC ash system is given in the Foster Wheeler report.

The carbonizer candle filter does not have any ash handling equipment because the ash from the filter is discharged directly into the carbonizer collecting hopper. A detail description of this equipment is given in the Foster Wheeler report.

\subsubsection{Ash Handling, Gasifier}

The ash system proposed for the gasifier in the Westinghouse study ${ }^{26}$ consists of a pressurized water-cooled screw conveyor to cool the ash then a series of lock hoppers for depressurizing the cooled ash. The information and description of this ash system given in the Westinghouse report consists of a process flow diagram mearly showing a concept of the equipment. Incidently, both the Grimethorpe ${ }^{4}$ and Tidd ${ }^{5}$ candle filter plants use this ash system approach. To obtain current costs and design information for the ash system for the gasifier candle filter, specifications were prepared for a pressurized water-cooled screw conveyor and required lock hopper valves and submitted to vendors for quotation. Information from reports on the ash systems at Grimethorpe and Tidd served as basis for these specifications.

\section{- Pressurized Ash, Screw Cooler}

The function of the pressurized ash, screw cooler is to reduce the candle filter ash temperature from $1600^{\circ} \mathrm{F}$ to approximately $400^{\circ} \mathrm{F}$ while the ash is still at full system pressure. In this arrangement, the inlet of the ash cooler is connected directly to the 
outlet of the gasifier candle filter, so the it must be designed for the same pressure conditions as the candle filter vessel, or 410 psig. There are advantages to cooling the ash from $1600^{\circ} \mathrm{F}$ down to $400^{\circ} \mathrm{F}$ before it is depressurized through lock hoppers. The first advantage is in cost savings on the lock hopper valves. A valve designed for operation in ash at $410 \mathrm{psig}$ and $1600^{\circ} \mathrm{F}$ has a high capital and maintenance cost. If the ash temperature is reduced to $400^{\circ} \mathrm{F}$ prior to depressurizing, both the capital and maintenance costs of the valves are greatly reduced. Information obtained from one valve manufacturers indicates that capital cost for the low temperature valves for a gasifier plant would be a $1 / 4$ of the cost for high temperature valves of the same size and pressure rating. The vendor also estimated that valve repair costs for the lower temperature valves over a 5 year period would be $1 / 8$ that of the high temperature valves, not including costs for down time. An estimate of the total savings in capital and repair costs for low temperature valves verses high temperature valves for the gasifier ash system is over $\$ 500,000$ in a 5 year period. In addition, the low temperature lock hoppers can be made from carbon steel without a refractory lining.

Figure 68 shows a typical arrangement of a pressurized ash screw cooler. It is comprised of a cylindrical outer shell, the cooling screw and the hydraulic drive unit. The ash cooler is similar to a standard water-cooled screw conveyor except the outer, watercooled shell is a pressure vessel. The unique feature of this equipment is the separate chambers on each end of the screw that house the cooling water transfer flexible coupling at one end and the hydraulic drive motor at the other. Both of these chambers are purged with nitrogen to keep these areas free of ash.

Since the screw cooler is directly connected to the gasifier filter, there could be condensation from the process gases on the cool metal surfaces of the screw if standard plant cooling water of approximately $90^{\circ} \mathrm{F}$ was utilized. In order to prevent this condensation from forming, causing ash flow problems, the water circulated through the screw remains heated in a separate, closed loop cooling water system. This closed loop circulation system allows the metal surfaces of the ash screw cooler to be maintained at temperatures of $350^{\circ} \mathrm{F}$ to $380^{\circ} \mathrm{F}$.

This closed loop cooling water circulation system consists of:

- a main water storage tank

- a electric heater for preheating the loop during startup

- two $100 \%$ capacity main circulation pumps each with $5 \mathrm{hp}$ motors

- flow meters, psv valves, and flow control valves

- water-cooled heat exchanger cooled with plant cooling water

- small water storage tank to feed boost pumps

- two small, 100\% capacity boost pumps with $1 \mathrm{hp}$ motors that maintain the loop at desired pressure at all times

- actuated valves to allow flow of plant cooling water through the screw cooler to protect the unit in case of complete failure of the closed loop system

- instruments and controls 
For a compete schematic of the closed loop circulation system, the pressurized ash screw, and the ash look hoppers see Figure 54, the piping and instrumentation diagram for the gasifier.

\subsection{Filter Plant Construction}

The Foster Wheeler study ${ }^{20}$ notes that considerable utility experience in bargeshipping and erection of large steam generator vessels exists as a result of the expanding nuclear industry in the 1960's and 1970's. Several vessels weighing up to 800 tons have been shipped and erected. Several contractors in the United States specialize in transporting and rigging this heavy equipment. Thus there appears to be no major obstacle to supplying the much smaller filter vessels in a similar way. Filter vessels are assumed to be moved from a barge to the construction site by crawler/transporters as shown in the Foster Wheeler report.

- General Installation Information

The following is installation information that applies to all three candle filter applications.

Candle Filter Vessel(s): Each candle filter vessel will be shipped to the site with the tubesheet and tubesheet support installed. Since the baffle when installed would interfere with the refractory installation it is shipped inside the vessel in three 120 degree sections. The internal refractory will be field installed after the vessel is positioned. Once the refractory is installed, the baffle will be assembled inside the vessel.

Candle Filter Element Installation: Each element is about 5 feet in length and weights about 9 pounds. Each element is supported in the tubesheet in a support fixture with ring gaskets on both sides of the element flange. All of the candle filter elements will have to be installed inside the vessel in the field after the internal refractory is installed. There is a total of 1572 elements per filter vessel in the CPFBC, 1130 elements per filter vessel in the carbonizer, and 906 elements per filter vessel in the gasifier. Installation of the filter elements is similar to installing bags in a pulse jet type baghouse in that care must be taken to prevent damage to the filter elements.

Pulse Piping Inside Vessels: Once the candle filter elements are installed, pulse air or gas manifolds and piping must be installed inside the vessel. All of the these manifolds and pipe spools will be shop fabricated to the greatest extent to reduce field installation labor.

Secondary Pulse Reservoirs: Each filter vessel has two of these reservoirs which have a number of nozzles to connect air or gas to the pulse piping. These reservoirs will be shop fabricated and lifted into place.

Pulse Valve Piping: This is the installation of valves and piping spools that supply air or gas from the secondary reservoirs to the nozzles in the head of the filter vessel. Figure 67 shows the typical installation details of this piping and valves. 
Compressor Skids and Refrigerated Dryer Skids: Each filter installation includes air or gas compressor and refrigerated dryer equipment. This equipment will be shipped to the site skid mounted and assembled to the greatest extend possible. Piping between skids will be installed in the field.

- CPFBC Candle Filters

Table 32 lists the equipment for this plant. Each candle filter plant consists of four filters as shown on Figure 64. There are two identical candle filter modules as the entire plant is divided into two identical trains of equipment, each sized for, nominally, 226 MWe.

Some costs are not included in the construction estimate, these are: refractory and instruments/controls. The candle filter vessels will have refractory installed in the vessels once they are in place at the site. Other smaller refractory lined vessels and piping for the ash system will have refractory installed off site. Refractory costs include installation.

The ash system installation for the CPFBC candle filters consists of installing block and vent valves, restricted pipe discharge hoppers, ash collecting hopper, ash screw coolers, and connecting refractory lined pipe.

- Carbonizer Candle Filter

Table 33 lists the equipment for this plant. Each filter module consists of one filter vessel with pulse gas reservoirs and piping as shown on above Figure 65 . The cyclone and the carbonizer collecting hopper, shown in phantom are not part of the installation. There are two identical filter modules as the entire plant is divided into two identical trains of equipment, each sized for, nominally, 226 MWe.

- Gasifier Candle Filter

Table 34 lists the equipment for this plant. Each filter module consists of one filter vessel with ash cooling and depressurization equipment as shown in above Figure 66. There is one filter vessel, sized for 100 MWe. 


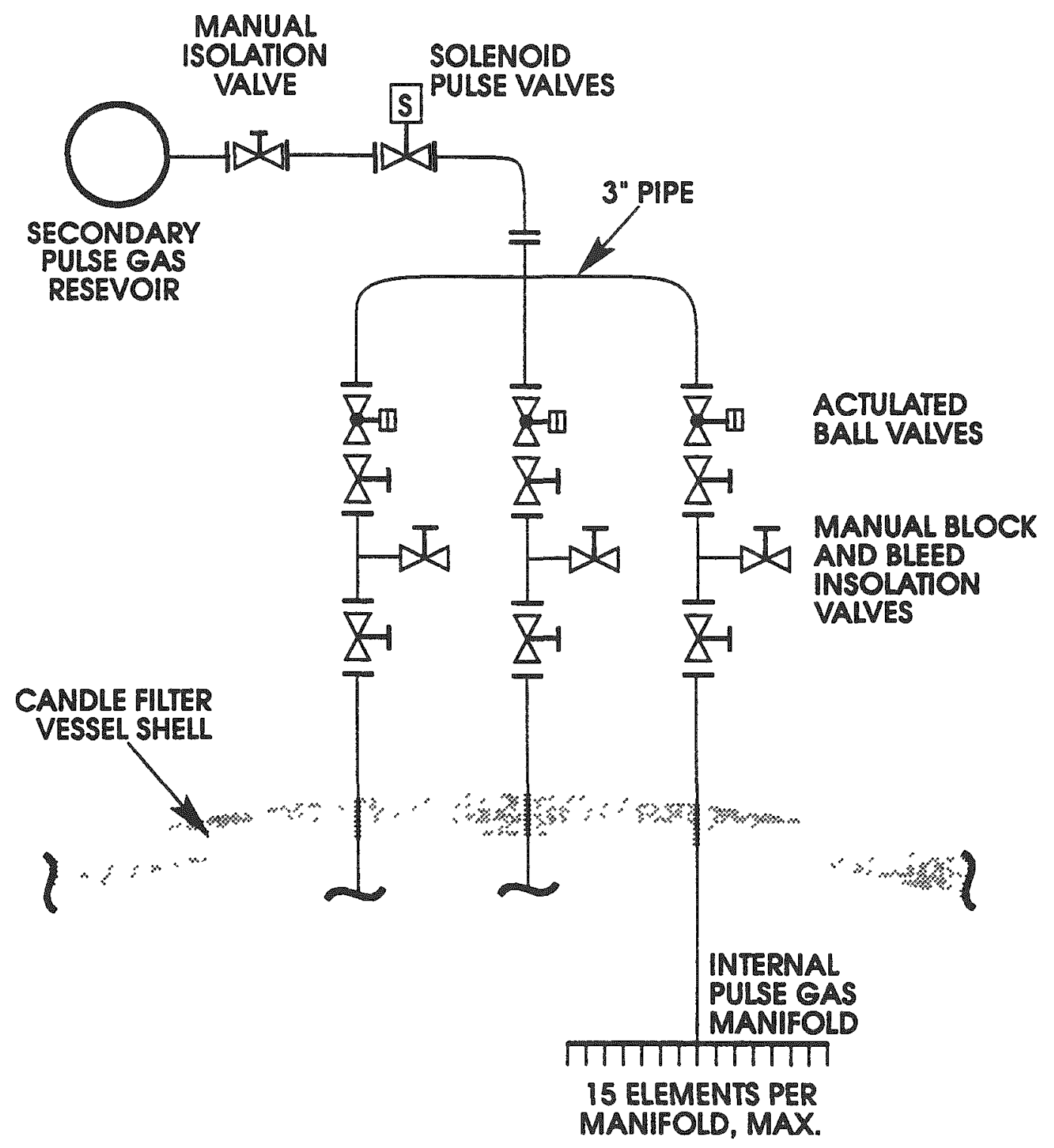

Figure 67 Pulse Gas Piping 


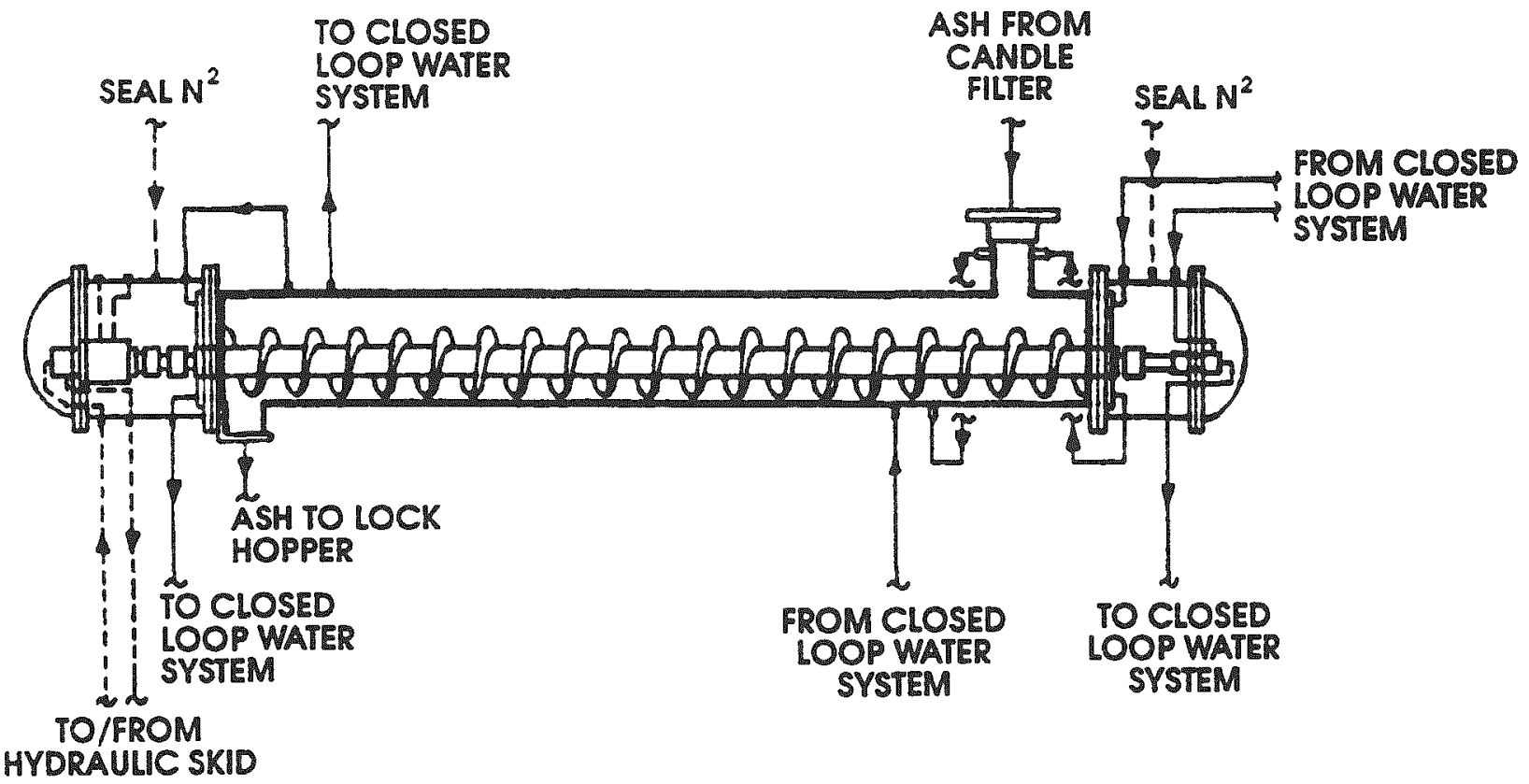

Figure 68 Water-Cooled Screw 
Table 32 CPFBC Candle Filter Equipment - 226 MWe Module

\begin{tabular}{|c|c|c|c|c|}
\hline $\begin{array}{l}\text { Filter } \\
\text { Components }\end{array}$ & Qty & $\begin{array}{l}\text { Unit } \\
\text { Weight } \\
\text { (lbs) }\end{array}$ & $\begin{array}{l}\text { Size or } \\
\text { Capacity, } \\
\text { (each) }\end{array}$ & $\begin{array}{l}\text { Installed/ } \\
\text { Operating } \\
\quad \mathrm{Hp}\end{array}$ \\
\hline $\begin{array}{l}\text { Filter Vessels } \\
\text { includes tubesheet an }\end{array}$ & $\begin{array}{c}4 \\
\text { affle }\end{array}$ & 232,000 & $22^{\prime}$ Dia X 51' & - \\
\hline Vessel Refractory & 4 & 138,000 & & - \\
\hline Candle Elements & 6288 & 9 & $60 \mathrm{~mm} \mathrm{OD} \mathrm{X} 1.5 \mathrm{~m}$ & - \\
\hline \multicolumn{5}{|l|}{ Pulse Air System } \\
\hline Air Compressor Skid & $1.5^{1}$ & 25,000 & $15^{\prime} \mathrm{L} \times 10^{\circ} \mathrm{W} \times 8^{\prime} \mathrm{H}$ & $250 / 237$ \\
\hline Refr. Dryer Skid & $1.5^{1}$ & 3,500 & $10^{\prime} \mathrm{L} \times 5^{\prime} \mathrm{W} \times 10^{\prime} \mathrm{H}$ & $25 / 20$ \\
\hline $\begin{array}{l}\text { Main Receiver Tank } \\
\text { and Filter Skid }\end{array}$ & 1 & 30,000 & $12^{\prime} \mathrm{L} \times 6^{\prime} \mathrm{W} \times 12^{\prime} \mathrm{H}$ & - \\
\hline Sec. Reservoir Tank & 8 & 6,000 & $3^{\prime}$ Dia X 22' & - \\
\hline Piping/Valves & $1 \mathrm{Lot}$ & 236,000 & & - \\
\hline Insulation & 1 Lot & - & & - \\
\hline Access/Support Stl. & $1 \mathrm{Lot}$ & 594,000 & & - \\
\hline Instr/Controls & $1 \mathrm{Lot}$ & - & & - \\
\hline Inlet/Outlet Ducting & 1 Lot & 470,000 & & - \\
\hline \multicolumn{5}{|c|}{ Ash System for CPFBC Candle Filter } \\
\hline C/F Ash Vessels & 2 & 5,600 & $7^{\prime}$ Dia X 10' & - \\
\hline Refractory & 2 & 10,200 & & - \\
\hline $500^{\circ} \mathrm{F}$ Ball Valve & 4 & 200 & $6^{\prime \prime}$ & - \\
\hline $500^{\circ} \mathrm{F}$ Bleed Valve & 2 & 50 & $2^{\prime \prime}$ & - \\
\hline RPD Vessel-C'Stl ${ }^{2}$ & 2 & 8,810 & $7^{\prime}$ Dia X $12.5^{\prime}$ & - \\
\hline Refractory & 2 & 12,900 & & - \\
\hline Throt'lg Slide Gate & 2 & 200 & $6^{\prime \prime}$ & - \\
\hline Ash Coll. Hopper & 1 & 5,300 & $7^{\prime}$ Dia X $10^{\prime}$ & - \\
\hline Refractory & 1 & 5,100 & & - \\
\hline Refr Lined Pipe & $1 \mathrm{Lot}$ & 18,700 & $18^{\prime}$ Pipe X $230^{\prime}$ & - \\
\hline Refractory & 1 & 12,200 & & - \\
\hline Slide Gate Valve & 2 & 200 & $6^{\prime \prime}$ & - \\
\hline Ash Screw Coolers & 2 & 28,000 & $25^{\circ} \mathrm{L} \times 4^{\prime} \mathrm{W} \times 3^{\circ} \mathrm{H}$ & $30 / 15$ \\
\hline \multicolumn{5}{|c|}{$\begin{array}{l}\text { Notes: } \\
\text { 1. Includes stand-by compressor equipment shared by each module. } \\
\text { 2. Restricted-Pipe Discharge ash hopper. }\end{array}$} \\
\hline
\end{tabular}


Table 33 Carbonizer Candle Filter Equipment - 226 MWe Module

\begin{tabular}{|c|c|c|c|c|}
\hline $\begin{array}{l}\text { Filter } \\
\text { Components }\end{array}$ & Qty & $\begin{array}{c}\text { Unit } \\
\text { Weight } \\
\text { (lbs) }\end{array}$ & $\begin{array}{c}\text { Size or } \\
\text { Capacity, } \\
\text { (each) }\end{array}$ & $\begin{array}{c}\text { Installed/ } \\
\text { Operating } \\
\mathrm{Hp}\end{array}$ \\
\hline $\begin{array}{l}\text { Filter Vessel } \\
\text { includes tubesheet and }\end{array}$ & $\begin{array}{c}1 \\
\text { baffle }\end{array}$ & 180,000 & $19^{\prime}-6^{\prime \prime}$ Dia X 46' & - \\
\hline Vessel Refractory & 1 & 110,000 & & - \\
\hline Candle Elements & 1130 & 9 & $60 \mathrm{~mm}$ OD X $1.5 \mathrm{~m}$ & - \\
\hline \multicolumn{5}{|l|}{ Pulse Gas System } \\
\hline Refr Lined Pipe & 1 & 11,000 & $18^{\prime \prime}$ Pipe X $135^{\prime}$ & - \\
\hline Refractory & 1 & 7,200 & & - \\
\hline Boiler/Cooler Skid & 1 & 10,000 & $15^{\prime} \mathrm{L} \times 5^{\prime} \mathrm{W} \times 8^{\prime} \mathrm{H}$ & - \\
\hline Gas Precooler Skid & 1 & 4,000 & $10^{\circ} \mathrm{L} \mathrm{X} 2^{\circ} \mathrm{W} \times 2^{\prime} \mathrm{H}$ & - \\
\hline Gas Compressor Skid & $1.5^{1}$ & 20,000 & $15^{\prime} \mathrm{L} X 10^{\prime} \mathrm{W} X 8^{\prime} \mathrm{H}$ & $125 / 100$ \\
\hline Refr. Dryer Skid & $1.5^{1}$ & 3,500 & $8^{\prime} \mathrm{L} \times 4^{\prime} \mathrm{W} \times 8^{\prime} \mathrm{H}$ & $10 / 5$ \\
\hline $\begin{array}{l}\text { Main Receiver Tank } \\
\text { and Filter Skid }\end{array}$ & 1 & 22,000 & $12^{\prime} \mathrm{L}$ X $6^{\circ} \mathrm{W} \times 12^{\prime} \mathrm{H}$ & - \\
\hline Sec. Reservoir Tank & 2 & 6,000 & $3^{\prime}$ Dia X 19'-6" & - \\
\hline Piping/Valves & 1 Lot & 46,400 & & - \\
\hline Insulation & 1 Lot & - & & - \\
\hline Access/Support Stl. & 1 Lot & 180,000 & & - \\
\hline Instr/Controls & 1 Lot & - & & - \\
\hline
\end{tabular}


Table 34 Gasifier Candle Filter Equipment - 100 MWe Plant

\begin{tabular}{|c|c|c|c|c|}
\hline $\begin{array}{l}\text { Filter } \\
\text { Components }\end{array}$ & Qty & $\begin{array}{c}\text { Unit } \\
\text { Weight } \\
\text { (lbs) } \\
\end{array}$ & $\begin{array}{c}\text { Size or } \\
\text { Capacity, } \\
\text { (each) }\end{array}$ & $\begin{array}{c}\text { Installed/ } \\
\text { Operating } \\
\mathrm{Hp}\end{array}$ \\
\hline $\begin{array}{l}\text { Filter Vessel } \\
\text { includes tubesheet and }\end{array}$ & $\begin{array}{c}1 \\
\text { affle }\end{array}$ & 265,000 & $18^{\prime}$ Dia X $46^{\prime}$ & - \\
\hline Vessel Refractory & 1 & 99,000 & & - \\
\hline Candle Elements & 906 & 9 & $60 \mathrm{~mm}$ OD X $1.5 \mathrm{~m}$ & - \\
\hline \multicolumn{5}{|l|}{ Pulse Gas System } \\
\hline Refr Lined Pipe & 1 & 9,300 & 18" Pipe X 75' & - \\
\hline Refractory & 1 & 4,000 & & - \\
\hline Boiler/Cooler Skid & 1 & 10,000 & $1^{\prime} \mathrm{L} \times 5^{\prime} \mathrm{W} \times 8^{\prime} \mathrm{H}$ & - \\
\hline Gas Precooler Skid & 1 & 4,000 & $10^{\prime} \mathrm{L} \times 2^{\prime} \mathrm{W} \times 2^{\prime} \mathrm{H}$ & - \\
\hline Gas Compressor Skid & $2^{1}$ & 20,000 & $15^{\prime} \mathrm{L} \times 10^{\circ} \mathrm{W} \times 8^{\prime} \mathrm{H}$ & $150 / 126$ \\
\hline Refr. Dryer Skid & $2^{1}$ & 3,500 & 8'L X 4'W X 8'H & $10 / 8$ \\
\hline $\begin{array}{l}\text { Main Receiver Tank } \\
\text { and Filter Skid }\end{array}$ & 1 & 22,000 & $12^{\prime} \mathrm{L} \mathrm{X} 6^{\prime} \mathrm{W} \times 12^{\prime} \mathrm{H}$ & - \\
\hline Sec. Reservoir Tank & 2 & 7,000 & 3' Dia X 19' & - \\
\hline Piping/Valves & 1 Lot & 38,000 & & - \\
\hline Insulation & 1 Lot & - & & - \\
\hline Access/Support Stl. & 1 Lot & 90,000 & & - \\
\hline Instr/Controls & 1 Lot & - & & - \\
\hline \multicolumn{5}{|c|}{ Ash System for Gasifier Candle Filter } \\
\hline Ash Screw Cooler & 1 & 90,000 & $25^{\circ} \mathrm{L} \times 3^{\prime} \mathrm{W} \times 3^{\prime} \mathrm{H}$ & - \\
\hline $\begin{array}{l}\text { Ash Screw Cooler } \\
\text { Hyd. Drive Unit Skid }\end{array}$ & 1 & 2,000 & $5^{\prime} \mathrm{L} \mathrm{X} \mathrm{3'W} \mathrm{X} \mathrm{3'H}$ & $5 / 5$ \\
\hline $\begin{array}{l}\text { Closed Loop Water } \\
\text { System Pump Skid }\end{array}$ & 1 & 9,000 & $10^{\prime} \mathrm{L} \mathrm{X} \mathrm{6'W} \mathrm{X} \mathrm{6'H}$ & $5 / 2$ \\
\hline $\begin{array}{l}\text { Closed Loop Water } \\
\text { System Water Tank }\end{array}$ & 1 & 5,000 & 4'-6" Dia X 14' & - \\
\hline Ash Lock Hoppers & 2 & 4,000 & $4^{\prime}$ Dia X 10' & - \\
\hline $500^{\circ} \mathrm{F}$ Ball Valves & 2 & 200 & $6^{\prime \prime}$ & - \\
\hline \multicolumn{3}{|l|}{ Notes: } & & \\
\hline
\end{tabular}




\subsection{References}

1. Alvin, M.A., T.E. Lippert, and J.E. Lane. 1991. Assessment of Porous Ceramic Materials for Hot Gas Filtration Applications. Ceramic Bulletin, Vols 70, No. 9.

2. Birkby, C., J.M. Wheeldon, O.J. Tassicker, and G.P. Reed. May, 1987. Process Design and Proposed Test Programme for a Filter Unit Operation in the Off-Gas Path of a Pressurized Fluidized Bed Combustor. In Proceedings of the 1987 International Conference on Fluidized Bed Combustion, ed. J.P. Mustonen, 993-999. Boston, MA.: New York, NY: ASME.

3. Reed, G.P., G.K. Burnard, G.K. Tassicker, and A.J. Leitch. 1987. A Large Ceramic Candle Filter Module on a Pressurized Bed Combustion - Description and Preliminary Data. In Advanced Coal Power Plant Technology and Hot Gas Cleaning Conference. Duesseldorf, Germany.

4. Stringer, J., A.J. Leitch, and R.K. Clark. April, 1991. The EPRI Hot Gas Filter Pilot Plant At Grimethorpe: What Worked, What Broke and Where Do We Go Now? In Proceedings of the 1991 International Conference on Fluidized Bed Combustion, ed. E.J. Anthony, 971-984. Montreal, Canada.: New York, NY: ASME.

5. Mudd, M.J., J.D. Hoffman, and C.M. Zeh. July, 1991. Update of Tidd PFBC Hot Gas Clean Up Test Facility. In Proceedings of the Eighth Annual Coal-Fueled Heat Engines and Gas Stream Cleanup Systems Contractors Review Meeting, ed. H.A. Webb, R.C. Bedick, D.W. Geiling, and D.C. Cicero, 89-97. DOE/METC-91/6122 (DE91002091). Morgantown, West Virginia: Morgantown Energy Technology Center.

6. Schiffer, H.P., U. Renz, O.J. Tassicker, and E.K. Reinhardt. May, 1987. Study of Ceramic Filter Elements For PFBC Hot Gas Cleanup. In Proceedings of the 1987 International Conference on Fluidized Bed Combustion, ed. J.P. Mustonen, 1000-1007. Boston, MA.: New York, NY: ASME.

7. Schiffer, H.P., U. Renz, and O.J. Tassicker. April, 1989. Hot Gas Filtration Research at the RWTH Aachen PFBC Facilities. In proceedings of the 1989 International Conference on Fluidized Bed Combustion, ed. A.M. Manaker, 487-494. San Francisco, CA: New York, NY: ASME.

8. Zievers, J.F., P. Eggerstedt, E.C. Zievers, and D. Nicolai. October, 1991. Lightweight Ceramic Materials Make High Temperature Gas Filtration Simpler. Deutsche Keramische Gesellschaft e.V. (DKG), Erlangen/Nurnberg.

9. Dennis, R.A. August, 1990. Evaluation of Dust Cake Filtration at High Temperature With Effluence from an Atmospheric Fluidized-Bed Combustor. Technical note: DOE/METC91/4105. Morgantown, West Virginia: Morgantown Energy Technology Center.

10. Notes from meeting with J. F. Zievers of Industrial Filter \& Pump Mfg. Co. at Combustion Power Co. offices in Menlo Park, CA on November 13, 1991 
11. Furuya, K. and K. Higashi. April, 1989. Advanced Filter Test Program at Wakawatsu For PFBC Hot Gas Clean Up. In proceedings of the 1989 International Conference on Fluidized Bed Combustion, ed. A.M. Manaker, 495-504. San Francisco, CA: New York, NY: ASME.

12. Cherish, P. and J.D. Holmgren. May, 1988. Hot Gas Cleanup Process Demonstration of Ceramic Filters For IGCC Power Generation. In Proceedings of the 1988 Seminar on Fluidized-Bed Combustion Technology For Utility Applications. 2-14-1 - 2-14-14. Palo Alto, CA: Palo Alto, CA: Electric Power Research Institute

13. Bossart, S.J.. October, 1989. Advanced Particle Control For Coal-Based Power Generation Systems. Presented at the Joint ASME/IEEE Power Generation Conference. Dallas, TX: New York, NY: ASME

14. Tassicker, O.J. and S.C. Yung. April, 1989. 700 Hour Test On A Tier Filter Module Utilizing Ceramic Filter Elements. In proceedings of the 1989 International Conference on Fluidized Bed Combustion, ed. A.M. Manaker, 1357-1361. San Francisco, CA: New York, NY: ASME.

15. Stephenson, M.D., L.H. Cowell, and R.T. LeCren. June, 1991. Ceramic Barrier Filters For Coal-Fueled Gas Turbine Service. Presented at the International Gas Turbine and Aeroengine Congress and Exposition. Orlando, FL: New York, NY: ASME.

16. Zeh, C.M., T-K. Chiang, and W.J. Ayers. May, 1990. Evaluating the Performance of Ceramic Candle Filters in a Hot Particulate-Laden Stream. Technical note: DOE/METC90/4099. Morgantown, West Virginia: Morgantown Energy Technology Center.

17. Mustonen, J.P., S.J. Bossart, and M. W. Durner. April, 1991. Technical and Economic Analysis of Advanced Particle Filters for PFBC Applications. In Proceedings of the 1991 International Conference on Fluidized Bed Combustion, ed. E.J. Anthony, 475-480. Montreal, Canada: New York, NY: ASME.

18. Hudson, D.M., A.N. Twigg, R.K. Clark, P. Holbrow, and A.J. Leitch. April, 1991. Durability of Ceramic Filtration Systems for Particulate Removal at High Temperature. In Proceedings of the 1991 International Conference on Fluidized Bed Combustion, ed. E.J. Anthony, 295-301, Montreal, Canada. New York, NY: ASME.

19. J.C. Haas's notes from: Second EPRI Workshop on Filtration of Dust from Coal-Derived Reducing and Combustion Gases at High Temperature. San Francisco, CA. March 11-13, 1992

20. Robertson, A., and R. Garland, R. Newby, A. Rehmat, and L. Rubow. September, 1989. Second-Generation Pressurized Fluidized Bed Combustion Plant Conceptual Design and Optimization of a Second-Generation PFB Combustion Plant, Phase 1, Task 1. Report DOE/MC/21023-2825, Vol.1. Prepared by Foster Wheeler Development Corporation, Livingston, New Jersey under contract No. DE-AC21-86MC21023.

21. Robert H. Mallett and Ray. G. Fasiczka of Swanson Engineering Associates Corp., Design, Thermal and Mechanical Analysis of a tubesheet support for a Hot Gas Cleanup 
Vessel, report No. SEAC-TR-576. Prepared for U.S. Department of Energy, Martin Marietta Energy Systems, Inc., Oak Ridge National Laboratory, Purchase Order 17X-SE259V, January 1990.

22. Fax, Mike Mudd of American Electric Power, "Hot Gas Cleanup Start-up Transient", dated March 30, 1992.

23. Mallett, R.H. and R.G. Fasiczka. January, 1990. Design, Thermal and Mechanical Analysis of a Tubesheet Support for a Hot Gas Cleanup Vessel. Report No. SEAC-TR-576. McMurray, Pennsylvania: Swanson Engineering Associates Corporation.

24. Howes, Maurice A.H. August 1987. High-Temperature Corrosion In Coal Gasification Systems. IIT Research Institute, Chicago, Illinois as subcontractor to The Materials Properties Council, Inc., New York, New York for Gas Research Institute, Chicago, Illinois. Report No. IrTRI-M08251-97. Chicago, Illinois: IIT Research Institute.

25. Kelly, J. September, 1991. RA-85H Performance in Hot Corrosion. In Heat Resistance Materials. Proceedings of the First International Conference, Fontana, Wisconsin, USA, ed. K. Natesan and D.J. Tillack, 653-658. Materials Park, Ohio: ASM International.

26. D. F. Ciliberti, T. E. Lippert. 1986. Performance Evaluation of a Ceramic Cross-Flow Filter on a Bench-Scale Coal Gasifier. Westinghouse Eighth Quarterly Report and Monthly Project Status Report for September 1, 1986 - September 30, 1986. DOE/METC Contract No. DE-AC21-84-MC21338. Morgantown, West Virginia: Morgantown Energy Technology Center. 


\section{SECTION 5}

\section{FILTER PLANT ECONOMIC ANALYSIS}

In this section the basis, approach, and outcome of the economic evaluation are described. Costs for the commercial size granular-bed and ceramic candle filter plants are presented in various forms for comparison. The cost of electricity (COE) is the key parameter and is calculated based on EPRI guidelines. These guidelines were incorporated into a Lotus 1-2-3 spreadsheet program by the Morgantown Energy Technology Center (METC). Upon completion of data entry in the form of capital costs, operating costs and fuel costs, the cost of electricity is automatically calculated and displayed. The calculation methodology is patterned after the method developed by the Electric Power Research Institute (EPRI) in their Technical Assessment Guide (TAG), Volume I, EPRI-4463-SR, December, $1986^{1}$. The cost of electricity is stated in terms of $10^{\text {th }}$ year levelized dollars.

Costs presented by Foster Wheeler for the $452 \mathrm{MWe}$, second generation pressurized fluidized bed combustion (PFBC) plant ${ }^{2}$ are updated to December 1991 costs to compare on an equivalent basis with the filters. Similarly, costs presented by Westinghouse for a 100 MWe integrated gasification combined-cycle (IGCC) plant which uses a Kellogg-RustWestinghouse (KRW) air blown gasifier ${ }^{3}$ are updated to December 1991 dollars. To the gasifier plant, the zinc ferrite system is revised according to guidelines issued by METC, and results are also presented. Both these commercial sized plant had cross-flow filters as part of the original technology.

\subsection{Cost Estimating Procedures}

Costs reported by Foster Wheeler and Westinghouse for the referenced base plants were input into the Lotus 1-2-3 spreadsheet program and manipulated to reproduce the costs of electricity reported in the source documents. This involved overriding many default values provided in the program. In the second step, the spreadsheet program was allowed to use the spreadsheet calculated financial parameters to calculate the cost of electricity. A levelizing factor is used as a financial parameter to spread costs over the 30 year life of each plant. This parameter is calculated as a different number in the spreadsheet than is reported by Foster Wheeler or Westinghouse. It is a major source of difference in the calculations by these sources. In the third step, costs for equipment, labor, fuel, and utilities were updated to December 1991 dollars. In the case of the gasifier plant, the zinc ferrite plant was updated based on information provided by METC. Costs associated with the cross-flow filters were then extracted from the plant costs and replaced with granular-bed filter costs and then with candle filter costs. The granular-bed filters required much simpler and less costly ash handling equipment than the cross-flow filters; consequently, this portion of the original cost estimates was revised. The candle filters required considerably more pulse gas than the cross-flow filters; consequently, these systems were resized and new estimates were obtained. 
Equipment specifications for major filter components were prepared and sent to qualified suppliers for quotations. Where possible, multiple quotations were received so a bid analysis could be made to identify the best response. A sampling of the new filter pressure vessels and stainless steel components were sent out for quotation. Quotations received were reduced to terms of cost-per-pound and used to estimate costs of all other similar pressure vessels and vessel internals. Refractory cost guidelines were prepared by a licensed refractory contractor familiar with these types of installations. Costs per unit area were submitted by the contractor based on the type of refractory, thicknesses, and logistics involved in applying the lining. For correlation, these costs were compared to the cost of refractory materials needed for each item, in dollars per ton, multiplied by a factor to allow for installation.

Annual operation and maintenance costs were reviewed for each power generation facility. Operating labor, based on the entire power plant, was left unchanged. The unit cost was updated for escalation. Maintenance was expressed as a percentage of each major category of equipment as proposed by the EPRI TAG. This percentage was left unchanged for all equipment except for the filters. Special consideration was given to the maintenance needed for the granular-bed and the ceramic candle filters, and separate calculations were made. Costs for fuel and other consumables were updated based on the best available information.

Erection costs were estimated by a Certified Cost Engineer that is president of a company specializing in construction cost estimating and planning. He has over 35 years of experience in engineering, construction, purchasing and cost estimating for firms like Dow Chemical, USA. Equipment details and piping material listings, prepared for each plant were used to prepare the erection estimates. Wage rates for the Ohio River Valley were used for both the $\mathrm{PFBC}^{2}$ and the gasifier ${ }^{3}$ based plant; which, is the location given for the Foster Wheeler second generation PFB combustion plant.

Other general estimate basis and assumptions are identified below:

- The plant site given for the second generation PFB combustion plant in the Foster Wheeler study is in the Ohio River Valley of southwestern Pennsylvania/eastern Ohio. This location was also used for the gasifier; since, no other location was given.

- All filter systems were designed to fit within the plant areas chosen by the original designers. For the second generation PFB combustion plant, layouts published in the report were used to define these areas. For the KRW gasification plant, only process schematics were published; therefore, layouts were prepared based on separatable ely supported filters.

- $\quad$ Plant costs are expressed in December 1991 dollars.

- Estimates represent a mature technology plant, as opposed to a first-of-a-kind plant. 
- $\quad$ Costs are presented consistent with the source documents, transferred to Lotus 1-2-3 spreadsheet format with as much accuracy as possible. For more information on the origin of other costs presented, refer to the source documents.

Each capital cost and annual cost category is determined on a first-year basis and levelized over the life of the plant through application of a levelizing factor to determine the significance as part of the COE. These costs and expenses are examined for the granular-bed and the ceramic candle filter in detail.

\section{- EPRI Technical Assessment Guide}

In order to provide a standard economic methodology, uniform cost estimating premises, and equivalent financial assumptions for evaluating electric utility technologies, the Technical Assessment Guide (TAG) is utilized for the basis of the cost of estimate. The cost estimate performed for these filters is classified by the TAG as Class II. In a Class II estimate, the design effort performed is preliminary, requiring the general site conditions, plant layouts, process flow diagrams, major equipment specifications, and preliminary piping and instrument diagrams. Costs for major and minor materials were determined by techniques normally characteristic of a Class III, or detailed, cost estimate; that is, quotations were received for equipment, and installation labor was estimated by determining manhours and labor rates for each job classification. It would have required a data base of information on equipment and labor to have performed a Class II estimate. Because of the developmental nature of this equipment, this data base is not available. Accuracy for these types of estimates is expressed by including a project contingency, which is a capital cost contingency factor covering the cost of additional equipment or other costs that would result from a more detailed design. For a Class II estimate the project contingency recommended by the TAG is $15-30 \%$, and for a Class III estimate it is $10-20 \%$. The cost estimate presented for the filter equipment is considered in the $20 \%$ accuracy category. Project contingency utilized was 15\% for the second generation PFB combustion plant and $18 \%$ for the KRW gasifier plant, as proposed in the base studies.

In the TAG methodology, costs are divided into three categories for which the contribution to COE is calculated. Costs associated with building the plant are totaled to yield the total capital requirement (TCR). Fuel costs to run the plant are broken out separately; since, this is a major operating cost. Operation and maintenance is the third category of expenses reported. The cost totaled to give the TCR are summarized in Table 35 .

\subsection{Base Cost of Electricity Calculations}

In order to compare the cost of competing hot gas clean-up technologies, the Cost of Electricity (COE) for power plants incorporating a granular-bed filter are compared to the COE for the same plant using a ceramic candle filter. The COE is calculated using the 
"Lotus Cost of Electricity" spreadsheet by T. J. Hand, December 1988 which was supplied by METC. This spreadsheet is based on methodology developed in the 1986 TAG, published by EPRI.

Table 35 Components of Capital Cost

\begin{tabular}{|c|c|c|}
\hline TAG Cost Category & Components & Explanation \\
\hline Bare erected cost & $\begin{array}{l}\text { Factory equipment } \\
\text { Direct field labor } \\
\text { Indirect field labor } \\
\text { Field mat'l \& supplies } \\
\text { Tools and facilities } \\
\text { Field engineering }\end{array}$ & supervision, payroll burden \\
\hline $\begin{array}{l}\text { Total Plant Cost } \\
\text { (TPC) }\end{array}$ & $\begin{array}{l}\text { Bare Erected Cost }+ \\
\text { Engineering \& } \\
\text { Home office } \\
\text { Process Contingency } \\
\text { Project Contingency }\end{array}$ & $\begin{array}{l}\text { Process capital \& } \\
\text { general facilities } \\
\text { overhead \& fee }\end{array}$ \\
\hline $\begin{array}{l}\text { Total Plant } \\
\text { Investment (TPI) }\end{array}$ & $\begin{array}{l}\text { Total Plant Cost + } \\
\text { Interest \& escal. } \\
\text { during construction }\end{array}$ & $\begin{array}{l}\text { Allowance for funds used } \\
\text { during construction }\end{array}$ \\
\hline $\begin{array}{l}\text { Total Capital } \\
\text { Requirement (TCR) }\end{array}$ & $\begin{array}{l}\text { Total Pl. Investm't + } \\
\text { Prepaid royalties } \\
\text { Preproduction costs } \\
\text { Inventory capital } \\
\text { Initial catalyst } \\
\text { Chemical charges } \\
\text { Land }\end{array}$ & $\begin{array}{l}\text { at in service date } \\
\text { Start-up costs } \\
\text { Working capital }\end{array}$ \\
\hline
\end{tabular}

\subsubsection{Second Generation PFB Combustion Plant}

Table 36 shows the base COE comparisons for the 452 MWe second generation pressurized fluidized bed (PFB) combustion plant incorporating ceramic cross-flow filters. 
Table 36 Second Generation PFB Combustion Plant

Base Cost of Electricity - Comparisons

\begin{tabular}{|c|c|c|c|}
\hline Parameter & $\begin{array}{c}\text { Foster } \\
\text { Wheeler } \\
\text { Base Cost } \\
\text { (Dec 1987) }\end{array}$ & $\begin{array}{c}\text { Adjusted to } \\
\text { EPRI TAG } \\
10^{\text {th }} \mathrm{yr} . \\
\text { Levelize }\end{array}$ & $\begin{array}{c}\text { Escalation } \\
\text { Included } \\
\text { (Dec 1991) }\end{array}$ \\
\hline Total Capital Req'mt, $\mathrm{K} \$$ & 469,504 & 464,668 & 508,866 \\
\hline Fuel Cost, $\mathrm{K} \$ \ldots \ldots \ldots$ & . 36,095 & 36,095 & 41,786 \\
\hline Operating \& Maint., $\mathrm{K} \$ \ldots$. & . 25,904 & 34,891 & 37,659 \\
\hline \multicolumn{4}{|l|}{ Levelizing Factors ${ }^{1}$} \\
\hline Capital Carrying Chrg & 0.173 & 0.175 & 0.175 \\
\hline Fuel $\ldots \ldots \ldots \ldots$ & $\ldots 1.9$ & 1.375 & 1.244 \\
\hline Oper. \& Maint. & . 1.75 & 1.321 & 1.202 \\
\hline \multicolumn{4}{|l|}{ Cost of Electricity ${ }^{1}$, mills $/ \mathrm{kWh}$} \\
\hline Capital Charges, mills/kWh & $\ldots 31.5$ & 31.6 & 35.0 \\
\hline Fuel Costs, mills/kWh . . . . & $\ldots 26.6$ & 19.2 & 20.2 \\
\hline Oper. \& Maint., mills/kWh . & $\ldots \underline{17.6}$ & 17.9 & $\underline{17.6}$ \\
\hline Total Cost of Electricity, $(\mathrm{COE})^{1}$ & $\ldots 75.7$ & 68.7 & 72.7 \\
\hline COE, Constant \$, (Reference) & - & 46.7 & 52.0 \\
\hline
\end{tabular}

Note 1. Expressed in current $\$$ in columns two and three.

The COE calculated by Foster Wheeler in the first column follows EPRI TAG methodology, but was accomplished without the benefit of the spreadsheet supplied by METC. Values for total capital requirement, fuel cost, and operation \& maintenance are those determined by Foster Wheeler. Levelizing factors and the resultant COE are also exactly as determined by Foster Wheeler. The COE calculation summarized in the second column is the same data adjusted to spreadsheet methodology as is described in this section. In column three, the costs presented in column two are adjusted for escalation per EPRI TAG guidelines. Detail spreadsheet output for each COE calculation summary above are given in Appendix A.

This COE information presented in the second and third columns is in Current $\$$ from the spreadsheets. Current dollar analysis includes the effect of inflation and real escalation. Real escalation is the annual rate of increase, or decrease, of an expenditure due to factors such as resource variation, demand fluctuation, and changes in design or 
manufacturing. Real escalation does not include inflation. The main reasons for the differences between the costs given by Foster Wheeler for the base costs, column 1 above, and the costs calculated by the spreadsheet, column 2 above, are given below.

- Project contingency is $15 \%$ of process plant cost plus general plant facilities plus engineering plus process contingency in the Foster Wheeler study. In the Lotus spreadsheet, based on the 1986 EPRI TAG, project contingency is a percentage of process plant cost plus general plant facilities only.

- $\quad$ Capital cost for spares was not detailed in the Foster Wheeler, base costs, but added into subsequent costing at $0.5 \%$ of the total plant cost per the spreadsheet.

- The cost for operation \& maintenance in column 2, above, is increased by the cost of insurance \& local taxes at $2 \%$ of the total plant cost $(\$ 8,086,000)$ and by other operating costs $(\$ 901,000)$ which is a function of operation labor and maintenance costs in the spreadsheet.

- $\quad$ Although there is difference in tax life and tax rates between the Foster Wheeler study and the spreadsheet, this does not account for the different levelizing factors used in the calculation of the COE. Tenth year levelized dollars is used in the spreadsheet calculation: whereas, the Foster Wheeler study uses first year levelized costs.

Escalated plant costs, summarized in Table 36 , column 3, were attained by applying the Chemical Engineering Plant Cost Index to applicable plant sections and by applying escalation factors recommended by the 1989 EPRI TAG to portions of the annual operating costs. The Chemical Engineering Plant Cost Index for December, 1987 is 332.5 and the value for December, 1991 is 359.3 . Not all items in the total capital requirement (TCR) are adjusted by this index, as some items are factored from other costs. Inflation used in the calculation of levelizing factors is $4 \%$, and the real escalation rate (over inflation) for fuel is $0.7 \%$ per year as recommended in the spreadsheet.

The annual operating costs are taken from the 1989 EPRI TAG if listed, and from the Foster Wheeler report otherwise. Inflation applied to the operating costs is $5 \%$ as recommended by the 1989 EPRI TAG. Note that while the methodology used in the calculation of the COE is based on the 1986 EPRI TAG, escalation of some of the operation costs and fuel costs is based on the 1989 edition of the EPRI TAG. The operating costs are summarized on Table 37.

\subsubsection{KRW Gasifier Based Power Plant}

On Table 38, the COE results are compared for the $100 \mathrm{MWe}$, KRW air blown gasifier. These values are based on the gasifier plant utilizing a ceramic cross-flow filter. The base costs derived by Westinghouse, in 1986 dollars, are presented for the gasifier in the first column. In the second column, the Westinghouse costs are adjusted to comply with 1986 EPRI TAG methodology programmed into the spreadsheet. The third column 
presents costs adjusted for escalation to December, 1991. The COE information presented is in current dollars from the spreadsheets.

Table 37 Second Generation PFB Annual Operating Costs

\begin{tabular}{|c|c|c|c|c|}
\hline Item & $\begin{array}{c}\text { Base } \\
\text { Unit Cost } \\
\$ \$\end{array}$ & Source & $\begin{array}{l}\text { No. Years } \\
\text { Inflation } \\
\text { @ } 5 \% / \mathrm{yr}\end{array}$ & $\begin{array}{c}\text { Unit Cost } \\
\text { Dec, } 1991 \\
\$\end{array}$ \\
\hline Plant Labor & $20.0 / \mathrm{hr}$ & EPRI TAG & 3 & $23.15 / \mathrm{hr}$ \\
\hline $\mathrm{Coal}^{1}$ & $44.57 /$ ton & F-W/ TAG & 3 & $51.60 /$ ton \\
\hline Raw Water & $0.60 / \mathrm{kgal}$ & EPRI TAG & 3 & $0.69 / \mathrm{kgal}$ \\
\hline Dolomite & $17.90 /$ ton & F-W & 4 & $21.76 /$ ton \\
\hline H20 Makeup/Trt. & $0.14 / 1 \mathrm{~b}$ & F-W & 4 & $0.17 / 1 \mathrm{~b}$ \\
\hline Liquid Effluent & $0.10 / 1 \mathrm{~b}$ & F-W & 4 & $0.12 / \mathrm{lb}$ \\
\hline Fuel oil & $0.53 / \mathrm{gal}$ & EPRI TAG & 3 & $0.61 / \mathrm{gal}$ \\
\hline Gases, N2 etc. & $0.29 / 100 \mathrm{scf}$ & F-W & 4 & $0.35 / 100 \mathrm{scf}$ \\
\hline Waste Disposal & $8.00 /$ ton & EPRI TAG & 3 & $9.26 /$ ton \\
\hline
\end{tabular}

The COE calculated by Westinghouse in the first column follows EPRI TAG methodology, but was accomplished without the benefit of the spreadsheet supplied by METC. Values for total capital requirement, fuel cost, and operation \& maintenance are those determined by Westinghouse. Levelizing factors and the resultant COE are also exactly as determined by Westinghouse. The COE calculation summarized in the second column uses the same data adjusted to appropriate spreadsheet methodology as is described in this section. In column three, the costs presented in column two are adjusted for escalation per EPRI TAG guidelines. Detail spreadsheet output for each COE calculation summary above are given in Appendix A.

The main reasons for the differences between the costs given by Westinghouse for the base costs, column 1 , Table 38 , and the costs calculated by the spreadsheet, column 2 , are given below. 
- $\quad$ Adjusting the total capital requirement between the Westinghouse base costs and the EPRI TAG methodology involves separate calculations for some items grouped together by Westinghouse. A single value is reported by Westinghouse for allowance for funds used during construction (AFUDC), working capital, etc. $(\$ 22,005,000)$. The spreadsheet breaks out costs for royalties, start-up costs, spare parts, and working capital. Also the spreadsheet uses a separate calculation for AFUDC and lists this as adjustment for interest and inflation during the construction period. The total of these values is calculated by the spreadsheet $(\$ 26,935,000)$.

Table 38 KRW Gasifier Power Plant Cost of Electricity - Comparisons

Parameter

Westinghouse

Base Cost

(Dec 1986)
Adjusted to EPRI TAG $10^{\text {th }} \mathrm{yr}$. Levelize
Escalation Included (DEC 1991)

Total Capital Req'mt, K\$ . . . . . . . 203,514

Fuel Cost, $\mathrm{K} \$$. . . . . . . . . . . . . . 9 9,685

208,253

245,745

Operating \& Maint., $\mathrm{K} \$ \ldots . . . \ldots$. . 11,090

6,508

7,534

Levelizing Factors ${ }^{1}$

Capital Carrying Chrg . . . . . . . . 0.223

Fuel . . . . . . . . . . . . . . . . . 1.0

Oper. \& Maint.

1.75

15,016

18,234

Cost of Electricity ${ }^{1}$, mills $/ \mathrm{kWh}$

Capital Charges, mills/kWh . . . . . . 79.7

Fuel Costs, mills/kWh . . . . . . . . 17.0

Oper. \& Maint., mills/kWh . . . . . . . . 19.5

Total Cost of Electricity, $(\mathrm{COE})^{1} \ldots \ldots 116.2$

0.175

0.175

1.244

1.244

1.202

1.202

65.1

76.8

14.2

16.5

$\underline{31.7}$

$\underline{38.5}$

111.0

131.7

COE, Constant \$, (Reference)

76.4

90.8

Note 1. Expressed in current $\$$ in columns two and three. 
- $\quad$ Coal cost used by Westinghouse was $\$ 1.89 / \mathrm{MMBtu}$ for Illinois No. 6 . This was changed the $\$ 1.27 / \mathrm{MMBtu}$ as listed in the $1989 \mathrm{EPRI}$ TAG.

- The spreadsheet adds funds for insurance \& local taxes $(\$ 3,385,000)$, royalties $(\$ 65,000)$, and other operation costs $(\$ 603,000)$ which do not appear in the Westinghouse estimate.

- Different levelizing factors are used by the calculation of COE as shown in Table 38. The spreadsheet used $10^{\text {th }}$ year levelized dollars.

Escalated plant costs for the gasifier plant, summarized in Table 38, column 3, were attained by applying the Chemical Engineering Plant Cost Index to applicable plant sections, and by applying escalation factors recommended by the EPRI TAG to the annual cost parameters. First, escalation added in the Westinghouse study to adjust costs from 1981 to 1986, was deducted, then these costs were adjusted to 1991. The Chemical Engineering Plant Cost Index for December, 1981 is 297.0 and the value for December, 1991 is 359.3 . Not all items in the total capital requirement (TCR) are adjusted by this index, as some items are factored from other costs.

The annual costs are taken from the 1989 EPRI TAG. Inflation applied is $5 \%$ as generally recommended by the 1989 EPRI TAG. Inflation used in the calculation of levelizing factors is $4 \%$ and the real escalation rate (over inflation) for fuel is $0.7 \%$ per year as recommended in the spreadsheet. These operating costs are summarized in Table 39.

\subsection{Granular-Bed Filter Costs}

Costs for granular-bed filters for the $452 \mathrm{MWe}$, second generation PFB combustion plant $^{2}$ and the $100 \mathrm{MWe}$, KRW air blown gasifier plant ${ }^{3}$ are presented in this section. The second generation PFBC plant consists of two identical trains of equipment, each having a capacity of 226 MWe and including a CPFBC and a carbonizer. For each CPFBC, there is a granular-bed filter module consisting of four filter vessels serviced by a single media circulation system. There is a granular-bed filter module for each carbonizer consisting of a single filter vessel with a circulation system. The KRW gasifier plant consists of one gasifier serviced by a single granular-bed filter vessel.

\subsubsection{Capital Costs of Granular-Bed Filters}

Table 40 presents a summary of granular-bed filter equipment for each plant with costs in thousands of dollars. Costs for the circulation system, pressure vessels and piping are grouped together under the single classification "vessels/piping". For the CPFBC filter, ducting is included within the envelope of the equipment. Ducting for the other filters was judged equivalent to the ducting for the cross-flow filters in the original studies and for the candle filters. Therefore it cancels out of the comparison. Ash systems are presented in more detail in another section. For reference, sizes and weights of this equipment is given is Section 3, Tables 22, 23, and 24. 
Table 39 KRW Gasifier Plant Annual Operating Costs

\begin{tabular}{|c|c|c|c|c|}
\hline Item & $\begin{array}{c}\text { Base } \\
\text { Unit Cost } \\
\$\end{array}$ & Source & $\begin{array}{l}\text { No. Years } \\
\text { Inflation } \\
\text { @ } 5 \% / y r\end{array}$ & $\begin{array}{l}\text { Unit Cost } \\
\text { Dec, } 1991 \\
\$\end{array}$ \\
\hline Plant Labor & $20.0 / \mathrm{hr}$ & EPRI TAG & 3 & $23.15 / \mathrm{hr}$ \\
\hline Coal $^{1}$ & 1.27/MMBtu & EPRI TAG & 3 & 1.47/MMBtu \\
\hline Raw Water & $0.60 / \mathrm{kgal}$ & EPRI TAG & 3 & $0.69 / \mathrm{k} \mathrm{gal}$ \\
\hline Catalyst \& Chem & $100 /$ ton & Note 2 & 4 & $\$ 127.63 /$ ton \\
\hline Sulfur & $81.8 /$ ton & EPRI TAG & 3 & $94.69 /$ ton \\
\hline Waste Disposal & $8.00 /$ ton & EPRI TAG & 3 & $9.26 /$ ton \\
\hline \multicolumn{5}{|l|}{ Notes: } \\
\hline \multicolumn{5}{|c|}{$\begin{array}{l}\text { 1. Illinois No. } 6 \text { coal. } \\
\text { 2. A variable operating cost of } \$ 455,000 \text { was given by Westinghouse which was } \\
\text { arbitrarily priced at } \$ 100 / \text { ton for this spreadsheet. This manipulation was done so some } \\
\text { of this material would be recognized by the spreadsheet as "consumable inventory" which } \\
\text { is part of "Working Capital". The unit cost chosen does not affect the COE unless it is } \\
\text { zero. }\end{array}$} \\
\hline
\end{tabular}

\subsubsection{Maintenance Costs}

Annual maintenance costs are determined as a percentage of the total installed cost of the filter system plus the cost of replacing systems expected to have a short life. The EPRI TAG procedure recommends maintenance costs ranging from $3 \%$ to $6 \%$ of the installed cost for processes handling solids at high temperature and pressure. Four percent is used in this study since the maintenance cost of major pieces of equipment needing periodic replacement are added to this base maintenance cost. For the granularbed filter, three areas are identified that will require periodic replacement. The bags in the pressurized baghouse are recommended for replacement on a yearly basis by the vendor. The lift pipe liner is assumed to need replacement every three years, based on the limited data from testing at NYU, and the filter internals for the carbonizer and gasifier are assumed to need replacement every five years, based on corrosion rates for metals in high temperature, reducing atmospheres. Table 41 shows the maintenance costs for each filter application. The basis for the yearly maintenance cost includes capital and installation costs for the base maintenance but only capital cost for lift pipe lining, baghouse bags, and filter internals. The rational is that labor for these additional items is accounted for in the percentage for base maintenance. A 40/60 split between maintenance labor and materials is shown as proposed by the EPRI TAG. 
Table 40 Granular-Bed Filter Capital Costs

\begin{tabular}{|c|c|c|c|c|c|c|}
\hline $\begin{array}{l}\text { Filter } \\
\text { Plant }\end{array}$ & \multicolumn{2}{|c|}{$\begin{array}{c}\text { CPFBC } \\
\text { Filter }\end{array}$} & \multicolumn{2}{|c|}{$\begin{array}{l}\text { Carbonizer } \\
\text { Filter }\end{array}$} & \multicolumn{2}{|c|}{$\begin{array}{l}\text { Gasifier } \\
\text { Filter }\end{array}$} \\
\hline Plant Capacity, MWe & \multicolumn{2}{|c|}{452} & \multicolumn{2}{|c|}{452} & \multicolumn{2}{|c|}{$\underline{100}$} \\
\hline Filter Components & Qty & $\begin{array}{c}\text { Cost } \\
\mathrm{k} \$\end{array}$ & Qty & $\begin{array}{c}\text { Cost } \\
\mathrm{k} \$\end{array}$ & Qty & $\begin{array}{c}\text { Cost } \\
\mathrm{k} \$\end{array}$ \\
\hline Filter Vessels & 8 & 4,031 & 2 & 460 & 1 & 405 \\
\hline Filter Internals & 8 & 2,121 & 2 & 186 & 1 & 99 \\
\hline Vessel Refractory & 2 Lot & 1,647 & 2 Lot & 232 & $1 \mathrm{Lot}$ & 116 \\
\hline Filter Media & 2 Lot & 2,070 & 2 Lot & 237 & 1 Lot & 119 \\
\hline \multicolumn{7}{|l|}{ Circulation System } \\
\hline Vessels/Piping & - & 2,476 & - & 1,182 & - & 666 \\
\hline De-Entrain. Ves. & 2 & incl & 2 & incl & 1 & incl \\
\hline Refr./Internals & 2 & incl & 2 & incl & 1 & incl \\
\hline Media Valve & 2 & incl & 2 & incl & 1 & incl \\
\hline Refr./Internals & 2 & incl & 2 & incl & 1 & incl \\
\hline Media Makeup Hpr. & 2 & incl & 2 & incl & 1 & incl \\
\hline Refractory & 2 & incl & 2 & incl & 1 & incl \\
\hline Refr Lined Pipe & 2 & incl & 2 & incl & 1 & incl \\
\hline Piping/Valves & 2 Lot & incl & 2 Lot & incl & 1 Lot & incl \\
\hline Media Add Hopper & 2 & incl & 2 & incl & 1 & incl \\
\hline Insulation & 2 Lot & incl & 2 Lot & incl & $1 \mathrm{Lot}$ & incl \\
\hline Regen. Ht. Exch. ${ }^{1}$ & 16 & 5,412 & 16 & 1,224 & 8 & 873 \\
\hline Water-cooled $\mathrm{Hx}$ & 2 & 81 & 2 & 32 & 1 & 19 \\
\hline Baghouse & 2 & 412 & 2 & 137 & 1 & 78 \\
\hline Boost Blower & 2 & 595 & 2 & 284 & 1 & 88 \\
\hline Maintenance Blr & 4 & 499 & 2 & 98 & 1 & 49 \\
\hline Access/Support Stl. & 2 Lot & 1,551 & 2 & 450 & 1 & 213 \\
\hline Foundation Mat'l & 2 Lot & 56 & 2 Lot & 28 & 1 Lot & 10 \\
\hline Instr/Controls & 2 Lot & 200 & 2 Lot & 148 & 1 Lot & 74 \\
\hline Inlet/Outlet Duct & 2 Lot & 3,062 & $\mathrm{~N} / \mathrm{A}$ & - & N/A & - \\
\hline Ash System & 2 Lot & 275 & 2 Lot & 168 & 1 Lot & 87 \\
\hline Erection & 2 Lot & 1,160 & 2 Lot & 442 & 1 Lot & 217 \\
\hline Engineering Fee & - & 949 & - & 377 & - & 561 \\
\hline Freight & 2 Lot & $\underline{743}$ & 2 Lot & $\underline{166}$ & 1 Lot & $\underline{102}$ \\
\hline Total & & 27,340 & & 5,851 & & 3,775 \\
\hline
\end{tabular}

Note 1. Eight sections for each 226 MWe module for the CPFBC and carbonizer filter. 
Table 41 Annual GBF Maintenance Costs

(in Thousands of Dollars)

\begin{tabular}{lccc}
\hline $\begin{array}{l}\text { Maintenance } \\
\text { Item }\end{array}$ & $\begin{array}{c}\text { CPFBC } \\
\text { Filter }\end{array}$ & $\begin{array}{c}\text { Carbonizer } \\
\text { Filter }\end{array}$ & $\begin{array}{c}\text { KRW Gasifier } \\
\text { Filter }\end{array}$ \\
\hline $\begin{array}{l}\text { Plant Output (Ref), MWe } \\
\begin{array}{l}\text { Base Maintenance Cost } \\
\text { (4\% of Installed Cost) }\end{array}\end{array}$ & 452 & 452 & 100 \\
$\begin{array}{l}\text { Lift Pipe Replacement } \\
\text { (Assumes Lift Pipe Liner } \\
\text { is Replaced Every 3 Years) }\end{array}$ & 969 & 232 & 129 \\
$\begin{array}{l}\text { Yearly Bag Replacement } \\
\begin{array}{l}\text { Metal Filter Internals } \\
\text { (Assumes Replacement Every }\end{array}\end{array}$ & 36 & 14 & 7 \\
5 Yrs. in reducing atm.) & - & 8 & 4 \\
Total Yearly Maintenance, $\mathrm{k} \$$ & 1040 & $\underline{32}$ & 17 \\
& & 286 & 156 \\
$\begin{array}{l}\text { Labor Maintenance Cost, } \mathrm{k} \$ \\
\text { Mat'ls Maintenance Cost, } \mathrm{k} \$\end{array}$ & 416 & 114 & 62 \\
\hline
\end{tabular}

\subsubsection{Operating Labor Costs}

Both the Foster Wheeler CPFBC study and the Westinghouse gasifier study determine the total number of personnel needed to operate the entire plant. No differentiation is made regarding which equipment and duties are assigned to a given operator so that is not possible to determine the number of personnel assigned to the hot gas clean up equipment.

Combustion Power Co. has extensive experience with a commercial product line of granular-bed filters in applications operating around $450^{\circ} \mathrm{F}$. In our many contacts with plants that have operated these devices, it was never considered that the number of personnel needed to operate these filter was any different from that required to operate a baghouse or an electrostatic precipitator. Consequently, no change will be made to number of plant operating personnel because the ceramic cross-flow filter is exchanged for a granular-bed filter. We assumed that the cross-flow filter, the granular-bed, and the candle filter require the same number of operating personnel. 


\subsubsection{Utility Requirements}

The Table 42 shows the utility requirements and media replacement rates for granular-bed filter modules for the CPFBC, carbonizer and gasifier. Electric power is used by the boost blowers and water circulation pumps. Compressed air is used to back-pulse the baghouse used with the CPFBC filter ( 35 scfm each baghouse, per vendor ${ }^{5}$ ) and for instrument air. Nitrogen is used to back-pulse the baghouse used with the carbonizer and gasifier filters ( $20 \mathrm{scfm}$ each baghouse, per vendor ${ }^{5}$ ) and to purge pressure sense lines in dirty gas streams. Nitrogen is also used to purge the ash depressurizing vessel on the gasifier filter $(60 \mathrm{scfm})$. Cooling water is used in the water-cooled heat exchanger to cool the recirculation gas before entering the boost blower. It is assumed that the plant circulating water system handles this utility. This cooling water could be incorporated into the steam cycle; although this is not the assumption in this study.

Table 42 Granular-Bed Filter Utility Requirements

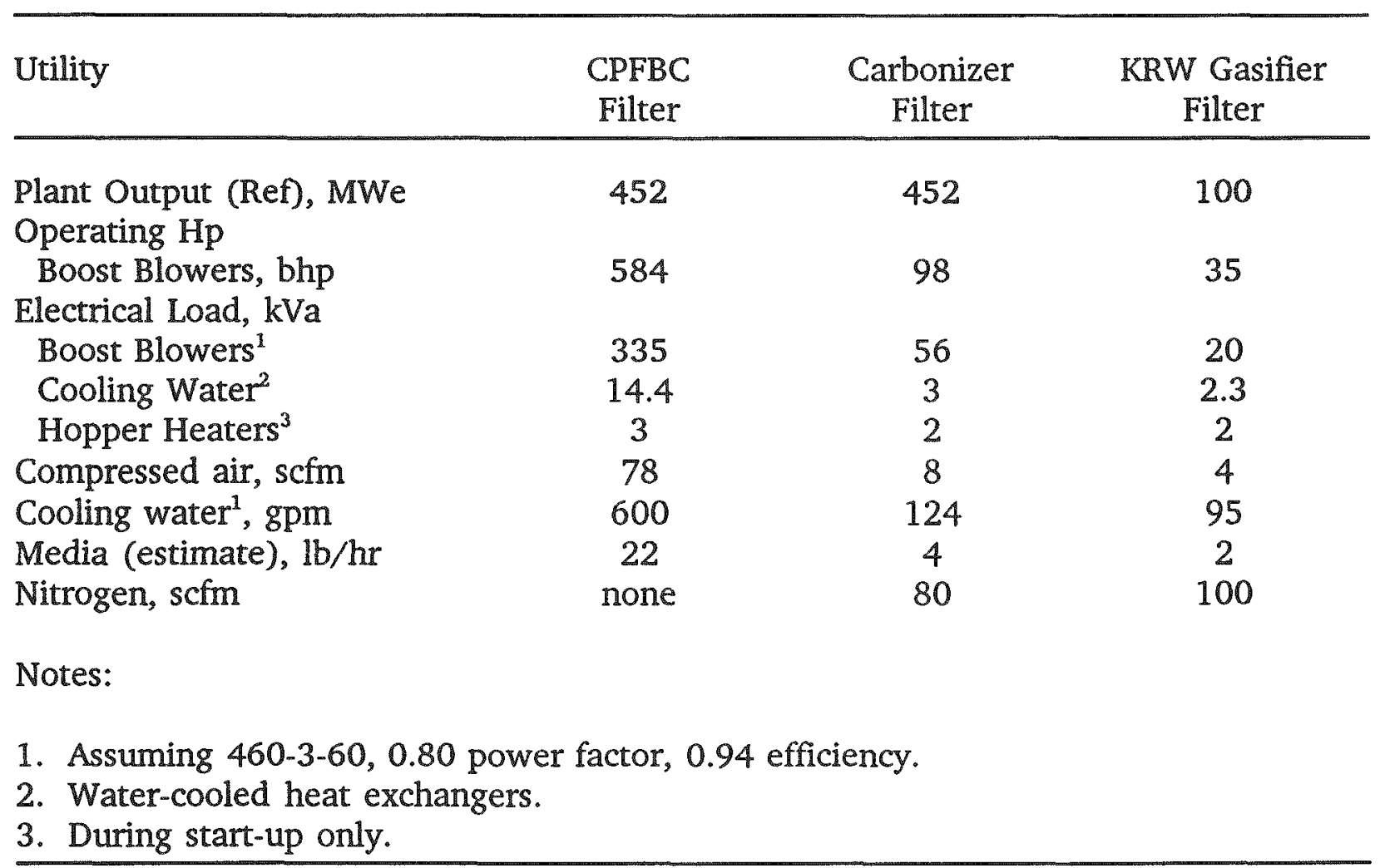

\subsubsection{Consumables Operating Costs}

Costs for power plant consumables are shown on Table 37 for the second generation PFB combustion plant and on Table 39 for the KRW gasifier based plant. The granular-bed filter uses relatively few consumables. Table 42 shows the utility requirements which also corresponds to the consumable for the GBF. The replacement 
media costs $\$ .45$ per pound. The compressed air requirements are so low that they are included as part of the general compressed air requirements of the plant. Cooling water flows are low compared to the condenser requirements so that the only charge for cooling water is the pumping cost to deliver the cooling water. It was assumed that the cooling water would be pumped to 50 psi. The power consumption in Table 42 may be added to power requirements to overcome filter pressure drop, giving the following total parasitic power for the combustor, carbonizer and gasifier filters.

Attempts have been made to measure the attrition of the dense ceramic filter media utilized in the granular-bed filter. These attempts have been unsuccessful; mainly, because the attrition rate is so small that no values have been produced in the test periods undertaken. Nevertheless, an initial estimate has been made equal to $10 \%$ of the media replacement rate which occurred in Combustion Power's commercial granular-bed filters which used natural occurring stone as media. It is expected that the attrition rate for the ceramic media used in the high temperature filter will be much lower than the river gravel used in the low temperature granular-bed filters.

A comparison of the operating cost of different filter types requires a means of accounting for the effects of different filter pressure drops and heat losses. The assumption is made that the process can be adjusted to maintain a constant turbine inlet pressure and temperature regardless of the pressure drop or heat loss from a filter. The cost of different filter pressure drops would be accounted for by the change in compressor power needed to provide for filter pressure drop. Filter heat loss is made up for by firing additional coal. Adjusting the amount of fuel gas produced by the carbonizer or the gasifier provides a means of maintaining a constant turbine inlet temperature.

The pressure drop for the filters used in the second generation PFB combustion plant is compared to the pressure drop of the Westinghouse cross-flow filter. The difference in compressive power corresponding to the difference in pressure drop is either added or subtracted from the net power generated, thus accounting for filter pressure drop on cycle performance. In addition to the change in power due to filter pressure drop, there is also a change of heat input because of the heat associated with the gas compression. Both the change in power and heat input associated with different filter pressure drops are taken into account.

Heat losses are accounted for by firing additional coal to make up for the heat loss by the filter. The calculations use the lower heating value of the coal, $11970 \mathrm{Btu} / \mathrm{lb}$, in determining the amount of coal to be fired to make up for the lost heat. Since the filter heat loss is a small fraction of the total heat input, the additional coal firing will not significantly effect mass flow or equipment size. Secondary effects associated with the firing of additional coal are not be taken into account. The firing of additional coal to make up for filter heat losses is factored into the cost of electricity.

\section{- CPFBC Granular-Bed Filter}

The pressure drop of the CPFBC granular-bed filter (GBF) is 2.97 psi. The crossflow filter has a projected pressure drop of 1.5 psi so that the outlet pressure of the turbine compressor must be increased by $1.47 \mathrm{psi}$. The efficiency of the turbine 
compressor used in the PFBC study was calculated by matching the compressor inlet and outlet conditions assuming an adiabatic compression. The compressor efficiency is $87.835 \%$. Corresponding to the $1.47 \mathrm{psi}$ increase in pressure, the compressor power increases 1.007 MWe. The heat associated with the additional compression is 3.255 MMBtu/hr. As result of the higher pressure drop through the combustor GBF, the net power is reduced by 1.007 MWe and the coal consumption is reduced by .135 tons/hr.

The temperature drop through the CPFBC granular-bed filter is expected to be $20^{\circ} \mathrm{F}$. This is due to radiation heat loss through the shell of the filter and auxiliary equipment, and due to heat lost from the system from the water-cooled heat exchanger. This corresponds to a heat loss of $15.1 \mathrm{MMBtu} / \mathrm{hr}$. In order to make up for the heat loss an additional 0.630 tons/hr of coal will need to be fired. This is offset by the heat due to additional compression; such that, the net additional coal firing is $0.495 \mathrm{ton} / \mathrm{hr}$.

\section{- Carbonizer Granular-Bed Filter}

The carbonizer has a boost compressor which raises the pressure of the gas which flows through the carbonizer train. The boost compressor is supplied with air from the turbine compressor which also supplies air for the PFB combustor. If the turbine compressor raises the pressure of the main air flow because of the additional pressure drop through the PFB combustor filter, then the boost compressor on the carbonizer will provide a lower increase in pressure because its supply is at a higher pressure. The expected pressure drop through the GBF associated with the carbonizer is 1.34 psi. The pressure drop through the cross-flow carbonizer filter was $1.5 \mathrm{psi}$. As a result of the lower pressure drop through the carbonizer GBF and the increased inlet pressure to the boost compressor, the pressure drop across the boost compressor is reduced by $1.63 \mathrm{psi}$. The power consumed by the boost compressor is reduced by $0.173 \mathrm{MWe}$ and the corresponding loss of heat of compression is $0.56 \mathrm{MMBtu} / \mathrm{hr}$. Corresponding to the loss of heat of compression, 0.023 tons/hr of additional coal will be needed to be fired.

The temperature drop through the GBF associated with the carbonizer is $34^{\circ} \mathrm{F}$. The corresponding heat loss is $2.72 \mathrm{MMBtu} / \mathrm{hr}$ which correspond to an increase in coal rate of 0.113 tons/hr. This is offset by the heat due to additional compression such that the net additional coal firing is $0.137 \mathrm{ton} / \mathrm{hr}$.

\section{- Combined Effects for CPFB Combustor and Carbonizer}

In order to account for the heat loss and pressure drop of the GBF's used with the PFBC filters when compared to the cross-flow filter, the net power should be reduce by 0.835 MWe and the coal firing rate increased by 0.632 tons $/ \mathrm{hr}$.

\section{- KRW Gasifier Granular-Bed Filter}

The air flow to the gasifier is raised in pressure by a boost compressor which provides for the pressure drop through the gasifier and for the hot gas clean-up (HGCU) system. The Westinghouse study did not provide complete information on the gasifier based power plant; therefore, several assumptions were made to evaluate the effects of filter pressure drop on system performance. It was assumed that the pressure drop 
through the gasifier is $10 \%$ of the system pressure. Correspondingly, the boost compressor will boost the air to the gasifier from 385 psia to 425 psia plus the pressure drop through the hot gas cleanup device. Based on the nitrogen content of the gas entering the filter, the air flow through the boost compressor is estimated to be $146,000 \mathrm{lb} / \mathrm{hr}$. In addition to the boost compressor for the process air to the gasifier there is also a boost compressor for the recycle gas which recycles $49,700 \mathrm{lb} / \mathrm{hr}$ of gas. The recycle boost compressor must make up for the pressure drop through the cyclones, the hot gas filter and the zinc ferrite system. It is estimated that the pressure drop through the recycle boost compressor is 7.5 psi plus the pressure drop through the hot gas filter.

The pressure drop through the gasifier GBF is estimated to be $1.31 \mathrm{psi}$. The incremental power to the air boost blower is $0.007 \mathrm{MWe}$ and the incremental power to the recycle compressor is $0.003 \mathrm{MWe}$. The heat of compression for the two compressors is $0.032 \mathrm{MMBtu} / \mathrm{hr}$, reducing the coal input by $0.001 \mathrm{tons} / \mathrm{hr}$.

The temperature drop through the GBF associated with the gasifier is $35^{\circ} \mathrm{F}$ which corresponds to a heat loss of $3.90 \mathrm{MMBtu} / \mathrm{hr}$ or $0.163 \mathrm{tons} / \mathrm{hr}$ of coal. The net result of the pressure drop and heat loss from the GBF when compared to the cross-flow filter proposed for the gasifier, is a reduction of power of $0.010 \mathrm{MWe}$ and a 0.162 tons/hr increase in coal usage.

\subsection{Ceramic Candle Filters Costs}

Costs for candle filters for the $452 \mathrm{MWe}$, second generation PFB combustion plant and the $100 \mathrm{MWe}$ KRW air blown gasifier plant are presented in this section. The second generation PFB combustion plant consists of two identical trains of equipment, each having a capacity of $226 \mathrm{MWe}$ and including a CPFBC and a carbonizer. For each CPFBC, there is a ceramic candle filter module consisting of four filters that dispenses ash to the same ash collecting system proposed for the cross-flow filters. There is a ceramic candle filter module for each carbonizer consisting of a single filter vessel with no ash handling system; since, the downstream equipment processes the hot ash at pressure according to the Foster Wheeler study. The KRW gasifier plant consists of a gasifier serviced by a ceramic candle filter vessel.

\subsubsection{Capital Costs of Candle Filters}

Table 43 presents candle filter equipment for each plant with costs in thousands of dollars. Filter internals includes the tubesheet, tubesheet support, gas baffling, element hold downs and gaskets. The pulse gas system is broken into two categories, "piping \& valves" and "compressors". The items included in each category is listed under each heading. Note that the CPFBC filter does not need a pulse gas boiler/cooler because the source air is at a suitable temperature. For the CPFBC filter, ducting is included within the envelope of the equipment. Ducting for the other filters was judged equivalent to the ducting for the cross-flow filters in the original studies and for the candle filters. 
Table 43 Ceramic Candle Filter Capital Costs

\begin{tabular}{|c|c|c|c|c|c|c|}
\hline $\begin{array}{l}\text { Filter } \\
\text { Plant }\end{array}$ & \multicolumn{2}{|c|}{$\begin{array}{c}\text { CPFBC } \\
\text { Filter }\end{array}$} & \multicolumn{2}{|c|}{$\begin{array}{l}\text { Carbonizer } \\
\text { Filter }\end{array}$} & \multicolumn{2}{|c|}{ Gasifier } \\
\hline Plant Capacity, MWe & \multicolumn{2}{|c|}{452} & \multicolumn{2}{|c|}{452} & \multicolumn{2}{|c|}{$\underline{100}$} \\
\hline Filter Components & Qty & $\begin{array}{c}\text { Cost } \\
\mathrm{k} \$\end{array}$ & Qty & $\begin{array}{c}\text { Cost } \\
\mathrm{k} \$\end{array}$ & Qty & $\begin{array}{c}\text { Cost } \\
\mathrm{k} \$\end{array}$ \\
\hline Filter Vessels & 8 & 5,385 & 2 & 972 & 1 & 738 \\
\hline Filter Internals & 8 & 7,142 & 2 & 761 & 1 & 340 \\
\hline Tubesheet/Suppt. & 8 & incl & 2 & incl & 1 & ind \\
\hline Baffling & 8 & ind & 2 & incl & 1 & ind \\
\hline Elem't Holddown & 12,576 & incl & 2,260 & ind & 906 & ind \\
\hline Vessel Refractory & 2 Lot & 2,135 & 2 Lot & 489 & 1 Lot & 182 \\
\hline Filter Elements & 12,576 & 3,447 & 2,260 & 784 & 906 & 314 \\
\hline \multicolumn{7}{|l|}{ Pulse Gas System } \\
\hline Piping/Valves & 1 Lot & 5,847 & 1 Lot & 1,181 & 1 Lot & 506 \\
\hline High Alloy Pipe & 8 Lot & incl & 2 Lot & incl & $1 \mathrm{Lot}$ & incl \\
\hline Carbon Stl Pipe & 2 Lot & incl & 2 Lot & incl & 1 Lot & ind \\
\hline Pulse Valves & 288 & ind & 52 & ind & 20 & incl \\
\hline Auto Isolat'n Vlvs & 864 & ind & 156 & ind & 60 & incl \\
\hline Hand Valves & 2 Lot & ind & 2 Lot & ind & $1 \mathrm{Lot}$ & ind \\
\hline Secondary Reserv. & 16 & ind & 4 & ind & 2 & incl \\
\hline Compressors & 2 Lot & 1,108 & 2 Lot & 771 & $1 \mathrm{Lot}$ & 542 \\
\hline Pulse Gas Blr/Clr & $\mathrm{N} / \mathrm{A}$ & - & 2 & incl & 1 & incl \\
\hline Pulse Gas Compr. & 2 & incl & 2 & incl & 1 & incl \\
\hline Std-by Compr. & 1 & ind & 1 & incl & 1 & incl \\
\hline Instr/Controls & 2 Lot & 196 & 2 Lot & 93 & $1 \mathrm{Lot}$ & 50 \\
\hline Inlet/Outlet Duct & 2 Lot & 3,730 & - & - & - & \\
\hline Access/Support Stl. & $2 \mathrm{Lot}$ & 1,486 & 2 & 450 & 1 & 113 \\
\hline Foundation Mat'l & 2 Lot & 42 & $2 \mathrm{Lot}$ & 19 & 1 Lot & 8 \\
\hline Ash System ${ }^{1}$ & & & None & & & \\
\hline Vessels/Pipe & 2 Lot & 390 & - & - & $1 \mathrm{Lot}$ & 31 \\
\hline Ash Coolers & 4 & 919 & - & - & 1 & 570 \\
\hline Ash Valves & 2 Lot & 1,436 & - & - & 1 Lot & 74 \\
\hline Erection & $2 \mathrm{Lot}$ & 2,871 & 2 Lot & 698 & $1 \mathrm{Lot}$ & 300 \\
\hline Freight & 2 Lot & 1074 & 2 Lot & 200 & 1 Lot & 130 \\
\hline Engineering & - & $\underline{949}$ & - & $\underline{377}$ & - & $\underline{561}$ \\
\hline Total & & 38,187 & & 6,795 & & 4,458 \\
\hline
\end{tabular}


Therefore it cancel out of the comparison. In the estimate for the KRW gasifier, all engineering for individual systems in included in the equipment price. The amount for engineering is the same as estimated for the granular-bed filter. For reference, sizes and weights of this equipment is given is Section 4 , Tables 32,33 , and 34 .

\subsubsection{Maintenance Costs}

Annual maintenance costs are determined as a percentage of the total installed cost of the filter system plus the cost of replacing systems expected to have a short life. The EPRI TAG procedure recommends maintenance costs ranging from $3 \%$ to $6 \%$ of the installed cost for processes handling solids at high temperature and pressure. Four percent is used in this study since the maintenance cost of major pieces of equipment needing periodic replacement are added to this base maintenance cost.

For the ceramic candle filters, three areas are identified that will require periodic replacement. It is assumed that filter elements will need replacement every three years. This is based on knowledge of the types of guarantees that suppliers of candle filter elements will offer ( 1 year) and the statistical study presented by Westinghouse for the cross-flow filter elements in the Foster Wheeler report ( 5 years). Solenoid pulse valve and isolating ball valve replacement is at $10 \%$ and $5 \%$ per year based on the high number of cycles. The filter internals for the carbonizer and gasifier are assumed to need replacement every five years, based on corrosion rates for metals in high temperature, reducing atmospheres. Table 44 shows the maintenance costs for each filter application. The basis for the yearly maintenance cost includes capital and installation costs for the base maintenance but only capital cost for filter elements, tubesheet components, and valves. The rational is that labor for these additional items is accounted for in the percentage for base maintenance. A 40/60 split between maintenance labor and materials is shown as proposed by the EPRI TAG.

\subsubsection{Operating Labor Costs}

Both the Foster Wheeler CPFBC study and the Westinghouse gasifier study determine the total number of personnel needed to operate the entire plant. No differentiation is made to which equipment and duties are assigned to a given operator, so that is not possible to determine the number of personnel assigned to the hot gas clean up equipment. Consequently, no change will be made to number of plant operating personnel because the ceramic cross-flow filter is exchanged for a candle filter. We assumed that the cross-flow filter, the granular-bed, and the candle filter require the same number of operating personnel.

\subsubsection{Utility Requirements}

The Table 45 shows the utility requirements for candle filter modules for the CPFBC, carbonizer and gasifier. Equipment vendors provided the electric power consumption for the pulse gas compressors and pulse gas refrigerated dryers for the 
CPFBC, carbonizer and gasifier filters. Ash cooling screws used in the CPFBC and gasifier candle filter systems are the same as proposed for the cross-flow filters in the base studies. Electric power consumption for the ash screws were provided by qualified vendors based on specifications prepared from the base studies. The ash cooling screw on the gasifier candle filter has a closed loop water circulation system that requires use of a water circulation pump that is included with the ash screw.

Table 44 Annual Candle Filter Maintenance Costs (in Thousands of Dollars)

\begin{tabular}{|c|c|c|c|}
\hline $\begin{array}{l}\text { Maintenance } \\
\text { Item }\end{array}$ & $\begin{array}{l}\text { CPFBC } \\
\text { Filter }\end{array}$ & $\begin{array}{c}\text { Carbonizer } \\
\text { Filter }\end{array}$ & $\begin{array}{c}\text { KRW Gasifier } \\
\text { Filter } \\
\end{array}$ \\
\hline Plant Output (Ref), MWe & 452 & 452 & 100 \\
\hline $\begin{array}{l}\text { Base Maintenance Cost } \\
\text { ( } 4 \% \text { of Installed Cost) }\end{array}$ & 1,377 & 271 & 156 \\
\hline $\begin{array}{l}\text { Ceramic Filter Elements } \\
\text { (Assumes } 1 / 3 \text { Elements } \\
\text { are Replaced Each Year) }\end{array}$ & 985 & 222 & 89 \\
\hline $\begin{array}{l}\text { Pulse Valves } \\
\text { (@ 10\% per year) }\end{array}$ & 82 & 15 & 6 \\
\hline $\begin{array}{l}\text { Ball Valves, Isolation } \\
\text { (@ } 5 \% \text { per year) }\end{array}$ & 78 & 14 & 5 \\
\hline $\begin{array}{l}\text { Metal Filter Internals } \\
\text { (Assumes Replacement Every } \\
5 \text { Yrs. in reducing atm.) }\end{array}$ & - & 97 & 44 \\
\hline Total Yearly Maintenance, $\mathrm{k} \$$ & 2522 & 619 & 300 \\
\hline $\begin{array}{l}\text { Labor Maintenance Cost, } \mathrm{k} \$ \\
\text { Mat'ls Maintenance Cost, } \mathrm{k} \$\end{array}$ & $\begin{array}{l}1009 \\
1513\end{array}$ & $\begin{array}{l}248 \\
371\end{array}$ & $\begin{array}{l}120 \\
180\end{array}$ \\
\hline
\end{tabular}

Cooling water is used in the pulse gas compressors of all three filter systems and in the ash cooling screws of the CPFBC and carbonizer filters. It is assumed that the plant cooling water system handles this utility. Boiler feedwater is used to cool process gas for use as pulse gas on the carbonizer and gasifier filters. It is assumed that the plant boiler water system handles this utility. No attempt was made to incorporate the heat lost in the cooling water or the boiler into the steam cycle. 


\subsubsection{Consumables Operating Costs}

Costs for power plant consumables are shown on Table 37 for the second generation PFB combustion plant and on Table 39 for the KRW gasifier based plant. The ceramic candle filter uses relatively small amounts of various consumables. Table 45 shows the utility requirements which also corresponds to the consumables for the candle filter. The compressed air requirements are so low that they are included as part of the general compressed air requirements of the plant. Cooling water and boiler feedwater flows are low compared to the condenser requirements so that the only charge for cooling water is the pumping cost to deliver the cooling water. Assumptions for cooling water pressure are included on Table 45. The power consumption in Table 45 may be added to power requirements to overcome filter pressure drop, giving the following total parasitic power for the $\mathrm{CPFBC}$, carbonizer and gasifier candle filters.

A comparison of the operating cost of different filter types requires a means of accounting for the effects of different filter pressure drops and heat losses. The assumption is made that the process can be adjusted to maintain a constant turbine inlet pressure and temperature regardless of the pressure drop or heat loss from a filter. The cost of different filter pressure drops can be accounted for by the change in compressor power needed to provide for filter pressure drop. Filter heat loss is made up for by firing additional coal. Adjusting the amount of fuel gas produced by the carbonizer or the gasifier provides a means of maintaining a constant turbine inlet temperature.

The pressure drop for the candle filters used in the second generation PFBC is compared to the pressure drop for the Westinghouse cross-flow filter. The difference in compressive power corresponding to the difference in pressure drop is either added or subtracted from the net power generated, thus accounting for filter pressure drop on cycle performance. In addition to the change in power due to filter pressure drop, there is also a change of heat input because of the heat associated with the gas compression. Both the change in power and heat input associated with different filter pressure drops are taken into account.

Heat losses are accounted for by firing additional coal to make up for the heat loss by the filter. The calculations use the lower heating value of the coal, $11970 \mathrm{Btu} / \mathrm{lb}$, in determining the amount of coal to be fired to make up for the lost heat. Since the filter heat loss is a small fraction of the total heat input, the additional coal firing will not significantly effect mass flow or equipment size. Secondary effects associated with the firing of additional coal will not be taken into account. The firing of additional coal to make up for filter heat losses is factored into the cost of electricity.

\section{- CPFBC Candle Filter}

The pressure drop of the CPFBC candle filter is $2.66 \mathrm{psi}$. The cross-flow filter has a projected pressure drop of $1.5 \mathrm{psi}$ so that the outlet pressure of the turbine compressor must be increased by 1.16 psi. The efficiency of the turbine compressor used in the PFBC study was calculated by matching the compressor inlet and outlet conditions assuming an adiabatic compression. The compressor efficiency is $87.835 \%$. Corresponding to the 
1.16 psi increase in pressure, the compressor power increases 0.799 MWe. The heat associated with the additional compression is $2.56 \mathrm{MMBtu} / \mathrm{hr}$. As result of the higher pressure drop through the CPFBC candle filter, the net power is reduced by $0.799 \mathrm{MWe}$ and the coal consumption is reduced by .107 tons $/ \mathrm{hr}$.

Table 45 Candle Filter Utility Requirements

\begin{tabular}{|c|c|c|c|}
\hline Utility & $\begin{array}{l}\text { CPFBC } \\
\text { Filter }\end{array}$ & $\begin{array}{c}\text { Carbonizer } \\
\text { Filter }\end{array}$ & $\begin{array}{l}\text { KRW Gasifier } \\
\text { Filter }\end{array}$ \\
\hline \multicolumn{3}{|l|}{ Operating $\mathrm{Hp}$} & 100 \\
\hline Pulse Gas Compr., bhp & 474 & 200 & 126 \\
\hline Ash Screw, bhp & 30 & - & 5 \\
\hline H20 Circ. Pump, bhp ${ }^{4}$ & - & - & 1.2 \\
\hline Pulse Gas Dryer, bhp & 40 & 10 & 8 \\
\hline \multicolumn{4}{|l|}{ Electrical Load, KVa } \\
\hline Pulse Gas Compr. ${ }^{1}$ & 272 & 115 & 72 \\
\hline Cooling Water ${ }^{2}$ & 1.4 & 1.6 & 1.4 \\
\hline Ash Screw ${ }^{1}$ & 17 & - & 3 \\
\hline H20 Circ. Pump 4 & - & - & 0.7 \\
\hline Cooling Water & $4.7^{(3)}$ & - & $1.8^{(2)}$ \\
\hline Pulse Gas Dryer & 23 & 6 & 4.5 \\
\hline Boiler Feedwater & - & .2 & .2 \\
\hline Compressed air, scfm & - & 8 & 4 \\
\hline \multicolumn{4}{|l|}{ Cooling water } \\
\hline Compressors, gpm ${ }^{5}$ & 58 & 68 & 57 \\
\hline Boiler, gpm & - & 5 & 5 \\
\hline Ash Screw, gpm & 73 & - & 76 \\
\hline Nitrogen, scfm & - & $8^{(6)}$ & $67^{(7)}$ \\
\hline
\end{tabular}

Notes:

1. Assuming 460-3-60, 0.80 power factor, 0.94 efficiency.

2. Assuming 50 psig, $70 \%$ pump eff; see also note 1 .

3. Assuming $135 \mathrm{psig}, 70 \%$ pump eff; see also note 1 .

4. Assuming $25 \mathrm{psi}, 380^{\circ} \mathrm{F}$ water, $70 \%$ pump eff; see also note 1 .

5. Precoolers, compressors \& aftercoolers

6. Purging of instrument pressure taps only

7. Purging of instrument pressure taps and pressurizing ash lock hopper during ash depressurization cycle

The temperature drop through the CPFBC candle filter is expected to be $12^{\circ} \mathrm{F}$. This is due to radiation heat loss through the shell of the filter, and due to dilution of the 
combustion gases by pulse air. Heat loss is due to the radiation heat losses only, and amounts to $3.94 \mathrm{MMBtu} / \mathrm{hr}$. Pulse air simply enters the system as excess combustion air in a different location. In order to make up for the heat loss, an additional 0.165 tons/hr of coal will need to be fired. This is offset by the heat due to additional compression such that the net additional coal firing is $0.058 \mathrm{ton} / \mathrm{hr}$.

\section{- Carbonizer Candle Filter}

The carbonizer has a boost compressor which raises the pressure of the gas which flows through the carbonizer train. The boost compressor is supplied with air from the turbine compressor which also supplies air for the CPFB combustor. If the turbine compressor raises the pressure of the main air flow because of the additional pressure drop through the CPFB combustor filter, then the boost compressor on the carbonizer will provide a lower increase in pressure because its supply is at a higher pressure. The expected pressure drop through the candle filter associated with the carbonizer is 1.96 psi. The pressure drop through the cross-flow carbonizer filter was $1.5 \mathrm{psi}$. As a result of the higher pressure drop through the carbonizer candle filter and the increased inlet pressure to the boost compressor, the pressure drop across the boost compressor is reduced by 0.70 psi. The power consumed by the boost compressor is reduced by 0.123 MWe and the corresponding loss of heat of compression is $0.398 \mathrm{MMBtu} / \mathrm{hr}$. Corresponding to the loss of heat of compression, 0.017 tons/hr of additional coal will be needed to be fired.

The temperature drop through the candle filter associated with the carbonizer is $27^{\circ} \mathrm{F}$. This is due to radiation heat loss through the shell of the filter vessel and from cooling process gas for use as pulse gas. The corresponding heat loss is $2.19 \mathrm{MMBtu} / \mathrm{hr}$ which correspond to an increase in coal rate of $0.091 \mathrm{tons} / \mathrm{hr}$. This is increased by the heat due to additional compression such that the net additional coal firing is 0.108 ton $/ \mathrm{hr}$.

\section{- Combined Effects for CPFB Combustor and Carbonizer}

In order to account for the heat loss and pressure drop of the candle filters used with the second generation PFB combustion plant in comparison to the cross-flow filters, the net power should be reduce by $0.676 \mathrm{MWe}$ and the coal firing rate increased by 0.166 tons/hr.

\section{- KRW Gasifier Candle Filter}

The air flow through the gasifier is increased in pressure by a boost compressor which provides for the pressure drop through the gasifier and the HGCU system. The Westinghouse study did not provide complete information on the gasifier based power plant; therefore, several assumptions were made to evaluate the effects of filter pressure drop on system performance. It is assumed that the pressure drop through the gasifier is $10 \%$ of the system pressure. Correspondingly, the boost compressor will boost the process air to the gasifier from 385 psia to 425 psia plus the pressure drop through the hot gas cleanup device. Based on the nitrogen content of the gas entering the filter, the 
air flow through the boost compressor is estimated to be $146,000 \mathrm{lb} / \mathrm{hr}$. In addition to the boost compressor for the air to the gasifier there is also a boost compressor for the recycle gas which recycles $49,700 \mathrm{lb} / \mathrm{hr}$ of gas. The recycle boost compressor must make up for the pressure drop through the cyclones, the hot gas filter and the zinc ferrite system. It is estimated that the pressure drop through the recycle boost compressor is 7.5 psi plus the pressure drop through the hot gas filter.

The pressure drop through the candle filter for the gasifier is estimated to be 1.99 psi. The incremental power to the air boost blower is $0.009 \mathrm{MWe}$ and the incremental power to the recycle compressor is.004 MWe. The heat of compression for the two compressors is $0.043 \mathrm{MMBtu} / \mathrm{hr}$, reducing the coal input by 0.002 tons $/ \mathrm{hr}$.

The temperature drop through the candle filter associated with the gasifier is $31^{\circ} \mathrm{F}$ which corresponds to a heat loss of $3.73 \mathrm{MMBtu} / \mathrm{hr}$ or $0.156 \mathrm{tons} / \mathrm{hr}$ of coal. The net result of the pressure drop and heat loss from the GBF used with the gasifier is a reduction of power of $0.013 \mathrm{MWe}$ and a 0.154 tons/hr increase in coal usage.

\subsection{COE Comparison, Second Generation PFBC Combustion Plant}

In the Foster Wheeler report on the $452 \mathrm{MWe}$, second generation PFB combustion plant, equipment costs are broken down by account numbers for cost of electricity (COE) calculations. Hot gas cleanup equipment and piping is summarized in account number 5 , and includes the CPFBC filter, carbonizer filter, hot gas ducting, and foundations. Ash handling equipment is contained in cost account number 10 which includes items for the ash and spent sorbent recovery system connected to the filters and connected to other equipment. There is also a separate cost account for instrumentation/control, but since this item was such a small amount for each filter, it was included with the filters. The bare erected costs for these items include equipment costs, material costs, and direct and indirect installation labor. Costs for all filter related equipment can be compared at this level, but must be segregated by cost account for further COE calculations because different contingencies apply.

\subsubsection{Bare Erected Costs, CPFBC and Carbonizer Filters}

Bare erected costs established for the granular-bed and the ceramic candle filters for the CPFBC outlet are compared in Tables 46 and 47 for the CPFBC and the carbonizer filters, respectively. These costs were originally presented separately in sections 5.3 and 5.4. Filter vessels are all estimated at $\$ 2.50 / \mathrm{lb}$ based on quotes received for shop fabrication. The candle filter vessels are larger, and heavier, than the granular-bed filter vessels. GBF internals are lighter than candle filter internals and are based on fabrication from RA253MA instead of RA333 for the CPFBC filters; although the sensitivity is analyzed in the COE calculation. Costing is at $\$ 10.50 / 1 \mathrm{~b}$ for the GBF internals and at $\$ 20 / \mathrm{lb}$ for the candle filter, for the CPFBC based on analysis of quotes received. For the carbonizer filters, internals for the granular-bed and candle filter are estimated assuming fabrication from RA85H. Costing for both sets of internals is assumed at $\$ 15 / \mathrm{lb}$, based on analysis of quotes received. Pressure vessel steelwork for all smaller vessels is 
included at $\$ 3.50 / 1 \mathrm{~b}$ for both filters. Small fabricated items made from $310 \mathrm{SS}$ sheet or plate for the items such as de-entrainment vessel internals and media valve internals for the granular-bed filter are included at $\$ 7.50 / 1 \mathrm{~b}$, again based on quotes. Carbon steel fabricated piping and ducting is $\$ 2.50 / \mathrm{lb}$ and stainless steel fabricated piping is $\$ 10.50 / \mathrm{lb}$. Filter media for the both the CPFBC and carbonizer granular-bed filters is

Table 46 Bare Frected Cost Comparison

CPFBC Filters, 452 Mwe

Granular-Bed Filter System

Candle Filter System

\begin{tabular}{lrlr}
\hline & $\$ / 1000$ & & \\
Filter Vessels (8) & 4,031 & Filter Vessels (8) & $\$ / 1000$ \\
Filter Internals (8) & 2,121 & Filter Internals (8) & 5,385 \\
Vessel Refractory & 1,647 & Vessel Refractory & 7,142 \\
Filter Media & 2,070 & Filter Elements & 2,135 \\
Circulation System & & Pulse Back & 3,477 \\
$\quad$ Vessels/Piping & 2,476 & Piping/Valves & \\
$\quad$ Regen. Ht. Exch. & 5,412 & Compressors & 5,847 \\
$\quad$ Water-Cooled Hx. & 81 & Ash System & 1,108 \\
$\quad$ Baghouse & 412 & Vessels/Piping & \\
$\quad$ Boost/Maint. Blower & 1,094 & Ash Coolers & 390 \\
Instr/Controls & 200 & Ash Valves & 919 \\
Inlet/Outlet Ducting & 3,062 & Instr/Controls & 1,436 \\
Access/Support Steel & 1,551 & Inlet/Outlet Ducting & 196 \\
Foundation Mat'1 & 56 & Access/Support Steel & 3,730 \\
Ash System & 275 & Foundation Mat'1 & 1,486 \\
Erection & 1,160 & Erection & 42 \\
Engineering & 949 & Engineering & 2,871 \\
Freight & 743 & Freight & 949 \\
& & & 1,074 \\
Bare Erected Cost, $k \$$ & 27,339 & Bare Erected Cost, k\$ & 38,187 \\
& & & \\
Breakdown: & 23,946 & Breakdown: & \\
Filter Equipment & 3,062 & Filter Equipment & 31,670 \\
Inlet/Outlet Ducting & 275 & Ash System & 3,730 \\
Ash System & 56 & Foundation Mat'l & 2,745 \\
Foundation Mat'1 & & & 42 \\
\hline
\end{tabular}


Table 47 Bare Erected Cost Comparison

Carbonizer Filters, 452 Mwe

Granular-Bed Filter System

Candle Filter System

\begin{tabular}{|c|c|c|c|}
\hline & $\$ / 1000$ & & $\$ / 1000$ \\
\hline Filter Vessels (2) & 460 & Filter Vessels (2) & 972 \\
\hline Filter Internals (2) & 186 & Filter Internals (2) & 761 \\
\hline Vessel Refractory & 232 & Vessel Refractory & 489 \\
\hline Filter Media & 237 & Filter Elements & 784 \\
\hline Circulation System & & Pulse Back & \\
\hline Vessels/Piping & 1,182 & Piping/Valves & 1,181 \\
\hline Regen. Ht. Exch. & 1,224 & Compressors & 771 \\
\hline Water-Cooled Hx. & 32 & Ash System & \\
\hline Baghouse & 137 & Vessels/Piping & - \\
\hline Boost/Maint. Blower & 382 & Ash Coolers & - \\
\hline Instr/Controls & 148 & Ash Valves & - \\
\hline Access/Support Steel & 450 & Instr/Controls & 93 \\
\hline Foundation Mat'1 & 28 & Access/Support Steel & 450 \\
\hline Ash System & 168 & Foundation Mat'1 & 19 \\
\hline Erection & 442 & Erection & 698 \\
\hline Engineering & 377 & Engineering & 377 \\
\hline Freight & $\underline{166}$ & Freight & $\underline{200}$ \\
\hline Bare Erected Cost & 5,851 & Bare Erected Cost & 6,795 \\
\hline Breakdown: & & Breakdown: & \\
\hline Filter Equipment & 5,823 & Filter Equipment & 6,776 \\
\hline Inlet/Outlet Ducting & - & Inlet/Outlet Ducting & \\
\hline Ash System & incl & Ash System & none \\
\hline Foundation Mat'l & 28 & Foundation Mat'l & 19 \\
\hline
\end{tabular}

estimated at $\$ 0.45 / \mathrm{lb}$. Filter elements for the CPFBC and carbonizer candle filters are priced at $\$ 235 /$ element and $\$ 295 /$ element, respectively. These costs are based on quotations from candle element manufacturers in quantities for each filter application. Other buyout equipment is priced based on quotes from qualified suppliers. Freight is estimated at $4 \%$ of the cost of filter items. The refractory contractors estimating factors include freight and installation. Erection for all filters was evaluated by an independent contractor specializing in construction cost estimating. General and administrative costs and allowance for profit is included for all items by dividing costs by 0.85 . 


\subsubsection{Ducting \& Foundations}

Hot gas piping for the granular-bed, ceramic candle, and cross-flow filter systems was estimated within equivalent envelopes. Identical cost factors were used. The bare erected cost for cross-flow filter ducting was estimated at $\$ 3,431,000$; for the granular-bed filter, $\$ 3,062,000$; and for the ceramic candle filter $\$ 3,730,000$. One reason that the ceramic candle filter ducting is the most costly is that the gas outlet elevation is higher in comparison to the granular-bed filter, and it must eventually reach grade level for the gas turbine. The difference between ducting costs in comparison to the cross-flow filter was used as a credit or debit to the hot gas cleanup and piping cost (account no. 5).

The bare erected cost for hot gas piping in the Foster Wheeler study was $\$ 12,716,000$ in December, 1987 dollars. This cost was escalated to December, 1991 by the Chemical Engineering Plant Cost Index (359.30/332.50) then adjusted for difference in ducting cost. This value is $\$ 13,382,000$ for the granular-bed filter plant and $\$ 14,050,000$ for the candle filter plant.

In a similar manner, the value estimated by Foster Wheeler for foundations was escalated to December, 1991 and adjusted for the difference between the granular-bed and the ceramic candle filter. In this case, mostly because the numbers were fairly small in comparison to others in account no. 5 , the cost of the candle filter foundations was assumed equal to the cross-flow filter foundations. The difference between foundations for the granular-bed filters and ceramic candle filters, for both the CPFBC and the carbonizer, was applied to the granular-bed filter plant cost. The bare erected cost for foundations in the Foster Wheeler study was $\$ 457,000$ in December, 1987 dollars. This was escalated to $\$ 494,000$ for the candle filter plant, and increased to $\$ 516,000$ for the granular-bed filter plant.

\subsubsection{Ash Systems}

The ash handling system for the CPFBC candle filter is almost the same as for the cross-flow filter originally included in Foster Wheeler's pricing. The equipment includes the restricted pipe discharge (RPD) vessels; the downstream, connected ash collecting vessels; the ash coolers; and the associated isolation and control valves. The difference is that because there are eight candle filters where there were four cross-flow filters, four extra ash collection vessels with connecting refractory lined piping are needed to complete the connection with the initial ash handling equipment. Therefore the CPFBC candle filter vessels and ash piping to the first set of ash collecting hoppers (see Figure 64, Section 4) is included with the account number 5, "Hot Gas Cleanup and Piping". There is no ash handling equipment for the carbonizer candle filter; since, it empties directly into a downstream processing vessel. The ash handling equipment for the carbonizer granular-bed filter is a small percentage of the cost; therefore, it is included with the filter (account no. 5) for simplicity. Under these circumstances, the ash handling equipment assigned to account number 10 remains unchanged between the cross-flow and the candle filter. This equipment is simply escalated by the Chemical Engineering Plant Cost Index. 
For the granular-bed filter, ash cooling screws and hot valving is not needed; since, ash is cooled in the regenerative heat exchanger and discharged at low temperature $\left(500^{\circ} \mathrm{F}\right)$. Consequently, ash handling equipment (account no. 10 for the cross-flow filter) is escalated, then reduced by the value of the items needed for the cross-flow/candle filter $(\$ 2,745,000)$ and then increased by the value of the items needed for the granular-bed filter $(\$ 275,000)$. Account number 10 for "Ash/Spent Sorbent Recovery and Handling" includes the ash coolers for the cross-flow or candle filters and the fluidized bed heat exchanger (FBHE), ash depressurization equipment for the FBHE and filters, ash storage silos, ash transport and feed equipment, and associated foundations. The bare erected cost was $\$ 7,335,000$ in 1987 dollars for the cross-flow filter, and was escalated to $\$ 7,926,000$ in 1991 dollars. The value of $\$ 7,926,000$ was used for the account number 10 for the candle filter. This was reduced to $\$ 5,456,000$ for the granular-bed filter as credit was applied for items not needed. The value of the ash handling equipment for the candle filter was determined by preparing specifications based on the Foster Wheeler study and obtaining quotes from qualified vendors.

\subsubsection{Power Plant Maintenance}

The Foster Wheeler report used EPRI TAG methodology to estimate the cost of power plant maintenance. For each item in the power plant, maintenance is estimated at a percentage of bare erected cost. Maintenance for the ash/spent sorbent handling system was proposed by Foster Wheeler at $3.2 \%$. With the exception of the value for hot gas cleanup equipment, this value and others proposed by Foster Wheeler were utilized in this study.

Results from maintenance calculations were presented for the CPFBC and the carbonizer filters in Tables 41 and 44 for the granular-bed and ceramic candle filter, respectively. The base maintenance cost of $4 \%$ of the bare erected cost is also applied to the remaining items in the hot gas cleanup and piping account; namely, hot gas piping and foundation. For the second generation PFB Combustion plant with granular-bed filters, the maintenance items for account number 5 include the CPFBC filter $(\$ 1,040,000)$, the carbonizer filter $(\$ 286,000)$, the hot gas piping $(\$ 535,000)$, and the HGCU foundations $(\$ 21,000)$. This totals to $\$ 1,881,000$. Maintenance items for the same plant with ceramic candle filters include the CPFBC filters $(\$ 2,522,000)$, the carbonizer filter $(\$ 623,000)$, the hot gas piping $(\$ 562,000)$, and the HGCU foundations $(\$ 19,000)$. This totals to $\$ 3,726,000$. These values for maintenance were used to calculate COE.

\subsubsection{Cost of Electricity}

Costs for HGCU equipment and piping are summarized in Table 48. To the bare erected cost, percentages are added for engineering, process contingency and project contingency to arrive at the total plant cost (TPC). Percentages are those proposed by Foster Wheeler. Engineering is added at $6.5 \%$ of bare erected costs. Project contingency is added at $15 \%$ of the sum of bare erected cost and general plant facilities. Process contingency is added at $20 \%$ of filter costs, but presented as a percentage of bare erected 
costs of all items in account number 5. Engineering (6.5\%) is for PFBC plant engineering and includes construction management, and home office fees. The cost for engineering services provided by the equipment manufacturers and vendors is included directly in the equipment costs. Process contingency is a factor added to account for the uncertainty in technical performance and cost of new technology. Foster Wheeler proposed $20 \%$ for the developmental cross-flow filter. This factor was also applied to portions of the granularbed and the candle filter. In both cases the factor was taken as a percentage of the filter vessel, filter refractory, internals, and filtration elements/media.

In a similar manor, the bare erected costs for ash/spent sorbent handling system is factored up to TPC. Engineering is added at $6.5 \%$ of bare erected costs. Project contingency is added at $15 \%$ of the sum of bare erected cost and general plant facilities. Process contingency is added at $50 \%$ of items involved with ash depressurization, which apparently averages to $11.8 \%$ of the total cost account for ash systems according to the Foster Wheeler report. For simplicity, $11.8 \%$ is utilized for both the ceramic candle and the granular-bed filter.

Clearly, the addition of engineering fees and contingencies adds significantly to the cost of the filter plants and the ash handling facilities. The addition to the granular-bed filter module is $\$ 25.6 / \mathrm{kW}$, or $26.6 \%$ of the bare erected cost. For the candle filter the addition cost is $\$ 34.5 / \mathrm{kW}$ or $29.5 \%$ of the bare erected cost.

To the TPC, additions are made for interest charges and inflation during the construction period, sometimes called allowance for funds used during construction. This yields the value for total plant investment (TPI). Foster Wheeler estimated a construction period of $3-1 / 2$ years with an interest rate of $12.5 \%$. These values were used in the updated calculation of COE. To the TPI, values were added according to the Foster Wheeler report for royalties, initial catalyst and chemical inventory, start-up costs, spare parts, working capital, and land. This resulted in the total capital requirement (TCR). If a value was included by Foster Wheeler, it was escalated and utilized. Otherwise the default value in the Lotus 1-2-3 program was used. Annual costs include consumables, ash disposal, plant labor, maintenance, insurance, local taxes, royalties, and by-product credits. The annual cost of fuel (coal) is calculated and listed separately. See Section 5.2 for additional explanation on the use of the Lotus 1-2-3, COE calculation program and on the origin of annual cost values. The results presented in Table 49 show that the constant dollar COE for the second generation PFB combustion plant is 52.8 mills $/ \mathrm{kWh}$ based on granular-bed filters and 54.5 mills $/ \mathrm{kWh}$ based on ceramic candle filters. This assumes that the parasitic power presented in Tables 42 and 45 is accounted for in the base calculations that arrived at 452.8 MWe because of the cross-flow filter analysis.

If the net power output is adjusted for the parasitic power calculated for the filters there is a slight increase in COE of 0.1 mills $/ \mathrm{kWh}$. This increase applies to the second generation PFB combustion plant based on either granular-bed or ceramic candle filters and to either the current or constant dollar COE.

If RA253MA is used for the CPFBC candle filter internals instead of RA333, the COE in both current and constant dollars drops by 0.2 mills $/ \mathrm{kWh}$. 
If process gas is replaced by nitrogen for candle filter pulse cleaning, the COE increases to 54.8 mills $/ \mathrm{kWh}$ in constant dollars and 76.9 mills $/ \mathrm{kWh}$ in current dollars. This change includes capital and operating costs associated with replacing the process gas cooling/compressing equipment with the PSA nitrogen generating system. A 12-hour nitrogen supply is included with the PSA generation system for backup. Values for this adjustment are presented on Table 31 , Section 4.

Table 48 Cost Summary, HGCU/Piping \& Ash Handling System (1991 Costs in Thousands of Dollars, 452.8 MWe Plant)

\begin{tabular}{|c|c|c|}
\hline Cost Item & $\begin{array}{c}\text { Plant with } \\
\text { Granular-Bed } \\
\text { Filters }\end{array}$ & $\begin{array}{l}\text { Plant with } \\
\text { Candle }\end{array}$ \\
\hline
\end{tabular}

Hot Gas Cleanup and Piping

CPFBC Filter Module

23,946

31,670

Carbonizer Filter Module

5,823

Hot Gas Piping

13,382

6,776

HGCU Foundations

$\underline{516}$

14,050

Bare Erected Cost

43,667

494

in $\$ / \mathrm{kW}$

96.4

52,989

117.0

Engineering Fee, 6.5\%

2,838

3,444

Process Contingency

2,197

4,229

Project Contingency, 15\%

$\underline{6,550}$

$\underline{7.948}$

Total Plant Cost (TPC), $\mathrm{k} \$$

55,252

68,610

Total Plant Cost, $\$ / \mathrm{kW}$

122.0

151.5

Ash/Spent Sorbent Handling System

Bare Erected Cost

7,926

5,456

in $\$ / \mathrm{kW}$

17.5

12.0

Engineering Fee, 6.5\%

515

355

Process Contingency

935

644

Project Contingency, 15\%

1,189

818

Total Plant Cost (TPC), $k \$$

$\underline{10,565}$

$\underline{7,273}$

Total Plant Cost, $\$ / \mathrm{kW}$

23.3

16.1 
Table 49 Cost of Electricity Comparison

Second Generation PFB Combustion Plant, 452 MWe

Cost of Electricity - Levelized

Granular-Bed Filter

Capital Charges

Fuel Charges

Operation \& Maintenance

Total Cost of Electricity

Candle Filter

Capital Charges

Fuel Charges

Operation \& Maintenance

Total Cost of Electricity
36.2

20.3

$\underline{17.6}$

74.1

Current \$

mills/kWh

Constant \$

mills/kWh

Tables 50 and 51 present the summary printouts from the Lotus 1-2-3 $\mathrm{COE}$ calculation with the assumption presented. 


\section{Table 50 COE Calculation, PFB Combustion Plant with GBF}

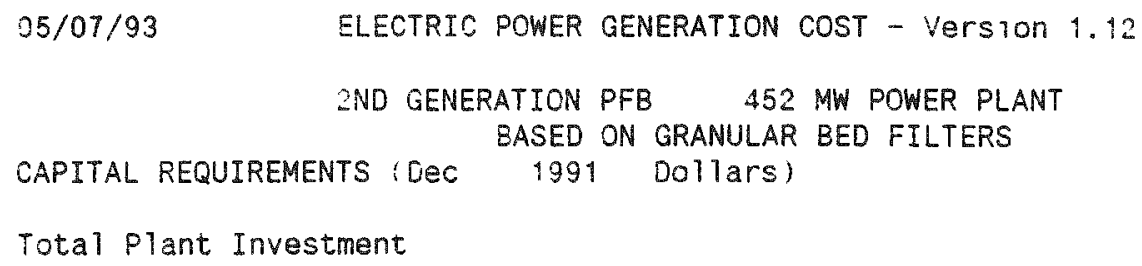

$\$ 19,774$

$\$ 50,670$

$\$ 43,667$

$\$ 55,681$

$\$ 26,959$

$\$ 37,050$

$\$ 9,775$

$\$ 5,457$

$\$ 14,131$

$\$ 11,502$

$\$ 9,492$

$\$ 12,283$
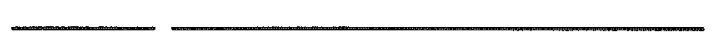

\section{st}

$\$ 354,184$

General Plant Facilities

Engineering Fees

Process Contingency (Using contingencies listed above)

Project Contingency,

$15 \%$ Proc Plt \& Gen Plt Fac

$$
\begin{array}{r}
\$ 23,022 \\
\$ 21,436 \\
\$ 53,128 \\
\$ 451,470
\end{array}
$$

Total Plant Cost (TPC)

Plant Construction Period, Construction Interest Rate,

3.5 Vears ( 1 or more) Adjustment for Interest and Inflation

$\$ 48,028$

Total Plant Investment (TPI)

$\$ 499,498$

Prepaid Royalties

Initial Catalyst and Chemical Inventory

Startup Costs

Spare Parts

Working Capital

Land,

200 Acres

Total Capital Requirement (TCR)

$$
\begin{array}{r}
\$ 0 \\
\$ 0 \\
\$ 14,864 \\
\$ 2,257 \\
\$ 13,527 \\
\$ 1,500 \\
\$ 531,646
\end{array}
$$


Table 50 COE Calculation, PFB Combustion Plant with GBF (continued)

ANNUAL OPERATING COSTS

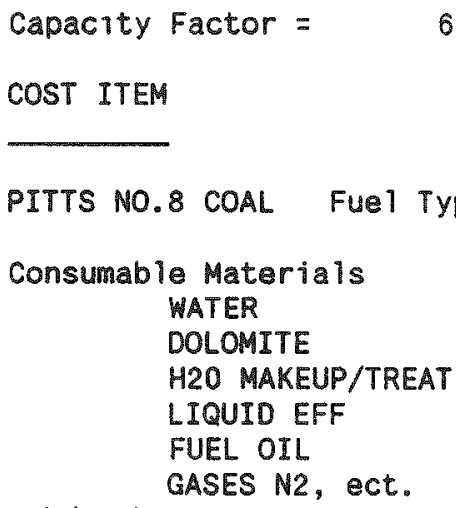

$\$ 919$
$\$ 5,099$
$\$ 206$
$\$ 390$
$\$ 608$
$\$ 421$
$\$ 2,403$
$\$ 5,273$
$\$ 2,750$
$\$ 9,734$
$\$ 9,029$
$\$ 0$
$\$ 917$
$\$ 79,720$

By-Product Credits

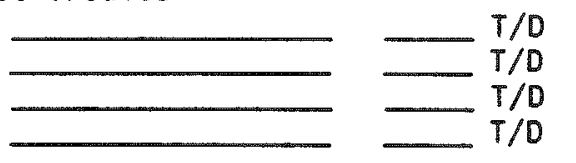

Total By-Product credits

Net Operating costs
$\$ 79,720$

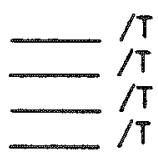

$\$ 79,720$ 
Table 50 COE Calculation, PFB Combustion Plant with GBF (continued)

BASES AND ASSUMPTIONS

4. CAPITAL BASES AND DETAILS

\begin{tabular}{l} 
intial Catalyst Inventory \\
\hline
\end{tabular}




\section{Table 50 COE Calculation, PFB Combustion Plant with GBF (continued)}

\section{B. ECONOMIC ASSUMPTIONS}

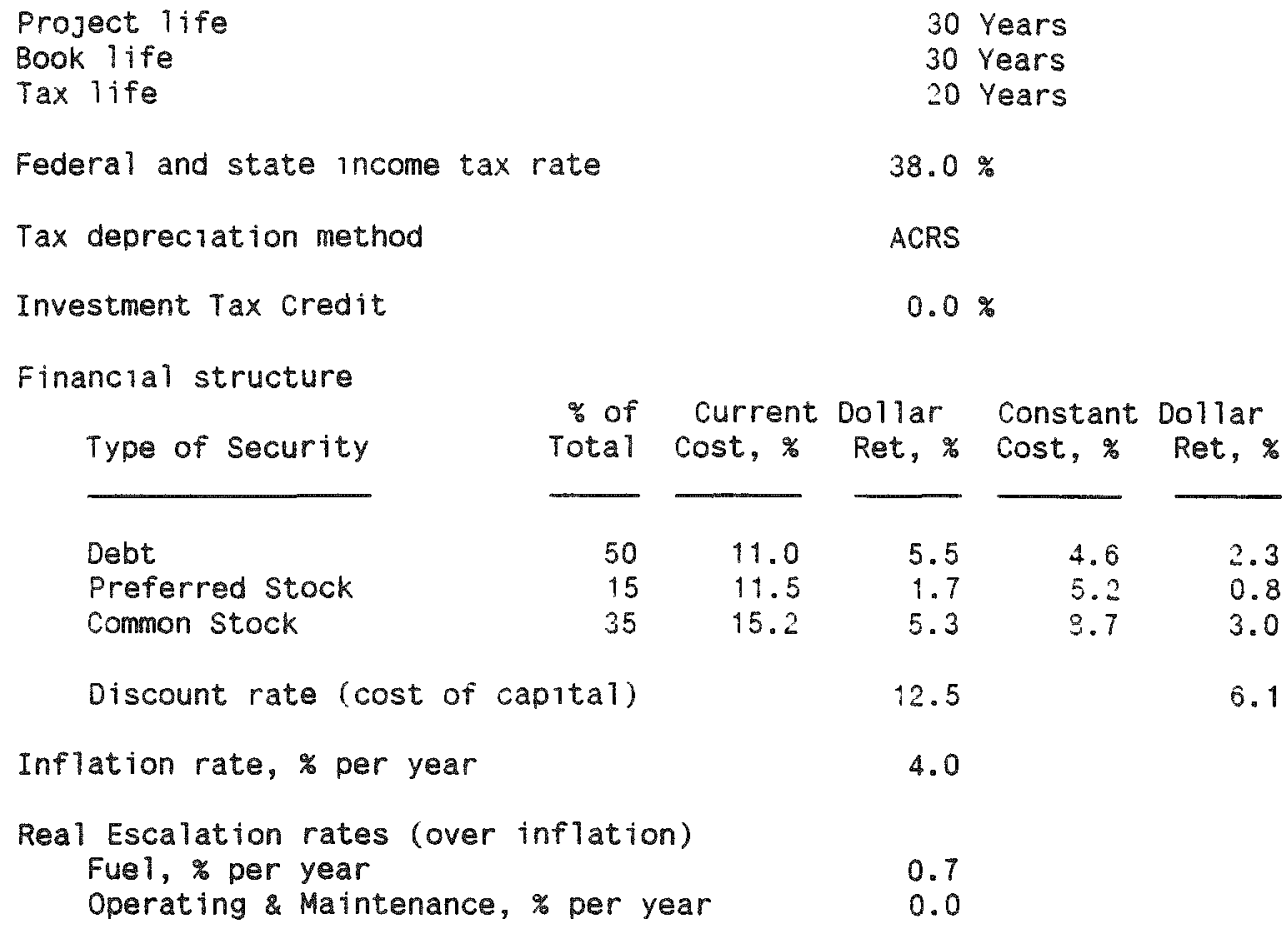

\section{COST OF ELECTRICITY}

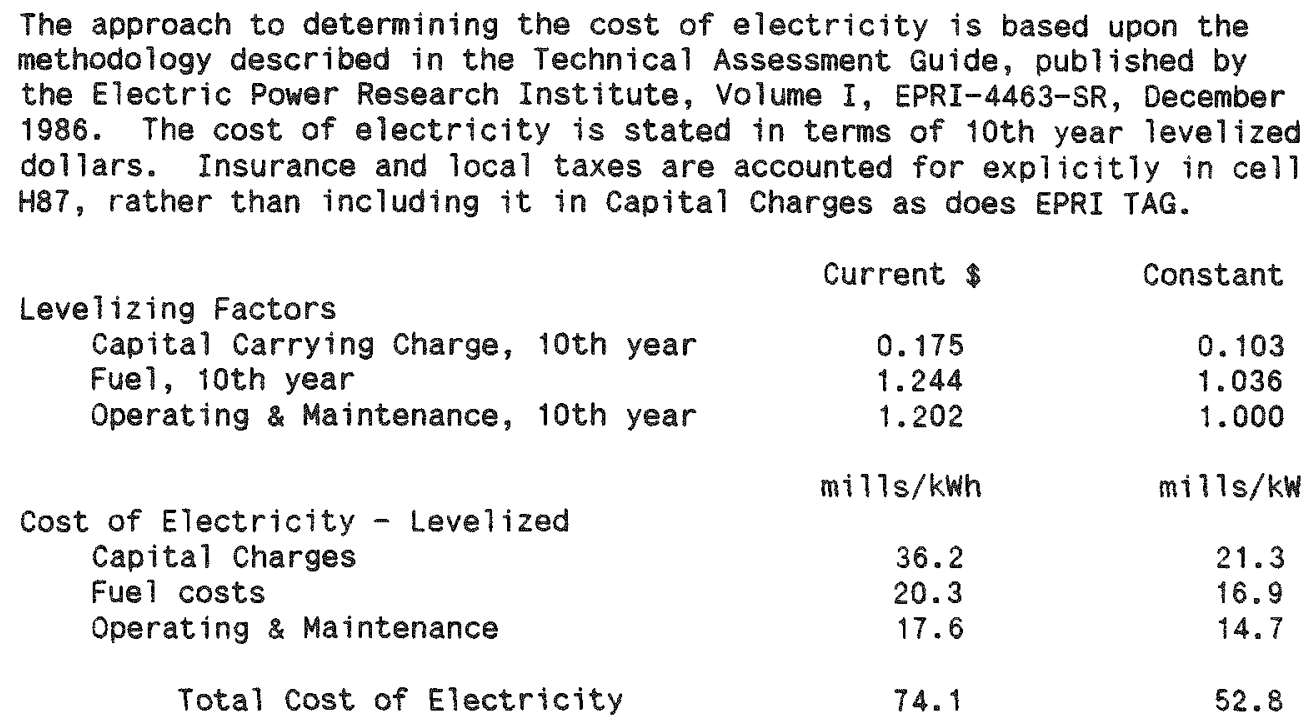


Table 51 COE Calculation, PFB Combustion Plant with Candle Filter

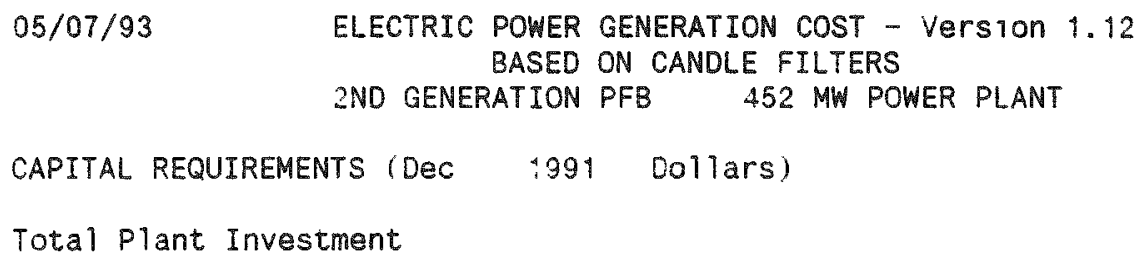

$\$ 55,681$

$\$ 26,959$

$\$ 37,050$

$\$ 9,775$

$\$ 7,926$

$\$ 14,131$

$\$ 11,502$

$\$ 9,492$

$\$ 12,283$

Subtota1, Process Plant cost

$\$ 365,976$

General Plant Facilities

$\$ 0$

$\$ 23,788$

$\$ 23,460$

Process contingency (Using contingencies listed above)

$\$ 54,896$

Total Plant cost (TPC)

$\$ 468,120$

Plant Construction Period, Construction Interest Rate,

3.5 Years ( 1 or more)

Adjustment for Interest and Inflation

$\$ 49,799$

Total Plant Investment (TPI)

$\$ 517,919$

Prepaid Royalties

Initial Catalyst and Chemical Inventory

Startup costs

Spare Parts

Working Capital

Land,

200 Acres

Total Capital Requirement (TCR) 
Table 51 COE Calculation, PFB Combustion Plant with Candle Filter (continued)

ANNUAL OPERATING COSTS

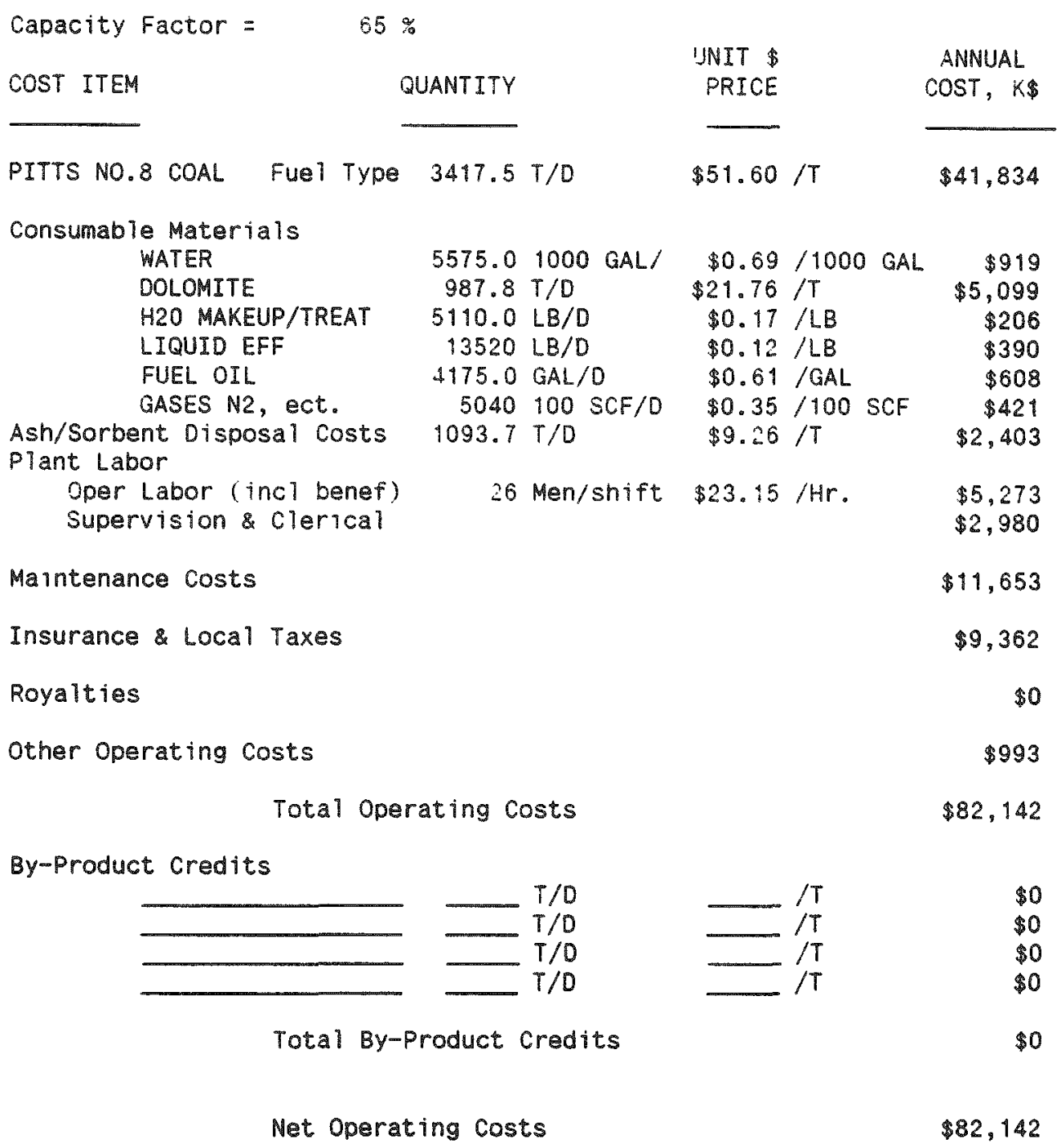


Table 51 COE Calculation, PFB Combustion Plant with Candle Filter (continued)

BASES AND ASSUMPTIONS

A. CAPITAL BASES AND DETAILS

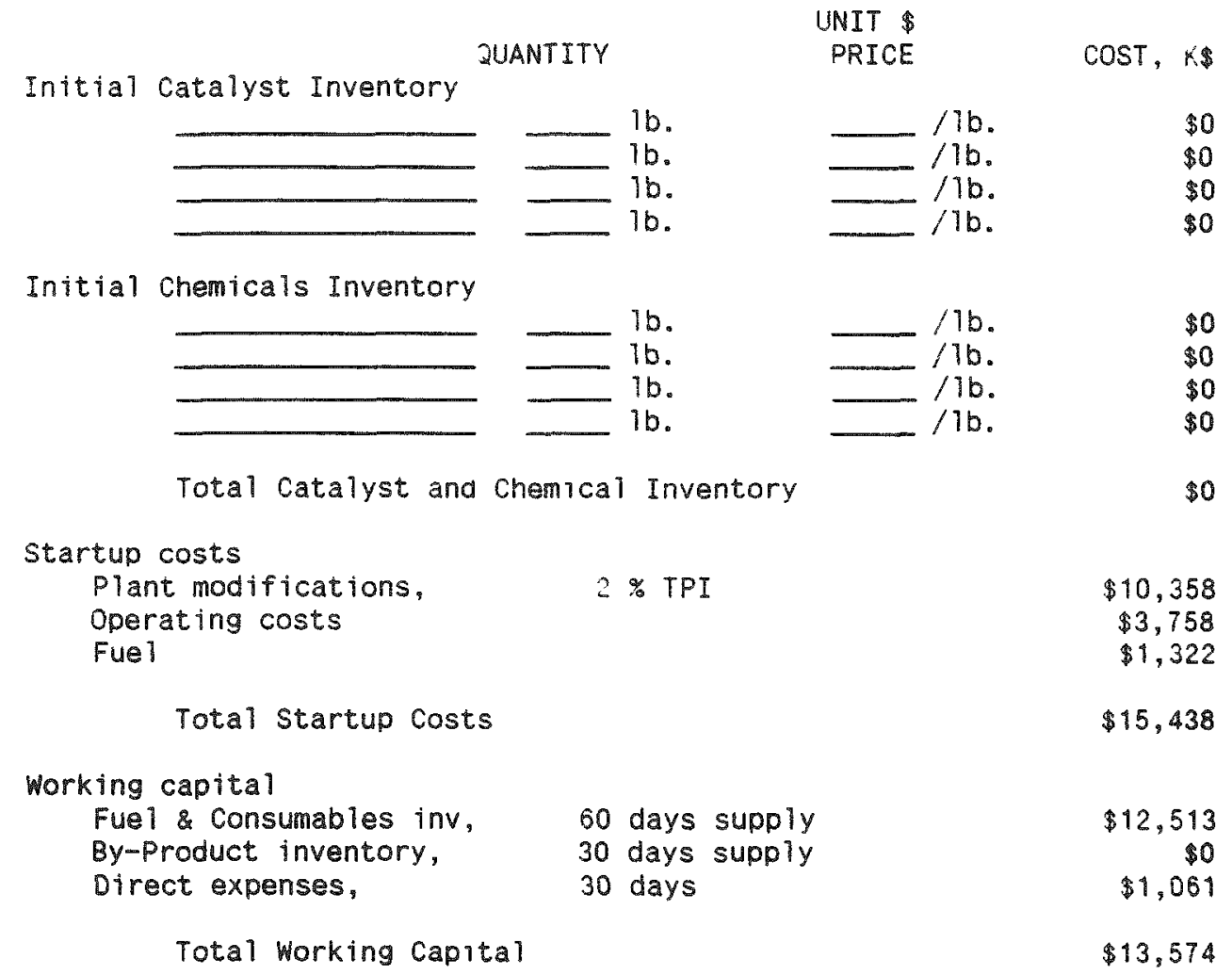


Table 51 COE Calculation, PFB Combustion Plant with Candle Filter (continued)

B. ECONOMIC ASSUMPTIONS

\begin{tabular}{|c|c|c|c|c|}
\hline $\begin{array}{l}\text { Project Iife } \\
\text { Book life } \\
\text { Tax life }\end{array}$ & & $\begin{array}{l}30 \\
30 \\
20\end{array}$ & $\begin{array}{l}\text { Years } \\
\text { Vears } \\
\text { Years }\end{array}$ & \\
\hline Federal and state income tax rate & & 38.0 & $\%$ & \\
\hline Tax depreciation method & & ACRS & & \\
\hline Investment Tax credit & & 0.0 & $\%$ & \\
\hline inancial structure & & & & \\
\hline Type of security & $\begin{array}{l}\text { Current } \\
\text { Cost, } \%\end{array}$ & $\begin{array}{l}\text { Dollar } \\
\text { Ret, \% }\end{array}$ & $\begin{array}{l}\text { Constant } \\
\text { Cost, } \%\end{array}$ & $\begin{array}{l}\text { Dollar } \\
\text { Ret, } \%\end{array}$ \\
\hline Debt & 11.0 & 5.5 & 4.6 & 2.3 \\
\hline Preferred stock & 11.5 & 1.7 & 5.2 & 0.8 \\
\hline Common stock & 15.2 & 5.3 & 8.7 & 3.0 \\
\hline Discount rate (cost of capital) & & 12.5 & & 0.1 \\
\hline Inflation rate, \% per year & & 4.0 & & \\
\hline $\begin{array}{l}\text { Real Escalation rates (over inflatio } \\
\text { Fuel, \% per year } \\
\text { Operating \& Maintenanca, \% per y }\end{array}$ & & $\begin{array}{l}0.7 \\
0.0\end{array}$ & & \\
\hline
\end{tabular}

C. COST OF ELECTRICITY

The approach to determining the cost of electricity is based upon the methodology described in the Technical Assessment Guide, published by the Electric Power Research Institute, Volume I, EPRI-4463-SR, December 1986. The cost of electricity is stated in terms of loth year levelized dollars. Insurance and local taxes are accounted for explicitly in cell H87, rather than including it in capital charges as does EPRI TAG.

Levelizing Factors

Capital Carrying charge, 10th year Fue 1, 10th year

Operating Maintenance, 10th year

Cost of Electricity - Levelized
Capital charges
Fuel costs
Operating \& Maintenance

Total Cost of Electricity current

0.175

1.244

1.202

mi11s/kWh

37.5

20.2

18.8

76.5
Constant

0.103

1.036

1.000

$\mathrm{mi} 11 \mathrm{~s} / \mathrm{kW}$

22.0

16.8

15.7

54.5 


\subsection{COE Comparison, KRW Gasifier Based Power Plant}

In the Westinghouse report on the $100 \mathrm{MWe}$, KRW air blown gasifier based power plant, filter costs are broken down into four categories. These categories included the cross-flow filter vessel with internals, nitrogen supply for pulse cleaning, nitrogen accumulator, and ash cooling and depressurizing. Labor and materials for erection are in another category and include instrumentation, controls, piping, structure, foundations, insulation, and engineering fees. These cost items generally fit the definition of bare erected costs for the filter based on EPRI TAG methodology. Another item of bare erected cost of the plant is the zinc/ferrite system for sulfur removal. Part of our contract was to update the cost of this plant based on published METC guidelines and include this in the COE calculation.

\subsubsection{Zine Ferrite Plant Cost Update}

The KRW air blown gasification plant is described in the Westinghouse report comparing numerous gasification plants ${ }^{3}$. Subsequent to this report, in 1989, EG\&G Washington Analytical Services Center issued "Conceptual Design and Cost Estimate for Zinc Ferrite Plant Section." ${ }^{4}$ The plant cost determined by the EG\&G report needed to be adjusted to match the plant size and operating conditions described in the Westinghouse report and then adjusted to December, 1991 dollars. The updated cost are incorporated into the cost of electricity for the KRW gasifier based power generation plant.

The plant used in the EG\&G study is a two train, zinc ferrite facility with a common sorbent handling system. The volumetric flow rate of a single train is close that of the flow through the zinc ferrite plant to be used in the GBF study. Table 52 shows the flow conditions for the two plants. The temperature of the gas entering the zinc ferrite section of both plants is nearly equal. The plants differ in three significant ways. The plant used in the EG\&G study operates at 600 psia while the plant in the GBF study operates at 385 psia. The EG\&G plant uses water quench to cool the gases from the hot gas particulate cleanup equipment while the plant in the GBF study uses a heat recovery boiler. The plant with the GBF is a single train plant. The cost analysis makes adjustments to the cost to account for the plant differences.

It was assumed that the reactors in both plants should operate at the same space velocity of 2000 reactor volumes per hour so that the gases will have the same residence time in the reactors. Consequently, the volumetric flow rate is used as the scaling factor between the two plants. Equipment cost are scaled by the ratio of the flow through the reactors of each plant raised to an exponential power. The exponential powers depend on the type of equipment being priced, and are given in handbooks on cost estimating. Fortunately the two plants have similar volumetric flow rates so that corrections for capacity are less than 5\%. 
Table 52 Relative Plant Capacities for Zinc Ferrite Plant

\begin{tabular}{lrl}
\hline & $\begin{array}{l}\text { EG\&G Report } \\
\text { Single Train } \\
\text { Plant Used in } \\
\text { Zinc Ferrite } \\
\text { Cost Estimate }\end{array}$ & $\begin{array}{l}\text { Plant Used, } \\
\text { GBF Development } \\
\text { Study }\end{array}$ \\
\hline Mass Flow, lb/hr & 534,769 & 312,800 \\
Volumetric Flow, acfm & 10,916 & 10,153 \\
Temperature, ${ }^{\circ} \mathrm{F}$ & 1,140 & 1,200 \\
Pressure, psia & 600 & 385 \\
\hline
\end{tabular}

The pressure vessel costs are adjusted to account for the difference in operating pressure as well as capacity. The cost of the pressure vessel without nozzles was adjusted by $110 \%$ of the pressure ratio between the two plants. The revised cost is then adjusted for capacity differences.

Table 53 shows the material cost breakdown for the EG\&G study and the revised cost for the GBF study. The comments after each itemized piece of equipment provide the basis for adjusting the EG\&G cost to obtain the revised cost. The revised costs are then adjusted by the ratio of the Chemical Engineering Plant Equipment Cost Index for Dec. 1991 to that of 3rd quarter 1988 to obtain Dec. 1991 costs.

The EG\&G plant cost estimate uses a factored cost method. Once the cost of the equipment is determined, other costs are then factored from this value. The same approach is used to determine the cost of the zinc ferrite equipment used in this study. The same factors are used in both cases. Table 54 shows the factored cost summary. The installed cost of the zinc ferrite plant to be used in the GBF study is $\$ 8,952,641$. 
Table 53 Material Cost Breakdown for Zinc Ferrite Plant

\begin{tabular}{|c|c|c|c|c|}
\hline Description & $\begin{array}{l}\text { EG\&G Report } \\
\text { Mat'1 Cost } \\
\text { Two Trains } \\
\text { @600 PSIA @ } \\
\text { 10,916 ACFM } \\
\text { 3rd Quarter } \\
\text { 1988 \$ }\end{array}$ & $\begin{array}{l}\text { GBF Study } \\
\text { Mat'1 Cost } \\
\text { One Train } \\
@ 385 \text { PSIA @ } \\
\text { 10,153 ACFM } \\
\text { 3rd Quarter } \\
\text { 1988\$ }\end{array}$ & $\begin{array}{l}\text { GBF Study } \\
\text { Mat'1 Cost } \\
\text { One Train } \\
@ 385 \text { PSIA @ } \\
\text { 10,153 ACFM } \\
\text { Dec } 1991 \$\end{array}$ & Notes \\
\hline Humidifiers & $\ldots \$ 176,000$ & $\mathrm{~N} / \mathrm{A}$ & $\mathrm{N} / \mathrm{A}$ & \\
\hline Desulfurizing Reactor & . $\$ 4,044,000$ & $\$ 1,586,838$ & $\$ 1,650,796$ & 1 \\
\hline Steam/Air Regen $\mathrm{Hx} \ldots$ & $\ldots \ldots 162,000$ & $\$ 78,458$ & $\$ 81,621$ & 2 \\
\hline Regenerative Gas Cooler & $\ldots \$ 154,000$ & $\$ 74,584$ & $\$ 77,590$ & 3 \\
\hline Valves $\ldots \ldots \ldots \ldots$ & . $\$ 2,291,000$ & $\$ 1,145,500$ & $\$ 1,191,670$ & 4 \\
\hline Sorbent Handling System. & $\ldots \ldots 316,700$ & $\$ 267,096$ & $\$ 277,861$ & 5 \\
\hline Shutdown Regen Coolers & $\ldots \$ 81,600$ & $\$ 39,520$ & $\$ 41,113$ & 6 \\
\hline Recycle N2 Compressor . & $\ldots \$ 232,000$ & $\$ 220,526$ & $\$ 229,401$ & 7 \\
\hline Instrumentation $\ldots \ldots$ & $\ldots \$ 403,400$ & $\$ 254,822$ & $\$ 265,092$ & 8 \\
\hline Sample Coolers ........ & $\ldots \ldots \$ 81,600$ & $\$ 40,800$ & $\$ 42,444$ & 9 \\
\hline Piping .. & . . $\$ 392,000$ & $\$ 247,660$ & $\$ 2576013$ & 10 \\
\hline Total Factored Mat'l . . . . & $\cdots \frac{\$ 1,568,700}{\$ 9,903,000}$ & & $\frac{\$ 773,154}{\$ 4,888,357}$ & 11 \\
\hline
\end{tabular}

NOTE: Chemical Engineering, Plant Equipment Cost Index:

Dec. $1991-394.9 \quad$ 3rd Quarter $1988-379.6$

Notes for Table 53

1. Costs halved, then adjusted for pressure then adjusted by (Volumetric Capacity Ratio) ${ }^{.68}$ See Table 54.

2. Cost halved, then adjusted by (Volumetric Capacity Ratio) ${ }^{44}$

3. Cost halved, then adjusted by (Volumetric Capacity Ratio) ${ }^{44}$

4. Valve cost assumed to be evenly Split between two trains.

5. Cost reduced by cost of 2 nd spent sorbent conveyor and feeder $(\$ 39,750)$ then adjusted by (Volumetric Capacity Ratio) ${ }^{.5}$

6. Cost halved, then adjusted by (Volumetric Capacity Ratio) ${ }^{44}$

7. Cost adjusted by (Volumetric Capacity Ratio) ${ }^{.70}$

8. Cost adjusted by (Two Train Volumetric Capacity Ratio) ${ }^{6}$

9. Cost halved.

10. Cost adjusted by (Two Train Volumetric Capacity Ratio) ${ }^{6}$.

11. $18 \%$ of (Material Less Sorbent Handling and Piping) $+50 \%$ of Piping.

Volumetric Capacity Ratio $=10153 / 10916$

Two Train Volumetric Capacity Ratio $=10153 /(2 * 10916)$

Exponents of Capacity Factor are from Perry \& Clinton "Chemical Engineers Handbook". 5th ed. Table 25-14. 
Table 54 Factored Cost Summary for Zinc Ferrite Plant - Dec. 1991 Dollars

\begin{tabular}{|c|c|c|c|c|c|c|c|}
\hline & $\begin{array}{l}\text { Material } \\
\text { Factor }\end{array}$ & $\begin{array}{l}\text { Material } \\
\text { Dollars } \\
\text { Jan } 1992\end{array}$ & $\begin{array}{l}\text { Labor } \\
\text { Factor }\end{array}$ & $\begin{array}{l}\text { Labor } \\
\text { Dollars }\end{array}$ & $\begin{array}{l}\text { Subcontract } \\
\text { Factor }\end{array}$ & $\begin{array}{l}\text { Total } \\
\text { Dollars }\end{array}$ & Dollars \\
\hline Equipment & 100 & $\$ 3,579,741$ & 8 & $\$ 286,379$ & & & $\$ 3,866,120$ \\
\hline Civil & 4 & $\$ 143,190$ & 10 & $\$ 357,974$ & & & $\$ 501,164$ \\
\hline Sorbent Handling System & & $\$ 277,861$ & & $\$ 69,465$ & & & $\$ 347,326$ \\
\hline Piping & & $\$ 386,401$ & & $\$ 270,481$ & & & $\$ 656,883$ \\
\hline Building (Control House) & 3 & $\$ 107,392$ & 3 & $\$ 107,392$ & & & $\$ 214,784$ \\
\hline Structures & 5 & $\$ 178,987$ & 2 & $\$ 71,595$ & & & $\$ 250,582$ \\
\hline Instrumentation Install. & 2 & $\$ 71,595$ & 2 & $\$ 71,595$ & & & $\$ 143,190$ \\
\hline Insulation & & & & & 7 & $\$ 250,582$ & $\$ 250,582$ \\
\hline Fireproofing & & & & & 1 & $\$ 35,797$ & $\$ 35,797$ \\
\hline Electrical & 4 & $\$ 143,190$ & 5 & $\$ 178,987$ & & & $\$ 322,177$ \\
\hline Painting & & & & & 2 & $\$ 71,595$ & $\$ 71,595$ \\
\hline Total Direct Costs & & $\$ 4,888,357$ & & $\$ 1,413,868$ & & $\$ 357,974$ & $\$ 6,660,199$ \\
\hline Testing (6.5\% Labor) & & & & & & & $\$ 91,901$ \\
\hline Labor Fringes ( $32 \%$ Labor) & & & & & & & . $\$ 452,438$ \\
\hline Field Indirects (54\% Labor) . . & & & & & & & . $\$ 763,489$ \\
\hline home office services ( $11 \%$ labor) & & & & & & & . $\$ 984,614$ \\
\hline $\begin{array}{l}\text { Total Installed Cost . . . . . . . . } \\
\text { (Excluding Contingency and Fee) }\end{array}$ & . . & 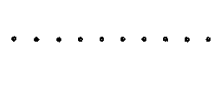 & & & & & $\$ 8,952,641$ \\
\hline
\end{tabular}




\subsubsection{Bare Erected Costs, Gasifier Filters}

Bare erected costs established for the granular-bed and the ceramic candle filters for the gasifier are compared on Table 55. These costs were originally presented separately in sections 5.3 and 5.4. As in the original cost estimate for the cross-flow filter, all costs associated with the filter are included as follows: filter, ash removal (media circulation or pulse cleaning), and ash handling. Filter vessels are all estimated at $\$ 2.50 / 1 \mathrm{~b}$ based on quotes received for shop fabrication. The candle filter vessels are larger, and heavier, than the granular-bed filter vessels. GBF internals are lighter and less complex than candle filter internals; but since they are based on fabrication from the same material, $\mathrm{RA} 85 \mathrm{H}$, costing is at $\$ 15 / \mathrm{lb}$ for both, based on analysis of quotes received. Pressure vessel steelwork for all smaller vessels is included at $\$ 3.50 / \mathrm{lb}$ for both filters. Small fabricated items made from 310 SS sheet or plate, for items such as the deentrainment vessel internals and the media valve internals for the granular-bed filter, are included at $\$ 7.50 / 1 \mathrm{~b}$, again based on quotes. Carbon steel fabricated piping and ducting is $\$ 2.50 / 1 \mathrm{~b}$ and stainless steel fabricated piping is $\$ 10.50 / \mathrm{b}$. Filter media for the granular-bed filter is priced at $\$ 0.45 / \mathrm{lb}$. Candle filter elements are priced at $\$ 295 /$ element based on quotations from manufacturers. Other buyout equipment is priced based on quotes from qualified suppliers. Freight is estimated at $4 \%$ of the cost of filter items. The contractors estimating factors for refractory include freight and installation. Erection for all filters was evaluated by an independent contractor specializing in construction cost estimating. General and administrative costs and allowance for profit is included for all items by dividing costs by 0.85 .

\subsubsection{Power Plant Maintenance}

The Westinghouse report used $2.7 \%$ of total plant, bare erected cost for power plant maintenance. For this study, this factor was applied to all capital cost items except the filter equipment. Results from maintenance calculations were presented for the gasifier filters in Tables 41 and 44 for the granular-bed and ceramic candle filter, respectively. These costs $(\$ 156,400$ for the granular-bed filter and $\$ 300,200$ for the candle filter) were used in the calculation of COE.

\subsubsection{Cost of Electricity}

Costs for hot gas cleanup equipment and piping are summarized in Table 56. To the bare erected cost, percentages are added for process contingency and project contingency to arrive at the total plant cost (TPC). Engineering is included with the filter. Percentages are those proposed in the Westinghouse report. Project contingency is added at $18 \%$ of the sum of bare erected cost and general plant facilities. Process contingency is added at $5.5 \%$ of bare erected costs of the entire plant. Engineering for the filters includes construction management, and home office fees in addition to the cost for engineering services provided by the filter manufacturers. 
Clearly, the addition of engineering fees and contingencies add significantly to the cost of the filter plants and the ash handling facilities. The addition to the granular-bed filter module is $\$ 7.7 / \mathrm{kW}$, or $20.4 \%$ of the bare erected cost. For the candle filter the addition cost is $\$ 9.1 / \mathrm{kW}$ or $20.4 \%$ of the bare erected cost.

Table 55 Bare Erected Cost Comparison Gasifier Filters, 100 Mwe

\begin{tabular}{lrlr}
\hline & $\$ / 1000$ & & $\$ / 1000$ \\
Filter Vessel & 405 & Filter Vessel & 738 \\
Filter Internals & 99 & Filter Internals & 340 \\
Vessel Refractory & 116 & Vessel Refractory & 182 \\
Filter Media & 119 & Filter Elements & 314 \\
Circulation System & & Pulse Back & \\
$\quad$ Vessels/Piping & 666 & Piping/Valves & 506 \\
$\quad$ Regen. Ht. Exch. & 873 & Compressors/Coolers & 542 \\
Water-Cooled Hx. & 19 & Ash System & \\
Baghouse & 78 & Ash Coolers & 570 \\
$\quad$ Boost/Maint. Blower & 137 & Ash Hoppers & 31 \\
Instr/Controls & 74 & Ash Valves & 74 \\
Access/Support Steel & 213 & Instr/Controls & 50 \\
Foundation Mat'1 & 10 & Access/Support Steel & 113 \\
Ash System & 87 & Foundation Mat'l & 8 \\
Erection & 217 & Erection & 300 \\
Engineering & 561 & Engineering & 561 \\
Freight & $\underline{102}$ & Freight & $\underline{130}$ \\
Bare Erected Cost, $\mathrm{k} \$$ & 3,775 & Bare Erected Cost, k\$ & 4,458 \\
\hline
\end{tabular}

To the TPC, additions are made for interest charges and inflation during the construction period, sometimes called allowance for funds used during construction (AFUDC). This yields the value for total plant investment (TPI). Westinghouse estimated $13 \%$ of total investment for AFUDC, working capital, etc. Since this value is very close to the spreadsheet calculation assuming $12.5 \%$ construction interest and a 4 year construction period, the substitution was made. These values were used in the updated 
Table 56 Cost Summary, KRW Gasifier Based Power Plant (1991 Costs in Thousands of Dollars, 100 MWe Plant)

Cost Item

$\begin{array}{cc}\text { Plant with } & \text { Plant with } \\ \text { Granular-Bed } & \text { Candle } \\ \text { Filters } & \text { Filters }\end{array}$

Filter Module

Bare Erected Cost

3,775

4,458

in $\$ / \mathrm{kW}$

37.8

44.6

Engineering Fee,

incl

incl

Process Contingency, $5.5 \%$

208

245

Project Contingency, $15 \%$

$\underline{566}$

$\underline{669}$

Total Plant Cost (TPC), $k \$$

4,549

5,372

Total Plant Cost, $\$ / \mathrm{kW}$

45.5

53.7

calculation of COE. To the TPI, values were added according to the Westinghouse report for royalties, initial catalyst and chemical inventory, start-up costs, spare parts, working capital, and land. This resulted in the total capital requirement (TCR). If a value was included by Westinghouse, it was escalated and utilized. Otherwise the default value in the Lotus 1-2-3 program was used. Annual costs include consumables, ash disposal, plant labor, maintenance, insurance, local taxes, royalties, and by-product credits. The annual cost of fuel (coal) is calculated and listed separately. See Section 5.2 for additional explanation on the use of the COE calculation program and on the origin of annual cost values. The results presented in Table 57 show that the constant dollar COE for the KRW gasifier based plant is 91.8 mills/kWh based on granular-bed filters and 92.4 mills $/ \mathrm{kWh}$ based on ceramic candle filters. This assumes that the parasitic power presented in Tables 42 and 45 is accounted for in the base calculations that arrived at $100 \mathrm{MWe}$ because of the cross-flow filter analysis.

If the net power output is adjusted for the parasitic power calculated for the filters there is a slight increase in COE of $0.1 \mathrm{mills} / \mathrm{kWh}$. This increase applies to the KRW gasifier based power plant based on either granular-bed or ceramic candle filters and to either the current or constant dollar COE.

If process gas is replaced by nitrogen for pulse cleaning, the COE increases 2.1 mills/kWh and 1.4 mills/kWh in constant dollars and current dollars, respectively. This change includes capital and operating costs associated with replacing the process gas cooling/compressing equipment with the PSA nitrogen generating system. A 12-hour nitrogen supply is included with the PSA generation system for backup. Values for this adjustment are presented on Table 31 , Section 4. 
Table 57 Cost of Electricity Comparison KRW Gasifier Based Power Plant, 100 MWe

\begin{tabular}{lcc}
\hline Cost of Electricity - Levelized & $\begin{array}{c}\text { Current } \$ \\
\text { mills/kWh }\end{array}$ & $\begin{array}{c}\text { Constant } \$ \\
\text { mills/kWh }\end{array}$ \\
\hline$\underline{\text { Granular-Bed Filter }}$ & & \\
$\quad$ Capital Charges & 77.8 & 45.7 \\
$\quad$ Fuel Charges & 16.5 & 13.8 \\
Operation \& Maintenance & $\underline{38.9}$ & $\underline{32.4}$ \\
$\quad$ & 133.2 & 91.8 \\
$\quad$ Total Cost of Electricity & & \\
Candle Filter & & 45.9 \\
$\quad$ Capital Charges & 16.5 & 13.8 \\
Fuel Charges & $\underline{39.4}$ & \\
Operation \& Maintenance & 134.0 & 92.4 \\
$\quad$ Total Cost of Electricity & & \\
\hline
\end{tabular}

Tables 58 and 59 present the summary printouts from the Lotus 1-2-3 COE calculation with the assumption presented. 


\section{Table 58 COE Calculation, KRW Gasification Plant with GBF}

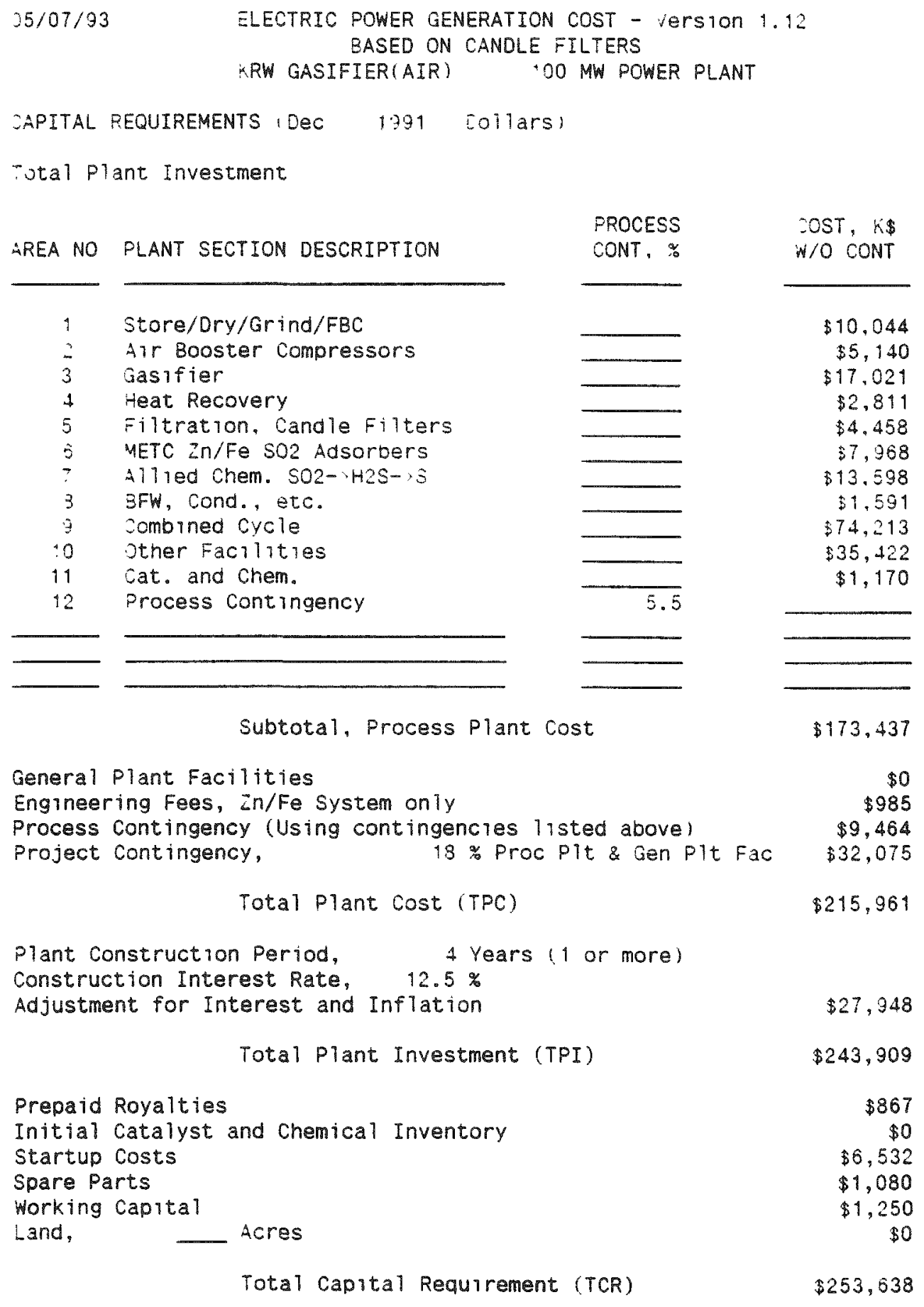

10,044

$\$ 5,140$

$\$ 17,021$

$\$ 2,811$

$\$ 4,458$

$\$ 7,968$

$\$ 13.598$

$\$ 1,591$

$\$ 74,213$

$\$ 35, \$ 22$

$\$ 1,170$

Subtota1, Process Plant Cost

$\$ 173,437$

General Plant Facilities

Plant Construction Period, Construction Interest Rate, 4 Years (1 or more) Adjustment for Interest and Inflation

Prepaid Royalties

Initial Catalyst and Chemical Inventory

Startup Costs

$\$ 6,532$

Spare Parts

Working Capital

Land,

\author{
Acres

$\$ 1,080$

$\$ 1,250$ 
Table 58 COE Calculation, KRW Gasification Plant with GBF (continued)

ANNUAL OPERATING COSTS

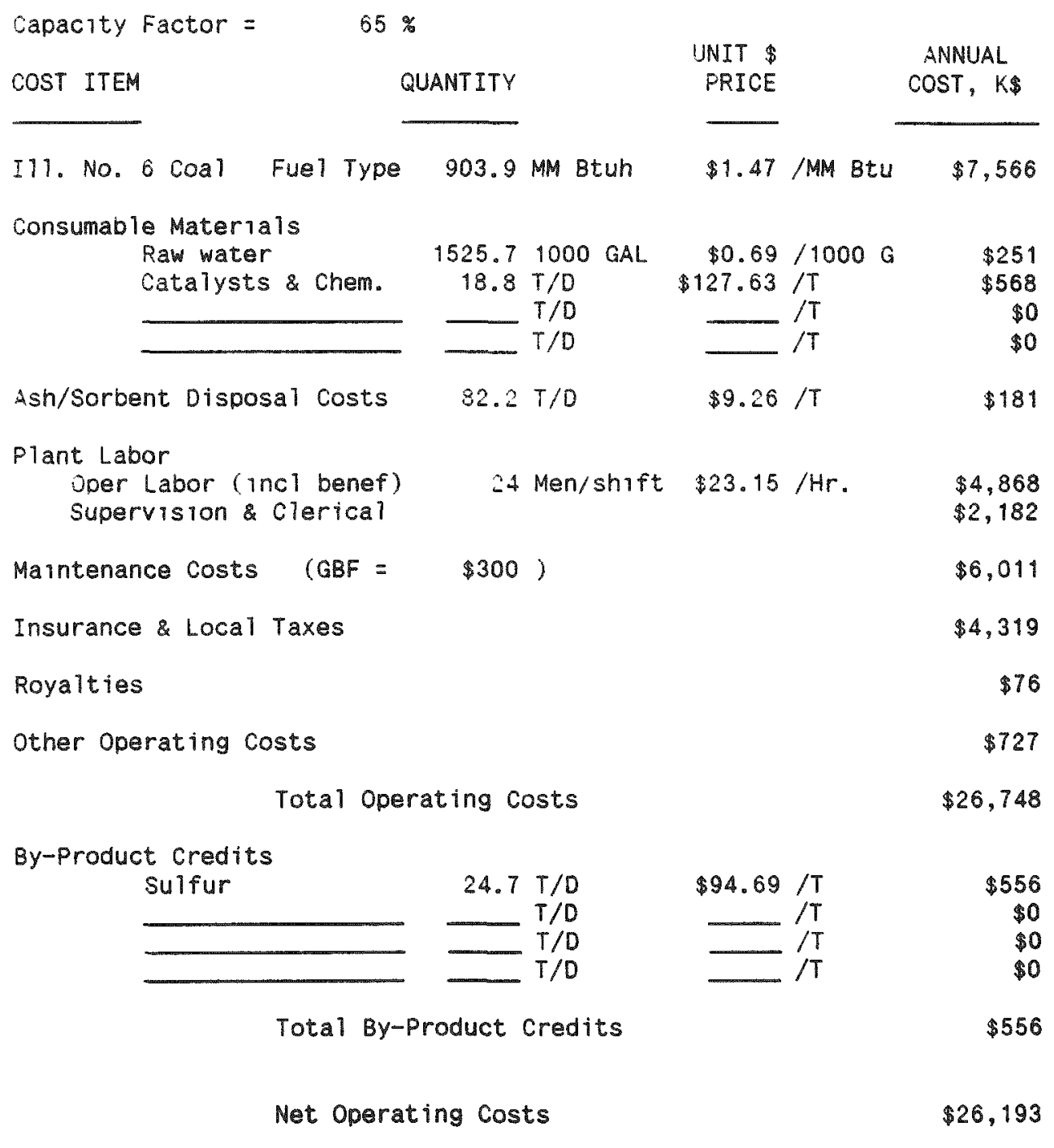


Table 58 COE Calculation, KRW Gasification Plant with GBF (continued)

BASES AND ASSUMPTIONS

A. CAPITAL BASES AND DETAILS

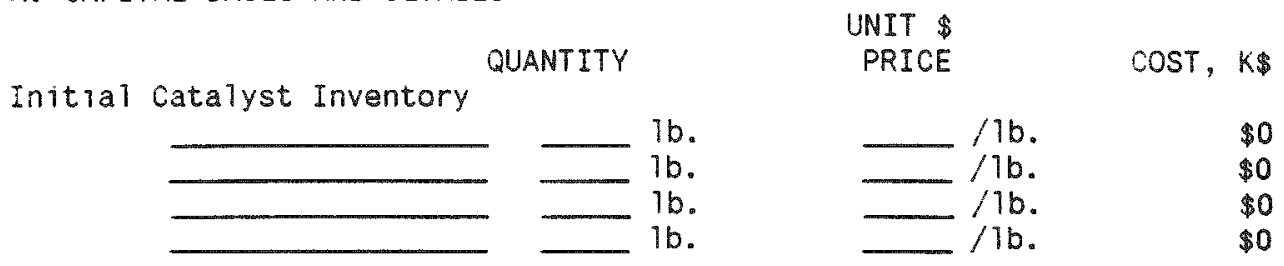

Initial Chemicals Invencory

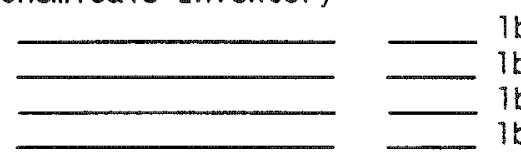

1b. $/ 7 b$.

$17 b$.

$\longrightarrow / 1 \mathrm{~b}$.

$1 \mathrm{~b}$.

/1b.

$\$ 0$

Total Catalyst and Chemical Inventory

$\$ 0$

Startup costs

Plant modifications,

$2 \%$ TPI

$\$ 4,878$

Operating costs

Fuel

Total Startup Costs

$\$ 6,532$

Working capital

Fuel \& Consumables inv,

60 days supply

$\$ 333$

By-Product inventory,

60 days supply

$\$ 140$

Direct expenses,

30 days

$\$ 777$

Total Working Capital

$\$ 1,250$ 


\section{Table 58 COE Calculation, KRW Gasification Plant with GBF (continued)}

B. ECONOMIC ASSUMPTIONS

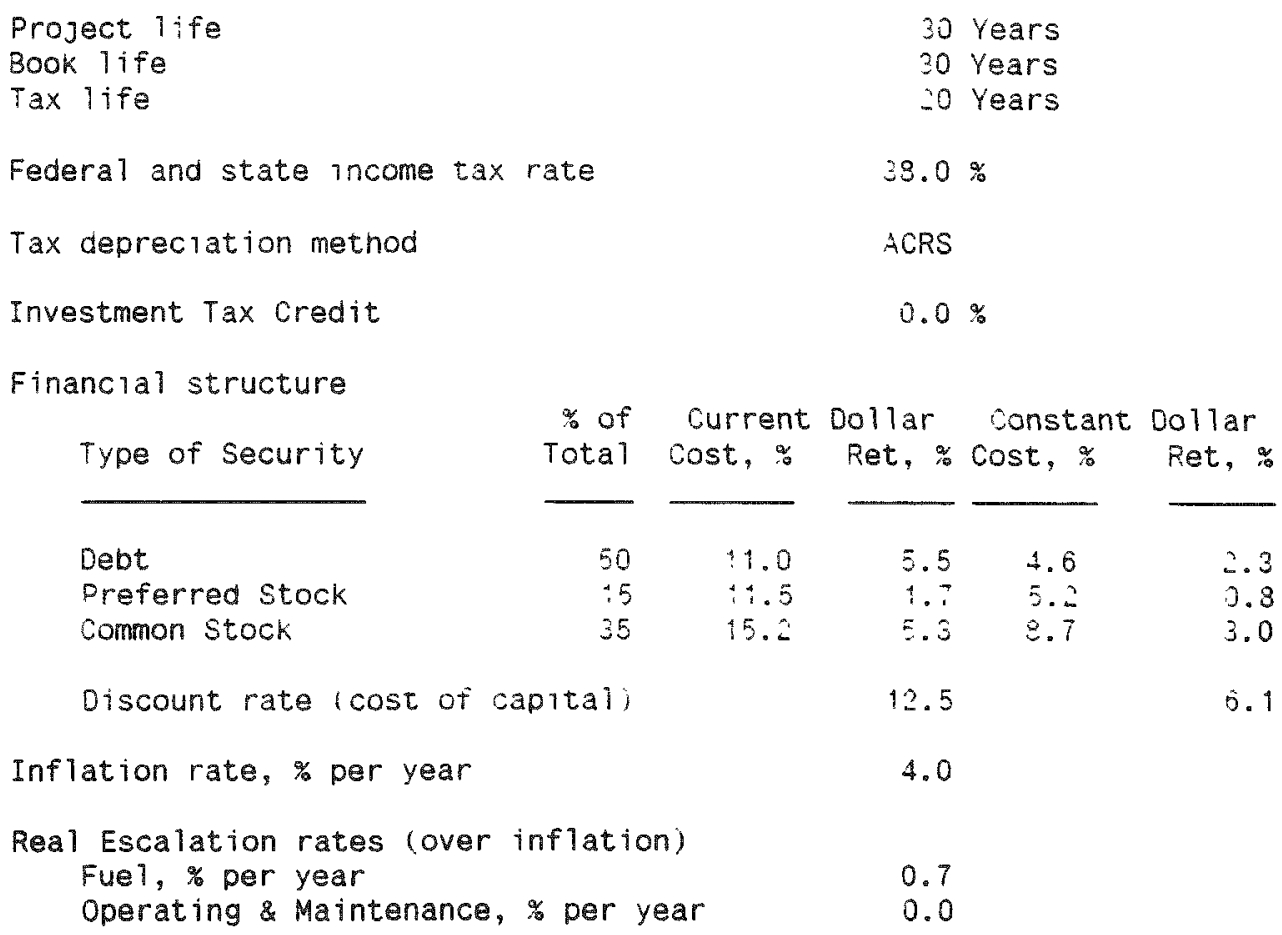

C. COST OF ELECTRICITY

The approach to determining the cost of electricity is based upon the methodology described in the Technical Assessment Guide, published by the Electric Power Research Institute, Volume I, EPRI-4463-SR, December 1986. The cost of electricity is stated in terms of loth year levelized dollars. Insurance and local taxes are accounted for explicitly in cell H87, rather than including it in Capital Charges as does EPRI TAG.

\section{Levelizing Factors}

Capital Carrying Charge, 10th year

Fue1, 10th year

Operating \& Maintenance, 10th year

Cost of Electricity - Levelized

Capital Charges

Fue 1 costs

operating \& Maintenance

Total Cost of Electricity
Current

0.175

1.244

1.202

mills/kWh

78.1

16.5

39.4

134.0
Constant $\$$

0.103

1.036

1.000

mil1s/kWh

45.9

13.8

32.7

92.4 
Table 59 COE Calculation, KRW Gasifier Plant with Candle Filter

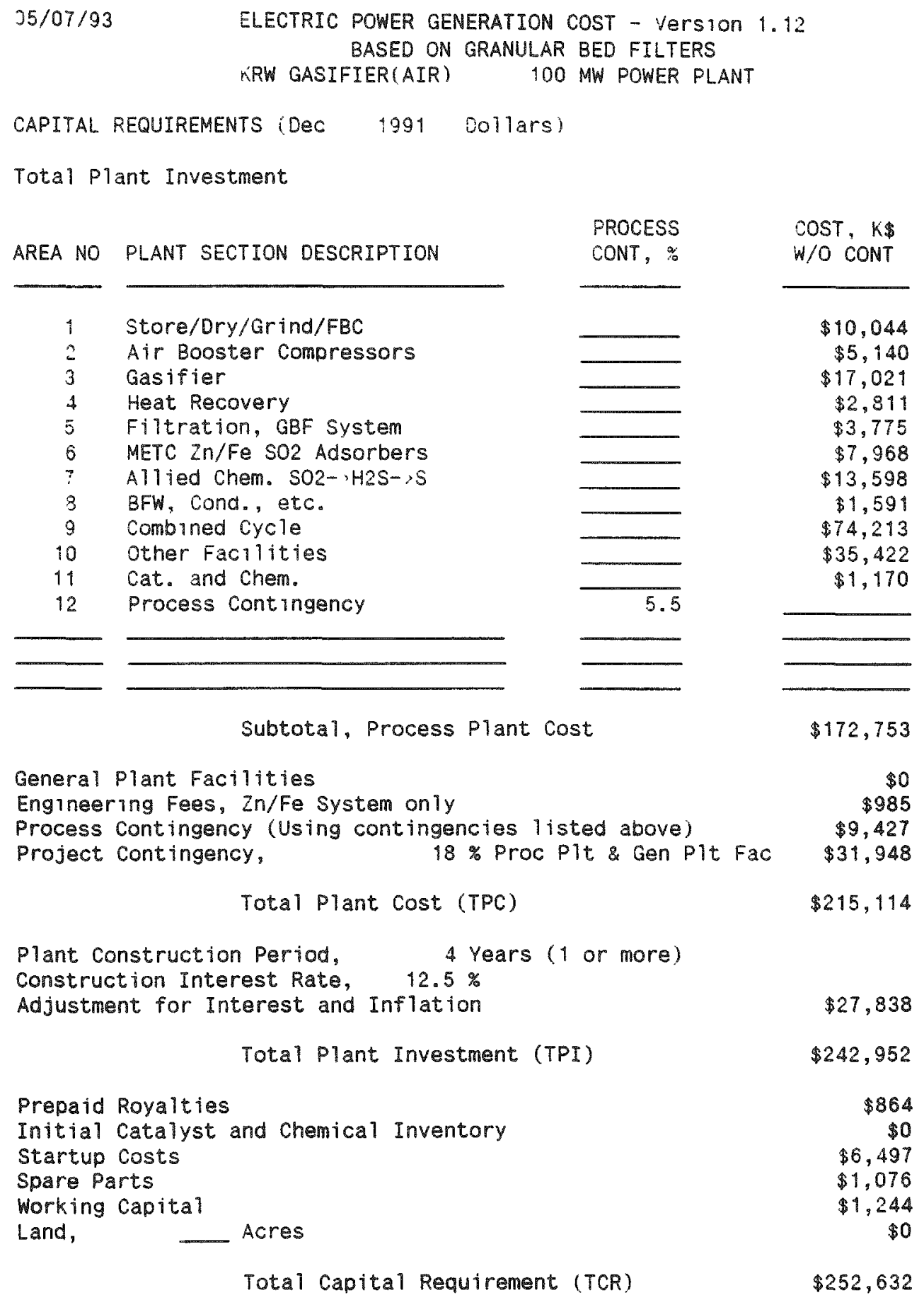


Table 59 COE Calculation, KRW Gasifier Plant with Candle Filter (continued)

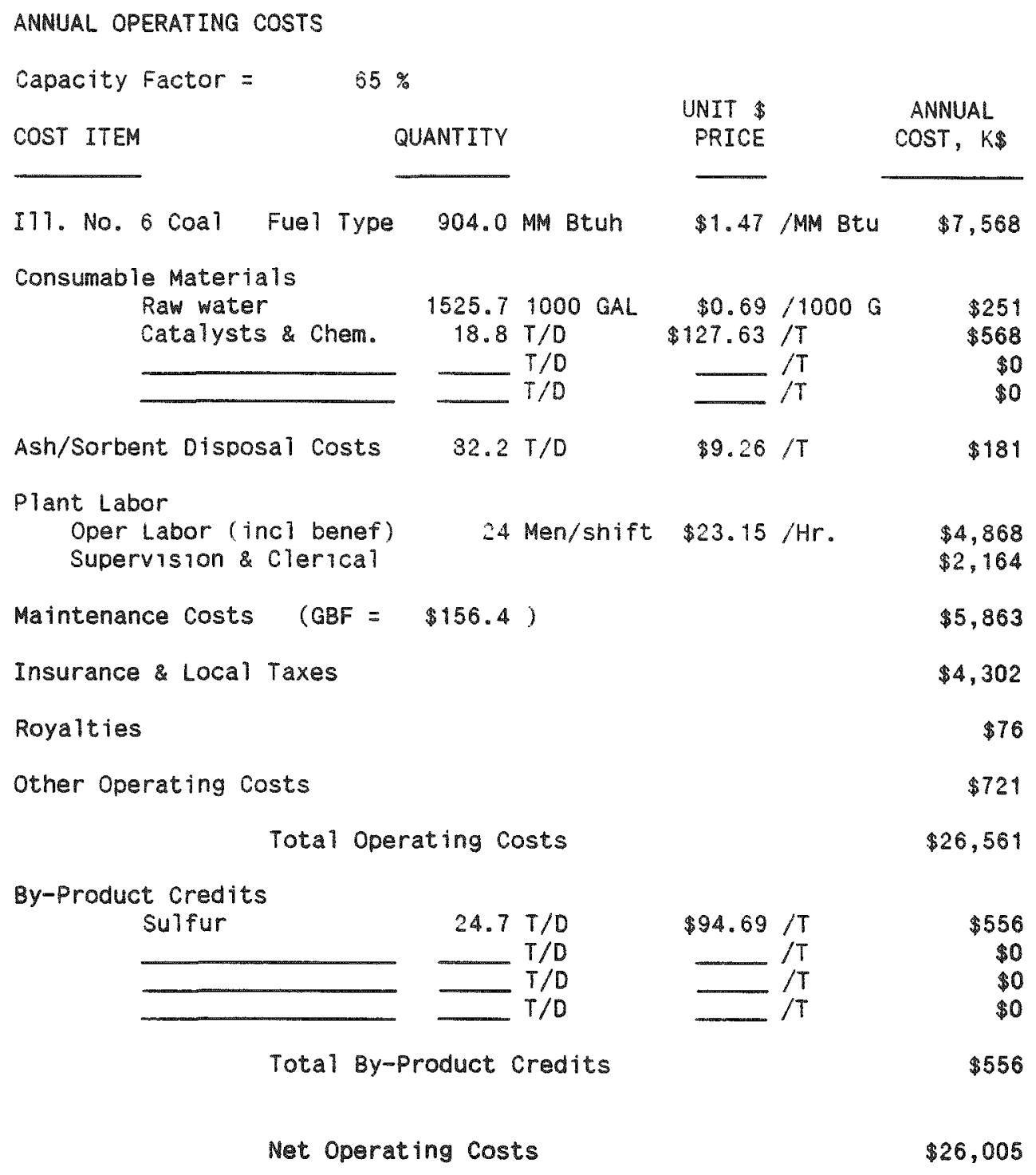


Table 59 COE Calculation, KRW Gasifier Plant with Candle Filter (continued)

BASES AND ASSUMPTIONS

A. CAPITAL BASES AND DETAILS

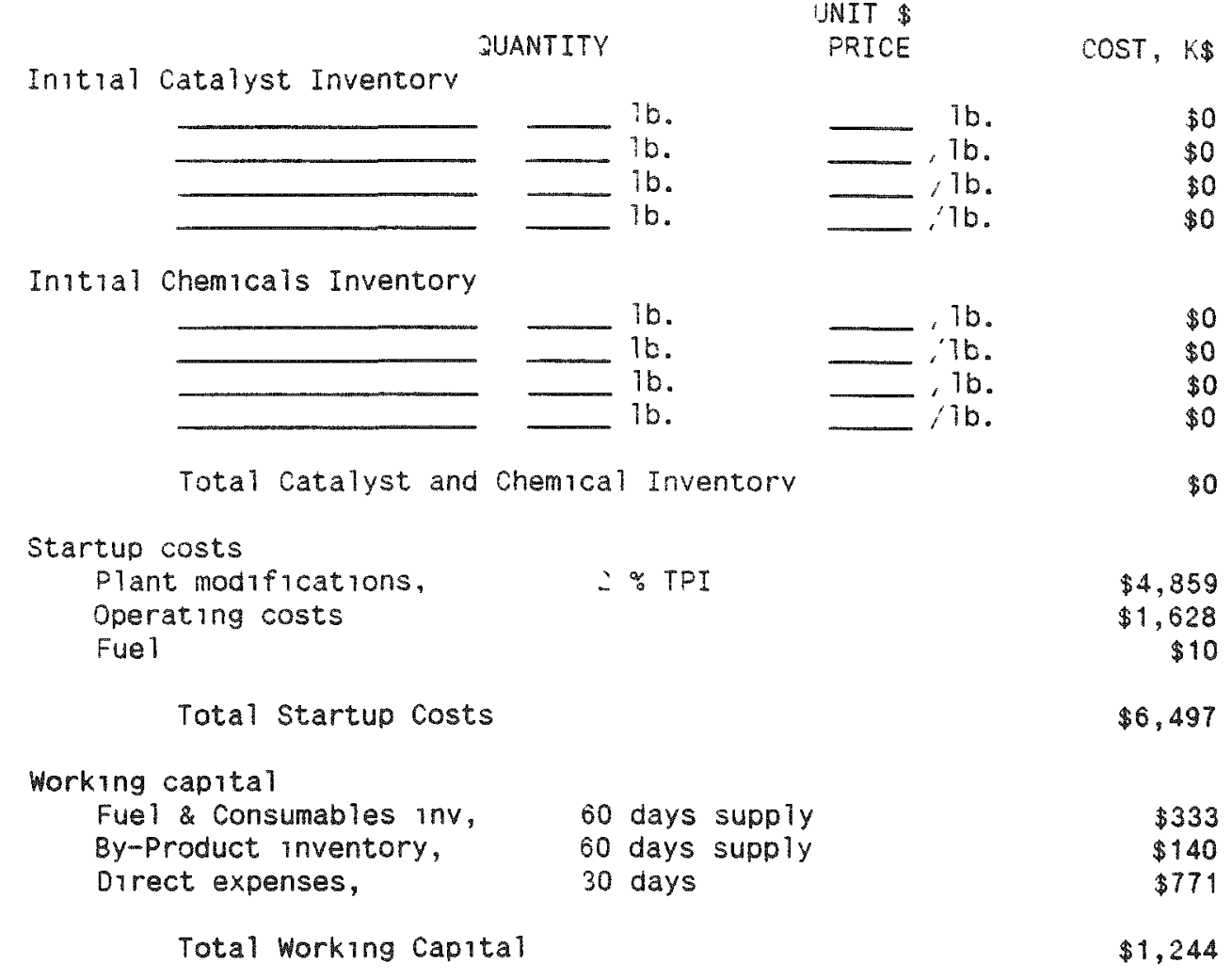


Table 59 COE Calculation, KRW Gasifier Plant with Candle Filter (continued)

B. ECONOMIC ASSUMPTIONS

\begin{tabular}{|c|c|c|c|c|}
\hline $\begin{array}{l}\text { Project life } \\
\text { Book Iife } \\
\text { Tax life }\end{array}$ & \multicolumn{4}{|c|}{$\begin{array}{l}30 \text { Years } \\
30 \text { Years } \\
-0 \text { Years }\end{array}$} \\
\hline Federal and state income tax rate & & 38.0 & $\%$ & \\
\hline Tax deprecration method & & ACRS & & \\
\hline Investment Tax credit & & 0.0 & $\%$ & \\
\hline inancial structure & & & & \\
\hline Type of Security & $\begin{array}{l}\text { Current } \\
\text { cost, } \%\end{array}$ & $\begin{array}{l}\text { Dollar } \\
\text { Ret, } \%\end{array}$ & $\begin{array}{l}\text { Constant } \\
\text { cost, } \%\end{array}$ & $\begin{array}{l}\text { Dollar } \\
\text { Ret, } \%\end{array}$ \\
\hline $\begin{array}{l}\text { Debt } \\
\text { Preferred Stock } \\
\text { Common Stock }\end{array}$ & $\begin{array}{l}11.0 \\
11.5 \\
15.2\end{array}$ & $\begin{array}{l}5.5 \\
1.7 \\
5.3\end{array}$ & $\begin{array}{l}4.6 \\
5.2 \\
8.7\end{array}$ & $\begin{array}{l}3.3 \\
0.8 \\
3.0\end{array}$ \\
\hline Discount rate (cost of capital) & & 12.5 & & 6.1 \\
\hline Inflation rate, * per year & & 4.0 & & \\
\hline $\begin{array}{l}\text { Real Escalation rates (over inflatio } \\
\text { Fue1, \% per year } \\
\text { Operating \& Maintenance, \% per y }\end{array}$ & & $\begin{array}{l}0.7 \\
0.0\end{array}$ & & \\
\hline
\end{tabular}

C. COST OF ELECTRICITY

The approach to determining the cost of electricity is based upon the methodology described in the Technical Assessment Guide, published by the Electric Power Research Institute, Volume I, EPRI-4463-SR, December 1986. The cost of electricity is stated in terms of loth year levelized dollars. Insurance and local taxes are accounted for explicitiy in cell H87, rather than including it in Capital charges as does EPRI TAG.

Levelizing Factors

Capital Carrying Charge, loth year Fue1, 10th year

Operating \& Maintenance, loth year

Cost of Electricity - Levelized

Capital charges

Fuel costs

Operating \& Maintenance

Total cost of Electricity

\section{Current $\$ \quad$ Constant $\$$}

$\begin{array}{ll}0.175 & 0.103 \\ 1.244 & 1.036 \\ 1.202 & 1.000\end{array}$

mi $11 \mathrm{~s} / \mathrm{kWh}$

mils/kwh

77.3

45.7

$\begin{array}{ll}16.5 & 13.8\end{array}$

$\begin{array}{ll}38.9 & 32.4\end{array}$

$\begin{array}{ll}133.2 & 91.8\end{array}$ 


\subsection{References}

1. Ramachandran, G. September, 1989. $T A G^{T M}$ Technical Assessment Guide, Electricity Supply-1989. EPRI P-6587-L, Volume 1: Rev. 6. Palo Alto, California: Electric Power Research Institute.

2. Robertson, A., and R. Garland, R. Newby, A. Rehmat, and L. Rubow. September, 1989. Second-Generation Pressurized Fluidized Bed Combustion Plant Conceptual Design and Optimization of a Second-Generation PFB Combustion Plant, Phase 1, Task 1. Report DOE/MC/21023-2825, Vol.1. Prepared by Foster Wheeler Development Corporation, Livingston, New Jersey under contract No. DE-AC21-86MC21023.

3. D. F. Ciliberti, T. E. Lippert. 1986. Performance Evaluation of a Ceramic Cross-Flow Filter on a Bench-Scale Coal Gasifier. Westinghouse Eighth Quarterly Report and Monthly Project Status Report for September 1, 1986 - September 30, 1986. DOE/METC Contract No. DE-AC21-84-MC21338. Morgantown, West Virginia: Morgantown Energy Technology Center.

4. EG\&G Washington Analytical Services Center. August, 1989. Conceptual Design and Cost Estimate for Zinc Ferrite Plant Section. DOE/MC/21353-2755 (DE90000411). For the U.S. Department of Energy, Morgantown Energy Technology Center. Morgantown, West Virginia.

5. Hall, Jim. July 14,1992 . Phone conversation with Coronado Systems Inc, representing Mikropul Environmental Systems. 


\section{SECTION 6}

\section{DEVELOPMENT OF MULTI-CONTAMINANT CONTROL GRANULAR-BED FILTERS}

\subsection{Objective}

The objective of this study is to develop conceptual designs of granular-bed filters (GBF) that are capable of removing a combination of pollutants in high temperature and high pressure (HTHP) gas streams from processes being developed for advanced coal utilization.

\subsection{Combustion Power's Approach to Multi-Contaminant Control}

Although we are still in the initial stages of our study, we have narrowed the many possible approaches down to the following concept. The media used in the granular-bed filter could be composed of two distinct size distributions. Larger, six mm diameter, spheres could be the same inert media used for particulate control. In addition to this media, a smaller ( 2 to $3 \mathrm{~mm}$ diameter) media could be supplied which would be chemically reactive and have a finite life. The smaller media could be separated pneumatically from the larger media in the lift pipe or removed by gradual attrition in the pneumatic conveying system. The frequency of removal and replacement of the chemically reactive media would depend on its reactivity and the extent of conversion in a single pass through the filter. There are several reasons for the dual media approach. The quantity of media which passes through the filter is so great that to be economically feasible the majority of the media has to pass through the filter millions of times. The larger media serves this purpose. A reactive media would no longer be active after passing through the filter so many times and is unlikely to have the attrition resistance required for a large number of passes through the filter. Secondly it is much more difficult to make a large, stable, attrition resistant particle than a smaller one. The large size media is necessary to maintain a high gas flow through the filter at a low pressure drop.

There are many possible materials which could be incorporated in a chemically reactive media. The initial work performed in this study has narrowed the field to three types of media. One is a reactive media composed of limestone and clay which could be used for control of sulfur, alkali, and some trace metals. The limestone /clay media would be used either with gasification or combustion processes at temperatures of $850^{\circ} \mathrm{C}$ to $950^{\circ} \mathrm{C}$. Another reactive media is composed of calcium oxide or nahcolite $\left(\mathrm{NaHCO}_{3}\right)$ and could be used for the removal of chlorides in coal gasification streams at temperatures of $600^{\circ} \mathrm{C}$. The reactive media could be pelletized from fine grain materials forming a $2-3$ $\mathrm{mm}$ pellets. The pelletized material has a large pore structure which allows high conversion rates. Cements are used to bind the grains of the pellets producing spheres with relatively high attrition resistance. The third type of media could be a catalyst for the decomposition of ammonia in coal gasification gas. The most promising of these are nickel based catalyst operating at $800-900^{\circ} \mathrm{C}$. The catalytic material would be 
incorporated in the larger $6 \mathrm{~mm}$ diameter media as either a coating or as separate material mixed with the bulk media.

\subsection{Background}

Previous work at New York University demonstrated that a granular-bed filter is capable of removing particulate from a high pressure and high temperature gas stream and meeting New Source Performance Standards ${ }^{1}$. The current contract has allowed Combustion Power Co. to improve on the design of the granular-bed filter so that it is cost competitive with ceramic candle filters for the removal of particulate from high temperature, high pressure (HTHP) gas streams. Besides removing particulate, a granular-bed filter has the potential of removing other pollutants in the gas stream. The filter is an excellent gas/solids contactor; in that, it has gas residence times in the order of several seconds, solids residence times in the order of several hours, uniform gas flow across the media, and the gas and filter media flow in opposite directions for the maximum driving potential.

The contaminants of major concern, besides particulate in coal utilization processes, are sulfur compounds, nitrogen compounds, alkali compounds, halogenated compounds, tars, and trace contaminants such as cadmium and mercury ${ }^{2}$. A granularbed filter which is able to capture particulate and one or more of these additional contaminants would have significant benefits over just a particulate removal system.

Many processes that are under development are able to meet current New Source Performance Standards, but may have trouble meeting more stringent requirements which could be promulgated in the future. As an example, pressurized fluidized bed combustors are able to meet New Source Performance Standards of $90 \%$ sulfur removal but probably will have difficulty obtaining $95-98 \%$ sulfur removal. A granular-bed filter with an $\mathrm{SO}_{2}$ absorbing media may be able to increase the overall sulfur removal efficiency from $90 \%$ to $98 \%$ in a PFBC system while maintaining a cost effective calcium to sulfur ratio.

\subsubsection{Control of Sulfur Emissions}

The control of sulfur emissions has historically been the major thrust of pollution control systems and still remains a primary focus of innovative technology. In combustion systems, the need is for the removal of $\mathrm{SO}_{2}$, and for gasification, the need is for the removal of $\mathrm{H}_{2} \mathrm{~S}$. There are several potential materials which may be suitable as a sorbent in a GBF for the control of sulfur emissions.

\subsubsection{1 $\mathrm{SO}_{2}$ Control}

For the control of $\mathrm{SO}_{2}$ at high temperature, the following materials could be used as sorbents in a granular-bed filter: limestone, dolomite, calcium silicates formed from Type III Portland cement ${ }^{3}$, and ground and pelletized fluid bed ash. Work by Spitsbergen of the University of Twente showed that agglomerates made from ground limestone are 
considerably more reactive that similar sized particles of naturally occurring stone $e^{4}$. Such agglomerates could be used as filter media. Inexpensive media made from limestone or recycled bed ash could be used in a once through process. More expensive calcium silicate material would probably be used in a regenerative cycle.

The pelletized agglomerates made from ground limestone tested at the University of Twente $e^{5}$ had an internal pore volume which was $50 \%$ greater than that of natural occurring limestones. The mean pore radius in the agglomerates was 20 to 40 times the mean pore radius of natural limestones. The pellets had good attrition resistance compared to hard natural limestones and far superior attrition resistance compared to soft limestone. TGA experiments showed $90 \%$ sulfidation conversion for the pelletized limestone compared to $60 \%$ conversions of naturally occurring limestones. For sulfation, the pelletized limestone had a conversion of $60 \%$ compared to $20 \%$ and $30 \%$ for two naturally occurring limestones. The agglomerated pellets were $0.85-1.00 \mathrm{~mm}$ in diameter and had higher conversions than naturally occurring limestones $1 / 5$ the size. The reason for the high conversions rates is the porosity created by the macro pores. These studies are encouraging in that they suggest that limestone pellets $2-3 \mathrm{~mm}$ in diameter can be made which would be attrition resistant and have a high conversion rate in either combustion or gasification environments.

Copper oxide has proved effective as an $\mathrm{SO}_{2}$ absorber and as a catalyst for the reduction of NOX with ammonia ${ }^{6}$. The optimum temperature for the absorption of $\mathrm{SO}_{2}$ is $750-800^{\circ} \mathrm{F}$. At $1200^{\circ} \mathrm{F}$, copper sulfate decomposes to copper oxide. Consequently, this material could not be used for sulfur removal at temperatures above $1000^{\circ} \mathrm{F}$ and would not be suitable for sulfur removal from the higher temperature gas stream leaving a PFBC.

Amoco Oil Company has developed $\mathrm{SO}_{2}$ sorbents which they believe would be suitable for capturing $\mathrm{SO}_{2}$ and particulate in a granular-bed filter ${ }^{7}$. The sorbent also contains catalytic material for the reduction of NOX. It is unknown whether or not such sorbents would remain active when contacting the trace species which are present in coal combustion products. Combustion Power Co. worked with Amoco on the development of a filter for the simultaneous removal of $\mathrm{SO}_{2}$ and particulate from the off-gas stream of a catalytic cracker in the early 1980's.

\subsubsection{2 $\mathrm{H}_{2} \mathrm{~S}$ Control}

The primary candidates for the sorption of $\mathrm{H}_{2} \mathrm{~S}$ are metal oxides such as iron oxide, zinc ferrite and zinc titinate. General Electric Co. demonstrated a moving bed process using a zinc ferrite sorbent ${ }^{8}$. They reported particulate removal efficiency of $82 \%$ for their initial trials. Sorbents such as zinc ferrite or zinc titinate require regeneration. The regeneration of the these compounds has to be carefully controlled because of the exothermic reactions and the temperature limits involved. These sorbents tend to be fragile and have a limited life even in a fixed bed configuration.

Other possible $\mathrm{H}_{2} \mathrm{~S}$ sorbents are limestone or dolomite. Scott Lynn of Lawrence Berkeley Laboratory is investigating the kinetics of limestone and dolomite in the absorption of $\mathrm{H}_{2} \mathrm{~S}^{9}$. In bench scale equipment, he was able to achieve $10-12 \%$ sulfur 
absorption and as high as 50\% utilization under ideal conditions. The reactions are sensitive to temperature and are carried out just under the calcination temperature of the limestone. Work at Brookhaven National Laboratory has also shown that calcium silicate is capable of absorbing $\mathrm{H}_{2} \mathrm{~S}$ as well as $\mathrm{SO}_{2}{ }^{10}$. Kawasaki Heavy Industries has developed a granular-bed filter which uses iron oxide as a coating on ceramic spheres to remove $\mathrm{H}_{2} \mathrm{~S}$ and particulate from gasification products ${ }^{11}$.

One possible mode of operation for a granular-bed filter using limestone or dolomite as a media would be as second stage absorber for $\mathrm{H}_{2} \mathrm{~S}$. Primary $\mathrm{H}_{2} \mathrm{~S}$ absorption would occur in the gasifier. The partially sulfided stone from the filter could be returned to the gasifier for further $\mathrm{H}_{2} \mathrm{~S}$ absorption or it could be oxidized for disposal with the spent sorbent from the gasifier. In this mode of operation, the filter would be used to remove the some remnants of $\mathrm{H}_{2} \mathrm{~S}$ with primary $\mathrm{H}_{2} \mathrm{~S}$ removal occurring in the gasifier. In a similar manner, a granular-bed filter with a limestone sorbent could be used as second stage $\mathrm{SO}_{2}$ removal device with a PFBC.

\subsubsection{Control of Nitrogen Compounds}

When gasifying coal, the fuel bound nitrogen is partially converted to ammonia and to a lesser extent, to cyanide. When the fuel gas is used as a heat source to a gas turbine, these nitrogen compounds are converted to oxides of nitrogen in the turbine combustor. Catalytic decomposition of ammonia and cyanide before the turbine combustor would significantly reduce the emissions of nitrogen oxides from the gas turbine. Several investigators have evaluated several catalytic materials for this purpose.

SRI Int. performed screening test on possible catalyst ${ }^{12}$. A proprietary nickel catalyst developed by Haldor Topsøe AG, Copenhagen, Denmark was found to be a suitable catalyst at temperatures above $750^{\circ} \mathrm{C}$. At lower temperatures, the presence of $\mathrm{H}_{2} \mathrm{~S}$ poisoned the catalyst. The catalyst was also effective in cracking tar simulant into $\mathrm{CO}$ and $\mathrm{H}_{2}$. In a high steam environment $\left(27 \% \mathrm{H}_{2} \mathrm{O}\right)$, the ammonia conversions were over 90\%; in a low steam environment, $\left(7 \% \mathrm{H}_{2} \mathrm{O}\right)$ ammonia conversion was $70 \%$.

A study of the decomposition of ammonia over dolomite and limestone ${ }^{13}$ found that ammonia was decomposed at $800^{\circ} \mathrm{C}$ when present in an inert carrier. In the presence of a simulated gasification process gas, no ammonia reduction occurred. The reason for the deactivation of the dolomite's catalytic activity was believed to be from the cracking of hydrocarbons such that a carbonaceous residue formed on the stone.

Two nickel catalyst from Ingelhard, Ni-0301 and Ni-1621, proved to be suitable catalyst for the reduction of ammonia ${ }^{14}$. A slip stream from a commercial peat gasifier was passed through beds of test catalysts. At $900^{\circ} \mathrm{C}$, the nickel catalysts were extremely effective, yielding nearly complete decomposition of the ammonia. Ferrous dolomite, containing $4.5 \%$ iron, reduced ammonia concentrations by $75 \%$, and sintered iron pellets reduced the ammonia concentration by $86 \%$ at a temperature of $900^{\circ} \mathrm{C}$. At $800^{\circ} \mathrm{C}$, these two compounds increased the concentration of ammonia. 
From these studies, it is evident that there are catalytic materials which can be used to reduce ammonia in coal gasification streams. The catalysts are most effective at a temperature of $800-900^{\circ} \mathrm{C}$. It is likely that a catalytic material could be incorporated into filter media as either a coating on media or as separate media mixed in with the bulk media.

\subsubsection{Alkali Control}

The presence of alkali species in PFBC or IGCC gas streams is of concern because of the potential corrosion which alkali species can cause in a gas turbine. Alkali species are also associated with low melting compounds which can provide the "glue" for forming deposits on turbine and heat exchanger surfaces. For these reasons, turbine manufactures have placed restrictions on the amount of alkali (sodium and potassium) that can enter a gas turbine. The acceptable levels of alkali in the fuel gas stream entering the turbine combustor ranges from 50 to $200 \mathrm{ppbw}^{15}$ depending on the gas temperature and the turbine manufacture. More recent studies give the permissible inlet concentration to the gas turbine itself as $24 \mathrm{ppbw}^{2,16}$. These levels are below expected alkali levels in processed coal streams.

Several investigators have reported that the alkali vapor concentration in PFBC gas range from 0.1 to $10.0 \mathrm{ppmw}^{17}$. Using an extractive technique to pass a slip stream through a bed of activated bauxite, Lee ${ }^{18,19}$ found sodium levels of 1.3 to $1.5 \mathrm{ppmw}$ and potassium levels of $0.10 \pm 0.01$ ppmw from the combustion of Buelah lignite at 9.2 atm and $850-750^{\circ} \mathrm{C}$. Ciliberti reported alkali concentration of 0.3 to $16 \mathrm{ppm}$ in the product gas from the Westinghouse pilot scale coal gasifier.

Using an in-situ mass spectrometer, researchers at SRI Int. ${ }^{20}$ report vapor concentrations of 0.08 and $0.04 \mathrm{ppm}$ for $\mathrm{NaCl}$ and $\mathrm{Na}_{2} \mathrm{SO}_{4}$ respectively when burning Beulah lignite at $900^{\circ} \mathrm{C}$ and $1 \mathrm{~atm}$. They also found the sodium vapor concentration was very sensitive to the chlorine content of the coal. Buelah lignite has a chlorine content of $<0.01 \%$. When the chlorine content was raised by doping with $\mathrm{NaCl}$, such that the sodium level was raised from $0.042 \%$ to $0.062 \%$ and the chlorine concentration was raised from $<.01 \%$ to $0.3 \%$, the $\mathrm{NaCl}(\mathrm{g})$ concentration increased from $0.08 \mathrm{ppm}$ to 6.0 ppm. The effect of chlorides on sodium levels found in the SRI study are substantiated by a General Electric study ${ }^{21}$. Combustion results from Illinois \#6 coal showed $\mathrm{NaCl}$ concentration of less than $0.02 \mathrm{ppm}$ and $\mathrm{a} \mathrm{NaSO}_{4}$ of abour $0.04 \mathrm{ppm}$. Initial gasification runs with Buelah lignite showed sodium concentrations of $5.0 \mathrm{ppm}$. These results are in line with non-equilibrium studies ${ }^{22}$ that showed at $823^{\circ} \mathrm{C}$ the non-equilibrium partial pressure of $\mathrm{NaCl}$ vapor is an order of magnitude higher than the equivalent result under combustion conditions. Mojthaedi ${ }^{23}$ found that the sodium and potassium levels from the gasification or combustion of peat were above acceptable turbine inlet levels especially during gasification.

At lower temperatures $\left(600^{\circ} \mathrm{C}\right.$ and less) used in some hot gas clean up systems for gasification processes, the alkali species are completely condensed so that they can be removed with the particulate filter. 
The inference from these works is that alkali will need to be controlled from coal combustion streams resulting from coals which have more than a minimum chlorine content and from gasification streams which are not cooled below $800^{\circ} \mathrm{C}$.

Various aluminum and silicate compounds have been found to be absorbers of alkali vapors ${ }^{24}$. Figure $69^{25}$ shows the alkali aluminosilicates which can form. The alkali compounds are listed in descending order of their vapor pressure. At fluidized bed conditions, the sulfates are usually present as liquids. The types of aluminum silicates which are effective getters or absorbers of alkali are: activated bauxite, attapulgus clay, calcium montmorillonite clay, diatomaceous earth, and kaolin clay and emathlite clay. ${ }^{26,27}$. Lee ${ }^{28}$ tested six possible alkali getters in an experiment in which $\mathrm{NaCl}$ vapors were passed through fixed beds of the getters. Activated bauxite and diatomaceous earth effectively capture $\mathrm{NaCl}, \mathrm{KCl}$, and $\mathrm{K}_{2} \mathrm{SO}_{4}$. About $10 \%$ of the captured alkali on the activated bauxite were irreversibly, chemically absorbed while the remainder was physically absorbed as a water soluble alkali. Because the activated bauxite captures alkali as a water soluble material, it can be regenerated by a simple water leaching. In contrast the diatomaceous earth was found to capture alkali by chemical reactions. The sorption of alkali by diatomaceous earth increased with temperature while sorption with activated bauxite decreased with temperature. Lee ${ }^{19}$ demonstrated the capture of alkali in fixed beds of activated bauxite and diatomaceous earth from a flue gas stream generated by the combustion of Buelah lignite. A small fixed bed of activated bauxite or diatomaceous earth can be used with a gas slip stream to measure the time average alkali concentration, and large fixed bed can be used for the removal and control of alkali in the process stream. Lee developed a mathematical model which can be used to design a fixed bed reactor for the removal of alkali using activated bauxite.

Jain ${ }^{29}$ performed sorbent screening experiments by passing sodium chloride vapor through a fixed bed of sorbent particles. The amount of $\mathrm{NaCl}$ captured by the sorbent was determined by analysis of the sodium content of the sorbent before and after the experiments. Thirteen sorbents were screened. In terms of weight gain, diatomaceous earth was the most effective followed by attapulgus clay and activated bauxite. Fullers Earth had negligible sorption capacity. Larger scale rate experiments were conducted in a single stage dry plate granular-bed scrubber operated in spouting bed and fixed bed modes using diatomaceous earth, activated bauxite and dolomite. Results showed that either diatomaceous earth or activated bauxite could be used for $99 \%$ removal of alkalies using 0.6 to $1.0 \mathrm{~mm}$ diameter sorbent with a contact times greater than 0.2 seconds.

Bachovchin ${ }^{30}$ found emathlite, a type of fullers earth, to be a leading getter of alkali. The clay has a high capacity for sodium and binds the sodium irreversibly. Water vapors were found to accelerate the reaction but not to be stoichiometrically involved. A wet extrusion process was used to make cylindrical pellets. The commercially produced pellets were considerably less reactive than the laboratory pellets ${ }^{30}$. A kinetic rate expression was developed in which the reaction rate is proportional to the alkali concentration and independent of temperature between $775^{\circ} \mathrm{C}$ and $900^{\circ} \mathrm{C}$. 


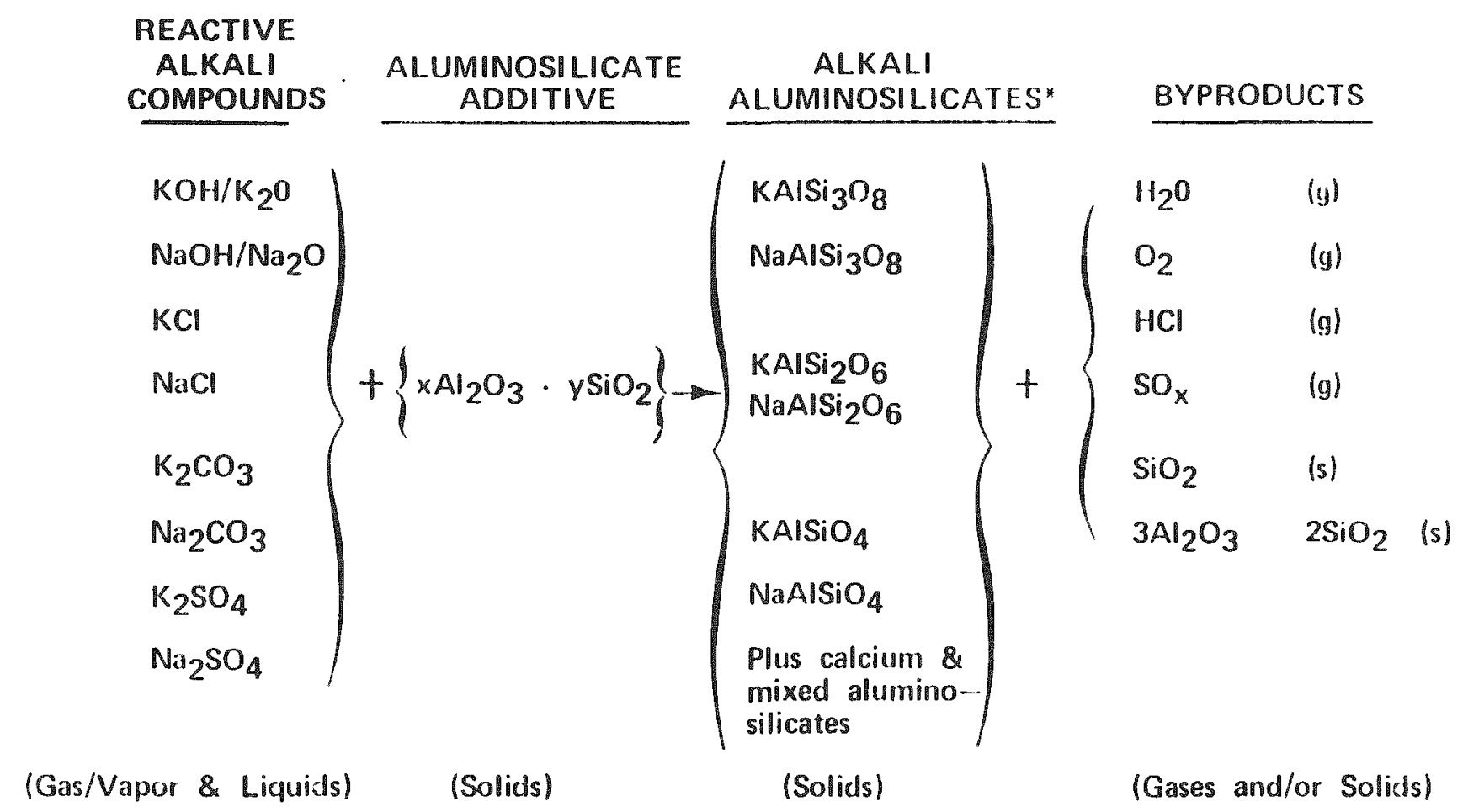

* Commonly found as feldspars and related compounds in nature, (e.g., orthoclase/sanidine/microcline, albite, leucite, kaliophyllite, nepheline, with anorthite/plagioclase, perthite, etc.)

Figure 69 General Reactions of Alkali Vapors with Aluminosilicate Additives ${ }^{25}$ at $1500^{\circ}-1800^{\circ} \mathrm{F}$ 
Except for fresh pellets, the rate limiting step was found to the diffusion through the glassy reactants. The sorption of alkali was demonstrated in a fixed bed in which $12 \mathrm{~kg}$ of pellets were exposed to $500 \mathrm{~m}^{3} / \mathrm{hr}$ of gas containing $10 \mathrm{ppmv} \mathrm{NaCl}$ at 11 atm and $827^{\circ} \mathrm{C}$ for up to 102 hours. Sorbent bed depth of $40 \mathrm{~cm}$ was able to reduce gas phase $\mathrm{NaCl}$ concentrations to $0.2 \mathrm{ppm}$. It was determined, at extreme conversions, that the sorbent can become sticky; thus causing problems in the operation of the fixed bed. Using the kinetic model, it was predicted that a bed of $1.2 \mathrm{~cm}$ diameter pellets with a 3.5 $m$ bed depth would have a life of 4000 hours.

Uberoi $^{27}$ found that kaolin, bauxite and emathlite were all capable of removing alkali from coal conversion streams. All sorbents experienced a decrease in absorption rate as the loading increased until the sorbents maximum capacity was reached and the sorption dropped to zero. Kaolin had the highest increase in mass, and bauxite had the highest initial sorption rate. The kaolin and emathlite sorption of alkali is an irreversible process while $10 \%$ of the total weight gain of the bauxite was due to physisorption. The maximum sorption capacity of the kaolin was about $25 \%$, while that of the bauxite and emathlite was about $15 \%$.

McLaughlin ${ }^{26}$ used a TGA \& DTA micro balance to screen alkali sorbents. Thirteen reactive sorbents were found. Calcium montmorillonite was chosen for further investigation. Similar to the finding of Bachovchin ${ }^{30}$, water vapor has a significate effect on the amount of alkali which is adsorbed. With a water concentration increase from 0 to $5 \%$, the saturation sorption capacity of the calcium montmorillonite increased from 5 to $12.6 \%$. The presence of $\mathrm{HCl}$ vapors reduced the rate and the saturation level of absorption. A $160 \mathrm{ppmv}$ of $\mathrm{HCl}$ reduced the saturation capacity of the calcium montmorillonite to $5.5 \% \mathrm{Na}$.

These studies indicate that there are several possible getters which can be used for the sorption of alkali from coal process streams. The choice of getter for use with a granular-bed filter will depend on cost and availability of the sorbent and the ability to incorporate the alkali getter into a sulfur sorbent granule.

\subsubsection{Trace Species Control}

Besides the control of sulfur, alkali, and ammonia, a granular-bed filter has the potential to control other contaminants such as tars and heavy metals. In a gasification environment, activated carbon may be suitable for the capture of heavy metals and possibly the cracking of tars. The $1100-1200^{\circ} \mathrm{F}$ temperature used in the zinc ferrite process for the absorption of $\mathrm{H}_{2} \mathrm{~S}$ would be at the upper temperature limit for the use of activated carbon. It may be possible to incorporate activated carbon into granular-bed filter media or use it as an additive to the gas stream before the filter.

Recent work by Uberoi at the University of Arizona indicates the potential of porous solids such as bauxite, kaolin or activated alumina for the absorption of heavy metals such as lead or cadmium ${ }^{31}$. These same materials have proven effective in the capture of alkali metals from flue gas streams; so that, a system designed for alkali removal may also be effective in the removal of heavy metals. 
Screening tests showed that bauxite was considerably more effective than kaolinite for the sorption of cadmium vapors ${ }^{32}$. Examination of the kaolinite particles showed that the surface of the kaolinite was almost completely reacted but that interior was unreacted, indicating pore blocking by the product layer. The use of kaolinite in a agglomerated pellet with large micro-pores may allow higher utilization just as it does for the sorption of sulfur species by limestone agglomerates. The theoretical sorption capacity of cadmium by kaolinite is a $51 \%$ weight increase which can be compared to a $19 \%$ weight gain of kaolin flakes which were only reacted on their surface. The kaolinite had a lower water soluble fraction of sorbed cadmium than the bauxite which is desirable from the point of view of ultimate disposal.

Uberoi ${ }^{33}$ also studied the sorption of lead vapors by various sorbents. Kaolinite proved to be the most effective sorbent evaluated. Theoretically the kaolinite can sorb $94 \%$ of its weight, forming in-soluble lead compounds. The measured weight gains were close to this value, indicating high utilization of the kaolinite.

Mojtahedi ${ }^{23}$ studied the removal of zinc and lead vapors from simulated flue gases. Limestone removed $81 \%$ of the zinc vapors and $41 \%$ of lead vapors. Dolomite with its more open pore structure removed $82 \%$ of lead vapors and $19 \%$ of the Zinc vapors.

These studies show that a limestone/clay pellet has excellent potential for the removal of lead, cadmium and zinc from either gasification or combustion streams.

\subsubsection{Halogen Control}

Chlorine and fluorine are present in coal as trace quantities; and as such, are found in coal gasification streams in concentrations ranging from 50 to $1000 \mathrm{ppm}$. These elements form acidic compounds which can cause acidic corrosion in downstream equipment such as gas turbine components and heat exchangers and cause poisoning of molten carbonate fuel cell electrodes ${ }^{34}$. They also represent the release of acidic compounds to the environment. For these reasons it would be desirable to remove halogen contamination from coal gasification streams before the gas turbine.

Researchers at SRI Int. found that Nahcolite, the natural occurring mineral form of $\mathrm{NaHCO} 3$, is an effective sorbent of $\mathrm{HCl}^{35}$. The nahcolite was pelletized and calcined at $600^{\circ} \mathrm{C}$, and had an eighty percent conversion in 250 minutes. The inlet concentration of $300 \mathrm{ppm}$ of $\mathrm{HCl}$ was reduced to $1.0 \mathrm{ppm}$ before break through occurred.

Researchers at Twente University found that calcined pellets of limestone were effective in absorbing $\mathrm{HCl}$. The $\mathrm{CaO}$ reacts with $\mathrm{HCl}$ to form $\mathrm{CaCl}_{2}$. At $600^{\circ} \mathrm{C}$, a $70 \%$ conversion of $\mathrm{CaO}$ was obtained after 25 minute exposure and $80 \%$ conversion was obtained after 66 minutes. While both $\mathrm{CaO}$ and $\mathrm{Na}_{2} \mathrm{CO} 3$ are both capable of reacting with $\mathrm{HCl}$, equilibrium calculations show that the equilibrium partial pressure of $\mathrm{HCl}$ with $\mathrm{Na}_{2} \mathrm{CO} 3$ is $1.5 \times 10^{-6}$ atm while that of $\mathrm{CaO}$ is $9.5 \times 10^{-4} \mathrm{~atm}^{35}$, so that $\mathrm{Na}_{2} \mathrm{CO} 3$ has the potential to obtain lower concentrations of $\mathrm{HCl}$. 
Either of the above approaches utilize pelletized material which could be used as a reactive media in a granular-bed filter. The work at Twente University demonstrated that the limestone pellets have good attrition characteristic after calcining.

\subsection{Developmental Work Plan for Multi-Contaminant GBF}

\subsubsection{Literature Review and Definition of Contaminant Levels}

In this work step, which has already been started, a detailed review of the literature will be completed. The purpose of the review will be to identify and rank candidate sorbents for control of contaminants. Particular emphasis will be on gathering data that can be used to design a process using the candidate sorbents. The review of literature on alkali control is nearly complete and as a result the background section on alkali is considerable more detailed than the other section.

\subsubsection{Process Definition}

Based on the literature review and the potential conceptual designs already described, candidate processes for multi-contaminant control which could be incorporated into a granular-bed filter will be identified. To large extent this has already occurred, with preliminary results described in section 6.2 . The concepts may change as more detailed information is collected. Flow sheets for potential processes will be developed. Primary emphasis will be on the development of processes for the further reduction of $\mathrm{SO}_{2}$ and alkali from a pressurized fluidized-bed combustor and for the removal of $\mathrm{H}_{2} \mathrm{~S}$, alkali and ammonia from gasification streams or halogen removal from lower temperature gasification streams.

In terms of filter configurations, both single and dual media filters will be evaluated. Once through media and regenerating media will be evaluated for the control of $\mathrm{SO}_{2}, \mathrm{H}_{2} \mathrm{~S}$, ammonia, alkali, tars, and heavy metals. Both mixed media and dual function single media will be evaluated.

A consultant, will be used to analyze the flow patterns through filter configurations with dual media. Previous work using computational fluid mechanics, was useful in predicting the flow field and pressure in the granular-bed filter designed for particulate collection. A chemical engineering consultant will be used to help design the chemical reactors used in the multi-contaminant control, granular-bed filter (GBF).

\subsubsection{Basis of Conceptual Design}

The conceptual designs of a multi-contaminant control, GBF will be based on the same size power plants that are being used in this program. The multi-contaminant control GBF will be applied to a second generation Pressurized Fluidized Bed Combustor (PFBC) being developed by Foster Wheeler ${ }^{36}$. For this application, we proposed using 10 granular-bed filters for particulate control. Eight filters are used on the flue gas from 
the PFB combustors with each filter having a capacity of 44,000 ACFM at 190 psia and $1600^{\circ} \mathrm{F}$. Two filters are used on the fuel gas from the carbonizers with each filter having a capacity of $15,800 \mathrm{ACFM}$ at $208 \mathrm{psia}$ and $1500^{\circ} \mathrm{F}$. In addition to the PFBC application, a multi-contaminant control GBF will be used in the KRW integrated combined cycle ${ }^{37}$. The IGCC filter will have a capacity of $12,600 \mathrm{ACFM}$ at 385 psia and $1600^{\circ} \mathrm{F}$. It is our goal that the multi-contaminant control GBF's have the same capacity as the GBF's proposed for particulate control.

\subsubsection{Test Plans for Proof of Concept Testing}

Having determined possible processes for multi-contaminant control, proof of concept testing will be required to establish feasibility of the proposed processes. In order to conduct the proof of concept testing, test plans and conceptual designs of the test equipment will be prepared. Actual testing will occur in the next phase of the program after approval of the test plans by DOE.

Test plans and test equipment designs will focus on the following areas:

- Manufacture and procurement of candidate sorbents

- Determination of size and chemical composition of candidate sorbents

- Thermal shock, crush strength, and dynamic attrition resistance of candidate sorbents

- Sorption capacity and kinetics of sorbent reactions

- For each filter configuration, control and distribution of media, media flow patterns, gas flow patterns and filter pressure drop.

- potential impact of multi-contaminant control on particulate removal efficiency

Test descriptions will include: objectives, experimental procedures, operating conditions, test duration, number of tests, experimental data to be collected during tests and post test inspections. An estimated cost of the experimental facilities and the proposed test programs will be determined.

\subsubsection{Topical Report}

The results of the conceptual design study for a multi-contaminant GBF and the proposed test plans for proof of concept testing will be reported in a topical report. 


\subsection{References}

1. Wilson, K.B., and J.C. Haas. October, 1989. Performance Analysis of a Screenless (Counter-Current) Granular Bed Filter on a Subpilot, Scale PFBC. Final Report DOE/MC21335. Menlo Park, CA: Combustion Power Company.

2. Bossart, S.J., D.C. Cicero, C.M. Zeh, and R.C. Bedick. August, 1990. Gas Stream Cleanup-Technology Status Report. DOE/METC-91/0273.

3. Yoo, H.J., P.J. McGauley, and M. Steinburg. June, 1982. Calcium Silicate Cements for Desulfurization of Combustion Gases. Final Report DOE/METC/834.

4. Spitsbergen, U., W.C. Van Werven, and H.A. Akse. September, 1988. Desulfurization Quality of Limestone-Based Sorbents Tested Under Multi-Stage Fluidized Bed Combustion Conditions. Presented at Fifth Annual International Pittsburgh Coal Conference. Pittsburgh, PA.

5. Akse, H.A., L. Ham, A. Heesink, B. Kamphuis, H.Nijmeijer, Q.Potma, W.Prins, and U.Spitsbergen. 1991. Development of a Regenerative Sulfur Dioxide Sorbent System. Commission of the European Communities, Energy. Report \# EUR 13643 en.

6. Yeh, J.T., C.J. Drummond, and J.I. Joubert. February, 1987. Process Simulation of the Fluidized-Bed Copper Oxide Process Sulfidation Reaction. Environmental Progress, Vol. 6, No.2, pp. 44-50.

7. Tolpoin, T.W. and R.A. Kretchmer. 1986. Nitrogen Oxide, Sulfur oxide, and Particulate Removal System. U. S. Patent 04617175.

8. Cook, C.S., B. Parekh, E. Gal, A.H. Furman, and R. Ayala. August, 1990. Integrated Operation a Pressurized Fixed-Bed Gasifier and Hot Gas Cleanup System. In Proceedings of the Tenth Annual Gasification and Gas Stream Cleanup Systems Contractors Review Meeting. ed. V.P. Kothari, and J.L. Beeson, DOE/METX-90/6115, Vol.1.

9. Lynn, S. and E.J. Cairns. August, 1990. Removal of $\mathrm{H}_{2} \mathrm{~S}$ Using Metal Salts. In Proceedings of the Tenth Annual Gasification and Gas Stream Cleanup Systems Contractors Review Meeting. ed. V.P. Kothari, and J.L. Beeson. DOE/METX-90/6115, Vol. 1.

10. Yoo, H.J. and M. Steinburg. October, 1983. Calcium/Silicate Cement Sorbent for $\mathrm{H}_{2} \mathrm{~S}$ Removal and Improved Gasification Processes. Final Report DOE/CH/00016-1494.

11. Ishikawa, K., H. Ito, Y. Kubo, M. Hirao, and K. Yoshida. 1991. Development of a Simultaneous Sulfur and Dust Removal Process for the Integrated Coal Gasification Combined Cycle Power Generation System. Kawaskaki Juko Giho, No. 109 1991-04-20, pp.30-38.

12. Krishnan, G.N., B. Wood, G. Tong, and J. Mc Carty. 1988.

Study of Ammonia Removal in Coal Gasification Processes. SRI International. DOE/MC/2308-2667. 
13. Björkman, E. and K. Sjöström. 1991. Decomposition of Ammonia over Dolomite and Related Compounds. Energy and Fuels, v5, n5 pp753-760.

14. Leppälahti, J., P. Simell, and E. Kurkela. 1991. Catalytic Conversion of Nitrogen Compounds in Gasification Gas. Fuels Processing Technology. 29, PP 43-56.

15. Tamhankar, S.S. and C.Y. Wen. 1981. Review of In-Bed Hydrocarbon, Alkali and Trace Metals Control in Coal Conversion Processes. Doe Report DE83006376, by West Virginia University.

16. Lee, S.D. and K.M. Myles. June, 1987. Measurement of Alkali Vapors in PFBC Process Stream and Their Removal With a Fixed Granular-Bed Sorber. Proceedings of the Seventh Annual Gasification and Gas Stream Cleanup Systems Contractors Review Meeting. ed. M.R. Ghate, K.E. Markel, Jr., L.A. Jarr, and S.J. Bossart. DOE/METC-87/6079, Vol. 2. Morgantown, WV: Morgantown Energy Technology Center.

17. Zakkay, V., J. McClung, P. Radhakrishnan, S Panunzio, K. Sillakumar, and A. Ganeish. 1985. Gas and Alkali Emission From Pressurized Fluidized-Bed Combustion of Lignite. In Proceedings of the Eighth International Conference on Fluidized Bed Combustion. pp. 1186-1196.

18. Lee, S.D. and E.L. Carls. 1990. Measurement of sodium and potassium Vapors in Pressurized fluidized-bed Combustion of Beulah Lignite. Journal of Institute of Energy, 63, pp. 203-210.

19. Lee, S.D. and W.M. Swift. April, 1991. A Fixed Granular-Bed Sorber for Measurement and Control of Alkali Vapors in PFBC. In Proceedings of the 1991 International Conference on Fluidized Bed Combustion, ed. E.J. Anthony, 1095-1103. Montreal, Canada. New York, NY.: ASME.

20. Krishnan, G.N., B.J. Wood, R.H. Lamoreaux, R.M. Platz, and G.P. Smith. August 1990. Determination of the Fate of Alkali Species in Advanced Coal Conversion Systems. In Proceedings of the Tenth Annual Gasification and Gas Stream Cleanup Systems Contractors Review Meeting. 340-351. Morgantown, West Virginia: Department of Energy, Morgantown Energy Technology Center.

21. Spacil H.S. and K.L. Luthra. 1982. Volatilization/Condensation of Alkali Salts in a Pressurized Fluidized Bed Coal Combustor/Gas Turbine Combined Cycle. Journal of Electrochemical Society, 128(9). pp. 2119-2126.

22. Sinha, S., K. Natesan, and M. Bander. October 1987. Condensed and Gaseous Products Chemistry in the Combustion and Gasification of High Sulfur Coal. In Proceedings of the Joint International Symposium On Molten Salts. 72-82. Honolulu, HI: Pennington, NJ: The Electrochemical Society.

23. Mojtahedi, W. and R. Backman. 1989. Release of Alkali Metals in Pressurized Fluidized-Bed Combustion and Gasification of Peat. Public Technical Research Center, Finland, 53. Mar, 1989, 48pp. 
24. Cooper J.L. and L.L. Moresco. 1981. Alkali Control in Fluidized Bed Combustion at CPC. Proceedings: High Temperature, High Pressure Particulate and Alkali Control in Coal Combustion Process Streams. 421-442. Doe Contractor's Review Meeting Morgantown, WV.

25. Guillory, J., J. Cooper, J. Ferguson, G. Goldbach, and F. Placer. 1983. Granular Bed filter Development Program. Phase II Final Report. Combustion Power Co. DOE/ET/10373T10.

26. Me Laughlin, J. 1990. The Removal of Volatile Alkali Salt Vapors from Hot Coalderived Gases. PhD thesis, Guildford, UK, Dept. of Chemical and Process Engineering, University of Surrey, $214 \mathrm{pp}$.

27. Uberoi, M., W.A. Punjak, and F. Shadman. 1990. Kinetics and Mechanism of Alkali Removal from Flue Gases by Solid Sorbents. Prog. Energy Combustion Science. Vol. 16, No. 4, pp. 205-211.

28. Lee S.D. and I. Johnson. 1980. Journal of Engineering Power. ASME Trans. 102, p 397.

29. Jain, R.C. and S.C. Young. 1985. Laboratory/Bench Scale Testing and Evaluation of A.P.T. Dry Plate Scrubber. Air Pollution Technology, Inc. DOE/ET/15492--2030.

30. Bachovchin, D.M., M.A. Alvin, E.A. Dezubay, and P.R. Mulik. 1986. Study of High Temperature Removal of Alkali of a Pressurized Gasification System. Final Report, DOE-MC20050-2226. Westinghouse Research and Development Center, Pittsburgh, PA.

31. Uberoi, M. and F. Shadman. 1991. High-Temperature Removal of Cadmium Compounds Using Solid Sorbents. Environmental Science Technology. Vol. 25, No. 7, pp. 1285-1289.

32. Uberoi, M. and F. Shadman. 1991. Fundamenals of Heavy Metal Removal by Dry Sorbents. Prepr. Pap. Am. Chem. Soc., Div. Fuel Chem. v36, n4, pp. 1724-9.

33. Uberoi, M. 1990. High-Temperature Removal of Metal Vapors by Solid Sorbents. Ph. D. Thesis, The University of Arizona.

34. TRW. May, 1981. Monitoring Contaminants in Coal Derived Gas for Molten Carbonate Fuel Cells. DOE/METC/82-44. Final Report to Argonne National Laboratory under contract No. 31-109-38-6108.

35. Krishnan, G., B. Wood, and G. Tong. June 1988. Removal of Hydrogen Chloride from High Temperature Coal Gases. Preprints of Papers Presented at 195th ACS National Meeting. Toronto, Canada. v33, no1.

36. Robertson, A., R. Garland, R. Newby, A. Rehmat and L. Rubow. 1989. SecondGeneration Pressurized Fluidized Bed Combustion Plant Conceptual Design and Optimization of a Second-Generation PFB Combustion Plant, Phase 1, Task 1. Report DOE/MC/210232825, vol.1. Prepared by Foster Wheeler Development Corporation. 
37. Ciliberti, D.F. and T.E. Lippert. 1986. Performance Evaluation of a Ceramic Cross-Flow Filter on a Bench-Scale Coal Gasifier. Westinghouse Eighth Quarterly Report and Monthly Project Status Report for September 1, 1986 - September 30, 1986, DOE/METC Contract No. DE-AC21-84-MC21338. 


\section{SECTION 7}

\section{CONCLUSIONS AND RECOMMENDATIONS}

This economic study shows that the granular-bed filter compares favorably with the ceramic candle filter from an economic standpoint. For the granular-bed filters, the capital costs are less, the projected maintenance costs are less, the costs of electricity are less. To illustrate, see Table 60.

The granular-bed filter was proven to be feasible in the tests at NYU. The new filter design has the same basic configuration, but different proportions. A new test series needs to be arranged to show that the design is practical. Presumably, this can be resolved at the Southern Company Services test facility that is being designed at this time.

- CPFBC Filters

For the 452 MWe second generation PFB combustion plant, the savings in capital cost for the CPFBC, granular-bed filter instead of the candle filter is about $28 \%$.

Capital costs for the candle filter include the eight filters vessels, pulse air compressor system, and ash depressurizing and cooling equipment. Capital costs for the granular-bed filter include the eight filter vessels, filter media circulation system, and ash cooling and depressurizing equipment. In EPRI TAG terminology, these are the bare erected costs as they include equipment, suppliers engineering, and installation, but none of the process or project contingencies. Costs are in December, 1991 dollars.

The estimated savings in yearly maintenance for the granular-bed filter is $59 \%$. The major component of maintenance for the filters is the $4 \%$ of the capital cost applied according to EPRI TAG guidelines. For the CPFBC candle filter, the major contributor to the additional expense is the cost of replacement filter elements at $\$ 985,000 /$ yearly assuming $1 / 3$ candles per year.

Electrical loads for both filter plants are within $10 \%$, with the candle filter lowest. The comparison is for all electrical loads associated with the filter equipment, and includes, pulse compressors for the candle filters, boost blowers for the granular-bed filters, and ash cooling equipment for both filters.

\section{- Carbonizer Filters}

For the 452 MWe second generation PFB combustion plant, the savings in capital cost for the carbonizer, granular-bed filter instead of the candle filter is about $14 \%$.

Capital costs for the candle filter include the two filters vessels, pulse air compressor system, but no ash system; since, the Foster Wheeler study assumes the filter discharges hot ash directly to adjacent combustion equipment. Capital costs for the granular-bed filter include two filter vessels, filter media circulation system, and ash cooling and depressurizing equipment. 
Table 60 Filter Comparisons

\begin{tabular}{lcc}
\hline Cost Item & Plant with & Plant with \\
& Granular-Bed & Candle \\
& Filters & Filters \\
\hline
\end{tabular}

452.8 Second Generation PFB Combustion Plant

CPFBC Filters

Capital Cost, $\mathrm{k} \$$

27,339

38,187

$\$ / \mathrm{kW}$

60.4

84.3

Filter Maint., $\mathrm{k} \$ / \mathrm{yr}$

1,040

2,522

Electric Load, kVa

349

318

Carbonizer Filters

Capital Cost, $\mathrm{k} \$$

$\$ / \mathrm{kW}$

5,851

12.9

6,795

286

15.0

Filter Maint., $\mathrm{k} \$ / \mathrm{yr}$

59

619

123

Cost of Electricity

Cument $\$$, mills/kWh

74.1

76.5

Constant $\$$, mills $/ \mathrm{kWh}$

52.8

54.5

100 MWe KRW Gasifier Plant

Hot Gas Filters

Capital Cost, $\mathrm{k} \$$

3,775

37.8

$\$ / \mathrm{kW}$

156

Filter Maint., $\mathrm{k} \$ / \mathrm{yr}$

22

4,458

44.6

300

Electric Load, kVa

84

Cost of Electricity

Current $\$$, mills $/ \mathrm{kWh}$

133.2

134.0

Constant $\$$, mills/kWh

91.8

92.4 
The estimated yearly maintenance for the carbonizer granular-bed filter is $46 \%$ of the candle filter maintenance. The major component of maintenance for both filters is the $4 \%$ of the capital cost applied according to EPRI TAG guidelines. For the candle filter, the major contributor to the additional expense is the cost of replacement filter elements at $\$ 222,000 /$ yearly assuming $1 / 3$ candles per year. Another significant cost is the replacement of filter internals due to corrosion in the reducing atmosphere. The yearly allocation for this item is $\$ 32,000$ for the granular-bed filter and $\$ 97,000$ for the candle filter.

Electrical loads for the granular-bed filter plant is estimated at slightly less than $50 \%$ than that of the candle filter plant. The main reason is that the boost blower horsepower drops considerably in comparison to the CPFBC filters due to the smaller media circulation system; because the flow varies as the square of the lift pipe size. On the other hand, the pulse gas flow for the candle filter does not decrease as dramatically, because is depends on other parameters. The comparison is for all electrical loads associated with the filter equipment, and includes ash cooling equipment for both filters.

\section{- Cost of Electricity for Second Generation PFB Combustion Plant}

Both the CPFBC and the carbonizer filters are included in the values for cost of electricity (COE). The COE is for the entire power generation plant and varies by 1.7 mills/kWh in constant dollars; the lower COE is for the plant with granular-bed filters. The values given in Table 60 include the capital costs and maintenance costs listed above. When the electrical loads are taken into account, the COE values listed above, all increase by 0.1 mills $/ \mathrm{kWh}$.

\section{- KRW Gasifier Filters}

For the 100 MWe KRW gasifier plant, the savings in capital cost for the granularbed filter instead of the candle filter is about $15 \%$.

Capital cost for the candle filter includes one filter vessel, pulse air compressor system, and ash depressurizing and cooling equipment. Capital cost for the granular-bed filter includes one filter vessel, filter media circulation system, and ash cooling and depressurizing equipment. Costs are in December, 1991 dollars.

The estimated savings in yearly maintenance for the granular-bed filter is $48 \%$. The major component of maintenance for the filters is the $4 \%$ of the capital cost applied according to EPRI TAG guidelines. For the candle filter, the major contributor to the additional expense is the cost of replacement filter elements at $\$ 89,000 /$ yearly assuming $1 / 3$ candles per year. Another significant cost is the replacement of filter internals due to corrosion in the reducing atmosphere. The yearly allocation for this item is $\$ 17,000$ for the granular-bed filter and $\$ 44,000$ for the candle filter. 
Electrical loads for the granular-bed filter plant is estimated at slightly less than $30 \%$ than that of the candle filter plant. The explanation is similar to that for the carbonizer filters; in that, the boost blower horsepower for the granular-bed filter diminishes with filter capacity more significantly than the pulse gas for the candle filter. The comparison is for all electrical loads associated with the filter equipment, and includes ash cooling equipment for both filters.

\section{- Cost of Electricity for KRW Gasifier Plant}

The COE is for the entire power generation plant and varies by 0.6 mills $/ \mathrm{kWh}$ in constant dollars with the lower value associated with the plant including granular-bed filters. The values given in Table 60 include the capital costs and maintenance costs listed above. When the electrical loads are taken into account, the COE values listed all increase by $0.1 \mathrm{mills} / \mathrm{kWh}$.

\section{- Multi-Contaminant Granular-Bed Filter}

Besides removing particulate, a granular-bed filter has the potential of removing other pollutants in the gas stream. The filter is an excellent gas/solids contactor; in that, it has gas residence times in the order of several seconds, solids residence times in the order of several hours, uniform gas flow across the media, and the gas and filter media flow in opposite directions for the maximum driving potential. The contaminants of major concern, besides particulate in coal utilization processes, are sulfur compounds, nitrogen compounds, alkali compounds, halogenated compounds, tars, and trace contaminants such as cadmium and mercury.

The objective is to develop granular-bed filters that are capable of removing a combination of pollutants in high temperature and high pressure (HTHP) gas streams from processes being developed for advanced coal utilization. Although we are still in the initial stages of our study on multi-comtaminant control, we have narrowed the many possible approaches down to a single concept. The media used in the granular-bed filter could be composed of two distinct size distributions. Larger, six mm diameter, spheres could be the same inert media used for particulate control. In addition to this media, a smaller ( 2 to $3 \mathrm{~mm}$ diameter) media could be supplied which would be chemically reactive and have a finite life.

Having determined possible processes for multi-contaminant control, proof of concept testing will be required to establish feasibility of the proposed processes. In order to conduct the proof of concept testing, test plans and conceptual designs of the test equipment will be prepared. Actual testing will occur in the next phase of the program after approval of the test plans by DOE. 


\section{SECIIIN 8}

\section{ACRONYMS AND ABBREVIATIONS}

$\begin{array}{ll}\text { ASME } & \text { American Society of Mechanical Engineers } \\ \text { CAD } & \text { Computer Aided Design } \\ \text { CFD } & \text { Computational Fluid Dynamics } \\ \text { CPC } & \text { Combustion Power Company } \\ \text { CPFBC } & \text { Circulating Pressurized Fluidized Bed Combustion } \\ \text { COE } & \text { Cost of Electricity } \\ \text { DCFT } & \text { Direct Coal-Fired Turbine } \\ \text { DOE } & \text { Department of Energy } \\ \text { EPRI } & \text { Electric Power Research Institute } \\ \text { FWDC } & \text { Foster Wheeler Development Corporation } \\ \text { FWEC } & \text { Foster Wheeler Energy Corporation } \\ \text { GBF } & \text { Granular-Bed Filter } \\ \text { HGCU } & \text { Hot Gas Clean Up } \\ \text { HHV } & \text { Higher Heating Value } \\ \text { HTHP } & \text { High Temperature High Pressure } \\ \text { I \& C } & \text { Instrumentation and Control } \\ \text { IGCC } & \text { Integrated Gasification Combined-Cycle } \\ \text { KRW } & \text { Kellogg-Rust-Westinghouse } \\ \text { LHV } & \text { Lower Heating Value } \\ \text { LMTD } & \text { Log Mean Temperature Difference } \\ \text { METC } & \text { Morgantown Energy Technology Center } \\ \text { NPHR } & \text { Net Plant Heat Rate } \\ \text { NSPS } & \text { New Source Performance Standards } \\ \text { NYU } & \text { New York University } \\ \text { PFB } & \text { Pressurized Fluidized Bed } \\ \text { PFBC } & \text { Pressurized Fluidized Bed Combustion } \\ \text { RPD } & \text { Restricted Pipe Discharge } \\ \text { TAG } & \text { Technical Assessment Guide (EPRI) } \\ \text { TCR } & \text { Total Capital Requirement } \\ \text { TPC } & \text { Total Plant Cost } \\ \text { TPI } & \text { Total Plant Investment } \\ & \end{array}$


APPENDIX 


\section{APPENDIX A}

\section{Lotus 1-2-3 Spreadsheet Results}

The COE is calculated using the "Lotus Cost of Electricity Spreadsheet" by T. J. Hand, December 1988 which was supplied by the Morgantown Energy Technology Center (METC). This spreadsheet is based on methodology developed in the Technical Assessment Guide (TAG), published by the Electric Power Research Institute (EPRI), Volume I, EPRI-4463-SR, December, 1986.

In Tables 1, 2, and 3, the spreadsheet calculations are displayed for the $452 \mathrm{MWe}$, Foster Wheeler, second generation pressurized fluidized bed combustion (PFBC) plant. These values are based on the PFBC plant utilizing a ceramic cross-flow filter. The COE calculated by Foster Wheeler in Table 1, follows EPRI TAG methodology, but was accomplished without the benefit of the spreadsheet supplied by METC. Values for total capital requirement, fuel cost, and operation \& maintanence are those detemined by Foster Wheeler. Levelizing factors and the resultant $\mathrm{COE}$ were also determined by Foster Wheeler. The COE calculatation shown in Table 2 is the same information adjusted to appropriate spreadsheet methodology. In Table 3 , the costs presented in Table 2 are adjusted for escalation to Dec 1991 per EPRI TAG guidelines.

The main reasons for the differences between the costs given by Foster Wheeler for the base costs, Table 1, and the costs calculated by the spreadsheet, Table 2, are given below:

- Project contingency is $15 \%$ of process plant cost plus general plant facilities plus engineering plus process contingency in the Foster Wheeler study. In the Lotus spreadsheet, based on the 1986 EPRI TAG, project contingency is a percentage of process plant cost plus general plant facilities only.

- Capital cost for spares was not detailed in the Foster Wheeler, base costs, but added into subsequent costing at $0.5 \%$ of the total plant cost per the spreadsheet.

- The cost for operation \& maintenance in Table 2 , is increased by the cost of insurance \& local taxes at $2 \%$ of the total plant cost $(\$ 8,086,000)$ and by other operating costs $(\$ 901,000)$ which is a function of operation labor and maintenance costs in the spreadsheet.

- Although there is difference in tax life and tax rates between the Foster Wheeler study and the spreadsheet, this does not account for the different levelizing factors used in the calculation of the COE. Tenth year levelized dollars is used in the spreadsheet calculation: whereas, the Foster Wheeler study uses first year levelized costs.

In Table 1, the Foster Wheeler results are shown in the spreadsheet format, but 
many of the spreadsheet calculations are overridden by inserting constants from the Foster Wheeler report. Furthermore a third column was added to Table 1, spreadsheet part "C. Cost Of Electricity", to input the levelizing factors used by Foster Wheeler. The Foster Wheeler report on the second generation pressurized fluidized bed combustion (PFBC) plant reports a total cost of electricity of 75.7 mills $/ \mathrm{kWh}$.

Table 2 presents the base costs of the second generation PFBC. The values presented are calculated by the spreadsheet methodology, and are based on the 1986 EPRI TAG. For this reason there are minor differences in the values for startup costs and working capital. In some cases where Foster Wheeler has presented information that differs with the assumptions made in the spreadsheet, the Foster Wheeler values are used. A 3.5 year plant construction period is assumed for this reason as is a $6.0 \% / \mathrm{yr}$ inflation rate and the $0.8 \% / y r$ real escalation rate (over inflation) for fuel. Levelizing factors calculated by the spreadsheet are in tenth year levelized dollars.

Escalated plant costs, in Table 3 , were attained by applying the Chemical Engineering Plant Cost Index to applicable plant sections and by applying escalation factors recommended by the 1989 EPRI TAG to portions of the annual operating costs. The Chemical Engineering Plant Cost Index for December, 1987 is 332.5 and the value for December, 1991 is 359.3. Not all items in the total capital requirement (TCR) are adjusted by this index, as some items are factored from other costs. Inflation used in the calculation of levelizing factors is $4 \%$, and the real escalation rate (over inflation) for fuel is $0.7 \%$ per year as recommended in the spreadsheet. The annual operating costs are taken from the 1989 EPRI TAG if listed, and from the Foster Wheeler report otherwise. Inflation applied to the operating costs is $5 \%$ as recommended by the 1989 EPRI TAG. Note that while the methodology used in the calculation of the COE is based on the 1986 EPRI TAG, escalation of some of the operation costs and fuel costs is based on the 1989 edition of the EPRI TAG. 
Table 1. Base Costs of the Second Generation PFBC Combustion Plant

$05 / 07 / 93$

ELECTRIC POWER GENERATION COST - Version 1.12

2ND GENERATION PFB 453 MW POWER PLANT

CAPITAL REQUIREMENTS (DeC 1987 DOllars)

Total Plant Investment

AREA NO PLANT SECTION DESCRIPTION

1 COAL AND SORBENT HNDLG

2 COAL AND SORBENT PREP

3 FEEDWATER AND MISC BOP SYSTEMS

4 CARBONIZER, CPFBC \& CPFBC FBHE

5 HOT GAS CLEANUP AND PIPING

6 COMBUSTION TURBINE /ACCESSORIES

$?$ HRSG, DUCTING AND STACK

8 STEAM TURBINE GENERATOR

9 COOLING WATER SYSTEM

10 ASH / SPENT SORBENT HNDL SYSTEM

11 ACCESSORY ELECTRIC PLANT

12 INSTRUMENTATION AND CONTROL

13 IMPROVEMENTS TO SITE

14 BUILDINGS AND STRUCTURES
PROCESS

CONT, \%
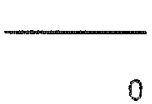

3

3

0
17

5

5
9

13

0

0

12

0

0

0

0
COST, $K \$$

W/O CONT

$\$ 32,763$

$\$ 20,673$

$\$ 18,299$

$\$ 46,891$

$\$ 27,314$

$\$ 51,528$

$\$ 24,948$

$\$ 34,286$

$\$ 9,046$

$\$ 7,335$

$\$ 13,077$

$\$ 10,644$

$\$ 8,784$

$\$ 11,367$

Subtota1, Process Plant Cost

$\$ 316,955$

General Plant Facilities

Engineering Fees

Process contingency (Using contingencies 1 isted above)

15 \% Proc Plt \& Gen Plt Fac

Project Contingency,

Total Plant cost (TPC)

Plant Construction Period, Construction Interest Rate,

3.5 Years ( 1 or more)

Adjustment for Interest and Inflation

Total Plant Investment (TPI)

Prepaid Royalties

Initial Catalyst and Chemical Inventory

Startup costs

Spare Parts

Working Capital

Land,

200 Acres

Total Capital Requirement (TCR)
$\$ 410,258$

$\$ 33,702$

$\$ 443,961$

$\$ 0$
$\$ 20,602$

$\$ 19,189$

$\$ 53,512$

$\$ 0$

$\$ 12,585$

$\$ 0$

$\$ 11,458$

$\$ 1,500$

$\$ 469,504$ 
Table 1. Base Costs of the Second Generation PFBC Combustion Plant (Continued)

ANNUAL OPERATING COSTS

Capacrty Factor $=\quad 05 \%$

COST ITEM

QUANTITY

UNIT $\$$

ANNUAL

PITTS NO.8 COAL FuE
Consumable Materiais
DOLOMITE

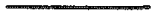

FRICE

COST, $K \$$

WATER

FUEL OIL

MISC.ITEMS

uel Type 3413.5 T/D

$\$ 44.57 / T$

$\$ 36,095$

Ash/Sorbent Disposal Costs

$987.8 \mathrm{~T} / \mathrm{D}$

$23136.3 \mathrm{~T} / \mathrm{D}$

$15.2 T / 0$

$3529.0 \mathrm{~T} / \mathrm{D}$

$\$ 17.90 / T$

$\$ 0.17 / T$

$\$ 205.48 / T$

$\$ 1.00 / T$

$\$ 946$

$\$ 743$

$\$ 837$

Plant Labor

Oper Labor (1ncl benef)

supervision \& Clerical

$26 \mathrm{Men} / \mathrm{shift} \$ 23.55 / \mathrm{Hr}$.

$\$ 7.60 / T$

$\$ 1,972$

Maintenance Costs

2,704

$\$ 9,157$

Insurance \& Local Taxes

$\$ 0$

Royalties

$\$ 0$

other Operating costs

$\$ 0$

Total Operating costs

$\$ 61,999$

By-Product Credits
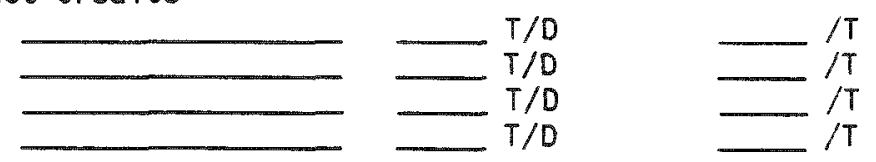

$\$ 0$

$\$ 0$

$\$ 0$

$\$ 0$

Total By-Product Credits

$\$ 0$

Net Operating Costs

$\$ 61,999$ 
Table 1. Base Costs of the Second Generation PFBC Combustion Plant (Continued)

BASES AND ASSUMPTIONS

A. CAPITAL BASES AND DETAILS

\begin{tabular}{l} 
Initial Catalyst Inventory \\
\hline
\end{tabular}




\section{Table 1. Base Costs of the Second Generation PFBC Combustion Plant (Continued)}

B. ECONOMIC ASSUMPTIONS

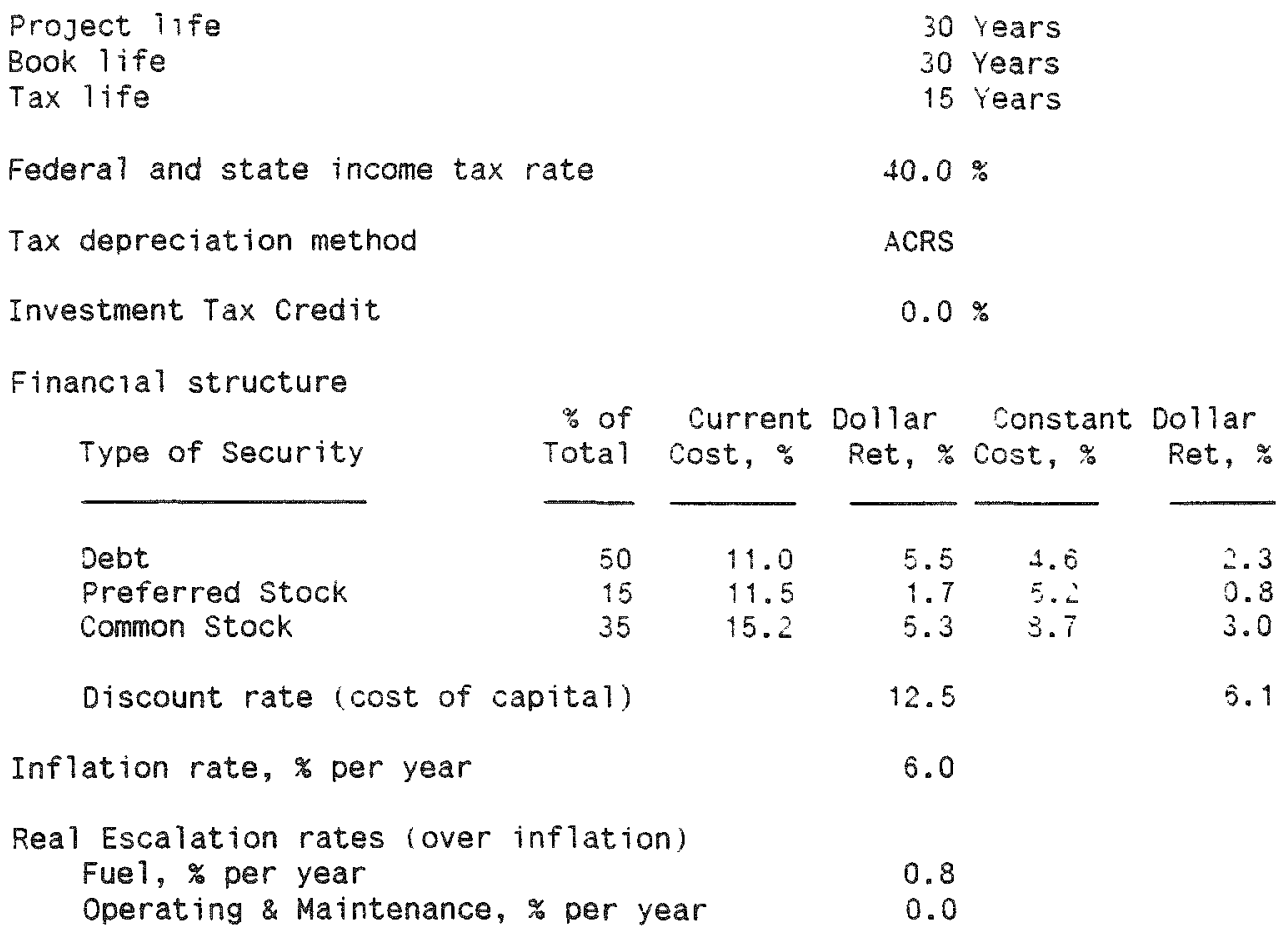

C. COST OF ELECTRICITY

The approach to determining the cost of electricity is based upon the methodology described in the Technical Assessment Guide, published by the Electric Power Research Institute, Volume I, EPRI-4463-SR, December 1986. The cost of electricity is stated in terms of loth year levelized dollars. Insurance and local taxes are accounted for explicitly in cell H87, rather than including it in Capital charges as does EPRI TAG.

Levelizing Factors

Capital Carrying charge, 10th year Fue ?, 10th year

operating \& Maintenance, 10th year

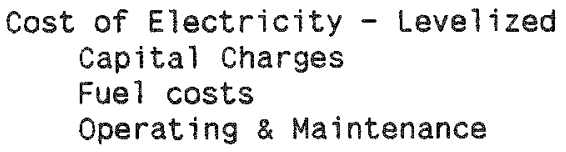

Total cost of Electricity current FW $\$$ Constant $\$$

$\begin{array}{rrr}0.178 & 0.173 & 0.104 \\ 1.375 & 1.9 & 1.041 \\ 1.321 & 1.75 & 1.000 \\ & & \text { mills/kWh } \\ 111 \mathrm{~s} / \mathrm{kWh} & -> & \\ & & 19.0 \\ 32.4 & 31.5 & 14.6 \\ 19.2 & 26.6 & 10.0 \\ 13.3 & 17.6 & \\ 64.9 & 75.7 & 43.0\end{array}$




\section{Table 2. Second Generation PFBC Costs Adjusted to EPRI TAG}

\author{
$05 / 07 / 93$ \\ $05 / 07 / 93$ \\ ELECTRIC POWER GENERATION COST - ierSION 1.12 \\ IND GENERATION PFB $\$ 53 \mathrm{MW}$ POWER PLANT \\ CAPITAL REQUIREMENTS (DeC 1987 Dollars) \\ Total Plant Investment
}

AREA NO PLANT SECTION DESCRIPTION

1 COAL AND SORBENT HNDLG

2 COAL AND SORBENT PREP

3 FEEDWATER AND MISC BOP SYSTEMS

4 CARBONIZER, CPFBC \& CPFBC FBHE

5 HOT GAS CLEANUP AND PIPING

6 COMBUSTION TURBINE / ACCESSORIES

7 HRSG, DUCTING ANO STACK

8 STEAM TURBINE GENERATOR

9 COOLING WATER SYSTEM

10 ASH / SPENT SORBENT HNDL SYSTEM

11 ACCESSORY ELECTRIC PLANT

12 INSTRUMENTATION AND CONTROL

13 IMPROVEMENTS TO SITE

14 BUILDINGS AND STRUCTURES

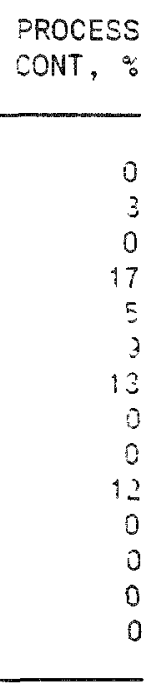

Subtotal, Process Plant Cost

General Plant Facilities

Engineering Fees

Process Contingency (Using contingencies 1 isted above)
Project contingency, $15 \%$ Proc Plt \& Gen P

$15 \%$ Proc Plt \& Gen Plt Fac

Total Plant cost (TPC)
$\operatorname{cosT}, k \$$ W/O CONT

$\$ 32,763$

$\$ 20,673$

$\$ 18,299$

$\$ 46,891$

$\$ 27,314$

$\$ 51,528$

$\$ 24,948$

$\$ 34,286$

$\$ 9,046$

$\$ 7,335$

$\$ 13,077$

$\$ 10,644$

$\$ 8,784$

$\$ 11,367$

$\$ 316,955$

$\$ 20,602$

$\$ 19,189$

$\$ 47,543$

$\$ 404,289$

Plant Construction Period,

3.5 Years ( 1 or more)

Construction Interest Rate, $12.5 \%$
Adjustment for Interest and Inflation

$\$ 31,947$

Total Plant Investment (TPI)

$\$ 436,236$

Prepaid Royalties

Initial Catalyst and Chemical Inventory

Startup Costs

Spare Parts

Working Capital

Land,

200 Acres

Total Capital Requirement (TCR)

$$
\begin{array}{r}
\$ 0 \\
\$ 0 \\
\$ 13,118 \\
\$ 2,021 \\
\$ 11,793 \\
\$ 1,500 \\
\$ 464,668
\end{array}
$$


Table 2. Second Generation PFBC Costs Adjusted to EPRI TAG (Continued)

ANNUAL OPERATING COSTS

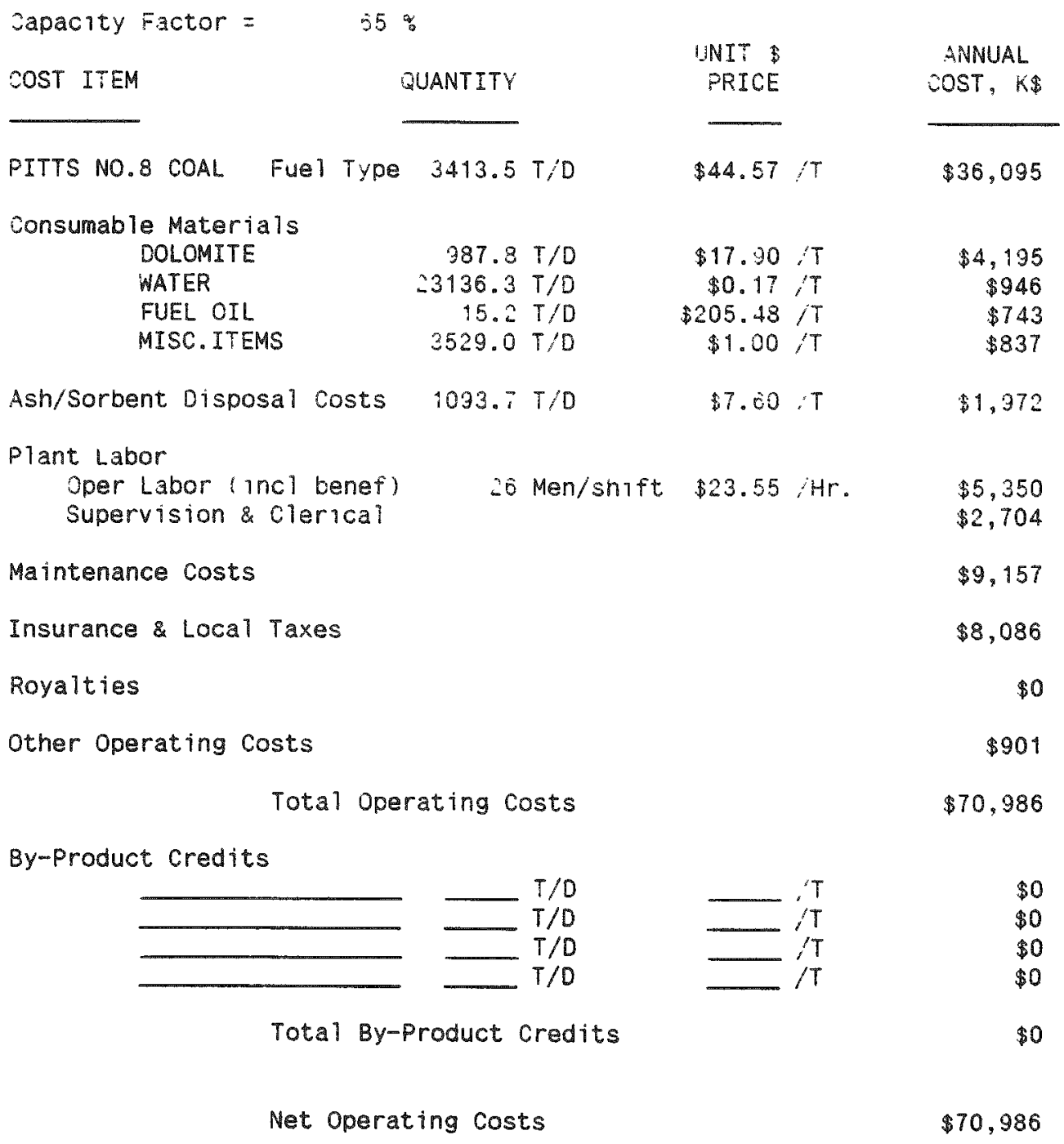


Table 2. Second Generation PFBC Costs Adjusted to EPRI TAG (Continued)

BASES AND ASSUMPTIONS

4. OAPITAL BASES AND DETAILS

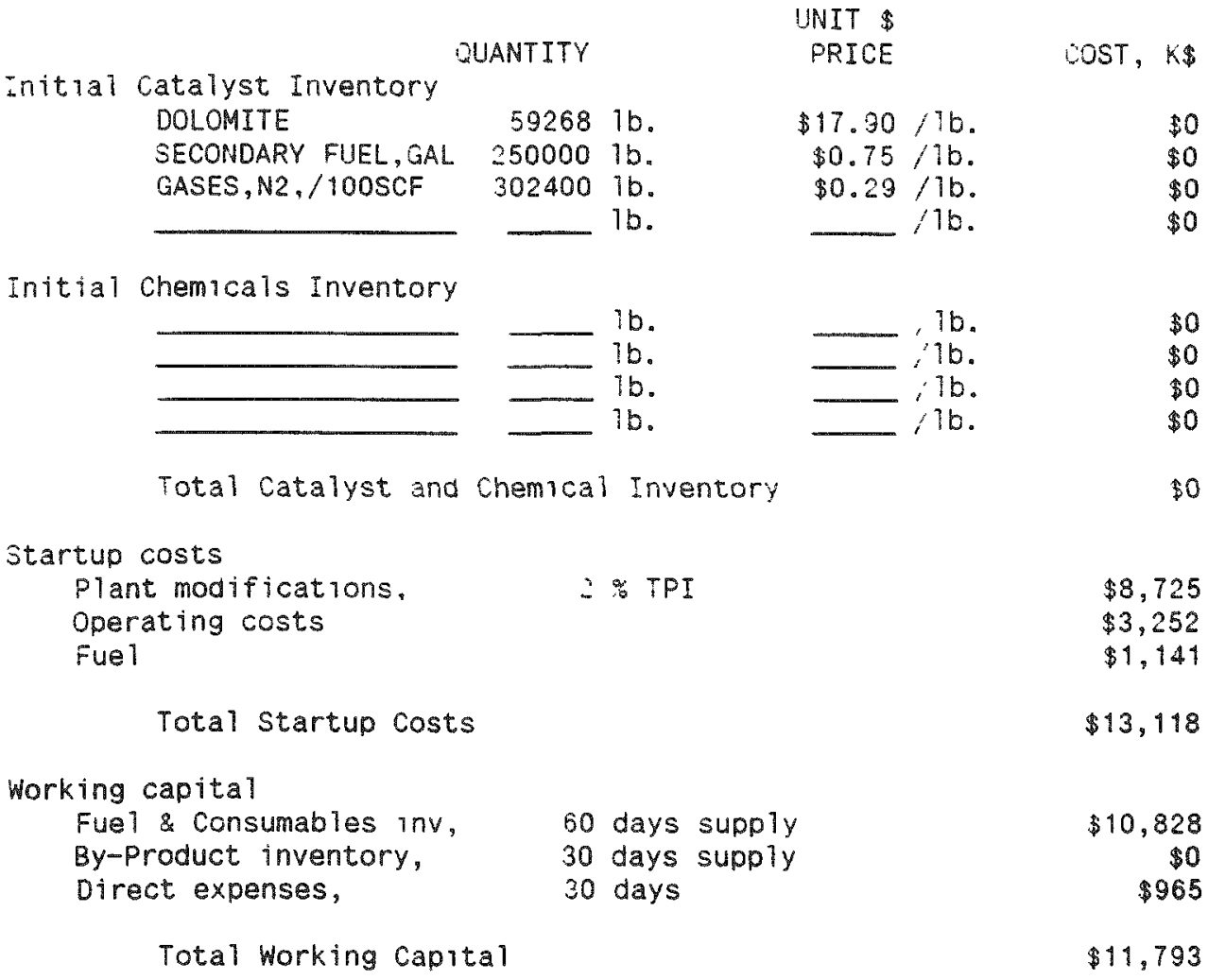


Table 2. Second Generation PFBC Costs Adjusted to EPRI TAG (Continued)

\author{
B. ECONOMIC ASSUMPTIONS
}

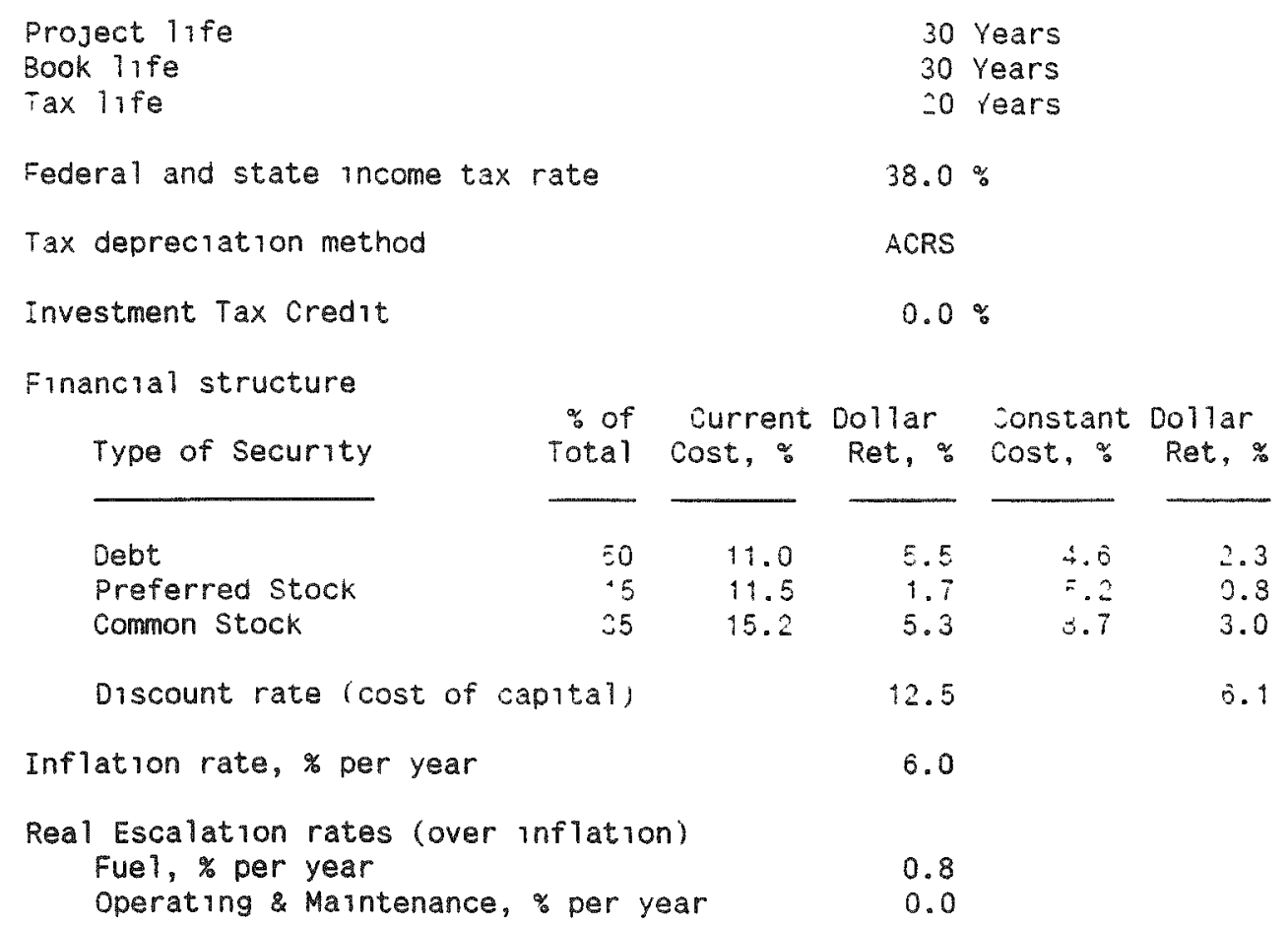

C. COST OF ELECTRICITY

The approach to determining the cost of electricity is based upon the methodology described in the Technical Assessment Guide, published by the Electric Power Research Institute, Volume I, EPRI-4463-SR, December 1986. The cost of electricity is stated in terms of 10 th year levelized dollars. Insurance and local taxes are accounted for explicitiy in cell H87, rather than including it in Capital charges as does EPRI TAG.

Levelizing Factors

Current $\$$

Constant

Capital Carrying Charge, 10th year Fuel, 10th year

0.175

0.103

operating \& Maintenance, 10th year

1.375

1.041

1.321

1.000

Cost of Electricity - Levelized

Capital Charges

Fuel costs

operating \& Maintenance

$\mathrm{m} 111 \mathrm{~s} / \mathrm{kWh}$

mr $11 s / k$ Wh

Total cost of Electricity

$\begin{array}{ll}31.6 & 18.6 \\ 19.2 & 14.6 \\ 17.9 & 13.5 \\ 68.7 & 46.7\end{array}$


Table 3. Second Generation PFBC Costs with Escalation to Dec, 1991

\author{
05/07/93 ELECTRIC POWER GENERATION COST - VerSION 1.12 \\ IND GENERATION PFB 153 MW POWER PLANT \\ CAPITAL REQUIREMENTS (DEC 1991 DO11arS) \\ Total Plant Investment
}

AREA NO PLANT SECTION DESCRIPTION

COAL AND SORBENT HNDLG

COAL ANO SORBENT PREP

FEEDWATER AND MISC BOP SYSTEMS

CARBONIZER, CPFBC \& CPFBC FBHE

HOT GAS CLEANUP AND PIPING

COMBUSTION TURBINE/ACCESSORIES

HRSG, DUCTING AND STACK

STEAM TURBINE GENERATOR

COOLING WATER SYSTEM

ASH / SPENT SORBENT HNDL SYSTEM

ACCESSORY ELECTRIC PLANT

INSTRUMENTATION AND CONTROL

IMPROVEMENTS TO SITE

BUILDINGS AND STRUCTURES

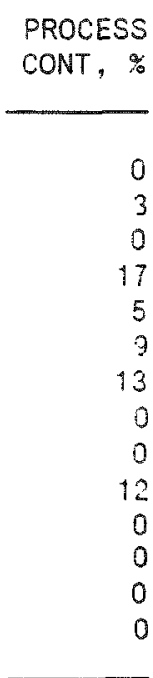

Subtotal, Process Plant cost

General Plant Facilities

Engineering Fees

Process Contingency (Using contingencies listed above)

Project Contingency,

$15 \%$ Proc Plt \& Gen Plt Fac

Total plant cost (TPC)

3.5 Years ( 1 or more)

Plant Construction Period, Construction Interest Rate, $12.5 \%$

Adjustment for Interest and Inflation

Total Plant Investment (TPI)

Prepaid Royalties

Initial Catalyst and chemical Inventory

Startup Costs

Spare Parts

Working Capital

Land,

200 Acres

Total Capital Requirement (TCR)
$\$ 46,475$

$\$ 483,351$

$\cos T, k \$$

W/O CONT

$\$ 35,404$

$\$ 22,339$

$\$ 19,774$

$\$ 50,670$

$\$ 29,516$

$\$ 55,681$

$\$ 26,959$

$\$ 37,050$

$\$ 9,775$

$\$ 7,926$

$\$ 14,131$

$\$ 11,502$

$\$ 9,492$

$\$ 12,283$

$\$ 342,502$

122,

$\$ 20,736$

$\$ 51,375$

$\$ 436,875$

$\$ 0$

$\$ 0$
$\$ 14,528$

$\$ 2,184$

$\$ 13,487$

$\$ 1,500$

$\$ 515,051$ 


\title{
Table 3. Second Generation PFBC Costs with Escalation to Dec, 1991 (Continued)
}

ANNUAL OPERATING COSTS

Capacity Factor $=$
COST ITEM

$65 \%$

$\begin{array}{lcc} & \text { UNIT } \$ & \text { ANNUAL } \\ \text { OUANTITY } & \text { PRICE } & \text { COST, K\$ }\end{array}$

PITTS NO.8 COAL FUE
Consumable Materials

\section{TUATITY}

PRICE

$\operatorname{COST}, k$

\author{
ue Type $3413.5 T / 0$
}

$\$ 51.60 / \mathrm{T}$

$\$ 41,786$ WATER DOLOMITE H2O MAKEUP/TREAT LIQUID EFF FUEL OIL GASES N2, ect.

$5575.01000 \mathrm{GAL} /$

$387.8 \mathrm{~T} / \mathrm{D}$

$5110.0 \mathrm{LB} / \mathrm{D}$

$13520 \mathrm{LB} / \mathrm{D}$

$\$ 175.0 \mathrm{GAL} / 0$

$5040 \quad 100 \mathrm{SCF} / \mathrm{D}$

Ash/Sorbent Disposal Costs

Plant Labor

Oper Labor (incl benef) Supervision \& Clerical

Maintenance Costs

Insurance \& Local Taxes

Royalties

$1093.7 \mathrm{~T} / \mathrm{D}$

$26 \mathrm{Men} / \mathrm{shift}$

other Operating costs

$$
\text { Total Operating Costs }
$$

By-Product Credits

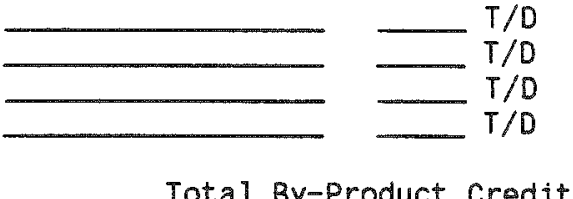

Net Operating Costs
$\$ 0.69 / 1000 \mathrm{GAL} \quad \$ 919$

$\$ 21.76 / T$

$\$ 0.17 / \mathrm{LB}$

$\$ 0.12 / L B$

$\$ 0.61 / \mathrm{GAL}$

$\$ 0.35 / 100 \mathrm{SCF}$

$\$ 9.26 / \mathrm{T}$

$\$ 23.15 / \mathrm{Hr}$ 。

10046.15

$\$ 5,273$

$\$ 2,771$

$\$ 9,908$

$\$ 8,738$

17952.13

$\$ 0$

$\$ 924$

$\$ 79,445$

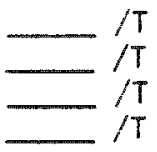

$\$ 0$

$\$ 0$

$\$ 0$

$\$ 0$

$\$ 0$

$\$ 79,445$ 
Table 3. Second Generation PFBC Costs with Escalation to Dec, 1991 (Continued)

BASES AND ASSUMPTIONS

4. CAPITAL BASES AND DETAILS

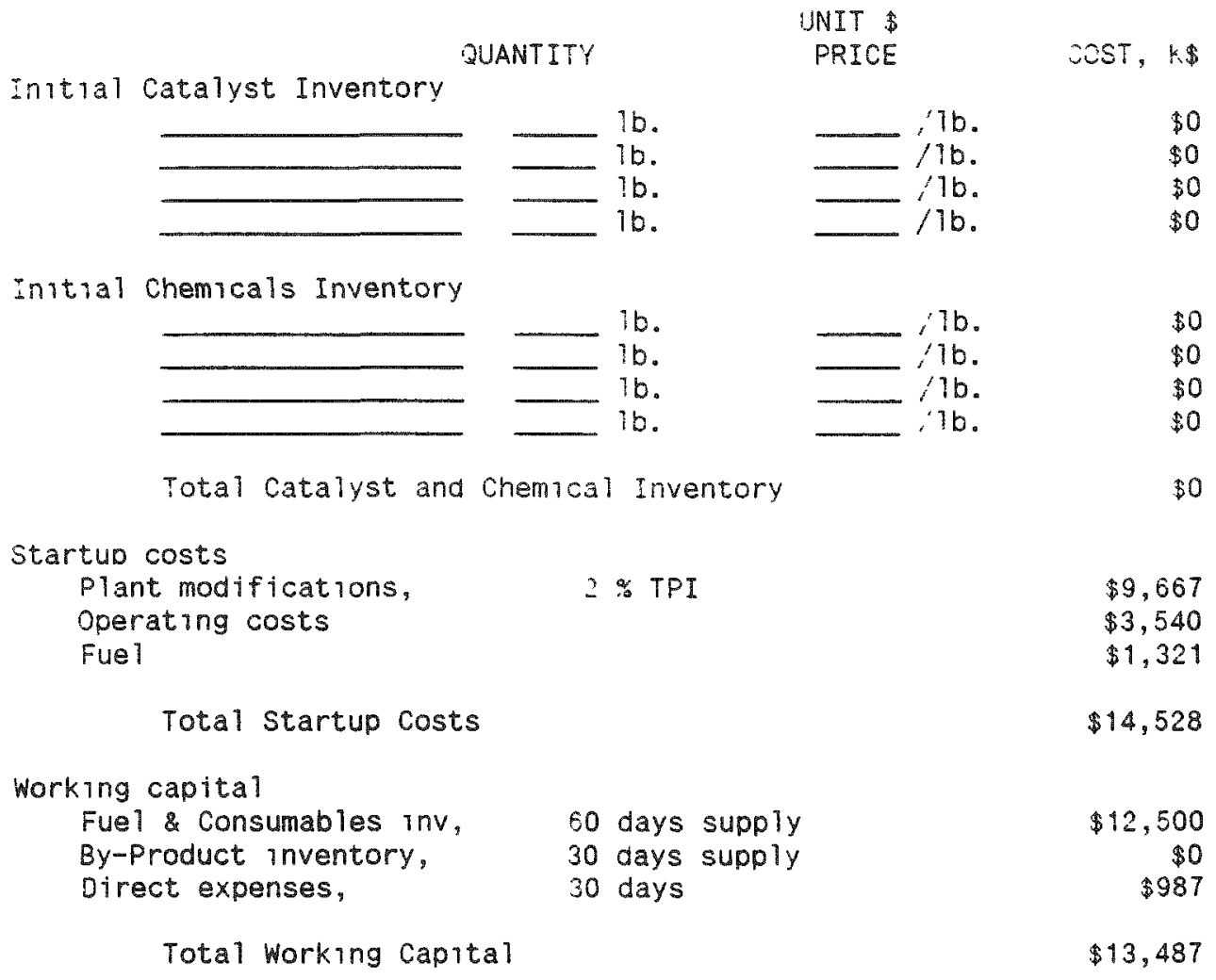


Table 3. Second Generation PFBC Costs with Escalation to Dec, 1991 (Continued)

8. ECONOMIC ASSUMPTIONS

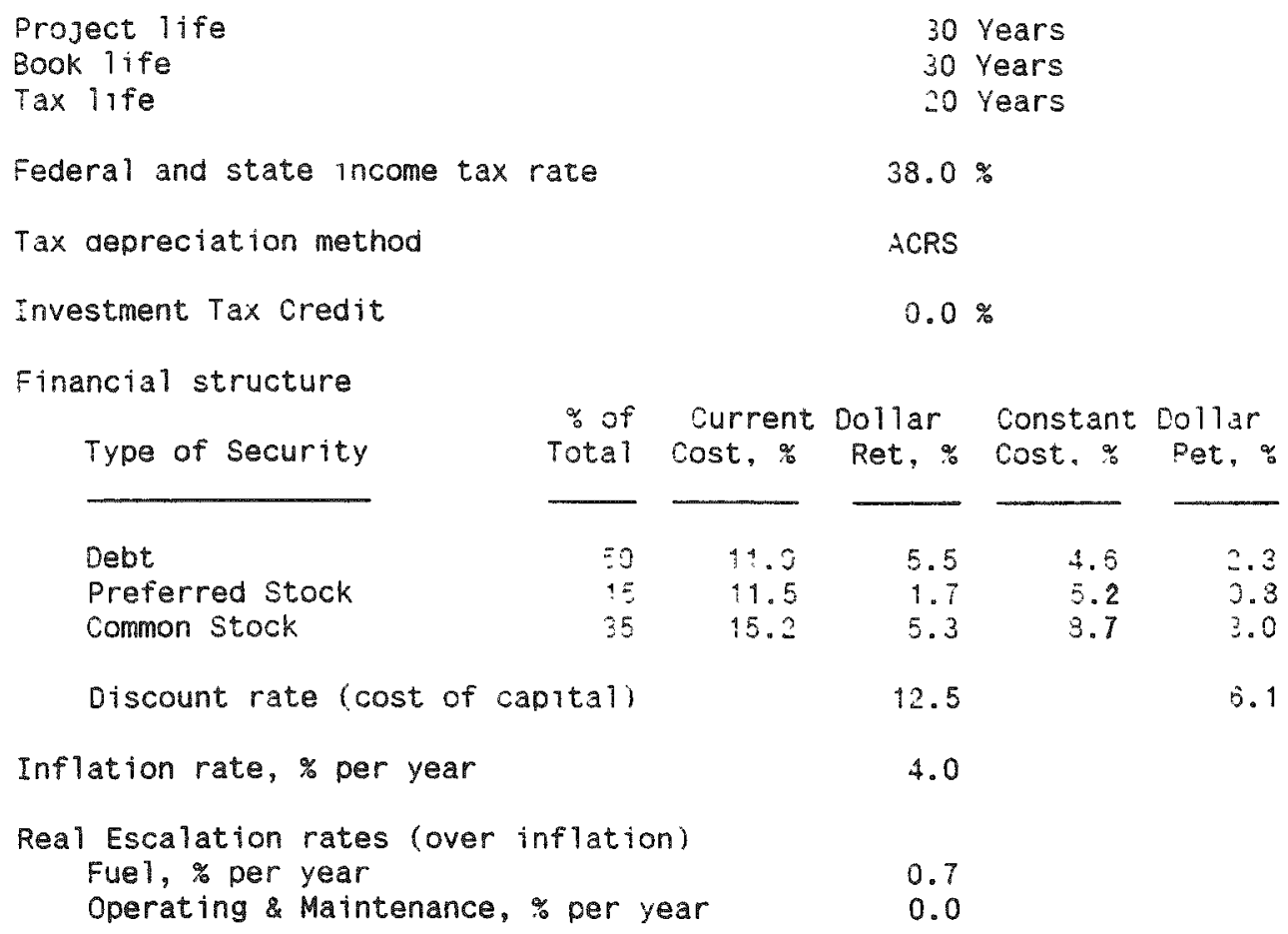

\section{COST OF ELECTRICITY}

The approach to determining the cost of electricity is based upon the methodology described in the Technical Assessment Guide, published by the Electric Power Research Institute, Volume I, EPRI-4463-SR, December 1986. The cost of electricity is stated in terms of 10th year levelized dollars. Insurance and local taxes are accounted for explicitly in cell H87, rather than including it in Capital Charges as does EPRI TAG.

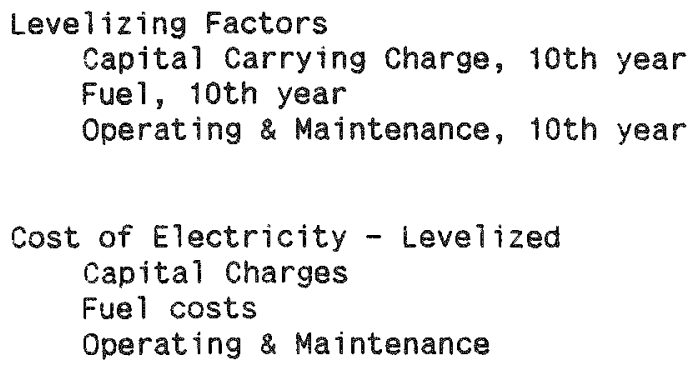

Current

$$
\begin{aligned}
& 0.175 \\
& 1.244 \\
& 1.202
\end{aligned}
$$

Constant

mi11s/kWh

$\begin{array}{ll}35.0 & 20.6 \\ 20.2 & 16.8 \\ 17.6 & 14.6 \\ 72.7 & 52.0\end{array}$


In Tables 4, 5, and 6, the spreadsheet calculations are displayed for the $100 \mathrm{MW}$, KRW air blown gasifier. These values are based on the gasifier plant utilizing a ceramic cross-flow filter. The base costs derived by Westinghouse, in 1986 dollars, are presented for the gasifier in Table 4. In Table 5, the Westinghouse costs are adjusted to comply with 1986 EPRI TAG methodology programmed into the spreadsheet. In Table 6, costs are adjusted for escalation to December, 1991.

The main reasons for the differences between the costs given by Westinghouse for the base costs, Table 4, and the costs calculated by the spreadsheet, Table 5, are given below.

- Adjusting the total capital requirement between the Westinghouse base costs and the EPRI TAG methodology involves separate calculations for some items grouped together by Westinghouse. A single value is reported by Westinghouse for allowance for funds during construction (AFDC), working capital, etc. $(\$ 22,005,000)$. The spreadsheet breaks out costs for royalties, startup costs, spare parts, and working capital. Also the spreadsheet uses a separate calculation for AFDC and lists this as adjustment for interest and inflation during the construction period. The total of these values is calculated by the spreadsheet $(\$ 26,935,000)$.

- Coal cost used by Westinghouse was $\$ 1.89 / \mathrm{MMBtu}$ for Illinois No. 6 . This was changed the $\$ 1.27 / \mathrm{MMBtu}$ as listed in the $1989 \mathrm{EPRI}$ TAG.

- The spreadsheet adds funds for insurance \& local taxes $(\$ 3,385,000)$, royalties $(\$ 65,000)$, and other operation costs $(\$ 603,000)$ which do not appear in the Westinghouse estimate.

- Different levelizing factors are used by the calculation of COE as shown in Tables 4,5 , and 6 . The standard spreadsheet used $10^{\text {th }}$ year levelized dollars.

Table 4 presents the Westinghouse derived values with many of the spreadsheet calculations nullified. A third column was added for the COE calculation, on the fourth page of Table 4, to input the levelizing factors used by Westinghouse. The Westinghouse report on the KRW (Air) gasifier, reports a total cost of electricity of 116.2 mills $/ \mathrm{kWh}$. The financial information presented in Table 4 provides the basis for the levelizing factors shown.

Table 5 presents the gasifier costs adjusted to 1986 EPRI TAG methodology. The 4 year plant construction period is the spreadsheet default value. Westinghouse used a factor of $1.064 \%$ for escalation from 1981 to 1986 . No information on land requirements was given, so this was left blank. The by-product credit for sulfur is $\$ 90 /$ long ton in the 1989 EPRI TAG. This was adjusted to $\$ 81.80 /$ (short)ton. Levelizing factors calculated by the spreadsheet are in 10th year levelized dollars.

Escalated plant costs for the gasifier plant, shown on Table 6, were attained by applying the Chemical Engineering Plant Cost Index to applicable plant sections, and by 
applying escalation factors recommended by the EPRI TAG to portions of the annual operating costs. First, escalation added in the Westinghouse study to adjust costs from 1981 to 1986 , was deducted, then these costs were adjusted to 1991. The Chemical Engineering Plant Cost Index for December, 1981 is 297.0 and the value for December, 1991 is 359.3. Not all items in the total capital requirement (TCR) are adjusted by this index, as some items are factored from other costs. The annual operating costs are taken from the 1989 EPRI TAG. Inflation applied is $5 \%$ as generally recommended by the 1989 EPRI TAG. Inflation used in the calculation of levelizing factors is $4 \%$ and the real escalation rate (over inflation) for fuel is $0.7 \%$ per year as recommended in the spreadsheet. 


\section{Table 4. Base Costs of the KRW Gasifier (Air) Plant}

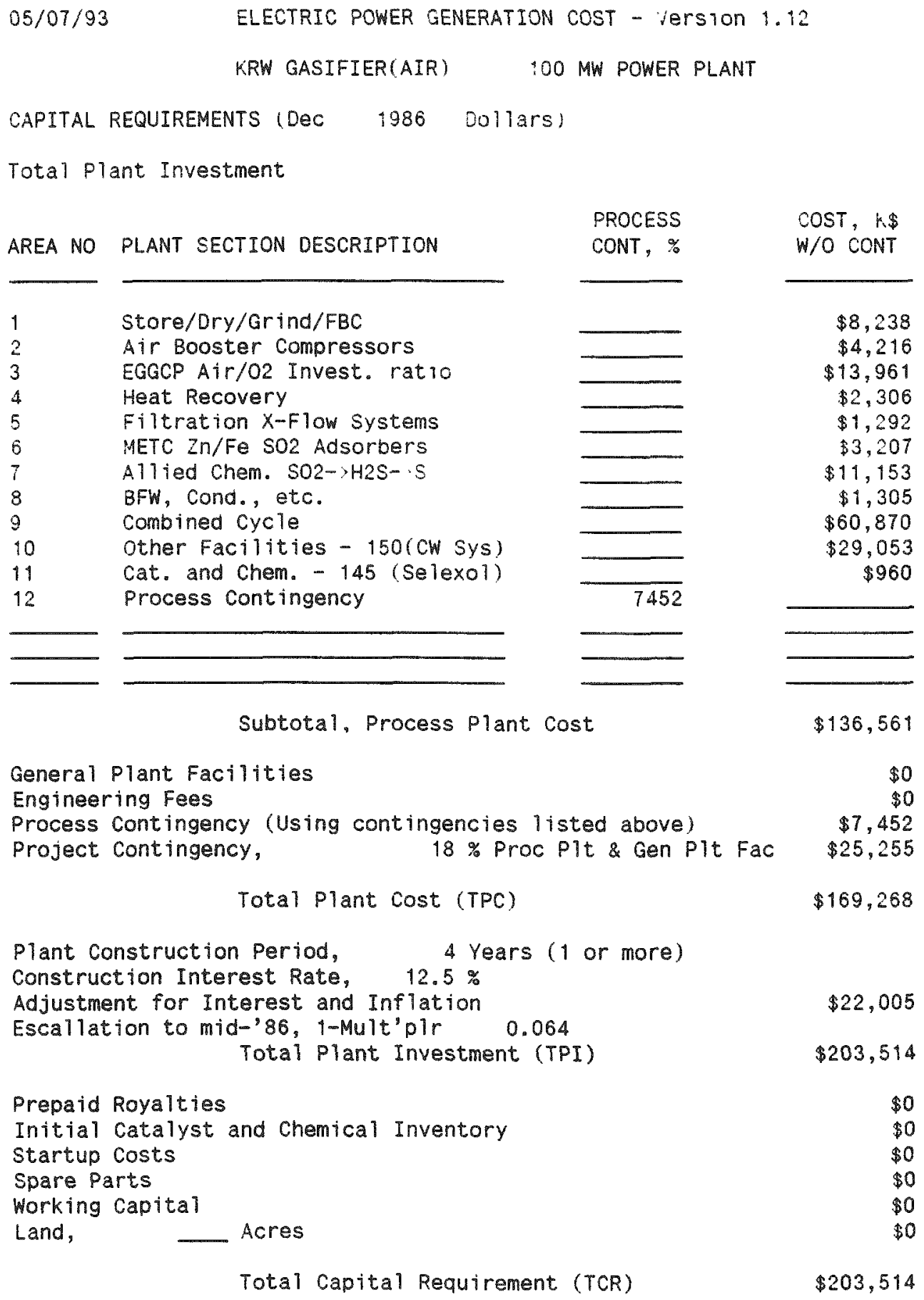

Subtotal, Process Plant Cost

$\$ 8,238$

$\$ 4,216$

$\$ 13,961$

\$2,306

$\$ 1,292$

$\$ 3,207$

$\$ 11,153$

$\$ 1,305$

$\$ 60,870$

$\$ 29,053$

$\$ 960$

$\$ 136,561$

General Plant Facilities

Engineering Fees

Process contingency (Using contingencies listed above)

Project Contingency,

$18 \%$ Proc Plt \& Gen Plt Fac

Plant Construction Period, Construction Interest Rate,

4 Years ( 1 or more)

Adjustment for Interest and Inflation

Escallation to mid-'86, 1-Mult'pir 0.064

Total Plant Investment (TPI)

$\$ 22,005$

$\$ 203,514$

Prepaid Royalties

$\$ 0$

Initial Catalyst and Chemical Inventory $\$ 0$

Startup Costs

Spare Parts

$\$ 0$

Working Capital

Land,

Acres

$\$ 0$

$\$ 0$

$\$ 0$

Total Capital Requirement (TCR)

$\$ 203,514$ 


\section{Table 4. Base Costs of the KRW Gasifier (Air) Plant (Continued)}

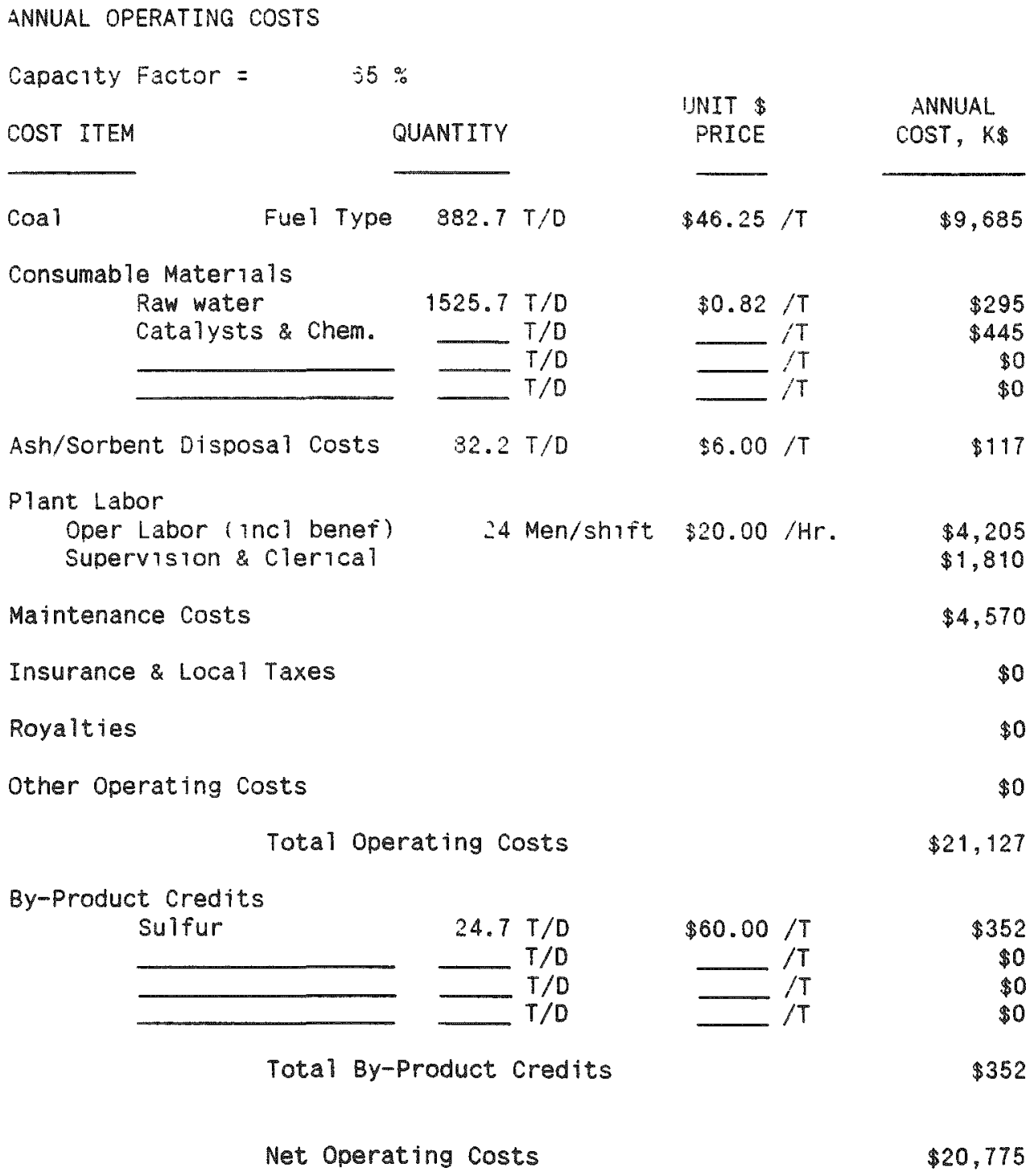

Total By-Product Credits 
Table 4. Base Costs of the KRW Gasifier (Air) Plant (Continued)

BASES AND ASSUMPTIONS

A. CAPITAL BASES AND DETAILS

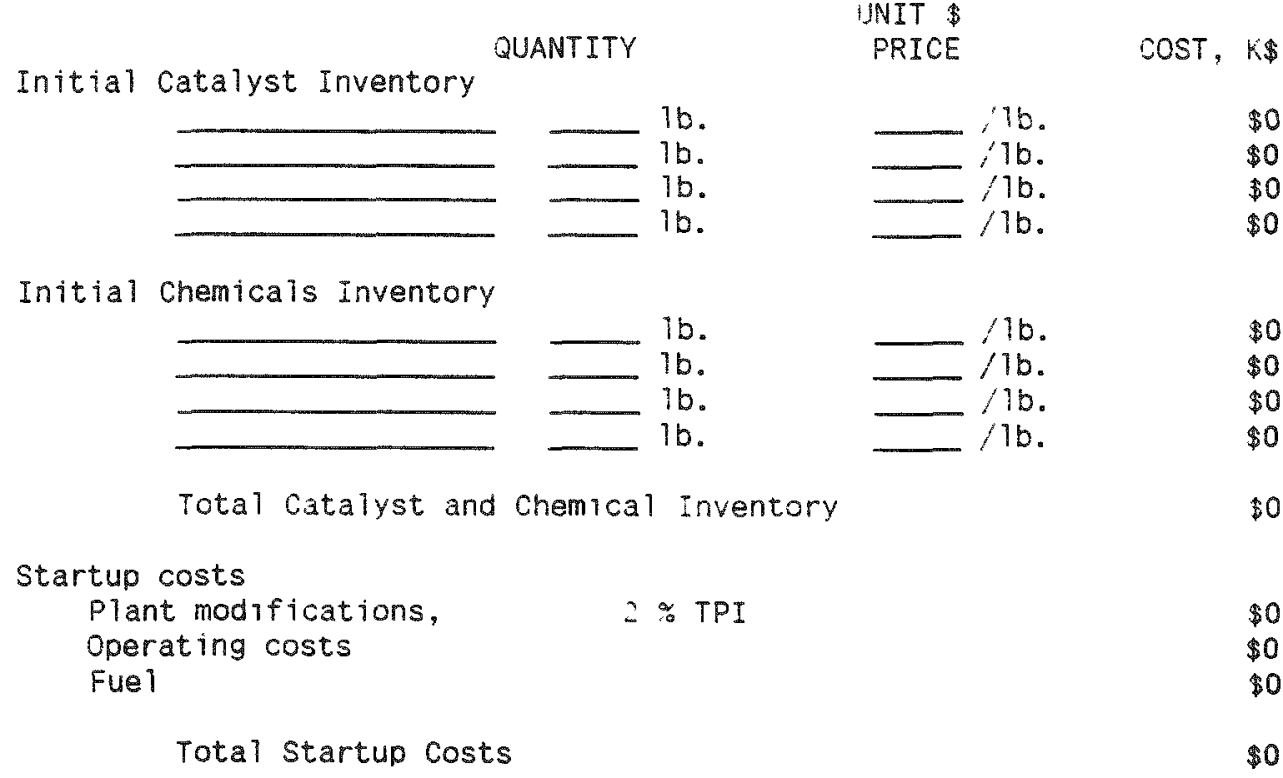

Working capital

Fuel \& Consumables inv, 0 days supply \$0

By-Product inventory, $\quad 0$ days supply

Direct expenses,

0 days

$\$ 0$

Total Working Capital

$\$ 0$

$\$ 0$ 


\section{Table 4. Base Costs of the KRW Gasifier (Air) Plant (Continued)}

B. ECONOMIC ASSUMPTIONS

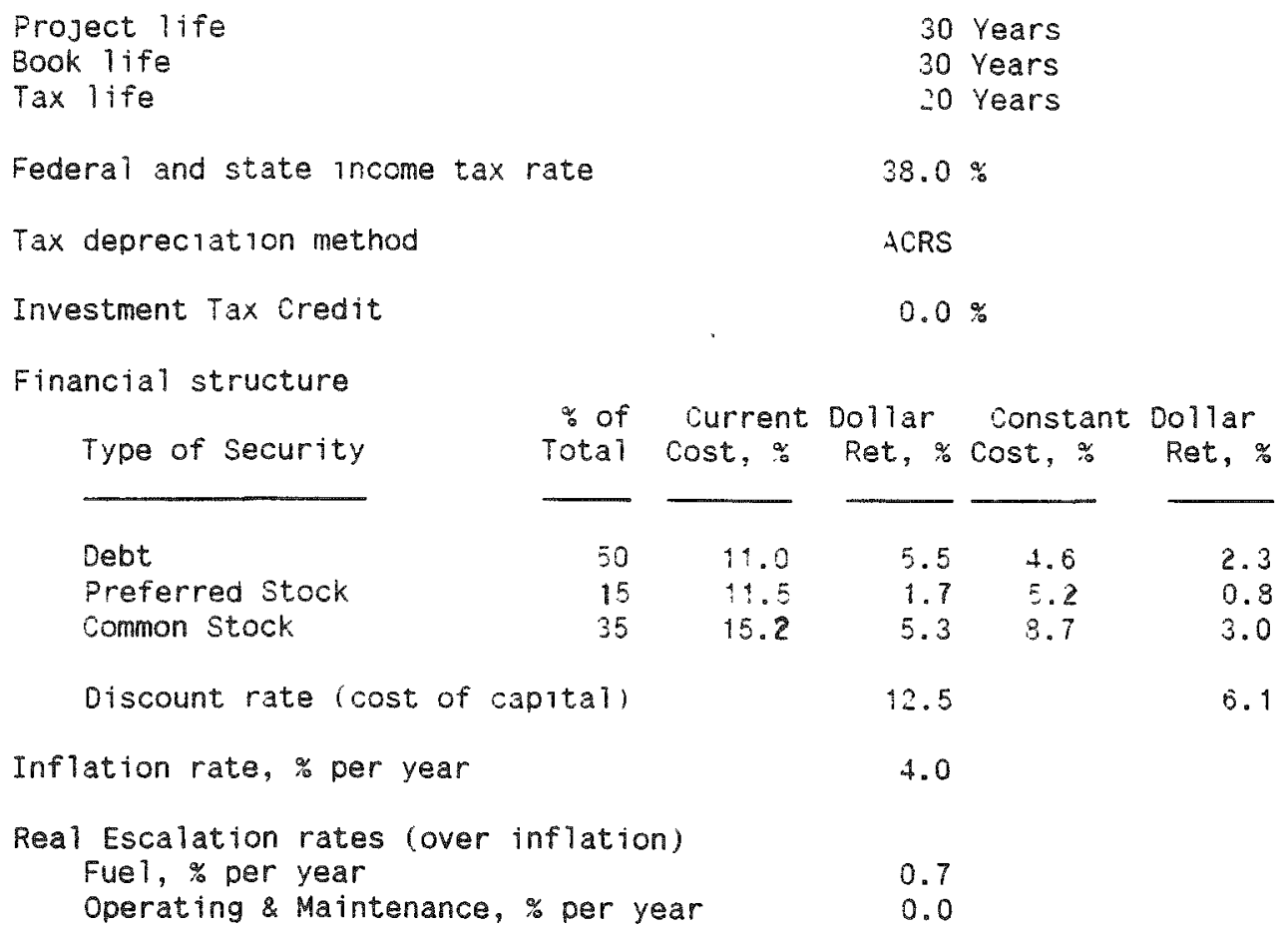

\section{COST OF ELECTRICITY}

The approach to determining the cost of electricity is based upon the methodology described in the Technical Assessment Guide, published by the Electric Power Research Institute, Volume I, EPRI-4463-SR, December 1986. The cost of electricity is stated in terms of 10th year levelized dollars. Insurance and local taxes are accounted for explicitly in cell H87, rather than including it in Capital charges as does EPRI TAG.

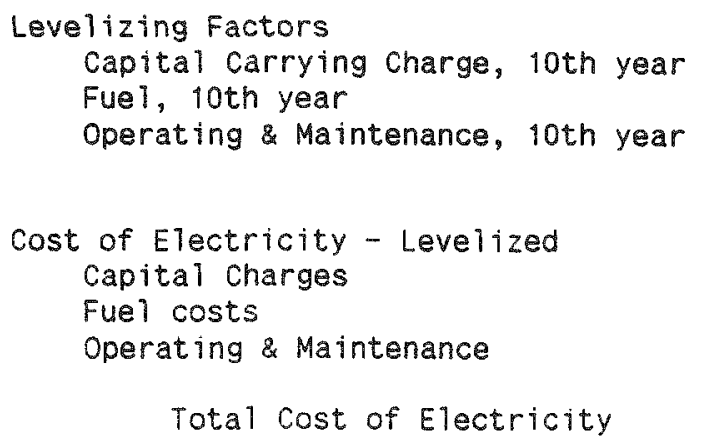

\section{Current $\$$ Constant $\$$}

$\begin{array}{rrr}0.175 & 0.223 & 0.103 \\ 1.244 & 1 & 1.036 \\ 1.202 & 1 & 1.000\end{array}$

mi11s/kwh

$\mathrm{mi} 11 \mathrm{~s} / \mathrm{kWh}$

$\begin{array}{rrr}62.6 & 79.7 & 36.3 \\ 21.2 & 17.0 & 17.6 \\ 23.4 & 19.5 & 19.5 \\ 107.2 & 116.2 & 73.9\end{array}$


Table 5. KRW Gasifier (Air) Costs Adjusted to EPRI TAG

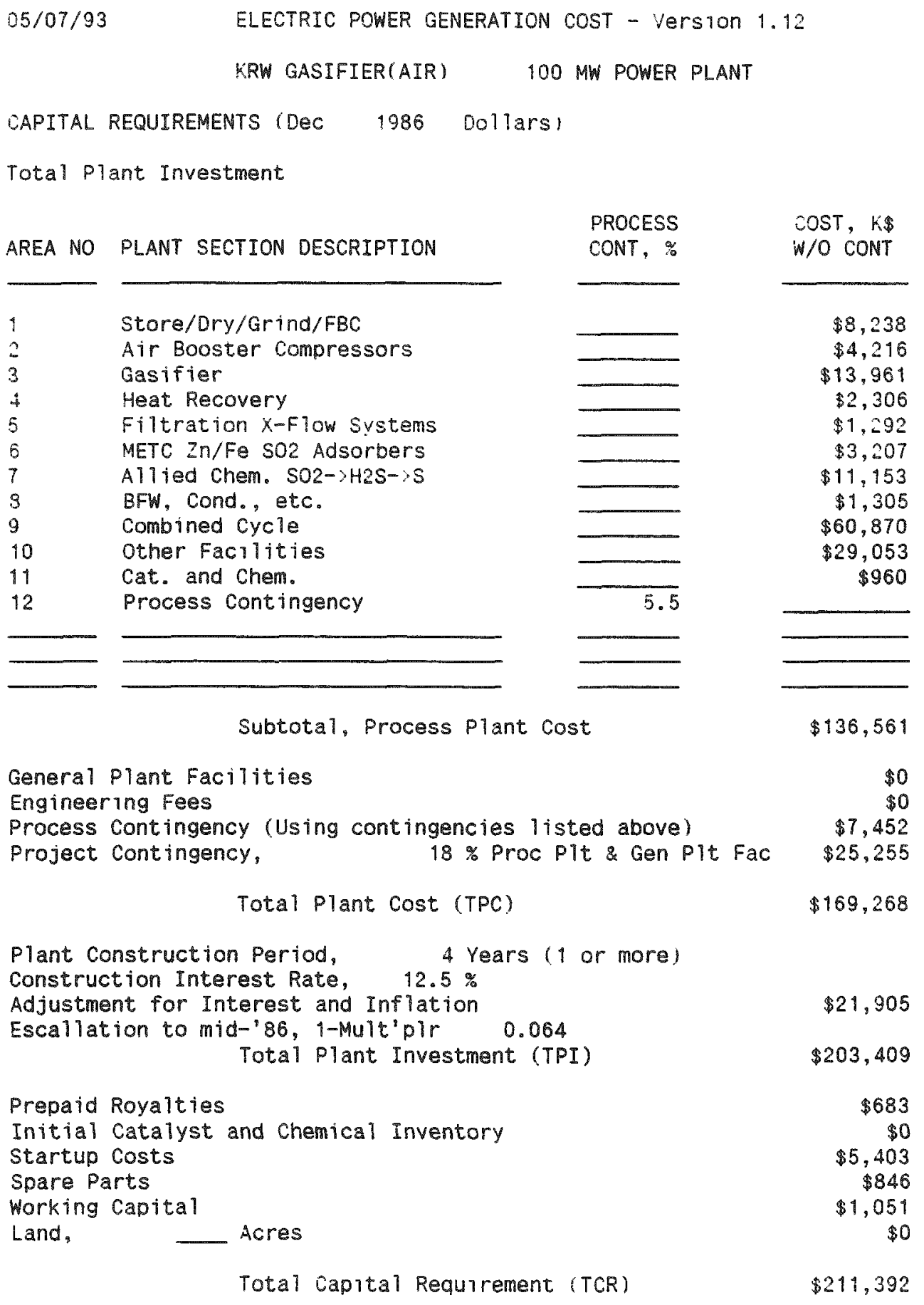


Table 5. KRW Gasifier (Air) Costs Adjusted to EPRI TAG

(Continued)

ANNUAL OPERATING COSTS

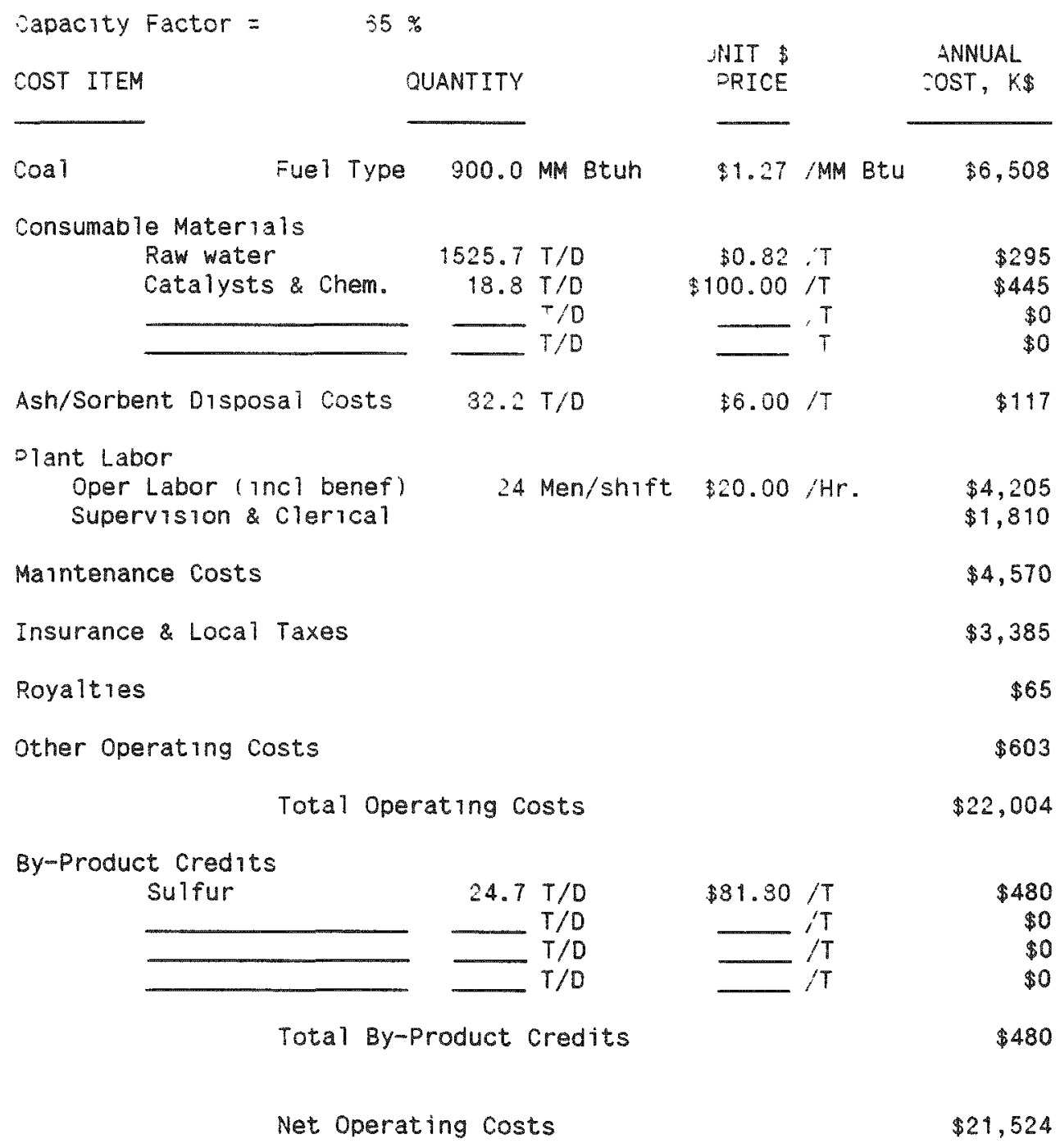


Table 5. IRRW Gasifier (Air) Costs Adjusted to EPRI TAG

(Continued)

BASES AND ASSUMPTIONS

A. CAPITAL BASES AND DETAILS

\begin{tabular}{l} 
Intial catalyst Inventory \\
\hline QUANTITY
\end{tabular} 


\section{Table 5. KRW Gasifier (Air) Costs Adjusted to EPRI TAG (Continued)}

3. ECONOMIC ASSUMPTIONS

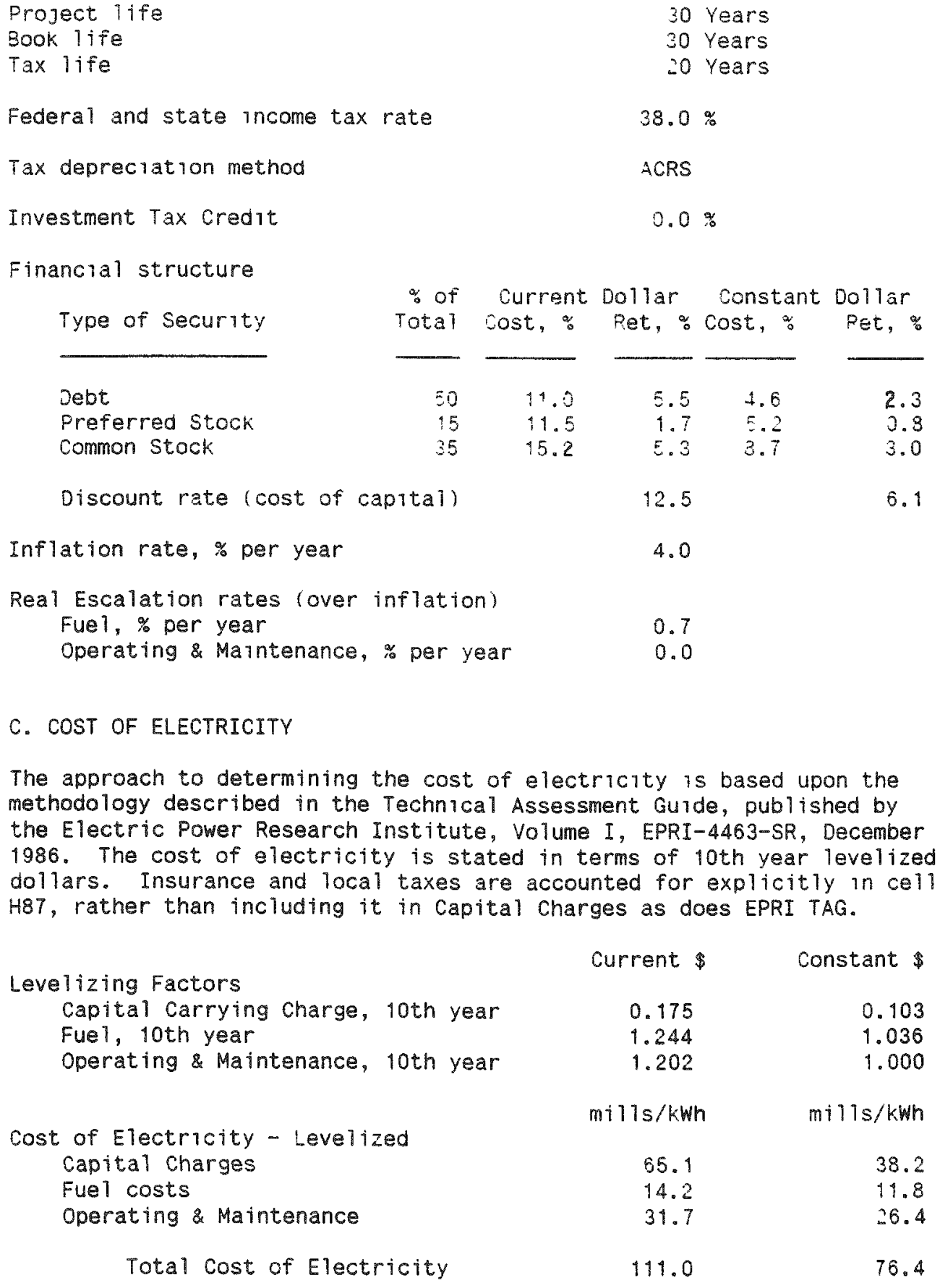

The approach to determining the cost of electricity is based upon the methodology described in the Technical Assessment Guide, published by the Electric Power Research Institute, Volume I, EPRI-4463-SR, December 1986. The cost of electricity is stated in terms of loth year levelized dollars. Insurance and local taxes are accounted for explicitly in cell H87, rather than including it in Capital charges as does EPRI TAG.

Levelizing Factors

Capital Carrying charge, 10th year Fuel, 10th year

Operating \& Maintenance, 10th year

Cost of Electricity - Levelized

Capital charges

Fuel costs

Operating \& Maintenance

$$
\text { Total Cost of Electricity }
$$

Current $\$ \quad$ Constant $\$$

$\begin{array}{ll}0.175 & 0.103 \\ 1.244 & 1.036 \\ 1.202 & 1.000\end{array}$

mills/kWh milis/kWh

$65.1 \quad 38.2$

$14.2 \quad 11.8$

$\begin{array}{ll}31.7 & 26.4\end{array}$

$111.0 \quad 76.4$ 
Table 6. KRW Gasifier (Air) Costs with Escalation to Dec, 1991

\author{
55/07/93 ELECTRIC POWER GENERATION COST - Version 1.12 \\ KRW GASIFIER(AIR) 100 MW POWER PLANT \\ CAPITAL REQUIREMENTS (DeC 1991 DO11ars) \\ Total Plant Investment
}

AREA NO PLANT SECTION DESCRIPTION

PROCESS COST, K\$

$\begin{array}{r}1 \\ 3 \\ 3 \\ 4 \\ 5 \\ 5 \\ 7 \\ 3 \\ 3 \\ 10 \\ 11 \\ 12 \\ \hline\end{array}$

Store/Dry/Grind/FBC

Air Booster Compressors

Gasifier

Heat Recovery

Filtration $X$-Flow systems

METC $\mathrm{Zn} / \mathrm{Fe} \mathrm{SO} 2$ Adsorbers

Allied Chem. SO2- H2S-, S

BFW, cond., etc.

Combined cycle

other Facilities

Cat. and Chem.

Process Contingency

CONT, \%

W/O CONT
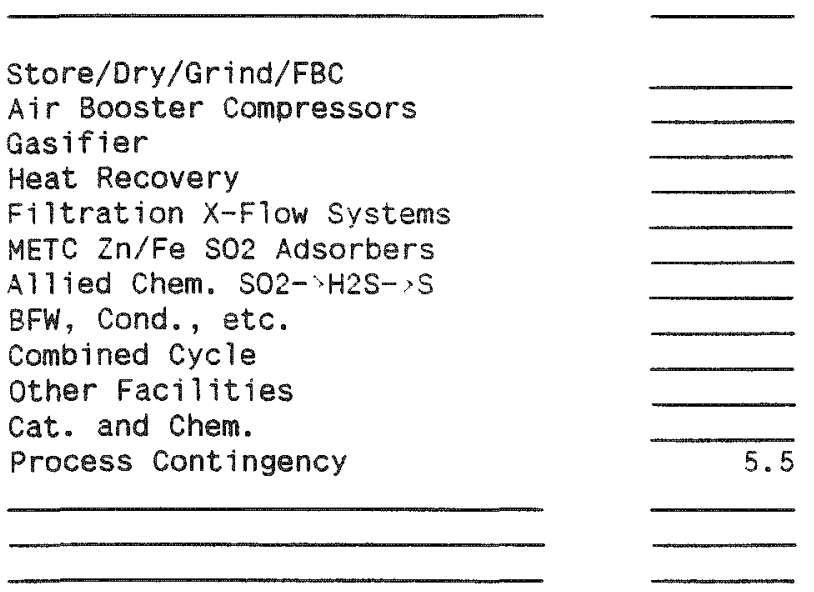

Subtota1, Process Plant cost

$\$ 170,554$

General Plant Faclities

Engineering Fees, $\mathrm{Zn} / \mathrm{Fe}$ system only

$\$ 0$

$\$ 985$

Process Contingency (Using contingencies listed above)

$\$ 9,307$

Project Contingency,

$18 \%$ Proc Plt \& Gen Plt Fac

$\$ 31,542$

Total Plant cost (TPC)

$\$ 212,387$

Plant Construction Period, Construction Interest Rate,

4 Years ( 1 or more)

Adjustment for Interest and Inflation

$\$ 27,486$

Total Plant Investment (TPI)

$\$ 239,873$

Prepaid Royalties

$\$ 853$

Initial Catalyst and chemical Inventory

$\$ 0$

Startup costs

Spare Parts

Working Capital

Land,

Acres

$\$ 6,419$

$\$ 1,062$

$\$ 1,238$

Total Capital Requirement (TCR)

$\$ 249,444$ 
Table 6. KRW Gasifier (Air) Costs with Escalation to Dec, 1991 (Continued)

ANNUAL OPERATING COSTS

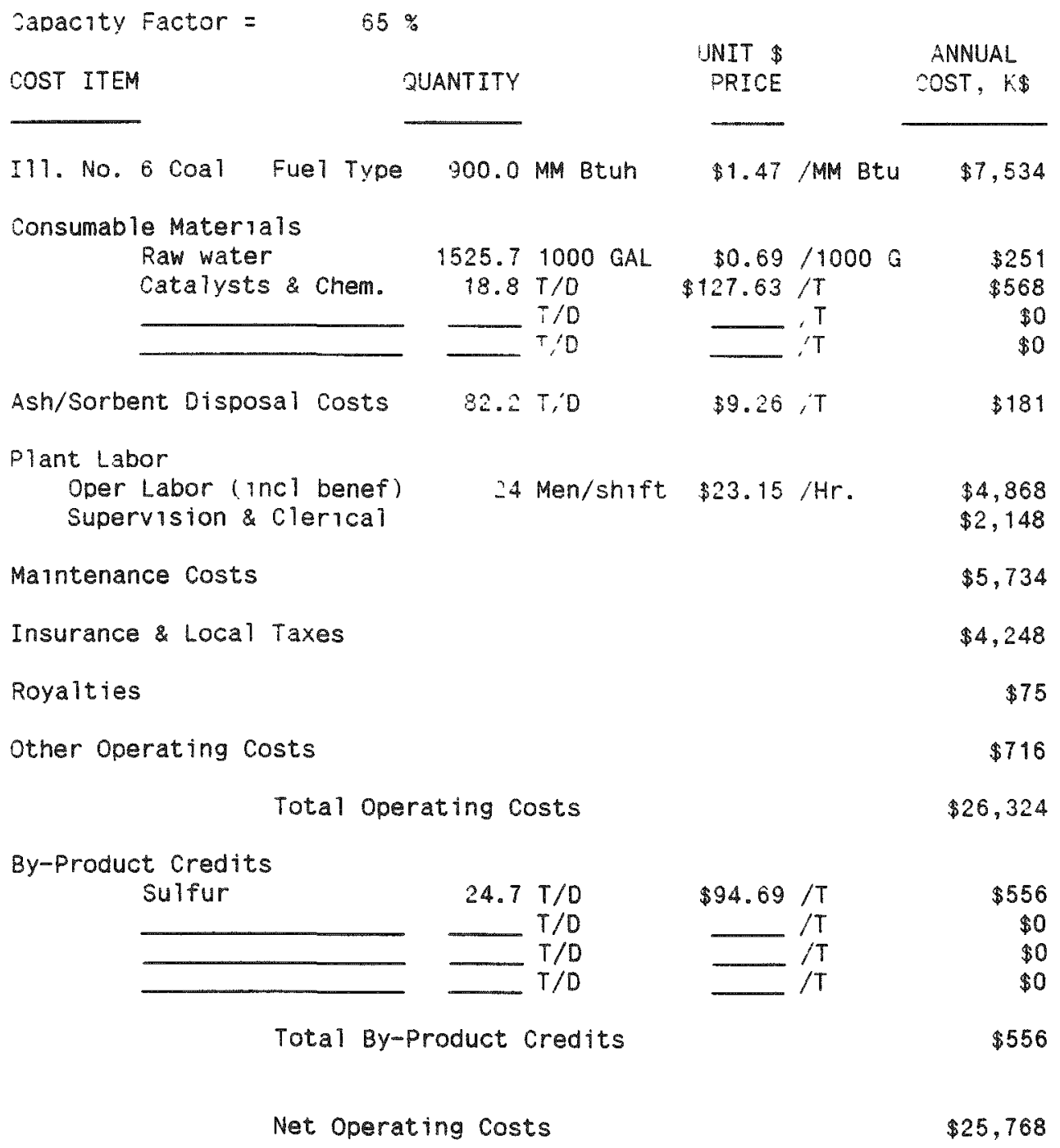


Table 6. KRW Gasifier (Air) Costs with Escalation to Dec, 1991 (Continued)

BASES AND ASSUMPTIONS

A. CAPITAL BASES AND DETAILS

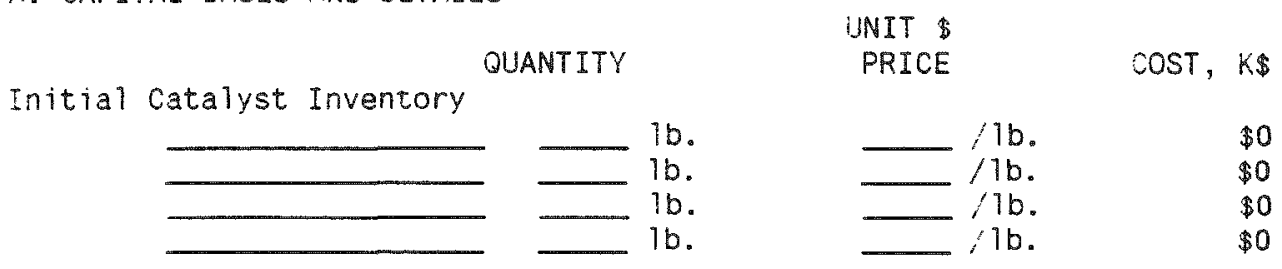

Initial Chemicals Inventory

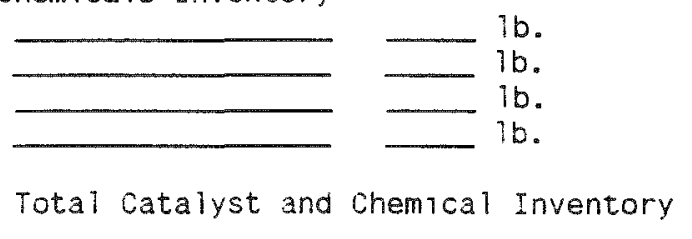

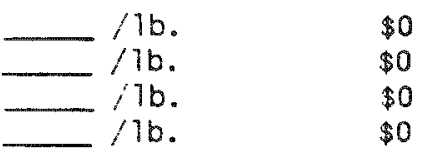

$\$ 0$

Startup costs

Plant modifications, $\quad=\%$ TPI

Operating costs

Fue 1

Total Startup costs

$\$ 4,797$

$\$ 1,611$

$\$ 10$

$\$ 6,419$

Working capital

Fuel \& Consumables inv, 60 days supply

60 days supply

$\$ 332$

By-Product inventory,

30 days

$\$ 140$

Direct expenses,

Total Working Capital

$\$ 1,238$ 
Table 6. KRW Gasifier (Air) Costs with Escalation to Dec, 1991 (Continued)

B. ECONOMIC ASSUMPTIONS

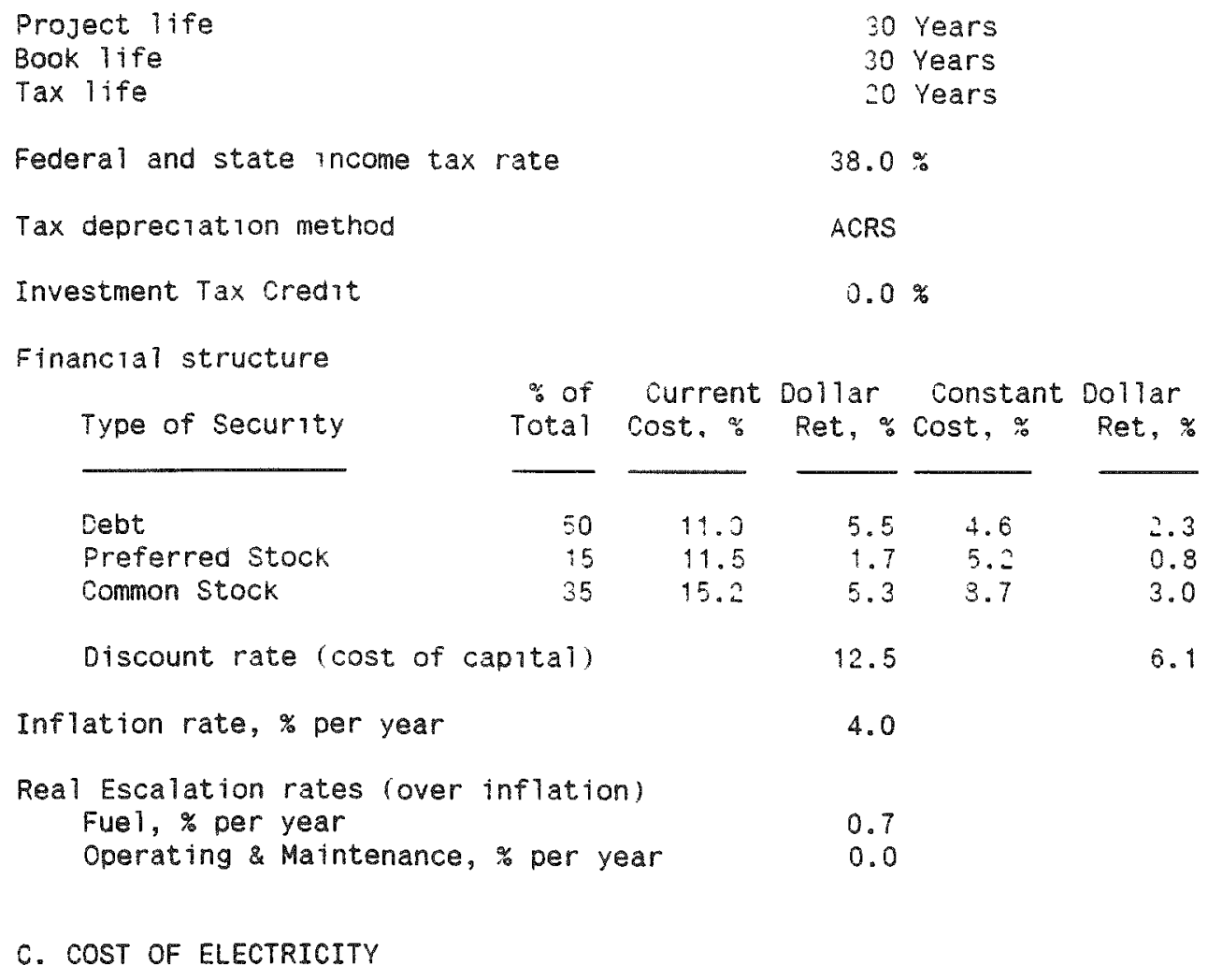

0.0

\section{COST OF ELECTRICITY}

The approach to determining the cost of electricity is based upon the methodology described in the Technical Assessment Guide, published by the Electric Power Research Institute, Volume I, EPRI-4463-SR, December 1986. The cost of electricity is stated in terms of 10th year levelized dollars. Insurance and local taxes are accounted for explicitly in cell H87, rather than including it in capital charges as does EPRI TAG.

Levelizing Factors

Capital Carrying Charge, loth year Fuel, 10th year

Operating \& Maintenance, 10th year

Cost of Electricity - Levelized

Capital charges

Fuel costs

Operating \& Maintenance

Total Cost of Electricity
Current $\$$

$$
0.175
$$

1.244

1.202

mi $11 \mathrm{~s} / \mathrm{kWh}$

76.8

16.5

38.5

131.7
Constant

$$
0.103
$$$$
1.036
$$$$
1.000
$$

mills/kwh

45.1

13.7

32.0

90.8 


\section{APPENDIX B}

\section{HEAT LOSS CALCULATIONS}

Heat losses for each granular-bed filter and candle filter application were calculated using a spreadsheet program. The results of these calculations are summarized in the following six tables. Each table has two sheets, Part 1 and Part 2. Part 1 of each table shows the thickness and conductivity of the heat loss per unit surface area of each vessel. Part 2 of each table defines the size, total surface area, and total heat loss from each vessel. In Part 2 of each table the total heat loss from the entire filter for each application is summed. Following is a listing of tables by application:

- Table 1: CPFBC Granular-bed Filter

- Table 2: Carbonizer Granular-bed Filter

- Table 3: KRW Gasifier Granular-bed Filter

- Table 4: CPFBC Candle Filter

- Table 5: Carbonizer Candle Filter

- Table 6: KRW Gasifier Candle Filter

The symbols used in Part 1 of each table are defined as follows:

R1 Inside Radius of vessel, duct, or pipe (FT)

R2 Outside Radius of first refractory layer (FT)

R3 Outside Radius of second refractory layer (FT)

R4 Outside Radius of vessel, duct, or pipe (FT)

K1 Thermal conductivity of inside layer of refractory $\left(\mathrm{BTU} / \mathrm{HR} / \mathrm{FT} /{ }^{\circ} \mathrm{F}\right)$

K2 Thermal conductivity of middle layer of refractory (BTU/HR/FT/ ${ }^{\circ} \mathrm{F}$ )

K3 Thermal conductivity of outside layer of refractory $\left(\mathrm{BTU} / \mathrm{HR} / \mathrm{FT} /{ }^{\circ} \mathrm{F}\right)$

Ho Convective Coefficient of outside surface (BTU/HR/FT $2 / F)$

$\mathrm{Hi}$ Convective Coefficient of inside surface (BTU/HR/FT ${ }^{2} / \mathrm{F}$ )

To Ambient Temperature (F) 
APPENDIX B

TABLE 1, PART 1

HEAT LOSS CALCULATIONS FOR CPFBC GRANULAR-BED FILTER

\begin{tabular}{|c|c|c|c|c|c|c|c|c|c|c|c|c|c|c|c|c|c|c|}
\hline & $R 1$ & $\mathrm{R} 2$ & $\mathrm{R} 3$ & $\begin{array}{l}\text { REFR. } \\
\text { WIDTH }\end{array}$ & $\mathrm{R} 4$ & $\mathrm{R} 5$ & $\mathrm{~K} 1$ & $\mathrm{~K} 2$ & $\mathrm{~K} 3$ & K4 & Hi & $\mathrm{HC}$ & $E$ & $\mathrm{Hr}$ & Ho & $\mathrm{Ti}$ & To & $\begin{array}{l}\text { HEAT } \\
\text { LOSS } \\
\text { BTU/ } \\
\text { HOUR/ } \\
\text { HT }^{2}\end{array}$ \\
\hline & $(\mathrm{FT})$ & (FT) & (FT) & $(\mathrm{IN})$ & (FI) & (FT) & & & & & & & & & & & & \\
\hline IIFT PIPE & 1.00 & 1.08 & 1.50 & 5.00 & 1.53 & 1.53 & 10.8 & 0.07 & 26 & & 80 & 0.88 & 1 & 1.24 & 2.12 & 1544 & 70 & 193 \\
\hline $\begin{array}{l}\text { GBI TOP } \\
\text { HAT }\end{array}$ & 3.00 & 3.33 & 3.75 & 5.00 & 3.81 & 3.81 & 0.51 & 0.10 & 26 & & 62 & 0.96 & 1 & 1.32 & 2.28 & 1592 & 70 & 265 \\
\hline $\begin{array}{l}\text { GBF TOP } \\
\text { CYC }\end{array}$ & 10.08 & 10.08 & 10.75 & 8.00 & 10.92 & 10.92 & 0.08 & 0.08 & 26 & & 10 & 0.85 & 1 & 1.21 & 2.06 & 1592 & 70 & 169 \\
\hline $\begin{array}{l}\text { GBF } \\
\text { PRESSURE } \\
\text { VESSEL }\end{array}$ & 10.00 & 10.38 & 10.75 & 4.5 & 10.76 & 10.93 & 1.33 & 0.09 & 0.05 & 26 & 10 & 0.98 & 1 & 1.35 & 2.33 & 1592 & 70 & 288 \\
\hline $\begin{array}{l}\text { TOP SEAL } \\
\text { LEG }\end{array}$ & 0.50 & 0.58 & 1.00 & 5.00 & 1.03 & 1.03 & 10.8 & 0.07 & 26 & & 80 & 0.85 & 1 & 1.21 & 2.06 & 1503 & 70 & 169 \\
\hline $\begin{array}{l}\text { BOTTOM } \\
\text { SEAL LEG }\end{array}$ & 0.50 & 0.58 & 1.00 & 5.00 & 1.03 & 1.03 & 10.8 & 0.07 & 26 & & 80 & 0.86 & 1 & 1.22 & 2.09 & 1583 & 70 & 179 \\
\hline $\begin{array}{l}\text { BOTTOM } \\
\text { DEV }\end{array}$ & 4.42 & 4.75 & 5.25 & 6.00 & 5.29 & 5.29 & 0.63 & 0.10 & 26 & & 80 & 0.92 & 1 & 1.28 & 2.19 & 1505 & 70 & 225 \\
\hline TOP DEV & 5.50 & 6.00 & 6.50 & 6.00 & 6.54 & 6.54 & 0.63 & 0.10 & 26 & & 60 & 0.91 & 1 & 1.27 & 2.18 & 1503 & 70 & 217 \\
\hline $\begin{array}{l}\text { DEV TO } \\
\text { HEAT } \\
\text { EXCH }\end{array}$ & 0.83 & 0.85 & 1.27 & 5.00 & 1.27 & 1.27 & 16.6 & 0.06 & & & 60 & 0.85 & 1 & 1.21 & 2.06 & 1500 & 70 & 167 \\
\hline $\begin{array}{l}\text { HEAT } \\
\text { EXCH TO } \\
\text { LIFT PIPE }\end{array}$ & 0.75 & 0.77 & 1.10 & 4.00 & 1.10 & 1.10 & 16.6 & 0.06 & & & 60 & 0.87 & 1 & 1.23 & 2.09 & 1315 & 70 & 182 \\
\hline
\end{tabular}


APPENDIX B

TABLE 1, PART 2

HFAT LOSS CALCULATIONS FOR CPFBC GRANULAR-FILTER

\begin{tabular}{|c|c|c|c|c|c|c|c|}
\hline LQUIPMENT & OD & LIDNGTH & ARFA & RATT: OR & HEAT & NO. & TOTAL. \\
\hline & & & & IHLAT IOSS & IOSS & OF & HFAT LOSS \\
\hline & $(\mathbb{N})$ & (FT) & $\left(\mathbb{F} \mathbb{1}^{2}\right)$ & (BTU/HR/IT $\left.{ }^{2}\right)$ & (BTU/HR) & UNTIS & (BIU/IIR) \\
\hline \multicolumn{8}{|l|}{$\mathrm{GBI}^{\circ}$} \\
\hline TOP MAT & & & 57 & 265 & 15103 & 4 & 60412 \\
\hline TOP HAT SIDE & 91.5 & 8 & 192 & 265 & 50777 & 4 & 203109 \\
\hline TOP CYLINDIER & 262.0 & 12 & 823 & 169 & 139362 & 4 & 557448 \\
\hline BOTTOM CYINNDFR & 262.3 & 9 & 601 & 288 & 172718 & 4 & 690873 \\
\hline CONE & 262.3 & 22 & 938 & 288 & 269680 & 4 & 1078720 \\
\hline TOP & & & 472 & 169 & 79916 & 4 & 319665 \\
\hline TOP SEAI. HEG & 24.8 & 25 & 162 & 169 & 27422 & 4 & 109690 \\
\hline IOWIR STAL. ISGG & 24.8 & 30 & 194 & 179 & 34747 & 4 & 138986 \\
\hline IIFT PPP: & 36.8 & 125 & 1203 & 193 & 232547 & 1 & 232547 \\
\hline LIIT PIPE TO MEAT EXCH & 30.5 & 10 & 80 & 166 & 13293 & 1 & 13293 \\
\hline HLAT EXCH TO LAHT PIPE & 26.5 & 125 & 867 & 182 & 157550 & 1 & 157550 \\
\hline BOTTOM DEV & 127.0 & 20 & 676 & 225 & 152071 & 1 & 152071 \\
\hline TOP DIV & 157.0 & 26 & 1069 & 217 & 231431 & 1 & 231431 \\
\hline WATER COOIFD HX & & & & & 9113483 & 1 & 9113483 \\
\hline TOTA. HEAT LOSS & & & & & & & 13059279 \\
\hline
\end{tabular}


APPENDIX B

TABLE 2, PART 1

HEAT LOSS CALCULATIONS FOR CARBONIZER GRANULAR-BED FILTER

\begin{tabular}{|c|c|c|c|c|c|c|c|c|c|c|c|c|c|c|c|c|c|c|}
\hline & R1 & $\mathrm{R} 2$ & $\mathrm{R} 3$ & $\begin{array}{l}\text { REFR。 } \\
\text { WIDTH }\end{array}$ & $\mathrm{R} 4$ & R5 & $\mathrm{K} 1$ & K2 & K3 & $\mathrm{K} 4$ & $\mathrm{Hi}$ & $\mathrm{Hc}$ & $\mathbf{E}$ & $\mathrm{Hr}$ & Ho & $\mathrm{Ti}$ & To & $\begin{array}{l}\text { HEAT } \\
\text { LOSS } \\
\text { BTU/ } \\
\text { HOUR/ } \\
\text { HT }^{2} \\
\end{array}$ \\
\hline & (FT) & (FT) & (FT) & (IN) & $(\mathrm{FI})$ & (FT) & & & & & & & & & & & & \\
\hline LIFT PIPE & 0.50 & 0.58 & 1.00 & 5.00 & 1.03 & 1.03 & 10.8 & 0.07 & 26 & & 80 & 0.83 & 1 & 1.20 & 2.03 & 1395 & 70 & 156 \\
\hline $\begin{array}{l}\text { GBH TOP } \\
\text { HAT }\end{array}$ & 0.80 & 0.80 & 1.30 & 6.00 & 1.36 & 1.36 & 16.7 & 0.12 & 26 & & 62 & 0.93 & 1 & 1.29 & 2.22 & 1470 & 70 & 238 \\
\hline $\begin{array}{l}\text { GBF TOP } \\
\text { CYC }\end{array}$ & 6.75 & 6.75 & 7.54 & 9.50 & 7.71 & 7.71 & 0.1 & 0.12 & 26 & & 10 & 0.87 & 1 & 1.23 & 2.10 & 1470 & 70 & 185 \\
\hline $\begin{array}{l}\text { GBF } \\
\text { PRESS URE } \\
\text { VESSEL } \\
\end{array}$ & 6.75 & 7.13 & 7.50 & 4.50 & 7.54 & 7.71 & 1.3 & 0.09 & 0.12 & 26 & 10 & 0.95 & 1 & 1.32 & 2.27 & 1470 & 70 & 253 \\
\hline $\begin{array}{l}\text { TOP SEAL } \\
\text { LEG }\end{array}$ & 0.46 & 0.54 & 1.04 & 6.00 & 1.07 & 1.07 & 10.8 & 0.07 & 26 & & 80 & 0.78 & 1 & 1.15 & 1.92 & 1336 & 70 & 120 \\
\hline $\begin{array}{l}\text { BOTTOM } \\
\text { SEAL LEG }\end{array}$ & 0.46 & 0.54 & 1.04 & 6.00 & 1.07 & 1.07 & 10.8 & 0.07 & 26 & & 80 & 0.79 & 1 & 1.16 & 1.96 & 1451 & 70 & 131 \\
\hline $\begin{array}{l}\text { BOTTOM } \\
\text { DEV }\end{array}$ & 1.58 & 1.59 & 2.09 & 6.00 & 2.14 & 2.14 & 16.7 & 0.06 & 26 & & 80 & 0.79 & 1 & 1.16 & 1.95 & 1336 & 70 & 129 \\
\hline TOP DEV & 1.33 & 1.66 & 2.16 & 6.00 & 2.21 & 2.21 & 0.4 & 0.10 & 26 & & 60 & 0.85 & 1 & 1.21 & 2.06 & 1335 & 70 & 169 \\
\hline $\begin{array}{l}\text { DEV TO } \\
\text { HEAT } \\
\text { EXCH }\end{array}$ & 0.17 & 0.19 & 0.60 & 5.00 & & & 16.6 & 0.06 & & & 60 & 0.75 & 1 & 1.13 & 1.88 & 1333 & 70 & 106 \\
\hline $\begin{array}{l}\text { HEAT } \\
\text { EXCH TO } \\
\text { LIFT PIPE }\end{array}$ & 0.17 & 0.19 & 0.52 & 4.00 & & & 16.6 & 0.06 & & & 60 & 0.76 & 1 & 1.14 & 1.90 & 1083 & 70 & 111 \\
\hline
\end{tabular}


APPENDIX B

TABLE 2, PART 2

HFAT LOSS CALCULATIONS FOR CARBONIZER GRANULAR-BED FILTER

\begin{tabular}{|c|c|c|c|c|c|}
\hline EQUIPMENT & $O D$ & LENGTH & AREA & $\begin{array}{l}\text { RATE OF } \\
\text { HEAT LOSS }\end{array}$ & $\begin{array}{l}\text { TOTAL } \\
\text { HEAT LOSS }\end{array}$ \\
\hline & $(\mathrm{IN})$ & (FT) & $\left(\mathrm{FT}^{2}\right)$ & $\left(\mathrm{BTU} / \mathrm{HR} / \mathrm{FI}^{2}\right)$ & (BTU/HR) \\
\hline \multicolumn{6}{|l|}{ GBF } \\
\hline TOP HAT & 32.7 & 6.0 & 4.3 & 238 & 1019 \\
\hline TOP CYLINDER & 185.0 & 7.0 & 339.0 & 185 & 62641 \\
\hline BOTTOM CYLINDER & 185.0 & 7.0 & 339.0 & 253 & 85674 \\
\hline CONE & 185.0 & 13.0 & 441.1 & 253 & 111467 \\
\hline TOP & & & 180.8 & 185 & 33412 \\
\hline BOTTOM & 54.0 & 5.0 & 70.7 & 253 & 17862 \\
\hline TOP SEAL LEG & 25.8 & 15.0 & 101.1 & 120 & 12087 \\
\hline LOWER SEAL LEG & 25.8 & 20.0 & 134.8 & 131 & 17595 \\
\hline LIFT PIPE & 24.8 & 100.0 & 648.0 & 156 & 101308 \\
\hline LIFI PIPE TO HEAT EXCH & 14.5 & 10.0 & 38.0 & 106 & 4027 \\
\hline HEAT EXCH TO LIFT' PIPE & 12.5 & 125.0 & 409.1 & 111 & 45542 \\
\hline BOTTOM DEV & 51.3 & 6.0 & 80.5 & 129 & 10345 \\
\hline TOP DEV & 52.9 & 15.0 & 207.8 & 169 & 35124 \\
\hline $\mathrm{HX}$ & & & & & 2179350 \\
\hline TOTAL HEAT LOSS & & & & & 2717452 \\
\hline
\end{tabular}


APPENDIX B

TABLE 3, PART 1

HEAT LOSS CALCULATIONS FOR KRW GASIFIER GRANULAR-BED FILTER

\begin{tabular}{|c|c|c|c|c|c|c|c|c|c|c|c|c|c|c|c|c|c|c|}
\hline & $\mathrm{R} 1$ & $\mathrm{R} 2$ & $\mathrm{R3}$ & $\begin{array}{l}\text { REFR. } \\
\text { WIDTH }\end{array}$ & $\mathrm{R} 4$ & R5 & $\mathrm{K} 1$ & $\mathrm{~K} 2$ & $\mathrm{~K} 3$ & $\mathrm{~K} 4$ & $\mathrm{Hi}$ & $\mathbb{H C}$ & $\mathrm{E}$ & $\mathrm{Hr}$ & Ho & $\mathrm{Ti}$ & To & $\begin{array}{l}\text { HEAT } \\
\text { LOSS } \\
\text { BTU/ } \\
\text { HOUR/ } \\
\text { HT' }^{2}\end{array}$ \\
\hline & (FT) & (FT) & (FT) & (IN) & (FT) & (FT) & & & & & & & & & & & & \\
\hline LIFT PIPE & 0.50 & 0.58 & 1.00 & 5.00 & 1.03 & 1.03 & 10.8 & 0.07 & 26 & & 80 & 0.85 & 1 & 1.21 & 2.06 & 1493 & 70 & 168 \\
\hline $\begin{array}{l}\mathrm{GBH}^{\circ} \mathrm{TOP} \\
\text { HAT }\end{array}$ & 0.80 & 0.80 & 1.30 & 6.00 & 1.36 & 1.36 & 16.7 & 0.12 & 26 & & 62 & 0.95 & 1 & 1.32 & 2.26 & 1581 & 70 & 257 \\
\hline $\begin{array}{l}\text { GBH TOP } \\
\text { CYC }\end{array}$ & 6.75 & 6.75 & 7.54 & 9.50 & 7.71 & 7.71 & 0.1 & 0.12 & 26 & & 10 & 0.89 & 1 & 1.25 & 2.14 & 1581 & 70 & 200 \\
\hline $\begin{array}{l}\text { GBF } \\
\text { PRHSSURE } \\
\text { VESSEL }\end{array}$ & 6.75 & 7.13 & 7.50 & 4.50 & 7.54 & 7.71 & 1.3 & 0.09 & 0.1 & 26 & 10 & 0.97 & 1 & 1.34 & 2.31 & 1581 & 70 & 273 \\
\hline $\begin{array}{l}\text { TOP SEAL } \\
\text { LEG }\end{array}$ & 0.46 & 0.54 & 1.04 & 6.00 & 1.07 & 1.07 & 10.8 & 0.07 & 26 & & 80 & 0.79 & 1 & 1.16 & 1.95 & 1421 & 70 & 128 \\
\hline $\begin{array}{l}\text { BOTTOM } \\
\text { SEAL LEG }\end{array}$ & 0.56 & 0.54 & 1.04 & 6.00 & 1.07 & 1.07 & 10.8 & 0.07 & 26 & & 80 & 0.81 & 1 & 1.18 & 1.99 & 1562 & 70 & 141 \\
\hline $\begin{array}{l}\text { BOTIOM } \\
\text { DFV }\end{array}$ & 1.58 & 1.59 & 2.09 & 6.00 & 2.14 & 2.14 & 16.7 & 0.06 & 26 & & 80 & 0.80 & 1 & 1.17 & 1.98 & 1421 & 70 & 137 \\
\hline TOP DEV & 1.33 & 1.66 & 2.16 & 6.00 & 2.21 & 2.21 & 0.4 & 0.10 & 26 & & 60 & 0.87 & 1 & 1.23 & 2.09 & 1420 & 70 & 181 \\
\hline $\begin{array}{l}\text { DEV TO } \\
\text { IIEAT } \\
\text { FXCH }\end{array}$ & 0.17 & 0.19 & 0.60 & 5.00 & & & 16.6 & 0.06 & & & 60 & 0.76 & 1 & 1.14 & 1.91 & 1419 & 70 & 113 \\
\hline $\begin{array}{l}\text { HEAT } \\
\text { EXCH TO } \\
\text { LIFT PIPE }\end{array}$ & 0.17 & 0.19 & 0.52 & 4.00 & & & 16.6 & 0.06 & & & 60 & 0.78 & 1 & 1.15 & 1.93 & 1168 & 70 & 121 \\
\hline
\end{tabular}


APPENDIX B

TABLE 3, PART 2

HEAT LOSS CALCULATIONS FOR KRW GASIFIER GRANULAR-BED FILTER

\begin{tabular}{|c|c|c|c|c|c|}
\hline EQUIPMENT & $O D$ & LENGTH & AREA & $\begin{array}{l}\text { RATE OF } \\
\text { HEAT LOSS }\end{array}$ & $\begin{array}{l}\text { TOTAL } \\
\text { HEAT LOSS }\end{array}$ \\
\hline & $(\mathrm{IN})$ & $(\mathrm{FT})$ & $\left(\mathrm{FT}^{2}\right)$ & $\left(\mathrm{BTU} / \mathrm{HR} / \mathrm{FT}^{2}\right)$ & $(\mathrm{BTU} / \mathrm{HR})$ \\
\hline \multicolumn{6}{|l|}{$\mathrm{GBF}^{2}$} \\
\hline TOP HAT & 32.7 & 6 & 4 & 257.4 & 1102 \\
\hline TOP CYLINDER & 185.0 & 7 & 339 & 199.7 & 67715 \\
\hline BOTTOM CYLINDER & 185.0 & 7 & 339 & 273.3 & 92653 \\
\hline CONE & 185,0 & 7 & 441 & 273.3 & 120547 \\
\hline TOP & & & 181 & 199.7 & 36118 \\
\hline BOTTOM & 54.0 & 5 & 71 & 273.3 & 19318 \\
\hline TOP SEAL LEG & 25.8 & 15 & 101 & 127.6 & 12905 \\
\hline LOWER SEAL LEG & 25.8 & 20 & 135 & 141.1 & 19031 \\
\hline LIFT PIPE & 24.8 & 100 & 648 & 168.1 & 108892 \\
\hline IIFT PIPE TO HEAT EXCH & 14.5 & 10 & 38 & 113.3 & 4302 \\
\hline HEAT EXCH TO LIFT PIPE & 12.5 & 125 & 409 & 120.9 & 49442 \\
\hline BOTTOM DEV & 51.3 & 6 & 81 & 137.2 & 11046 \\
\hline TOP DEV & 52.9 & 15 & 208 & 180.6 & 37525 \\
\hline $\mathrm{HX}$ & & & & & 2940600 \\
\hline TOTAL HEAT LOSS & & & & & 3521196 \\
\hline
\end{tabular}


APPENDIX B

TABIE 4, PART 1

HEAT LOSS CALCULATIONS FOR CPFBC CANDIE FILTER

\begin{tabular}{|l|c|c|c|c|c|c|c|c|c|c|c|c|c|c|c|c|c|c|}
\hline & R1 & R2 & R3 & $\begin{array}{l}\text { REFR. } \\
\text { WIDTH }\end{array}$ & R4 & R5 & K1 & K2 & K3 & K4 & Hi & Hc & E & Hr & Ho & Ti & To & $\begin{array}{l}\text { HEAT } \\
\text { lOSS } \\
\text { BTU/ } \\
\text { HOUR/ } \\
\text { FT }^{2}\end{array}$ \\
\hline & (FT) & (FT) & (FT) & (IN) & (FT) & (FT) & & & & & & & & & & & & \\
\hline $\begin{array}{l}\text { ABOVE } \\
\text { TUBE } \\
\text { SHEET }\end{array}$ & 10.25 & 10.25 & 11.00 & 9.0 & 11.17 & 11.17 & 1.16 & 0.16 & 26 & & 10 & 0.97 & 1 & 1.34 & 2.31 & 1599 & 70 & 279.2 \\
\hline $\begin{array}{l}\text { BELOW } \\
\text { TUBE } \\
\text { SHEET }\end{array}$ & 10.25 & 10.58 & 11.00 & 9.0 & 11.17 & 11.17 & 0.46 & 0.11 & 26 & & 10 & 0.97 & 1 & 1.34 & 2.30 & 1599 & 70 & 293.3 \\
\hline
\end{tabular}




\section{APPENDIX B}

TABLE 4, PART 2

HEAT LOSS CALCULATIONS FOR CPFBC CANDLE FILTER

\begin{tabular}{|c|c|c|c|c|c|c|c|}
\hline BQUIPMPDT & OD & IHAGTII & ARIPA & RATT: OF & MEAT & NO. & TOTAL \\
\hline & & & & HHAT LOSS & Loss & $O P^{2}$ & HEAT LOSS \\
\hline & (IN) & (FT) & $\left(\mathrm{FT}^{3}\right)$ & $\left(\mathrm{BTU} / \mathrm{HR} / \mathrm{FT}^{2}\right)$ & (BTU/HR) & UNTIS & (BTU/HR) \\
\hline $\begin{array}{l}\text { ABOVE TUBASHIST } \\
\text { GYLINDFR }\end{array}$ & 268.0 & 11.0 & 771.8 & 279.2 & 215447 & 4 & 861788 \\
\hline $\begin{array}{l}\text { BHIOW TUBESHEITI } \\
\text { GYINNDER }\end{array}$ & 268.0 & 18.3 & 1280.5 & 293.3 & 375564 & 4 & 1502256 \\
\hline CONE: & 268.0 & 22.8 & 890.8 & 293.3 & 261262 & 4 & 1045048 \\
\hline TOP & & & 472.0 & 279.2 & 131761 & 4 & 527044 \\
\hline TOTAI. IHEAT LOSS & & & & & & & 3936136 \\
\hline
\end{tabular}




\section{APPENDIX B}

TABLE 5, PART 1

HEAT LOSS CALCULATIONS FOR CARBONIZER CANDIE FLTER

\begin{tabular}{l|l|c|c|c|c|c|c|c|c|c|c|c|c|c|c|c|c|c|c|}
\hline \hline & R1 & R2 & R3 & $\begin{array}{l}\text { REFR. } \\
\text { WIDTH }\end{array}$ & R4 & R5 & K1 & K2 & K3 & K4 & Hi & Hc & E & HIr & Ho & Ti & To & $\begin{array}{l}\text { HEAT } \\
\text { LOSS } \\
\text { BTU/ } \\
\text { HOUR/ } \\
\text { FT }\end{array}$ \\
\hline & (FT) & (FT) & (FT) & (IN) & (FT) & (FT) & & & & & & & & & & & & \\
\hline
\end{tabular}


APPENDIX B

TABLE 5, PART 2

HEAT LOSS CALCULATIONS FOR CARBONIZER CANDLE FILTER

\begin{tabular}{|c|c|c|c|c|c|}
\hline EQUIPMENT & OD & LENGTH & AREA & $\begin{array}{l}\text { RATE OF } \\
\text { HEAT LOSS } \\
\end{array}$ & $\begin{array}{l}\text { TOTAL } \\
\text { HEAT LOSS }\end{array}$ \\
\hline & (IN) & $(\mathbb{F I})$ & $\left(\mathrm{FT}^{2}\right)$ & $\left(\mathrm{BTU} / \mathrm{HR} / \mathrm{FT}^{2}\right)$ & (BTU/HR) \\
\hline ABOVE TUBESHEET CYLINDER & 238.0 & 11.0 & 685.4 & 277.4 & 190137 \\
\hline BFLOW TUBESHEET CYLINDER & 238.0 & 18.3 & 1137.1 & 291.9 & 331893 \\
\hline CONE & 238.0 & 20.3 & 702.5 & 291.9 & 205038 \\
\hline TOP & & & 472.0 & 277.4 & 130940 \\
\hline TOTAL HEAT LOSS & & & & & 858008 \\
\hline
\end{tabular}


APPENDIX B

TABLE 6, PART 1

HEAT LOSS CALCULATIONS FOR KRW GASIFIER CANDLE FILTER

\begin{tabular}{|l|c|c|c|c|c|c|c|c|c|c|c|c|c|c|c|c|c|c|}
\hline & $R 1$ & $R 2$ & R3 & $\begin{array}{l}\text { REFR. } \\
\text { WIDTH }\end{array}$ & R4 & R5 & K1 & K2 & K3 & K4 & Hi & Hc & E & Hr & Ho & Ti & To & $\begin{array}{l}\text { HEAT } \\
\text { LOSS } \\
\text { BTU/ } \\
\text { HOUR/ } \\
\text { FT }^{2}\end{array}$ \\
\hline & (FT) & (FT) & (FT) & (IN) & (FT) & (FT) & & & & & & & & & & & & \\
\hline $\begin{array}{l}\text { ABOVF } \\
\text { TUBE } \\
\text { SHEET }\end{array}$ & 8.33 & 8.33 & 9.08 & 9.0 & 9.25 & 9.25 & 0.16 & 0.16 & 26 & & 10 & 0.97 & 1 & 1.34 & 2.30 & 1599 & 70 & 276.3 \\
\hline $\begin{array}{l}\text { BELOW } \\
\text { TUBE } \\
\text { SHEET }\end{array}$ & 8.33 & 8.67 & 9.08 & 9.0 & 9.25 & 9.25 & 0.46 & 0.11 & 26 & & 10 & 0.97 & 1 & 1.34 & 2.30 & 1599 & 70 & 290.9 \\
\hline
\end{tabular}


APPENDIX B

TABLE 6, PART 2

HEAT LOSS CALCULATIONS FOR KRW GASIFIER CANDLE FILTER

\begin{tabular}{|c|c|c|c|c|c|}
\hline EQUIPMENT & $O D$ & LENGTH & AREA & $\begin{array}{l}\text { RATE OF } \\
\text { HIEAT LOSS } \\
\end{array}$ & $\begin{array}{l}\text { TOTAL } \\
\text { HEAT LOSS }\end{array}$ \\
\hline & $(\mathrm{IN})$ & (FI) & $\left(\mathrm{FT}^{2}\right)$ & $\left(\mathrm{BTU} / \mathrm{HR} / \mathrm{FT}^{2}\right)$ & (BT'U/HR) \\
\hline ABOVE TUBESHEET CYLINDER & 222.0 & 11.0 & 639.3 & 276.3 & 176637 \\
\hline BELOW TUBESHEET CYLINDER & 222.0 & 18.3 & 1060.7 & 290.9 & 308600 \\
\hline CONE & 222.0 & 18.9 & 611.2 & 290.9 & 177831 \\
\hline TOP & & & 472.0 & 276.3 & 130409 \\
\hline TOTAL HEAT LOSS & & & & & 793477 \\
\hline
\end{tabular}











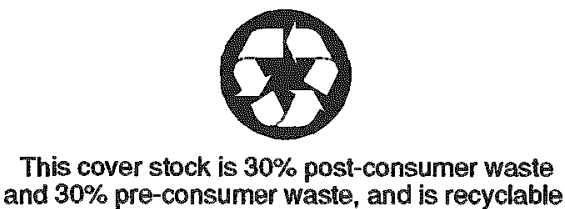
and $30 \%$ pre-consumer waste, and is recyclable. 
